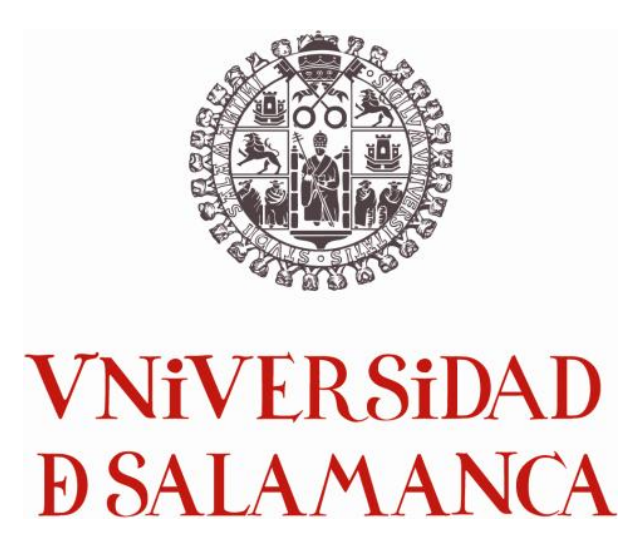

\title{
CONTRIBUCIÓN A LA HISTORIA DE LA GRAMÁTICA BRASILEÑA DEL SIGLO XIX
}

TESIS DOCTORAL

Alumna: Andressa Dorásio Parreira Directora: Dra. Margarita Lliteras Poncel Tutor: Dr. Julio Borrego Nieto

Facultad de Filología

Departamento de Lengua Española

Programa de Doctorado: Análisis del discurso y sus aplicaciones Julio de 2011 
Porque de Él, y por Él, y en Él, son todas las cosas.

A Él sea gloria por siglos.

Amén.

Romanos 11:36

(Reina Valera) 
Deseo expresar mi más sincero agradecimiento a mi directora de Tesis, Dra. Margarita Lliteras, por su apoyo, atención, dedicación, paciencia, amistad, palabras de ánimo y por guiarme con su experiencia y conocimiento.

A mi tutor, Dr. Julio Borrego, por sus consejos, su amabilidad, comprensión y diligencia.

A los profesores del Programa de Doctorado Análisis del discurso y sus aplicaciones, por compartir con nosotros sus conocimientos, motivar e inspirar mi crecimiento académico.

A la Universidad de Salamanca, en convenio con el Banco Santander, por proporcionarme esta singular e inolvidable oportunidad a través del programa de Becas Internacionales.

A la Biblioteca Nacional do Rio de Janeiro, a la Universidade de São Paulo y a la Universidade Federal de Minas Gerais por poner a nuestra disposición su acervo de obras raras y su espacio de investigación.

A mi familia, por el amor, por el consuelo, palabras de ánimo, estimulantes consejos $y$, principalmente, por compartir este sueño a pesar de las circunstancias. Doy las gracias especialmente a mi madre, por su amor y dedicación incondicionales, por apoyarme siempre, eres un ejemplo.

A mis amigos de cerca y de lejos, por la compañía, el cariño y el ánimo. Sois el ejemplo de que la amistad traspasa fronteras.

A todos, muchas gracias. 


\section{ÍNDICE}

1 Introducción

2 Historiografía Lingüística del Portugués

2.1 El estado actual de las investigaciones historiográficas sobre la lengua portuguesa

2.2 Principales propuestas de periodización de la gramática brasileña decimonónica

3 La tradición gramatical portuguesa anterior al siglo XIX

3.1 La etapa renacentista

3.2 La etapa ilustrada

4 Fuentes primarias de los gramáticos brasileños del siglo XIX

4.1 Autores renacentistas

4.2 Autores ilustrados

4.3 Autores de las corrientes lingüísticas histórico-comparadas

4.4 Neogramáticos

4.5 Autores contemporáneos portugueses y brasileños

4.6 Resultados

5 Análisis de la teoría gramatical brasileña del siglo XIX

5.1 El modelo racionalista: el Epítome de Grammatica Portugueza de Antonio Moraes Silva (1806)

5.1.1 El autor y su época

5.1.2 Fundamentos gramaticográficos de Moraes

5.1.3 Definición y división de la gramática

5.1.4 El tratamiento de las partes de la oración

5.1.5 El tratamiento de la sintaxis 
5.2 La introducción del modelo taxonómico en la Grammatica Portugueza de Augusto Freire (18751-1877²)

5.2.1 El autor y su obra

5.2.2 División y definición de la gramática

5.2.3 El corpus de autoridades literarias

5.2.4 El tratamiento de la lexicología

5.2.5 El tratamiento de la sintaxis

5.2.6 La primera semiología

5.2.7 Resumen

5.3 El modelo brasileño de gramática normativa: Grammatica Portugueza de Júlio Ribeiro (1881 1-18852)

5.3.1 El autor y su obra

5.3.2 Fundamentos gramaticográficos de Ribeiro

5.3.3 El corpus literario

5.3.4 Concepto de lengua

5.3.5 Definición de la gramática

5.3.6 División de la Grammatica Portugueza

5.3.7 El tratamiento de la lexeología

5.3.8 La clasificación de las palabras

5.3.9 El tratamiento de la sintaxis

5.3.10 Reconocimiento de las variedades lingüísticas del portugués

5.3.11 Resumen

5.4 El modelo de gramática descriptiva: Grammatica Descriptiva de Maximino Maciel (18871-18942)

5.4.1 El autor y su obra

5.4.2 División de la gramática

5.4.3 La base textual

5.4.4 Definición de la gramática

5.4.5 El tratamiento de la fonética, la fonología y la ortografía

5.4.6 El tratamiento de las partes de la oración

5.4.7 El tratamiento sintáctico

5.4.8 La nueva semiología 
6 Terminología y terminografía en la gramática brasileña del siglo XIX 249

6.1 Interés historiográfico del metalenguaje 249

6.2 Terminología y terminografía de las partes de la gramática 253

6.2.1 De la etymologia a la morphologia 254

6.2.2 Syntaxe y syntaxologia 264

6.2.3 Semiologia y sus variantes 268

6.3 Terminología y terminografía de las clases de palabras 271

6.3.1 La terminología del sustantivo 272

6.3.2 La terminología del adjetivo 274

$\begin{array}{ll}\text { 6.3.3 La terminología del verbo } & 279\end{array}$

6.3.4 La terminología del adverbio 284

6.3.5 La terminología de la conjunción 286

6.3.6 La preposición y la interjección 289

6.4 Terminología y terminografía de la sintaxis 290

6.4.1 La terminología de las proposiciones 291

6.4.2 La terminología de las figuras y vicios del lenguaje 295

6.5 Terminología y terminografía de la semiología 298

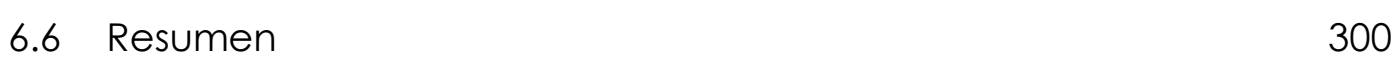

7 Cambios en la gramatización del portugués en el siglo XIX brasileño 303

7.1 Evolución de la definición de gramática 304

7.2 Definición de las partes de la gramática 309

7.2.1 Evolución de la definición de morfología 310

7.2.2 Evolución de la definición de sintaxis 316

7.2.3 Evolución de la «semiologia» 320

7.3 Evolución de las definiciones de las clases de palabras 321

$\begin{array}{lll}7.3 .1 & \text { El sustantivo } & 324\end{array}$

$\begin{array}{ll}\text { 7.3.2 El adjetivo } & 325\end{array}$

$\begin{array}{ll}\text { 7.3.3 El pronombre } & 328\end{array}$

$\begin{array}{lll}7.3 .4 \text { El verbo } & 330\end{array}$

7.3.5 La preposición 331

7.3.6 El adverbio 333 
8 Contrastes Románicos en el proceso de codificación del portugués

8.1 Introducción

8.2 El contraste racionalista en la obra de Moraes Silva

8.3 La aplicación de procedimientos contrastivos en la Gramática de Augusto Freire

8.4 Alcance del método contrastivo de Júlio Ribeiro

8.5 Contrastes románicos en la Grammatica Descriptiva de Maciel

10 Bibliografía

10.1 Corpus

10.2 Fuentes primarias

10.3 Fuentes secundarias 


\section{$1 \quad$ INTRODUCCIÓN}

La historia de la gramática en Brasil constituye un campo de estudio de la Historiografía Lingüística que, hasta periodos muy recientes, ha recibido escasa atención por parte de los lingüistas del Nuevo y del Viejo Continente. Actualmente, las investigaciones gramaticográficas relativas a la tradición brasileña se limitan, en general, a descripciones muy someras -cuando no, simples enumeraciones- de las gramáticas y además se centran especialmente en los aspectos externos de la Historiografía, como son el contexto social, cultural y político en el que se inscriben las obras y sus autores. Esta perspectiva, aunque puede representar un valioso complemento, suele aportar solo interpretaciones parciales de la historia de la gramática brasileña, si no se consideran conjuntamente los aspectos internos de la propia disciplina historiográfica.

El estado actual de los estudios historiográficos en Brasil ha sido una de las motivaciones para la realización de esta investigación, pues son muy pocos los estudios que han abordado la evolución de la gramática brasileña en su conjunto. En este sentido, se propone aquí contribuir a la gramaticografíal brasileña a partir de la descripción, el análisis y la interpretación de los principios teóricos y metodológicos utilizados por los principales gramáticos brasileños para la codificación de la lengua portuguesa durante el primer siglo de esta tradición formada por autores nacidos en Brasil.

Pues bien, el estudio de la lengua propia en Brasil comienza a desarrollarse en el siglo XIX a partir de Antonio de Moraes Silva (1806) y experimenta durante este periodo una importante expansión. Solo hasta finales

\footnotetext{
I Se entiende aquí por gramaticografía la disciplina que «debe ocuparse de los principios teóricos y metodológicos en que se basa la composición de gramáticas» (Lliteras 1997: 57). Sin embargo, este término es empleado ocasionalmente en esta investigación como sinónimo de «tradición gramaticals.
} 
de la centuria se calcula que se publican en Brasil al menos 21 gramáticas destinadas a la enseñanza de la lengua materna, si bien es probable que este número sea considerablemente superior. La tabla siguiente representa la cronología de las gramáticas brasileñas decimonónicas:

\begin{tabular}{|c|c|c|c|c|}
\hline Autor & Título de la gramática & Año & Lugar & $\begin{array}{l}\text { N. }{ }^{\circ} \text { de } \\
\text { eds. }\end{array}$ \\
\hline Antonio de Moraes Silva & $\begin{array}{l}\text { Epítome de Grammatica } \\
\text { Portugueza }\end{array}$ & 1806 & Lisboa & \\
\hline $\begin{array}{l}\text { Frei J. do Amor Divino } \\
\text { Caneca }\end{array}$ & $\begin{array}{l}\text { Breve Compendio de } \\
\text { Grammatica Portugueza }\end{array}$ & 1817 & Salvador & \\
\hline $\begin{array}{l}\text { Antonio da Costa } \\
\text { Duarte }\end{array}$ & $\begin{array}{l}\text { Compendio de Grammatica } \\
\text { Portugueza }\end{array}$ & 1829 & Maranhão & 6 \\
\hline $\begin{array}{l}\text { Antonio Álvares Pereira } \\
\text { Coruja }\end{array}$ & $\begin{array}{l}\text { Compendio da Grammatica da } \\
\text { Lingua Nacional }\end{array}$ & 1835 & $\begin{array}{l}\text { Porto } \\
\text { Alegre }\end{array}$ & 2 \\
\hline $\begin{array}{l}\text { Salvador Henrique de } \\
\text { Albuquerque }\end{array}$ & $\begin{array}{l}\text { Breve Compendio de } \\
\text { Grammatica Portugueza }\end{array}$ & 1844 & Recife & 2 \\
\hline José Alexandre Passos & $\begin{array}{l}\text { Compendio de Grammatica } \\
\text { Port. pelo methodo analytico }\end{array}$ & 1848 & $\begin{array}{l}\text { Rio de } \\
\text { Janeiro }\end{array}$ & \\
\hline $\begin{array}{l}\text { Policarpo José Dias da } \\
\text { Cruz }\end{array}$ & $\begin{array}{l}\text { Compendio de Grammatica } \\
\text { Portugueza }\end{array}$ & 1859 & $\begin{array}{l}\text { Rio de } \\
\text { Janeiro }\end{array}$ & 4 \\
\hline $\begin{array}{l}\text { Manoel Soares da Silva } \\
\text { Bezerra }\end{array}$ & $\begin{array}{l}\text { Compendio de Grammatica } \\
\text { Philosophica }\end{array}$ & 1861 & Ceará & \\
\hline $\begin{array}{l}\text { Francisco Sotero dos } \\
\text { Reis }\end{array}$ & Grammatica Portugueza & 1865 & Maranhão & \\
\hline $\begin{array}{l}\text { Charles Adrien Olivier } \\
\text { Grivet }\end{array}$ & $\begin{array}{l}\text { Nova Grammatica Analytica da } \\
\text { Lingua Portugueza }\end{array}$ & 1865 & $\begin{array}{l}\text { Rio de } \\
\text { Janeiro }\end{array}$ & \\
\hline $\begin{array}{l}\text { Laurindo José da Silva } \\
\text { Rabelo }\end{array}$ & $\begin{array}{l}\text { Compendio de Grammatica da } \\
\text { Lingua Portugueza }\end{array}$ & 1872 & $\begin{array}{l}\text { Rio de } \\
\text { Janeiro }\end{array}$ & \\
\hline Augusto Freire da Silva & Grammatica Portugueza & 1875 & Maranhão & 8 \\
\hline Júlio Ribeiro & Grammatica Portugueza & 1881 & São Paulo & 11 \\
\hline $\begin{array}{l}\text { A. Estevão da Costa e } \\
\text { Cunha }\end{array}$ & $\begin{array}{l}\text { Principios de Grammatica } \\
\text { Historica e Comparada }\end{array}$ & 1883 & - & - \\
\hline Pacheco da Silva Jr. \& & Grammatica da Lingua & 1887 & Rio de & 2 \\
\hline
\end{tabular}




\begin{tabular}{|l|l|l|l|l|}
\hline Lameira de Andrade & Portugueza & & Janeiro & \\
\hline Alfredo Gomes & Grammatica Portugueza & 1887 & $\begin{array}{l}\text { Rio de } \\
\text { Janeiro }\end{array}$ & 15 \\
\hline João Ribeiro & Grammatica Portugueza & 1887 & $\begin{array}{l}\text { Rio de } \\
\text { Janeiro }\end{array}$ & 25 \\
\hline Ernesto Carneiro Ribeiro & Serões Grammaticaes & 1890 & Bahia & 6 \\
\hline Maximino Maciel & Grammatica Descriptiva & $\mathbf{1 8 9 4}$ & $\begin{array}{l}\text { Rio de } \\
\text { Janeiro }\end{array}$ & 11 \\
\hline
\end{tabular}

1.1 Cronología de las principales gramáticas brasileñas del siglo XIX

Ante la fructífera producción gramatical en Brasil, hemos procedido a una breve revisión de estos tratados, con el fin de determinar cuáles contienen los principales avances de esta tradición y cuáles, en cambio, forman más bien el grupo de seguidores que recogen las novedades introducidas por las obras paradigmáticas.

Este análisis muestra que las gramáticas publicadas entre los años de 1817 y 1872 (ambos incluidos) no representan necesariamente un cambio fundamental del marco teórico y metodológico de esta tradición, pues los pequeños hallazgos en la codificación de la lengua portuguesa presentados por sus autores no llegan a sustanciar un cuerpo de doctrina que caracterice un cambio de orientación gramatical o el inicio de una etapa gramaticográfica nueva. En efecto, las gramáticas publicadas durante más de medio siglo suponen, en general, la reproducción (como mucho, alguna reorganización) del modelo más consolidado y vigente de este periodo, el tradicionalracionalista. Esta noción puede extenderse también a los manuales publicados en 1887, que tratan principalmente de adecuarse al marco positivista iniciado en los años anteriores.

Paralelamente, este cotejo permite observar que las obras de los gramáticos Antonio de Moraes Silva (1806), Augusto Freire (1875), Júlio Ribeiro (1881) y Maximino Maciel (1894) se constituyen en verdaderos referentes de los distintos cambios de orientación de la gramática en Brasil y, además, 
determinan los principales avances teóricos y metodológicos correspondientes a cada una de las etapas gramaticográficas del siglo XIX brasileño.

A partir de estas hipótesis previas, se pretende en este trabajo someter a investigación las gramáticas escritas por los autores que, en su momento, sentaron nuevas bases teóricas y metodológicas en la tradición brasileña y que orientaron, en cierto modo, las producciones subsiguientes. Así pues, el objeto de estudio de esta investigación está constituido por un corpus de cuatro gramáticas que, en primer lugar, cumplen con los criterios básicos de fecha y lugar (Brasil, siglo XIX), origen del autor (brasileño) y lengua gramatizada (portugués) y, en segundo lugar, son representativas (e incluso determinantes) de la evolución de la doctrina gramatical en Brasil.

El Epítome de Grammatica Portugueza de Antonio de Moraes Silva, publicado en 1806 en Lisboa, pero compuesto en 1802 en Engenho Novo da Moribeca (Pernambuco), comienza la tradición brasileña de acuerdo con los fundamentos teóricos de la corriente racionalista difundidos por Port-Royal y, posteriormente, reformulados por los sensualistas y enciclopedistas. Esta doctrina se arraiga en esta tradición, de modo que hasta el último tercio del siglo todavía se publican gramáticas de corte logicista en Brasil.

La Grammatica Portugueza de Augusto Freire da Silva, publicada en São Luis do Maranhão en 1875, parte de criterios de clasificación, sistematización y nomenclatura propios de las ciencias naturales, además de aplicar a la codificación del portugués una metodología próxima a algunos principios de la gramática histórico-comparada. Estos rasgos distintivos permiten considerar la Grammatica Portugueza como el primer intento en la tradición brasileña de construir un modelo taxonómico de gramática portuguesa.

La Grammatica Portugueza de Júlio Ribeiro, que vio la luz en 1881 en Campinas (São Paulo), reúne los fundamentos de la tradición anterior, proporciona un modelo descriptivo del idioma contemporáneo y aporta conocimientos históricos y contrastivos del portugués en sus diferentes variedades, de modo que esta obra constituye la primera propuesta cabal de una gramática normativa del portugués. 
Finalmente, la Grammatica Descriptiva de Maximino Maciel, publicada en Rio de Janeiro en 1894, comprende los más extensos corpora de autoridades filológicas y literarias de la tradición gramatical brasileña decimonónica. Esta obra puede ser considerada como el primer modelo brasileño de gramática descriptiva del portugués.

El análisis de estas gramáticas está fundamentado en una metodología historiográfica que para el estudio de la tradición gramatical española ha dado excelentes resultados (véase por ejemplo los estudios de Gómez Asencio 1981, 1985; Sarmiento 1986, 2002; Ridruejo 1985, 2001, 2002; Calero Vaquera 1986; Ramajo Caño 1987; Lliteras 1992a, 1996a/b, 1997, 2002; Fries 1989; Martínez Gavilán 1989; García Folgado 2005; entre otros).

No obstante, hemos propuesto además una estructuración del análisis gramaticográfico distinta de la organización habitual, que obedece a la división de la gramática. Así, a esta introducción le siguen siete capítulos, los tres primeros descriptivos y los cuatro restantes analíticos.

El capítulo siguiente se refiere al panorama de los estudios gramaticográficos en Brasil y en Portugal. Consiste en una exposición general sobre el estado actual de las investigaciones historiográficas de la lengua portuguesa a uno y otro lado del Atlántico. El tercer capítulo contiene una breve descripción de los estudios gramaticales portugueses anteriores al siglo XIX. Se trata de recoger los principales fundamentos del pensamiento gramatical portugués entre los siglos XVI y XVIII. En el capítulo cuarto se desarrolla una breve contextualización sobre la biografía, la trayectoria académica y la contribución lingüística de los autores que constituyen las fuentes primarias citadas en las gramáticas brasileñas sometidas a estudio.

El capítulo quinto trata de la evolución de la teoría lingüística defendida en manuales compuestos por autores nacidos en Brasil, que se caracteriza por el cambio desde una concepción racionalista de la gramática hasta el alcance de los modelos descriptivos, tras la aplicación de métodos positivistas y la influencia de las corrientes histórico-comparadas. A partir del análisis de los recursos teóricos y metodológicos introducidos por Antonio de Moraes Silva, 
Augusto Freire da Silva, Júlio Ribeiro y Maximino Maciel, se pretende poner de manifiesto la evolución de la teoría gramatical brasileña del siglo XIX.

El capítulo sexto corresponde al análisis terminológico y terminográfico de las gramáticas brasileñas que constituyen nuestro objeto de estudio. Se analizan los rasgos, la organización, los parámetros de definición, entre otros aspectos relativos a los aspectos metalingüísticos de los autores brasileños (Swiggers 2009b).

El capítulo séptimo se refiere a los cambios en la gramática del portugués. Consiste en describir y analizar la evolución de la materia gramatical durante el siglo XIX brasileño, con la finalidad de determinar el avance que ha experimentado la codificación del portugués en este periodo.

Por último, el capítulo octavo se dedica al análisis de los contrastes románicos en la gramática brasileña decimonónica. Se trata de estudiar las características de la metodología contrastiva que aplican los autores brasileños para la gramatización de la lengua portuguesa y poner de manifiesto el interés de estos gramáticos por la descripción de la lengua propia también mediante el recurso de la comparación entre el portugués y otras lenguas próximas.

Los propósitos fundamentales de este trabajo son, en suma, determinar la aportación de la gramática brasileña decimonónica al conocimiento lingüístico del portugués, mostrar la evolución de la historia de la gramática portuguesa en Brasil y poner de manifiesto la posición que ocupan los gramáticos brasileños de este periodo en el contexto internacional de los estudios lingüísticos de la época. Se pretende así contribuir de algún modo al conocimiento de la gramática brasileña del siglo XIX. 


\section{HISTORIOGRAFÍA LINGÜÍSTICA DEL PORTUGUÉS}

\subsection{Estado actual de las investigaciones historiográficas sobre la lengua portuguesa}

Las primeras investigaciones sobre historiografía lingüística del portugués, o como es más conocida esta disciplina en Brasil «História das idéias lingüísticas», tuvieron lugar a uno y otro lado del Atlántico casi simultáneamente. En la década de los años ochenta las profesoras Eni P. Orlandi, en Brasil, y Leonor Buescu, en Portugal, publicaron diversos estudios sobre la «historia de lo escrito en portugués» (Gonçalves 2006b). En particular, la investigadora portuguesa se dedicó al análisis de las obras de Fernão de Oliviera, João de Barros, Duarte Nunes de Leão y Pêro de Magalhães de Gândavo, mientras que Eni P. Orlandi examinó la «língua brasileira» y algunos aspectos socioculturales de las gramáticas brasileñas.

En el artículo titulado Treinta años de Historiografía Lingüística del portugués, Filomena Gonçalves describe la trayectoria de los estudios historiográficos en Brasil y Portugal. La autora pone de manifiesto algunas particularidades de la disciplina en el contexto lusófono y muestra los principales avances en ambos países, pero con especial atención a los estudios desarrollados en Portugal.

Con respecto a Portugal, Gonçalves (2006b) afirma que las principales contribuciones de los trabajos de Leonor Buescu a la historiografía lingüística fueron, sin lugar a duda, la recuperación del corpus gramatical portugués representativo de los siglos XVI y XVII, además del reconocimiento de la tradición portuguesa en el campo de la investigación gramaticográfica nacional e internacional. Sin embargo, la autora asevera que, pese al avance de estas investigaciones en el contexto portugués de la época, los estudios de Buescu presentaban cierta indefinición: 
Maria Leonor Buescu no cuestiona el estatus epistemológico de los estudios historiográficos en el ámbito lingüístico, ni tampoco indaga las ventajas o desventajas de atribuir a ese género de investigaciones la denominación de "Historiografía Lingüística". La autora parece dar por sentado que el término "historiografía" es consensual, no siendo objeto de definición o problematización (Gonçalves 2006b: 733).

Los primeros estudios de esta disciplina en Brasil empezaron a desarrollarse a través del proyecto «História das Idéias Lingüísticas». Esta línea de investigación fue el resultado de un convenio firmado en la década de los años noventa entre el Instituto de Estudos da Linguagem da Universidade de Campinas y la Université Paris VII, bajo la supervisión de Orlandi y Auroux. A esta iniciativa se han incorporado otros importantes investigadores brasileños de las ciencias lingüísticas, como Eduardo Guimarães (Universidade de Campinas) y Diana Luz Pessoa de Barros (Universidade de São Paulo).

Actualmente, este proyecto trata de explicar el desarrollo del conocimiento lingǘstico en una época y en un contexto sociocultural determinados, en concreto el siglo XX, con especial interés por las dimensiones cognitiva, individual y social del lenguaje. Las bases teóricas provienen especialmente de los trabajos de Kuhn, Koerner, Swiggers, Auroux y Altman. Así pues, estas investigaciones están más orientadas hacia el presente que hacia el pasado de las disciplinas lingüísticas.

Sin embargo, el convenio entre la universidad francesa y la brasileña favoreció la creación de otras nuevas líneas y grupos de investigación, que actualmente representan una fuente importante en el conjunto de las publicaciones lingüísticas. El Grupo de Pesquisa em Historiografia da Língua Portuguesa (GPeHLP), coordinado por Neusa M. ${ }^{a}$ O. B. Bastos de la Pontificia Universidade Católica de São Paulo, por ejemplo, se dedica a la reflexión sobre la constitución y el desarrollo de la gramática portuguesa en el contexto brasileño desde finales del siglo XIX hasta mediados del XX y, en particular, investiga la relación entre las gramáticas y la enseñanza del portugués. 
Ahora bien, es evidente que los primeros modelos de investigación que introdujeron Buescu y Orlandi han servido de base para los estudios posteriores. Los lingüistas que siguieron a esta primera generación han construido su conocimiento historiográfico sobre los mismos paradigmas establecidos por aquellas primeras autoras, pues continúan dedicándose a la presentación general de textos gramaticales y a los aspectos socioculturales del corpus.

Estos criterios de análisis explican la propensión, común a las dos escuelas, de privilegiar el análisis del contexto histórico en el que se sitúan los autores y sus obras, frente al escaso interés que suelen mostrar por el estudio de los cambios teóricos y metodológicos que se suceden en la construcción de las disciplinas lingüísticas. Gonçalves (2006b) también reconoce que esta orientación se mantiene desde los primeros trabajos historiográficos de la lengua portuguesa y admite, además, que muchas investigaciones actuales todavía se configuran de este modo:

Pero tanto en Brasil como en Portugal, a semejanza de muchos otros senderos historiográficos, en este se nota asimismo la prevalencia de la historiografía externa sobre la interna, es decir, en lugar de la historia de los datos metalingüísticos las publicaciones privilegian el inventario de los textos (gramáticas y vocabulario), la descripción de su contenido y los aspectos de política lingüística, como se nota en los trabajos de Buescu (1983) o Fonseca (2004) (Gonçalves 2006b: 739).

En el contexto brasileño, la recepción de las nuevas teorías lingüísticas e historiográficas ha sido casi siempre tardía. La lingüística como ciencia del lenguaje, por ejemplo, tuvo sus bases asentadas en el siglo XX a través de las publicaciones de Mattoso Câmara Jr. (1971, 1974, 1975), «a quem cabe a autoria do único manual brasileiro de história da lingüística, suficientemente abrangente, publicado até a década de 80» (Altman 2009: 125).

Las consecuencias de este retraso se han manifestado desde las primeras generaciones de lingüistas a través de una incesante carrera por el conocimiento de las teorías «revolucionarias» y por un intento de recuperar el «tiempo perdido» para que el país pudiera ocupar su espacio en la 
investigación lingüística contemporánea internacional (Altman 2009: 127). Este empeño por la búsqueda de información, renovación y asimilación de las nuevas teorías ha repercutido en el desarrollo de la lingüística.

Sin embargo, la superficialidad, la imprecisión, la mezcla indiscriminada de teorías, el exceso de informaciones diversas y la escasez de reflexión han caracterizado innumerables investigaciones lingüísticas brasileñas durante siglo XX. Sin embargo, tal vez en la actualidad este panorama se está modificando, pues, como afirma Altman (2009), los investigadores han decidido redescubrir sus bases teóricas y, por consiguiente, contribuir al crecimiento y definir el objeto de estudio de la historiografía lingüística:

O Brasil parece, finalmente, ter redescoberto o Brasil na medida em que pesquisadores das mais diferentes especialidades têm sido atraídos para a revisão das tradições diacrônicas do pensamento lingüístico, aqui ostracizadas desde os anos sessenta, e, por extensão, para a história da nossa produção lingüística, lato sensu, e de suas origens. Neste sentido, nossa historiografia lingüística deverá ainda procurar conciliar e/ou resolver as orientações que apenas se delineiam entre uma História da Ciência Brasileira e/ou uma História da Cultura Brasileira (Altman 2009: 129).

Con respecto a las producciones científicas en Portugal, Gonçalves manifiesta que son escasos los trabajos teóricos «en torno al quehacer historiográfico, a sus supuestos metodológicos y prácticos, al análisis historiográfico y a la relación de la historiografía con la Lingüística, la Filología y la Historia de la Lengua». La autora afirma, además, que esta «ausencia de publicaciones» pone de manifiesto un «prejuicio respecto del estatus epistemológico de la Historiografía» (Gonçalves 2006b: 735).

En este sentido, se puede afirmar que los primeros estudios historiográficos luso-brasileños carecen, en general, de bases epistemológicas sólidas. La recepción parcial e imprecisa de diferentes perspectivas teóricas -europeas y norteamericanas- tuvo como consecuencia una producción dispar, aunque se dedicó fundamentalmente a seleccionar, inventariar y describir el corpus de análisis. 
Para superar estas deficiencias, los historiógrafos actuales han tratado de reestructurar las bases de la disciplina en sus respectivas comunidades científicas. Uno de los primeros retos fue especificar la terminología y establecer el uso de la «variedad denominativa». Tanto en Portugal como en Brasil se empleaban términos como «Historiografía Lingüística», «Historia de las Ideas Lingüísticas», "Historiografía de la Lingüística» para representar diferentes corrientes y enfoques de la historiografía lingüística. Gonçalves (2006b) explica que en Portugal, hasta una determinada época, cada denominación representaba la afiliación o bien a la escuela francesa, o bien a la anglosajona:

En la segunda mitad del siglo XX, los estudios de naturaleza historiográfica suelen ser reconocidos como "Historiografía Lingüística", "Ideas Lingüísticas" e "Historia de la Lingüística", denominaciones concurrentes que transcienden la mera variedad denominativa, llegando a denunciar la afiliación de los autores a ciertas escuelas o perspectivas dentro del ámbito historiográfico. Ejemplo cabal de ello es la evidente polarización entre, por un lado, el modelo anglosajón, que impulsó y dio preferencia a la "Historiografía Lingüística", (...) y, por otra parte, el modelo francófono (si no francófilo), decantándose por una de las expresiones siguientes: "Ideas Lingüísticas", "Pensamiento Lingüístico" (...) , y por último, "Gramaticografía", este sí, genéticamente vinculado a la producción del género metalingüístico conocido como gramática (Gonçalves 2006b: 734).

En cuanto a los investigadores brasileños, no hay distinción entre los diferentes términos designativos. Altman (2009), por ejemplo, destaca que la oposición entre «Historiografía» e «Historia de las Ideas» es falsa y manifiesta que las distintas denominaciones pueden ser utilizadas como sinónimos:

No Brasil, ao lado do termo historiografia da lingüística, duas outras designações relativas ao campo têm ocorrido com certa freqüência: historiografia lingüística e história das idéias lingüísticas, aparentemente representativas de orientações diferentes que se tem procurado imprimir ao nosso incipiente trabalho e prática historiográficos. A oposição entre historiografia ou história das idéias é, entretanto, uma falsa questão (Altman 2009:129 [la negrita es mía]). 
Con respecto a la definición de la historiografía lingüística, la versión más difundida entre los estudiosos brasileños corresponde a la propuesta por Auroux (1989). Del autor francés se toma la idea de que la lingüística es todo el saber constituido en torno a una lengua, en un momento específico, como producto de una reflexión metalingüística o de una actividad metalingüística no explícita (Fávero y Molina 2006).

A pesar de que esta concepción se aplica normalmente al análisis lexicográfico y gramaticográfico, Fávero y Molina tratan de extender el método de Auroux a otros objetos de estudio, como, por ejemplo, a las instituciones y a los medios de difusión que gestionan el conocimiento lingüístico. Para justificar estas ideas, las autoras afirman que el historiador debe proyectar los hechos en un hiperespacio que abarca las dimensiones cronológica, geográfica y «um conjunto de temas») (Fávero y Molina 2006: 25).

Por su parte, Altman (2009) entiende que la historiografía lingüística es una disciplina de carácter científico que describe y explica cómo se produce y se desarrolla el conocimiento lingüístico en un determinado periodo y contexto. La autora destaca también que aunque esta disciplina requiera procedimientos metodológicos distintos, como historiografías orientadas hacia el contenido -que se articulan sobre las dimensiones internas de las teorías lingüísticas- e historiografías orientadas hacia el contexto -que se asientan en teorías que tienen como prerrogativa el contexto social, cultural y político- contenido y contexto están ineludiblemente relacionados, por más que se hayan concebido hasta ahora como metodologías opuestas (Altman 2009: 128).

Respecto a su objeto de estudio, la historiografía lingüística en Brasil y Portugal ha extendido su análisis hacia las producciones menos tradicionales. En Brasil, particularmente, los estudios sobre la "Historiografía Canónica» (Altman 2009) se dedican al periodo posterior a la reforma educativa de Fausto Barreto',

\footnotetext{
1 Fausto Barreto fue un profesor del Colégio Pedro II en Rio de Janeiro que, en 1887, reformó el plan de enseñanza de la lengua portuguesa en Brasil. Inspirado en las ideas positivistas, Barreto desarrolló un programa que sirvió de base no solo para los exámenes preparatorios, sino también para la elaboración de gramáticas del portugués.
} 
a las publicaciones con objetivos pedagógicos y al análisis de los procedimientos de difusión, instituciones y contextos, como ya se ha mencionado. Otra rama de la historiografía brasileña, la lingüística misionera, analiza los diversos registros de autoría misionera en los que se documentaron las lenguas no indoeuropeas habladas en las antiguas colonias, especialmente las gramáticas. El éxito de esta especialidad es el resultado del interés por la descripción de las lenguas exóticas y por la importante representatividad que alcanzan estos textos en el conjunto de los conocimientos historiográficos. Actualmente, la lingüística misionera constituye una de las más destacadas líneas de investigación de la historiografía lingüística.

En Portugal no cabe duda de que la «Historiografía Ibérica» (Gonçalves 2006b) desempeña un papel importante en el estudio de la recuperación y difusión de las ideas lingüísticas en la península ibérica entre los siglos XVI y XVIII. Gonçalves (2005b) también muestra la relevancia de las investigaciones relacionadas con la «Historiografía Menor», que tiene como objeto de estudio a los autores y las obras que constituyen las fuentes indirectas de información lingüística, frecuentemente marginados por la historiografía canónica. La autora afirma que esta especialidad de la historiografía lingüística trata de «explorar os canais subterrâneos que [...] permitem explicar a propagação das ondas transmissoras de teorias e de saberes constituídos à volta das línguas naturais, ajudando a responder à dicotomia teórica entre continuidade e descontinuidade na história do pensamento lingüístico» (Gonçalves 2005b: 399).

Por otra parte, son escasas las investigaciones sobre las metodologías, las bases epistemológicas y los avances de la historiografía lingüística en Brasil y en Portugal. Sin embargo, cabría aquí destacar los estudios de Altman (1996, 1998, 2009), Gonçalves (2006b), Gärtner (1997) y Orlandi (1997, 2001) dedicados a estos aspectos de la historia de la gramática brasileña.

En cuanto a los estudios sobre la gramática portuguesa de los siglos XVI al XVIII, pueden ponerse de relieve las contribuciones de Gonçalves (e.p, 2002a/b, 2005a/b/c, 2006a), Assunção (1997 a/b, 1999, 2000), Kosarik (2000), Buescu (1978, 1983, 1984), Cardoso (2004) y Ponce de León Romeo (2000, 2001, 2002, 2003, 
2004, 2005a/b/c, 2006, 2008a/b). Se observa, sin embargo, que la mayoría de los estudios dedicados a este periodo, a excepción de algunas publicaciones de Gonçalves, Assunção y Ponce de León Romeo, se orientan más hacia los aspectos contextuales y muy rara vez tratan de temas estrictamente gramaticales. Las investigaciones que prestan atención a la evolución del proceso de codificación del portugués son todavía relativamente escasas tanto en la gramaticografía brasileña como en la portuguesa.

Los estudios gramaticográficos tal vez más representativos de la historiografía portuguesa actual son el Arte da Grammatica da Lingua Portuguesa de Antonio José dos Reis Lobato (1770) y el Methodo Grammatical para todas as Linguas de Amaro de Roboredo (1621). En el primero, Assunção (1997a/b, 2000) destaca, entre otros aspectos, la función pedagógica desempeñada por Reis Lobato durante el periodo pombalino y, en el segundo, Fernandes (2002) y Fernandes, Ponce de León Romeo y Assunção (2007) ponen de manifiesto el avance y la importancia de la obra de Roboredo para la enseñanza del latín en Portugal.

En cuanto a los estudios sobre la gramática portuguesa decimonónica, es importante destacar los trabajos de autores como Gonçalves (2000b, 2004), Amadeu Torres (2004), Casteleiro (1980/81) y Simão Cardoso (1986). Asimismo, cabe señalar que la mayoría de estas investigaciones recaen en el análisis de la Grammatica Philosophica da Lingua Portugueza de Jeronimo Soares Barbosa (1822), la obra más representativa de la corriente racionalista en la gramaticografía portuguesa del siglo XIX.

No obstante, la segunda mitad del siglo XIX constituye el periodo de mayor interés para los historiógrafos de la lengua portuguesa. Gonçalves (2006b) considera que esta inclinación se debe, por un lado, a la publicación tardía de gramáticas filosóficas $y$, por otro, a la influencia del método históricocomparativo:

Quizá por ello, cuando se compara con la segunda mitad del siglo, la primera no haya suscitado, en historiografía relativa al siglo XIX, el interés de aquella, pues en verdad se trata de descubrir la transición hacia el 
paradigma histórico-comparativo a través de corrientes de transición subterráneas, es decir, textos menos conocidos y menos canónicos. Eso explica que la bibliografía se centre en las evidencias del cambio paradigmático, es decir, los autores que ya se declaran representantes del nuevo método, como los ya citados Francisco Adolfo Coelho, José Leite de Vasconcelos, y Gonçalves Viana (Gonçalves 2006b: 743).

Además, Gonçalves (2006b) añade que la fonética, la ortografía, las cuestiones etimológicas, la constitución de la gramática y la terminología son los aspectos más estudiados por los investigadores. A estos estudios, sin embargo, puede decirse que les falta sistematización y profundidad analítica.

A propósito de las investigaciones historiográficas en Brasil, sobresalen principalmente los estudios de Altman (1997a/b, 2003, 2007), Barros (2000), Bessa Freire y Rosa (2003), Rosa (1995), Zimmerman (1997), Zwartjes y Altman (2005), entre otros, sobre la lingüística misionera y su papel en la historiografía lingüística brasileña. Guimarães y Orlandi (1996), Bastos y Palma (2004) y otros investigadores que forman parte del GPeHLP también pueden ser considerados una referencia en el análisis de los aspectos pedagógicos que desarrollan las gramáticas brasileñas publicadas a finales del siglo XIX y principios del XX.

Los estudios sobre la gramática brasileña del siglo XIX normalmente se fundamentan en los tratados de Cavaliere (2000, 2003), Fávero (2002a/b, 2010), Fávero y Molina $(2006,2007)$. Estos y otros autores brasileños han prestado especial atención al análisis del Epitome da Grammatica Portugueza de Antonio de Moraes Silva (1806) y de la Grammatica Portugueza de Júlio Ribeiro (1881), obras modélicas en la gramaticografía brasileña decimonónica.

Del mismo modo que ocurre en Portugal, los investigadores brasileños también privilegian el estudio de las obras publicadas en la segunda mitad del siglo XIX, periodo denominado «científico» por la generalidad de estos historiógrafos. Las dos escuelas coinciden, además, en las razones que motivan esta predilección, como son la publicación tardía de gramáticas filosóficas y la influencia de la corriente histórico-comparatista. Igualmente, los aspectos más analizados recaen en la constitución de la gramática, la terminología, el contexto histórico, la importancia social y pedagógica de los manuales, las 
normas discursivas y la cuestión de la identidad brasileña. Sin embargo, por lo general, los estudios brasileños tampoco pueden considerarse un modelo de investigación historiográfica rigurosa.

\subsection{Principales propuestas de periodización de la gramática brasileña decimonónica}

La mayoría de los estudios historiográficos brasileños analiza los tratados gramaticales a partir de una perspectiva histórica y contextual que suele entrecruzarse con alguna novedad en la oferta de publicaciones. En este sentido, algunos historiógrafos brasileños como Bastos (2006), Cavaliere (2000, 2010) o Fávero y Molina (2006) están de acuerdo en señalar dos fechas que marcan cambios de rumbo en la tradición brasileña. La primera se corresponde con la presencia de una gramática supuestamente innovadora, cuya recepción pertenece al ámbito de la historia interna de la disciplina, pero la segunda fecha se sitúa propiamente en el terreno de la historia externa:

1) En 1881 tiene lugar la publicación de la Grammatica Portugueza de Júlio Ribeiro. Con esta obra -según los autores citados- se introducen en la gramaticografía brasileña las primeras concepciones históricocomparatistas.

2) Poco después, en 1887, se aprueba el Programa de Ensino Fausto Barreto (1887), que condiciona la orientación teórica y metodológica los textos gramaticales publicados en esta época.

Por nuestra parte, podemos precisar que estos puntos de inflexión en la historia de la gramática brasileña deberían replantearse a la luz del análisis riguroso de la Grammatica Portugueza de Augusto Freire (1875). Con anterioridad a la reforma de la enseñanza y a la publicación de la Gramática 
de Ribeiro, Freire ya presentaba en su obra influencias de las doctrinas historicistas. A pesar de que el autor no menciona explícitamente la mayoría de las fuentes teóricas y de que conserva las bases tradicionales-característica también bastante presente en la Gramática de Ribeiro-, el tratado de Freire demuestra que la orientación histórico-comparatista ya había sido introducida en la tradición brasileña.

Desde el principio de la investigación historiográfica en Brasil, los autores insisten en formular propuestas de periodización que muestren la evolución de los estudios gramaticales brasileños. La mayoría de estas propuestas se fundamentan en los hechos políticos, sociales y culturales que acompañaron el desarrollo de la tradición gramatical brasileña, como la influencia de la gramática lusitana, el sentimiento nacionalista, la independencia política del país y la creación de instituciones educativas.

El primer autor que trató de esbozar una división de los estudios filológicos brasileños fue Antenor Nascentes (1939). Su propuesta comprende cuatro periodos:

1) El embrionário, que se extiende desde los principios de la cultura brasileña hasta 1835, fecha de publicación del Compêndio da gramática da língua nacional de Antônio Álvares Pereira Coruja. Según el autor, este fue el periodo orientado hacia el pensamiento lusitano.

2) El empírico, que empieza en 1835 con la publicación de la Coleção de Vocábulos e frases usadas na provincia de S. Pedro do Rio Grande do Sul también de Coruja, y termina en 1881, fecha de la Grammatica Portugueza de Júlio Ribeiro.

3) El gramatical, desde 1881 hasta 1939, periodo en que se fundó la Faculdade Nacional de Filosofia da Universidade do Brasil (Fávero y Molina: 2006).

4) A partir de 1939, Nascentes abre una etapa indefinida que coincide con la fecha de su propia publicación. 
La segunda propuesta de periodización se debe a Silvio Elia (1975), que distingue dos etapas:

1) La vernaculista, desde 1820, fecha de la independencia política de Brasil, hasta 1881 con la publicación de la Gramática de Júlio Ribeiro. Según el autor, este periodo se caracteriza por el «encontro da corrente classicizante -dos que queriam a Língua Portuguesa calcada no modelo lusitano- com a dos reformistas -dos que aceitavam os vários falares que começavam a construir a Língua Portuguesa do Brasil») (Fávero y Molina 2006: 48).

2) La científica, de 1881 a 1960, que el autor divide en dos fases:

a) De 1881 a 1900, caracterizada como periodo de transición, «em que a renovação prevalece sobre o conservadorismo da época anterions (Fávero y Molina 2006: 48).

b) De 1900 a 1960, caracterizada básicamente por el rechazo a las bases normativas.

El tercer intento corresponde a la propuesta de Guimarães (1996), que divide los estudios filológicos en cuatro etapas:

1) Desde el descubrimiento hasta mediados del siglo XIX se extiende el periodo caracterizado por las polémicas acerca de la lengua portuguesa hablada en Brasil y por la ausencia de estudios sobre esta variante.

2) Entre 1881 y 1930 se prolonga la etapa marcada por la publicación de la Grammatica Portugueza de Júlio Ribeiro.

3) De 1930 a 1960, periodo marcado especialmente por la elaboración de la «Nomenclatura Gramatical Brasileira». 
4) Desde 1965 hasta la actualidad tiene lugar el desarrollo de las diversas corrientes de investigación lingüística (estructural, funcional, generativa, etc.) (Fávero y Molina 2006).

La propuesta quizá más generalizada en la actualidad es la de Cavaliere (2002), que utiliza como criterios básicos de división las fuentes teóricas utilizadas en las gramáticas modélicas de la tradición brasileña. En este sentido, el autor distingue cuatro periodos en esta gramaticografía:

1) El embrionário, que se extiende desde los descubrimientos hasta 1802 , año en que Moraes Silva termina de escribir su Epítome, que se publicaría en 1806.

2) El racionalista, desde 1802 hasta 1881, periodo destacado por la publicación de la Grammatica Portugueza de Sotero dos Reis (1835).

3) El científico, de 1881 a 1941, que se divide en dos fases:

a) Fase fundadora (1881-1920), que comienza con la Gramática de Júlio Ribeiro.

b) Fase legatária (1920-1941), «em que os pesquisadores preocupamse exclusivamente com o fato em língua vernácula» (Fávero y Molina 2006: 51).

4) El lingüístico, de 1941 a la actualidad, marcado por el estructuralismo y la especialización de los estudios lingüísticos.

A pesar de la importancia relativa que adquieren estos intentos de periodización en la historiografía brasileña, hay que poner de manifiesto que la generalidad de estas teorías se basa en criterios heterogéneos, suele carecer de coherencia interna y prescinde casi siempre de contenidos metalingüísticos fundamentales, como las fuentes teóricas implícitas o explícitas, la aplicación metodológica, la presencia de rasgos descriptivos, la utilización de corpus o archivos de autoridades literarias, la evolución del proceso de codificación de la lengua, el interés por la fijación normativa, el alcance prescriptivo, las 
consideraciones diacrónicas y diatópicas, la atención a la lengua oral, la cuestión terminológica, entre otros aspectos relevantes en los estudios historiográficos actuales. En suma, la excesiva simplificación y superficialidad de los análisis historiográficos reseñados, junto a la mezcla indiscriminada de criterios de periodización, frecuentemente ajenos a la propia disciplina, son algunos factores que explican las habituales clasificaciones de las gramáticas brasileñas decimonónicas en «racionalistas», de un lado, y «científicas», del otro.

Al contrario de lo que las propuestas de periodización indican, la tradición brasileña no sufre cambios bruscos de doctrina gramatical, sino que experimenta un desarrollo continuo caracterizado por la superposición de diferentes corrientes teóricas. En el caso de las gramáticas brasileñas decimonónicas, las obras de la primera mitad del siglo XIX mantienen sus bases tradicionales $y$, al mismo tiempo, aplican las concepciones normativas $y$ logicistas a la codificación del portugués, mientras que las finiseculares concilian la doctrina tradicional de tipo normativo con los métodos históricocomparatistas y, en algunos casos, también con los procedimientos descriptivos. Así pues, resulta insuficientemente justificada la clasificación, por ejemplo, de la Grammatica Portugueza de Augusto Freire (1875) como filosófica o de los manuales de Júlio Ribeiro (1881) y Maximino Maciel (1894) como históricocomparatistas, cuando en realidad estas obras acumulan diferentes corrientes gramaticales $^{2}$. El análisis riguroso de las obras fundamentales del siglo XIX brasileño conduce a un nuevo sistema de periodización basado en criterios coherentes con la evolución doctrinal. La propuesta trata de ordenar y precisar los modelos vigentes, resumidos hasta aquí.

\footnotetext{
2 Los gramáticos brasileños de este periodo, en general, se podrían identificar con la corriente de los "eclécticos» (o «reformistas incoherentes»), como denomina Gómez Asencio (1981) a aquellos autores que, upreocupados por la innovación de los estudios gramaticales, se dejan convencer por las novedades recién importadas [...]; son gramáticos que respetuosos con la tradición o temerosos de abandonarla, aceptan ideas y métodos rutinarios que eran propios de esa tradición [...]; los gramáticos no seleccionaron los materiales de acá y de allá para elaborar un único cuerpo sólido y coherente de doctrina, sino que procedieron por acumulación, sumando teorías dispares de orígenes diversos») (Gómez Asencio 1981: 352-352).
} 
En este sentido, se pretende determinar la evolución y las aportaciones de las gramáticas brasileñas del siglo XIX. Este trabajo también descarta la denominación utilizada actualmente en la historiografía brasileña para designar las gramáticas publicadas en el último cuarto del siglo XIX. Por nuestra parte, creemos que el empleo de la expresión "gramática científica» parece indicar que únicamente las obras novecentistas finiseculares son científicas o basadas en métodos científicos. Por el contrario, aquí se sostiene que, además de la imprecisión en el uso de estas etiquetas, cualquier gramática que sigue una metodología coherente con la finalidad de codificar una determinada lengua presenta un carácter científico.

Con respecto a las gramáticas analizadas en esta investigación, es importante poner de manifiesto la posición que las obras de Moraes Silva, Augusto Freire, Júlio Ribeiro y Maximino Maciel ocupan en la historia de la gramática en Brasil, así como el tratamiento que han recibido estas gramáticas en los estudios historiográficos.

Pues bien, la primera aportación brasileña a la historia de la gramática del siglo XIX está representada aquí por el Epítome de Grammatica Portugueza de Moraes Silva (1806). La obra de Moraes comienza esta tradición gramatical sobre la base de las ideas racionalistas procedentes de Europa a través de la influencia de algunas gramáticas portuguesas, como la de Reis Lobato (1770). La primera polémica en torno a la obra de Moraes reside en su clasificación como una obra portuguesa o brasileña. La generalidad de los historiógrafos considera que el Epítome forma parte de la tradición portuguesa (Assunção 2002, Gonçalves 2006b) e incluso Fávero y Molina (2006) están de acuerdo con esta idea, aunque defienden que Moraes Silva es un autor brasileño:

Embora Moraes Silva tenha nascido no Brasil e aqui escrito sua gramática, podemos considerá-la um livro português, pois não trata de particularidades que apresentava a língua aqui falada, e segue, como vimos, a linha filosófica que imperava em Portugal.

[...]

Mesmo considerando a obra um livro português, não podemos concordar com Sá Nogueira (1936: 202), que disse ser Moraes Silva um escritor de 
nacionalidade portuguesa porque "nasceu no Rio de Janeiro entre os anos de 1756 e 1758 e publicou a primeira edição de seu dicionário em 1789, e a segunda em 1813, tudo isto ainda quando o Brasil era de Portugal" (Fávero y Molina 2006: 69).

Los argumentos utilizados por los historiógrafos para corroborar esta opinión están relacionados con las circunstancias políticas y sociales en torno a la publicación del Epítome. En el año de publicación del Epítome de Moraes, Brasil todavía era colonia portuguesa y solo ganó su independencia en 1822. Sin embargo, en este periodo Portugal ya dependía económicamente de su colonia, es decir, en la práctica, Brasil era independiente mucho antes de la fecha oficial. Asimismo, los ciudadanos nacidos en territorio brasileño en esta época poseían nacionalidad portuguesa y eran considerados portugueses de Brasil. De acuerdo con estas circunstancias, tanto Moraes como el Epítome pertenecen a la tradición gramatical portuguesa.

Por este motivo, muchos autores consideran que la primera obra de la gramaticografía brasileña es el Compendio de Lingua Nacional de Pereira Coruja, publicado en 1835, después de la fecha oficial de la independencia. A propósito de este tema, Molina (2008) cita a Nascentes (1939):

Coruja, que inaugurou a nossa gramaticografia, vai também inaugurar a dialetologia publicando em 1852 no tomo XV da Revista do Instituto Histórico e Geográfico Brasileiro a Coleção de vocábulos e frases usados na província de São Pedro do Rio Grande do Sul, que saiu em $2^{a}$ edição, em Londres, em 1856, graças ao príncipe Luciano Bonaparte (Nascentes 1939:23 apud Molina 2008: 1394).

Frente a las opiniones actuales, se defiende aquí que el Epítome de Moraes Silva también puede ser incluido en la gramaticografía brasileña, del mismo modo que los investigadores incluyen el Breve Compendio de Grammatica Portugueza de Frei Caneca (1817) en la tradición del Nuevo Continente, pues estas obras tienen en común, además del contexto político y social, la doctrina logicista. 
Por nuestra parte, creemos que algunos criterios de clasificación utilizados habitualmente, como no tratar «de particularidades que apresentava a língua aqui falada, e segue, como vimos, a linha filosófica que imperava em Portugal» (Fávero y Molina 2006: 69) no justifican la exclusión de la obra de Moraes de la tradición brasileña, pues conviene tener presente que en la mayoría de las gramáticas de la primera mitad del siglo XIX se presta escasa atención a la variante brasileña.

Asimismo, se pueden aportar otros argumentos a favor de la relación del Epítome con la gramaticografía brasileña, como la independencia económica y cultural del país, pese a su condición de colonia, que se revela, por ejemplo, en la fecunda producción literaria de Brasil en este periodo.

Con todo, después de la publicación del Epítome, la tradición brasileña experimenta un notable crecimiento en su producción gramatical. Las principales obras que siguieron al tratado de Moraes fueron las gramáticas de Frei Joaquim do Amor Divino Caneca (1817), Antonio Álvares Pereira Coruja (1835), Policarpo José Dias da Cruz (1853), José Alexandre Passos (1855), Francisco Praxedes de Andrade Pertence (1861), Manoel da Silva Bezerra (1861), Joaquim Caetano Fernandes Pinheiro (1864), Francisco Sotero dos Reis (1865), Charles Adrien Olivier Grivet (1865) y Laurindo José da Silva Rabelo (1867). Estas obras se caracterizan por su finalidad pedagógica, por el carácter racionalista y por el sentido normativo o preceptivo de la doctrina.

Esta perspectiva empieza a cambiar con la Gramática de Augusto Freire (1875) y, consecuentemente, las obras posteriores también comienzan a aplicar al portugués nuevos métodos de codificación gramatical. El tratado de Freire ha sido considerado en la mayoría de los estudios historiográficos como un representante más de la escuela racionalista en Brasil. Incluso Fávero y Molina (2006) reconocen que la Grammatica Portugueza de Freire presenta un carácter más bien filosófico, en sintonía (según las autoras) con la época anterior a la institucionalización del Programa Fausto Barreto (1887).

Sin embargo, esta investigación trata de mostrar que pese a ciertas raíces teóricas y metodológicas de corte racionalista, la Grammatica de Freire 
presenta cambios innovadores en la estructura y en la teoría gramatical, de tal modo que puede considerarse una de las primeras gramáticas brasileñas que introduce los estudios historicistas y positivistas en esta tradición.

Con respecto a la Grammatica Portugueza de Júlio Ribeiro (1881 1-18852), ya se ha mencionado que los estudios historiográficos desarrollados desde Nascentes (1939) hasta Cavaliere (2002) reconocen esta obra como el punto de inflexión de la tradición brasileña. Estos estudios defienden que Júlio Ribeiro fue el primer gramático brasileño que sistematizó un cuerpo de doctrina que se mantuvo vigente en Brasil hasta bien entrado el siglo XX. En realidad, la obra se constituye en la primera de su tradición que supone el fin del racionalismo para dar paso a un modelo gramatical basado en el concepto de codificación normativa, con cierto trasfondo de los supuestos positivistas e historicistas.

Las gramáticas posteriores a la de Ribeiro, en particular las de João Ribeiro 1887, Pacheco y Silva 1887 y Alfredo Gomes 1887 muestran el desarrollo de la aplicación de los aspectos fundamentales de las corrientes históricocomparatista y positivista en la codificación del portugués. Finalmente, con la Grammatica Descriptiva de Maximino Maciel (18871-18942) estas teorías alcanzan su expresión más consolidada. Aunque algunos estudios historiográficos clasifican las obras posteriores a la Gramática de Júlio Ribeiro más bien en las corrientes histórico-comparatistas, cabría señalar, por nuestra parte, que son más bien positivistas. La cita siguiente de Maciel apunta, en efecto, hacia la novedad que representa en la lingüística de la época la introducción del positivismo:

Os espíritos dir-se-ia que acordavam para transfundir na linguistica o criterio experimental e positivo, rompendo de vez com a tradição e rotina, immobilisadas na deficiencia de incentivo, apesar da nova orientação que se vinha impondo aos poucos que se dedicavam a esses estudos (Maciel 1926[1894]: 500 [la negrita es mía]).

Con anterioridad, también Júlio Ribeiro se había referido a algunas diferencias fundamentales entre su propio trabajo y las corrientes historicistas. Advirtió el autor que e estudio desarrollado en una gramática histórica va 
mucho más allá de unas cuantas observaciones superficiales acerca de algunos aspectos etimológicos de la lengua. Respecto a este tema, el autor reconoce que su Gramática no analiza de forma detallada la evolución de la lengua:

Claro está que só uma grammatica especialmente histórica e um diccionario etymologico poderão tratar detidamente das palavras portuguezas oriundas de todas essas fontes [latín, griego, árabe, tupy], e quiça de outras (Ribeiro 1899[1885]: 163).

Las gramáticas brasileñas denominadas explícitamente históricas no se publican antes del primer tercio del siglo XX. Las más representativas de esta orientación son: la Syntaxe e grammatica histórica da lingua portuguesa de P.S. (1909); Grammatica histórica de Eduardo Carlos Pereira (1916); Grammatica histórica e comparada da lingua portuguesa de Hermínio Sarmento (1917). La única excepción a esta cronología quizá sean los Principios de grammatica histórica e comparada de Antonio Estevão da Costa e Cunha publicados en 1883. Sin embargo, solo hemos encontrado una breve referencia a esta obra en el Diccionario Bibliographico Brazileiro de Sacramento Blake (1902).

En conclusión, teniendo en cuenta el contexto actual en el que se desarrollan los estudios historiográficos de la lengua portuguesa, se propone aquí una nueva perspectiva para el análisis de los modelos gramaticales brasileños. Se han seleccionado, de una parte, las obras más representativas que han sido objeto de estudios más o menos exhaustivos, pero no siempre concluyentes, como son el Epítome de Grammatica Portugueza de Moraes Silva (1806), la Grammatica Portugueza de Júlio Ribeiro (1881) y la Grammatica Descriptiva de Maximino Maciel (1894). Pero, junto a estos textos, que ocupan una posición destacada en la investigación gramaticográfica, también se incluye en este trabajo el análisis de una obra aparentemente menos canónica, por así decirlo, como es la Grammatica Portugueza de Augusto Freire (1875).

Así pues, el objetivo de esta investigación consiste en analizar los modelos gramaticales seleccionados con el fin de mostrar la evolución de los principios teóricos y metodológicos que determinan el proceso de codificación del 
portugués. Se pretende, en suma, contribuir de este modo al conocimiento de la historia de la gramática brasileña del siglo XIX.

Por último, cabe resaltar que en este trabajo se prescinde de las demás gramáticas publicadas en la primera mitad del siglo XIX, pues tales obras representan modelos tardíos y reiterados de gramáticas racionalistas que no aportan cambios significativos a la estructura interna, la metodología, la terminología y los conceptos gramaticales, en general. A diferencia de estos tratados que suelen preservar el modelo y la doctrina gramatical de sus predecesores, los autores seleccionados aquí rompen con la rutina, consiguen reorientar la herencia recibida y logran incorporar novedades que favorecen el avance del pensamiento gramatical. 


\section{LA TRADICIÓN GRAMATICAL PORTUGUESA ANTERIOR AL SIGLO XIX}

Este breve panorama de los estudios gramaticales anteriores al siglo XIX persigue la finalidad de señalar algunas de las características propias de la evolución general de la gramaticografía en lengua portuguesa. Con este capítulo se pretenden alcanzar dos objetivos. Por un lado, se trata de reunir los principales fundamentos del pensamiento gramatical portugués entre los siglos XVI y XVIII. Pero al mismo tiempo, también interesa distinguir las aportaciones de la tradición que sirvieron de base para la construcción de la gramática portuguesa decimonónica compuesta especialmente en Brasil y no solo en Portugal.

Sin embargo, no es el objetivo de este trabajo proporcionar una descripción exhaustiva de la tradición gramatical portuguesa anterior al siglo XIX, pues la historiografía lingüística dispone actualmente de una extensa bibliografía sobre este asunto. Al respecto, se pueden citar, por ejemplo, los estudios de Buescu (1978, 1983, 1984, 2000), Verdelho (1982, 1995, 1997, 1998), Torres (1982, 1998, 2004, 2005), Assunção (1997a/b, 2000, 2007), Cardoso (1994, 2004), Assunção y Fernandes (2007), Fávero (1996), Fonseca (2004), Ponce de León Romeo (1996, 2000, 2001, 2002, 2003, 2004, 2005a/b/c, 2006), Gonçalves (2002a/b, 2005 a/b/c, 2008c), entre otros.

Por seguir la ordenación más habitualmente admitida en la investigación historiográfica, se refleja aquí la evolución del pensamiento gramatical portugués en dos periodos, correspondientes al Renacimiento y a la llustración. 


\subsection{La etapa renacentista}

Los primeros intentos de gramatización del portugués tuvieron lugar en la tradición portuguesa a mediados del siglo XVI. En este periodo, los estudios humanísticos se dirigían al conocimiento del latín. Pero, paralelamente a esta hegemonía, algunas obras ya presentaban avances con respecto a la codificación de las lenguas vernáculas (Percival 1992: 153). A pesar de que estas aportaciones tenían la finalidad de facilitar la comprensión y el aprendizaje del latín, su enseñanza a través del vernáculo constituye uno de los principales fenómenos que motivaron la codificación de las lenguas vulgares (Ponce de León Romeo 2004).

En 1536 Fernão de Oliveira publica la Grammatica da Lingoagem Portuguesa, considerada como la primera gramática portuguesa. Aunque esta obra abrió camino a otros estudios en portugués, como la gramática de João de Barros (1540) y la Orthographia da Lingoa Portugueza de Duarte Nunes de Leão (1576), los tratados gramaticales de este periodo todavía sostienen que su objetivo principal es la enseñanza del latín.

Algunas gramáticas latinas de esta tradición publicadas en el siglo XVI también atendieron a determinados aspectos de la lengua portuguesa. Este es el caso de De institutione grammatica libri tres de Manuel Álvares (1572), que «presenta versiones en portugués de los paradigmas verbales y de parte de los ejemplos y de valiosos comentarios sobre aquella lengua») (Ponce de León Romeo 2004: 55).

Los primeros gramáticos portugueses, preocupados por codificar la lengua nacional, tenían como principal objetivo «estabelecer o que o uso introduziu e consagrouı) (Buescu 1978: 17), es decir, determinar las reglas que rigen la lengua, con especial énfasis en la ortografía. En el siglo XVI, algunas partes de la gramática todavía carecían de metodología y sistematización. Este es el caso de los estudios etimológicos, que empiezan a desarrollarse en la gramaticografía portuguesa a finales del siglo XVI y principios del XVII. El Origem da Lingoa Portugueza de Duarte Nunes de Leão (1606) constituye una de las 
primeras publicaciones que describe el origen y la evolución del portugués. En cuanto al trabajo de este autor, Swiggers (1992) destaca su contribución al estudio histórico del portugués:

The best results were obtained, however, in short-range comparisons, especially in the Romance field. Duarte Nunes de Leão (1606) and Bernardo Aldrete (1606) had a basically correct view of the historical relationship between Latin and Portuguese or Spanish; they also identified a number of diachronic correspondences (Swiggers 1992: 158).

Este periodo renacentista también se caracteriza por el tratamiento de los problemas relacionados con la definición de norma, la corrupción y la evolución de la lengua. Con respecto a este tema, Fernão de Oliveira afirma en su Gramática que no se debe desconfiar «da nossa língua, porque os homens fazem a língua e não a língua os homens») (Fernão de Oliveira apud Buescu, 1978: 26). Se puede observar que el autor portugués ya consideraba que la lengua no es estable sino que evoluciona según las modificaciones introducidas por los hablantes. Las gramáticas renacentistas portuguesas también se interesaron por otras cuestiones que formaban parte de las preocupaciones de este siglo, como la clasificación de las palabras, las flexiones nominal y verbal, la diferencia entre conjugación y declinación, la división de los verbos en sustantivos y adjetivos, la terminología, entre otros aspectos.

En este sentido, Verdelho (1995), en la obra As origens da Gramaticografia e da Lexicografia latino-portuguesas, propone una división del periodo renacentista en Portugal. El autor estudia las principales características de las gramáticas portuguesas publicadas en el siglo $\mathrm{XVI}$ y, a partir de este análisis, establece en esta centuria tres etapas diferentes:

Poderemos diferenciar ao longo do século, três momentos bem distintos da formulação e exercitação gramatical portuguesa. Um momento préhumanista, que se prolonga até aos anos trinta [denominado pastrano]; um segundo período de consagração dos valores lingüísticos do humanismo, que ocupa o meio século e que se caracteriza por uma intensa produção de manuais escolares, pelo aparecimento das primeiras gramáticas da 
língua portuguesa, e pela impressão em Portugal dos primeiros textos lexicográficos [llamado vernáculo]; finalmente, a partir de 1572, ano da publicação da gramática de Manuel Álvares, um terceiro momento, marcado pelo predomínio da escolarização dos Jesuítas e pelo início da gramaticografia moderna (Verdelho 1995: 90).

En cuanto al desarrollo de la gramaticografía portuguesa en el siglo XVII, Maria do Céu Fonseca (2004) en el artículo Historiografia lingüística portuguesa: o contributo do século XVII describe las contribuciones más significativas de los estudios humanísticos europeos, en especial los franceses, para la tradición portuguesa y su influencia en la constitución de la gramática renacentista en Portugal.

La autora destaca en su trabajo que el pensamiento gramatical europeo en este periodo se caracteriza por la influencia del cartesianismo y la recuperación del racionalismo formulado por el Brocense. La combinación de estas doctrinas abrió camino a los métodos empírico-inductivos y a una reformulada gramática universal (Fonseca 2004, Buescu 1978, 1983, 1984). En este sentido, la Grammaire Générale et Raisonnée de Port-Royal (1660) constituye el punto de inflexión en la gramaticografía europea pues, como bien señala Fonseca (2004), esta obra determina la transformación del pensamiento gramatical:

No que toca a ciência gramatical, os seus princípios metódicos vêm sugeridos em aposto do título de uma das obras de Port-Royal: "Grammaire générale et raisonnée contenant les fondements de l'art de parler, expliques d'une manière claire et naturelle; les raisons de ce qui est commun à toutes les langues, et des principales différences qui s'y rencontrent" (Arnauld e Lancelot, 1660; cf. ed. de Jean-Marc Mandosio [1997]), onde se reconhece a mesma preocupação pelo rigor demonstrativo que moveu Descartes a procurar um sistema universal do saber, sob inspiração do formalismo das deduções matemáticas. Daí que a ciência gramatical do século XVII e sobretudo XVIII não tenha ficado imune ao influxo da investigação filosófica cartesiana, que concorreu para o programa das chamadas "gramáticas cartesianas", "gramáticas filosóficas" e "gramáticas gerais" (Fonseca 2004: 91 [la negrita es mía]). 
La autora también afirma que la confluencia de las doctrinas racionalista, especulativa y cartesiana permitió que los gramáticos de Port-Royal determinaran los principios y reglas comunes a todas las lenguas:

Quando os messieurs de Port-Royal -o gramático C. Lancelot e o lógico A. Arnauld- defendem a idéia de racionalismo gramatical ou o princípio de regras comuns e universais a todas as línguas, a sua teoria não é apenas de inspiração cartesiana, mas também a síntese fecunda de duas influências maiores. A mais directa veio do humanismo gramatical, representado por novas gramáticas latinas assentes em pressupostos racionalistas, e que teve um expoente maior em Francisco Sánchez de las Brozas; mais recuada no tempo, a doutrina medieval dos baptizados modistas, com as suas investigações sobre os 'modos de significação' das categorias gramaticais, forneceu a Port-Royal os fundamentos da universalidade, uma vez elaborada na base filosófica do paralelismo entre a linguagem e a lógica da mente humana. Assim, conceitos lingüísticos e respectivas abordagens da Grammaire, aparecendo filtrados pelo racionalismo da filosofia de Descartes, são também largamente tributários, quer da corrente, dita especulativa, dos modistas, quer da obra do gramático espanhol (Fonseca 2004: 92).

Ahora bien, esta nueva concepción lingüística, basada en el «estabelecimento de um paralelismo entre a linguagem e o pensamento» (Fonseca 2004: 94), ha producido una serie de transformaciones en la gramática. Este es el caso, por ejemplo, de los cambios en la estructura gramatical, en la clasificación y definición de las unidades gramaticales, en la terminología, en el estudio sintáctico, entre otros (Gonçalves 2008b). En muchas tradiciones gramaticales, como la portuguesa, la doctrina de Port-Royal no terminó de establecerse hasta la segunda mitad del siglo XVIII y estuvo vigente hasta bien entrado el siglo XIX, más de dos siglos después de la publicación de la Grammaire. Para Filomena Gonçalves (2002b), el pensamiento gramatical en este periodo puede ser resumido del siguiente modo:

A reflexão lingüística privilegiava a definição da norma e a normalização dos usos, a codificação gráfica, a validação dos usos dos autores, e a apologia do vernáculo, assuntos que no seu conjunto enformava um discurso apologético da língua portuguesa. Mas a questão da normalização, 
nos vários aspectos que ela assumia, sobre ser indicio de uma consciência normativa, adquire um valor acrescido numa época de variação lingüística (Gonçalves 2002b: 11).

A pesar de las innovaciones, en la tradición gramatical portuguesa el latín todavía se consideraba durante esta centuria la lengua oficial de la expresión cultural y de la transmisión de conocimientos, de modo que las ciencias y la pedagogía se desarrollan de acuerdo con este paradigma (Ponce de León Romeo 2006). El interés preferente por el conocimiento de la lengua clásica se refleja en el número de gramáticas latinas publicadas en el siglo XVII, que supera al repertorio de gramáticas de la lengua vernácula. En cambio, la mayoría de las obras sobre la lengua vulgar consistía en tratados de carácter pedagógico escritos en latín y destinados especialmente a la enseñanza del portugués como lengua extranjera.

Paralelamente, en esta primera mitad del siglo XVII también se publica una serie de gramáticas pedagógicas latinas escritas en portugués. El Arte de Grammatica, para em breve se saber latim: composta em lingoagem e verso portuguez. Com um breve vocabulario no cabo, e algumas phrazes latinas de Pedro Sanches (1610) se considera en la actualidad la primera gramática latina escrita en portugués. Esta obra se caracteriza especialmente por introducir en la gramaticografía portuguesa los principios racionalistas de la Minerva del Brocense (1562) (Ponce de León 1996, 2002, 2005b). Sin embargo, las obras más representativas de este periodo son, en realidad, la Verdadeira Grammatica latina para se bem saber em breve tempo, scritta na lingua portugueza com exemplos na latina (1615) y el Methodo Grammatical para todas as Linguas (1619), ambas de Amaro de Roboredo.

No cabe duda de que estas dos obras presentan importantes contribuciones teóricas y metodológicas en la tradición gramatical portuguesa, como la utilización del vernáculo como «metalenguaje científico» (Kosarik 2000), la introducción de una nueva metodología pedagógica, la alteración de las bases teóricas de la gramática portuguesa, la promoción del equilibrio entre el ratio y el usus, entre otros aspectos. En este sentido, Fernandes, Ponce de León 
Romeo y Assunção (2007), en su estudio sobre la Verdadeira Grammatica latina (1615), resumen brevemente las innovaciones y los logros alcanzados por el gramático portugués:

A Verdadeira grammatica latina, para se bem saber em breve tempo, scritta na lingua Portuguesa com exemplos na Latina (Lisboa 1615) de Amaro de Roboredo é um marco na historiografia lingüística portuguesa, pela ruptura epistemológica que o seu autor procurou aplicar ao ensino da língua latina em Portugal: é a segunda gramática latina escrita em Português; Amaro de Roboredo pretendeu um equilíbrio entre a ratio e o usus, de modo a satisfazer quer as necessidades de aprendizagem dos alunos quer de ensino dos professores, especificando o que devia ser trabalhado pela memória daqueles e o que devia ser exposto nas aulas por estes; organizou o curso em dois níveis ou fases, o inicial e o de consolidação, particularizando a aprendizagem de um seqüencialmente e de outro em espiral ou "circulo"; e sistematizou aquilo que hoje são classificados pela lingüística como morfemas casuais e modotemporais, de modo a visualmente os alunos estabelecerem as conexões respectivas (Fernandes, Ponce de León Romeo y Assunção 2007: XXXV).

Por su parte, el Ars Grammaticae pro Lingua Lusitana Addiscenda de Bento Pereira (1672) representa, quizá, en la tradición portuguesa el tipo de gramáticas que en este periodo mostraban cierta preocupación por la enseñanza del portugués como lengua extranjera, tanto en el contexto europeo como en los nuevos dominios ultramarinos:

En efecto, la gramática portuguesa del padre jesuita va dirigida principalmente a lectores no nativos, tal como ya han puesto de manifiesto ciertos estudiosos (Schäfer-Priess 1993: 287; Fonseca 2000: 184); esto es, se trata ante todo de una gramática de portugués como lengua extranjera [...]. De las palabras del gramático jesuita, en efecto, pueden deducirse dos objetivos: el primero se refiere al desarrollo de la actividad comercial entre extranjeros y portugueses a partir del aprendizaje del portugués; el segundo concierne al ámbito de la religión y, especialmente, a la evangelización de las nationes barbaras a través de un instrumento lingüístico común (Ponce de León Romeo 2006: 14).

En el estudio titulado Un capítulo de la historia de las ideas sintácticas en Portugal: en torno a la teoría sintáctica del Ars Grammaticae pro Lingua Lusitana 
Addiscenda, Ponce de León Romeo (2006) también destaca la especial contribución de la obra de Bento Pereira para la gramaticografía portuguesa, especialmente en el desarrollo del estudio sintáctico:

Resulta evidente que la preocupación primera del jesuita es describir las conexiones de las partes de la oración en la, por así decir, "estructura superficial", con el objetivo de que haga más accesible al hablante no nativo el aprendizaje de la lengua portuguesa, si bien es cierto que la abundante información gramatical sirve también como consolidación del conocimiento lingüístico de los lusófonos. En suma, el Ars grammaticae pro lingua lusitana addiscenda no supone sólo, en el contexto de las gramáticas de la lengua portuguesa, una de las primeras aportaciones para la enseñanza del portugués como lengua extranjera, sino también una contribución a la Historia de la teoría gramatical del portugués (Ponce de León Romeo 2006: 28).

La producción gramatical portuguesa en este periodo fue considerablemente fecunda. Además de las gramáticas mencionadas, se pueden citar también los tratados de Bartolomeu Rodrigues Chorro (1619), Domingos de Araújo (1627), Frutuoso Pereira (1636), João Nunes Freire (1644) y Antônio Franco (1699) (Ponce de León Romeo 1996, 2001 y Fernandes 2009). La elevada cantidad de gramáticas latinas escritas en portugués en contraste con el escaso número de gramáticas del portugués pone de manifiesto, por un lado, el desarrollo de la gramaticografía portuguesa en el siglo XVII, pero, por otro, la dificultad de codificar una lengua viva mediante una nueva doctrina gramatical (Fonseca 2004). En esta línea, Fonseca (2004) determina algunos de los recursos empleados por los gramáticos renacentistas para superar esta dificultad:

Sistematizar essas causas lógicas da estrutura gramatical numa língua moderna [...] foi o desafio que o gramático seiscentista enfrentou, recorrendo a diversas estratégias de descrição da língua. Sirvam aqui de amostragem as seguintes:

- A descrição gramatical contrastiva, privilegiando o latim, mas intentando o gramático ampliá-las à línguas modernas; 
- A observação de dois níveis de descrição gramatical: o particular e o geral/universal;

- O propósito predominantemente pedagógico e a ele adstrito o ensino do vernáculo, propedêutico do de latim (Fonseca 2004: 94-96).

Sin embargo, los efectos de estos cambios teóricos y metodológicos solamente se consolidarían en las gramáticas portuguesas de la segunda mitad del siglo XVIII. Este fenómeno se debe, quizá, a la necesidad de establecer el dominio lingüístico en los territorios colonizados durante el periodo de expansión ultramarina, pues «o argumento épico de que a língua é instrumento do império sofreu a intermediação do proceso de aprendizagem das línguas de territórios do Oriente e do Ocidente como medida profiláctica de instaurar a comunicação para depois melhor se exercer o magisterio» (Fonseca 2004: 98). Dicho de otro modo, antes de proceder a la enseñanza de la lengua portuguesa en los territorios colonizados, era necesario codificar las «línguas estranhas ao paradigma greco-latino») (Fonseca 2004: 98). Esta preocupación por facilitar la comunicación entre la metrópoli y las colonias ha sido determinante en la producción de las gramáticas misioneras que, de acuerdo con Fonseca (2004), concedieron a las lenguas exóticas la misma importancia atribuida al portugués y al latín:

Reduzir a língua dos bárbaros que se vão conquistando a método gramatical significa poderem os idiomas de reinos extra-europeus receberem a denominação de línguas gramaticais (categoria reservada a línguas cultas). Em lugar do desarraigo de tais línguas nativas, por força de outras tendências lingüísticas hegemônicas, passa-se-lhes a ser conferida importância (também ao sabor da maré protecionista do poder político), distinção qualitativa e individualidade que era preciso regular e ilustrar através do estudo contrastivo com o português e o latim (Fonseca 2004: 98).

Entre las obras publicadas en esta época sobre idiomas asiáticos, africanos y amerindios' se pueden citar las gramáticas del tamul, concani,

\footnotetext{
1 Altman (2009), en su artículo titulado "Retrospectivas e perspectivas da historiografia da lingüística no Brasillı, señala que durante los siglos XVI, XVII y XVIII fueron publicadas más de 650 obras en lenguas no indo-europeas: «Wonderly \& Nida (1963: 117) dão uma medida do volume da
} 
japonés y anamita, como el Arte da lingoa lapam (1604) y el Arte da lingoa iapoa (1620), del Pe. João Rodrigues, y el Arte da lingoa canarim composta pelo Padre Thomaz Estevão da Companhia de lesv (1640); del guaraní y del kiriri como el Arte da lingva brasílica (1621), escrita por el Pe. Luís Figueira, el Arte de Grammatica da Lingoa mais Vlada na Colta do Brafil del Pe. José de Anchieta (1595) y el Arte grammatica da lingua brasilica da naçam kiriri (1697) del Pe. Luís Vincêncio de Mamiani; y, finalmente, de lenguas africanas como el Arte da lingva de Angola (1699) del Pe. Pedro Dias.

Es interesante notar que las gramáticas misioneras parecen coincidir en su estructura, del mismo modo que los tratados sobre las lenguas vulgares, pues fueron considerablemente influidas por el modelo grecolatino. En efecto, Altman (2009) señala la presencia de la gramática grecolatina en la codificación de las lenguas amerindias, africanas y asiáticas:

As primeiras descrições das artes de gramática foram, pois, inevitavelmente mediatizadas não apenas pelo conhecimento formal que os missionários tinham da gramática latina, mas também pelo conhecimento dos modos de descrição do seu vernáculo (v. Barros 1994; Gonzáles 1994), e por certa intuição da língua sob descrição, que acabaram por adquirir ao longo do intercurso com os falantes nativos (Hernández-Sacristán 1994: 129; Rosa 1995: 276) (Altman 2009: 121).

El influjo en la gramaticografía misionera de los autores más representativos de la tradición latina, como Prisciano, Despauterio, Nebrija o Manuel Álvares, también ha sido señalado por González Luis (1994), Rosa (1995), Zimmermann (1997), Zwartjes (2000, 2002), Altman (2007), entre otros.

produção hispano-americana. Só para o século XVI afirmam ter registrado 212 trabalhos de missionários. Desses, 30 sobre línguas sulamericanas; 27 sobre línguas da América Central e 155 sobre o México, sendo que o Náhuatl clássico, língua dos astecas do México central, foi a mais representada, com 92 trabalhos. No século XVII, registraram mais de 250 trabalhos sobre as mesmas línguas; no XVIII, 210. Se incluirmos nessa conta as gramáticas missionárias escritas no período colonial sobre as línguas asiáticas (por ex.: japonês, chinês, vietnamita; línguas filipinas: tagala, bisaya, pampango, iloko, pangasinán, ibanag; indianas: tamil), além das africanas e australianas, esse número cresce sensacionalmente (cf. Ridruejo 2000; Zwartjes \& Hovdhaugen 2003. Zwartjes \& Altman 2005, Zwartjes, James e Ridruejo 2007)» (Altman 2009: 118). 


\subsection{La etapa ilustrada}

En la segunda mitad del siglo XVIII, los gramáticos portugueses muestran su preocupación creciente por la codificación y la enseñanza del portugués. Este interés fue motivado por las reformas educativas promovidas durante el gobierno de Pombal (1750-17772). Las principales medidas adoptadas en este periodo fueron la institución del portugués como lengua oficial del Estado, la obligatoriedad de la enseñanza de la lengua en todos los niveles de la educación escolar y la creación de la Academia Real das Sciencias de Lisboa (1779). Estas reformas fueron determinantes para el desarrollo de la gramática portuguesa en el XVIII, que alcanzó la consolidación de la doctrina logicista en esta tradición.

La fundación de la Academia Real das Sciencias de Lisboa produjo importantes transformaciones en la tradición gramatical portuguesa. Sus principales objetivos fueron, en primer lugar, la publicación de gramáticas y diccionarios que normalizaran las reglas y principios de la lengua oficial del Imperio y que sirvieran de paradigma teórico, estructural y metodológico para otros gramáticos. Sin embargo, la mayoría de sus proyectos no fueron concluidos (Gonçalves, 2002a).

En segundo lugar, la Academia también pretendía defender la norma e ilustrar el uso culto del portugués: «la definición del buen uso de la lengua portuguesa, la discusión de los autores que constituyen el paradigma de la vernaculidad y de la perfección lingüística en el siglo XVIII») (Gonçalves 2002a: 549-550). A estas discusiones se suman las de carácter más teórico, como la definición de lengua y lenguaje o el desarrollo de la tipología lingüística (Gonçalves 2002a).

Paralelamente, los gramáticos portugueses buscaban la consolidación de los principios racionalistas en su propia tradición. En este sentido, en 1783 se publica una de las primeras gramáticas con el título de «filosófica» (y «racional»),

\footnotetext{
2 Las consecuencias del periodo pombalino se extendieron, en Portugal, hasta 1808 y, en Brasil,
} hasta 1822. 
la Grammatica Philosophica e Orthographia racional da Lingua Portugueza, para se pronunciarem e escreverem com acerto os vocabulos d'este idioma de Bernardo de Lima e Melo Bacelar (1783). Para Assunção (1999, 2007), la obra de Melo Bacelar contribuye significativamente a la renovación de la gramática portuguesa, pues -entre otros aspectos- cambia el concepto de la disciplina para destacar el carácter razonado de sus reglas y la función comunicativa que desempeña esta disciplina, definida como «huma colecção de leis com que arrazoadamente fabricamos e dispomos os sons que comunicão aos outros os nossos conceitosı (Bacelar 1783 apud Assunção 2007: 288).

Sin embargo, no cabe duda de que el Arte da Grammatica da Lingua Portugueza de Antonio José dos Reis Lobato (1770) es la obra modélica de este periodo en la tradición gramatical portuguesa. Esta gramática se impone a los demás tratados por su prolongada presencia en el ámbito educativo portugués durante el gobierno del Marqués de Pombal, pues fue considerada como la gramática pedagógica oficial en la instrucción pública. La obra alcanzó más de 40 ediciones durante los siglos XVIII y XIX (Assunção 1999, 2000). El autor también se distinguió por la apertura de nuevas escuelas y por la capacitación de profesores para la enseñanza del portugués.

Por último, no se puede dejar de mencionar que la gramática de Reis Lobato (Assunção 1997a/b, 1999 y 2000) ha contribuido de forma sustancial al desarrollo de la tradición portuguesa por la aplicación y difusión de un amplio y variado repertorio de fuentes -Restaut, Buffier, Peli, Martin, Benedito Dogacci, Salvador Corticelli, Nebrija, Gonzalo Correas, Juan Caramuel, Gómez Gayoso, Sánchez, Vossio, Perizonio, Escalígero, Lancelot, entre otros (Assunção 1999)- y con la defensa de la finalidad «manifestadamente prática» de la gramática (Assunção 1999). 


\subsection{Resumen}

Durante los siglos XVI y XVII la tradición gramatical portuguesa experimentó una importante evolución, caracterizada por el renovado interés de los gramáticos por la codificación del portugués. Las influencias procedentes de las gramáticas latinas y de otras tradiciones europeas motivaron la reflexión sobre algunos temas fundamentales, como la necesidad de la enseñanza de la lengua vernácula, la definición de la norma lingüística, la terminología, la clasificación de las palabras, la variabilidad de los vocablos, entre otros. Así pues, se pueden identificar en este periodo dos nuevos tipos de gramáticas pedagógicas, las latinas escritas en portugués y las portuguesas escritas en latín.

En la etapa renacentista destaca, además, la influencia de la reformulada gramática universal, que en el siglo XVII determina nuevas y profundas transformaciones en las gramáticas portuguesas, como la constitución de la gramática, la clasificación y definición de las unidades gramaticales, el estudio sintáctico, etc. No obstante, estos cambios solamente se consolidarían a mediados del siglo XVIII.

La producción gramatical en Portugal fue promovida especialmente por la política pombalina y la creación de la Academia Real das Sciencias de Lisboa, en la segunda mitad del siglo XVIII. Este periodo se caracteriza por la preocupación y obligatoriedad del uso del portugués como lengua oficial, por la apología del purismo lingüístico, por el rechazo de las influencias francesas y castellanas, por la lengua como instrumento de poder, por asentar definitivamente los ideales logicistas, por la formación de un corpus de autoridades literarias, entre otros aspectos.

A partir de este breve panorama de la evolución gramatical portuguesa, se puede observar que, pese a un cierto retraso en la recepción de teorías gramaticales con respecto a las demás tradiciones europeas, la gramática portuguesa como tal, su organización, estructura, metodología y bases teóricas, responde durante este proceso a las necesidades sociales y pedagógicas de su contexto y contribuye a la consolidación política y cultural de Portugal. De este 
modo, la tradición gramatical portuguesa alcanzó una identidad propia mediante la recepción y adaptación a la lengua vernácula de los avances lingüísticos procedentes de fuentes francesas y españolas.

El alcance de esta tradición en las gramáticas portuguesas y brasileñas del siglo XIX es incuestionable. Los fundamentos lingüísticos de las gramáticas latinas, tradicionales, pedagógicas y filosóficas anteriores al periodo decimonónico, han incidido, en mayor o menor medida, en la mayoría de los tratados que les sucedieron en la enseñanza y codificación del portugués. Las obras de los gramáticos renacentistas e ilustrados constituían una referencia obligada en la construcción del pensamiento gramatical en lengua portuguesa a uno y otro lado del Atlántico. 


\section{FUENTES PRIMARIAS DE LOS GRAMÁTICOS BRASILEÑOS DEL SIGLO XIX}

Este capítulo proporciona una breve descripción de la biografía, la trayectoria académica y la contribución lingüística de las fuentes primarias citadas textualmente por los gramáticos Antonio de Moraes Silva, Augusto Freire, Júlio Ribeiro y Maximino Maciel. Los objetivos de esta revisión son los siguientes:

1) Situar el primer siglo de producción gramatical brasileña en el contexto de los conocimientos lingüísticos europeos y americanos.

2) Reunir el corpus de las autoridades filológicas que contribuyeron directa 0 indirectamente a la construcción y evolución del pensamiento gramatical en Brasil.

3) Determinar el posible origen de las ideas que recogen las gramáticas brasileñas decimonónicas.

4) Seguir la trayectoria de las doctrinas gramaticales que influyeron en la formación de los primeros autores brasileños, bien por contacto directo o a través de fuentes intermedias.

5) Interpretar los cambios que experimentaron los conocimientos heredados en las gramáticas brasileñas.

6) Distinguir entre las corrientes teóricas que se consolidaron y las que, por el contrario, fueron superadas durante este periodo.

Las gramáticas de Antonio de Moraes Silva, Augusto Freire, Júlio Ribeiro y Maximino Maciel presentan, en conjunto, alrededor de setenta fuentes primarias. Este número excluye las referencias incompletas, pero incluye las repeticiones, como en el caso de Humboldt, Theophilo Braga, Brachet, Whitney, Max Müller, Bréal o F. Diez, mencionados en varias gramáticas. Debido al elevado número de autores, se consideran aquí solamente los más citados y 
representativos de las diversas corrientes de la gramática, la filología o la lingüística que pudieron influir en los autores brasileños.

\subsection{Autores renacentistas}

\section{João de Barros (1496?-1570)}

João de Barros fue un humanista, historiador, filósofo y uno de los primeros gramáticos portugueses. Nació en Viseu, alrededor de 1496, y murió en Ribeira de Litém en 1570. Es el autor de la Gramática da Língua Portuguesa (1540), la primera obra de la tradición portuguesa que aplica los principios de la corriente renacentista a la lengua vernácula.

La mayoría de los estudios sobre la Gramática de Barros pone de manifiesto las influencias que el autor inevitablemente recibió de los gramáticos

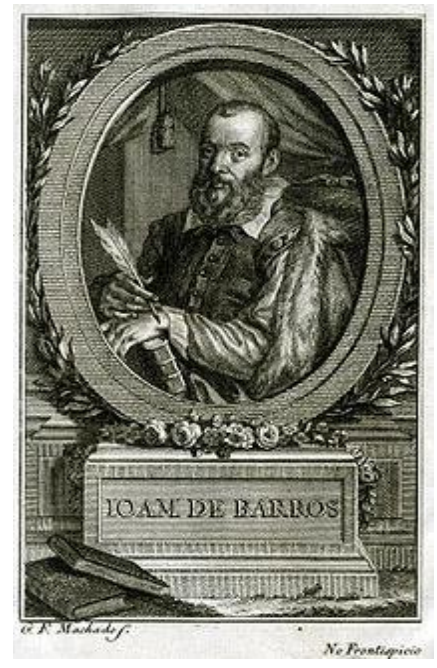
clásicos latinos e italianos y de la Gramática de Antonio de Nebrija y las características que obviamente comparte con estas obras. En este sentido, los principales rasgos distintivos de la Gramática de Barros son las siguientes:

1) La apología a la lengua portuguesa, evidente en el Diálogo em louvor da nóssa linguágem que acompaña la Gramática.

2) El carácter normativo, que, según el propio gramático, es lo que diferencia su obra de las gramáticas especulativas (Buescu 1984: 61, Fernandes 2006: 566).

3) Las analogías entre el portugués y el latín con propósitos pedagógicos (facilitar el aprendizaje del latín) y apologéticos (reconocer el origen latino del portugués). 
4) El ideal nacionalista de la lengua («la lengua como compañera del imperio»).

La influencia de João de Barros en la Gramática de Moraes Silva se observa especialmente en los aspectos formales del portugués, como por ejemplo la ortografía de las formas verbales y del diptongo "ão»", las reglas sobre la variación de género del sustantivo y algunas indicaciones sobre el comportamiento de las interjecciones. El texto del maestro renacentista supone además una importante fuente de ejemplos para ilustrar las reglas gramaticales, como ocurre eventualmente en la obra de Júlio Ribeiro.

Las investigaciones sobre la producción gramatical de João de Barros y su importancia para la historia de la lengua portuguesa giran en torno a algunos estudios básicos, entre los que cabe destacar Pinto (1961), Buescu (1978, 1983, 1984: 28-108, 2000: 756-764), Verdelho (1995), Martí Sánchez (1996), Schäfer-Priess (2000) y Fernandes (2006).

\section{Duarte Nunes de Leão (1530?-1608)}

Duarte Nunes de Leão fue un historiador, jurista y gramático portugués. Nació en Évora, probablemente en 1530, y murió en Lisboa en 1608. Publicó varias obras sobre derecho, historia y lengua portuguesa. Las aportaciones lingüísticas más significativas de Nunes de Leão a la tradición gramatical portuguesa son la Orthographia da Lingoa Portugueza (1576) y el Origem da Lingoa Portugueza (1606).

Diversos estudios historiográficos se muestran de acuerdo en que la Orthographia da Lingoa Portugueza de Nunes de Leão representa uno de los primero intentos de fijar (y normalizar) la ortografía del portugués. Los principales

\footnotetext{
1 Causa extrañeza la autoridad que otorga Moraes Silva a João de Barros en la temática de la ortografía del diptongo "ão», teniendo en cuenta que en la Gramática de Barros el empleo de "am» y "ão» finales todavía no estaba fijado. En efecto, Barros frecuentemente alterna su ortografía entre las dos formas (Buescu 1983: 138).
} 
rasgos metodológicos de esta obra son la conciliación entre diferentes sistemas ortográficos, el etimológico y el fonético, aunque se puede notar cierta preferencia del primero sobre el segundo criterio, y la institución de principios teóricos y de reglas aplicables a la ortografía portuguesa que, en algunos casos, siguen vigentes.

Las características del Origem da Lingua Portugueza son fundamentalmente la descripción y la apología a la lengua portuguesa. De hecho, esta obra trata de describir la relación histórica entre el portugués y el latín y, a partir de las analogías entre las dos lenguas, el autor justifica la noción de corrupción (o perfección) del portugués en relación con las demás lenguas vulgares. Otro aspecto relevante en esta obra es el reconocimiento por parte del autor de los préstamos léxicos de otras lenguas, en especial de los pueblos germánicos y los árabes (Buescu 1984).

En cuanto a la influencia de Duarte Nunes de Leão en los tratados brasileños, Moraes Silva cita a este autor para autorizar reglas sobre aspectos ortográficos del portugués y para avalar afirmaciones de Moraes sobre el origen de algunos vocablos. En el caso de la obra de Ribeiro, Nunes de Leão representa una fuente importante de ejemplos para ilustrar las reglas gramaticales.

Respecto a los estudios básicos relativos a la contribución gramatical de Duarte Nunes de Leão a la tradición portuguesa, se pueden poner de relieve las investigaciones de Buescu (1978, 1983, 1984: 143-167, 2000: 756-764) y Swiggers (1992).

\subsection{Autores ilustrados}

\section{Antoine Arnauld (1612-1694)}

Antoine Arnauld nació en Paris en 1612 y murió en Bruselas en 1694. Fue un importante teólogo, filósofo y jansenista francés cuya principal contribución a los 


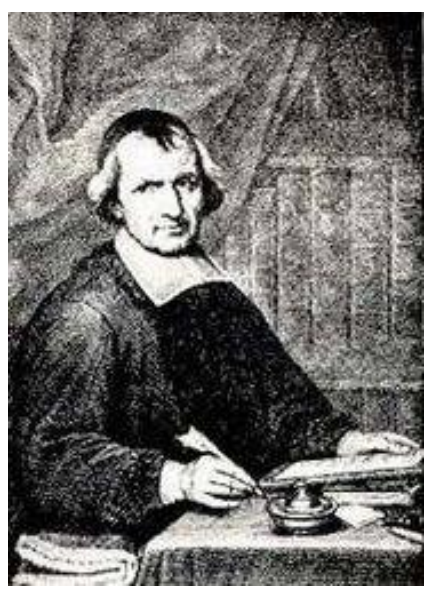

estudios lingüísticos fue la coautoría de la Grammaire générale et raisonnée de Port-Royal (1660).

Sin embargo, la labor lingüística de Arnauld solo empezó a ser reconocida a finales del siglo XVIII, periodo en el que su Gramática tuvo mayor difusión en la tradición europea en general. A partir de este momento, fue considerado el introductor de la gramática general en Francia.

Actualmente, los estudios sobre la GGR atribuyen a Arnauld la elaboración de ciertas características esenciales de la Grammaire. Este es el caso del sistema oracional basado en principios cartesianos, el estudio de los valores semánticos y los usos sintácticos de los artículos definido e indefinido, la sistematización de los pronombres y las oraciones de relativo, el tratamiento de las oraciones subordinadas con infinitivo, entre otros aspectos (Dominicy 1996: 42).

La Grammaire constituye, en realidad, un esfuerzo por describir los fenómenos gramaticales desde una perspectiva general, válida y aplicable a todas las lenguas. Sin embargo, sus autores no alcanzan a sistematizar la noción de universal lingüístico, pues en gran medida se limitan a generalizar los rudimentos de la lengua latina aplicados al francés.

Las referencias explícitas a Arnauld (y Lancelot) en las gramáticas brasileñas están relacionadas -como cabe suponer- con la GGR. En la Gramática de Moraes Silva, estas citas se concentran principalmente en el «livro |1), que trata de las clases de palabras. Esta es una de las obras citadas principalmente en la descripción del verbo y del artículo, para autorizar la metodología empleada por el gramático brasileño en la descripción de estas clases de palabras. Tanto en el caso de la teoría del verbo único como en el estudio del valor semántico del empleo (u omisión) del artículo detrás de sustantivos, Moraes sigue de cerca los principios fundados por los autores de la Grammaire (véase §5.1). 
La influencia de la GGR en la Gramática de Moraes excede las cuestiones relativas al verbo y al artículo, donde está citada textualmente, e implícitamente incide también en la percepción de Moraes de los universales lingüísticos. Así, se puede notar que el gramático admite ciertos rasgos de la lengua latina como generales y comunes a todas las lenguas (véase el capítulo 8).

En la Gramática de Augusto Freire, por otra parte, las referencias a la GGR son muy escasas. El gramático brasileño presenta solamente una referencia textual a esta obra en la valoración de la propuesta de Arnauld y Lancelot para simplificar el método de enseñanza del alfabeto. Sin embargo, algunos principios establecidos por Arnauld y Lancelot siguen vigentes en la Gramática de Freire, aunque el autor no reconoce textualmente este influjo, como en la teoría del verbo único, todavía presente en esta obra. Del mismo modo, las ideas de Freire sobre la significación del nombre se remontan a La Logique ou l'Art de penser (1662), compuesta por Arnauld y Nicole, aunque el brasileño tampoco desvela sus fuentes.

Con respecto a las investigaciones sobre la GGR y su importancia en la historiografía lingüística, en general, se dispone actualmente de una extensa bibliografía, de la que aquí pueden seleccionarse algunos estudios básicos, como los de Donzé ([1967]1971), Robins (1967), Chevalier (1968), Arens (1975), Auroux (1973, 1992a/b), Padley (1976/85), Dominicy (1984, 1987, 1996), Swiggers (1984a/b, 1992), entre otros.

\section{Dom Claude Lancelot (1616-1695)}

Dom Claude Lancelot nació en Paris en 1616 y murió en Quimperlé en 1695. Fue un gramático y educador francés que colaboró con Antoine Arnauld en la composición de la Grammaire générale et raisonnée de Port-Royal (1660).

En cuanto a su trabajo como coautor de la Grammaire, cabe señalar que escasean las aportaciones teóricas en la obra que sean de su propia autoría. En 
general, las adiciones de Lancelot al texto de la GGR corresponden a principios extraídos de la Minerva de Sánchez de las Brozas, como la división de la sintaxis en simple y figurada, la teoría de la elipsis o la simplificación de las reglas gramaticales (Colombat 1996).

La GGR constituye, quizá, la principal contribución de Lancelot a la lingüística, aunque también se valora su labor gramatical en la confección de las Nouvelles méthodes pour apprendre facilement las lenguas latina, griega, italiana y española $(1644,1655$ y 1660). En cierto modo, las Nouvelles Méthodes fueron las primeras obras influenciadas por el paradigma teórico y metodológico fundado (o reformulado) por la GGR, pues, en las ediciones posteriores a la publicación de la Gramática de Port-Royal, Lancelot modificó una serie de conceptos relativos a las clases de palabras (Colombat 1996).

Los estudios sobre Claude Lancelot están generalmente relacionados con sus aportaciones a la GGR y su trabajo en colaboración con Arnauld. En este sentido, se pueden consultar igualmente las investigaciones de Donzé ([1967]1971), Robins (1967), Chevalier (1968), Auroux (1973, 1992a/b), Padley (1976/85), Dominicy (1984, 1987, 1996), Swiggers (1984a/b, 1992), Arens (1975), entre otros.

\section{César Chesneau Dumarsais (1676-1756)}

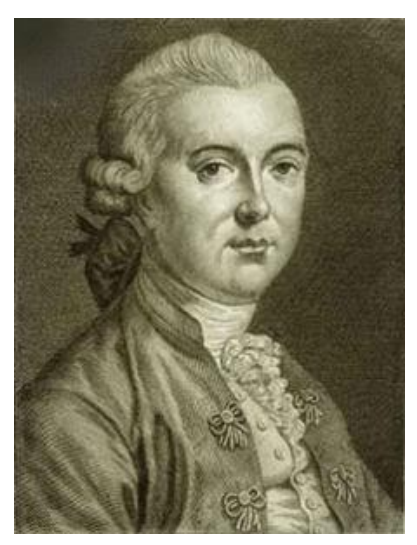

César Chesneau Dumarsais nació en Marseille en 1676 y murió en Paris en 1756. Fue gramático y filósofo. También es considerado uno de los fundadores de la gramática general en Francia.

Las ideas lingüísticas de Dumarsais giran en torno al racionalismo y, de acuerdo con esta doctrina, el gramático publica en 1722 el Nouvelle méthode pour apprendere la langue latine. En esta obra Dumarsais desarrolla un nuevo método de aprendizaje del latín, las 
versions interlinéaires, que consiste básicamente en un esquema de líneas que traducen palabra por palabra del latín al francés. También son de autoría de Dumarsais la Logique \& Principes de grammaire (1769) y un estudio inacabado sobre la sintaxis del que solamente se publicó el prefacio (1729) y el último capítulo sobre los tropos (1730) (Douay-Soublin 1996: 259).

La producción lingüística de Dumarsais cuenta además con una serie de artículos sobre gramática publicados en la Encyclopédie. De hecho, estos trabajos constituyen la aportación más importante del autor a los estudios gramaticales y están relacionadas, fundamentalmente, con la sintaxis.

La primera contribución de Dumarsais consiste, en líneas generales, en la diferenciación entre los términos sintaxis y construcción, que hasta este periodo eran considerados sinónimos. Para el autor, la sintaxis consiste en el tratamiento de las relaciones entre las palabras y la construcción se ocupa de la organización de las palabras en un orden lineal. Dicho de otro modo, una única oración puede variar de orden (construcción) pero conserva las mismas relaciones entre los vocablos (sintaxis) (Gómez Asencio 1981, Rojo 2001).

La reformulación del estudio de la sintaxis constituye la segunda innovación propuesta por Dumarsais. El gramático prescinde de la tradicional división de la sintaxis en concordancia y régimen, pero fundamenta su tratamiento en dos tipos de relaciones entre las palabras, las relaciones de identidad y de determinación (Rojo 2001).

En la tradición gramatical brasileña, los avances de Dumarsais en los estudios sintácticos fueron escasamente explorados por los gramáticos racionalistas. En el Epítome de Moraes Silva, por ejemplo, la presencia de citas textuales muestra que el gramático conoce la obra de Dumarsais, pero no aplica sus fundamentos a la descripción de la sintaxis portuguesa. El autor cita uno de los artículos de la Encyclopédie solamente como recomendación de lectura para aclarar la teoría de los verbos.

Respecto a los estudios básicos sobre la contribución gramatical de Dumarsais, a los enciclopedistas y sobre la gramática general en Francia, cabría 
Citar los estudios de Sahlin (1928), Swiggers (1984a/b), Douay-Soublin (1976, 1996), Rojo (2001), entre otros.

\section{James Harris (1709-1780)}

James Harris fue un político y filósofo inglés. Nació en Salisbury, Wiltshire en 1709 y murió, probablemente en esta misma ciudad, en 1780. Harris escribió varias obras filosóficas además de una gramática universal titulada Hermes: or a philosophical inquiry concerning language and universal grammar (1751).

El Hermes constituye una gramática filosófica, basada en las ideas contemporáneas acerca de la correspondencia entre los universales mentales y los lingüísticos. Se distingue de otras gramáticas generales por prescindir de las bases racionalistas y cartesianas para descansar en principios clásicos fundados por Platón y Aristóteles. Esta obra se divide en tres partes, las dos primeras comprenden la gramática filosófica en sí y la última parte se ocupa de la filosofía del lenguaje.

Las novedades que distinguen el Hermes de los demás tratados filosóficos de este periodo están relacionadas con las nociones desarrolladas por Harris de palabra, oración y significado. Esta relación estrecha que establece el autor entre los procesos mentales y el lenguaje sirve de base para apoyar su sistema de clases de palabras y oraciones. Para Harris las palabras son de dos tipos, las que son independientes de significado («significant by themselves» o «principals») y las que para expresar su significado necesitan estar relacionadas con otras palabras («significant by relation» o «accessories»). Las oraciones se dividen en aquellas que expresan una percepción («sentence of assertion») y aquellas que expresan una voluntad («sentence of volition»).

Cabe destacar además que la Gramática de Harris se caracteriza por el rechazo a la noción del desarrollo del lenguaje por medio de imitación, por diferenciar la sustancia fónica del contenido semántico, por el interés hacia la 
estructura profunda de la lengua y por proponer una codificación gramatical más descriptiva que propiamente prescriptiva (Nelson 1996: 390-391).

Entre los gramáticos brasileños, el Hermes es citado solamente por Moraes Silva en el estudio sobre el carácter sustantivo y atributivo del verbo, en el «livro |l.. Estas citas cumplen dos propósitos distintos. Por un lado, sirven para apoyar la concepción de Moraes sobre el carácter esencial del verbo y la teoría del verbo único. Por otro, se presentan como sugerencia de lectura para aquellos que desean profundizar en el estudio del verbo.

Con respecto a las investigaciones sobre la contribución gramatical de James Harris y el Hermes, se toman en consideración algunos estudios básicos, como los de Robins (1967), Joly (1972, 1976), Subbiondo (1976), Bergheaud (1979), Nelson (1996), entre otros.

\section{Robert Lowth (1710-1787)}

Robert Lowth nació en Winchester, Hampshire en 1710 y murió en Fullham, Middlesex en 1787. Fue obispo de Londres y autor de A short introduction to English Grammar with critical notes (17621 - 17632), su única obra relativa a los estudios lingüísticos.

A Short Introduction to English Grammar es considerada por muchos investigadores como una obra especialmente conservadora y de carácter

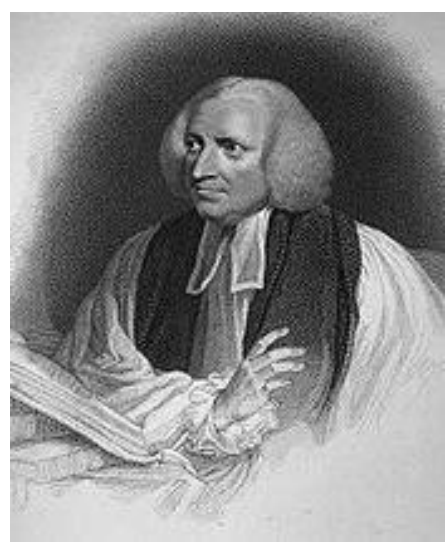
normativo. Alcanzó cierta importancia en su tiempo debido a la necesidad de establecer normas de corrección lingüística para el inglés.

En la Short Introduction to English Grammar se puede observar la profunda influencia de la gramática latina, desde la definición y división de las oraciones y clases de palabras (identifica doce tipos de oraciones y acepta las nueve clases de palabras) hasta la justificación del estudio de la gramática (facilitar el aprendizaje del latín). A pesar de los rasgos metodológicos tradicionales, la 
Gramática de Lowth presenta considerables avances con respecto a la terminología (empleo de time por tense y de sentences por syntax) (Michael 1996, Tieken-Boon van Ostade 2010).

En cuanto a su difusión, la gramática de Lowth fue ampliamente utilizada en las escuelas inglesas. Algunos autores mencionaron en sus tratados los comentarios de Lowth sobre el "abandono de la gramática» y la gramática general, mientras que otros trataron de copiar y plagiar sus ideas esbozadas en la gramática, como es el caso de Lindley Murray (Michael 1996, Tieken-Boon van Ostade 2010).

La Gramática de Lowth es citada únicamente en el Epítome de Moraes Silva como sugerencia bibliográfica para el estudio de los modos del verbo.

Sobre la A short introduction to English Grammar with critical notes se pueden consultar también los estudios de Michael (1970), Pullum (1974) y TiekenBoon van Ostade (1997, 2000, 2001, 2008, 2010).

\section{Nicolas Beauzée (1717-1789)}

Nicolas Bauzée nació en 1717 en Verdun y murió en 1789 en Paris. Fue uno de los representantes de la gramática general en Francia y colaborador de la Encyclopédie.

Las ideas gramaticales de Beauzée se fundamentan en los principios racionalistas basados en la consideración de la lógica como prerrequisito para la gramática (Auroux 1996: 201). De acuerdo con estos planteamientos filosóficos, Beauzée publica en 1767 la Grammaire Géneral, ou, Exposition raisonnée des éléments nécessaires du langage, pour servir de fondement à l'étude des toutes les langues. En esta obra, Beauzée presenta una serie de aportaciones para los estudios lingüísticos, en especial, la demostración de que la lengua es un sistema lógico y analítico. La Gramática de este enciclopedista supone el desarrollo de las nociones sintácticas formuladas por Dumarsais; el nuevo tratamiento de las clases de palabras, especialmente del artículo, del 
pronombre, del adverbio, de la preposición y de la conjunción; la comprensión de los modos y tiempos verbales; la descripción de universales lingüísticos, entre otros aspectos.

En la tradición brasileña, los estudios de Beauzée parecen no haber tenido mucha difusión entre los gramáticos. El Epítome de Moraes Silva constituye una de las pocas gramáticas que citan textualmente al enciclopedista. Sin embargo, la presencia de Beauzée en esta obra no demuestra que hubo un entendimiento cabal y una aplicación al portugués de las teorías del autor francés, pues Moraes solamente lo menciona como sugerencia de lectura para aclarar la teoría de los verbos. No obstante, directa o indirectamente, la influencia de Beauzée también marcó a otros gramáticos brasileños, particularmente a Freire, que asimiló algunas ideas básicas del enciclopedismo para el análisis semántico de las unidades gramaticales (véase $\S 5.2 .4)$.

Respecto a los estudios relativos a la contribución gramatical de Nicolas Beauzée, resultan de interés los de Harnois (1928), Wagner (1973), Bartlett (1975), Auroux (1979), Swiggers (1984a/b), entre otros.

\section{Baron Antoine Isaac Silvestre de Sacy (1758-1838)}

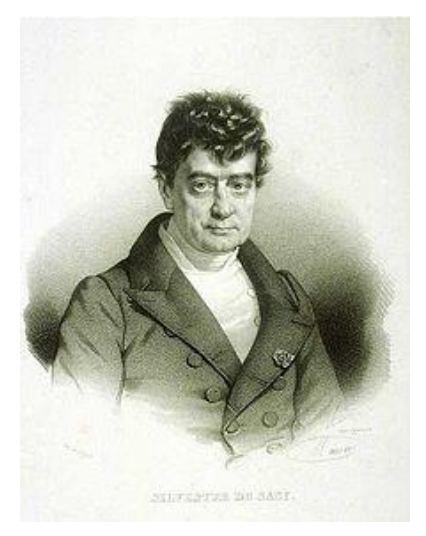

El Barón Antoine Isaac Silvestre de Sacy nació en Paris en 1758 y murió en esta misma ciudad en 1838. Fue un especialista en lenguas semíticas y del medio oriente y profesor de árabe en la École spéciale des Langues Orientales Vivantes, donde formó una generación de investigadores y desarrolló una gramática y una serie de textos para el estudio de las lenguas exóticas.

A pesar de su labor como investigador de las lenguas del medio oriente, Sacy no rompió definitivamente con la corriente racionalista, pues en sus 
estudios frecuentemente trataba de adecuar las lenguas al modelo lógico (Baggioni 1996b: 901). En efecto, se puede destacar que el propósito fundamental de los estudios lingüísticos de Sacy no era contribuir a la gramática histórica y comparada, como bien señala Baggioni:

For Sacy the reconstructions of the ancient structures of these languages or the knowledge of them [...], don't serve the imposition of a historical comparative model. Moreover Sacy, like other French philologists of his generation, expressed on several occasions his defiance and incomprehension of the comparative grammar then flourishing across the Rhine (Baggioni 1996b: 901).

La bibliografía de Sacy cuenta con anotaciones, traducciones y ediciones de textos relacionados con las civilizaciones del medio oriente, además de gramáticas del árabe, como los Principes de Grammaire générale, mis à la portée des enfans, et propres à servir d'introduction à l'étude de toutes les langues (1799), la Grammaire arabe à l'usage des élèves de l'École Spéciale des Langues Orientales Vivantes: avec figures (1810) y la Anthologie grammaticale arabe, ou morceaux choisis de divers grammairiens et scholiastes arabes (1829).

La influencia de Silvestre de Sacy en la tradición brasileña se manifiesta especialmente en la Gramática de Freire. Las citas textuales de los Principes de Grammaire générale (1799) están relacionadas con el estudio de la sintaxis, más concretamente, con la función que desempeña el «adjectivo determinativo» (este, esta, estes, estas) en el complemento de la oración. Cabe destacar también el influjo de Sacy en el modelo oracional de Augusto Freire, aunque con respecto a este asunto el gramático brasileño no lo cita textualmente (véase §5.2).

Con respecto a los estudios sobre Silvestre de Sacy se pueden poner de relieve las investigaciones de Salmon (1905), Brekle y Asbach-Schitker (1975), Decobert (1989), Baggioni (1996b), entre otros. 


\subsection{Autores de las corrientes lingüísticas histórico-comparadas}

\section{Wilhelm von Humboldt (1767-1835)}

Wilhelm von Humboldt nació en Potsdam en 1767 y murió en Tegel (actualmente parte de Berlín) en 1835. Fue escritor, político, lingüista y filósofo del lenguaje. Desarrolló los principios básicos de la teoría del lenguaje y ejerció una profunda influencia en la lingüística sincrónica, estructural y descriptiva.

La labor lingüística de Humboldt fue profundamente influenciada por los principios


filosóficos de Leibniz, Kant y Goethe. Sobre estos fundamentos y orientado hacia la antropología, el autor desarrolló diversos estudios sobre la estructura de las lenguas («sprachbau»). Su primer trabajo relacionado con la lingüística descriptiva tuvo como objeto de estudio la lengua vasca. Posteriormente, Humboldt amplió el análisis hacia las lenguas amerindias, las asiáticas, las semíticas, entre otras. Muchas obras sobre estas lenguas están inacabadas. En algunas de ellas, Humboldt sustituye el modelo tradicional latino de codificación lingüística por un modelo más descriptivo, que refleja la estructura específica de cada lengua (Trabant 1996).

La combinación de las ideas lingüísticas y antropológicas permitió que Humboldt elaborase teorías sobre el lenguaje, entendido como una capacidad innata del hombre. Las lenguas, para el autor, constituyen una manifestación de la identidad nacional, de modo que los cambios lingüísticos están ineludiblemente relacionados con los cambios sociales. A pesar de que esta orientación fue ajena al enfoque histórico-comparado que caracterizó la lingüística decimonónica, se convirtió, a través de Steinthal, Pott, Gabelentz, en un marco teórico fundamental para la lingüística moderna.

La presencia de Humboldt en la tradición brasileña resulta explícita en la Gramática de Ribeiro. Las referencias a la producción lingüística de Humboldt se 
limitan a algunas citas a propósito del carácter esencial del verbo. Ribeiro llama la atención sobre la idea del tiempo, que es intrínseca a esta clase de palabras en la mayoría de las lenguas modernas. No obstante, trae a colación un texto de Humboldt en el Journal des Savants (1828)2, en el que el autor afirmaba que en algunas lenguas amerindias el verbo no expresa tiempo.

Con respecto a las investigaciones sobre las concepciones lingüísticas de Wilhelm von Humboldt, se dispone actualmente de una extensa bibliografía, entre la que pueden mencionarse los estudios de Chomsky (1964), Liebrucks (1965), Robins (1967), Chevalier (1968), Arens (1975), Padley (1976/85), Gipper y Schmitter (1979), Borsche (1981), Manchester (1985), Trabant (1986, 1996), Swiggers (1992), Agud (1990), entre otros.

\section{Franz Bopp (1791-1867)}

Franz Bopp nació en Mainz en 1791 y murió en Berlín en 1867. Es considerado actualmente como uno de los fundadores de la lingüística comparada.

Los estudios lingüísticos de Bopp se centraron fundamentalmente en comparaciones entre las formas verbales de las lenguas germánicas, las medio-orientales y las clásicas. Posteriormente, también añadió a sus investigaciones el eslavo, el

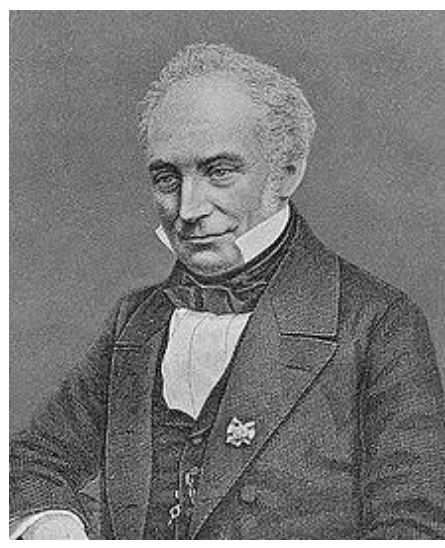
armenio, el lituano y el zendo. Esta labor tenía como objetivo principal la reconstrucción del indoeuropeo (Robins 1967).

La principal aportación de Bopp a la lingüística es, obviamente, la propia fundación de la gramática comparada y la determinación de los principios que rigen la comparación de las lenguas. Además, se pueden poner de relieve

\footnotetext{
2 La publicación citada por el gramático es en realidad un artículo de Silvestre de Sacy titulado «Lettre à $M$. Abel-Rémusat sur la nature des formes grammaticales en général, et sur le génie de la langue chinoise en particulier, par M. G. Humboldtı. En Journal des Savants 1828: 66-80.
} 
algunos rasgos distintivos de su trabajo, como la perspectiva menos romántica y más positivista sobre el análisis contrastivo, el enfoque puramente lingüístico, el concepto de lengua, entre otros aspectos (Schimitter 1996).

El alcance de Bopp en la tradición brasileña se reconoce en las gramáticas de Júlio Ribeiro y Maximino Maciel. En el caso de la Gramática de Ribeiro, las menciones a este autor son muy escasas y están acompañadas de referencias a Adolpho Coelho. La ausencia de citas que remitan directamente al trabajo de Bopp muestra que el conocimiento de Ribeiro de las teorías de este autor se debe posiblemente a la influencia de Coelho. En todo caso, se puede observar que estos autores son mencionados en el "Annexo» de la Gramática para autorizar la hipótesis de Ribeiro sobre el sujeto indeterminado, donde el gramático analiza este fenómeno en todas las lenguas románicas (véase el capítulo 8).

Maciel, por su parte, alude a los estudios de Bopp en la morfología, más concretamente en el estudio de las raíces monosilábicas, con la finalidad de autorizar el cambio del término «radical» por «raíz»».

Con respecto a las investigaciones sobre Franz Bopp y la gramática comparada en general se dispone actualmente de una extensa bibliografía. Aquí se destacan solamente algunos estudios básicos, como los de Verburg (1950), Robins (1967), Timpanaro (1973), Paustian (1977), Sternemann (1984a/b), Hiersche (1985), Amsterdamska (1987), Morpurgo Davies (1987), Koerner (1989a), Schlerath (1990), Schimitter (1996), Swiggers (1992), Aarsleff (1975), entre otros.

\section{Friedrich Christian Diez (1794-1876)}

Friedrich Christian Diez nació en 1794 en Giessen y murió en 1876 en Bonn. Fue el fundador de la filología románica.

Sus primeros estudios sobre el provenzal fueron publicados entre los años 1818 y 1829. Más tarde, Diez publicó su obra maestra, la Grammatik der Romanischen Sprachen (1836-1843), fundada en los principios comparatistas de 


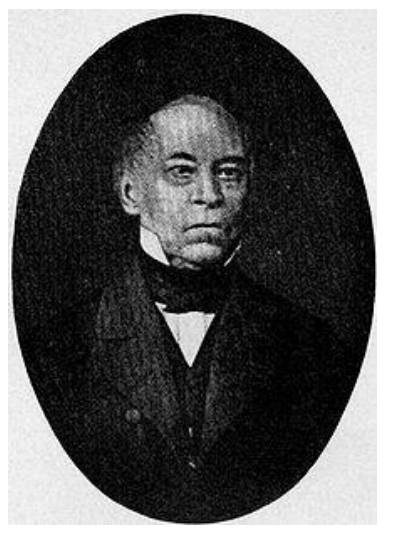

Grimm (1819-1837) y Bopp (1833-1852). Diez divide la Grammatik en tres partes (fonética, morfología y sintaxis) $y$, por medio del estudio comparado de las lenguas románicas, el latín vulgar y el clásico, el autor trata de determinar el parentesco entre estas lenguas.

La principal contribución de Diez a los estudios lingüísticos fue, sin duda, la aplicación del método comparado al estudio de las lenguas románicas, lo que le permitió determinar su verdadero origen (el latín vulgar). La importancia y la repercusión de sus estudios se muestran en las diversas traducciones que tuvo la Grammatik. En definitiva, el trabajo de Diez se ha convertido en una referencia fundamental para el desarrollo de la filología en los países de habla románica y muchas de sus teorías siguen vigentes actualmente (Schweickard 1996).

Friedrich Diez constituye una de las fuentes más comunes en las gramáticas brasileñas de la segunda mitad del XIX. Tanto Freire como Ribeiro y Maciel recogen las teorías de este autor, considerado como el fundamento de sus estudios gramaticales y la garantía de su modernidad. Augusto Freire parece seguir a Diez en la descripción y en la terminología de las oraciones subordinadas adverbiales. En particular, el gramático brasileño explica el empleo de los modos indicativo y subjuntivo en oraciones subordinadas introducidas por conjunción o por alguna locución conjuntiva formada por el relativo «que», según los criterios que defiende Diez en la Grammatik der Romanischen Sprachen (volumen 3, 306-308).

Por su parte, Júlio Ribeiro cita a Diez en casi todas las partes principales de su Gramática con diferentes propósitos:

1) Acerca de los universales románicos, para poner de relieve algunas características del portugués que son comunes a las demás lenguas románicas (véase el capítulo 8). 
2) En el estudio etimológico, con la finalidad de desacreditar otras teorías contrarias a la suya sobre el origen del artículo indefinido y para mostrar la evolución de los modos y tiempos verbales.

3) Respecto a la descripción de los cambios fonéticos, para explicar el origen de ciertos diptongos y para demostrar la existencia de triptongos en portugués.

4) Con relación a la descripción de determinados aspectos sintácticos, la autoridad de Diez está presente en el tratamiento de la concordancia entre sustantivo y adjetivo, sujeto y verbo, y en el empleo del infinitivo. Además, el brasileño recurre frecuentemente a las obras de Diez como fuente de ejemplos para ilustrar las reglas de la sintaxis.

Finalmente, el influjo de Diez en la Gramática de Maciel se muestra en el estudio fonético del portugués, para desacreditar la opinión de otros gramáticos que defienden la inexistencia del triptongo en la lengua portuguesa, y en el resumen histórico de la evolución del portugués y otras lenguas románicas.

En cuanto al estado de las investigaciones historiográficas sobre Friedrich Diez y su aportación a la lingüística comparada, se dispone actualmente de diversos estudios, como los de Curtius (1960), Meier (1965), Malkiel (1976), Niederehe \& Haarmann (1976), Gauger et. al. (1981), Gumbrecht (1986), Schweickard (1996), entre otros.

\section{Maximilien Paul Émile Littré (1801-1881)}

Maximilien Paul Émile Littré nació en Paris en 1801 y murió en esta misma ciudad en 1881. Fue editor, historiador, traductor y lexicógrafo.

La principal aportación de Littré a los estudios lingüísticos fue el Dictionnaire de la langue française (1863-1873). Los primeros estudios del autor estaban relacionados con la medicina $y$, paralelamente a su trabajo lexicográfico, publicó diversos artículos sobre filología. Su bibliografía refleja la 


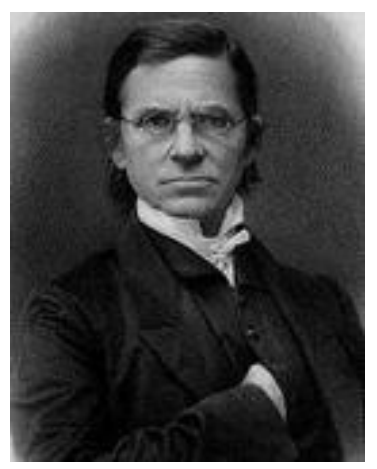

profunda influencia que recibió de la filosofía alemana y del positivismo. De hecho, Littré es reconocido como uno de los primeros comparatistas franceses por su importante papel en la introducción de la filología alemana en Francia (Desmet 1996).

Entre los autores brasileños, Júlio Ribeiro es el único gramático que cita a Émile Littré. Las referencias a este autor se limitan a una breve mención en la dedicatoria y en la portada de la Gramática (véase apéndice), pero la obra no presenta citas que indiquen concretamente algún influjo teórico de Littré. Según Fávero y Molina (2006: 127), el «epígrafe de Littré [...] representa sua adesão [de Ribeiro] ao método histórico-comparativols. Sin embargo, creemos que no hay suficientes datos que determinen, como afirman las autoras, la influencia de este autor en la teoría gramatical de Ribeiro. Además, el carácter positivista de la obra de Ribeiro se debe más bien al influjo de otros autores.

Respecto a los estudios relativos a la contribución de Émile Littré a la lingüística, véase Aquarone (1958), Rey (1970, 1996), Huisman (1981, 1984) y Hamburger (1988).

\section{Friedrich Max Müller (1823-1900)}

Friedrich Max Müller nació en Dessau en 1823 y murió en Oxford en 1900. Fue orientalista, traductor, filósofo y filólogo.

Max Müller es conocido especialmente por la traducción y edición del Rig-Veda (1845-46) y por la publicación de The Science of Language (1861). En su obra, Müller parece seguir de cerca las ideas de Schleicher, especialmente por la adhesión del autor a la teoría de la tripartición de las lenguas (aislantes,

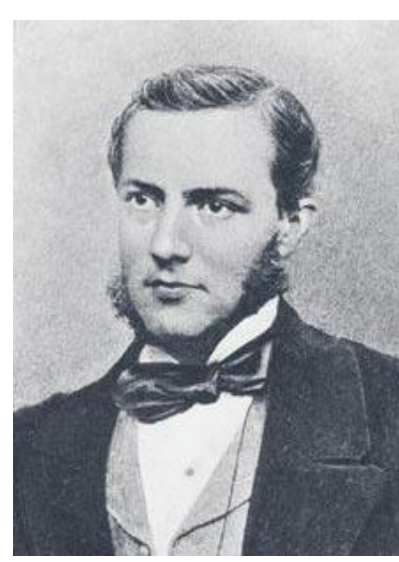


aglutinantes y reflexivas) y por su concepción naturalista del lenguaje. De hecho, el autor alemán es considerado como uno de los primeros que introdujo en Inglaterra la lingüística de orientación naturalista (Desmet 1996).

En cuanto a la influencia de Max Müller en Ribeiro, la Grammatica Portugueza presenta solamente tres referencias textuales a este autor. La primera está en la dedicatoria y las demás tratan de la distinción que establece Ribeiro entre las «vozes» y las «consonancias» (véase §5.3.7), de acuerdo con las descripciones de la gramática hindi en The Science of Language de Müller. En la obra de Maciel, por otro lado, esta influencia puede ser observada con más frecuencia. En la morfología, el gramático se apoya en las ideas de Müller para dividir las raíces de las palabras en tres grupos:

1) Las primarias: vocal

2) Las secundarias: vocal + consonante

3) Las terciarias: 2 consonantes + vocal, vocal +2 consonantes y 2 consonantes $+\mathrm{vocal}+2$ consonantes.

En la «semiologia», Maciel cita a Müller en el estudio de las «alterações semanticası, en particular, en la descripción de algunos fenómenos que suponen este tipo de transformación. Así, el gramático afirma que la «alteração phonetica», la «dialectação» y los «tropos» son fenómenos que pueden afectar al significado de las palabras.

Sobre Max Müller, véase Müller (1902), Chaudhuri (1974), Cawthra (1996), Stone (2002) y Van den Bosch (2002).

\section{Nicolas-Louis-Cyprien Ayer (1825-1884)}

Nicolas-Louis-Cyprien Ayer nació en Sorens/Gruyère en 1825 y murió en Neuchatêl en 1884. Fue periodista, profesor y gramático. 
Los intereses lingüísticos y gramaticales de Ayer giraban en torno a las implicaciones políticas y sociales de estas ciencias. Su trabajo fue considerablemente marcado por Friedrich Diez. Su bibliografía cuenta con obras relativas a la geografía, la gramática comparada y la fonología del francés (Saint-Gérand 1996: 58).

La gramática de Ayer influyó notablemente en los gramáticos brasileños. Así, Freire cita a Ayer en la sintaxis, particularmente en la descripción del uso del sustantivo en funciones sintácticas predicativas, comúnmente atribuidas al adjetivo. De hecho, el texto de Freire constituye en realidad una traducción literal de las palabras de Ayer (véase §5.2). Se puede observar también el influjo de Ayer en otras dos ocasiones más en la Gramática de Freire: como autoridad para corroborar la opinión del gramático sobre la necesidad de reformar la ortografía del portugués y como fuente de ejemplos que ilustran las reglas gramaticales.

En la Gramática de Ribeiro, Ayer está citado solamente una vez en la introducción de la obra para autorizar la división de los estudios gramaticales en dos partes (lexeologia y sintaxis). Ribeiro reconoce, entre otras obras, la influencia de la Grammaire de Ayer (véase §5.3).

Maciel expresa la influencia de este autor en la fonología, al clasificar los fonemas vocálicos en pleno (/a/), medio (/e/ y /o/), agudo (/i/) y grave (/u/); en la descripción del proceso de formación del verbo por medio de la aglutinación de prefijos y sufijos («parasynthese»); y en la clasificación de los verbos que expresan fenómenos de la naturaleza en el grupo de los verbos impersonales.

\section{William Dwight Whitney (1827-1894)}

William Dwight Whitney nació en Northampton en 1827 y murió en New Haven en 1894. Fue un lingüista americano, colaborador en la edición del Atharva-Veda, profesor de sánscrito, francés, alemán y gramática comparada en la Universidad de Yale. Whitney también popularizó el estudio de la lingüística 


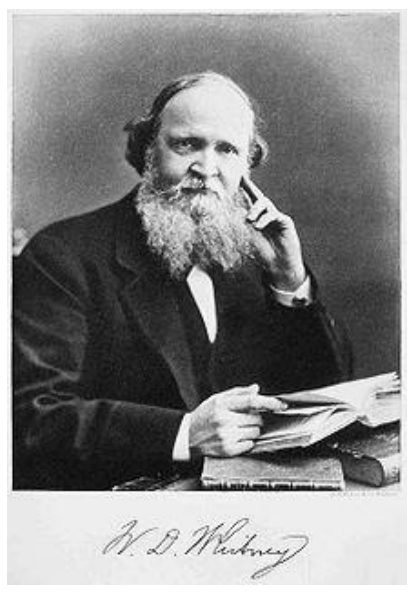

en Estados Unidos y es reconocido actualmente como el primer profesional de la lingüística en este país.

En el estudio del sánscrito, Whitney contribuyó con un extenso número de ediciones, traducciones y organizaciones sistemáticas de textos y contenidos léxicos y gramaticales, además de reformular la gramática sánscrita a partir de pruebas textuales, de acuerdo con la metodología de la escuela alemana. El autor también publicó una serie de gramáticas pedagógicas (del francés, del inglés y del alemán), en las que aplicó los mismos principios descriptivos utilizados en la gramática del sánscrito (Silverstein 1996: 1008).

Los estudios lingüísticos de Whitney se apoyan en las doctrinas naturalistas e historicistas, inspiradas principalmente en las ideas de Bopp y de Schleicher. En pocas palabras, Whitney concibe el lenguaje como una estructura que sirve a la comunicación, que está en constante proceso de desarrollo y que es susceptible de transformaciones (o selección natural) acumulativas e irreversibles en sus formas y construcciones debido a la interferencia de los hablantes (Silverstein 1996).

Whitney es, quizá, una de las fuentes más destacadas por Júlio Ribeiro en su Gramática. Se puede observar el influjo de Whitney en las definiciones de gramática y de verbo. Estos textos constituyen en realidad traducciones literales de las definiciones de la Essentials of English Grammar (véase §5.3). En la segunda edición de la Gramática, Ribeiro reconoce en el prólogo la influencia de Whitney también en la sistematización de la sintaxis, aunque no presenta referencias textuales del autor norteamericano. En la Gramática de Maciel, este influjo no parece tan frecuente. La única referencia del autor a Whitney está relacionada con los argumentos en contra de la teoría racionalista sobre el verbo único, donde Maciel cita un pasaje de The life and growth of language (1875: 90) sobre la función conectiva del verbo «sen», su contenido semántico y 
la ausencia de este verbo en diversas lenguas para justificar la inviabilidad de la doctrina port-royalista.

Sobre la contribución de Whitney a los estudios lingüísticos, véanse los estudios de MacCawley (1967, 1973), Jakobson (1971), Nerlich (1990), Wächtler (1991), Alter (1993), Silverstein (1996), entre otros.

\section{Michel Bréal (1832-1915)}

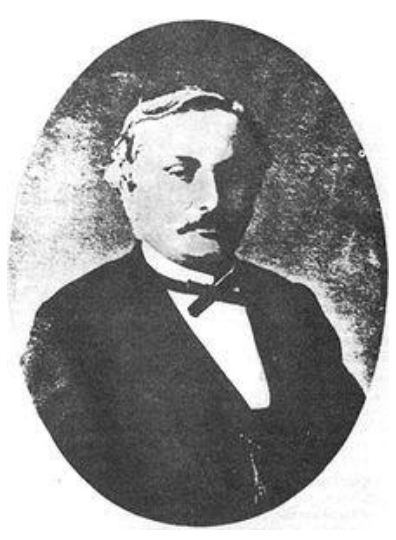

Michel Jules Alfred Bréal nació en Landau en 1832 y murió en Paris en 1915. Fue el fundador de la semántica en Francia y el primero que introdujo en este país la gramática histórico-comparada alemana (Desmet y Swiggers 1995)

Los estudios lingüísticos de Michel Bréal se dirigieron fundamentalmente al análisis del significado de las palabras. En esta línea, las obras que más destacan en su bibliografía son Mélanges de mythologie et de linguistique (1877) y el Essai de Sémantique (1897). Este último representa, quizá, su contribución más importante a los estudios lingüísticos. De acuerdo con Delesalle (1996a: 128), el Essai aporta una nueva perspectiva a los estudios lingüísticos, entre otras razones, por establecer las leyes que gobiernan los cambios de significado en la lengua, por ampliar el ámbito del significado a las relaciones entre el léxico y los campos sintácticos, por fundamentar el análisis de los significados en la analogía, y no en la etimología, y por separar el estudio del significado de las leyes fonéticas.

Michel Bréal está citado en la Gramática de Ribeiro en dos ocasiones, en la dedicatoria de la Gramática y en el estudio de las formas no personales del verbo. Ribeiro se apoya en la autoridad de Bréal para justificar su noción de modo verbal, que excluye las "formas nominaes» (participio e infinitivo). Maciel cita a Bréal en su Gramática a propósito de la "semiologia», que estudia los 
cambios de significado. El brasileño recoge la cita de los Mélanges de mythologie et de linguistique (1877), donde el semantista francés afirmaba que los cambios de significado de las palabras son independientes de las leyes fonéticas. Sin embargo, el sentido crítico de Maciel y su compromiso de ofrecer al público un panorama completo de las corrientes contemporáneas se muestran con claridad en este punto de su obra, donde intenta plasmar dos perspectivas distintas con respecto a los cambios semánticos, la de Bréal, que sostiene la independencia de las leyes fonéticas, y la de Max Müller, que establece una relación de causa y efecto entre los cambios semánticos y los fonéticos. A pesar de que el gramático alude brevemente a la relación que establece Bréal entre forma y significado, hay que reconocer la novedad que representa este concepto en la Grammatica Descriptiva.

En cuanto a las investigaciones sobre Michel Bréal, se toman en consideración aquí los estudios de Aarsleff (1982), Delesalle y Chevalier (1986), Delesalle (1987, 1996a), Nerlich (1990), Desmet y Swiggers (1995), entre otros.

\section{Auguste Brachet (1845-1898)}

Auguste Brachet nació en Tours en 1845 y murió en Cannes en 1898. Sus estudios lingüísticos se desarrollaron según los principios histórico-comparados y la mayoría de sus aportaciones están relacionadas con el estudio histórico del francés. La Grammaire Historique de la langue française (1867) y el Dictionaire des doublets ou doublets formes de la langue française (1868) constituyen las principales contribuciones de este autor a la lingüística. Los últimos trabajos de Brachet presentan un cambio de marco teórico, pues ponen de manifiesto la adhesión del autor al «paradigma schleicheriano» (Koerner 1978, 1982, 1989b).

La bibliografía de Brachet alcanzó cierta difusión entre los gramáticos brasileños del siglo XIX. Augusto Freire cita el Morceaux Choisis Des Grands Écrivains Française du XVle Siècle en la ortografía de la Gramática, para justificar su opinión sobre la reforma ortográfica de la lengua portuguesa. Freire afirma 
que todos los gramáticos contemporáneos (entre los que incluye a Brachet) reconocen esta necesidad de reformar la ortografía en sus respectivas lenguas. Por su parte, Ribeiro hace referencia a la Nouvelle Grammaire Française en el análisis etimológico del verbo «ser». En una observación por separado de la descripción gramatical, Ribeiro cita las palabras de Brachet cuando este afirmaba que la función de la desinencia «re» en los infinitivos latinos como «essere» es la de "dar mais corpo a la palabra» (Ribeiro 1881: 171). Maciel, finalmente, cita la Grammaire Historique en el estudio de los verbos irregulares, a propósito de los verbos «anomalos» o «especificos», donde recoge el testimonio de Brachet para justificar la ausencia de sistematización de este tipo de verbos, que presentan una conjugación especial, sin que sea posible reducirla a normas. En la fonología, Maciel se apropia de las definiciones de Brachet de «phonetica historica» y «corrupção phonetica» y, siguiendo los principios del autor francés, clasifica los monosílabos como sílabas breves. El gramático brasileño también menciona a Brachet y Dussouchet en el estudio de las palabras cognadas y parónimas. De acuerdo con estos autores, Maciel divide las palabras cognadas en «proximas» y «remotas», por la similitud de las raíces. Pero en la división de las palabras parónimas señala que la propuesta de estos autores no puede aplicarse a la lengua portuguesa. Una vez más, conviene destacar la independencia teórica y metodológica de Maciel. El brasileño muestra la actualización de sus conocimientos, pero al mismo tiempo decide y selecciona los recursos que pueden ser aplicados a la descripción coherente del portugués.

En cuanto al estado de las investigaciones historiográficas sobre Auguste Brachet, son de interés algunos estudios básicos, como los de Desmet y Swiggers (1996), Chervel (1977), Bergounioux (1984) y D'Amat (1956).

\section{Arsène Darmesteter (1846-1888)}

Arsène Darmesteter nació en Château-Salins en 1846 y murió en Paris en 1888. Sus estudios lingüísticos se dirigieron fundamentalmente al estudio histórico 
de la lengua francesa, a la evolución del léxico y a las variaciones de forma y significado. Sus principales aportaciones teóricas en este campo consisten en la determinación de las leyes fonéticas para el cambio de sonido en las palabras, la sistematización de los cambios de significado y el análisis de los diferentes parámetros (lingüísticos, psicológicos y sociológicos) que intervienen en el nacimiento, vida y muerte de las palabras (Delesalle

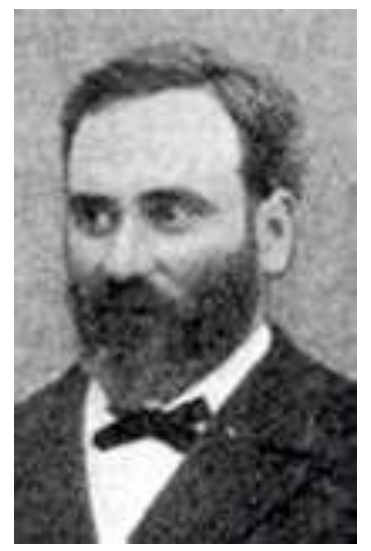
1996b: 225).

La vie des mots étudiée dans leurs significacions (1886) constituye la aportación más influyente de Darmesteter en la tradición brasileña. De los autores analizados, se pueden observar referencias a esta obra en la Gramática de Maximino Maciel. La vie des mots está citada en la definición de las leyes fonéticas, al lado de Brachet, para describir los fenómenos que producen cambios regulares en las lenguas («lei da transição» y «lei do menor esforço») y en la introducción de la Gramática, cuando el autor brasileño llama la atención sobre la notoriedad que los estudios semánticos alcanzaron en este periodo, hasta el punto de constituir una parte independiente en la división de la gramática. Además Maciel señala a Darmesteter como una de las principales autoridades en el tema. En el tratamiento de la interjección, Maciel cita los Études Iraniennes (1883) para justificar el carácter esencial de esta categoría y para corroborar su afirmación de que son «palavras destituidas de significação, mas que exprimem um sentimento ou sensação» (Maciel 1926[1894]: 156). Sin embargo, la referencia que presenta el autor no trata de la interjección (ni siquiera de la gramática), sino que corresponde en realidad a la traducción del Khorda Avesta.

Sobre la contribución de Arsène Darmesteter a la lingüística francesa, véanse los estudios de Delesalle $(1987,1996 b)$. 


\subsection{Neogramáticos}

\section{Abel Hovelacque (1843-1896)}

Abel Hovelacque nació en Paris en 1843 y murió en esta misma ciudad en 1896. Fue antropólogo, lingüista y el principal responsable de introducir el «paradigma schleicheriano» en Francia. Fue el defensor más destacado de la lingüística naturalista y antropológica en su país (Desmet 1996: 223).

Hovelacque fundamentó sus estudios lingüísticos en el marco teórico de la gramática comparada, entendida como una disciplina que forma parte de las ciencias naturales. Para el autor, la lingüística comparada no constituye en sí misma el objetivo de la lingüística, sino que debe ser considerada un método complementario que tiene el propósito fundamental de contribuir a la historia natural del hombre (Baggioni 1996a).

La aportación de Hovelacque a los estudios lingüísticos cuenta con dos libros inspirados en las teorías de Schleicher y Max Müller, La Linguistique (1877) y los Études de linguistique et d'ethnographie (1878).

La obra de Hovelacque que tuvo mayor difusión entre los gramáticos brasileños fue La Linguistique. Ribeiro hace referencia a este tratado en el estudio etimológico del portugués, para reforzar su afirmación sobre el origen latino de las lenguas románicas. Maciel, por su parte, cita a Hovelacque en la morfología, cuando trata de la descripción de los rasgos distintivos de las raíces de las palabras, para señalar que la raíz es el elemento común en una familia de palabras.

En cuanto al estado de las investigaciones historiográficas acerca de Abel Hovelacque y la lingüística naturalista en Francia, se destacan aquí solamente algunos estudios básicos, como los de Aarsleff (1982), Auroux (1984), Baggioni (1996a), Desmet (1996), entre otros. 


\section{Wilhelm Meyer-Lübke (1861-1936)}

Wilhelm Meyer-Lübke nació en Dübendorf en 1861 y murió en Bonn en 1936. Romanista y neogramático suizo, Meyer-Lübke estudió filología clásica, románica e indo-europeo y fue profesor de las universidades de Jena, Viena y Bonn.

Las principales aportaciones de Meyer-Lübke a los estudios lingüísticos son la Grammatik der romanischen Sprachen (1890-1902), la Einführung in das Studium der romanischen Sprachwissenschaft (1901) y el Romanisches etymologisches Wörterbuch (1935). Estos estudios están basados fundamentalmente en los principios establecidos por los neogramáticos, pero comprenden una gran variedad de lenguas y dialectos románicos y sobre todo destacan por la coherencia, la claridad y por presentar principios que todavía se mantienen vigentes (Kramer 1996: 635).

En la tradición brasileña, Meyer-Lübke es mencionado solamente en la Gramática de Maciel. El autor cita la Grammatik der romanischen Sprachen en la descripción de la evolución de las lenguas románicas, al lado de otros autores como Brunot y Diez, con la finalidad de autorizar la teoría sobre el desarrollo de las lenguas románicas desde el latín.

Respecto a las investigaciones básicos sobre Wilhelm Meyer-Lübke, véase Richter (1936), Kramer (1996), Battisti (1937), Gamillscheg (1936), Greive (1970) y Iordan (1970).

\subsection{Autores contemporáneos portugueses y brasileños}

\section{Jerónimo Soares Barbosa (1737-1816)}

El portugués Jerónimo Soares Barbosa nació en Ansião en 1737 y murió probablemente en 1816. Fue abogado, pedagogo y gramático. 
Soares Barbosa es uno de los representantes más destacados de la corriente racionalista en Portugal. Sus principales aportaciones a los estudios lingüísticos son As duas línguas (1807), considerada como una gramática pedagógica que estudia los principios comunes a todas las lenguas aplicados al portugués y comparados con el latín, y la Grammatica philosophica da lingua portugueza ou Principios da grammatica Geral applicados á nossa linguagem (1822), basada fundamentalmente en la doctrina logicista. Soares Barbosa presenta en su Gramática una serie de innovaciones para el estudio de la lengua portuguesa, como por ejemplo la clasificación de las preposiciones a partir de las nociones de tiempo y espacio, la atribución al artículo de la función de determinación del género gramatical y la división de los verbos irregulares en grupos más o menos organizados según sus semejanzas. Sin embargo, la mayoría de las novedades propuestas por el autor fueron ignoradas por los gramáticos posteriores (Ranauro 2003).

En la Gramática de Júlio Ribeiro son muy frecuentes las críticas a Soares Barbosa. Ribeiro cuestiona la descripción de las reglas sobre el infinitivo flexionado y las explicaciones del autor portugués sobre algunos fenómenos fonéticos, como la clasificación de los fonemas en «vozes» y «consonancias» y la exclusión de la división de la cantidad silábica en «breve» y «longa». Con todo, Ribeiro también reconoce algunas contribuciones de Soares Barbosa a la codificación del portugués, como la extensión de la función del adverbio a modificador del sustantivo y la clasificación como verbos regulares de los que se modifican para conservar la pronunciación, como es el caso de los verbos «julgan» y «ficar» con respecto a las formas conjugadas «julgue» y «fique».

En cuanto al estado de las investigaciones historiográficas sobre Soares Barbosa, conviene tener presente los estudios de Ranauro (2003, 2005), Casteleiro (1980/81), Torres (1982, 2004), Cagliari (1985), Penha (1989), Fávero (1996) y Amor Couto (2004). 


\section{Francisco Sotero dos Reis (1800-1871)}

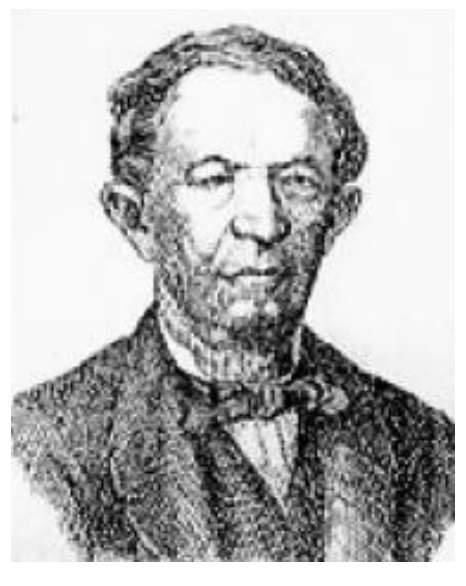

Francisco Sotero dos Reis nació en São Luis do Maranhão (Brasil) en 1800 y murió en esta misma ciudad en 1871. Fue periodista, poeta, profesor, traductor, político y gramático.

La mayoría de las obras de Sotero dos Reis están relacionadas con los estudios lingüísticos y literarios. Su contribución a la gramaticografía brasileña reside en la publicación de las Postillas de grammatica geral aplicada á lingua portugueza pela analize dos classicos (1862) y la Grammatica Portugueza (1865)³.

Son todavía escasos los estudios sobre el alcance de Sotero dos Reis en los estudios lingüísticos y en la tradición brasileña. Sin embargo, algunos ensayos generales destacan que el gramático fue considerablemente influido por la corriente racionalista y que su obra sigue el mismo modelo propuesto por la GGR.

En la Gramática de Freire, Sotero dos Reis está citado a propósito de la descripción de la "concordancia semiotica» (la silepsis), para autorizar esta construcción. En la Gramática de Ribeiro, este autor es muy criticado por las reglas relativas al infinitivo flexionado, por el rechazo al carácter impersonal del verbo «haver» -justificado por la teoría de la elipsis del sujeto-, y por la explicación de la presencia de galicismos en el portugués, que, según Sotero dos Reis, se debe al escaso estudio de la lengua materna y a la frecuente lectura de libros franceses. Por último, Maximino Maciel critica a este autor por clasificar los «adjectivos personativos» como pronombres posesivos, pero se muestra de acuerdo con la opinión de Sotero dos Reis en que la reforma de la ortografía es totalmente innecesaria.

\footnotetext{
3 Fávero y Molina (2006: 92) señalan que hay un cierto desacuerdo en cuanto a la fecha de publicación de la primera edición de la Grammatica de Sotero dos Reis, pues se duda entre 1865 y 1866.
} 
Sobre la Grammatica Portugueza, sus características fundamentales y alguna información adicional relativa al autor, véanse también los trabajos de Nascentes (1939), Silvio Elia (1975), Araújo (2003) y Fávero y Molina (2006).

\section{Charles Adrien Olivier Grivet (1816-1876)}

Charles Adrien Olivier Grivet nació en Villars-le-Terroir (Suiza) en 1816 y falleció en Brasil en 1876. Fue profesor de Humanidades en Rusia y Suiza. En 1856, por motivos políticos, emigró a Brasil donde alcanzó cierto reconocimiento como profesor y gramático.

En 1865 publicó su único trabajo sobre la lengua portuguesa, la Nova Grammatica Analytica da Língua Portugueza (18651-18812), que puede considerarse como una obra de carácter normativo y con finalidad pedagógica.

Actualmente, los estudios historiográficos caracterizan la Gramática de Grivet como un tratado que «ao mesmo tempo em que [continua] valorizando preceitos da gramática geral filosófica, [insere] muitos dos elementos advindos das novas correntes de estudos da linguagem» (Fávero y Molina, 2006: 120). En efecto, en algunas ocasiones es evidente el desacuerdo del gramático con ciertas normas de la GGR. Este es el caso de las críticas a las teorías del verbo sustantivo y de la elipsis:

Ela [la teoría del verbo sustantivo] veio a dominar soberanamente na gramática portuguesa; e hoje não há, neste assunto, autor que deixe de lhe fazer a devida continência, embora nem todos pareçam igualmente convencidos de sua desmascarada eficácia (Grivet 1881: 227 apud Fávero y Molina 2006: 117).

Qual é, portanto, a teoria que natural e ostensivamente daí decorre em relação aos verbos impessoais? Simplesmente que são impessoais porque não têm pessoa; e não têm pessoa porque não têm sujeito: pois pessoa e sujeito é uma só e a mesma coisa (Grivet 1881: 424 apud Fávero y Molina 2006: 120) 
Las citas de Olivier Grivet en las gramáticas de Freire, Ribeiro y Maciel solamente recogen ejemplos de su obra para ilustrar las reglas gramaticales.

Sobre la Nova Grammatica Analytica, véanse los trabajos de Nascentes (1939), Silvio Elia (1975), Araújo (2003) y Fávero y Molina (2006).

\section{Ernesto Carneiro Ribeiro (1839-1920)}

Ernesto Carneiro Ribeiro nació en Itaparica (Brasil) en 1839 y murió en Salvador en 1920. Era mestizo, hijo de una esclava liberta y de un portugués. Fue médico, profesor, lingüista y gramático.

Carneiro Ribeiro fue profesor de gramática, latín, francés e inglés, además de ser uno de los primeros médicos brasileños que se dedicó al estudio de la psicología.

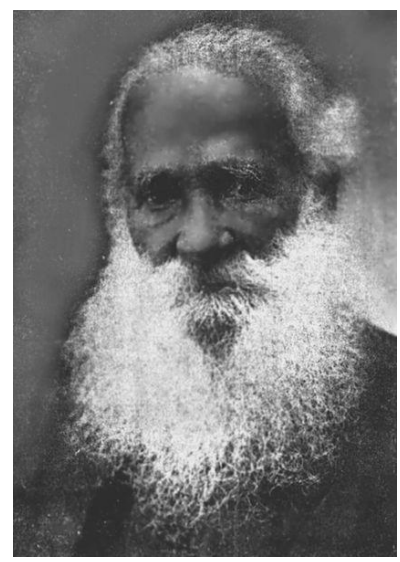

La bibliografía de Carneiro Ribeiro relativa a los estudios lingüísticos cuenta con tres gramáticas del portugués, los Elementos de Grammatica Portugueza (1879), la Grammatica Portugueza Philosophica (1881) y los Serões Grammaticaes ou Nova Grammatica Portugueza (1890), obras que, por lo general, manifiestan cierto carácter tradicional y prescriptivo.

Maximino Maciel es el único gramático que hace referencia a la Gramática de Carneiro Ribeiro. Los aspectos más relevantes que Maciel comparte con este autor son el reconocimiento del valor pronominal de los "adjectivos personativos» y algunas explicaciones sobre el cambio de registro lingüístico, especialmente las diferencias entre el lenguaje formal y el familiar.

Son escasas las investigaciones sobre Ernesto Carneiro Ribeiro y su contribución a los estudios lingüísticos. Sin embargo, cabe destacar los trabajos de Carneiro Ribeiro (1939) y Cavaliere $(2000,2002,2010)$. 


\section{Augusto Epiphanio da Silva Dias (1841-1916)}

Augusto Epiphanio da Silva Dias nació en Lisboa en 1841 y murió en esta misma ciudad en 1916. Fue profesor y gramático. Epiphanio da Silva es reconocido actualmente por promover la reforma de la educación en Portugal en $1894 / 95$.

Los estudios lingüísticos de Epiphanio da Silva Dias comprenden obras relativas a las lenguas clásicas, al francés y al portugués,

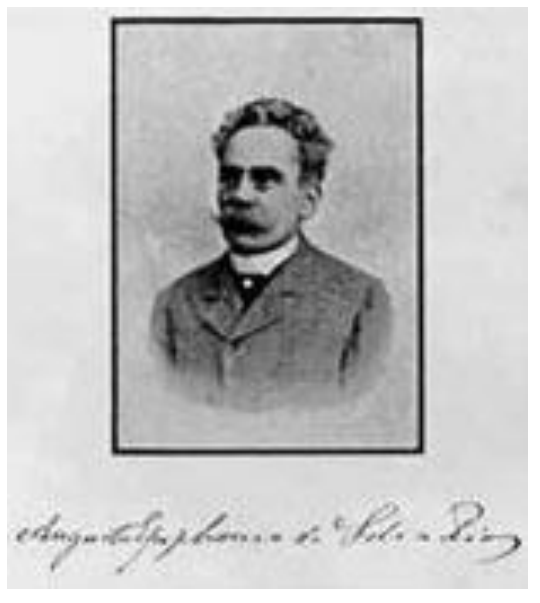
como la Grammatica practica da lingua portugueza para uso dos alumnos do primeiro anno do curso dos lyceus (1870), la Grammatica franceza para uso das escolas, por J. E. Von Hafe e A. Epiphanio da Silva Dias (1875), la Grammatica portugueza para uso das aulas de instrucção primaria (1876) y la Sintaxe historica portuguesa (1918).

Las ideas lingüísticas de Epiphanio da Silva Dias se inscriben en las corrientes positivistas y comparatistas introducidas en Portugal por Adolpho Coelho. De acuerdo con estos principios, Epiphanio da Silva publica la Grammatica Pratica, considerada como «la primera [obra de la tradición portuguesa] en que son adoptadas, para fines de enseñanza, las nuevas concepciones y métodos filológicos») (Gonçalves 2003: 113).

En la Gramática de Augusto Freire, Epiphanio da Silva Dias está citado en el tratamiento de las oraciones subordinadas adverbiales como fuente teórica de esta descripción. Por su parte, Maximino Maciel utiliza las obras del autor portugués solamente con la finalidad de recoger ejemplos para ilustrar las reglas de su Gramática.

Sobre Augusto Epiphanio da Silva Dias y su bibliografía, véase Leite de Vasconcelos (1922), Gonçalves (1996), Verdelho (1997) y Marçalo (2010). 


\section{Joaquim Theophilo Fernandes Braga (1843-1924)}

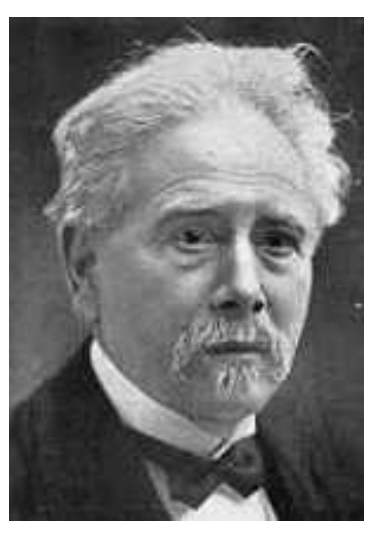

Joaquim Theophilo Fernandes Braga nació en Azores en 1843 y murió en Lisboa en 1924. Fue escritor, dramaturgo y político. Llegó ser presidente del gobierno provisional y el segundo presidente de Portugal.

La principal contribución de Theophilo Braga a los estudios lingǘsticos fue la Grammatica portugueza elementar, fundada sobre o método historicocomparativo (1876). Como se desprende del propio título, esta obra se asienta en el marco teórico positivista.

Theophilo Braga proporciona a las gramáticas de Freire, Ribeiro y Maciel un buen número de ejemplos para ilustrar reglas de uso. Solamente Ribeiro aprecia también aspectos teóricos de la Gramática del autor portugués, como la referencia al uso del sustantivo "homem» como pronombre indefinido y la crítica a un sistema ortográfico basado exclusivamente en la fonética.

En cuanto a las investigaciones en el campo de la historiografía lingüística sobre Theophilo Braga, véase Catroga $(1976,1977,1998)$ y Gonçalves $(2004)$.

\section{Francisco Adolpho Coelho (1847-1919)}

Francisco Adolpho Coelho nació en Coimbra en 1847 y murió en Carcavelos en 1919. Fue profesor, filólogo, pedagogo, etnógrafo, historiador, crítico literario y gramático. Es reconocido en su tradición por introducir el método histórico-comparado en Portugal y por fundar la filología portuguesa.

Adolfo Coelho posee una extensa bibliografía relacionada con los estudios lingüísticos, de la que destacan A lingua portugueza. Phonologia, etymologia, morphologia e syntaxe (1868), A ciência alemã e a ignorância portuguesa (1870), el Estudo de grammatica comparativa (1870), la Theoria da conjugação em latim e portuguez (1871), la Chrestomatia Historica da Lingua 


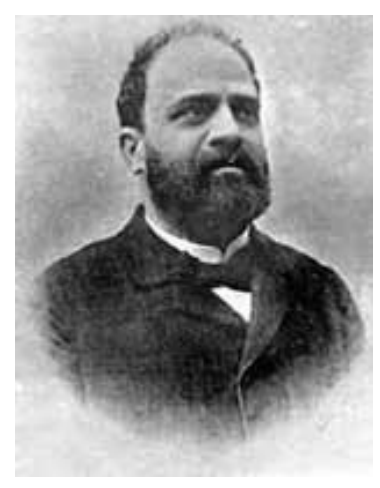

Portugueza (1873), las Questões da lingua portugueza (1874), Os dialectos romanicos ou neo-latinos na Africa, Asia e America (1881) y A lingua portugueza. Noções de glottologia geral e especial portugueza (1881). Tales obras representan la aplicación al portugués de las teoría y métodos de las corrientes histórico-comparada y positivista.

No cabe duda de que el Adolpho Coelho es el autor portugués que más profundamente ha influido en las gramáticas brasileñas de la segunda mitad del siglo XIX. Este influjo se manifiesta con claridad en el estudio histórico de la lengua portuguesa proporcionado por Freire en su Gramática, que constituye claramente un resumen de la Chrestomatia Historica da Lingua Portugueza. En la Gramática de Ribeiro, Adolpho Coelho es, sin duda, el autor portugués más citado. Las referencias a sus estudios sirven para autorizar las teorías sobre el origen de la expresión «no mais» en portugués, que ambos autores desligan de la influencia del español. La evolución de la conjugación del verbo «sen» y la clasificación del infinitivo y del participio como formas no personales del verbo reflejan también la impronta del autor portugués en la obra de Ribeiro, así como la clasificación de la desinencia verbal "ria» en «imperfeito do condicional», frente a la opinión de sus predecesores que solían denominarlo presente o futuro del condicional. En la obra de Maciel, Adolpho Coelho está citado solamente en el tratamiento de la formación de los sonidos.

Sobre Adolpho Coelho y su producción bibliográfica, se pueden consultar también los estudios de Vasconcelos (1929), Boléo (1948), Coelho (1948), Fernandes (1973), D'Andrade \& Kihm (1997), Cadernos da Associação Portuguesa de Lingüística (1995) y Gonçalves $(2003,2004)$. 


\subsection{Resultados}

Respecto al origen de las doctrinas que sirven de base a las obras de Antonio de Moraes Silva, Augusto Freire, Júlio Ribeiro y Maximino Maciel, las descripciones bibliográficas muestran que la mayoría de las fuentes teóricas presentes en estas gramáticas procede de las escuelas europeas, mientras que las fuentes brasileñas y portuguesas son más bien escasas. Sin embargo, las fuentes europeas, aunque posteriormente hayan influido directamente en la tradición brasileña, habían sido utilizadas con anterioridad por las fuentes portuguesas. Este fenómeno de intermediación explica las referencias a Friedrich Diez en la Gramática de Augusto Freire y la presencia de Humboldt y Bopp en la Gramática de Júlio Ribeiro.

Con todo, no se puede afirmar categóricamente que la gramaticografía brasileña esté fundamentada básicamente en obras lusas que reinterpretaron y aplicaron al portugués los métodos históricos, comparados, positivistas, etc., pues en muchas ocasiones los gramáticos del Nuevo Continente reciben la influencia directa de las corrientes francesas, alemanas e inglesas.

En cuanto a las referencias a autores portugueses, merece destacarse la ausencia de algunos gramáticos del renacimiento y del racionalismo, como Manuel Álvares (1526-1582), Amaro de Roboredo (1580?-1653?) y Antônio José dos Reis Lobato4 ${ }^{4}$ Con todo, la omisión especialmente de Álvares y Roboredo demuestra que las gramáticas brasileñas decimonónicas parecen haber superado, por lo general, la influencia renacentista. Cabe añadir que los gramáticos brasileños tampoco mencionan a autores españoles, excepto alguna referencia aislada a Nebrija (Ribeiro 1881: 181).

Asimismo, estas fuentes bibliográficas están relacionadas con periodos y autores específicos, de modo que la presencia, la ausencia o la repetición de estas referencias manifiestan las doctrinas vigentes, las superadas y las que

\footnotetext{
${ }^{4}$ Con respecto a la biografía de Antonio José dos Reis Lobato, las diferentes hipótesis en cuanto a su identidad (o existencia), origen y nacimiento léase Assunção (1997 a/b/c, 2000) y Kemmler (2005).
} 
coexistían en las gramáticas decimonónicas. Con estas informaciones, es posible determinar, en general, la evolución de los conocimientos lingüísticos y gramaticales de la tradición brasileña, pero también el grado de actualización que muestra cada autor con respecto a los cambios del paradigma científico.

En el Epítome, Moraes Silva cita a autores portugueses renacentistas (Nunes de Leão y João de Barros), a los gramáticos-filósofos franceses representativos de la gramática general (Arnauld, Lancelot, Dumarsais y Beauzée) y a los principales gramáticos ingleses que concilian la doctrina racionalista con la prescripción de los tratados pedagógicos (R. Lowth y J. Harris).

La influencia renacentista presente en la obra de Moraes está relacionada más bien con los aspectos formales del portugués. En cambio, el gramático muestra haber superado ciertas características tipológicas frecuentes en el Renacimiento y Barroco, como el discurso apologético, el ideal nacionalista y el incentivo del estudio del latín por medio de la gramática portuguesa o, simplemente, de la gramática en portugués.

En cuanto a las teorías racionalistas, los conocimientos de Moraes se muestran bastante acordes con los de su tiempo. Teniendo en cuenta que en la península ibérica se difundían por entonces las ideas racionalistas y enciclopedistas, el autor brasileño también manifiesta su conocimiento de las novedades en el campo de la morfología y sintaxis desarrolladas por Dumarsais y Beauzée. Sin embargo, estas teorías no conocieron una aplicación en su Gramática, por lo que el modelo racionalista del Epítome quedó en la práctica limitado a los principios de la GGR.

Las fuentes primarias de Augusto Freire se dividen entre los autores que representan la corriente racionalista (Arnauld, Lancelot y Sylvestre de Sacy), los que concilian la gramática normativa y el logicismo (Sotero dos Reis y Olivier Grivet), los que cultivan la gramática comparada (Cyprien Ayer y Friedrich Diez) y los que introdujeron el positivismo lingüístico en Portugal (Epiphanio da Silva Dias y Adolpho Coelho). 
El influjo racionalista en la Gramática de Freire apenas se diferencia de lo que se presentaba en la tradición brasileña desde la obra de Moraes. El modelo de la GGR se convirtió más bien en un paradigma que difícilmente se podía evitar. De hecho, podría ser considerado el punto de partida para muchos gramáticos de este periodo, a los que les resultaba casi inevitable la presencia de ciertos rasgos logicistas en sus obras. En este sentido, Freire escasamente cita a Arnauld y Lancelot, al tiempo que prescinde de referencias explícitas a los enciclopedistas. Al parecer, el objetivo en este momento consiste en ocultar todo lo que aparentemente es repetitivo y tradicional. Se trata, pues, de renovar la gramática de la lengua portuguesa.

La novedad de la Gramática de Freire (y de la tradición brasileña) reside en la introducción de las fuentes histórico-comparadas y positivistas. El influjo de Diez, Ayer, Coelho y Epiphanio da Silva Dias, autores contemporáneos suyos, muestra que nuestro gramático participaba de la lingüística de su tiempo. Consecuentemente, Freire trata de aplicar los avances teóricos y metodológicos de sus fuentes a la codificación del portugués, ya sea en la clasificación, en la terminología, en el metalenguaje o en la descripción de la Gramática.

Por su parte, Júlio Ribeiro es el autor que más refleja a través de las fuentes bibliográficas su eclecticismo teórico, pero también sus amplios conocimientos de las obras y corrientes que le precedieron. El gramático menciona autores renacentistas (Nunes de Leão y João de Barros), normativos y racionalistas (Soares Barbosa, Sotero dos Reis y Olivier Grivet), históricocomparados (Cyprien Ayer, Friedrich Diez, Émile Littré, Humboldt, Bopp, entre otros), neogramáticos y positivistas (Hovelacque y Adolpho Coelho).

Los gramáticos del Renacimiento no influyen de forma profunda en la Gramática de Ribeiro, pues estas referencias son utilizadas más bien como corpus de autoridades. Sin embargo, respecto a las fuentes logicistas, Ribeiro parece seguir en parte la misma estrategia de Freire, en el sentido de que no solo trata de superar su influencia en la Gramática sino que también critica en muchas ocasiones a sus predecesores. Dicho de otro modo, para alcanzar la 
modernización de la gramática hay que rechazar toda fuente que lleve el rótulo de racionalista.

El conocimiento por parte de Ribeiro de las fuentes contemporáneas, ya sea histórico-comparadas, positivistas o neogramáticas, refleja la actualidad de su obra. Sin embargo, el exceso de novedades, el eclecticismo teórico y, en muchas ocasiones, la falta de aplicación juiciosa de estos avances desembocaron en una codificación del portugués más bien de carácter normativo, obviamente con un enfoque diferente de los gramáticos anteriores, pero de resultados teóricos en cierto modo superficiales. Las críticas a Ribeiro por su falta de asimilación de las novedades extranjeras no tardaron en llegar, como cabe suponer, desde las páginas de la Gramática que trataba de abrirse paso en la tradición brasileña. En efecto, Maciel opina lo siguiente de la obra de Ribeiro:

Mais ou menos por esta época apparecera a Grammatica de Júlio Ribeiro, baseada nos trabalhos dos philologos allemães, inglezes e francezes. Tão de perto se lhes abeirava, porém, que se diria antes uma adaptação á lingua vernácula do que um trabalho onde transluzissem, com a individualidade do autor, os seus processos, o seu methodo, enfim norteação propria, oriunda de um trabalho de assimilação. Até pontos havia em que o Sr. Júlio Ribeiro se adscrevia a transverter, quasi ipsis verbis, para o vernaculo, as novas doutrinas dos autores estrangeiros, de Guardia, de Mason, de Bergmann. Além disso, resumbrava-lhe do estylo certo gráo de frouxidão e obscuridade; do methodo, certa desorientação [...].

O que se nos afigura é que se apressurou o Sr. Júlio Ribeiro a de chofre quebrar a rotina, fosse como fosse, embora ainda não houvesse assimilado o quanto lera nos philologos estrangeiros (Maciel 1926[1894]: 500).

En esta línea, Maximino Maciel es el gramático que cita textualmente el mayor número de fuentes teóricas, pues además de los autores aquí mencionados y de los que no se han podido identificar por falta de datos, el brasileño aporta más de sesenta referencias. La mayoría de las fuentes son autoridades de las corrientes histórico-comparadas (Ayer, Diez, Whitney, Müller, Bréal, Humboldt, Bopp, entre otros), seguidas de los neogramáticos (Hovelacque, Vinson, Meyer-Lübke) y los textos escolares (Pacheco da Silva 
Junior, Ernesto Carneiro Ribeiro, Júlio Ribeiro, Hemetério José dos Santos, Augusto Freire, entre otros). El propio Maciel reconoce esta característica de su Gramática y asegura que la presencia de un gran número de obras citadas no implica la generalización y la superficialidad de su tratado:

Apesar porém do grande numero de obras citadas, parece-nos que se não perdeu a nossa individualidade nesse compendio, porque á doutrina assimilada juntamos as nossas observações proprias, como verão os competentes (Maciel 1926[1894]: Prólogo de la $2^{a}$ edición).

Maciel muestra estar al tanto de los avances y las nuevas teorías y, más que conocer los nombres de autoridades, el autor procuró aplicar estos conocimientos a la Gramática del portugués de manera juiciosa, teniendo en cuenta que no todos los principios resultan útiles para explicar el portugués, que las reglas construidas para otras lenguas no siempre dan cuenta de los fenómenos particulares de esta lengua $y$, principalmente, que no todas las teorías son coherentes con un modelo descriptivo de gramática. Así, Maciel no dejó de actualizar los conceptos, las definiciones, la terminología, la clasificación, la organización, entre otros aspectos de su Gramática, pero mantuvo el foco en la descripción del portugués.

Cabe destacar además que la presencia de referencias a textos escolares en la Gramática de Maciel tiene una finalidad distinta a la de sus predecesores. La generalidad de las citas (la mayoría de autores brasileños) sirve como fuente de ejemplos para ilustrar las reglas gramaticales, lo que muestra que la obra no se asienta en estos modelos normativos, sino que más bien los reemplaza por un modelo descriptivo.

En resumen, la presencia y ausencia de determinadas fuentes primarias en las obras analizadas muestran que durante los primeros años de la gramaticografía brasileña decimonónica se siguen modelos prescriptivos, racionalistas de corte tradicional, como es el caso del Epítome de Moraes Silva. Algunas de estas características parecen haber sido superadas en la Gramática de Freire, pues el autor no cita textualmente las fuentes renacentistas y 
escasamente menciona a los autores racionalistas. Sin embargo, el segundo gramático de este estudio se inclina hacia la introducción de referencias histórico-comparadas. Por su parte, Júlio Ribeiro, a pesar de preservar el carácter normativo de su obra, amplia las fuentes histórico-comparadas, al mismo tiempo que adopta nuevas teorías positivistas a partir de los autores portugueses y de los neogramáticos. Por último, Maximino Maciel amplia aún más las fuentes histórico-comparadas y positivistas. Pero, su principal aportación quizá consistió en su capacidad para sustituir las fuentes primarias que habían orientado a los gramáticos de la primera mitad del siglo hacia la idea de la codificación normativa por un modelo coherente y metódico de gramática descriptiva del portugués.

Finalmente, cabe afirmar que, en general, los gramáticos brasileños del siglo XIX estuvieron al corriente de las novedades que se iban consolidando en la lingüística de su época. La tabla siguiente reúne, en fin, el corpus de las autoridades citadas por cada uno de los cuatro autores brasileños:

\begin{tabular}{|c|c|c|c|}
\hline $\begin{array}{c}\text { Moraes Silva } \\
\text { Leão }\end{array}$ & Augusto Freire & Júlio Ribeiro & Maximino Maciel \\
\hline $\begin{array}{c}\text { Duarte Nunes de } \\
\text { João de Barros }\end{array}$ & $\begin{array}{c}\text { Duarte Nunes de } \\
\text { Leão }\end{array}$ & \\
\hline Antoine Arnauld & Antoine Arnauld & João de Barros & \\
\hline $\begin{array}{c}\text { Dom Claude } \\
\text { Lancelot }\end{array}$ & $\begin{array}{c}\text { Dom Claude } \\
\text { Lancelot }\end{array}$ & & \\
\hline Robert Lowth & & & \\
\hline James Harris & & & \\
\hline $\begin{array}{c}\text { César Chesnau } \\
\text { Dumarsais }\end{array}$ & & & \\
\hline Nicolas Beauzée & & & \\
\hline \multicolumn{2}{|c}{} & & \\
\hline
\end{tabular}




\begin{tabular}{|c|c|c|c|}
\hline Moraes Silva & Augusto Freire & Júlio Ribeiro & Maximino Maciel \\
\hline & $\begin{array}{c}\text { Augusto Epiphanio } \\
\text { da Silva Dias }\end{array}$ & & $\begin{array}{c}\text { Augusto Epiphanio } \\
\text { da Silva Dias }\end{array}$ \\
\hline & $\begin{array}{c}\text { Friedrich } \\
\text { Christian Diez }\end{array}$ & $\begin{array}{c}\text { Friedrich } \\
\text { Christian Diez }\end{array}$ & $\begin{array}{c}\text { Friedrich } \\
\text { Christian Diez }\end{array}$ \\
\hline & $\begin{array}{c}\text { Francisco } \\
\text { Adolpho Coelho }\end{array}$ & $\begin{array}{c}\text { Francisco } \\
\text { Adolpho Coelho }\end{array}$ & $\begin{array}{c}\text { Francisco } \\
\text { Adolpho Coelho }\end{array}$ \\
\hline & $\begin{array}{l}\text { Nicolas Lovis } \\
\text { Cyprien Ayer }\end{array}$ & $\begin{array}{l}\text { Nicolas Louis } \\
\text { Cyprien Ayer }\end{array}$ & $\begin{array}{l}\text { Nicolas Louis } \\
\text { Cyprien Ayer }\end{array}$ \\
\hline & $\begin{array}{c}\text { Francisco Sotero } \\
\text { dos Reis }\end{array}$ & $\begin{array}{c}\text { Francisco Sotero } \\
\text { dos Reis }\end{array}$ & $\begin{array}{c}\text { Francisco Sotero } \\
\text { dos Reis }\end{array}$ \\
\hline & $\begin{array}{l}\text { Charles Adrien } \\
\text { Olivier Grivet }\end{array}$ & $\begin{array}{l}\text { Charles Adrien } \\
\text { Olivier Grivet }\end{array}$ & $\begin{array}{l}\text { Charles Adrien } \\
\text { Olivier Grivet }\end{array}$ \\
\hline & Auguste Brachet & Auguste Brachet & Auguste Brachet \\
\hline & & $\begin{array}{c}\text { Jerónimo Soares } \\
\text { Barbosa }\end{array}$ & \\
\hline & & $\begin{array}{c}\text { Maximilien Paul } \\
\text { Émile Littré }\end{array}$ & \\
\hline & & Abel Hovelacque & \\
\hline & & Émile Ferrière & \\
\hline & & Augusto Freire & Augusto Freire \\
\hline & & $\begin{array}{c}\text { Wilhelm von } \\
\text { Humboldt }\end{array}$ & $\begin{array}{c}\text { Wilhelm von } \\
\text { Humboldt }\end{array}$ \\
\hline & & $\begin{array}{l}\text { Joaquim Theophilo } \\
\text { Fernandes Braga }\end{array}$ & $\begin{array}{l}\text { Joaquim Theophilo } \\
\text { Fernandes Braga }\end{array}$ \\
\hline & & Alexis Chassang & Alexis Chassang \\
\hline & & $\begin{array}{c}\text { William Dwight } \\
\text { Whitney }\end{array}$ & $\begin{array}{c}\text { William Dwight } \\
\text { Whitney }\end{array}$ \\
\hline & & Max Müller & Max Müller \\
\hline & & Michel Bréal & Michel Bréal \\
\hline & & $\begin{array}{l}\text { Pacheco da } \\
\text { Silva Junior }\end{array}$ & $\begin{array}{l}\text { Pacheco da } \\
\text { Silva Junior }\end{array}$ \\
\hline
\end{tabular}




\begin{tabular}{|c|c|c|c|}
\hline Moraes Silva & Augusto Freire & Júlio Ribeiro & Maximino Maciel \\
\hline & & $\begin{array}{l}\text { Guardia et } \\
\text { Wierzeyski }\end{array}$ & $\begin{array}{l}\text { Guardia et } \\
\text { Wierzeyski }\end{array}$ \\
\hline & & Franz Bopp & Franz Bopp \\
\hline & & & Júlio Ribeiro \\
\hline & & & Arsène Darmesteter \\
\hline & & & $\begin{array}{c}\text { Ernesto Carneiro } \\
\text { Ribeiro }\end{array}$ \\
\hline & & & $\begin{array}{c}\text { Wilhelm Meyer- } \\
\text { Lübke }\end{array}$ \\
\hline & & & $\begin{array}{c}\text { Monier Monier- } \\
\text { Williams }\end{array}$ \\
\hline & & & Lindley Murray \\
\hline & & & Larive et Fleury \\
\hline & & & Paul Regnaud \\
\hline & & & $\begin{array}{c}\text { Hemetério José } \\
\text { dos Santos }\end{array}$ \\
\hline & & & Adolphe D'Assier \\
\hline & & & Julien Vinson \\
\hline & & & $\begin{array}{l}\text { Karl Marquard } \\
\text { Saver }\end{array}$ \\
\hline & & & $\begin{array}{c}\text { Charles Peter } \\
\text { Mason }\end{array}$ \\
\hline & & & $\begin{array}{l}\text { Robert Gordon } \\
\text { Latham }\end{array}$ \\
\hline
\end{tabular}

4.1 Fuentes primarias de los gramáticos brasileños del siglo XIX 


\section{ANÁLISIS DE LA TEORÍA GRAMATICAL BRASILEÑA DEL SIGLO XIX}

Este capítulo se dedica al análisis de la evolución que experimenta la gramática de la lengua portuguesa durante el primer siglo de manuales compuestos por autores nacidos en Brasil. Se defiende aquí que los principales cambios en la historia de la gramática portuguesa desarrollada desde el Brasil del siglo XIX están representados por las obras de Moraes Silva, Augusto Freire, Júlio Ribeiro y Maximino Maciel. Cada uno de estos cuatro autores brasileños, cuyos textos recorren la centuria de principio a fin, introduce un conjunto de recursos teóricos y metodológicos en la codificación del portugués que pone de manifiesto la evolución desde una concepción racionalista de la gramática hasta el alcance de los modelos descriptivos, que siguen tras las huellas de métodos positivistas y de la influencia de las corrientes histórico-comparadas.

El siglo XIX brasileño se abre con la publicación del Epítome de Grammatica Portugueza de Moraes Silva (1806). El autor construye la gramática portuguesa de acuerdo con algunas ideas racionalistas difundidas por PortRoyal y, posteriormente, reformuladas por los sensualistas y enciclopedistas. Se ha utilizado en este estudio la edición del Epítome fechada en 1824. El texto es una reimpresión de la obra publicada en Lisboa en 1806 y añadida, en 1813, al Diccionario da Língua Portugueza de Rafael Bluteau. Al parecer, la Gramática no ha pasado por revisiones ni correcciones por parte del autor o de editores, de modo que, hasta la fecha de la muerte de Moraes Silva (1824), las impresiones y ediciones del Epítome corresponden al texto original tal como lo dejó el autor.

La fase siguiente de esta evolución comienza con la Grammatica Portugueza de Augusto Freire (18751-18772). Esta obra representa el primer intento en la tradición gramatical brasileña de construir un modelo taxonómico de gramática portuguesa, basado en criterios de clasificación, sistematización y nomenclatura propios de las ciencias naturales y de aplicar a la codificación 
del portugués una metodología próxima a algunos principios de la gramática histórico-comparada. En este estudio se ha utilizado la 8. ${ }^{a}$ edición de la Grammatica Portuguesa de 1894. La primera edición fue publicada en 1875 y premiada por el Governo Geral en 1877, con ocasión de su segunda edición. La obra conoció al menos otras nueve ediciones posteriores a estas dos, pero ninguna reimpresión experimentó modificaciones profundas por parte del autor o editores.

El tercer cambio que tuvo lugar en la historia de la gramática brasileña del siglo XIX se corresponde con la publicación la Grammatica Portugueza de Júlio Ribeiro (1881 1-18852). Se trata, en nuestra opinión, de la primera propuesta cabal de una gramática normativa del portugués, que reúne los fundamentos de la tradición anterior, proporciona un modelo descriptivo del idioma contemporáneo y al mismo tiempo aporta conocimientos históricos y contrastivos del portugués en sus diferentes variedades. En este trabajo se ha utilizado la primera impresión de la Grammatica Portugueza fechada en 1881. También se han consultado las reimpresiones de 1899 y 1911 que siguen fielmente el texto de la 2. ${ }^{a}$ edición de 1885, tal como quedó fijada por el autor, cinco años antes de su muerte. Sin embargo, el estudio de estas adiciones posteriores no forma parte de este trabajo de investigación, salvo muy ocasionalmente.

Finalmente, el cuarto modelo de gramatización que cierra el siglo llega con la primera gramática brasileña titulada descriptiva por el propio autor: la Grammatica Descriptiva de Maximino Maciel (18871-18942). El análisis de la Gramática de Maciel se basa en la edición fechada en 1926 que sigue el texto de la 2. ${ }^{a}$ edición publicada por el autor en 1894. Maciel publicó en vida once ediciones de su obra. La última está fechada en 1928, tres años antes de la muerte del gramático. El texto no sufre modificaciones desde la 2. ${ }^{a}$ edición de 1894. En este trabajo se han tomado en consideración las variantes entre las dos primeras ediciones, el prólogo de la 3. a edición (1901), que incluye observaciones acerca de la recepción de la obra entre quienes la utilizaron para la enseñanza y, por último, también incluimos en este estudio el Apéndice 
de Maciel añadido a la Grammatica Descriptiva desde la edición de 1910. En este Apéndice el autor ofrece una revisión crítica de la historia de la gramática portuguesa.

Las cuatro obras sobre las que gravitan los principales cambios gramaticográficos del siglo XIX brasileño proporcionaron un cuerpo de doctrina que se mantuvo vigente en Brasil hasta bien entrado el siglo XX. La demanda en la enseñanza de las obras tanto de Augusto Freire (18751-18772) y Júlio Ribeiro (1881'18852) como de Maximino Maciel (18871-18942) se refleja en las numerosas ediciones que vieron la luz:

1) Augusto Freire: al menos 9 ediciones. La última edición que se ha podido encontrar es la 9. ${ }^{a}$ de 1906.

2) Júlio Ribeiro: al menos 11 ediciones tras la muerte del autor. La última edición que se ha podido encontrar es la 11. a de 1913.

3) Maximino Maciel: al menos 11 ediciones. La última edición de la que se tiene noticia es la de 1931.

La organización y definición de la gramática, las partes que la componen, el contenido sistematizado en cada caso, la selección de conocimientos y recursos, el grado de generalización descriptiva, la terminología son, entre otros, aspectos importantes en los que se manifiesta el desarrollo de la disciplina en cualquier tradición gramatical. Mediante el análisis de estos y otros elementos en las obras de referencia, se propone aquí determinar el avance de la gramaticografía brasileña y la cronología de los principales cambios durante el primer siglo de manuales compuestos por autores del Nuevo Continente. 


\subsection{El modelo racionalista: el Epítome de Grammatica Portugueza de Antonio de Moraes Silva (1806)}

Como es sabido, la gramática general y razonada', de carácter logicista, cuyos mayores exponentes son la Minerva de Sánchez de las Brozas (1587) y la Grammaire de Port-Royal (1660), se remonta a las teorías aristotélicas sobre la concepción del pensamiento y del lenguaje. Los escolásticos medievales y los renacentistas siguieron las mismas postulaciones del griego. De ahí que en la Gramática de Port-Royal confluyan las escuelas especulativa y cartesiana. Fue a partir de este periodo, además, cuando la gramática pasó a valorar la razón más que el uso (Robins 1967, Yllera 1983, Černý 1998, Fonseca 2004).

En pocas líneas, esta teoría deductiva se asienta en el concepto de que la lengua apriorísticamente es una expresión del pensamiento. Igualmente admite que el pensamiento supuestamente sigue un mismo sistema, es decir, independiente del individuo o de factores externos, pues su proceso de construcción es siempre idéntico. Consecuentemente, se entiende que todas las lenguas tienen una base común que reflejan el pensamiento que, a su vez, es común a todas las lenguas. En palabras de Yllera (1983), «existe una estructura abstracta universal común a todas las lenguas que es perfectamente racional y natural y que es posible descubrir bajo la aparente diversidad de las lenguas particulares. Todo estudio de una lengua particular debe partir de ella») (Yllera 1983: 654).

La creencia de que "las lenguas eran en lo esencial muy semejantes y que sólo diferían en lo accidentalı (Yllera 1983: 651) permitió que los gramáticos ilustrados establecieran una serie de universales lingüísticos. Así por ejemplo,

\footnotetext{
1 Respecto a esta nomenclatura, Yllera (1983) señala que uno coinciden necesariamente gramática general y gramática racional, aunque a partir de la GGR se presenten en general unidas. Una gramática general supone: (1) la creencia en la existencia de categorías gramaticales universales, comunes a todas las lenguas; (2) el deseo de atender más a los rasgos generales en los que coinciden todas las lenguas que a los rasgos particulares de una de ellasil (Yllera 1983: 650). En cambio, una gramática razonada se refiere a «que la razón puede aplicarse a la explicación de los hechos del lenguaje sin que por ello la lengua se base en un esquema racional» (Yllera 1983: 656).
} 
Yllera afirma que el Brocense «no enumera los rasgos que considera generales 0 comunes a todas las lenguas, pero implícitamente se deduce su creencia en la universalidad de algunos principios descubiertos en la lengua latina) (Yllera 1983: 653 [la negrita es mía]). Como las gramáticas o describían el latín o partían del modelo latino para describir las lenguas vulgares, consecuentemente, use aceptó la universalidad de categorías gramaticales que hoy parecen propias de un grupo de lenguas [las derivadas del latín]» (Yllera 1983: 651). Por esta razón es común en las gramáticas particulares razonadas, como la de Moraes Silva, la aceptación de principios como la elipsis; el verbo sustantivo; la existencia de dos géneros naturales, masculino y femenino (el neutro sería una irregularidad); la noción de conjunción como partícula que une solamente oraciones; el carácter natural de las interjecciones; entre otros (Yllera 1983: 653-655).

Al parecer, en este periodo la noción de universal lingüístico era en cierto modo subjetiva, pues, por un lado las gramáticas no «presenta[n] una lista completa de los rasgos universales del lenguaje» (Yllera 1983: 654) y, por otro, a la medida en que se iban publicando gramáticas particulares razonadas, algunos autores llamaban la atención sobre aspectos universales que hasta entonces no habían sido mencionados.

Pues bien, esta concepción filosófica, que defiende la correspondencia entre los procesos lógicos y los procesos lingüísticos, ha producido en su aplicación a la gramática, entre otros, cambios diversos en la estructura, en la definición de la disciplina, en la clasificación de las palabras, en el análisis de la oración (Martínez Gavilán 1996, 2006). Su influjo se ha podido sentir hasta casi finales del siglo XIX, más de dos siglos después de la publicación de la Gramática de Port-Royal (Ridruejo 2001).

En la tradición gramatical brasileña la difusión de la gramática racionalista y de la ideología sensualista ha sido tardía en relación con otras tradiciones. Tanto es así que a finales del siglo XIX todavía se difundían las ideas racionalistas en el país. De hecho, se considera que sigue publicándose en Brasil este tipo de obras hasta 1881, fecha de la última gramática denominada razonada por el propio autor, la Nova Grammatica Analytica da Lingua 
Portugueza de Olivier Grivet (1865). En definitiva, aun a finales del siglo XIX las gramáticas filosóficas y las de tipo descriptivo coexistían en esta tradición.

\subsubsection{El autor y su época}

El primer análisis historiográfico de este capítulo se centra en la primera gramática filosófica brasileña, el Epítome da Grammatica Portugueza de Antonio de Moraes Silva (1824[1806]). Esta obra fue escrita en 1802 en el estado de Pernambuco y publicada cuatro años después en Lisboa, por la falta de imprentas en el país de origen del autor.

Antonio de Moraes Silva, considerado una de las autoridades canónicas de la Universidade de Coimbra, nació en Rio de Janeiro en 1755. De joven se trasladó a Portugal donde se tituló en Derecho civil. Durante sus estudios universitarios formó parte de un grupo estudiantil progresista perseguido por la inquisición. En el ejercicio de su magistratura fue denunciado por su condiscípulo Francisco Cândido Chaves por herejía y procesado dos veces por el Tribunal do Santo Oficio de Coimbra, en 1779 y 1806, esta última fecha fue la de publicación de su Gramática.

Vivió el exilio en Inglaterra, donde empezó su trabajo lexicográfico, bajo la protección de Luis Pinto de Sousa Coutinho-Vizconde de Balcemão, de Tendaes e Ferreiros y del representante de Portugal en este país. En 1785 volvió a Lisboa, después de una estancia en Italia y Francia, y contrajo matrimonio con Narcisa Pereira da Silva. En 1794 vuelve a Brasil por motivos políticos y laborales. Se instala en Pernambuco, donde escribe su Gramática. Muere el 11 de abril de 1824 en Engenho Novo de Moribeca, donde vivió durante su estancia en Pernambuco.

La producción bibliográfica de Moraes Silva consta de una traducción al portugués de la Historia de Portugal (1788), obra compuesta por una sociedad de literatos en inglés y del Diccionario da lingua portuguesa publicado en 1789. 
Tras la primera edición de su Gramática (Lisboa 1806), el autor publica una segunda edición en 1813, como apéndice del Diccionario Rafael Bluteau.

Al Epítome da Grammatica Portugueza de Moraes Silva precede un hecho histórico que debe ser tomado en cuenta. Casi medio siglo antes de esta publicación, en 1770, el Marqués de Pombal promulgó en Portugal el Diretorio dos Indios. Este decreto prohibía en la entonces colonia portuguesa la enseñanza y el uso de la lengua general -el tupí- para la comunicación. Se imponía el uso del portugués a los indios. Esta política desencadenó la expulsión de los jesuitas, responsables del sistema educativo y, en la práctica, también paralizó la imprenta en Brasil.

Las consecuencias sociales más destacables de estas medidas fueron, entre otras, la marginación de los indios, generalmente reacios al aprendizaje del portugués y la dependencia cultural e intelectual de la metrópoli, tras el cierre de las escuelas jesuíticas. El retraso en la educación afecta a todas las disciplinas, incluida la gramática. Además, conviene tener presente que hasta el siglo XIX, los estudios gramaticales eran exclusivamente misioneros y bilingües (lengua general/portugués o lengua general/latín) (véase el capítulo 2).

Sería temerario afirmar que el decreto mismo de Pombal haya motivado la producción de la Gramática de Moraes Silva cuando éste no es el caso. Pero sí parece indudable que la Gramática está de acuerdo con algunos supuestos del Diretorio, más bien por circunstancias políticas que lingüísticas.

\subsubsection{Fundamentos gramaticográficos de Moraes}

Moraes Silva introduce el Epítome con una cita de la Gramática de Condillac (1714-1780), en la que el autor francés manifiesta el rechazo hacia las corrientes latinizantes:

Nous avons compliqué nôtre Grammaire, parce que nous l'avons voulu faire d'après les grammaires Latines. Nous ne la simplifierons, qu'autant que nous rappellerons les expressions aux élémens du discours. Condillac, 
Gramm, p. 2. Chap. 21 note $^{2}$ p. 205. Édit. de 1780 à Geneve (Moraes Silva 1824[1806]: I).

Al parecer, la propuesta del gramático brasileño es aplicar a la lengua portuguesa la ideología descrita en la Grammaire de Condillac y privilegiar el estudio del portugués en menoscabo de las referencias y las comparaciones con el latín.

Un examen del prólogo permite verificar que el autor solamente ofrece una razón para el estudio de la lengua propia, «Alem d'isto: a tua lingua deve servir te de meyo para aprenderes as estranhas») (Moraes Silva 1824[1806]: I). Sin embargo, las demás razones no se refieren al estudio de la lengua sino a las ventajas de su propia obra, del Epítome. El autor basa esta propaganda en la objetividad y claridad de su estudio frente a los anteriores, en la superación de la doctrina latinizante, en las explicaciones innovadoras sobre el uso de determinadas clases de palabras sin precedentes en otras gramáticas, en el desarrollo de la sintaxis y en la aportación de numerosos ejemplos. A continuación, se puede comprobar de qué manera el gramático divulga las supuestas ventajas de su obra en comparación con las demás:

Propuz me nesta Grammatica dar te idéyas mais claras, e exactas, do que commmumente se achão nos livros d'este assumpto, que tenho visto no nosso idioma, tanto a cerca das Partes Elementares da Oração como da sua emendada composição.

Nelles não se explica, por exemplo, o que é artigo; dizem te que se ajunta aos nomes para mostrar os numeros, e os casos.

Mas alem de que são idéyas falsas dizer, que ha genitivos, dativos, \&c, em Portuguez, tambem serião falsas noções as que se dessem de correspondências entre o Latim, e o Portuguez.

Eu cuido que te expliquei esta parte da grammatica [la sintaxis] com assás curiosidade, propondo te o que nella é mais recôndito, e muitos exemplos de bons autores, que seguramente imites, porque também a copia delles te fará cair mais fácilmente na intelligencia, e explicação das regras (Moraes Silva 1824[1806]: I).

\footnotetext{
2 Na ortografia da Lingua Portugueza, pag. 106. e seg. da edição de 1784 [nota del gramático].
} 
En esta cita se manifiestan, además, los principios de autoridad y uso de la lengua. El autor asevera que el arte del buen hablar y escribir procede de la imitación de los buenos autores que, a su vez, justifican el empleo de un corpus de autoridades literarias especialmente del periodo clásico, en consonancia con la corriente conservadora de la época (Yllera 1983, Lliteras 1997).

En cuanto a la disposición gráfica del Epítome, el autor establece una organización del contenido en partes y capítulos, pero como un texto corrido, sin distinguir las reglas de los ejemplos ni por tamaño de letra ni por espacios. En cambio, separa con una raya horizontal el cuerpo del texto de la nota al pie de página, aunque el tamaño de la letra no varía. En general, las notas a pie contienen ejemplos complementarios, referencias a otros autores $y$ explicaciones teóricas.

La división y las proporciones de cada parte de la Gramática reflejan las concepciones teóricas y metodológicas del autor. El Epítome consta de 177 páginas distribuidas en dos partes: libro I - «das palavras por si sós ou partes da sentença» - con 78, que corresponde a un $47 \%$ del total de la Gramática; y libro II - «da composição das partes da sentença entre si ou sintaxe» - con 42 páginas, que corresponde a un 25\%, la introducción con 9, que corresponde a un $5 \%$ del total de la obra y el resto son tablas de conjugación verbal:

Quasi todos os Grammaticos, que tenho visto, engrossão os seus livros com conjugações: as regras da composição, parte tão principal das Grammaticas, reduzem-nas a muito poucas. Eu cuido que te expliquei esta parte da Grammatica com assás curiosidade, propondo-te o que nella é mais recôndito [...] (Moraes Silva 1824[1806]: I).

Las proporciones de la obra confirman el avance progresivo de los estudios sintácticos en este periodo y el equilibrio que comienza a mostrarse con respecto al análisis de las clases de palabras. De hecho, la sintaxis en las gramáticas anteriores apenas ocupaba un 10\% del total.

Los portugueses Lobato (1770) y Dias de Souza (1804) ya habían propuesto una división de la gramática en dos partes con anterioridad a Moraes 
Silva. No obstante, cambian no solo los términos sino también los contenidos, pues el primer gramático divide la gramática en etimología y sintaxis, mientras que para Dias de Souza las partes de la gramática son la ortología y la ortografía. Sin embargo, pese a que estas denominaciones de las partes de la gramática contaban con cierta tradición, como vemos Moraes Silva elude este problemático asunto mediante el recurso a la simple secuencia de dos «livros».

Después de Moraes Silva, la tradición brasileña en general se muestra notablemente conservadora en la división de la gramática. Por un lado, hay autores como Frei Caneca (1817) y Sotero dos Reis (1865) que aún utilizan el término «etimología» en el mismo sentido utilizado por Nebrija. Por otro lado, no se tiene noticia de gramáticas brasileñas del XIX que utilicen la denominación de analogía en referencia al tratado de las clases de palabras, a pesar de que no faltan autores que emplean otros términos como «lexicologia», «lexeologia» o «lexiologia» (véase capítulo 6 sobre terminología y terminografía en las gramáticas brasileñas).

En el análisis gramaticográfico, el examen de un corpus textual (sea o no de autoridades) desempeña un papel sustancial. Este procedimiento permite determinar el carácter descriptivo de una obra, el interés del gramático por mostrar las generalizaciones de las unidades analizadas (Lliteras 1997: 58) y la dirección metodológica que adopta el tratado, bien sea esta de tipo inductivo (del dato hacia la regla) o deductivo (de la regla hacia el ejemplo). Actualmente, la definición y la función de un corpus de autoridades pueden entenderse de la siguiente manera:

Un corpus de referencia es definido como un conjunto homogéneo de documentos lingüísticos de cualquier tipo (...) que se toman como representativos de un estado, variedad o nivel de lengua predeterminado. (...) El corpus, necesariamente delimitado por el campo de investigación (...) y a su vez, de extensión limitada, desempeña, pues, una función de representatividad de los fenómenos generales o universales (Lliteras 1997: 58). 
Del análisis gramatical de un corpus depende, en gran medida, el desarrollo de los estudios sintácticos. Los textos representativos del idioma y las citas literarias constituyen las principales fuentes de observación y tratamiento sintáctico y, al mismo tiempo, permiten la suparación de los enfoques gramaticales limitados al estudio de la palabra aislada (Lliteras 1997: 66):

La utilización de un corpus en la gramática conduce indefectiblemente al desarrollo de la sintaxis, puesto que son los mismos textos las principales fuentes del conocimiento sintáctico (Lliteras 1997: 66).

Pues bien, en la gramaticografía brasileña del siglo XIX el corpus de autoridades literarias ${ }^{3}$ del Epítome de Moraes Silva está formado por algo más de 30 autores. En su mayoría son clásicos portugueses del siglo XVI y XVII como Camões, Sá de Miranda, João de Barros, Ferreira, Padre Vieira, Mendes Pinto, entre otros. Algunos clásicos grecolatinos también están presentes en la Gramática, y en general se usan para justificar determinadas construcciones oracionales del latín que han persistido en la lengua portuguesa. Como cabe suponer, el corpus no consta de autoridades brasileñas, pues al contrario, era recomendable que el portugués hablado en Brasil se adecuara a las normas europeas. No hay duda de que el uso lingüístico que se describe y se prescribe en el Epítome de Moraes Silva es la variante clásica, culta y europea del portugués.

Los ejemplos que se han podido contabilizar giran en torno a 200. El autor más citado es Camões, con aproximadamente 55 textos. Le sigue João de Barros (1536) con más 15 citas y luego los «autores menores» cuyos ejemplos no superan los 5 o 6 cada uno.

\footnotetext{
${ }^{3}$ En la tradición gramatical española, y quizás en otras tradiciones europeas y americanas, la obra de Salvá supera con creces las cifras de otros gramáticos «El corpus utilizado por Salvá supera la centena de autores y obras anónimas, desde el Cantar del Cid hasta los que "han florecido - dice - después de mediado del último siglo" (§ [036]). Solo en la Analogía y la Sintaxis las referencias textuales corresponden a más de sesenta autores, casi todos contemporáneos del auton) (Lliteras 1997: 67).
} 
Como suele ser habitual desde el periodo ilustrado4, los gramáticos dan cuenta en el prólogo de sus principios metodológicos. En esta línea, Moraes Silva avanza al lector que el suyo es un estudio basado en un corpus de autoridades literarias y al mismo tiempo explica que mediante este procedimiento se persiguen dos propósitos, facilitar la imitación del buen uso y acreditar las reglas gramaticales:

Eu cuido que te expliquei esta parte da Grammatica [la sintaxis] com assás curiosidade, propondo-te o que nella é mais recondito, e muitos exemplos dos bons autores, que seguramente imites, porque também a copia delles te fará cair mais facilmente na intelligencia, e explicação das regras (Moraes Silva 1824[1806]: I [la negrita es mía]).

En resumen, el corpus literario desempeña en la Gramática dos objetivos:

1) El ejemplo ilustra una regla previamente establecida, que generalmente se refiere al estudio de las clases de palabras.

2) A partir del ejemplo se presenta una descripción sintáctica de alguna categoría léxica.

Las citas siguientes de Moraes representan, respectivamente, cada uno de estos procedimientos:

Os adverbios regem ou pedem outras palavas, que completem, e determinem a significação de uma das palavras, de que os mesmos advérbios se compõem: v. g.

Não podia em meu verso o meu Ferreira Igualmente á dor minha ser chorado:

(Caminha, Eleg. 4.)

i. é., ser chorado de modo igual á minha dor (Moraes Silva 1824[1806]: 60).

\footnotetext{
${ }^{4}$ Sobre la ilustración y la gramática de Benito de San Pedro, véase Lliteras 1992, Hernández Sánchez y López Martínez 2002.
} 
"Dormimos sonos alheyos, os nossos não o dormimos: rimos os risos alheyos": dis Sa de Mir. pintando o caracter servil, e lisongeiro, e para ajuntar os epítetos, expressa os pacientes cognatos sonos, e risos juntos a dormimos, e rimos. Semelhantes a estes são: por seculos dos seculos, (...) (Moraes Silva 1824[1806]: 113).

La construcción de la norma discursiva ${ }^{5}$ en el Epítome puede ser considerada heterogénea, aunque no haya muchas marcas discursivas que expresen otras normas de uso que no sea la culta o estándar. Aun así, Moraes Silva alude a una segunda norma discursiva no recomendada por la gramática, formada por usos vulgares o plebeyos. No se aprueban en el texto otros usos que no sean los clásicos amparados por escritores canónicos. Los usos que no se ajustan a las reglas establecidas por la gramática son propios de personas de escasa o nula instrucción:

O vulgo diz erradamente o cujo, a cuja em vez de o qual, a qual (Moraes Silva 1824[1806]: 17 [la negrita es mía]).

A plebe diz certas tafulas devendo dizer certas tafues (Moraes Silva 1824[1806]: 31 [la negrita es mía]).

Todavia os nomes proprios usados sempre em um genero não se alterão: e é erro vulgar dizer todo Lisboa: todo Castella (Moraes Silva 1824[1806]: 30 [la negrita es mía]).

A'cerca dos Modos verbáes advertiremos que os Poetas, imitando a simplicidade primitiva (...) usarão pedindo, do modo Mandativo (Moraes Silva 1824[1806]: 45 [la negrita es mía]).

Quiçáis é rusticidade, vista a sua origem de chi sá, quem sabe (Moraes Silva 1824[1806]: 63 [la negrita es mía]).

\footnotetext{
5 En la gramática española es notable el avance con relación al reconocimiento de distintas normas discursivas. Véase la gramática de Jiménez Patón (1614): «en el hablar, escribir, vestir y moneda se a de estar a lo que el vso aprovare y tubiere receuido [...] De suerte que el legislador y el maestro del hablar y del escribir a de ser el vso [...] Al cual vso es bien seguir, para acertar, sus leyes y preceptos y reglas» (Jiménez Patón 1965[1614]: 43 apud Lliteras 2001 a: 299).
} 


\subsubsection{Definición y división de la gramática}

Algunos investigadores como Gonçalves (e.p.) y Assunção (2002) afirman que la Gramática de Moraes Silva se divide en dos partes: «Das palavras por si sós ou partes da sentença» y «Da composição das partes da sentença entre si ou sintaxe $)$. Sin embargo, otros como Fávero y Molina (2006) consideran la introducción, que versa sobre los sonidos y las letras, como una de esas partes, por contener un prólogo que se ocupa de la metodología e intenciones gramaticales y por su contenido mismo. Aquí se afirma la propia declaración del gramático que afirma:

Trata pois a Grammatica das Sentenças (isto é, ensina a fazer proposições, ou sentidos perfeitos) e das diversas partes, de que ellas se compõem (Moraes Silva 1824[1806]: III [la negrita es mía]).

Moraes Silva define la gramática como «arte, que ensina a declarar bem os nossos pensamentos, por meyo de palabrası) (Moraes Silva 1824[1806]: III [la negrita es mía]) y la divide en universal, donde el lenguaje es analizado científicamente; y particular, cuyo objeto de estudio, el portugués, es técnicamente estudiado:

2. A Gramática Universal ensina os methodos, e principios de falar communs a todas as línguas.

3. A Grammatica particular de qualquer lingua, v. g. da Portugueza, applica os principios communs de todos os idiomas ao nosso, segundo os usos adoptados pelos que melhor o falão (Moraes Silva 1824[1806]: III [la negrita es mía]).

De acuerdo con la tradición logicista, Moraes Silva amplía las competencias de la gramática. Según el autor, esta disciplina no se limita a la enseñanza del buen hablar y escribir, sino que además instruye en la declaración perfecta de los pensamientos y en su conversión en palabras. La gramática particular deja de ser el arte del latín para convertirse en el arte de la lógica que se aplica a una lengua determinada. La diferenciación entre 
gramática general y particular deja patente el influjo de los enciclopedistas que, según Swiggers (1984: 9 apud Fávero y Molina 2006: 60), difundieron esta segmentación.

Con respecto al estudio de los sonidos, el autor diferencia las letras de los «sons elementares» y asevera que aquellas son señales gráficas de estas. Sin embargo, al definirlos y dividirlos, utiliza los términos «vogaes» y «consoantes» en lugar de «vozes» y "articulações», pero sin la finalidad de distinguir entre la manifestación oral y escrita de la lengua. Este fenómeno muestra además la diferencia entre la terminología adoptada por Moraes Silva y algunos gramáticos portugueses de la misma época, como Dias de Souza (1804):

6. Os sons elementares, que a voz humana articúla, formados pelos orgãos da fala, são ou vogáes, ou consoantes (Moraes Silva 1824[1806]: IIIIV).

As letras que representão as vozes chamão-se vogaes, e as que representão as articulações chamão-se consoantes (Dias de Souza 1804: 4).

El gramático brasileño expone el tema con mucha brevedad pues considera que el objeto de estudio de la gramática es la sentencia y sus partes, cómo formarlas y organizarlas para que tengan sentido perfecto. Por esta razón, prioriza los estudios léxicos y sintácticos en menoscabo de los estudios fonéticos.

\subsubsection{El tratamiento de las partes de la oración}

Moraes Silva organiza las clases de palabras en ocho categorías: nome o sustantivo, adjetivo articular, adjetivo attributivo, verbo, adverbio, preposição, conjunção e interjeição. Las siete primeras son denominadas «palavras discursivas» y la interjección, «sentença sentimental». De su clasificación quedan excluidos el artículo, el pronombre y el participio. El pronombre, con excepción de los personales, y el artículo están incluidos en los adjetivos articulares y el 
participio en los adjetivos atributivos. En la clasificación de palabras se prima la coherencia teórica y metodológica:

De facto, todos estes gramáticos se preocuparam em «ordenar y clasificar las palabras, agrupándolas según rasgos y características comunes y estableciendo con ellas clases más o menos homogéneas con el fin de facilitar metodológicamente el estudio de la gramática») (Calero Vaquera 1986: 51 apud Assunção 2002: 20).

Assunção (2002) en un análisis de las clases de palabras en las gramáticas portuguesas, citando a Calero Vaquera (1986), afirma que las clasificaciones más relevantes e innovadoras son aquellas que dividen el nombre en sustantivo y adjetivo. Este avance se da por primera vez en la gramática del portugués en el siglo XIX y los dos precursores de esta nueva categorización son el portugués Dias de Souza (1804) y Moraes Silva. Otro aspecto reformador de estas gramáticas es la exclusión del participio como clase de palabra independiente.

La clasificación de palabras de Moraes Silva no tiene precedentes en la tradición gramatical en lengua portuguesa. Esta división solo vuelve a aparecer ochenta años más tarde en la Grammatica Portugueza de João Ribeiro (1887). Sin embargo, esta distancia no reduce la notable influencia del Epítome en las generaciones inmediatamente posteriores.

Las clases de palabras son definidas por sus afinidades y usos en la proposición, mediante propiedades semánticas, sintácticas, formales, entre otras, con el objetivo de demostrar la existencia de cierta uniformidad lingüística. De esta forma, se pone de manifiesto la decadencia del criterio etimológico, propio de la gramática tradicional, y el desarrollo de un nuevo criterio, el analógico para definir las categorías gramaticales (Lliteras 1996a: 138).

Los pronombres personales están incluidos en los nombres. En realidad, para el gramático, ambas clases de palabras forman una misma categoría. El pronombre, de acuerdo con la tradición más generalizada, sustituye al nombre. Sin embargo, el Brocense (1587), había afirmado que esta categoría es 
equivalente al nombre y lo que diferenciaría el primero del segundo es que el referente del pronombre está implícito, mientras que el del nombre se manifiesta por sí mismo. Esta doctrina es la que parece seguir Moraes Silva en su caracterización del pronombre:

As diversas relações, que as coisas significadas pelos nomes tem entre si, em algǔas Inguas se declarão, variando as finaes dos nomes, (...). Estas diversas terminações dos nomes se chamão casos.

Nós em Portuguez temos algǔa semelhança de casos nos nomes seguintes [eu, me mim, migo, nós, nos, nosco, tu, te ti, tigo, vós, vos, vosco], que os Grammaticos chamão Pronomes (Moraes Silva 1824[1806]: 5-6 [la negrita es mía]).

Los artículos y los demás pronombres se asocian a los adjetivos articulares precisamente por la función que desarrollan junto al sustantivo, pues determinan su extensión y su significación, por ejemplo: «homem, o homem; laranjeira, a laranjeira; espada, aquella espada») (Moraes Silva 1824[1806]: 8).

La inclusión del artículo en la clase de los adjetivos articulares evidencia que Moraes Silva estaba al tanto de la teoría de Dumarsais (1676-1756), que también los incluía en esta categoría. Además, no coinciden solamente en la clasificación, sino también en la definición funcional, en el sentido de que para el autor brasileño el artículo equivale al demostrativo «aquelle» y «aquella», de acuerdo con la relación que se establece en la gramática francesa con el demostrativo latino illé .

Moraes considera el participio un adjetivo atributivo verbal o derivado de los verbos y lo analiza en el capítulo correspondiente al verbo. Las palabras derivadas de los verbos pueden asumir dos funciones, una de adjetivo atributivo, por ejemplo: "a casa caĭda» y la otra de sustantivo que acompaña los verbos auxiliares «haver» y «ter», como: «tenho lido, tenho leitura». Serían los supinos del latín. En suma, son verbos a los que se pueden atribuir funciones

\footnotetext{
6 "En las gramáticas españolas no se descubre la vinculación del artículo el con el demostrativo aquel, probablemente porque se considera, de acuerdo con Nebrija (1492/1980, p. 180), que este demostrativo es un "compuesto" del pronombre personal él. La observación de Salvá (1830-1847) no había sido utilizada hasta entonces con finalidad gramaticalı) (Lliteras 1996b: 183-184 [nota]).
} 
adjetivas y sustantivas conforme al uso. En nota explicativa sobre el uso de los adjetivos atributivos, el gramático explicita las fuentes en las que ha bebido para autorizar su posición en el tratamiento del participio:

A' cerca dos Adjetivos verbáes em ante, ente inte, dos Participios, e Gerundios, e Supinos vejão-se as notas de Duclos à la Gramaire Générale \& Raisonée, Past. 2. Chap. 201. e Condillac, Grammaire, Part 2. Chap. 21. Pax. 203. Édit. De 1780. à Géneve (Moraes Silva 1824[1806]: 44 [la negrita es mía]).

A pesar las citas a autores más recientes en la tradición logicista, en algunas ocasiones Moraes Silva abraza una postura más conservadora de esta misma corriente.

El gramático sigue la tradición latina y la de Port-Royal en cuanto al reconocimiento de la interjección ${ }^{7}$ como clase de palabra independiente. No obstante, define la interjección como equivalente a una proposición discursiva de sentido completo, una «sentença sentimental». Para corroborar su doctrina, Moraes Silva compara: «ai significa eu tenho dor, guai significa eu me compadeço, ui significa eu me admiro» (Moraes Silva 1824[1806]: 76). Además, atribuye a las interjecciones la función de adjuntarse a una oración para completar su sentido: «ai de mim».

Los sustantivos y los adjetivos no forman una única clase de palabras sino que son analizados por separado. Estas tres clases, a saber los adjetivos, atributivo y articular, y el sustantivo, se caracterizan por variaciones de género y número. En el caso de los adjetivos, el grado no es considerado una variación, sino una subclase de los atributivos. Las variaciones de género y número son analizadas fuera del capítulo correspondiente a cada categoría de vocablos.

\footnotetext{
7 En La teoría gramatical de Vicente Salvá (1992), Lliteras asevera que "con respecto a las interjecciones, la modificación más destacable consiste en que Salvá admitió desde 1835 la idea divulgada por Destutt de Tracy, y recogida igualmente en las gramáticas del Calleja o Hermosilla, por la que se consideran las interjecciones como proposiciones completas (§[18.2]), porque según indica Salvá - contienen "un pensamiento cabal" (§ [15.2.3])».
} 
Moraes Silva se muestra particularmente explícito en el rechazo de la doctrina latinizante. El autor defiende la autonomía de la gramática portuguesa con relación a la del latín, especialmente en el tratamiento de los casos:

Mas além de que são ideyas falsas dizer, que ha genitivos, dativos, \&c. em Portuguez tambem serião falsas noções as que se dessem de correspondencias entre latim e o Portuguez (Moraes Silva 1824[1806]: IV).

Según el gramático, el género de los sustantivos está determinado por el referente extralingüístico, de modo que cuando representa un ser sexuado el sustantivo, sea propio o sea común, varía conforme el sexo de éste:

Os nomes, que significão o macho da especie, se dizem masculinos; os que significão as fêmeas são femeninos; e ésta differença dos sexos: indicada pelos nomes se diz o genero d'elles, na linguagem dos Grammaticos (Moraes Silva 1824[1806]: 5).

En caso de que este referente sea inanimado, el autor admite la imposibilidad de aportar una explicación lógica, simplemente porque asume que no tiene razón de ser atribuir género a palabras cuyo referente carece de sexo, y pasa a listar reglas según la terminación:

Não se vè porèm a razão, porque dicémos o Páo, o Pão masculinos, a Pedra, a Farinha femininos. Nestes de coisas sem sexo, appellativos, ou communs, seguiremos as regras adiante (Moraes Silva 1824[1806]: 32 [la negrita es mía]).

El adjetivo atributivo se caracteriza en la obra de Moraes Silva de igual manera que en las gramáticas filosóficas francesas. Los adjetivos de esta categoría sintáctica semánticamente son equivalentes a la unión de una preposición y un nombre sustantivo. A título de ejemplo cita: «homem de valor, ou valoroso» (Moraes Silva 1824[1806]: 21).

Tanto la definición como la sistematización de la clase verbal reflejan los supuestos filosóficos más claramente que otras categorías. Incluso en la 
definición se muestra la primacía que el gramático atribuye al verbo frente a las demás partes de la proposición. Su función consiste en el enlace de los dos componentes del juicio lógico:

O verbo é a palavra com que declaramos o que a alma julga, ou quer á cerca dos Sujeitos, e dos attributos, das sentenças; com elle affirmamos e mandamos: (...) (Moraes Silva 1824[1806]: 38).

De acuerdo con las ideas de Arnauld y Lancelot (1660), segmenta esta clase en dos categorías: verbo sustantivo, que se corresponde con la cópula o el elemento mismo que une sujeto y atributo; y verbo adjetivo, que es la fusión del verbo sustantivo con un atributo. El verbo sustantivo es único y los verbos adjetivos son todos los demás que se fragmentan en un verbo único y un atributo. El atributo es el componente del verbo adjetivo:

A' significação, ou officio principal dos verbos anda annexa a significação de algum attributo, e da pessoa ou coisa, em que o attributo existe, ou queremos; que exista; e das divérsas épocas em que o attributo existe, existiu, ou existirá no sujeito (Moraes Silva 1824[1806]: 38).

Dicho de otro modo, hay un verbo que expresa existencia que es el verbo ser. Este verbo unido a un adjetivo forman todos los demás verbos, «assim Amo por si só equivale a Eu sou amante actualmenteı) (Moraes Silva 1824[1806]: 38).

Modo, tiempo y persona son denominados variaciones del verbo, en lugar de los llamados accidentes de la tradición latina. Las subclases del verbo, denominadas por el gramático «attributos», son tres: activo, de estado y neutro. Los activos son los que expresan acción y se segmentan en otras tres categorías, transitivo, reflexo y reciproco. Los de estado no tienen definición, pero son verbos que expresan existencia. Los neutros son aquellos que no expresan ni acción ni estado, no poseen paciente y, como el gramático no acepta la existencia de verbos sin sujeto, no menciona el hecho de que tampoco tienen agente. No utiliza la elipsis para explicar el fenómeno, como sugiere Sánchez de las Brozas (1578), únicamente formula ejemplos adjuntando al verbo sujeto y 
atributo: «Deus chovia maná aos Israelitas» (Moraes Silva 1824[1806]: 49). Los neutros son generalmente verbos que expresan fenómenos de la naturaleza, como llover y nevar, de modo que, por consiguiente, son impersonales o sin sujeto.

Un aspecto destacable de este capítulo es la observación respecto a la inexistencia del verbo ser en algunas lenguas. En particular, el autor cita lenguas que no derivan del latín:

O mais notavel é, que em mǔitas Linguas falta o verbo correspondente ao substantivo ser, como é na Chinesa, o na dos Indios Galibis, e na Lingua geral dos Brasis, e quando querem affirmar ajuntão o sujeito ou nome com o adjetivo: v.g "Francisi irupa:" Franceses (sc. são) bons (Moraes Silva 1824[1806]: 58).

El gramático se percata de que no todas las lenguas se rigen por el mismo sistema lógico establecido en la gramática racionalista, pero no se compromete hasta el punto de cuestionar tales teorías. Al contrario, para explicar el fenómeno sugiere la lectura de los manuales de Dumarsais (16761756) y de Beauzée (1717-1789):

(...) e negão por meyo do adverbio: "Francisi irupa va": litteralmente; Franceses bons não; sem verbo (V. Harris Hermes, pag, 164. Grammaire Génerale \& Raisonnée, Part. 2. Ch. 13. Encyclop. Articl. Construction, par Du Marsais. A theorica dos tempos dos verbos assas engenhosa, mas difícil na Gram. Génér. de Beauzée, acha se mais simplificada no Hermes de Harris, L. 1. c. 8.) (Moraes Silva 1824[1806]: 58 [la negrita es mía]).

Respecto a la negación y afirmación como carácter esencial del verbo, el autor brasileño cuestiona la afirmación de Condillac de que si los verbos afirmaran, sería imposible formular proposiciones negativas. Pero, según el gramático, la idea propuesta por el autor francés es parcial en el sentido de que la negación no afecta al verbo, sino al atributo que se le adjunta. Por ejemplo en «eu não amo é eu existo não-amante» (Moraes Silva 1824[1806]: 47). El gramático reconoce dos atributos: uno de ellos es la existencia en sí misma, 
expresada por el verbo sustantivo e implícita en los demás verbos; el otro es el atributo mismo acompañado por el adverbio de negación. El autor denomina «geral» el primer atributo y «privado» al segundo.

De acuerdo con la doctrina de Port-Royal, Moraes considera la equivalencia del adverbio con el grupo formado por preposición + nombre:

Nós dizemos, v.g. amo com ternura, com constancia; e no mesmo sentido: amo ternamente, constantemente (...). Todas estas frases com ternura, com constancia modificão o verbo amo (...). Estas frases pois se chamão frases adverbiais (Moraes Silva 1824[1806]: 59).

Del mismo modo, admite que esta categoría no solamente modifica a los verbos, sino también a los adjetivos atributivos y a los nombres cuando desempeñan funciones adjetivas. Con todo, el adverbio no constituye en el Epítome una parte elemental de la oración, pues carece de significado autónomo y depende de otros vocablos para completar y determinar su sentido, como se puede demostrar en la cita siguiente:

Deve porèm notar, que os adverbios não são uma parte elementar das sentenças, porque todos elles são nomes, e talvez combinados com attributivos, e regidos de proposições claras, ou occultas, que por brevidade se ommitem, e tambem se exprimem (Moraes Silva 1824[1806]: 59).

Respecto a la clase de las preposiciones Moraes Silva adopta una perspectiva acumulativa pues, intenta reunir los «criterios etimológicos» y «analógicos» (Lliteras 1996a) en la misma definición:

As preposições (assim chamadas, porque se prepõem, ou põem antes dos nomes, a que se referem outros nomes correlativos antecedentes, e que as preposições atão entre si) servem de mostrar a connexão, e correlações, que $\mathrm{o}$ entendimento concebe entre dois objetos significados pelos nomes sós, ou modificados por adjetivos, ou verbos (Moraes Silva 1824[1806]: 64).

No rompe con la tradición de la gramática renacentista, pero tampoco abraza totalmente la gramática racionalista. Según el gramático, las 
preposiciones se anteponen al nombre y establecen alguna relación entre estos últimos y la «concepção do entendimento». Asimismo, juntamente con las dieciséis preposiciones que registra en el Epítome, el autor añade las llamadas preposiciones inseparables de los nombres, es decir, los que hoy se conoce como prefijos.

Las conjunciones como clase de palabra, al parecer no demandan mucha atención por parte del gramático, puesto que este se limita a la definición de la categoría y a la clasificación de las unidades. Define las conjunciones del modo siguiente:

As conjunções átão as sentenças que tem alguma connexão, ou correlação entre si, de semelhança de juízo, de opposição, de modificação (...). Assim as conjunções indicão os modos de ver da nossa alma entre diversas sentenças, os quaes ás vezes se expréssão por mais de uma palavra (Moraes Silva 1824[1806]: 74).

Siguiendo, una vez más, la postura más conservadora, no admite el uso de la conjunción para unir palabras sino oraciones, pues lo que no está dicho, está elíptico.

\subsubsection{El tratamiento de la sintaxis}

La última parte del Epítome se dedica a la sintaxis. En ella el autor define el comportamiento sintáctico de las partes de la oración, regula el uso de las clases de palabras y establece normas de construcción de la sentencia. Divide esta parte en sintaxis y composición figurada. A su vez, distingue entre sintaxis de la concordancia y del régimen. Assunção (1999) ha valorado acertadamente la aportación de Moraes Silva al desarrollo de los estudios sintácticos:

Nas gramáticas filosóficas [de lengua portuguesa] (...) deve destacar-se o tratamento dado por Moraes Silva à Sintaxe nas trinta e oito páginas que the dedica e que revela um estudo evoluído para o tempo e que se poderá 
considerar como o grande precursor de Epifânio Dias. Com efeito no livro II, dividido em quatro capítulos, Moraes deu amplitude à sintaxe, que chama regras de composição (Assunção 1999: 35).

La sintaxis de la Gramática de Moraes Silva desempeña un papel fundamental no solamente en la tradición brasileña, sino también en la tradición portuguesa. Por la singularidad en la aplicación de las teorías logicistas en muchos aspectos y por la importancia que adquiere el corpus literario como base del análisis sintáctico.

Assunção (1999) describió en pocas palabras en qué consisten los estudios sintácticos en el Epítome:

Ao estudar a sentença, que concebe como num sentido perfeito, dividea, segundo os logicistas (Port-Royal, Condillac, Destutt de Tracy) sujeito, atributo e verbo, divisão bipartida que se atribuiu a Aristóteles. Não aceita sentença sem verbo. Da sintaxe estuda somente a concordância e a regência. Simplifica o estudo das figuras, como particularidades estuda a zeugma, a enálage, a perissologia, e a síquese. Ao estudar os vícios da composição, detém-se na anfibologia, no barbarismo e no solecismo (Moraes Silva 1824[1806]: 35).

Ahora bien, Moraes Silva empieza a describir la sentencia según su propiedad formal y la concibe como un elemento apriorísticamente gráfico. Así pues, afirma que la sentencia se compone de palabras y esta, a su vez, de sílabas que, por consiguiente, están formadas de letras:

5. As sentenças constão de Palavras (8): as Palavras de Sillabas: as Sillabas de Sons elementares, e suas modificações; e estes representão se aos olhos com Letras (Moraes Silva 1824[1806]: III).

Según el gramático, la sentencia es la expresión perfecta de lo que se juzga de las cosas o «aquillo que queremos que as pessoas ou coisas sejão,

\footnotetext{
8 A palabra é uma quantidade de som articulado, que significa algum conceito em qualquer idioma: o som contínuo não articulado, insignificante, não é objecto da Grammatica, nem o são palavras, ou particulas, que por sí nada significão, como alguns chamão ao adverbio, interjeição, preposição, \&c. [nota del gramático].
} 
fação, ou sofrãoı (Moraes Silva 1824[1806]: 79). Afirma que hay dos tipos de proposiciones, la principal y la incidente. La sentencia incidente es aquella que está unida o relacionada a la sentencia principal por medio de un «articular relativo conjuntivoı, denominación que utiliza para referirse a los relativos que, quem, qual, quando, entre otros.

Las oraciones incidentes atribuyen carácter explicativo o determinativo a la palabra con la que se relacionan. Es interesante poner de relieve que para el gramático no existen relaciones de dependencia entre los elementos oracionales, tampoco entre proposiciones. Los componentes ya sean oracionales ya sean discursivos se unen, se relacionan, se determinan, se modifican, pero nunca dependen.

Sujeto, verbo y atributo son los tres elementos de los que consta el análisis sintáctico, como aclara Assunção (1999). Una proposición no puede tener más que un sujeto, es decir, debe ser siempre un único nombre acompañado de sus modificantes. El verbo y el atributo también pueden estar acompañados por sus modificantes.

En cuanto a la sintaxis de la concordancia, el autor propone las reglas que enseñan a conectar los nombres, adjetivos y verbos. Estas conexiones pueden darse de tres maneras; mediante la variación de la terminación del nombre, por medio de la preposición y por el verbo. Asevera que existen tres tipos de concordancia: entre adjetivos y sustantivos, que se relacionan por medio del género y el número, del sustantivo con el verbo a través del número y de la persona y del sustantivo con otro sustantivo', por medio de un verbo o una preposición.

Todo artificio pois de compor sentenças consiste em mostrar as connexões, ou correlações entre os nomes de coisas, e seu attributos significados pelos adjetivos; entre os nomes das coisas, e os adjetivos

\footnotetext{
9 En la tradición española la concordancia sustantivo/sustantivo también puede ser apreciada en las gramáticas de Mata (1805) y Muñoz (1779) «Las concordancias son cuatro, á saber: de nombre y verbo, de sustantivo y adjetivo, de relativo y antecedente, y de dos sustantivos) (Mata 1805: 102 [la negrita es mía]); «Hay tres especies de concordancia: una de sustantivo con sustantivo; otra de adjetivo con sustantivo; y otra de verbo con el supuesto» (Muñoz 1799: 140[la negrita es mía]).
} 
articulares, que os modificão determinando a extensão, em que se tomão; e entre os nomes sujeitos, e os attributos annexos aos verbos com a affirmação, ou querer. As regras, que ensinão a mostrar as connexões entre os nomes, e os adjetivos e os verbos se dizem sintaxe de concordância (Moraes Silva 1824[1806]: 81 [la negrita es mía]).

La primera de las tres especies de concordancia citadas está intrínsecamente relacionada al sistema de clases de palabras de Moraes Silva. Como agrupa los artículos y pronombres en una de las clases del adjetivo, el «articulan», y los adjetivos propiamente dichos están reunidos en los «atributivos», hay tres relaciones en una: la del artículo con el sustantivo, del pronombre con el sustantivo y del adjetivo con el sustantivo.

En la sintaxis de régimen, el autor se limita a señalar el uso de las preposiciones y las relaciones del verbo con el sujeto y éste último puede expresarse mediante un sustantivo o un pronombre personal, que para el autor son nombres sustantivos, y el orden de la regencia es siempre agente, verbo, paciente.

O lugar indica a relação de sujeito, ou de paciente da mesma palavra, e não o artigo, que se não muda, variando as relações tanto (Moraes Silva 1824[1806]: 83 [la negrita es mía]).

Este orden, que también se puede nombrar sujeto, verbo y atributo, según el autor, sigue ciertas reglas que se resumen en que el agente siempre se antepone al verbo y el paciente puede posponerse al verbo o estar antepuesto al sujeto. Este último caso, para identificar al atributo, requiere una preposición. El orden inverso va detallado en la sintaxis figurada juntamente con las figuras.

Quando na composição não observamos as regras expostas, a sentença é incorrecta. Mas ás vezes a incorrecção é apparente, e dá uma nova figura, ou apparencia á composição, que por isso se diz figurada (Moraes Silva 1824[1806]: 103)

En la sintaxis figurada, el gramático se ocupa de las desviaciones de las reglas sintácticas. Distingue entre las «figuras», cuando se trata de la oración, y 
las «figuras de dicção», si corresponden a la palabra. Tres son las figuras que se aplican a una oración de orden natural: la elipsis, cuyas subclases son el zeugma, la silepsis y la síntesis; el pleonasmo, que incluye la perisología; y la enallage. La figura que se aplica a las oraciones de orden inverso es el hipérbaton o synchise. En cuanto a las «composições viciosas», el gramático proporciona un análisis de ejemplos, en su mayoría literarios, en los que se manifiestan vicios de dicción como la anfibología, el barbarismo y el solecismo.

A propósito de la enallage, el gramático explica un fenómeno interesante. Señala que consiste en usar unas partes de la oración y sus accidentes en función de otras, por ejemplo: «Que foi daquelle cantar das gentes tão celebrando?) (Moraes Silva 1824[1806]: 110). El infinitivo cantar es formalmente un verbo que desempeña en la oración la función de nombre, es decir, está sustantivado. Según el testimonio de este gramático, el singular del infinitivo desempeña también en esta época funciones sustantivas, que con anterioridad quedaban restringidas solo a las formaciones de plural:

Os Grammaticos chamão Ennalage á figura de composição, que se faz usando as partes da oração, e seus accidentes uns por outros, sem razão, nem fundamento: v.g. "Que foi daquelle cantar das gentes tão celebrado?" (Camões). Mas cantar é nome, e tem plural, os cantares (Moraes Silva 1824[1806]: 110).

En la Gramática no faltan diversas críticas contra el uso latinizante de la lengua portuguesa. Por ejemplo, «deu a penas, por foi castigado, que é um Latinismo; porque dar penas em Portuguez é causá-las, impô-las») (Moraes Silva 1824[1806]: 119) (sobre los contrastes entre las lenguas románicas en la Gramática de Moraes, véase § 8.2). 


\subsubsection{Resumen}

La Gramática de Moraes Silva ha sido una obra de referencia para varias gramáticas filosóficas que siguieron a su publicación en la primera mitad del siglo XIX. Trabajos como los de Frei Caneca (1817) y Pereira Coruja (1835), entre otros, desarrollaron las teorías difundidas por Moraes Silva en su compendio de la lengua portuguesa.

La obra de Moraes Silva merece destacarse por ser la primera de la gramaticografía brasileña en lengua portuguesa. Además, conviene poner de relieve los aspectos principales de su aportación teórica y metodológica, tales como el corpus de autoridades literarias e incluso las autoridades no recomendadas, el incremento del estudio sintáctico y el sistema de clases de palabras, principalmente las que pertenecen a la categoría de los nombres.

El Epítome ha marcado la tradición gramatical brasileña no solamente por ser la primera en sistematizar las teorías racionalistas y sensualistas del siglo $\mathrm{XVIII}$, sino también y especialmente por ser la primera gramática en lengua portuguesa de un autor brasileño.

Tras la publicación del Epítome de Grammatica Portugueza, las obras de los gramáticos brasileños Frei Caneca (1817), Pereira Coruja (1835), Dias da Cruz (1853), Alexandre Passos (1855), Andrade Pertence (1861), Silva Bezerra (1861), Fernandes Pinheiro (1864), Sotero dos Reis (1865), Grivet (1865) y Silva Rabelo (1867) también contribuyeron a la consolidación de la metodología adoptada por Moraes.

\subsection{La introducción del modelo taxonómico en la Grammatica Portugueza de Augusto Freire (18751-18772)}

La mayoría de los estudios sobre la gramaticografía brasileña señala que la Grammatica Portugueza de Augusto Freire debe ser considerada como una 
obra de carácter racionalista. En efecto, Fávero y Molina (2006) se muestran de acuerdo con las propuestas de periodización de los estudios lingüísticos en Brasil que clasifican la obra de Freire como «filosófica»:

A gramática de Augusto Freire da Silva foi editada pela primeira vez antes mesmo do Programa de Fausto Barreto, mais aos moldes das gramáticas filosóficas, tendo sido premiada pelo governo geral em 1877 em sua segunda edição, por isso podemos inscrevê-la no período empírico, delimitado por Nascentes (1939) e chamado vernaculista por Elia (1975) (Fávero y Molina 2006: 101).

Ahora bien, estas periodizaciones están centradas principalmente en el análisis contextual del modelo gramatical y en la corriente teórica principal, pero no toman en cuenta otros aspectos importantes que ayudan a determinar con más precisión el carácter de una gramática.

Por nuestra parte, creemos que la Grammatica Portugueza de Augusto Freire no constituye propiamente un modelo de gramática filosófica pues, como la mayoría de las gramáticas brasileñas publicadas en la segunda mitad del siglo XIX, esta obra conserva ciertas bases logicistas, pero introduce los avances teóricos procedentes de la doctrina histórico-comparada.

Esta investigación tiene la finalidad de analizar el modelo gramatical de Augusto Freire, de distinguir su contribución a la tradición gramatical brasileña decimonónica $y$, en relación con el examen de las otras obras del mismo periodo histórico, determinar la evolución general del primer siglo de gramática portuguesa compuesta por autores brasileños. Con todo, no es el propósito fundamental de este trabajo cuestionar las clasificaciones y periodizaciones de las obras publicadas en Brasil durante el siglo XIX, aunque en algún momento se pueda poner de manifiesto inevitablemente la superficialidad de estas propuestas. 


\subsubsection{El autor y su obra}

Augusto Freire da Silva nació en la ciudad de São Luis en Maranhão el 17 de octubre de 1836. Estudió Humanidades en su provincia y años después se trasladó a Rio de Janeiro donde se dedicó al comercio y a la taquigrafía. Dio continuidad a sus estudios gracias a la motivación de sus amigos, pero las dificultades personales le obligaron a abandonarlos y empezar a trabajar.

Más tarde, uno de sus amigos fundó el Colegio Ipiranga en São Paulo, donde Freire actuó como subdirector y así pudo seguir con sus estudios. Concluyó la carrera jurídica en 1862 y en 1864 ejerció el cargo de profesor de Gramática Expositiva e Histórica y Lengua Nacional en la Facultad de Derecho. En 1865 fue nombrado juez municipal y de huérfanos y en 1873, fiscal del Estado de São Paulo. En 1878 fue nombrado inspector interino de Instrucción Pública y en el mismo año fue inspector de la Hacienda. En 1898 fue nombrado director del Ginásio de São Paulo, cargo que desempeñó hasta 1917, año de su muerte.

Augusto Freire publicó diversas obras, entre las que se pueden citar las siguientes:

Novo methodo de ensinar a ler e escrever. Paris, 1863.

Noções de prosodia e orthographia para uso da infancia que frequenta as aulas do primeiro grau do Instituto Santista, intercaladas de um resumo de etymologia e syntaxe, estrahido da "Grammatica Portugueza» de Francisco Sotero dos Reis pelo doutor Pedro Nunes Leal. São Luis do Maranhão, 1871.

Novo methodo de ensinar a ler e escrever, acresccentado da «Civilidade primária» de Chantal, de um resumo da doutrina christã, extrahido do catechismo historico de Fleury e das primeiras noções de calculo. Paris, 1875.

Compendio da Grammatica Portugueza. São Luis do Maranhão, 1875. Rudimentos da grammatica portugueza para uso dos alumnos de primeiras letras. São Paulo, 1879. 
La Grammatica Portugueza de Augusto Freire se publicó en 1875 y fue premiada por el Governo Geral en 1877, fecha de su segunda edición aumentada ${ }^{10}$. La obra alcanzó, al menos, hasta nueve ediciones y en las tres primeras el propio autor introdujo modificaciones.

La actividad docente de Freire, dedicada a materias innovadoras del ámbito universitario y de la enseñanza media, como la Gramática Expositiva e Histórica y la Lengua Nacional, permite explicar el interés del autor por las nuevas corrientes filológicas que se desarrollaban en Europa y Estados Unidos a mediados del siglo XIX y por la aplicación de métodos renovados al estudio y codificación del portugués.

\subsubsection{División y definición de la gramática}

La Grammatica Portugueza de Augusto Freire se divide en tres partes denominadas lexicologia, syntaxe y semiologia. El autor sustituye el índice tradicional por un «Quadro Synoptico» (véase tabla 5.1) que muestra el orden y las partes en que se divide la Gramática. Desde estas primeras páginas, en efecto, se pone de manifiesto con claridad una de las principales claves de esta obra, si no la principal: Freire trata de proporcionar a sus lectores el primer modelo de gramática taxonómica del portugués. La novedad de su planteamiento consiste en aplicar al estudio de la lengua materna la complejidad de las clasificaciones, por entonces habituales en los estudios de las ciencias naturales, para la jerarquización, sistematización y nomenclatura de todas las especies que forman (y han formado) parte de la lengua portuguesa.

Antecede al texto gramatical propiamente dicho el «Resumo Historico do Latim e das Linguas Romanası, que contiene 14 páginas y ocupa un 3\% del total

\footnotetext{
10 Con respecto a la segunda edición de la Gramática de Freire, cabe destacar la aclaración de Sacramento Blake "É uma segunda edição, com aumentos da obra acima [Compendio da grammatica protugueza, 1875], que o doutor Freire da Silva deu á estampa para compendio de sua aula no curso anexo á faculdade de S. Paulo. Por se haver esgotado esta edição foi em 1879 dada á luz terceira edição muito mais completa, e quarta no Rio de Janeiro, 1883 (Sacramento Blake 1883: 359).
} 
de la obra, y una breve introducción, de 2 folios, que se ocupa de la definición de la gramática.

La Lexicologia alcanza el $58 \%$ del total de la Gramática y se divide en phonologia, lexigraphia y morphologia. La phonologia estudia la phonetica (dividida en phonetica physiologica y phonetica histórica), la prosodia y la orthoepia. La lexigraphia se ocupa de la phonographia, la orthographia y la semiographia. Por último, la morphologia trata de la lexiologia (o taxionomia) y de la organographia, que se divide en flexionismo (también denominado kampenomia, ptoseonomia o flexiologia) y etymologia (o morphogenia o lexiogenia).

La syntaxe ocupa un 33\% de la obra, con un total de 142 páginas, y se divide en syntaxe gramatical, que a su vez se divide en syntaxe de palabras (geral y particular) y syntaxe de proposições; y syntaxe litteraria o estylistica. El estudio de la semiologia no es muy extenso. Consiste en un análisis semántico de 24 páginas, poco más de $5 \%$ de toda la Gramática, pero es reconocido por el ser primer intento en la tradición brasileña de estudiar la lengua desde una perspectiva semántica. La siguiente tabla muestra la división de la Gramática de Freire:

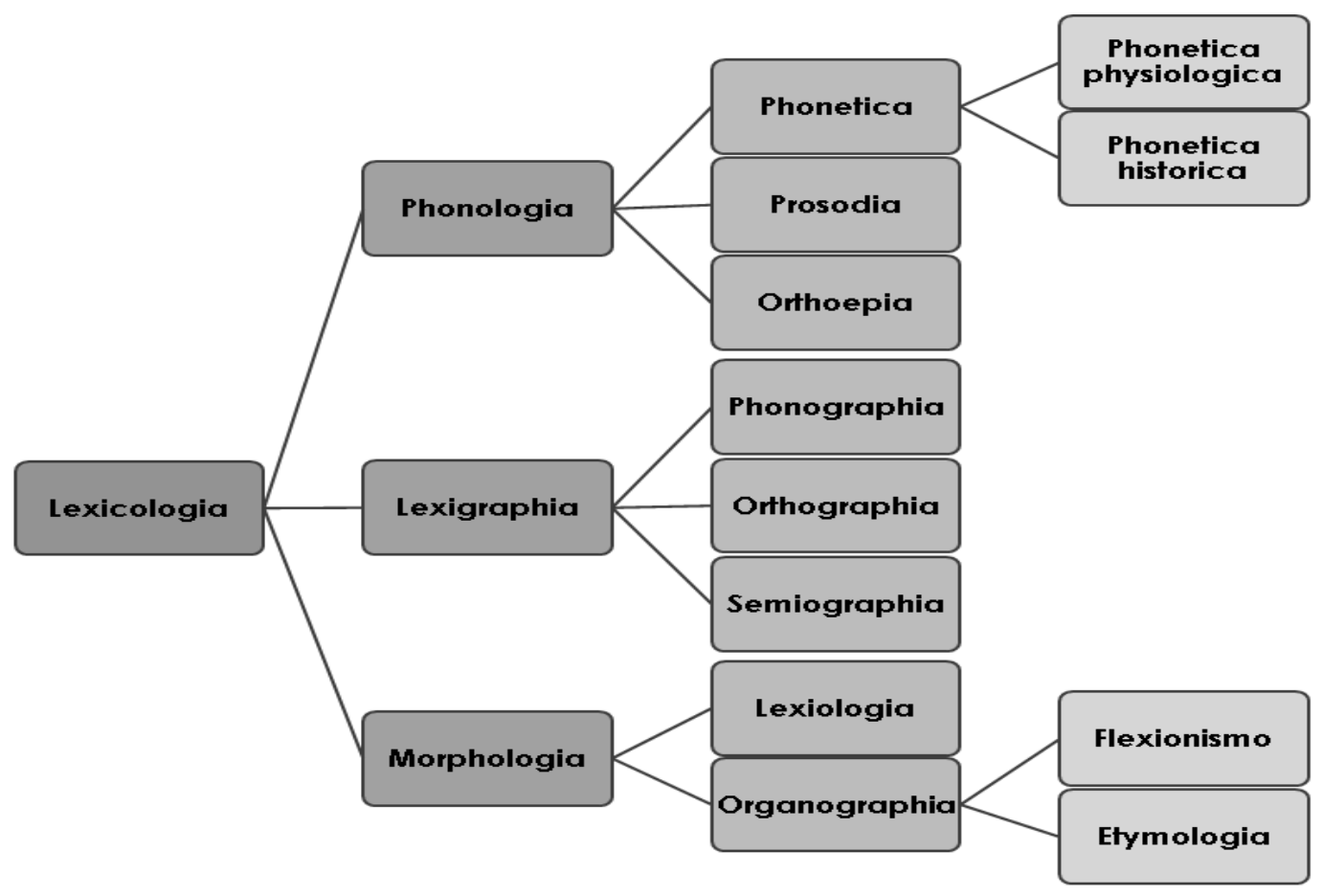




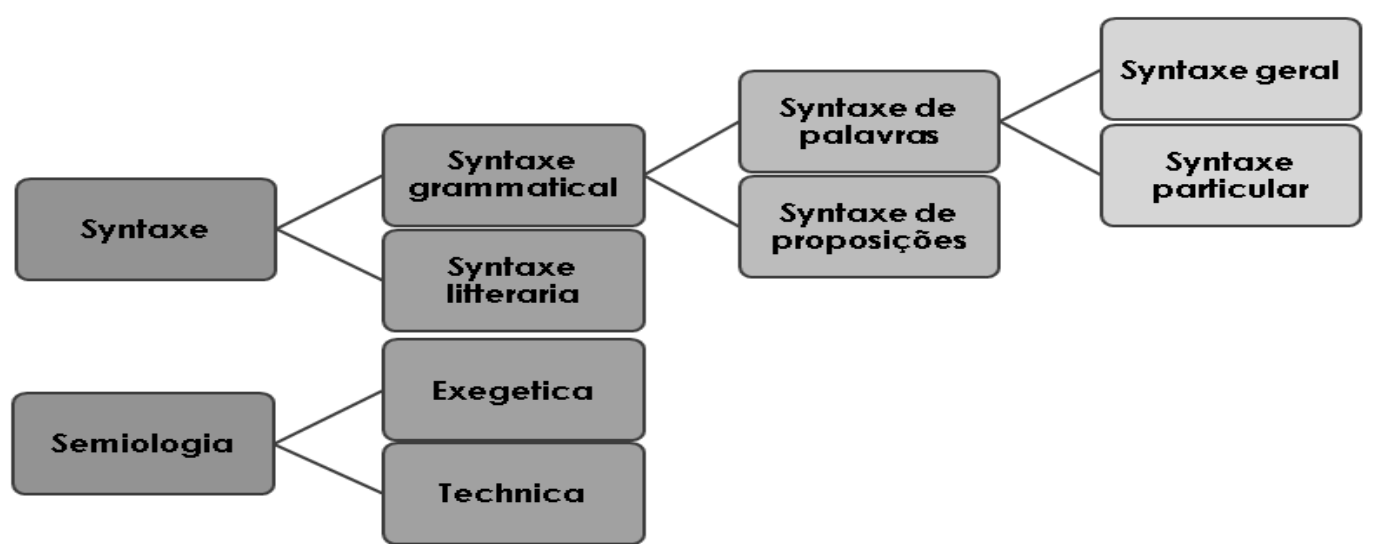

Tabla 5.1 División de la Gramática de Augusto Freire

Al contrario de la mayoría de las gramáticas de este periodo, la obra de Freire no presenta un prefacio que haga mención de las fuentes utilizadas, la importancia del estudio de la gramática de la lengua materna, los objetivos de la obra, el público al que va dirigido u otras observaciones relevantes acerca del estudio gramatical. Sin embargo, los elementos que sustituyen el prólogo (y que permiten atribuir un cierto avance a esta Gramática) son la cita de Almeida Garrett (1799-1854) acerca del estudio de la gramática y el «Resumo Historico do Latim e das Linguas Romanas». La cita de Garrett hace referencia a la función social y pedagógica de la gramática y su definición como ciencia y no como arte:

De toda a educação do espirito a grammatica é a base. A grammatica é a sciencia das palavras, isto é, dos signaes de nossas idéas; e, entre estas e aquellas,- pela construcção physica do homem, por suas relações com os outros e com o resto do mundo visivel, por sua educação, por sua natureza,é tão intima da connexão, tão estreita e quasi indivisível, que jamais conhecerá bem as cousas o que não conhecer bem as palavras, jamais adquirirá idéas exactas ou formará juizos distinctos, o que; das palavras, suas combinações e ligações, não tiver noção exacta,- e, no modo de as empregar e usar, não for igualmente correcto e habil (Garrett - Da Educação apud Freire 1894[1875]: 6 [la negrita es mía]).

El «Resumo Histórico do Latim e das Linguas Romanicas» contiene un breve panorama sobre la extensión del dominio del latín en Italia; la 
romanización de la península ibérica; el latín vulgar y el latín literario; la decadencia de la cultura romana; la invasión de los bárbaros; las influencias de los pueblos romanizados y de los bárbaros sobre el latín; la formación de las lenguas romanas; los musulmanes en España y el portugués y su variedad escrita. El autor concluye este análisis con los «Breves Specimens da Chrestomathia Historica da Lingua Portugueza»», extraídos de una obra de Adolpho Coelho (1873) de mismo nombre.

En cuanto a la situación de la lengua portuguesa, el autor trata con brevedad la «edad de la decadencia» (finales del siglo XVII hasta mediados del XVIII) y la «edad de la restauración» (finales del XVIII hasta su época). Alude como principales autoridades literarias a Francisco Manoel do Nascimento (1734-1819), Alexandre Herculano (1810-1877), Almeida Garrett (1799-1854), Antonio Feliciano de Castilho (1800-1875), Antonio Gonçalves Dias (1823-1864), João Francisco Lisboa (1812-1863) y Latino Coelho (1825-1891), a los que atribuye la responsabilidad de haber restaurado la unorma da boa e san vernaculidade» (Freire 1894[1875]: 17).

En este «Resumo Histórico» el gramático expone además un breve panorama de la clasificación genealógica de las lenguas, divididas según su parentesco genético. A continuación, Freire trata de las diferentes alteraciones que pueden experimentar las lenguas y analiza el caso particular de la lengua portuguesa. Según el gramático, «as alterações das linguas extendem-se a todos os seus elementos: são por isso lexicologicas, syntacticas e semiológicası (Freire 1894[1875]: 21). En cuanto a los dialectos portugueses, el autor menciona el gallego, el indo-portugués (o reinol) y el africano (o creoulo). Sin embargo, advierte que el portugués hablado en Brasil no debe ser considerado un dialecto, sino que constituye un mismo idioma con el portugués de Portugal, aunque con algunas diferencias en la pronunciación, el léxico y la sintaxis:

O portugues hodierno do Brazil não constitue dialecto, é o mesmo de Portugal, não obstante ir-se já differenciando, principalmente na pronuncia (...). Conta tambem o luso-americano algumas palavras que mudaram de significação (...). Alem disso, tem se opulentado o seu vocabulário com 
provincianismos e brasileirismos, ou sejam palavras tupis, ou africanas, ou meramente populares. As divergencias syntacticas são em geral solecismos usados pelas clases incultas (...) que vão desapparecendo com a reacção culta e litteraria, que trata de fazer approximar a linguagem das fontes vernaculas e classicas (Freire 1894[1875]: 21-22 [la negrita es mía]).

Ahora bien, la introducción de la obra comprende las definiciones de los diferentes tipos de gramáticas y una breve aclaración acerca de la ciencia del lenguaje. El autor define la gramática como «o estudo dos factos da linguagem», que «tem por fim a expressão do pensamento pela palavra, e por objecto o estudo das palavras») (Freire 1894[1875]: 23). Por primera vez en la tradición brasileña, la gramática abandona la definición generalizada de arte que enseña a hablar y escribir bien y con corrección, para utilizar el concepto de gramática como ciencia. De acuerdo con esta definición, la obra de Freire no pretende alcanzar un carácter prescriptivo propio de las gramáticas pedagógicas, pues su objetivo no es imponer reglas sobre la lengua, sino estudiarla científicamente.

Pero la originalidad de esta introducción también se advierte en la ausencia de lugares comunes. El autor no menciona las ventajas del estudio de la gramática ni se detiene en la función social de la disciplina en la formación del individuo. Tampoco busca otorgar credibilidad a su obra aludiendo a las fuentes teóricas contemporáneas, ni promueve el aprendizaje de la lengua materna. Para Freire, la gramática no necesita razones previas para su estudio, pues en la introducción no expone ninguno de los aspectos comunes a los manuales al uso, como el carácter didáctico, práctico, inmanente o propedéutico (Garrido Vílchez e.p.). Así, el objetivo del estudio de la gramática cambia desde facilitar el aprendizaje de otros idiomas y hablar y escribir bien la lengua hasta servir a la expresión del pensamiento por medio de la palabra.

Con todo, Freire toma de sus predecesores la división de la gramática en particular y general. Define esta última disciplina como «o estudo dos factos e das leis da linguagem em toda a sua extensão» (Freire 1894[1875]: 23). El gramático no solo llama la atención sobre el carácter científico de la materia, 
sino que determina el objeto de estudio y las diferentes orientaciones teóricas en que se apoya la glottologia o linguistica, y asevera que es más provechoso para el desarrollo científico de la ciencia del lenguaje que estas orientaciones no sean exclusivas sino complementarias:

Assim entendida, é a grammatica geral o mesmo que glottologia ou linguistica, porque é a sciencia da linguagem, ou a sciencia que estuda o maior numero das linguas conhecidas, coordenando as semelhanças e divergencias dos seus vários processos oraes, por meio dos quaes, na diversidade das raças e na sucessão dos tempos, tem o genero humano enunciado o pensamento; e estabelecendo ao mesmo tempo regras geraes, princípios fundamentaes, leis communs e positivas.

No dominio da grammatica geral, há duas orientações: - a tendência, exclusivamente lógica, que impõe a priori uma theoria do pensamento a todas as modalidades linguisticas; a tendência exclusivamente morphica, que procura explicar o sentido pela estructura, o interno pelo externo. Quando exclusivas, systematicas, ciumentas, essas orientações tornam-se viciosas; pois cumpre não esquecer que a palavra se compõe de dous factores invariáveis - o psycologico e o physiologico, a idéia e a fórma. Para perfeita constituição da glottologia, é pois mister a intima combinação dos dous processos. (Freire 1894[1875]: 23).

Este pasaje muestra el interés de Freire por conciliar la doctrina racionalista (bastante arraigada en la tradición brasileña) con los principios histórico-comparados y positivistas. Por un lado, el gramático reconoce que las lenguas son «produtos históricos, subordinados a determinações de ordem cronológica, geográfica, etnográfica, demográfica, administrativa, etc.ll (Gonçalves 2004: 34) y que la función de la lingüística es, por tanto, «fixar tais determinações por meio das chamadas causas externas e internas») (Gonçalves 2004: 34). Teniendo en cuenta las fuentes teóricas del gramático (véase capítulo 4), es posible afirmar que su concepción de la glotología (o lingüística) encuentra un precedente en las ideas positivistas introducidas en Portugal por el gramático Adolpho Coelho (1847-1919), que, en ensayo Sobre a lingua portugueza (1871), procuraba determinar y definir una terminología propia para esta doctrina de orientación naturalista. El modelo de Coelho, inspirado en última instancia en el lingüista alemán August Schleicher (1821-1868), a quien el 
autor portugués cita en varias ocasiones, desemboca en la gramaticografía brasileña a través de la obra de Freire, el primero que -según nuestros datosutiliza en esta tradición el término «lingüistica». Por otro lado, la definición de Freire todavía acepta que la glotología (o lingüística o aun gramática general) «debe examinar el discurso pasando por el estudio reflexivo de la lógica [...] (Swiggers 1984: 8-9)» (Calero Vaquera 2010: 69).

En su planteamiento general, el autor distingue claramente entre las dos perspectivas del estudio lingüístico, que dan lugar a disciplinas diferentes por la orientación diacrónica o sincrónica y por la finalidad que se persigue en cada caso:

A grammatica é comparativa ou histórica, quando estuda os factos da linguagem em differentes epocas de uma lingua ou em differentes linguas, investigando que leis presidem ás suas alterações (Freire 1894[1875]: 23).

A grammatica é descriptiva ou expositiva, quando se limita a expor os factos da linguagem, observados no emprego de uma lingua em uma dada epoca, abstrahindo do estudo suas transformações. Não investiga as causas, nem explica as leis; seu fim é apenas classificar, definir e exemplificar os materiaes linguisticos (Freire 1894[1875]: 23).

Por primera vez en la tradición brasileña, la obra de Freire aporta definiciones de otros tipos de gramáticas (además de la general y la particular) y reconoce la existencia de otros paradigmas teóricos para la descripción del lenguaje.

Finalmente, Freire define la gramática portuguesa como «o estudo geral, descriptivo, historico e comparativo dos factos da linguagem e das leis que os regem, no dominio tão somente da língua portugueza») (Freire 1894[1875]: 24). Esta definición muestra que, para el autor, la gramática de una lengua particular, como es el caso del portugués, debe comprender e integrar tanto la investigación histórica de los cambios como la descripción sincrónica que hace abstracción de sus transformaciones. 


\subsubsection{El corpus de autoridades literarias}

El análisis del corpus disponible en la obra de Freire permite determinar su grado de descripción. La Gramática cuenta con un corpus de autoridades literarias considerablemente más extenso comparado con gramáticas anteriores, como la de Moraes Silva, e incluso posteriores como la de Júlio Ribeiro.

El número de autores citados por el gramático suma más de 70, de los cuales 30 son portugueses. La mayoría son autores consagrados de la literatura clásica como Camões, Vieira y Gil Vicente, además de algunos autores decimonónicos como A. Herculano, Garrett, Latino Coelho, Frei Luiz de Souza, entre otros. El gramático también cita a 20 autores brasileños, de los que 15 pertenecen al siglo XIX como el Marquês de Maricá, Gonçalves Dias, Casimiro de Abreu, entre otros. Las otras 20 autoridades restantes se dividen en diferentes nacionalidades, pero algunos de ellos no se han podido identificar por falta de datos.

El número total de ejemplos utilizados en la Gramática supera los 400 y se concentran sobre todo en la lexiologia y la syntaxe. Aproximadamente, la mitad son citas de los autores anteriores al siglo XIX, la mayoría portugueses. Las otras citas restantes se dividen entre autores portugueses y brasileños del siglo XIX. Las demás nacionalidades presentan poco más de 50 citas, muchas de ellas en latín.

La interpretación de estos datos permite afirmar que la obra de Augusto Freire presenta un claro componente sincrónico y descriptivo de la lengua portuguesa al apoyarse en un amplio archivo representativo de citas y de autores contemporáneos. Con todo, el gramático no deja de considerar la norma portuguesa clásica a partir del numeroso corpus los autores clásicos portugueses, aunque también aprecia la descripción de la variante brasileña, en contraposición a la variante europea. Este interés por describir el uso contemporáneo de sus compatriotas se revela en la selección de más de 100 
citas de escritores brasileños del siglo XIX y poco más de 70 ejemplos de autores portugueses del mismo periodo.

Aunque no haya afirmaciones concretas por parte del gramático que justifiquen la presencia y el objetivo de un corpus de autoridades literarias tan extenso, se puede notar que los ejemplos cumplen fundamentalmente las mismas funciones que desempeñaban en la obra de Moraes Silva, que son las siguientes:

1) Comprobar las reglas formuladas por el gramático:

$2^{\circ} \mathrm{O}$ verbo da proposição qualificativa que tem por sujeito a fórma que do adjectivo conjunctivo, não concorda com esta, mas sim com o termo antecedente, si é o caso recto de um pronome pessoal. Exemplo:

$<<$ És tu que do oceano á fúria insana

Pões limites e cobro, (G. Dias).>> (Freire 1894[1875]: 283).

2) Deducir reglas a partir de los ejemplos:

Ha escriptores que tambem põem em pratica esta concordancia, quando a forma do adjectivo conjunctivo é quem, como se vê destes exemplos: <<Somos quem somos. (Paiva) >>, <<Dize que sou quem te mando. - (Gonzaga - Lyra, XXXVI, verso 38)>>, Mas tu és, ó meu Deus, quem me soltaste das maternaes entranhas. (S. Caldas - Ps. XXI) (Freire 1894[1875]: 283).

\subsubsection{El tratamiento de la lexicología}

Augusto Freire define la lexicología como el estudio de las palabras «considerando-as, já em seus elementos materiaes - sons e lettras, já em suas fórmas» (Freire 1894[1875]: 25). La fonología, la lexigraphia y la morfología son las partes de la lexicología que se ocupan, respectivamente, de estos tres aspectos de la palabra. En la fonética (primera parte de la fonología), los sonidos son estudiados a partir de una perspectiva physiologica, que describe los sonidos como resultado de la articulación vocal, y otra perspectiva historica, que 
«expõe as leis que determinam a transformação dos sons nas diversas idades da lingua») (Freire 1894[1875]: 36).

En cuanto a la fonética fisiológica, el primer aspecto relevante es el uso de esta terminología claramente influida por las ideas positivistas. La fonética fisiológica estudia básicamente los sonidos relacionados con los órganos articulatorios:

A Phonetica physiologica trata dos sons articulados relativamente aos órgãos que os formam.

Som articulado é toda emissão da voz, que se transforma em som pela acção do apparelho vocal.

Os sons articulados, ou são simples, ou compostos

Os simples não teem mais de um som. Taes são os phonemas, isto é, as vozes ou sons vogaes $e$ as consonancias ou sons consoantes (Freire 1894[1875]: 26).

De esta definición es importante destacar que el gramático introduce una novedad en la terminología, pues por primera vez en la gramaticografía brasileña se utiliza el término phonema para designar una unidad mínima de sonido («som articulado simples»).

Por su parte, el estudio de la fonética histórica gira en torno a las «leis da alteração phonetica»ı, que se resumen en la Gramática de Freire en los siguientes principios:

1) El «principio da mínima acção», que consiste en la descripción de las transformaciones del latín en su evolución a las lenguas románicas, como el portugués, mediante cambios de simplificación y economía en la emisión de ciertos sonidos (Freire 1894[1875]: 36).

2) El «principio de transição», que estudia las transformaciones de las grafías («lettras») a partir de las formas intermedias que presentaron los vocablos hasta alcanzar la forma más actual (Freire 1894[1875]: 37).

3) Los «metaplasmos», que comprenden tres tipos de procesos: 
a) La permuta de grafías («lettras»), que consiste en el cambio de un sonido, representado por una determinada letra, por otro. Según Freire, este proceso es el resultado de la debilidad de un sonido y su consecuente sustitución, o bien del contacto entre vocales y consonantes (Freire 1894[1875]: 38).

b) La «elisão de lettras», que es el resultado de la eufonía y del ensordecimiento de las letras vecinas a la sílaba tónica (Freire 1894[1875]: 41).

c) La "adição de lettras euphonicas» (Freire 1894[1875]: 43).

4) La «analogia morphica», que es definida por el gramático como la tendencia natural de la lengua a preservar las formas más generales y conocidas en detrimiento de las formas irregulares (Freire 1894[1875]: 43).

El estudio fonético de Freire supone claramente la influencia de la corriente histórico-comparada. En efecto, algunas de las mudanzas señalas por el autor ya habían sido analizadas en el ensayo Sobre a Lingua Portugueza (1871) por el gramático portugués Adolpho Coelho (Gonçalves 2004).

Las últimas partes de la fonología son la prosodia que estudia la «quantidade e do accento das syllabas constituidas em vocabulos» (Freire 1894[1875]: 43), y la orthoepia que «trata da correcta pronuncia dos vocábulos» (Freire 1894[1875]: 51).

En la prosodia, Freire describe en qué consiste la cantidad de las sílabas. Explica que la duración de la pronunciación de cada voz es variable y concluye que no es posible medir su velocidad sino por las proporciones entre ellas:

Esta duração é toda relativa; não se mede pela velocidade ou lentidão accidental, com que se pronunciam as syllabas, mas pelas proporções immutaveis que as tornam breves ou longas. [...] A medida portanto da duração de cada syllaba é a proporção invariavel que teem umas para com outras, proporção que nunca se pode determinar mathematicamente, porque, em todas as linguas, ha syllabas breves mais breves que outras e longas mais longas que outras (Freire 1894[1875]: 44). 
Respecto a las sílabas breves y largas, el autor señala que su cantidad puede ser determinada por la naturaleza o por el uso (Freire 1894[1875]: 44). La naturaleza se refiere a una relación de dependencia con el movimiento del aparato vocal. Así, el movimiento rápido o lento condiciona la cantidad de la sílaba (Freire 1894[1875]: 45), mientras que el uso trata de las voces sobre las que incide la tonicidad, es decir, las sílabas tónicas son largas y las átonas son breves (Freire 1894[1875]: 45).

En cuanto a los acentos tónicos (prosódicos o fonéticos), el gramático considera que una de sus principales funciones consiste en proporcionar unidad e individualidad a la palabra, pues «faz de uma reunião de syllabas um todo perfeito e distinctol (Freire 1894[1875]: 46). Freire se refiere además a la tendencia «geral e absoluto» de las lenguas románicas a conservar el acento latino:

No portuguez, como nas linguas suas congeneres, conservam as palavras o accento tonico na mesma syllaba das palavras latinas de que veem [...]. Este facto da persistência do accento latino, que contitue uma lei geral e absoluta, é de summa importancia, por sua influencia, na formação da lingua portugueza (Freire 1894[1875]: 46).

Con respecto a la terminología de los acentos prosódicos, Freire mantiene la nomenclatura más tradicional (grave, aguda y esdruxula) aunque aporta también los cultismos técnicos (oxyłona, paroxytona y proparoxitona):

Quando o accento prosódico reae na ultima syllaba, chamam-se as palavras agudas; quando na penúltima, graves; quando na antepenúltima, esdruxulas ou dactylicas.

As palavras agudas chamam-se oxytonas [...]. As graves tomam a denominação de paroxytonas [...]. E as esdruxulas ou dactylicas dá-se o nome de proparoxitonas (Freire 1894[1875]: 49).

La orthoepia es, en la obra de Freire, la parte de la fonología que estudia la pronunciación de los vocablos. En su estudio, el gramático describe los vicios 
de dicción y las diferencias entre la pronunciación portuguesa, brasileña e, incluso, de las variaciones en las diferentes regiones de estos países. En este sentido, Freire pone de relieve la necesidad de normalizar esta cuestión, al parecer, por medio del establecimiento de una variedad estándar del portugués:

Em assumpto de tanto momento, qual a pronuncia, é de intuitiva necessidade haver uma norma de reconhecida autoridade, que sirva de correctivo ás suas aberrações (Freire 1894[1875]: 51).

Esta afirmación también pone de manifiesto que en esta época ya había una cierta preocupación por el tema de las variedades dialectales y sociales del portugués. Así, Freire explica que la pronunciación puede estar condicionada por diveros factores, como la geografía -la variante de algunas regiones tienen más prestigio que otras-, el clima, los cataclismos sociales, el grado de cultura literaria, el tiempo, los grupos sociales, entre otros:

O portuguez falado no Brazil apresenta innúmeras differenças do que se maneja em Portugal; o do Rio de Janeiro, do do interior de S. Paulo, bem como este do do Ceará ou das Alagoas. O mesmo se dá com muitas localidades dos estados, cujos modos de pronunciar diversificam dos das capitaes.

Vem a pello lembrar ainda que, numa mesma cidade, o erudito se exprime de modo muito outro do da plebe que altera ou mutila os elementos phoneticos, corrompendo-os a final.

De uma epoca para outra tambem se modifica sensivelmente a pronuncia. Remontando apenas á idade aurea da nossa litteratura, vemos pela orthographia então em uso, quão dissemelhante da de hoje era a pronuncia dos vocabulos seguintes: [...]

Muitas vezes a pronuncia condemnada numa epoca é mais tarde a correcta e seguida, em quanto que a até então tida como exacta é julgada erronea e reprovada (Freire 1894[1875]: 51-52).

Para el gramático, las variaciones en la pronunciación del portugués se caracterizan por la «vivacidade ou lentidão da articulação, [la] dureza ou doçura das inflexões, [la] repetição obligada de certas cadenciası (Freire 
1894[1875]: 53). Estos fenómenos no constituyen «vicios de pronuncia». Sin embargo, la sustitución de unas vocales por otras (i por e, o por $u$, e por i), de unas consonantes por otras (I por $r$ ) o el cambio de tonicidad de las sílabas son verdaderas «violações da correcta pronuncia» (Freire 1894[1875]: 54 - 57).

La segunda parte de la lexicología, la lexigraphia, estudia las letras, useu uso na correcta escriptura dos vocabulos, e das notações léxicası (Freire 1894[1875]: 57). El estudio de las letras en sí mismas se denomina phonographia que describe las formas y los nombres de las letras, las combinaciones posibles entre ellas y los casos específicos de insonoridad. Cabe destacar que en la phonographia se encuentra la primera mención textual de Freire a una de sus fuentes teóricas, la Gramática de Port-Royal. El autor brasileño se muestra partidario del método empleado por los gramáticos franceses para la enseñanza de las primeras letras:

Ha ainda profesores que ensinam a nomear as letras consoantes, por este modo: bê, cê, dê, éfe, gê, jóta, ká, éle, émme, énne, pê, quê, érre, ésse, tê, vê, xiz, zê. Este methodo tem graves inconvenientes. Para obsta-los, tiveram Arnauld e Lancelot de Port-Royal de propor outro mais simples, e applicavel a todas as línguas. Dizem estes celebres e profundos grammaticos não ser penoso a quem começa a aprender a ler, o trabalho de conhecer simplesmente as lettras, mas summamente ímprobo o de reuni-las, porque, tendo aprendido a designar cada lettra, estando só, com um nome ou som, Ihe ensinam outro, differente daquelle com que é nomeada, quando trata de junta-la a vogaes (Freire 1894[1875]: 58).

La orthographia, por su parte, «ensina a escrever os vocabulos, com rigorosa applicação das leis da alteração phonetica») (Freire 1894[1875]: 61) y constituye la parte más extensa de la lexigraphia. Para el autor, estas leyes equivalen al estudio histórico-comparado de las palabras:

A applicação de taes leis á escriptura das palavras constitue o estudo historico-comparativo dos vocabulos, que consiste en investigar, atravez do tempo (historia) atravez do espaço ou dos logares (comparação), as funções e permutas das letras na formação e derivação de palavras (Freire 1894[1875]: 62). 
En esta línea, Freire estudia el origen, la evolución y la combinación de las letras a partir de fenómenos como la uapherese, [la] syncope, [la] apocope, [la] attracção, [la] metathese e [la] consonantisação» (Freire 1894[1875]: 62). Para ilustrar las diferencias entre vocales y consonante, el autor recurre a una interesante comparación entre la organización de las grafías («letras») y la constitución del cuerpo humano:

Comparando a palavra com um organismo vivo, podemos dizer que são as consoantes o esqueleto dellas, porque não se podem mover sinão com o auxilio das vogaes que constituem, por assim dizer, os músculos que as ligam entre si. As voages são por isso a parte movel e fugitiva da palavra, em quanto que as consoantes formam essencialmente a sua parte estavel e resistente (Freire 1894[1875]: 62).

Freire explica los tres sistemas que regulan la ortografía de la lengua. En primer lugar, se refiere al sistema fonético, que consiste en la correspondencia fiel entre la «correcta pronuncia» y la representación gráfica. De su concepción se puede deducir que, para el autor, hay pronunciaciones que no son correctas ni aceptadas $y$, dada su diversidad, no es recomendable representar gráficamente todas las diferencias orales posibles, por lo que este sistema debe limitarse a una sola variante. Con respecto al sistema etimológico, el gramático destaca la dificultad de su aplicación y critica la excesiva preocupación por conservar las características de la ortografía original. En su opinión, este sistema es «o mais impraticavel de todos, porque, observado á risca, daría em resultado uma escriptura ridicula e pedantesca, que não seria portuguez, nem latim» (Freire 1894[1875]: 83). El autor manifiesta además que la ortografía debe tener como base un sistema de fácil comprensión, accesible a los menos instruidos y que no debe ser un «amalgama de doutrinas casuisticas e só accessiveis aos doutos») (Freire 1894[1875]: 82). En este sentido, el sistema mixto, usual o ecclectico parece ser el más adecuado, según el gramático, pues privilegia «as fórmas em uso, já phoneticas, já etymologicas, que forem consideradas pelos 
glottologos, como sendo o resultado do estudo histórico-comparativo dos vocábulos» (Freire 1894[1875]: 83).

La última parte de la lexigraphia, denominada semiographia, comprende el estudio de los signos gráficos o notaciones («notações») que pueden acompañar a las palabras e incluye también las reglas de formación de abreviaturas. Para el autor, las notaciones son de tres tipos:

1) La «notação phonica» que estudia los signos que marcan los cambios en el sonido de las palabras.

2) La «notação etymologica» que regula el uso del apostropho (') y el hyphen (-).

3) La «notação tachygraphica» relacionada con las abreviaturas.

Es importante observar que en su definición de notación, Freire no aporta el significado (cabría decir, intensional) de este término, sino que el autor, en el empeño por las clasificaciones, se limita a enumerar los signos a los que, por extensión, se puede aplicar este concepto:

São notações phonicas: - os accentos, o til, o trema, o agá e a cedilha (Freire 1894[1875]: 85).

As notações etymológicas são: - o apostropho e o hyphen (Freire 1894[1875]: 88).

As notações tachygraphicas são as abreviaturas (Freire 1894[1875]: 89).

En la Gramática de Freire la morfología se ocupa de la organización de las palabras en clases, del origen, la evolución y la descripción de los vocablos y del análisis de las flexiones. Esta parte de la Gramática se divide en lexiologia (o taxionomia), que clasifica las «palavras em varias especies ou categorías, correspondentes ás idéias que exprimem» (Freire 1894[1875]: 90) y organographia que describe «os orgãos dos vocabulos» (Freire 1894[1875]: 113). 
Respecto a las partes del discurso, Freire propone tres criterios de clasificación:

1) Ocho «especies», según sus propiedades y características: sustantivo, pronombre, adjetivo, verbo, preposición, adverbio, conjunción e interjección.

2) Tres clases, según la analogía de sus funciones (en este caso se excluye la interjección):

a) Nominativas (sustantivo y pronombre).

b) Modificativas (adjetivo y adverbio).

c) Conectivas (verbo, preposición y conjunción).

3) Dos grupos, según la forma:

a) Palabras variables o inflexas (sustantivo, pronombre, adjetivo y verbo).

b) Palabras invariables o ininflexas (preposición, adverbio, conjunción e interjección) (Freire 1894[1875]: 90-91).

Estas clasificaciones ponen de manifiesto el interés del gramático en cruzar criterios diferentes (etimológicos, formales, nocionales, sintácticos y funcionales) para presentar la complejidad del sistema de las categorías gramaticales.

Con respecto al sustantivo, Freire lo define como «palavra que designa pessoa ou cousa [...] é o sujeito por excellencia») (Freire 1894[1875]: 91) y señala la importancia del estudio de su significación a partir de los conceptos de extensión y comprensión:

Chama-se extensão o maior ou menor numero de individuos ou cousas que o nome significa; e comprehensão, o maior ou menor numero de qualidades características do objeto significado pelo nome. Assim a extensão do nome homem são todos os seres a que se applica este nome; sua comprehensão, as qualidades que constitivem essencialmente a espécie humana, como sejam: ser organisada de certo modo, e dotada de 
sensibilidade, intelligencia, vontade, etc. A comprehensão está na razão inversa da extensão, e reciprocamente (Freire 1894[1875]: 91).

Como es sabido, los conceptos de comprensión y extensión fueron introducidos en La Logique de Port-Royal (1662). Arnauld y Nicole definen la comprensión como «les attributs qu'elle [l'idée] enferme en soi, et qu'on ne lui peut ôter sans la destruiren, mientras que denominan extensión (étendue) de una idea a «les sujets à qui cette idée convient, ce qu'on appelle aussi les inférieurs d'un terme généralı. Estas nociones se aplican a los estudios gramaticales del nombre sobre todo a partir de la obra de Beauzée (1767), que considera que la comprensión de la idea del nombre es «la collection des idées partielles qui constituent l'idée totale de la nature commune exprimé par les Noms» y la extensión de la significación es -como recogería más tarde el gramático brasileño- «la quantité des individus auxquels on applique actuellement l'idée de la nature commune enoncée par les Nomsı) (Bartlett 1975: 55-56).

El autor sigue la división más generalizada del sustantivo en proprio o particular y appellativo o commum (concreto y abstracto). Un aspecto en la descripción del sustantivo que llama la atención es la referencia de Freire a las «locuções substantivas», en cuya definición se manifiesta especialmente el carácter funcional de su doctrina:

Ha ainda locuções substantivas que consistem no emprego de duas ou mais palavras, exercendo a funcção de um substantivo (Freire 1894[1875]: 92).

Freire define el pronombre como «a palavra que se põe em logar do nome ou do sujeito, para evitar a sua repetição» (Freire 1894[1875]: 93) e incluye en esta clase solamente a los pronombres personales, pues entiende que «só os pronomes pessoaes teem, na nossa lingua, esta propriedade») (Freire 1894[1875]: 93-94). Asimismo, el autor se muestra contrario a la concepción de pronombre adoptada por muchos gramáticos de la primera mitad del siglo (portugueses y 
brasileños) como Moraes Silva (1806), Soares Barbosa (1822) y Costa Duarte (1829):

Considera Antonio Moraes Silva o pronome pessoal, como um verdadeiro substantivo; sensivel porem é a differença que ha entre estas duas especies de palavras [...]. Tambem não é o pronome pessoal adjectivo determinativo, como em suas Grammaticas Philosophicas da Lingua Portugueza, opinam Jeronymo Soares Barbosa e o Padre Antonio da Costa Duarte (Freire 1894[1875]: 94).

El gramático brasileño critica la teoría de Soares Barbosa y de Costa Duarte porque entiende que esta clase de palabras «não extende a significação do nome a maior ou menor número de individuos») (Freire 1894[1875]: 94).

En la Grammatica, los adjetivos están divididos en dos grupos:

1) Adjetivos qualificativos, que «exprime[m] a qualidade ou maneira de existir da pessoa ou cousa significada pelo appelativo a que se junta: é o attributo por excellencia. Dahi the vem o nome de attributivo» (Freire 1894[1875]: 96). Este grupo se divide en explicativo, restrictivo, verbal, participio, patrio, gentilico y posesivo.

2) Adjetivos determinativos, que «junto ao appellativo, fa-lo significar uma, algumas, ou todas as pessoas ou cousas da classe a que pertencem» (Freire 1894[1875]: 97). Se dividen en articular, numeral, conjuntivo, quantitativo, interrogativo, demostrativo y posesivo.

Es importante señalar que el artículo y el participio formaban clases independientes en algunas gramáticas racionalistas brasileñas, como la de Frei Caneca (1817), Pereira Coruja (1835) y Olivier Grivet (1865). Pero en la obra de Freire forman parte de los adjetivos, siguiendo el modelo de la Gramática de Sotero dos Reis (1865), como se refleja en la tabla siguiente: 


\begin{tabular}{|c|c|}
\hline Sotero dos Reis (1865) & Augusto Freire (18751-18772) \\
\hline Adjetivo qualificativo & Adjetivo qualificativo \\
\hline Explicativo & Explicativo \\
Restritivo & Restritivo \\
Verbal & Verbal \\
Participio & Participio \\
Pátrio ou gentílico & Pátrio \\
& Gentílico \\
\hline Adjetivo determinativo & Possessivo \\
\hline Articular & Adjetivo determinativo \\
Conjuntivo & Articular \\
Interrogativo & Conjuntivo \\
Numeral & Interrogativo \\
Quantitativo & Numeral \\
Possessivo & Quantitativo \\
Demonstrativo & Possessivo \\
Pronominal & Demonstrativo \\
\hline
\end{tabular}

Tabla 5.2 Los adjetivos en las gramáticas de Sotero dos Reis y Augusto Freire

Constituye una novedad la idea de los posesivos que defiende el autor. Para Freire, los adjetivos posesivos pueden ser clasificados igualmente como qualificativos y determinativos. La diferencia que el autor establece con respecto a los dos tipos de posesivos es la siguiente:

1) El adjetivo calificativo posesivo expresa «a qualidade de ser alguem possuidor de algum objecto: leis manoelitas, isto é, leis de El-rei D. Manoel; bandeira nacional, isto é, bandeira da naçãol) (Freire 1894[1875]: 97).

2) El adjetivo determinativo posesivo «determina o appellativo, indicando que o objecto certo e determinado, que faz o appellativo significar, pertence a alguma das pessoas grammaticaes. Exemplo: seu livro, isto é, o livro delle, ou o livro que Ihe pertence») (Freire 1894[1875]: 102). 
Augusto Freire define el verbo como «palavra de affirmação, ou mostra que a qualidade convem ao sujeito: é por conseguinte o nexo ou copula que une o attributo ao sujeito») (Freire 1894[1875]: 103). Esta definición pone de manifiesto que la doctrina gramatical de Freire todavía conserva una base racionalista. El conservadurismo del autor se muestra, además, en que utiliza la misma teoría del Epítome de Moraes Silva (1806) para explicar el carácter afirmativo de los verbos:

Quer a proposição seja affirmativa, quer negativa, como se vê nos seguintes exemplos: «Deus é eterno.» «Deus não é injusto.» No primeiro caso, o verbo é mostra que a qualidade de ser eterno convem ao sujeito Deus; no segunto, o verbo é mostra igualmente que a qualidade de não ser injusto convem ao mesmo sujeito Deus. Todo juízo é affirmativo. O enunciado ou a proposição é que pode tomar a fórma negativa. Afectando porem o attributo, só ha juizos affirmativos [...] (Freire 1894[1875]: 103).

El gramático también sigue la tradición más generalizada al describir la clase de los verbos según la teoría del verbo único. Así por ejemplo, Freire divide esta categoría en sustantivo y adjetivo y, posteriormente, divide los verbos adjetivos en transitivos, intrantivos y relativos (según su atributo) y en denominativo, imitativo, frequentativo, inchoativo, augmentativo, diminutivo y negativo (según su derivación). El autor también divide los verbos transitivos en proprio, reflexivo y pronominal reflexo (según su complemento).

Con respecto al problema de los verbos sin sujeto, hasta entonces explicado en la tradición brasileña por la elisión del sujeto, Freire advierte que se trata de verbos impersonales «que, em accepção propia, [são] usado[s] na terceira pessoa do singular, sem sujeito conhecido»l (Freire da Silva 1894[1875]:189).

El autor define las partes invariables de la oración según la función que desempeñan. La preposición consiste en «uma parte invariavel da oração, que liga complementos ao sujeito ou ao attributoı (Freire 1894[1875]: 106). Los adverbios constituyen «uma parte invariavel da oração, que modifica o nome adjectivo, ou attributivo incluído ou não no verbo, accrescentando-lhe alguma 
circunstancia [...]» (Freire 1894[1875]: 106) y pueden ser de modo, tiempo, orden, cantidad, afirmación, negación, interrogación, lugar, duda y exclusión. Las conjunciones son «uma parte invariavel da oração, que, para formar um corpo de discurso, ou liga palavras, proposições ou períodos a outros termos da mesma espécie, [...]» (Freire 1894[1875]: 108) y se dividen en de approximação (que une dos términos pero mantiene su independencia) y de subordinação (que une y subordina unos elementos a otros en la oración). Finalmente, la interjección se caracteriza por expresar los sentimientos súbitos del alma y por encerrar en sí una proposición implícita (Freire 1894[1875]: 112).

El gramático propone, además, otras tres divisiones de clases de palabras, «conforme a analogia do som, fórma ou sentido, que teem entre si»» (Freire 1894[1875]: 112):

1) La familia phonica, que comprende las palabras homónimas, homófonas, homógrafas y parónimas.

2) La familia morphica, que se ocupa de las palabras cognatas próximas y remotas.

3) La familia ideologica, que está formada por las palabras mononymas, sinonymas, polynonymas y antonymas.

Por primera vez en la gramaticografía brasileña se propone la división de las palabras a partir de propiedades fonéticas, morfológicas, sintácticas y semánticas. Aunque estas características ya habían sido señaladas por otros autores, el avance de la propuesta de Freire consiste en la sistematización de su estudio.

La organographia constituye la segunda parte de la morfología que se ocupa de la descripción de los «órganos» del vocablo, es decir, «qualquer parte delle, que exerce uma função, ou tem um sentidoı) (Freire 1894[1875]: 113) y se divide en flexionismo y etymologia. 
El flexionismo estudia las variaciones de terminación de las palabras a partir de la descripción y análisis de las partes que las componen, como el radical o tema y la terminación o desinencia (Freire 1894[1875]: 114).

En el estudio de la flexión nominal (relativa a los sustantivos, los pronombres y los adjetivos), el autor explica, en primer lugar, la evolución de los casos latinos en la lengua portuguesa. Freire se muestra de acuerdo en que «se distinguem vestigios dos casos latinos» (Freire 1894[1875]: 115) fijados en algunas palabras del portugués, como Deus, Jesus, simples (nominativo); aqueducto, cabisbaixo, cujo (genitivo); devoto, fideicommisso (dativo); sabão, imagen, tempo (acusativo); agora, logo, como (ablativo) (Freire 1894[1875]: 116-117).

Pero Freire no solo explica la cuestión de la flexión de género, número y grado de los nombres sino que proporciona además un detallado análisis histórico sobre el proceso de evolución de estas flexiones en el portugués y en otras lenguas románicas. Así por ejemplo, el autor describe el origen de las terminaciones masculinas (-o, -a, -e, -um, -ão, -l, -r, etc.) y femeninas (-a, -e, -ie, -ão, -z, -ade, -ez, -gem, -or, etc.), la mudanza de género en la evolución del latín y el griego al portugués y la derivación de la «ss) plural del acusativo latino (Freire 1894[1875]: 117-144).

El estudio histórico del género es un aspecto gramatical al que el autor presta especial atención. Augusto Freire describe el desarrollo de la expresión del género de los seres y los objetos en las lenguas y explica las variaciones de esta flexión, como la adopción de diferentes vocablos para designar los géneros masculino y femenino, el cambio de terminación y la presencia del género neutro:

Nas linguas primitivas, era o sexo dos individuos indicado, por meio de substantivos differentes. Da lingua-mãe nos advieram os seguintes: bode, cabra; boi, vacca; cão, cadella; [...]. Esta classe de nomes pertence ao fundo primitivo da linguagem humana, e está por isso fora das regras da analogia.

Com o correr dos tempos, adoptaram as linguas o fácil artifício de serem os sexos designados pelo mesmo substantivo, com a simples mudança da terminação (Freire 1894[1875]: 118). 
A lingua ingleza é a única que segue este caminho natural [la constitución del género neutro]; por isso é nella a doutrina do genero dos nomes matéria summamente fácil, ao envez do que se dá nas outras. (Freire 1894[1875]: 120).

Finalmente, el gramático concluye la morfología con el estudio etimológico del portugués. Freire define la etimología como la descripción de la constitución del léxico (Freire 1894[1875]: 193) por medio de la filiación o «historia dos vocabulos» (fundamentada en las leyes fonéticas) y la comparación de las lenguas. En este sentido, el gramático defiende la premisa de que la lengua presenta un carácter vivo y mutable, sobre la que inciden diferentes fenómenos que determinan su evolución:

As linguas estando sujeitas, como tudo quanto existe, á lei fatal da transformação, nunca se podem considerar fixadas: - desenvolvem-se e envolvem-se continuamente.

Concorrem muito para o seu desenvolvimento e continuo evolucionar duas forças oppostas, que manteem o equilíbrio da vida que lhes é propria, uma que elimina, outra que assimila (Freire 1894[1875]: 273).

Los cambios léxicos se corresponden con los arcaísmos y los neologismos:

Essas duas forças são conhecidas pelas denominações de archaismos e neologismos.

Os archaismos são as folhas seccas que vão caindo da arvore da linguagem; os neologismos, a folhagem com que os idiomas se renovam, e revestem de frescura e graça (Freire 1894[1875]: 273).

La etimología de Freire guarda una semejanza notable con las ideas de Adolpho Coelho (1871). En el caso del arcaísmo, por ejemplo, ambos autores determinan como causas de este fenómeno el «desaparecimento do referente significado pelo nome; na moda; no pedantismo literário; na imitação da linguagem de escritores; na sinonímia; na perda de significados; na substituição 
de uma palavra por outra dela derivada, [...] [aquisição de um novo sentido], aquisição de um sentido obsceno») (Gonçalves 2004: 44).

En la descripción de los neologismos también se puede notar la influencia de Adolpho Coelho, pues tanto el gramático brasileño como el portugués reconocen que los neologismos provienen, por un lado «do fundo da língua», que Freire denomina «neologismos intrínsecos» y, por otro, «importado de línguas modernas») («neologismos extrínsecos») (Gonçalves 2004: 44). El autor observa, además, la derivación y la composición del léxico portugués, en el que identifica la influencia de diferentes lenguas, como el español, el francés, el inglés, el alemán, el árabe, las «linguas americanas», las «linguas africanas», entre otras.

El estudio etimológico de Freire alcanza una extensión sin precedentes en la gramaticografia brasileña. De hecho, tampoco en las gramáticas brasileñas posteriores se recogieron modelos de análisis de la evolución del portugués semejantes al de Freire. Los estudios más detallados sobre la etimología portuguesa solo tuvieron lugar en las gramáticas históricas, ya bien entrado el siglo XX.

\subsubsection{El tratamiento de la sintaxis}

La sintaxis constituye la segunda parte de la Grammatica de Freire, definida como el estudio que «ensina a coordenar as palavras e as proposições, de modo que sejam a expressão pura ou artística do pensamentol) (Freire 1894[1875]: 276) y se divide en «syntaxe grammatical» y «litteraria».

La «syntaxe gramatical» describe las relaciones que las palabras y las proposiciones pueden establecer entre sí y sus funciones. La base de la sintaxis está en la correspondencia entre el juicio y la proposición que, a su vez, está compuesta de sujeto, verbo y atributo. En el análisis de la proposición Freire señala que el sujeto (gramatical) puede ser representado por un «substantivo, [un] pronome, [una] parte da oração substantivada [o una] oração») (Freire 
1894[1875]: 277) y que el atributo (gramatical), por su parte, debe estar representado por un adjetivo o «cousa equivalente» (Freire 1894[1875]: 278).

Las definiciones de Freire muestran que su doctrina sintáctica todavía presenta el influjo del pensamiento racionalista sobre la correspondencia entre la proposición y el pensamiento lógico. No obstante, se puede notar la aplicación de modelos histórico-comparados y positivistas en la sintaxis, pues el autor recurre a una cita de C. Ayer (1876) para justificar el uso del sustantivo como atributo de la oración:

O substantivo figura em geral na proposição, como sujeito ou complemento, mas pode tambem, como adjectivo, servir de attributo, e então designa o conjuncto das qualidades que constituem o genero ou a especie. Quando dizemos: "O cão é fiel», apenas attribuimos ao sujeito uma qualidade, a de ser fiel. Dizendo porem: "O cão é um animal», affirmamos que $o$ cão tem todas as qualidades ou propriedades que caracterisam 0 animal; noutros termos, comprehendemos a especie cão na especie superior ou no genero, o animal (11) (Freire 1894[1875]: 278).

Con respecto al orden de palabras en la construcción de la oración, Freire sigue la tradición más generalizada al distinguir entre el orden directo (analítico) y el inverso (sintético). El autor también señala las relaciones que los vocablos establecen entre sí en la construcción de la proposición: de nexo, de concordancia y de dependencia o subordinación. Las relaciones de nexo se establecen mediante la conjunción, la preposición y el verbo; las de concordancia por medio de las correlaciones verbo-sujeto y adjetivo-sustantivo; y las de dependencia o subordinación a partir del empleo de los «complementos» restrictivos, objetivos, terminativos y circunstanciales (Freire 1894[1875]: 280-294).

Acerca de la terminología empleada en la sintaxis, cabe destacar el intento del autor por diferenciar los términos «complemento» y «attributo». Según Freire, estos elementos cumplen diferentes funciones en la estructura oracional:

11 C. Ayer. - Grammaire comparée de la langue française, première edition, $n^{\circ} 361$, in fine; e quatrième edition, § 165, l, b, in fine [nota del gramático]. 
Attributo é a qualidade que convem ao sujeito: é a idéia accessoria (Freire 1894[1875]: 277).

Complemento é toda a palavra ou oração, que completa o sujeito ou o attributo (Freire 1894[1875]: 290).

La sintaxis es la parte de la Gramática de Freire que presenta el mayor número de referencias a las fuentes teóricas del autor. La primera cita textual está relacionada con su modelo oracional, en el que se manifiesta la influencia de Silvestre de Sacy (1758-1838). Swiggers (2005, 2009 e.p.) en el estudio sobre la estructura de la oración de Sacy muestra que para el gramático la proposición está formada por sujeto y atributo lógicos. El sujeto lógico puede presentar un nombre (sujeto gramatical) o estructuras compuestas por artículo + pronombre (o nombre) + adjetivo, o un complemento, o una proposición conjuntiva o una aposición. El atributo lógico, por su parte, presenta un verbo (sustantivo) acompañado de un adjetivo (atributo gramatical) o distintos complementos. Swiggers (2009 e.p.) ilustra este modelo de proposición como se muestra a continuación:

\begin{tabular}{|l|l|l|}
\hline \multicolumn{1}{|c|}{ Sujeto (lógico) } & \multicolumn{2}{c|}{ Atributo (lógico) } \\
\hline & \multicolumn{1}{c|}{ verbo (sustantivo) } & \multicolumn{1}{c|}{ Atributo } \\
\hline artículo+(pro)nombre(+adjetivo) & Verbo & adjetivo (o participio) \\
\hline artículo+proposición conjuntiva & +complemento & $\begin{array}{l}+ \text { complemento } \\
\text { (términos } \\
\text { circunstanciales) }\end{array}$ \\
\hline artículo+complemento & & +adverbio \\
\hline artículo+aposición & & \\
\hline
\end{tabular}

Nombre=sujeto gramatical

Atributo=atributo gramatical

Tabla 5.3 Modelo oracional de Sivestre de Sacy

Por su parte, el modelo de proposición defendido por Freire (Freire 1894[1875]: 277-278) puede ser ilustrado del siguiente modo: 


\begin{tabular}{|c|c|c|}
\hline \multirow{5}{*}{ Proposição } & \multirow{2}{*}{ Sujeito lógico/ total } & Sujeito gramatical \\
\hline & & Complementos \\
\hline & \multicolumn{2}{|c|}{ Verbo (sustantivo) } \\
\hline & \multirow{2}{*}{ Attributo lógico/ total } & Attributo gramatical \\
\hline & & Complementos \\
\hline
\end{tabular}

Sujeto gramatical=sustantivo, pronombre, parte de una oración sustantivada, oración.

Atributo gramatical=adjetivo, «cousa equivalente» (Freire 1894[1875]: 278).

Tabla 5.4 Modelo oracional de Augusto Freire

Otro autor francés que parece hacer influido en la sintaxis de Freire es Domergue (1745-1810). Aunque el gramático brasileño no presenta ninguna referencia textual a este autor, se puede notar cierta relación entre los términos utilizados por Domergue para referirse a los tipos de atributo: «surattribut, attribut d'union, attribut combiné, attribut commun y attribut particulier») (Swiggers 2003, 2009 e.p.) y la terminología empleada por Freire: «subattributo, attributo composto, attributo complexo, attributo simples y attributo incomplexo») (Freire 1894[1875]: 278-279). Sin embargo, el contenido a que se refieren estos términos en uno y otro autor son diferentes.

En la sintaxis general, el autor también hace referencia a las gramáticas de Sotero dos Reis (1865) y Grivet (1865). Con respecto a Sotero dos Reis, Freire parece seguir algunos principios establecidos por el gramático brasileño que regulan la «concordancia semiotica» (silepsis), es decir, la de un elemento oracional, como el verbo o el adjetivo, que no concuerda formalmente con su antecedente, como el sujeto o el sustantivo, sino por el sentido de la proposición:

$1^{\circ}$ "A primeira e a segunda pessoa teem precedencia sobre a terceira, ou, noutros termos, são aquellas mais nobres que esta.» $2^{\circ} " O$ adjectivo conjunctivo identifica-se por tal modo com o primeiro termo ou com o termo 
antecedente, que faz ser perfeita repoducção deste o segundo ou o termo conseqüente (12)» (Freire 1894[1875]: 289).

En cuanto a Grivet, el gramático brasileño emplea solamente algunas citas con el fin de ejemplificar reglas de concordancia:

Exemplo em que o verbo parece discordar do seu sujeito em pessoa: «Na innocencia do infante és tu quem falas. (13) (Dias)») (Freire 1894[1875]: 289).

Cabe señalar que Freire no expone ninguna crítica a las doctrinas de estos autores. La presencia de las referencias bibliográficas muestra que el gramático tiene en cuenta la contribución de los gramáticos brasileños, sobre todo para los aspectos formales de la lengua. Esta presencia, consecuentemente, conecta la obra de Freire a la tradición.

También se pueden encontrar precedentes de Freire en algunos aspectos del tratamiento diacrónico del portugués. El estudio del cambio sintáctico constituye posiblemente una reelaboración de planteamientos anteriores. Freire define las "alterações syntacticas» como "as mudanças que, nos diversos periodos de uma lingua, experimenta um tipo syntactico, sem deixar de exprimir a mesma relação gramatical»» (Freire 1894[1875]: 298), es decir, consiste en la descripción de los cambios de relación gramatical, la creación de nuevos procesos sintácticos y las modificaciones en las formas gramaticales en la evolución de la lengua.

Una vez más, en efecto, se puede establecer alguna relación entre la obra de Freire y la de Adolpho Coelho (1871), pues ambos autores consideran las «alterações syntacticas» como una de las causas de la mudanza del sistema lingüístico. Sin embargo, Adolpho Coelho interpreta este fenómeno desde una perspectiva mucho más amplia que Freire, como pone de relieve Gonçalves (2004):

\footnotetext{
12 F. Sotero dos Reis, - Gram. Port. 3a, ediç., pag. 26 [nota del gramático].

${ }^{13}$ A. Grivet. - Nova Gram. Analyt. da Ling. Port., pag. 478, nº 574 [nota del gramático].
} 
As "alterações sintácticas» correspondem ao quinto e último tipo de "alteração» apresentada por Adolpho Coelho. Definida como a colecção de modas por que uma língua emprega as suas fórmas para a expressão do pensamento, das condições d'esse emprego das funcções d'essas formas, e dos typos de construcção proposicional ([Coelho 1871]: p. XXXIII); é-lhe atribuída a designação de sintaxologia, expressão que pretende fazer uma distinção ôntica entre a disciplina e o seu objecto (Gonçalves 2004: 45).

Ahora bien, en la sintaxis particular Freire trata de describir las funciones que cada clase de palabra desempeña en la oración (Freire 1894[1875]: 302). El autor es bastante claro sobre las funciones del sustantivo, del pronombre personal («do caso recto» [nominativo] y «do caso obliquo» [dativo y acusativo]), del demostrativo («o, a, os, as» cuando equivalen a «tal, taes, aquelle, aquella, aquillo, aquelles, aquellası) y del indefinido (se). El sustantivo puede desempeñar la función de sujeto y de complemento (atributo, aposición y «subattributo»). Respecto al «subattributo», cabe notar la preocupación del gramático por definir esta nueva función sintáctica (al contrario de lo que ocurre con las demás funciones sintácticas del sujeto):

Chama-se subattributo o adjectivo ou substantivo adjectivado, que como o attributo propriamente dito, tambem attribue ao sujeito uma maneira de existir. Exemplos: «Estou cansado». "A primeira habitação de Adão foi chamada paraiso»». No primeiro exemplo, é subattributo o particípio passado cansado, que, como o attributo estante incluido no verbo, tambem attribue uma qualidade ao sujeito eu; no segundo, é subattributo o substantivo adjectivado paraiso que, como o attributo chamada, separado do verbo, tambem attribue uma qualidade ao sujeito a primeira habitação de Adão (Freire 1894[1875]: 302).

Freire atribuye a los pronombres personales las funciones de sujeto, de atributo (muy ocasionalmente) y de complemento (objetivo, terminativo, circunstancial, restrictivo); y de sujeto, de atributo, de «subattributo» y de «complemento objectivo» a los demostrativos (Freire 1894[1875]: 303-306).

En cuanto a la descripción de las funciones sintácticas del adjetivo y del verbo, llama la atención el cambio en el discurso de la Gramática. En lugar de exponer las funciones del adjetivo y del verbo, el autor describe básicamente la 
posición del adjetivo en la frase (antepuesto o pospuesto al sustantivo), los cambios de significación y variabilidad cuando acompaña el sustantivo y, en el caso de los verbos, describe los tipos de verbos (auxiliar, atributivo, intransitivo, relativo y transitivo), su significado en la oración, los complementos que les acompañan y el empleo de los tiempos verbales (Freire 1894[1875]: 331-337). Esta descripción se muestra más bien como una extensión de la morfología.

Por último, el autor asigna a la preposición y la conjunción la función de unir dos o más elementos de la oración y sobre la interjección afirma que esta clase de palabra no posee reglas de sintaxis, pues constituye el enunciado completo de un juicio.

En el tratamiento de la «syntaxe de proposição», Freire pone de manifiesto las relaciones que las proposiciones pueden establecer entre sí para formar períodos compuestos (Freire 1894[1875]: 350). El gramático divide las oraciones en dos grupos («absolutas» y «subordinadas») y describe las reglas que rigen la organización de las proposiciones en la construcción del discurso.

Freire utiliza los criterios formales, sintácticos y semánticos para definir la proposición absoluta (o «consideradas sob a relação de nexo»):

Proposição absoluta é a que constitue, por si só, periodo simples, ou não depende de outra em sua construcção; tem o seu verbo no indicativo, imperativo ou condicional (Freire 1894[1875]: 350).

Freire divide las oraciones absolutas en principal y «approximada» (coordinada). Las aproximadas son de dos tipos, las «syndeticas», que presentan una conjunción para conectarse a la oración principal, y las «asyndeticas», que no van marcadas por conjunción. Por su parte, las oraciones «syndeticas» pueden ser copulativas, disyuntivas, continuativas, adversativas, conclusivas 0 explicativas, dependiendo de la conjunción que se emplea (Freire 1894[1875]: 350-352). El gramático identifica además un tercer tipo de oración absoluta, «proposição complexa» o "composta por subordinação», que consiste en un periodo compuesto por una oración absoluta modificada por una oración subordinada (Freire 1894[1875]: 351). 
La propuesta sintáctica de Freire llama la atención por la preferencia que concede el autor al estudio de las oraciones subordinadas con respecto a la descripción de las oraciones coordinadas. Este desequilibrio entre las materias sintácticas se revela en la ausencia de definición y sistematización de las subclases de oraciones «syndeticas») (copulativa, disyuntiva, adversativa, conclusiva, explicativa y continuativa). El autor solo enumera estas estructuras, pero no se detiene en su estudio. En cambio, la descripción de las oraciones subordinadas ocupa la mayor parte de la sintaxis de las proposiciones.

Así pues, el gramático define la proposición subordinada como aquella «que depende de outra em sua construcção» (Freire 1894[1875]: 352) y la divide en «circunstancial» e «integrante». Las «circunstanciaes» son de cuatro tipos: «conjunccional, qualificativa, infinitiva preposicional y participio» (Freire 1894[1875]: 352) y las «integrantes» pueden ser «subjunctiva, interrogativa e infinitiva»» (Freire 1894[1875]: 360).

El gramático explica con detalle cada tipo de oración subordinada y, aunque presenta un considerable número de referencias teóricas, la mayoría está relacionada con la terminología. El autor más citado es Friedrich Diez (17941876) y el estudio en el que es más evidente la presencia de este autor es en la «Proposição subordinada circunstancial infinitiva proposicional». En nota al pie de página Freire pone de manifiesto la influencia de F. Diez tanto en la teoría del infinitivo como en la terminología gramatical:

Adoptamos esta denominação da divisão que faz Frederico Diez do infinito em puro e preposicional, na página 204 do tomo $3^{\circ}$ da sua Grammatica das Linguas Romanas (Freire 1894[1875]: 357).

Diz Frederico Diez (14) que o infinito pessoal, tenha ou não sujeito proprio se emprega, quando é possivel substitui-lo por um modo finito. Exemplos: "Basta sermos dominantes, isto é, que sejamos dominantes". "Não podeis achar, sem me matardes, isto é, sem que me mateis" (Freire 1894[1875]: 357).

14 Obra cit., tomo 3․ pag. 202 [nota del gramático]. 
En la Grammatica Portugueza, la «syntaxe litteraria» (o «estylistica») «trata do estylo» (Freire 1894[1875]: 375), pues estudia las diferentes maneras de coordinar las palabras y proposiciones, además de su influjo en la lengua oral y escrita. Para Freire, el estilo puede ser analizado desde dos perspectivas: la cantidad y la calidad de la elocución. En cuanto a la cantidad, el discurso puede ser «attico, asiatico, rhodio e laconico»; y con relación a la calidad, se divide en «simples, sublime e temperado». El autor valora la «quantidade» y la «qualidade» de las expresiones discursivas del siguiente modo:

O melhor delles é o attico, e depois o rhodio; os outros, como extremos, são na generalidade viciosos.

O attico tambem se chama preciso; o asiatico, prolixo, diffuso ou verboso; o rhodio, desenvolvido ou abundante; o laconico, conciso ou apanhado.

[O estilo simples] É peculiar ás obras didacticas e ás narrativas vulgares (Freire 1894[1875]: 376).

[O estilo sublime] É proprio das paixões violentas, do heroísmo, dos assumptos épicos.

[O estilo temperado] É o mais empregado na poesía, na historia e no romance.

O simples tem por fim a convicção; o temperado, o deleite; o sublime, a persuasão.

A fusão destes tres estylos é a eloquencia por excelencia (Freire 1894[1875]: 377).

Pero según la construcción de los periodos, el autor añade otra posible clasificación del estilo:

Si todos ou a maior parte dos periodos de um discurso ou escripto constam de uma só phrase curta ou de phrases curtas e desligadas, toma o estylo a fórma de solto ou cortado; si apresentam singela e directamente, sem symetria de partes, nem suspensão de sentido, uma phrase extensa ou varias phrases ligadas, toma o estylo a fórma ordinaria; emfim se apresentam duas ou mais partes cadenciadas e dispostas artificiosamente, de modo que o ouvido se deleita, e o sentido vae incompleto até a conclusão, tem o estylo a fórma periodica (Freire 1894[1875]: 377). 
Freire también propone otras clasificaciones según las escuelas literarias y el género literario (Freire 1894[1875]: 378-379):

Os estylos das escolas litterarias são múltiplos. Na Litteratura portugueza porem, distinguem-se quatro categorias que accentuam perfeitamente as transições ou evoluções: - o clássico, o gongórico, o romântico, o naturalista (Freire 1894[1875]: 378).

Tambem se classificam os estylos, segundo o genero litterario em que são usados. Taes são: - o estylo epistolar, o dramático, o didascalico, o elegíaco, o épico, etc. (Freire 1894[1875]: 379).

El autor brasileño cierra la sintaxis literaria con un análisis detallado de las cuatro «virtudes para a elocução» (Freire 1894[1875]: 379). La primera virtud es la "clareza» cuyas características principales son la precisión, el orden, la corrección y la propiedad de los términos. A propósito de la claridad, el autor distingue algunos «vicios léxicos e syntacticos» que son causas de su corrupción:

1) Vicios léxicos: el solecismo, el arcaísmo, el neologismo, el provincianismo, las palabras técnicas y los homónimos.

2) Vicios sintácticos: el «longo rodeio de palavras», la perisología, la "demasiada concisão», las «expressões refinadas», la «requintada transposição de palavras»», el «extenso parenthesis» y la ambiguedad.

La segunda virtud señalada por el gramático es la «pureza» que consiste en el empleo de «palavras ou expressões autorizadas pelo uso dos que bem falam ou escrevem (Freire 1894[1875]: 382). Los vicios contra la pureza son los mismos -dice- que pueden afectar la clareza además del barbarismo, del purismo y del «cacographismo».

La tercera virtud es el «ornato» que, según Freire, «é o que dá mais força, vigor e belleza ao discurso, já claro e puro». De esta virtud depende la «simpatía del discurso»» (Freire 1894[1875]: 383): 
Si ainda nos conservassemos no estado das hordas barbaras, bastar-nosia manjar a lingua com simples clareza.

Si fossemos apenas um povo civilisado, ser-nos-ia sufficiente enunciar o pensamento com tal ou qual pureza.

Não somos bárbaros, nem tampouco civilisados; temos alguma cousa mais: - somos políticos.

Portanto cumpre-nos ter uma linguagem, não só clara, como os bárbaros, não só pura, como os civilisados, mas principalmente ornada, como as nações políticas do globo, porque a linguagem ornada é a elocução por excellencia (Freire 1894[1875]: 382-383).

Según Freire, los vicios que corrompen esta virtud son la «mollicie» o el «vicio que enlanguesce e effemina a expressão», la «affectação» o el «vicio que contrafaz a expressão», la «incongruencia» o el «vicio que desune a expressão do pensamentol, entre otros (Freire 1894[1875]: 383).

La última virtud es la «harmonia» que se divide en «musical» (o mecánica) y «onomatopica» (o imitativa). La «harmonia» musical trata de la melodía y la cadencia y la «onomatopica», de los sonidos y las pausas. Los vicios relativos a esta virtud son el cacofaton, el hiato, la colisión, la disonancia, la monofonía y el eco. Es interesante notar que la Gramática de Freire es la que presenta el número más elevado de vicios y figuras de lenguaje en la tradición brasileña en este periodo: en su obra, el gramático cita 18 tipos de vicios de lenguaje y más de 50 figuras.

Finalmente, la sintaxis de Freire tiende a basarse en presupuestos más oracionales y no tanto lexicales (Zamorano Aguilar 2006, Calero Vaquera 1986) y trata de desarrollarse desde una perspectiva gramatical menos dependiente del logicismo. Así, el reconocimiento de la oración como la unidad del análisis sintáctico permitió a Freire -y a otros gramáticos de finales de siglo- entender la sintaxis no ya como una extensión de la morfología o las clases de palabras, según el modelo de Moraes -y de otros autores de principios de siglo (García Folgado 2003)- sino también como el estudio de la composición oracional. 


\subsubsection{La primera semiología}

Freire define la semiologia como «o estudo que, para a interpretação do sentido total da phrase, se faz das translações ou mudanças, que, no tempo e no espaço, experimenta a significação das palavras, consideradas como signaes das idéias») (Freire 1894[1875]: 419). Esta parte de la Gramática también es denominada por el autor de «semantica, sematologia o semeiotica» y se divide en «exegética» y «technica».

Antes de empezar el estudio del significado, Freire plantea una importante observación sobre el estado de la cuestión metodológica de esta disciplina y señala que hasta la fecha de publicación de su obra eran escasos los tratados sobre la semántica:

Desta parte da grammatica, cuja doutrina é complexa e difficilima, ha apenas materiais esparsos ou notas fragmentarias, que ainda não foram concatenadas ou reduzidas a systema (Freire 1894[1875]: 419).

La exegética es la primera parte de la semántica que tiene como objetivo investigar los fenómenos referentes a la significación de las palabras (Freire 1894[1875]: 419). Para el autor, las palabras analizadas a partir de su significado deben llamarse «termos» y como tal se dividen en cuatro grupos: «mononymos, synonymos, polynonymos y antonymos». Esta clasificación ya había sido mencionada con anterioridad por el gramático al tratar de la morfología de las palabras.

Para Freire el léxico es un producto social que varia diacrónicamente como otros elementos de la lengua. Señala que la influencia de la analogía en los cambios léxicos:

O léxico, como as fórmas grammaticaes e a pronunciação, varia de época para época. O povo não se contenta com exprimir o pensamento e as idéas novas; é-lhe forçoso apresenta-los animados e revestidos de variadas cores; não lhe basta pois o processo de importação de vocábulos novos de origem estrangeira, nem o da formação portugueza propriamente 
dita. Aquella tendência natural e espontânea da sua vida intellectual leva0 , sob a acção da analogia, a alterar, renovar, e accrescer o léxico pelo processo modificador sentido das palavras (Freire 1894[1875]: 419-420).

El autor cita algunas causas de esta variación, como las siguientes: «generalisação do particular, especialisação do geral, mudança de numero, mudança de genero, mudança por encarecimento, mudança por degradação, degeneração phonetica, origem histórica, falsa etymologia, limitação regional ou dialectal, mudança de categoria gramatical, mudança de categoria mentalı) (Freire 1894[1875]: 420-422), entre otras.

La semiología «technica» se ocupa de la lectura de los signos gráficos como instrumento para la interpretación correcta del sentido de las frases. En esta parte el autor describe los pasos que se debe observar para hacer una buena lectura y enfatiza el cuidado en las pausas y la entonación (Freire 1894[1875]: 423). En la entonación, el gramático identifica seis tipos de acentos:

1) El «acento tonico».

2) El «accento emphatico».

3) El «accento oratorio».

4) El «accento nacional» (la pronunciación propia de cada país).

5) El «accento provinciano» (pronunciación propia de un estado o provincia).

6) El «accento grammatical».

Por último, el gramático concluye la semiología con un breve estudio sobre la puntuación. Explica que el empleo de estos signos puede cambiar el sentido de las proposiciones y cita algunos ejemplos:

«Propagou a sua religião; com o Alcorão em uma das mãos e a espada na outra, morreu envenenado.l)

«Propagou a sua religião, com o Alcorão em uma das mãos e a espada na outra; morreu envenenado.» 
Conforme a primeira pontuação, estas palavras «com o Alcorão em uma das mãos e a espada na outra» designa a maneira pela qual Mahomet morreu; conforme a segunda, essas mesmas palavras mostram a maneira pela qual Mahomet propagava a sua religião (Freire 1894[1875]: 426).

\subsubsection{Resumen}

Aunque la mayoría de las investigaciones relacionadas con la tradición brasileña no muestra especial interés hacia el estudio del tratado de Freire, esta breve descripción ha tratado de demostrar que la Grammatica Portugueza es una obra de cierta importancia en esta gramaticografía. Sin romper totalmente con la tradición, Freire concibe uno de los modelos más completos de sistematización de la lengua portuguesa en Brasil. Como afirma en su definición de gramática portuguesa, esta disciplina tiene como objetivo «o estudo geral, descriptivo, histórico e comparativo dos factos da linguagem e das leis que o regem» (Freire 1894[1875]: 24).

Así pues, aquí se considera que las principales aportaciones del autor fueron principalmente las siguientes: 1) la reformulación de algunas ideas tradicionales ya arraigadas en la gramática; 2) la presentación de un contenido sistematizado, más amplio y detallado; 3) la aplicación a la gramática portuguesa de algunos principios de la gramática general y de la gramática histórico-comparada; 4) el desarrollo del corpus de autoridades literarias; 5) la atención al estudio de la variante brasileña del portugués; 6) la superación de la perspectiva tradicional de la gramática.

Con todo, quizá la contribución más relevante de Freire a la historia de la gramática portuguesa compuesta por los autores brasileños del siglo XIX consistió en definir un modelo de análisis taxonómico de la lengua materna, caracterizado por la novedad y complejidad de un aparato de clasificaciones y nomenclaturas formado para designar y ordenar jerárquicamente las partes constitutivas de la disciplina. Hemos sugerido que Freire pudo encontrar el precedente más claro de esta metodología taxonómica en la obra del 
portugués Adolpho Coelho, quien a su vez aplica al análisis de su lengua materna algunos fundamentos naturalistas divulgados por Schleicher.

Las innovaciones propuestas en la obra de Freire repercutieron hasta finales del siglo, no solo por las más de ocho ediciones que llegaron a publicarse sino también por servir de referencia a las gramáticas posteriores, especialmente a la de Maciel (18871-18942).

\subsection{El modelo brasileño de gramática normativa: Grammatica Portugueza de Júlio Ribeiro $\left(1881^{1}-1885^{2}\right)$}

Antes de proceder al análisis de la Grammatica Portugueza de Júlio Ribeiro (1881 1-18852), es importante ubicarla en la tradición gramatical brasileña, según los estudios historiográficos desarrollados principalmente desde Nascentes (1939) hasta Cavaliere (2002).

Nascentes propuso en 1939 dividir los estudios filológicos brasileños en cuatro periodos:

1) El embrionario, que se extiende desde los principios de la cultura brasileña hasta 1835, fecha de publicación del Compêndio da gramática da língua nacional de Antônio Álvares Pereira Coruja, periodo orientado por el pensamiento lusitano.

2) El empírico, que empieza en 1835, cuando se publica la Coleção de Vocábulos e frases usadas na provincia de S. Pedro do Rio Grande do Sul también de Coruja, hasta 1881, cuando Júlio Ribeiro dio a luz la Grammatica Portugueza.

3) El gramatical, desde 1881 hasta 1939, cuando se fundó la Faculdade Nacional de Filosofia da Universidade do Brasil.

4) A partir de 1939 (Fávero y Molina 2006). 
Otros autores siguen la misma línea de Nascentes (1939) o se basan en ella para proponer sus propias divisiones de los estudios filológicos brasileños, como es el caso de Sílvio Elia (1975) y Guimarães (1996). Otras dos propuestas de periodización se deben, más recientemente, a Azevedo Filho (2000) y Cavaliere (2002).

Sin embargo, pese a las diferencias, la característica común a todas estas propuestas es el reconocimiento de la Grammatica Portugueza de Júlio Ribeiro (1881'-18852) como un punto de inflexión en el siglo XIX. La fecha de su publicación divide, en efecto, los periodos empírico y gramatical (Nascentes 1939), vernacular y científico (Elia 1975), purista y de diferenciación idiomática, y vernacular y de evolucionismo lingüístico (Azevedo Filho 2000) y racionalista y científico (Cavaliere 2002).

A continuación se analizan los aspectos lingüísticos, estructurales, teóricos y metodológicos que han permitido clasificar y caracterizar la Grammatica Portugueza como una obra modélica de la codificación normativa del portugués americano.

\subsubsection{El autor y su obra}

Júlio César Ribeiro Vaughan, periodista, filólogo y romancista, nació en Sabará, Minas Gerais, el 16 de abril de 1845. Era hijo de George Washington Vaughan y Maria Francisca Ribeiro Vaughan, profesora de educación primaria y responsable de sus primeros estudios. Terminó de cursar la enseñanza primaria en esta misma ciudad y a los diecisiete años se trasladó a Rio de Janeiro donde empezó los estudios en la Escuela Militar, que abandonó poco después para dedicarse al periodismo y al magisterio. En la ciudad de Lorena inició su carrera como profesor. Más tarde se mudó a Campinas, donde compaginó la docencia con el periodismo. Este último ha sido, quizá, su campo de actividad intelectual más constante. Colaboró en el Estado de São Paulo, en el Diário Mercantil, en la Gazeta de Campinas, en el Almanaque de São Paulo, donde publicaba sus 
estudios sobre filología. En São Paulo también fundó los periódicos A procelária y O rebate. En esta misma ciudad impartió la asignatura de latín en la Facultad de Derecho y la de Retórica en el Instituto de Instrucción Secundaria. Falleció en 1890 víctima de tuberculosis.

La producción bibliográfica de Ribeiro está compuesta por novelas, como Padre Belchior Pontes (1867/ 1868), en dos volúmenes; Cartas Sertanejas (1885); A carne (1888), obra polémica para su época pues trata los temas del amor libre y el divorcio. También publicó algunos estudios lingüísticos, como Traços Gerais de Lingüística (1880); Procelárias e Holmes Brasileiro o Gramática da Puerícia (1887). Esta última es la traducción de la Introduction to English Grammar de G. F. Holmes y, finalmente, la Grammatica Portugueza, impresa en 1881, obra con una única revisión hecha por el autor, publicada en 1885 en su versión definitiva.

\subsubsection{Fundamentos gramaticográficos de Ribeiro}

Júlio Ribeiro en su Grammatica Portugueza pretende romper con la tradición grecolatina con la corriente racionalista que había caracterizado las gramáticas decimonónicas brasileñas que le precedieron. El autor señala en la introducción:

As antigas grammaticas portuguezas eram mais dissertações de métaphysica, do que exposições dos usos da lingua. Para afastar-me da trilha batida, para expôr com clareza as leis deduzidas dos factos e do fallar vernáculo, não me poupei a trabalhos (Ribeiro 1899[1885]: I - Prefacio de la segunda edición).

Este planteamiento de Ribeiro demuestra que el objetivo de la obra es proporcionar una gramática que no se centre en discusiones teóricas acerca de la lengua y del lenguaje, sino que describa los usos y los hechos lingüísticos 
de manera objetiva. También queda claro en esta afirmación que el uso al que se refiere el autor es el de la lengua vernácula.

El gramático no explicita a qué público va dirigido el estudio. No obstante, algunos datos permiten comprender que el alcance de su trabajo era la instrucción pública. En particular, resulta significativa la presencia de dos notas que acompañan el prefacio. Una es un fragmento de una carta de Antonio José Viale, representante de la comisión de instrucción pública que elogia la Gramática. La otra nota es un dictamen de la propia comisión para avalar la obra y ponderar la nueva base teórica adoptada por Ribeiro. Estos textos, fechados ambos en 1882, un año después de la publicación de la primera edición de la Gramática, fueron incluidos en la segunda edición, de 1885. Las citas siguientes revelan estas opiniones favorables hacia la obra de Ribeiro:

Fragmento de uma carta do conselheiro Antonio José Viale ao Exmº Sr. Dr. Rozendo Muniz.

"Li com grande satisfacção a nova Grammatica Portugueza do professor paulista $\left({ }^{15}\right)$ o Sr. Júlio Ribeiro. Aprendi nella muita e muita cousa. Na minha opinião, leva a palma a quantas grammaticas portuguezas conheço, algumas das quaes tenho approvado na junta central de instrucção publica, de que sou vogal."

Parecer e projecto da Comissão de instrucção publica, apresentado á Camara dos Deputados, em 12 de Setembro de 1882; Relator Ruy Barbosa. Pagina 172; nota:

Louvores ao nosso distincto philologo, o Sr. Júlio Ribeiro, pela intelligencia com que comprehendeu e traduziu esta nova direcção (a de Whitney) dos estudos grammaticaes (...) (Ribeiro 1899[1885]: IV).

Respecto a la finalidad del estudio de la gramática el mineiro asevera:

Ha muitos outros pontos de vista sob os quaes é util o estudo da gramática. Nós começamos a aprendizagem da falla (...). Um pouco mais tarde, (...) temos de escrevel-as. Será então dever nosso usar da linguagem, não só com correcção, mas tambem de modo que agrade aos outros, que

\footnotetext{
15 Júlio Ribeiro era mineiro [nota de la $5^{a}$ edición].
} 


\begin{abstract}
sobre elles exerça influencia. Muitas pessôas terão ainda de aprender linguas estranhas, linguas que servem aos mesmos fins a que serve a nossa, mas de modo diverso. Nós temos mais de estudar as fórmas varias porque passou a nossa lingua, temos de comparar essas fórmas com a fórma actual, para que melhor entendamos o que esta é e como veiu a ser o que é. Não nos basta usar a linguagem; é mister saber o que constitue a linguagem, e o que ella nos importa. $O$ estudo da linguagem diz-nos muito sobre a natureza e sobre a historia do homem. Como a linguagem é o instrumento e o meio principal das operações da mente, claro está que não podemos estudar essas operações e a sua natureza sem um conhecimento cabal da linguagem (Ribeiro 1881: 1-2 [la negrita es mía]).
\end{abstract}

Es de notar que el autor brasileño añade nuevas atribuciones a la gramática que aún no habían sido consideradas en esta tradición. Por una parte, Ribeiro pone de relieve la función comunicativa y, especialmente, social de la lengua, lo que permite afirmar que su interpretación del lenguaje traspasa la concepción de una simple producción mental individual y más bien depende de los factores sociales que intervienen en las interacciones entre hablantes y oyentes.

Por otra parte, el mineiro manifiesta la importancia del conocimiento del lenguaje y del estudio de los diferentes aspectos que conforman una lengua, incluidos los históricos y contrastivos. Según el autor brasileño, el avance de las investigaciones acerca del lenguaje tiene como consecuencia el entendimiento de la propia naturaleza humana.

No obstante, hay que poner de manifiesto que el avance de la nueva definición de Ribeiro respecto a la finalidad del estudio gramatical está en la aplicación de los conceptos presentados en la Essentials of English Grammar de William Dwight Whitney (1877). La adopción de esta nueva perspectiva por parte del gramático brasileño permite extender la finalidad de la gramática a las esferas comunitativa y social. Además, supone una cierta apertura a nuevos pensamientos teóricos como la corriente historicista. La definición de la Grammatica Portugueza no difiere mucho de la que propone Whitney, como se puede ver a continuación: 
14. Then there are many other respects in which the study of grammar is useful.

At the very beginning of language-learning, we have to learn to understand the words which we hear others make. Then we learn to make them ourselves, and to put them together correctly - that is, in the same way that others do - in order to express our thoughts and fe elings. A little later, we have to learn to understand them as they are put before our eyes, writen or printed; and then to make them in the same way, - that is, to read and spell and write: and this also correctly, or as other people do. But then we want to use our English not only correctly, but well, so as to please and influence others. Many of us, too, want to learn other languages than English, languages which answer the same purposes as our own, but have other means of doing it. Or, we want to study some of the other forms of English, and to compare them with our own, so as to understand better what it is, and how it came to be what it is. We are not content, either, wth merely using language; we want to know something of what language is, and realice what it is worth to us. The study of language has a great deal to tell us about the history of man, and of what he has done in the world. And as language is the instrument of the mind's operations, and the principal means by which they are disclosed, we cannot study the mind's workings and its nature without a thorough understanding of language (Whitney 1899[1877]: 5 [la negrita es mía]).

A pesar de la novedad de este planteamiento, en el que se refleja la relevancia social del lenguaje en el conocimiento humano, también se puede notar cierta dependencia de la tradición gramatical anterior.

El discurso gramatical de Júlio Ribeiro merece una atención especial por los recursos que utiliza el gramático para construir la norma discursiva de la Grammatica Portugueza. Un análisis superficial del texto, mediante la teoría de la semiótica discursiva de Greimas y Courtés (1979), conduce a interesantes conclusiones sobre el carácter discursivo de este texto. Esta metodología consiste en examinar el discurso gramatical como un discurso temático, en el que figuran dos elementos fundamentales: el que enuncia que en este caso es el gramático, y el destinatario, que se corresponde con el lector o estudiante de gramática.

En pocas palabras, el discurso normativo de una gramática puede basarse en tres tipos de norma: 
1) Norma única o natural: se defiende que la lengua es homogénea, sin variación.

2) Norma prescriptiva: se considera que la lengua es heterogénea pero con variaciones que se diferencian en grados de aceptación.

3) Norma usual o de frecuencia de uso: se admite que la lengua es heterogénea y que las variaciones, cuando se dan, consisten en frecuencias de uso diferentes (Pessoa de Barros 2005).

Pues bien, Ribeiro admite la existencia de distintas normas discursivas, la brasileña, la portuguesa, las regionales, las de diferentes grupos sociales y de usos actuales y arcaicos. No obstante, se explicita en la introducción que la Gramática se ocupa de la variante estándar, si bien en algunos casos esta variedad no es la más difundida. Asimismo, tanto en notas a pie de página como en el cuerpo mismo del texto, el gramático se ocupa muchas veces de explicar determinadas desviaciones de la norma, pero sin emitir juicios de valor. Así por ejemplo:

O artigo serve tambem para uma construcção especialissima da lingua portugueza; junta-se a um adjectivo ou substantivo de qualificação, que se prende pela preposição de a um nome de individuo que se queira qualificar energicamente, ex.: "O bom do homem -a pobre da mulher -O tratante do alfaiate -a burra da criada".

Esta construcção é familiar e não se usa em estylo elevado (Ribeiro 1899[1885]: 231-232 [la negrita es mía]).

De este modo, se puede afirmar que la norma discursiva de la Grammatica Portugueza pretende comprender tanto la norma de tipo prescriptiva, que privilegia la variante estándar, rasgo esperable de una gramática destinada a la enseñanza, como la de tipo usual, propia de una gramática descriptiva, aunque esta última tiene menor presencia. 


\subsubsection{El corpus literario}

Los ejemplos y el corpus que utiliza el gramático son parte importante de la Grammatica Portugueza. Aunque predominan los ejemplos elaborados por el propio autor, la obra se apoya en un corpus literario que cuenta con muy pocas muestras de autores brasileños contemporáneos en comparación con las citas de autoridades portuguesas. La finalidad de los ejemplos propuestos por Ribeiro ha merecido la atención de los estudiosos:

Esse corpus, então, é formado por cem exemplos, dentre os quais trinta são relativos a aspectos dialetais, dezesseis a registros, vinte à variação temporal e trinta e quatro a referências gerais a propósito do uso, da prática lingüística (Quadros Leite 2005: 105).

Sin embargo, el análisis de las citas textuales ha pasado desapercibido. Por nuestra parte, los datos que se han cotejado en la Grammatica Portugueza respecto a las autoridades literarias seleccionadas por el gramático son los siguientes: un total de 37 autoridades de las que 30 son de nacionalidad portuguesa, 4 de nacionalidad brasileña y 3 de otras partes de Europa. De estos 37 autores 15 pertenecen al siglo XIX, 1 al XVIII, 4 al XVII, 7 al XVI, 2 al XV, 3 son anteriores a este último periodo y en 5 de ellos no fue posible determinar el periodo por falta de datos.

Estos datos reflejan la presencia bastante superior de los autores contemporáneos frente a los clásicos. Podría, pues, afirmarse que la norma literaria predominante en la obra es más contemporánea que clásica. No obstante, el número de ejemplos de cada autor contradice esta deducción. Son en torno a 25 ejemplos de diferentes escritores del siglo XIX, mientras que los ejemplos de autores clásicos de los siglos XVI y XVII, como Camões (1572) y Gil Vicente $(1502,1510,1523$, etc.), sobrepasan ampliamente esta cifra. 
Las tres autoridades medievales son Gregorio de Tours (550), Dom Diniz (1300) y Santa Rosa Viterbo (1233). Sus citas ilustran explicaciones sobre la evolución de la lengua portuguesa a partir del latín.

En cuanto al breve corpus literario brasileño, solo consta de cuatro escritores del siglo XIX. Uno de ellos es el propio gramático que cita su propio libro Padre Belchior de Pontes (1876). La timidez de esta cifra puede ser explicada por la precariedad de la tipografía brasileña. En la primera mitad del siglo XIX solo había dos imprentas en todo el país.

En definitiva, tan solo por los corpora de autoridades utilizado por Ribeiro, no se puede identificar y caracterizar con exactitud el uso que se hace del portugués brasileño en el siglo XIX, pues la subordinación al portugués europeo es todavía muy notable. Las muestras expuestas por el gramático son reflejo de aquella realidad lingüística.

\subsubsection{Concepto de lengua}

Ribeiro aplica al estudio del portugués los conocimientos más avanzados de su época. En particular, las investigaciones darwinistas sobre el origen y evolución de las especies habían dado lugar a comparaciones entre la evolución de las lenguas y la vida de los organismos. Respecto a sus ideas evolucionistas, deja patente, principalmente en su explicación sobre la etimología, la concordancia con los supuestos de Ferrière (1872):

Bem como as especies organicas que povôam o mundo, as linguas, verdadeiros organismos sociologicos, estão sujeitas á grande lei da lucta pela existencia á lei da selecção. E é para notar-se que a evolução linguistica se effectua muito mais promptamente do que a evolução das especies: nenhuma lingua parece ter vivido por mais de mil annos, ao passo que muitas especies parece terem-se perpetuado por milhares de séculos (Ribeiro 1881: 142). 
En la afirmación queda patente la concepción defendida en la Grammatica acerca de la lengua, su origen y evolución. Este organismo sociológico, como el propio autor denomina a la lengua, se desarrolla a partir de las influencias e interacciones culturales y sociales. Ribeiro presenta dos cuadros comparativos, extraídos de la obra Le darwinisme (1872), para demostrar que los factores que influyen en la selección y clasificación genealógica de las especies son los mismos que pueden aplicarse a las lenguas. Este es uno de ellos:

\section{A SELECÇÃO}

\begin{tabular}{|l|l|}
\hline \multicolumn{1}{|c|}{ nas especies } & \multicolumn{1}{|c|}{ nas linguas } \\
\hline $\begin{array}{l}\text { 1) As especies têm suas variedades, } \\
\text { obra do meio ou de cousas } \\
\text { physiologicas. }\end{array}$ & $\begin{array}{l}\text { 1) As linguas têm os seus dialectos, obra } \\
\text { do meio ou dos costumes. }\end{array}$ \\
\hline $\begin{array}{l}\text { 2) As especies vivas descendem } \\
\text { geralmente das especies mortas do } \\
\text { mesmo paiz. }\end{array}$ & $\begin{array}{l}\text { 2) As linguas vivas descendem } \\
\text { geralmente das linguas mortas do } \\
\text { mesmo paiz. }\end{array}$ \\
\hline $\begin{array}{l}\text { 3) Uma especie em um paiz isolado } \\
\text { passa por menos variações. }\end{array}$ & $\begin{array}{l}\text { 3) Uma língua em um paiz isolado passa } \\
\text { por menos variações. }\end{array}$ \\
\hline $\begin{array}{l}\text { 4) Variações produzidas pelo } \\
\text { cruzamento com especies distinctas ou } \\
\text { extrangeiras. }\end{array}$ & $\begin{array}{l}\text { 4) Variações produzidas pela } \\
\text { introducção de palavras novas, devidas } \\
\text { ás relações exteriores, ás sciencias, á } \\
\text { industria. }\end{array}$ \\
\hline $\begin{array}{l}\text { 5) A superioridade das qualidades } \\
\text { physicas que asseguram a victoria dos } \\
\text { individuos de uma especie, causa da } \\
\text { selecção. }\end{array}$ & $\begin{array}{l}\text { 5) } \text { publica cenio litterario e a instrucçãontralizada, causas da } \\
\text { selecção. }\end{array}$ \\
\hline $\begin{array}{l}\text { 6) A belleza da plumagem ou a melodia } \\
\text { do canto, causa da selecção. }\end{array}$ & $\begin{array}{l}\text { 6) A brevidade ou a euphonia, causa da } \\
\text { selecção. }\end{array}$ \\
\hline $\begin{array}{l}\text { 7) Lacunas numerosas nas especies } \\
\text { extinctas. }\end{array}$ & $\begin{array}{l}\text { 7) Lacunas numerosas nas linguas } \\
\text { extinctas. }\end{array}$ \\
\hline $\begin{array}{l}\text { 8) Probabilidades de duração de uma } \\
\text { especie em o numero dos individuos } \\
\text { que a compõem. }\end{array}$ & $\begin{array}{l}\text { 8) Probabilidades de duração de uma } \\
\text { língua em o numero dos individuos que a } \\
\text { fallam. }\end{array}$ \\
\hline $\begin{array}{l}\text { 9) As especies extinctas não } \\
\text { reapparecem mais }\end{array}$ & $\begin{array}{l}\text { 9) As linguas extinctas não reapparecem } \\
\text { mais. }\end{array}$ \\
\hline $\begin{array}{l}\text { 10) Progresso nas especies pela divisão } \\
\text { do trabalho physiologico. }\end{array}$ & $\begin{array}{l}\text { 10) Progresso nas linguas pela divisão do } \\
\text { trabalho intelectual. }\end{array}$ \\
\hline
\end{tabular}

(Ferrière 1872: 121- 123 apud Ribeiro 1881: 142-143) 
Los principios evolucionistas se manifiestan en la Grammatica Portugueza a través de la aplicación a los estudios lingüísticos de los mismos métodos científicos utilizados en las ciencias naturales. Por ello, el autor atiende a los orígenes de la lengua, en un análisis diacrónico que se dirige al estudio de las formas escritas y a la valoración de la etimología (Fávero 2006: 130).

Morpurgo Davies (1992) en su artículo para la International Encyclopedia of Linguistics sobre la lingüística histórico-comparativa trata, entre otros temas, de la clasificación del lenguaje y aclara que esta disciplina fue inspirada e influenciada directamente por las ciencias naturales, lo que demuestra que el autor brasileño estaba al tanto de las teorías de Schlegel:

Language classification was inspired by the model of the natural sciences. Initially at least, the distinction between genealogical affinity and typological similarity was blurred. Both were based on morphological comparison-until it was made clear that, for genealogical purposes, it was necessary to compare the phonological form of functionally similar elements; for typological analysis, what mattered was the general structure. In 1808, Friedrich Schlegel argued that the basic distinction was that of "inflected" (or "organic") languages vs. "non-inflected" languages (Morpurgo Davies 1992: 161).

No solo el prólogo confirma las corrientes teóricas a las que sigue el gramático. Nombres como C. Ayer (1825-1884), Max Müller (1823-1900), Allen and Cornwell (1865) y F. Diez (1794-1876) son constantemente citados para justificar el punto de vista defendido por Ribeiro frente a las perspectivas gramaticales que le anteceden. Básicamente, el gramático utiliza a estos autores como autoridades teóricas para avalar las teorías y métodos gramaticales en los que se basa para componer su obra.

Un análisis más profundo de la Grammatica Portugueza demuestra que la influencia del pensamiento positivista, evolucionista y los supuestos de la gramática histórico-comparada no afectan solamente a la estructura y división de la obra, pues determinan también las definiciones, la elección y análisis de los ejemplos y los razonamientos sobre el uso del portugués. 
La perspectiva de los neogramáticos se presenta más fuertemente en las definiciones, como es el caso de Whitney. El método comparativo, por su parte, es evidente en la aplicación de las leyes de Grimm y el método histórico está más presente en la etimología. Pese a todas estas novedades metodológicas, la Gramática no pierde su carácter normativo.

\subsubsection{Definición de la gramática}

Júlio Ribeiro define la gramática como «exposição methodica dos factos da linguagem», traducción de la proposición de Whitney para ese término en la Essentials of English Grammar (1887: 4-5), «English grammar is a description of the usages of the English language in this sensel, y seguidamente explica la finalidad de esta disciplina utilizando las palabras del gramático estadounidense:

A grammatica, não faz leis e regras para a linguagem; expõe os factos della, ordenados de modo que possam ser aprendidos com facilidade. 0 estudo da grammatica não tem por principal objecto a correção da linguagem. Ouvindo bons oradores, conversando com pessoas instruidas, lendo artigos livros bem escriptos, muita gente consegue fallar e escrever correctamente, sem ter feito estudo especial de um curso de grammatica. Não se pode negar, todavia, que as regras do bom uso da linguagem, expostas como ellas o são nos compendios, facilitam muito tal aprendizagem; até mesmo o estudo dessas regras é o único meio que têm de corrigir-se os que na puericia aprenderam mal a sua língua (Ribeiro 1881: 1 [la negrita es mía]).

Al trasladar a su obra el concepto de Whitney (1877) de que la gramática tiene como objetivo exponer los hechos lingüísticos y no corregir o formular leyes o reglas sobre el lenguaje, el autor hizo notoria su intención de aplicar las premisas de la gramática descriptiva, que se ocupa de la descripción de los fenómenos lingüísticos sin emisión de juicios o intento de establecimiento de reglas o normas sobre el lenguaje y su uso. 
A diferencia del gramático americano, Júlio Ribeiro opta por un punto de vista más moderado, pues Whitney considera que la gramática «only reports the facts of good language $\left.{ }^{16}\right)$. No obstante, aún se reflejan las ideas de la gramática tradicional, como, por ejemplo, cuando afirma que hay una forma correcta de escribir y de hablar, que esta forma correcta está expuesta en los compendios, que éstos, consecuentemente, enseñan el buen uso del lenguaje y facilitan su aprendizaje, y que el estudio de la gramática es el único medio de corrección de los hablantes. Tampoco pierde su carácter prescriptivo puesto que, para el autor, las reglas expuestas en la obra facilitan y mejoran la lengua del hablante. Aunque, para él, el buen uso de la lengua no necesariamente está relacionado con la enseñanza de la gramática y puede ser adquirido por otras vías.

En la definición de la gramática presentada por el mineiro se manifiesta la influencia de las nuevas ideas y el intento de romper con el pensamiento logicista de la primera mitad del siglo XIX. La relación entre norma y descripción en la Grammatica Portuguesa se plantea frecuentemente en términos como los de Silva (2006):

Evidentemente, (...), pode haver divergências de concepção e fatura, intersecções profundas e contatos superficiais entre $O$ que aqui consideramos descritivismo, por um lado, e normativismo, por outro. A bem da verdade, parece ponto pacífico entre os pesquisadores do assunto ou para o observador mais atento o fato de que toda gramática normativa apresenta certo grau de descrição da língua, da mesma maneira que qualquer gramática descritiva, ainda que não seja esse seu propósito final, traz subentendido modos exemplares de atualização lingüística (Maurício Silva 2006: 3).

Esta tendencia de pretender compatibilizar los argumentos de la tradición y las nuevas proposiciones positivistas es común en las gramáticas brasileñas a finales del siglo XIX. Hecho notable en los tratados de Pacheco da

\footnotetext{
16 Esta expresión viene definida en la Essentials of English Grammar como "those words and those meanings of them, and those ways of putting them together, which are used by the best speakers, the people of best education" (Whitney 1877: 3).
} 
Silva Jr. y Lameira de Andrade (1887), Alfredo Gomes (1887), João Ribeiro (1887) e incluso Augusto Freire (1875'-18772), el único que antecede a Ribeiro, en cuya Gramática es notable la presencia, aunque tímida, de la lingüística históricocomparada, o bien en algunas definiciones o bien en la sistematización de los contenidos.

Así por ejemplo, en los Annexos de la Gramática, Ribeiro no solo se dedica a la comparación de las lenguas románicas, sino también al planteamiento de cuestiones cuyas respuestas, según el autor, están en la lingüística histórico-comparada. Se ha de mencionar, particularmente, la polémica de la cuarta conjugación. No pocas fueron las gramáticas que defendían la existencia de solo tres conjugaciones del verbo en portugués (AR, $E R, I R)$ y que la cuarta conjugación (OR) es contracción de la segunda. De ahí que el verbo por, derivado de poer, fuera considerado de la segunda y no de cuarta. Ribeiro no desmiente la segunda afirmación, más bien la complementa al advertir que, pese a su derivación, el verbo por y sus compuestos presentan una flexión propia, de modo que forman por separado otra conjugación, más por praxis y por uso que por teoría y ciencia.

\subsubsection{División de la Grammatica Portugueza}

En la segunda mitad del siglo XIX un cierto inmanentismo caracteriza los estudios lingüísticos en Brasil, frente a la tradición de principios del siglo que preconizaba como eje gramatical el pensamiento lógico. Por consiguiente, se avanza en la noción de las relaciones sintácticas, pues dejan de ser especulaciones metafísicas para analizarse mediante criterios formales. Esta concepción se presenta por primera vez en la Grammatica Portugueza de Augusto Freire (18751-18772), que segmenta la sintaxis en syntaxe de palavra y syntaxe de proposições. Esta división es retomada pocos años después en la Grammatica Portugueza de Júlio Ribeiro en 1881. 
En esta línea, la Grammatica Portugueza de Ribeiro se divide en dos partes: la primera es denominada lexeologia que «considera as palavras isoladas, já em seus elementos materiais ou sons, já em seus elementos morphicos ou fórması (Ribeiro: 1881: 3). A su vez, el autor divide la Lexeologia en:

1) Phonologia, que, por su parte, comprende la phonetica, la prosodia y la orthographia.

2) Morphologia, que incluye la taxeonomia, la kampenomia o Ptoseonomia y la etymologia.

Tales innovaciones terminológicas y el esfuerzo del autor por establecer esta clasificación se muestran en fragmentos como los siguientes:

Phonologia é o tratado dos sons articulados.

A phonologia considera os sons articulados:

1) isoladamente, como elementos constitutivos das palavras [phonetica];

2) aggrupados, já constituídos em palavras [prosodia];

3) representados por simbolos [orthographia] (Ribeiro 1881:3).

Morphologia é o tratado das fórmas que tomam as palavras para constituir a linguagem.

A morphologia considera as palavras sob a relação de fórma

1) como constituindo grandes grupos de idéias de que se compõe o pensamento [taxeonomia];

2) como entidades phonicas, que se modificam individualmente, para representar cada Idea em particular [kampenomia o ptoseonomia];

3) como originando-se umas das outras [etymologia] (Ribeiro 1881:51).

Cavaliere (2000) ha puesto de relieve el interés de esta parte de la Grammatica de Ribeiro:

A lexeologia é certamente, no projeto de descrição gramatical proposto por Ribeiro, a célula de onde reverberam todos os campos da investigação lingüística. Isso porque é efetivamente a palavra que sintetiza o foco das atenções, seja como elemento monolítico isolado, seja enquanto conjunto 
de segmentos morfológicos, seja como item da organização frasal. (Cavaliere 2000)

La segunda parte trata de la sintaxis que "considera as palavras como relacionadas umas com as outras na construção de sentenças, e considera as sentenças no que diz respeito á sua estructura, quer sejam simples, quer se componham de membros ou de clausulası (Ribeiro 1881: 193). Según el gramático, pueden distinguirse dos tipos de sintaxis: la léxica y la lógica que analizan, respectivamente, la relación de las palabras entre sí y la relación de las oraciones simples o compuestas.

Además, también forman parte de la sintaxis las regras de syntaxe, que se ocupa de la concordancia; los additamentos, que tratan de la puntuación, orden de palabras y cláusulas, las reglas de estilo y vicios del lenguaje; y los annexos, que se centran en un estudio histórico del portugués comparado con otros idiomas con el objetivo de justificar algunos fenómenos lingüísticos que causaban controversia entre filólogos y gramáticos.

En las ediciones posteriores a la muerte del autor y, concretamente, en la décima edición de 1911 también hay otro additamento, añadido por los editores, con el objetivo de satisfacer los programas de enseñanza oficial. La sección consta de dos tratados: el primero es un estudio de los sinónimos, homónimos, parónimos y antónimos y el segundo trata de los arcaísmos, neologismos e hibridismos. Como se ha indicado anteriormente, es importante resaltar que tan solo hubo una edición de la Grammatica Portugueza revisada por el propio autor, la de 1885. Así pues, la división de la Gramática se dispone de la siguiente forma: 


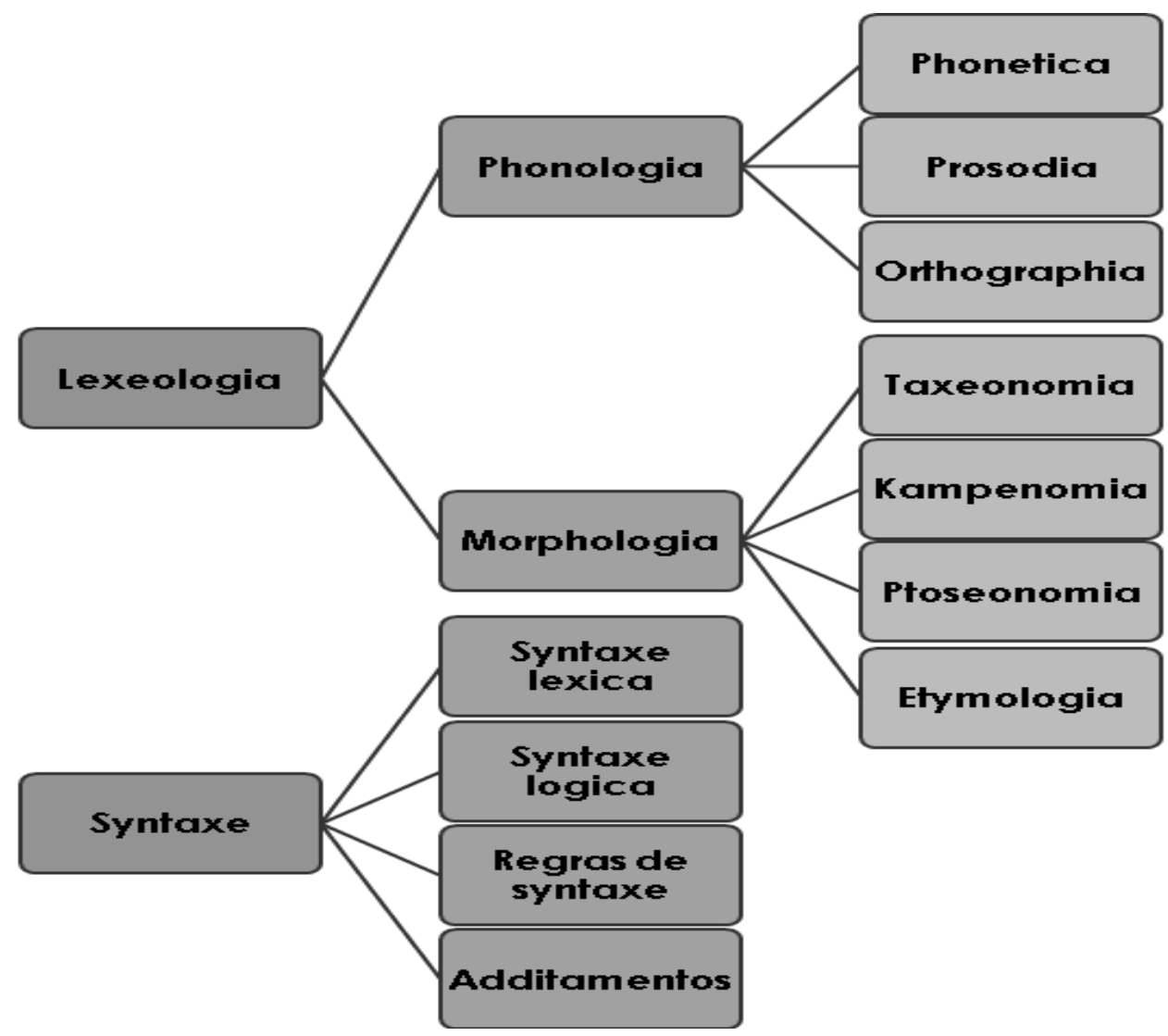

Tabla 5.5 División de la Gramática de Júlio Ribeiro

Acerca de la división de la Gramática, Ribeiro afirma que siguió la corriente de Bain (1863), incluso hace suyas las palabras del autor inglés:

Agora faço minhas as seguintes considerações de Bain, mutatis levemente mutandis: While availing myself <<of the Best works on the English Language, I have kept steadily in view the following plan. Under Etymology (Lexeologia) the three departments: 1st, Classification of Worde or the Parts of Speech (Taxeonomia); 2.nd, Inflexion (Kampenomia); 3.rd, Derivation (Etymologia), have been separately discussed. This method I think better adapted for conveying grammatical information than the older one, of exhausting successively each of the Parts of Speech in all its relations.

For the sake of accurate definition or the Parts of Speech, as well as for General Syntax, the recently introduced system of the Analysis of Sentences is fully explained. On this subject the method given by Mr. C. P. Mason has been principally followed >> (Ribeiro 1899[1885]: II-III). 
Júlio Ribeiro es el primer gramático brasileño que propuso esta división de la Gramática en dos partes. Entre sus antecesores, la gramática solía constar de tres partes (lexiología, sintaxis, semiología o morfología/etimología, sintaxis, sonidos y letras [prosodia, fonética y ortografía]), como es el caso de Augusto Freire (18751-18772) y Moraes Silva (1806), respectivamente. Pero no faltan autores más próximos a la tradición clásica que mantuvieron las cuatro partes de la gramática (ortografía, prosodia, etimología, sintaxis o ortoepía, ortografía, etimología, sintaxis), como es el caso de Frei Caneca (1817), Coruja (1835) y Sotero dos Reis (1865).

En la tabla siguiente se puede observar la evolución de la división de la gramática en la tradición brasileña hasta Júlio Ribeiro:

\begin{tabular}{|c|c|c|c|c|c|c|}
\hline $\begin{array}{c}\text { Moraes Silva } \\
\mathbf{( 1 8 0 6 )}\end{array}$ & $\begin{array}{c}\text { Frei Caneca } \\
\mathbf{( 1 8 1 7 )}\end{array}$ & $\begin{array}{c}\text { Coruja } \\
\mathbf{( 1 8 3 5 )}\end{array}$ & $\begin{array}{c}\text { Grivet } \\
\mathbf{( 1 8 6 5 )}\end{array}$ & $\begin{array}{c}\text { S. dos Reis } \\
\mathbf{( 1 8 6 6 )}\end{array}$ & $\begin{array}{c}\text { A. Freire } \\
\mathbf{( 1 8 7 5 )}\end{array}$ & $\begin{array}{c}\text { J. Ribeiro } \\
\mathbf{( 1 8 8 1 )}\end{array}$ \\
\hline $\begin{array}{c}\text { Livro I: das } \\
\text { palavras... }\end{array}$ & Etimología & Etimología & Lexiología & Etimología & Lexiología & Lexiología \\
\hline $\begin{array}{c}\text { Livro Il: da } \\
\text { composição... }\end{array}$ & Ortografía & Ortografía & Sintaxis & Ortografía & Sintaxis & Sintaxis \\
\hline & Prosodia & Prosodia & Ortografía & Prosodia & Semiología & \\
\hline & Sintaxis & Sintaxis & Prosodia & Sintaxis & & \\
\hline & & & Puntuación & & & \\
\hline
\end{tabular}

Tabla 5.6 Modelos de división de la gramática en la tradición brasileña

La división de la Gramática en dos partes, dedicadas a las palabras y a las oraciones, respectivamente, está inspirada también en otras gramáticas europeas contemporáneas al trabajo de Ribeiro, a las que él mismo cita como referencia. El autor brasileño incluye entre sus fuentes a Burgraff, Principes de Grammaire Générale (1863), Allen and Cornwell, English Grammar (1865), C. Ayer, Grammaire Comparée de la Langue Française (1876), Bastin, Étude Philosophique de la Langue Française (1878) y Chassang, Nouvelle Grammaire Grecque (1876). En este momento, la sintaxis no solo deja de ser el «finis 
grammaticae») (Brocense 1587) sino que pasa a formar parte de ella (Fávero y Molina 2006).

Pese a las fuentes citadas como referencia para justificar la estructura de la Gramática, conviene advertir que este sistema figura, entre otras, en teorías lingüísticas francesas del siglo XVIII de carácter logicista. Beauzée (1717-1789) ya defendía, antes mismo de Burgraff (1863), C. Ayer (1825-1884) y otros, que la gramática era equivalente a la ortología que, a su vez, está compuesta por la lexicología y la sintaxis. Además, el propio Moraes Silva (1806), de acuerdo con el logicismo, ya dividía la gramática en dos partes, aunque adoptaba otra terminología (véase $\$ 5.1$ ).

Así pues, el contenido de la Grammatica Portugueza se organiza y se divide en lexeologia y syntaxe, con 217 y 133 páginas respectivamente. Esta última ocupa entonces $38 \%$ de la obra mientras que la lexeologia ocupa un 72\%. El estudio sintáctico no alcanza pues, todavía, la mitad de la Gramática.

Las principales fuentes utilizadas por el gramático vienen destacadas en el prefacio de la segunda edición. Para las definiciones de las partes de la Gramática, sigue a Burgraff (1863) en la primera edición. En la segunda, el propio autor asegura seguir más de cerca de Whitney (1827-1894) por su claridad y precisión:

Abandonei por abstractas e vagas as definições que eu tomára de Burgraff: preferi amoldar-me ás de Whitney, mais concretas e mais claras (Ribeiro 1899[1885]: I-II).

Respecto a la sistematización de la sintaxis, declara seguir también a Whitney y a otros autores alemanes e ingleses:

O systema de syntaxe é o systema germanico de Becker. Modificado e introduzido na Inglaterra por C. P. Mason, e adoptado por Whitney, por Bain, por Holmes, por todas as summidades da grammaticographia saxônia (Ribeiro 1899[1885]: II). 
También destaca en la Grammatica la influencia de los estudios de Bréal (1832-1915), por ejemplo, en esta cita sobre los modos del verbo y las formas nominales de infinitivo y partipicio:

A este respeito diz o grande philologo indianista, Sr. Miguel Bréal (17): "Há erros mais graves que se deveriam expungir dos livros de estudos. Esses erros imbuem no espírito de nossos meninos idéias que 'prejudicam mais tarde a intelligencia da syntaxe.

Nada é mais simples que a noção do modo, si nos limitamos ao 'indicativo, ao imperativo e ao subjuntivo'. O modo, diremos nós ao menino, muda conforme a maneira por que se apresenta a proposição (Ribeiro 1881: 76).

Las nuevas aportaciones a los estudios gramaticales portugueses están representadas principalmente por Adolpho Coelho (1847-1919). Ribeiro valora positivamente las investigaciones del gramático portugués, además de resaltar la importancia de otros autores como Lefèvre:

Pelo que respeita a Adolpho Coelho, pergunto: quem poderá escrever hoje sobre philologia portugueza, sem tomal-o por guia, sem se ver forçado a copial-o a cada passo?

Apresento ao publico esta segunda edição de meu livro, escudando-o com os louvores de três homens venerados, Ruy Barbosa, o conselheiro Viale, André Lefèvre (Ribeiro 1899[1885]: III).

Es de notar que la mayoría de los autores citados por el gramático han bebido en las mismas fuentes: Grimm (1785-1863), Humboldt (1767-1835), Bopp (1791-1867), entre otros filólogos del siglo XIX, representantes de la lingüística histórica y comparada. El pensamiento gramatical que aflora en Europa en este momento llega a Brasil a través de la Grammatica Portugueza y, como consecuencia de ello, desencadena una renovación y, por qué no decir, una revolución lingüística y gramatical.

17 Mélanges de Mythologie et de Linguistique, Paris, 1877 pag.328-329 [nota del gramático]. 


\subsubsection{El tratamiento de la lexeología}

La primera parte de la Gramática denominada lexeologia por el autor, tiene como objeto de estudio la palabra en cuanto a:

1) La materia, que puede ser fonética o prosódica y ortográfica.

2) La forma, que puede ser discursiva o interjectiva. El agrupamiento de la fonología y la morfología en una misma sección demuestra que el gramático ha considerado relevante el concepto nuclear del análisis gramatical que, en este caso, se asienta en la palabra (Cavaliere 2000).

La fonética, uno de los elementos materiales de la palabra (Ribeiro 1881: 3), se define como «tratado dos sons articulados, considerados em sua maxima simplicidade, como elementos constitutivos das palavrası (Ribeiro 1881: 3). En este punto, el autor brasileño sigue a Bergman (1875: 261) en su Résumé d'Études d'Ontologie Générale et de Linguistique Générale.

En este apartado el gramático, además de tratar de la naturaleza del aparato fónico humano y la producción de los sonidos que constituyen las palabras, también critica a los gramáticos anteriores en la distribución de los elementos fonológicos. En su crítica a Duvivier (1873) y Soares Barbosa (1822), argumenta Júlio Ribeiro:

A velha distribuição dos elementos phonologicos em sons simples e em articulações, em vozes e em consonancias, provém da observação imperfeita que dos phenomenos de vocalização têm feito os grammaticos (18) (Ribeiro 1881:5).

La crítica reside en que anteriormente los gramáticos consideraban las consonancias (sonido representado gráficamente por consonantes) como sonidos equiparados a las voces. Sin embargo, para el autor, las consonancias

18 Girault Duvivier, Grammaire des Grammaires, edition de Lemaire, Paris, 1873, vol. I, pág. 4 [nota del gramático]. 
son ruidos que no pueden ser pronunciados sin estar asociados a una voz (sonido representado gráficamente por vocales). Ribeiro trata de ratificar tanto su punto de vista en cuanto a la distinción entre vozes e consonancias como las críticas a Duvivier y a Soares Barbosa. Para manifestar esta superación del antiguo tratamiento de los sonidos, el gramático cita a Max Müller (1867):

Os grammaticos da India conheceram e discriminaram bem estes factos: ás vozes chamaram elles svara (sons), ao passo que ás pretendidas consonancias deram o nome de vyanjana (o que torna distinto, o que manifesta) (19) (Ribeiro 1881:5).

A partir de esta hipótesis, Ribeiro propone que las consonancias (de latín cum sonare) son voces modificadas por el aparato fónico y las divide en livres, contrictas y explodidas.

Además, en esta primera parte de la Gramática, el autor analiza la pronunciación del portugués en Portugal y en Brasil, lo que pone de manifiesto la importancia que va adquiriendo en este periodo la lengua nacional. El tratamiento de estas variedades revela el creciente interés en distinguir el portugués de Brasil del de la antigua metrópolis. Aunque todavía, la variante brasileña no sea objeto central de estudio, se observa que comienzan los autores -como Ribeiro- a prestarle atención y, posteriormente, será considerada incluso, como una nueva lengua, independiente del portugués europeo.

Os caipiras de S. Paulo pronunciam djente, djogo. Os mesmos e também os Minhotos e Trasmontanos dizem tchapéo, tchave (Ribeiro 1881:9).

La prosodia constituye la segunda sección del estudio sobre la lexeologia. El autor define esta parte como «o tratado dos sons articulados em relação á sua intensidade comparativa, quando constituidos em palavras) (Ribeiro 1881: 10). A partir de las teorías de Balmes (1872), F. Diez (1794-1876), el autor profundiza su razonamiento sobre la constitución de la palabra.

19 MAX MÜLLER, Nouvelles Leçons sur la Science da Langage, trad. De Harris et Perrot, Paris, 1867 , vol. I, pag. 155 [nota del gramático]. 
Afirma el mineiro que en las lenguas modernas la cantidad vocálica y el acento tónico se confunden y solamente se considera verdaderamente larga la sílaba predominante, es decir, la que lleva el acento tónico, como asienta Sotero dos Reis (1865), J. A. Passos (1865) e incluso A. J. Lobato (1837). De ahí la crítica a Soares Barbosa (1822), quien distinguía en la prosodia entre cantidad vocálica (larga/breve) y acento tónico (grave/agudo), posición también seguida por Alfredo Gomes (1887).

Júlio Ribeiro cierra la segunda sección con una nota sobre la diferencia entre la pronunciación portuguesa y brasileña en la que reitera una vez más la disparidad entre las dos variantes. Verifica que hay dos cambios en la pronunciación del portugués:

1) La synalepha, que consiste en la supresión de la voz livre pura al final de un vocablo por la inicial del vocablo siguiente. Se trata según el autor de una práctica más común en Portugal que en Brasil. Por ejemplo: onde é por ondé, que está por questá.

2) La ecthlipse, que consiste en la supresión de la voz libre nasal de un vocablo por la inicial livre del vocablo siguiente. Ribeiro limita esta variación a la poesía y conversaciones familiares. Por ejemplo: com as por co'as, com os por c'os (Ribeiro 1881: 22).

La ortografía, «tratado da representação symbolica dos sons articulados» (Ribeiro 1881: 22), en este periodo, resulta todavía un obstáculo en los estudios, pues aún no se había consolidado la ortografía de la lengua, pese a los intentos de los gramáticos y la Academia de Portugal:

Não está ainda fixa a orthographia da lingua portugueza; prevalece comtudo nella o elemento etymologico.

Varias tentativas se têm feito para estabelecer em Portuguez a orthographia exclusivamente phonetica; todas têm abortado. 
Ainda ultimamente subiu em Portugal á consideração da Academia Real das Sciencias o parecer de uma commissão que advogava e punha em pratica tal systema ${ }^{20}$ : nada produziu.

Orthographia phonetica em Portuguez é utopia: como muito bem disse o sr. Theophilo Braga ${ }^{21}$ : $<<0$ partidarios da orthographia phonetica representam modernamente na grammatica o papel dos que procuravam a linguagem natural.>> (Ribeiro 1881: 26-27 [la negrita es mía]).

Para Ribeiro, la base de la ortografía es la pronunciación, pero siempre que esta se ajuste a la etimología. De ahí que las reglas ortográficas que el mineiro formula están justificadas bien por la prosodia o bien por el origen de determinadas palabras, de acuerdo con los supuestos de la gramática histórica.

Es interesante notar que en las reglas generales de la ortografía solamente la pronunciación y la etimología, en este orden de importancia, son los criterios presentados por Ribeiro para establecer la grafía de las palabras. El autor no aporta ninguna observación sobre el uso de los hablantes, a no ser en los casos en que hay disparidad entre éste y la prosodia o la etimología. Sin embargo, otros autores como Garret (1869) admitían solamente la etimología como criterio para la ortografía y João Ribeiro (1887) y Alfredo Gomes (1887) aceptaban el criterio etimológico y el fonético, en este orden.

A finales del siglo XIX y principios del XX la polémica ortográfica alcanza proporciones intercontinentales. Algunos reformistas de la lengua, en particular, Gonçalves Vianna y Cândido de Figueiredo, proponen la regulación del sistema ortográfico del portugués y del brasileño separadamente. En este contexto, se tiende a excluir casi totalmente el criterio etimológico y se generaliza la ortografía basada en la pronunciación normal brasileña y la ortografía basada en la pronuncia normal portuguesa, cada una válida solo en su propio territorio.

La reforma fue bastante criticada entre lingüistas, gramáticos y escritores de la época. Unos, los más conservadores, la condenaban totalmente. Otros la aceptaban con suspicacia, dado que algunas reglas contradecían las propias leyes gramaticales.

20 Representação á Academia Real das Ciencias sobre a reforma da Ortografia, Lisbôa, 1878 [nota del gramático].

${ }^{21}$ Grammatica Portugueza Elementar, Porto, 1878, pag. 145 [nota del gramático]. 
Como puede advertirse, la constitución de reglas ortográficas solía ser fuerte motivo de discordancia entre los gramáticos brasileños del siglo XIX. Cada uno establecía un fundamento distinto que apoyara una grafía determinada. Como había diferentes grafías, había, pues, diferentes reglas. Por ejemplo, Garrett (1869) afirmaba que el acento grave estaba excluido del uso general del portugués, mientras que Moraes Silva en su Diccionario da Lingua Portugueza (1877/1878 - 7ª edición) afirmó que algunos lexicógrafos usan esta tilde para marcar los sonidos cerrados. Ribeiro prefiere adoptar solamente cuatro acentos: agudo ('), circunflexo (^), til $(\sim)$ y apostropho ('), y excluye al acento grave (').

La etimología en la Grammatica Portugueza presenta un carácter histórico y evolucionista. El autor se ocupa de la derivación de las palabras en las diversas lenguas y, como ya se ha mencionado, explica que se fundamenta en el supuesto de que las lenguas son organismos como las especies y están sujetas a las mismas leyes. A título de ejemplo, se puede hacer referencia a la relación que se establece en la obra entre el principio biológico del mínimo esfuerzo y el principio de economía lingüística en el caso de la contracción de los sonidos de las vocales. Se trata de un principio básico también de la ley de Grimm (Ribeiro 1881: 144).

Conviene resaltar la interpretación de los términos etimología y analogía que ofrece el autor. En su opinión, la etimología ya no es el tratado de la clasificación de las palabras según sus funciones y propiedades (Soares Barbosa 1822: X), sino que es el estudio del origen y derivación de los vocablos. Entiende por analogía, en cambio, la manifestación de la uniformidad o similitud en determinados rasgos del idioma.

\subsubsection{La clasificación de las palabras}

Ribeiro adopta un criterio semántico para distinguir entre palabras discursivas e interjectivas. Las primeras enuncian ideas y las segundas expresan 
sentimientos (Fávero 2006: 132). Júlio Ribeiro no profundiza en la definición de las palabras interjectivas, solamente expone, brevemente, que las interjecciones son:

A interjeição, grito involuntario, instinctivo, animal, não representa idéa, não constitue parte do discurso, é mais som do que palavra22 (Ribeiro 1881: 52).

La definición de la interjección como clase de palabra o como elemento discursivo fue tema controvertido. A pesar de que la gramática latina, en general, y las tradiciones vernaculares coincidieran en admitirla como clase de palabra, algunos gramáticos siguen otra corriente, lo que resulta ser bastante original en comparación con otros que se inclinaban hacia la tradición. Es el caso de Júlio Ribeiro (1881'1-18852) y Alfredo Gomes (1887), en la tradición brasileña y de Hermosilla (1835), en la tradición gramatical española.

La omisión de la interjección es criticada por Oiticica (1955):

Na impossibilidade de reconhecerem idéia nas interjeições, suprimiramnas da taxionomia, considerando-as simples gritos da alma, sem refletirem que há expressões interjectivas e frases interjectivas com pensamento analisável, como: raios te partam! (Oiticica 1955:50 apud Fávero 2006: 132).

Al excluir la interjección, por no considerarla palabra propiamente dicha, y el participio, por ser parte integrante del verbo, quedan divididas las palabras en ocho categorías en la obra de Ribeiro: el sustantivo, el artículo, el adjetivo, el pronombre, el verbo, el adverbio, la preposición y la conjunción. Las cinco primeras son variables o sujetas a flexión y las tres restantes son invariables o no sujetas a flexión.

El sistema de clases de palabras de la Grammatica Portugueza no es semejante a ningún otro sistema presente en otras gramáticas brasileñas decimonónicas ni anteriores ni posteriores, pues todos los gramáticos brasileños

22 Guardia et Wierzeyski, Obra citada, pag. 72-75; Burgraff, Obra citada, pag. 526; Bastin, Obra citada, pag. 303 [nota del gramático]. 
de este periodo incluían la interjección entre las clases de palabras y excluían, en cambio, el artículo.

En la primera mitad del siglo XIX, los sistemas de nueve o diez clases de palabras, bien con el participio, con la interjección o con el adjetivo como parte de la oración, eran los más difundidos. Más tarde, en la segunda mitad del siglo, el participio pasa a ser una forma nominal del verbo y no una clase independiente de palabras. La interjección aún sigue siendo objeto de discusión y se considera en varias otras gramáticas contemporáneas a ésta como una clase de palabra independiente, tomando el lugar del artículo.

La comparación entre los distintos sistemas de clases de palabras, como el de la tradición latina, la Gramática de Port-Royal y algunos gramáticos novecentistas brasileños, puede quedar representada en la siguiente tabla:

\begin{tabular}{|l|c|c|c|c|c|c|}
\hline & $\begin{array}{c}\text { M. Silva } \\
\mathbf{( 1 8 0 6 )}\end{array}$ & $\begin{array}{c}\text { Coruja } \\
\mathbf{( 1 8 3 5 )}\end{array}$ & $\begin{array}{c}\text { A. Freire } \\
\mathbf{( 1 8 7 5 )}\end{array}$ & $\begin{array}{c}\text { J. Ribeiro } \\
\mathbf{( 1 8 8 1 )}\end{array}$ & $\begin{array}{c}\text { A. Gomes } \\
\mathbf{( 1 8 8 7 )}\end{array}$ & $\begin{array}{c}\text { M. Maciel } \\
\text { (1894) }\end{array}$ \\
\hline Nombre & SUST/ADJ & SUST/ADJ & SUST/ ADJ & SUST/ADJ & SUST/ADJ & SUST/ADJ \\
\hline Artículo & & $\mathrm{X}$ & & $\mathrm{X}$ & & \\
\hline Pronombre & & $\mathrm{X}$ & $\mathrm{X}$ & $\mathrm{X}$ & $\mathrm{X}$ & $\mathrm{X}$ \\
\hline Verbo & $\mathrm{X}$ & $\mathrm{X}$ & $\mathrm{X}$ & $\mathrm{X}$ & $\mathrm{X}$ & $\mathrm{X}$ \\
\hline Preposición & $\mathrm{X}$ & $\mathrm{X}$ & $\mathrm{X}$ & $\mathrm{X}$ & $\mathrm{X}$ & $\mathrm{X}$ \\
\hline Adverbio & $\mathrm{X}$ & $\mathrm{X}$ & $\mathrm{X}$ & $\mathrm{X}$ & $\mathrm{X}$ & $\mathrm{X}$ \\
\hline Participio & & $\mathrm{X}$ & & & & \\
\hline Conjunción & $\mathrm{X}$ & $\mathrm{X}$ & $\mathrm{X}$ & $\mathrm{X}$ & $\mathrm{X}$ & $\mathrm{X}$ \\
\hline Interjección & $\mathrm{X}$ & $\mathrm{X}$ & $\mathrm{X}$ & & & $\mathrm{X}$ \\
\hline
\end{tabular}

Tabla 5.7 Las clases de palabras en las gramáticas brasileñas

Para delimitar la línea que sigue Ribeiro en la división de las clases de palabras, se requiere retroceder en el tiempo. Su propuesta parece no estar inspirada en un autor específico o una tradición específica. Se trata más bien de una mezcla, por incluir el participio en la clase de los verbos, por admitir el artículo como clase independiente y por omitir la interjección. 
El sistema adoptado por Ribeiro divide las palabras en afectivas (interjección) y enunciativas (nombre/sustantivo, pronombre, adjetivo, verbo, preposición, adverbio y conjunción). Las cuatro primeras clases enunciativas son declinables y las tres últimas son indeclinables.

La distribución de las palabras en cada una de las clases, las modificaciones que pueden experimentar cuando están relacionadas o no, y su estudio histórico constituyen el objeto de la taxeonomia, kampenomia o ptoseonomia y la etimologia, respectivamente. Estos tres estudios forman parte de la morfología.

Con respecto a la taxeonomia, la obra de Ribeiro se distingue de las obras precedentes en la exclusión del artículo indefinido «um», que pasa a formar parte del grupo de los adjetivos indeterminativos, juntamente con el numeral, el demostrativo, el distributivo, el conjuntivo, el posesivo y el indefinido (Fávero y Molina 2006: 133). Este cambio no tiene justificación explicita en la Gramática, a no ser que el autor asume el cambio que sugiere Chassang (1881). Esta innovación solo figura en la segunda edición de la obra, revisada por el propio autor y publicada en 1885.

En la clasificación de la palabra «um», Ribeiro apunta hacia otro camino. No solamente lo incorpora a la clase de los adjetivos numerales sino que también lo clasifica como adjetivo determinativo indefinido, juntamente con «algum, certo, qualquer, outro, tal», etc.

Por las definiciones del artículo y del adjetivo determinativo indefinido que proporciona el autor, desprende que la clasificación de «um» entre los adjetivos y la permanencia de «o» en el grupo del artículo se debe a que la partícula «o» determina, o, como afirma Júlio Ribeiro, particulariza el sustantivo al que está antepuesto.

Según el gramático no es lo mismo decir dá-me pão que dá-me o pão, pues en la última oración el sustantivo pão está determinado por «o», es decir, no es cualquier pan, sino el pan. En cambio, «um» en el mismo ejemplo, dá-me um pão, limita al sustantivo, pero no le atribuye individualidad o particularidad. 
De ahí que no pueda ser clasificado como un artículo, pues no particulariza el sustantivo.

En la Grammatica Portugueza se concibe el pronombre como sustituto de un sustantivo. En este punto, Ribeiro se diferencia de Soares Barbosa (1822) y Moraes Silva (1806), pues ambos afirman que los pronombres no sustituyen a los nombres, sino que se identifican con los nombres. En cuanto a su división, los clasifica en sustantivo (personal) y adjetivo (demostrativo, distributivo, conjuntivo, posesivo e indefinido), a diferencia de la línea de Frei Caneca (1817) y Reis Lobato (1770) que siguen la clasificación tradicional en: personal, posesivo, recíproco, relativo, interrogativo, demostrativo e indefinido.

Se puede observar que en la clasificación propuesta por Ribeiro no se presenta la subclase de los interrogativos. El autor explica de este modo su decisión:

Muitos grammaticos admittem uma classe de determinativos interrogativos; não ha razão para a existencia de tal classe. Em todo periodo interrogativo dá-se a ellipse da preposição principal, e o chamado determinativo interrogativo é sem tirar nem pôr, o determinativo conjunctivo servindo para ligar duas proposições (Ribeiro 1881: 58).

Esta posición no la comparten muchos autores de la tradición brasileña. No obstante, algunos gramáticos españoles de la primera mitad del siglo XIX, como Cortés (1808), Costa Vall (1827) y Alemany (1838), siguen, en parte, esta línea, a pesar de que no cuentan en sus gramáticas con la subclase de los pronombres distributivos.

Por otro lado, Ribeiro asevera que los pronombres adjetivos son los mismos adjetivos determinativos cuando se emplean en proposiciones sin sustantivo explícito. Pese a que el gramático no lo explique con claridad, se infiere a partir de esta afirmación que los pronombres propiamente dichos son los personales.

Acerca del polémico tratamiento de la conjunción, en este periodo se discutía si las conjunciones unían solamente las proposiciones o si unían proposiciones y palabras. La unión de palabras por conjunciones solía explicarse 
por medio de la elipsis (Burgraff 1863). El gramático brasileño asume la segunda posición y afirma que las conjunciones enlazan oraciones y palabras entre sí y, en el caso de las subordinadas, solamente enlazan oraciones. Dicho de otro modo, trata de definir las conjunciones según su función sintáctica.

Según Ribeiro, las conjunciones son once: seis coordinadas (copulativa, continuativa, explicativa, disyuntiva, adversativa y conclusiva), y cinco subordinadas (condicional, causal, concesiva, temporal e integrante). Esta clasificación manifiesta una inclinación hacia los valores semánticos de las conjunciones: el significado de cada forma conjuntiva al enlazar oraciones determina su clasificación.

En el caso de los gramáticos de principios del siglo, las conjunciones eran definidas sintácticamente y clasificadas conforme a los criterios lógicos y semánticos. En especial, Moraes Silva (1806) asegura que las conjunciones únicamente unen proposiciones. Las clasifica en copulativas, disyuntivas, condicionales, causales, comparativas y adversativas, sin distinción entre subordinadas y coordinadas.

La kampenomia o ptoseonomia, comprende el conjunto de leyes que versan sobre la flexión de palabras. Ribeiro (1881: 73), trata de distinguir entre los vocablos que varían en género número y grado y las que no varían. En este campo, es pertinente destacar el estudio del género gramatical.

En las gramáticas brasileñas del siglo XIX, como explica Francisco Dias (2009), el estudio del género gramatical se localizaba fuera del objeto del estudio del sustantivo. El lingüista alude a la Gramática de João Ribeiro (1887), en la que la taxionomia se dedicaba a la clasificación de las palabras y la flexão, separada de la Gramática, discurría sobre el género.

La Gramática de Júlio Ribeiro, sigue, en parte, tales fundamentos sobre el estudio del género. Dedica su estudio fuera del ámbito de las clases de palabras y, respecto a la definición de género, subordina la distinción flexiva de los nombres al género de su referente extralingüístico o a su modificativo. Cuando estos referentes no tienen sexo, asumen uno u otro género por analogía con la flexión. 
Al mismo tiempo, asevera que el género del sustantivo es determinado por la significación y por la terminación (Ribeiro 1881: 74). Aunque en nota a la definición, afirma que la desinencia está, generalmente, subordinada a la significación (Ribeiro 1881: 74), su concepto de género no se centra exclusivamente en el referente extralingüístico. Hay, por tanto, palabras masculinas y femeninas de acuerdo con el significado y con la desinencia.

La formación del femenino como un rasgo flexivo está reflejada en todas las clases de palabras en las que hay variación de género. Cuando ordena las palabras según su clase correspondiente, se muestran solamente las de género masculino, mientras que las del femenino únicamente son representadas en la sección de la flexión.

\subsubsection{El tratamiento de la sintaxis}

La segunda parte de la obra está dividida en sintaxis léxica, que versa sobre la relación de las palabras entre sí para formar sentencias; sintaxis lógica, que trata de la estructura misma de la sentencia y su relación con otras; reglas de sintaxis, que reza sobre las reglas de concordancia y additamentos, que discurre sobre la puntuación, el orden de las palabras y los miembros en la oración, el estilo y vicios de lenguaje. Define la sintaxis del modo siguiente:

A syntaxe considera as palavras como relacionadas umas com outras na construcção de sentenças, e considera as sentenças no que diz respeito á sua estructura, quer sejam simples quer se componham de membros ou de clausulas (Ribeiro 1881: 193).

Para entender el avance que supone la definición de Ribeiro frente a sus predecesores, parece conveniente presentar brevemente la evolución de la sintaxis hasta este momento. En este periodo, debido a las influencias de la gramática filosófica, se concebía la sintaxis como un elemento articulado por los hechos extraoracionales. 
Desde este punto de vista, las ideas o nociones de las cosas no eran más que el mundo en sí mismo, el conocimiento o la historia propiamente dicha que el lenguaje expresa. Esta expresión, la sintaxis, está condicionada por los hechos, las ideas, y con ellos se establece relación de proximidad o distancia. Lo que determinaría la validez sintáctica de una oración sería la armonía con su referente extralingüístico. De este modo, el verbo transitivo, por ejemplo, no acepta cualquier complemento, sino solamente aquellos que hacen de la sentencia un pensamiento completo, armónico y lógico (Dias 2008).

La ruptura con el dictamen de la gramática filosófica se manifiesta principalmente en que, para Ribeiro, la sintaxis ya no se rige por referencias extralingüísticas, sino que está centrada en palabras y miembros de la estructura oracional. La relación entre el verbo y el complemento ilustra claramente este cambio en la articulación sintáctica:

Para Júlio Ribeiro, o verbo enuncia, diz ou declara alguma coisa. Sendo assim, há uma predicação contida nos verbos (Ribeiro, 1881. P. 67). Usar um verbo é predicar. E quando essa predicação envolve um estado de coisas no qual há a produção de um efeito, esse efeito recai sobre um objeto. $O$ verbo transitivo expressaria esse estado de coisas em que uma entidade é diretamente afetada por outra. O complemento verbal é assim uma entidade de ordem lingüística e da ordem do estado do mundo ao mesmo tempo: o verbo abriga a possibilidade do complemento e abriga uma predicação, e a entidade afetada é relativa a essa predicação (Dias 2008: 130).

La cuestión de la transitividad verbal, propuesta por Dias $(2005,2008)$, aplicada a la Gramática de Júlio Ribeiro, radica en que, según la concepción del gramático, hay verbos de predicación completa (intransitivos) e incompleta (transitivos). Estos últimos son los que necesitan complemento. Esta noción, en la tradición gramatical brasileña, perdura hasta mediados del siglo XX. Dos aspectos importantes pueden destacarse de este planteamiento. En primer lugar, la idea de que el verbo es el que posee significado o sentido incompleto se corresponde con lo que Dias (2005) denomina sedimentación histórica de los conceptos, es decir, la definición se generaliza en las gramáticas que se han 
producido a lo largo del siglo, unas reproduciendo las ideas de las otras y transmitiendo a las postreras, hasta que se solidifica el fundamento y el concepto arraiga. A partir de este punto, el concepto ya sedimentado permite concebir nuevos postulados.

En segundo lugar, se refiere a la apreciación de los diversos modos de enunciación. La mayoría de las gramáticas del siglo XIX ignora la existencia de enunciados con verbos transitivos sin objeto. En palabras de Dias:

Trazer enunciados desse tipo implica uma responsabilidade de explicar o efeito de completude num enunciado com verbo de significação incompleta sem o complemento. Normalmente, a explicação adquire um caráter sumário, como na gramática de Júlio Ribeiro: "os verbos transitivos, si são tomados em sentido geral, dispensam o objeto, e tornam-se intransitivos, ex.: Antônio come pouco" (p. 259) (Dias 2005: 108).

La distancia con el pensamiento logicista también se revela en el tratamiento de una categoría de verbos impersonales y de verbos que presentan atribución impersonal en una oración:

4) Impessoal - quando em accepção propia não pode ter por sujeito um nome de pessôa, ex.: trovejar-acontecer (Ribeiro 1881: 67).

El autor aclara que los verbos impersonales contienen en su propia significación un sujeto impersonal que no se expresa, pues el verbo en sí tiene sentido absoluto. Esta observación sintáctica permite deducir que el autor admite oraciones de un solo término, como por ejemplo «troveja» o "chove». En estos casos, en particular, no se afirma nada sobre nadie, simplemente se afirma algo. De ahí que esta clase de verbos carece de sujeto personal, pues la acción del verbo no se atribuye a un agente, sino al propio verbo.

Con respecto al análisis de otros componentes sintácticos, Ribeiro (1881: 194) define el sujeto como «o que representa a cousa a cujo respeito se falla» y aclara que el sujeto no necesariamente es una persona o un sustantivo, pues puede ser también una clausula: 
Póde estar em relação subjectiva, um nome, um pronome, uma parte da oração substantivada, uma phrase, uma clausula, um membro, uma sentença (Ribeiro 1881: 196).

El concepto de sujeto propuesto por el autor no difiere de las obras que marcaron la corriente racionalista.

Ribeiro admite que el sujeto juntamente con el predicado son los dos elementos que forman la oración. Este último se subdivide en otros dos partes, la cópula, que enlaza el sujeto al predicado, y el predicado propiamente dicho, que es la idea que se dice del sujeto. Atestigua Ribeiro, en consonancia con Mason (1820-1900), que la cópula de todas las sentencias es la flexión del verbo. Ahora bien, si la cópula une el sujeto y predicado y, a su vez, es siempre un verbo, las partes de la proposición son tres: sujeto, verbo y predicado. En definitiva, la concepción de la oración en la Grammatica Portugueza no difiere sustancialmente de las gramáticas racionalistas en cuanto a los conceptos sintácticos básicos, sino más bien en la nomenclatura y organización.

La unión de las palabras para Júlio Ribeiro se da de tres maneras: por medio de la flexión de las palabras, por medio de las preposiciones y las conjunciones y por el orden de los elementos en las proposiciones. Augusto Freire (18751-18772) y Moraes Silva (1806) igualmente habían adoptado esta posición, si bien este último autor no incluía las conjunciones en este punto.

Según Ribeiro, las relaciones que los componentes de una sentencia pueden establecer entre sí son cinco:

1) La subjetiva, que consiste en la relación del sujeto con el predicado.

2) La predicativa, que es la relación del predicado con el sujeto, manifestada en la transitividad verbal, como ya se ha mencionado.

3) La atributiva, referida a la relación de una palabra que expresa calidad con otra que representa algo o alguien sin el auxilio del verbo.

4) La objetiva, trata de la relación del verbo con el objeto al que se dirige o sobre el que incide la acción. 
5) La adverbial, que es la relación de un adjetivo, adverbio o verbo con la palabra, frase o clausula que califica (Ribeiro 1881: 196-198).

Estas cinco relaciones listadas por Ribeiro pueden remontarse a los estudios de Girard (1747), pero este clasificaba las relaciones que establecen las partes de la oración en siete grupos: subjectif, attributif, objectif, terminatif, circonstanciel, conjonctif y adjonctif. Antes de Ribeiro, Soares Barbosa (1822) ya había propuesto una clasificación más o menos próxima, pero con las denominaciones de complemento objetivo, terminativo, restrictivo y circunstancial. João Ribeiro (1887), siguiendo en parte la misma línea de sus antecesores, había considerado tan solo tres: la predicativa, la atributiva y la adverbial, esta última subdivida en objetiva directa e indirecta.

La definición de la sintaxis lógica conduce a una concepción sistemática de las relaciones sintácticas, especialmente por el empleo del término estructura. Con todo, las explicaciones del autor guían el análisis por otra vía, pues Ribeiro vincula la relación sintáctica, no con la función sintáctica, sino con las clases de palabras. Dicho de otro modo, para Ribeiro la estructura está formada por vocablos y no tanto por sintagmas (Cavaliere 2000).

Ribeiro divide las proposiciones en simples y compuestas. Las primeras se clasifican conforme a su significación en declarativas, imperativas, condicionales, interrogativas y exclamativas, y las segundas se clasifican en coordinadas y subordinadas.

La mayor parte de los gramáticos del siglo XIX reconoce que las oraciones compuestas se dividen en coordinadas y subordinadas. En cambio, con relación a las clases de oraciones simples, el criterio del significado permite a cada autor construir su propia clasificación, solo en parte coincidente con otras propuestas. Es el caso de João Ribeiro (1887), que las clasifica en positivas, negativas, enumerativas, interrogativas, optativas, imperativas y explicativas.

Respecto a la disposición de los vocablos en las oraciones, la Grammatica de Ribeiro distingue entre el orden directo y el orden inverso. De acuerdo con la concepción logicista, el autor brasileño admite que el consiste 
en disponer las palabras y frases según la lógica de la concepción del pensamiento, mientras que el inverso representa la intención de atribuir mayor energía a la expresión.

\subsubsection{Reconocimiento de las variedades lingüísticas del portugués}

Las diferencias más representativas entre las dos variantes del portugués se constituyen en materia de estudio en gramáticas, compendios y diccionarios de aquella época. Las distinciones básicas giraban en torno a la fonética, la prosodia y el léxico. Sin embargo, el contraste más polémico y a la vez más abordado por los gramáticos de finales del siglo fue el uso de los pronombres.

Esta diferencia sintáctica se expresa muy claramente en la Grammatica Portugueza, donde los ejemplos, que en su gran mayoría son llamados brasileirismos, se manifiestan ya como hechos lingüísticos a partir de que puede mostrarse la disparidad entre el portugués de Brasil y de Portugal. Para Dias y Bezerra (2006), la idiomatização representa la especificidad del portugués brasileño.

El tratamiento de esta cuestión en la obra de Ribeiro resulta particularmente interesante desde la perspectiva historiográfica, pues permite observar la progresiva aceptación en la gramática de las nociones relativas a la norma y a las variedades lingüísticas. Así, en primer lugar Ribeiro destaca la norma que la gramática considera adecuada para el uso del hablante, para luego compararla con las variaciones de ambas variedades del portugués. El primer ejemplo ilustra la norma general para el uso del pronombre como complemento directo del verbo:

5) O pronome objecto, o pronome em relação objectiva adverbial e a particula apassivadora se nunca devem começar a sentença: Seria incorrecto dizer Me querem lá - Te vejo sempre - Nos parece - Vos offereço - Lhe digo - Lhes peço - Se contam cousas feias - Se diz que elle vai, etc. Deve-se dizer: Querem-me lá - Vejo-te sempre, etc. (Ribeiro 1899[1885]: 253). 
La siguiente nota explicita no solamente el uso del portugués brasileño sino también el cambio de la norma, puesto que el uso actual de la colocación del pronombre va suplantando la regla.

2) Nas sentenças interrogativas pospõe-se o pronome sujeito ao verbo, ex.: Queres TU vir almoçar commigo?

Cumpre notar que, principalmente no Brazil, vai-se estabelecendo o uso de construir as sentenças interrogativas em ordem directa, deixando-se o seu sentido de pergunta a cargo somente da inflexão da voz, ex.: Tu queres vir almoçar commigo? (Ribeiro 1881: 221).

En esta observación sobre el uso del pronombre personal en lugar del complemento, el gramático llama la atención sobre la evolución lingüística por la que pasó tal construcción, tal vez con el objetivo de apoyar la regla en detrimento del uso encontrado en la variante brasileña.

1) O pronome substantivo sujeito de um verbo no infinito, dependente de um verbo no finito23, põe-se em relação objectiva, ex.: Eu vi-O caminhar ás pressas - Deixa-O ir.

Esta syntaxe, commum a varias linguas romanicas, é tomada directamente do Latim, em o qual o sujeito do verbo no infinito vai para o accusativo. E' erro vulgar no Brazil usar-se em casos taes da relação subjectiva: diz-se, por exemplo: Vi ELLE caminhar ás pressas. —Deixa ELLE ir (Ribeiro 1881: 228).

Pôr em relação subjectiva o pronome substantivo que serve de objecto a um verbo, é erro comezinho no Brazil, até mesmo entre os doutos: ouvem-se a cada passo as locuções incorrectas: Eu vi elle - Espere eu (Ribeiro 1881: 230).

Como en el ejemplo anterior, es patente el rasgo prescriptivo de la aseveración de Ribeiro. Pero en este caso no hay justificación histórica sino una base sintáctica:

${ }^{23}$ Chamam-se finitos os quatro modos, - indicativo, imperativo, condicional e subjunctivo [nota del gramático]. 
478. - Os pronomes substantivos, em relação adverbial, nunca podem servir de sujeitos, nem mesmo nas phrases infinitivas que vêm depois de uma preposição. Em taes casos usa-se da relação subjectiva, ex.: Esta laranja é para EU comer. No Brazil pecca-se contra este preceito, dizendo-se: «Para MIM comer, etc ॥ (Ribeiro 1881: 228 [la negrita es mía]).

A partir de los ejemplos que se acaban de presentar, se observa claramente el carácter normativo de la Gramática de Júlio Ribeiro. Aunque el autor afirme en la introducción que su tratado es descriptivo y que no tiene intención de formular reglas sobre la lengua sino solamente exponer los hechos lingüísticos, son frecuentes en esta obra las referencias a las desviaciones de la norma propuesta por el propio gramático.

La variación diatópica del portugués no se manifiesta en la Grammatica solo en los aspectos fonéticos, sino también ocasionalmente en la morfología y en la sintaxis léxica y lógica, como se explica en los siguientes casos:

(1) O gerundio latino, que é, por assim dizer, uma verdadeira declinação do nome verbal infinito presente, passou para o romanico na fórma ablativa. Que o gerundio é o mesmo que o infinito presente acompanhado de preposição, prova-se pelas seguintes identicas phrases: Vi-o chorando (Brazil), vi-o chorar (Portugal) (Ribeiro 1899[1885]: 199).

Acerca del léxico se puede citar:

Galopar (Portugal) andar a galope; galopear (Brazil) andar a galope, e tambem, com sentido transitivo, principiar a domar uma cavalgadura, montando-a pelas primeiras tres vezes (Ribeiro 1899 [1885]: 203).

Respecto al uso del artículo antes del nombre, comenta:

Em Portugal usa-se do artigo antes dos nomes de parentesco e de relações sociaes, ainda mesmo dirigindo-se á pessôa que falla ao interlocutor, ex. : Rapaz, onde foste a estas horas? - Pois o thio não me mandou á botica? Quer o amigo almoçar comnosco? (Ribeiro 1899[1885]: 233). 
Y aclara que en algunas regiones de Brasil no se utiliza esta construcción. llustra el empleo del pronombre en la posición del sujeto neutro o impersonal en la norma portuguesa y brasileña:

(2) Parece ser tambem este o uso corrente em Portugal. Garret o põe na bocca da gente do povo que faz entrar em suas composições: «Tambem vós, Gertrudinhas! ELLE era o que faltava (Arco de Sant'Anna, Tomo I, pag. 120)». E só assim se explica a existencia de tal uso no fallar da gente rude brazileira: é um legado dos colonizadores (Ribeiro 1899 [1885]: 300).

A finales del siglo XIX empieza a establecerse cada vez más las diferencias de la norma lingüística del portugués europeo y americano, aspecto notable en las gramáticas brasileñas decimonónicas, en especial las de finales del siglo. La aceptación de la norma brasileña, en un primer momento, representó un conflicto con el modelo lusitano, cuya influencia fue dominante en la primera mitad del XIX. La Grammatica Portugueza es un ejemplo de esta dificultad.

La postura de Ribeiro fue seguida por otros gramáticos, en particular, por João Ribeiro. Este último autor, después de su Grammatica Portugueza (1887) publicó A Lingua Nacional, en fecha desconocida, pero la $2^{a}$ edición está datada de 1933. Durante estas primeras décadas del siglo XX, comienza el movimiento en defensa de la lengua brasileira. La obra, una de las más representativas de esta corriente, propone otra mirada hacia los cambios lingüísticos en el idioma portuguez na America, independiente de Portugal, del mismo modo que se alcanzó la independencia política:

Parece todavia incrivel que a nossa Independencia ainda conserve essa algema ${ }^{24}$ nos pulsos, e que a personalidade de americanos pague tributo á submissão das palavras.

(...)

A nossa grammatica não póde ser inteiramente a mesma dos portuguezes. As differenciações regionaes reclamam estylo e methodo diversos.

${ }^{24}$ El autor se refiere a la corrección del portugués brasileño según las normas de Coimbra y Lisboa. 
A verdade é que, corrigindo-nos, estamos de facto a mutilar idéas e sentimentos que não são pessoaes (João Ribeiro 1933: 8).

El tratamiento de la variación diacrónica del portugués constituye un aspecto central en la Gramática de Ribeiro, que está presente en todos los apartados de la obra, pero especialmente en la etimología, como se verá más adelante. Esta variación temporal permite al autor brasileño justificar a determinados fenómenos lingüísticos. Como ejemplo hay que citar la argumentación de Ribeiro acerca de la conservación de algunos sonidos en el portugués americano que se justifican históricamente en el contexto románico:

Dje é um som romanico genuíno: existe em Provençal, em Italiano, e no seculo XII existia no Francez, que o transmittiu ao Inglez, onde até agora se acha.

Tche é também som romanico castiço: existe em Provençal, em Italiano, em Hespanhol, e existiu no Francez, onde passou para o Inglez, que ainda hoje o conserva.

A existência de ambas estas fórmas no fallar do interior do Brazil prova que estavam ellas em uso entre os colonos portuguezes do século XVI (Ribeiro 1881: 10).

Con todo, el autor adopta una posición prescriptiva en cuanto al uso de determinadas pronunciaciones. En las notas, Ribeiro explica detalladamente las variantes cultas y vulgares de determinados sonidos y, en ocasiones, se detiene en los usos conservadores o arcaicos:

25. - Trinta e duas são, pois, as vozes elementares essenciaes da lingua portugueza.

Ha mais dous sons distinctos, banidos hoje do uso da gente culta: dje, tche.

Os caipiras de S. Paulo pronunciam djent, djogo. Os mesmos e tambem os Minhotos e Transmontanos dizem tchapeo, tchave

(...) como se sabe, o povo rude é conservador tenaz dos elementos archaicos das línguas (Ribeiro 1881: 9 [la negrita es mía]).

La Gramática de Ribeiro describe los hechos de una lengua determinada, en este caso la portuguesa; en una época determinada - finales 
del siglo XIX; un registro determinado - el culto; $y$, en fin, una variante determinada - la escrita. Dicho de otro modo, la obra de Ribeiro expone los hechos del lenguaje culto, escrito y restringido al uso de los que viven en los centros urbanos. Todo lo que no se conforma a esta delimitación queda fuera de análisis. Sin embargo, esto no quiere decir que está fuera de la norma, sino que está fuera de la norma estipulada por el gramático.

El carácter normativo de la Grammatica Portugueza de Ribeiro viene determinado por la finalidad pedagógica que requeriría aquel momento histórico. Se trataba de exponer y divulgar la variante que debía ser objeto de estudio por parte de un hablante nativo. La Gramática iba dirigida a la enseñanza del portugués a hablantes nativos que, en su mayoría, desconocían el portugués escrito, culto, urbano y acorde con el uso de los doctos. La variante culta debía, además, basarse en principios gramaticales:

Não há, contudo, uma postura meramente normativa, já que o fato gramatical descrito [en la gramática] repousa sobre segura fundamentação lingüística e é ordinariamente abonado mediante corpus extraído dos textos literários contemporâneos (Cavaliere: 2000).

La delimitación de la variante lingüística en los términos aludidos no significa que las variaciones diastrática y diafásica del portugués quedaran excluidas del trabajo de Júlio Ribeiro. Pero claramente se nota que el autor no concedió la misma importancia a todas las variaciones lingüísticas que, a saber, son cuatro: la diacrónica, la diatópica, la diafásica y la diastrática.

La diacronía es de suma importancia pues refleja la corriente teórica seguida por Ribeiro. Por otro lado, el autor distingue variaciones dialectales entre el portugués americano y europeo, a fin de manifestar no solo la independencia lingüística sino también el sentimiento nacionalista. Además, la variación diatópica también se muestra en las observaciones respecto al portugués hablado en distintas regiones brasileñas. Así, por ejemplo:

240. - Ha ainda:

1) um diminutivo em ébre - casebre 
2) diminutivos familiares, ex.: de pae, papae, - de thio, titio, - de senhor, sor, sã e até seu - de senhora, sóra, sia (Minas), nhã (S. Paulo) - de soror, sor (Ribeiro 1899[1885]: 105 [la negrita es mía]).

Las variaciones diafásica y diastrática corresponden con el concepto de norma lingüística del autor. La primera consiste en diferentes realizaciones de la misma norma según la situación conversacional y la segunda, en realizaciones según las características de los hablantes, grupos sociales, por ejemplo, que no necesariamente rompen con la norma. Puede leerse:

Os caipiras, fieis aos usos arkhaicos da lingua, como sóe sel-o a gente do povo, exprime-se de modo analogo ao dos Francezes: põem claro um pronome que represente o sujeito neutro e impessoal dos verbos impessoaes. Dizem: ELLE chove muito lá - ELLE hai ainda algûas fruitas - ELLE corre por ahi que o rei vem vindo (2) ». Substituem tambem ter a haver, e dizem: "TEM muita gente na egreja - Agora TEM muito peixe no tanquell. Este uso vai-se tornando geral no Brazil, até mesmo entre as pessôas illustradas (Ribeiro 1881: 257 [la negrita es mía]).

El uso arcaico, según el autor, es característico de un grupo social denominado caipira, identificado con la gente simple del campo, del interior del país. No obstante, Ribeiro señala que el uso de la gente distinguida se ve afectado por estos usos más coloquiales. Aunque el registro caipira no sea objeto preferente de estudio, el gramático lo describe en oposición al registro culto.

Así, la cita siguiente hace referencia tanto al uso de diferentes grupos sociales, como escritores y terratenientes en el trato de éstos últimos con sus inferiores. En una determinada situación conversacional entre un terrateniente y un empleado, el uso de los pronombres difiere del uso de este mismo hablante con otro interlocutor:

444. - Em lugar do pronome da primeira pessoa do singular eu, usam os escriptores da forma da primeira pessoa do plural nós. $O$ verbo vai para 0 plural; os adjectivos em relação attributiva ou predicativa com esse pronome ficam no singular, ex.: Antes sejamos breve que prolixo. 
Antigamente, dava-se geralmente o mesmo uso com o pronome da segunda pessoa; ainda hoje, neste Estado (S. Paulo), os velhos fazendeiros, conservadores tenazes dos hábitos fidalgos de seus avós, usam de tal tratamento em relação aos inferiores a quem votam affecto (Ribeiro 1899 [1885]: 250 [la negrita es mía]).

\subsubsection{Resumen}

Júlio Ribeiro fue el primer gramático de la tradición brasileña que llamó la atención sobre lo que actualmente se conoce como la hiperlengua brasileña. Aunque tales observaciones sobre esta variedad queden relegadas casi siempre a notas marginales y se recojan como usos familiares, vulgares o rurales, no cabe duda de que suponen un avance en su época frente a las gramáticas anteriores. Ribeiro fue consciente de este carácter innovador de su Gramática, en la que se daba preferencia a los dialectos y registros del uso brasileño del portugués y, en general, al uso real de la lengua. En este sentido, el autor afirma:

As antigas grammaticas portuguezas eran mais dissertações de methaphysica do que exposições dos usos da língua (Ribeiro 1899[1885]: 1).

Con todo, el carácter contrastivo de la Grammatica no se limita únicamente a la comparación entre las variedades del portugués. También el gramático dedica algunas páginas al estudio de las diferencias entre el portugués y el español, el francés, el italiano y el latín:

Os factos de uma lingua qualquer só podem ser cabalmente elucidados pelo estudo historico comparativo da grammatica dessa lingua.

As explicações metaphysicas, mais ou menos subtis, mais ou menos engenhosas, nunca satisfazem.

Os meios que emprega o Latim, que empregam as inguas romanicas para indicar de modo abstracto a indeterminação do agente de um verbo, têm servido de thema a milhares de divagações tão prolixas quanto abstrusas, tão requintadas quanto estereis. 
Analysar esses meios á luz do estudo histórico comparativo das grammaticas romanicas e da latina, eis o fim que levo em vista (Ribeiro 1881: 286).

La aplicación teórica y metodológica de la lingüística históricocomparada en una gramática con fines pedagógicos abrió paso en la gramaticografía brasileña a la recepción de nuevas concepciones lingüísticas. Fue también un incentivo a las nuevas producciones, más críticas hacia el quehacer gramatical y hacia las teorías ya arraigadas.

Obviamente, el intento de conformar las leyes de la gramática general y las de la gramática histórica tuvo como consecuencia choques de pensamiento y contradicciones en muchos momentos. Tales desajustes se manifiestan principalmente en las definiciones y notas del gramático. Las primeras siguen la tradición anterior, mientras que las anotaciones tratan de adecuarse a las nuevas corrientes filológicas.

Seis años después de la publicación de la Gramática de Júlio Ribeiro, vieron la luz, casi simultáneamente, otras cuatro gramáticas, al parecer bastante influenciadas por los fundamentos renovadores de la obra de Ribeiro. Se trata de las obras de João Ribeiro (1887), Manuel Pacheco da Silva Jr. y Boaventura Plácido Lameira de Andrade (1887), Alfredo Gomes (1887) y Maximino Maciel (1894). Entre estas obras, la más relevante es la Grammatica Descriptiva de Maciel. 


\subsection{El modelo de gramática descriptiva: Grammatica Descriptiva de Maximino Maciel $\left(1887^{1}-1894^{2}\right)$}

\subsubsection{El autor y su obra}

Maximino Maciel nació en Rosário do Catete, Sergipe en abril de 1866 y falleció en Rio de Janeiro en 1923. Se graduó en Derecho y Medicina y ejerció como pedagogo y profesor del Colégio Militar. Además fue reconocido como filósofo y poeta. Sus producciones bibliográficas incluyen tratados de química y biología y la Grammatica Descriptiva baseada nas doutrinas modernas (Fávero y Molina 2006: 174).

La Grammatica Descriptiva baseada nas doutrinas modernas de Maximino Maciel tuvo su primera edición en 1887 con el título de Grammatica Analytica. El nuevo título figura desde la segunda edición de 1894. La obra de Maciel fue la que más claramente se dirigió hacia la descripción del portugués entre las gramáticas brasileñas publicadas en el último cuarto del siglo XIX.

Desde el punto de vista tipográfico, la Grammatica de Maciel presenta los títulos y subtítulos destacados en negrita y tamaño de fuente más grande. Los ejemplos también se destacan o bien en negrita o en cursiva. Las observaciones del gramático son de dos tipos: unas se dedican a las referencias bibliográficas y las menciones sobre otras gramáticas y están ubicadas a pie de página, separadas por raya, con tamaño de fuente menor. La segunda clase de notas se refiere a las constataciones de los fenómenos gramaticales. Se presentan en letra más pequeña, pero integradas en el cuerpo del texto sin ningún otro recurso gráfico. El gramático advierte en el prólogo que, pese a las fuentes citadas, su Gramática no es un resumen o copia de las teorías que le sirvieron de base:

Apesar porém do grande numero de obras citadas, parece-nos que se não perdeu a nossa individualidade nesse compendio, porque á doutrina 
assimilada juntamos as nossas observações proprias, como verão os competentes (Maciel 1926[1894]: Prólogo de la 2a edición [la negrita es mía]).

La disposición textual de la Grammatica refleja algunos objetivos implícitos ya en la estructura misma de la obra. Las observaciones y deducciones del autor en cuanto a los preceptos no solamente gramaticales sino también lingüísticos no quedan en segundo plano. Es notable que para Maciel son fundamentales las consideraciones que expone. La ciencia misma de la gramática es más relevante que la autoría o fuente del saber gramatical, dado que las notas bibliográficas y de otros gramáticos sí que están en un segundo plano.

\subsubsection{División de la gramática}

La Gramática tiene un total de 513 páginas divididas en seis apartados. La phonologia con 73 páginas, la «lexeologia» con 195 páginas, la «sintaxologia» con 192, la "semiologia» con 16, la técnica con 6 y los modelos de análisis sintáctico con 17 páginas. El estudio morfológico («lexeologia») y sintáctico prima sobre todos los demás apartados de la Gramática. Cada uno de estos ocupa un $38 \%$ del total de páginas.

La fonología alcanza cierta presencia con 17\% de la Gramática. Las tres grandes áreas de estudio de la Grammatica Descriptiva son, pues, la palabra como sonido, producto orgánico del aparato fonético; como organismo y considerada aisladamente; y como función, colectivamente considerada (Maciel 1926[1894]).

El estudio semántico («semiologia»), aunque ocupe solamente un tres por ciento del total de la obra, representa un avance comparado con las gramáticas anteriores, dada la relevancia que se otorga al estudio del significado en este periodo.

El análisis del discurso gramatical de Maciel, según la teoría de la semiótica discursiva de Greimas y Courtés (1979), muestra que la discursividad 
practicada por el gramático oscila entre la norma heterogénea y la norma de frecuencia de uso. Respecto al carácter prescriptivo, propio de normas homo y heterogéneas, muy pocas veces se deja notar en la Gramática, pues de acuerdo con la propia fundamentación teórica utilizada, predomina el criterio descriptivo e histórico de la lengua. El propio Maciel afirma que su Gramática tiene como prerrogativa reflejar el uso, independientemente de la imposición de la norma:

Experimentemos, observemos, systematisemos, mas não lhes oponhamos obstaculos ao desenvolvimento, pois se effectuam segundo leis fataes, independentes da nossa vontade, impostas pelo uso popular ou a influencia erudita (Maciel 1926[1894]: 41 [la negrita es mía]).

Es patente que para Maciel la gramática ya no asegura la uniformidad de la lengua, como creía la gramática clásica, sino que representa la cientificidad del lenguaje, acorde con las nuevas teorías histórico-comparativas.

La Grammatica Descriptiva presenta un carácter pedagógico, pues va dirigida a la enseñanza secundaria, en particular a los alumnos del tercer año. La preocupación del autor por la doctrina y el estudio de la gramática se hace notar en su examen de la enseñanza del portugués en Brasil, que se publica como un apéndice de la edición de 1910 de la Gramática, bajo el título de «Breve retrospecto sobre o ensino de lingua portugueza».

Se trata, en realidad, de un recorrido por la historia de la gramática brasileña hasta la $2^{a}$ edición de la Grammatica Descriptiva. Según el autor, hasta 1887 las gramáticas pedagógicas reproducen la tradición portuguesa y algunas obras, concretamente en las de Soares Barbosa, Bento J. de Oliveira, Lage, eran el pilar de la enseñanza de la lengua portuguesa en Brasil. Maciel afirma que hasta Grivet (1865) los gramáticos brasileños seguían los criterios filológicos de entonces, que consistían sobre todo en la separación de la lengua y las doctrinas gramaticales.

También menciona el desfase de la educación en los pueblos del país, la difusión del método histórico-comparado entre las escuelas y profesores, y la 
importancia del programa Fausto Barreto de reformulación de la enseñanza, apoyado en los nuevos criterios filológicos, que se convirtió en el eje de las nuevas producciones histórico-comparadas nacionales. Sobre la importancia de este programa en la gramaticografía brasileña, afirma:

O que foi este programma [Fausto Barreto], a influencia que exerceu, o effeito que produziu pela orientação que paleava, desviando o álveo do curso das linguas, agitando questões a que se achavam alheios muitos docentes, é mister assegurarmo-lo: assignalou nova época na docencia das linguas e, quanto á vernacula, a emancipava das retrogradas doutrinas dos autores portuguezes que esposávamos (Maciel 1926[1894]: apéndice).

En los prólogos de la segunda y tercera edición, de las ocho revisadas por el autor, Maciel dirige una autocritica a las primeras ediciones. Sobre la primera edición, justifica que la heterogeneidad teórica se debe al periodo de transición de las doctrinas y reconoce que estaba basada más en lecturas que en su propia observación de la lengua:

Por esta occasião vínhamos nós de apparecer com o publicar o nosso modesto trabalho, Grammatica Analytica, na qual, embora collaborassemos para quebrar a tradição, no entanto sobrelevavam defeitos e senões, porquanto, além da nossa pouca idade, trazíamos apenas o preparo que hauríramos em nosso Estado, Sergipe.

De mais, as doutrinas modernas contrastavam com as antigas, claudicavamos na collocação de pronomes, incidindo em dyssynclises, como quase todos os escriptores e publicistas de então, até que lograssemos estatuir as bases deste importante instituto syntactico (Maciel 1926[1894]: apêndice [la negrita es mía]).

La relectura y un examen crítico de las nuevas teorías produjeron cambios de tipo sistemático y metodológico de la segunda edición: adopción de rasgos menos metafísicos y más positivistas; ampliación del estudio de la semiologia; cambio del corpus de autoridades literarias, y añade:

Quanto aos demais pontos, ampliámos alguns; documentámos mais outros, de molde que ao leitor se offerecerão fructos, não sabemos si bons si 
maos, das investigações nossas, colhidos na messe opíma dos phenomenos da mais formosa, da mais dificil, da mais plastica das linguas vivas (Maciel 1926[1894]: prólogo $2^{a}$ edición).

Concluye el prólogo afirmando que la segunda edición en nada se parece con la primera.

\subsubsection{La base textual}

Con respecto al corpus de autoridades literarias de la Grammatica Descriptiva, el análisis de datos revela que en esta obra domina el criterio descriptivo y que el uso de corpus determina el incremento de la sintaxis y al mismo tiempo permite abrir camino al estudio de la semántica.

Se ha contabilizado un total de 112 autores diferentes, de los que 39 son portugueses, 38 son brasileños, 35 no se ha podido identificar por falta de datos y 5 son de otras nacionalidades. Están repartidos entre los siglos XVI al XIX pero predominan los autores de este último periodo.

El total de ejemplos analizados por Maciel, es aún más significativo de su planteamiento metodológico. El autor reunió un total aproximado de 848 citas, de las que 543, o sea, el $64 \%$ corresponde a autores portugueses. A los escritores brasileños pertenecen 218 ejemplos que corresponde a un $26 \%$. El 10\% restante corresponde a los autores no identificados.

Todos los escritores que forman el corpus de autoridades literarias brasileñas pertenecen al siglo XIX. Los portugueses de este mismo periodo suman un total de 19. Los demás autores portugueses se dividen entre los siglos XVI al XVIII. Así pues, la literatura brasileña contemporánea se constituye, para el gramático, en norma autorizada. Sin embargo, la mayor cantidad de ejemplos proviene de autores canónicos portugueses como Camões (s. XVI), con aproximadamente 120 ejemplos, y A. Herculano (s. XIX) con 84 citas.

Los autores brasileños más representativos del corpus reunido por Maciel son Castro Alves (1847-1871), con 21 ejemplos; Gonçalves Dias (1823-1864), con 
28; y José de Alencar (1829-1877) con 18. El gramático también incluye dos ejemplos de su propia autoría y los lista en las notas de referencia bibliográfica como "O autor», juntamente con las demás autoridades. El prólogo de la segunda edición da cuenta del esfuerzo realizado por el autor para desarrollar la sintaxis según el uso literario:

Rarissimos são os exemplos nossos e esses poucos devidos ao trabalho ímprobo de estarmos folheando escriptores para colher o exemplo adequado, de modo que a nossa syntaxe está de accordo com os monumentos da língua (Maciel 1926[1894]: Prólogo de la $2^{a}$ edición [la negrita es mía]).

Se observa además que el gramático es consciente de la importancia de los textos para los estudios sintácticos, pues afirma que la teoría debe desprenderse de los datos y no al contrario. De ahí la crítica a los gramáticos que no describen la norma a partir del uso:

É um dos maiores defeitos e até falta de criterio formular o autor a regra e fazer o exemplo, o que largamente tem contribuido para o divorcio entre a grammatica e os phenomenos da lingua, quando aquella deve ser 0 codigo, o registro em que se achem consignados (Maciel 1926[1894]: Prólogo de la $2^{a}$ edición).

Otro tema general al que el autor dedica bastante atención es a la terminología utilizada en la Gramática. Son frecuentes las ocasiones en que a Maciel le parece imprescindible aclarar la cuestión de la nomenclatura de los temas gramaticales. Cada cambio terminológico está justificado o por la interferencia de una nueva doctrina lingüística, o por la influencia de nuevas disciplinas en la Gramática, o por la antigüedad del término que se utilizaba, o por la claridad que transmite la nueva nomenclatura, o aun por mantener la coherencia y uniformidad en la organización del compendio. Las pocas veces que el autor mantiene el término utilizado por otros gramáticos aporta alguna justificación relativa al arraigo y tradición que ha adquirido el vocablo. 


\subsubsection{Definición de la gramática}

La definición de la gramática recibe en la obra de Maciel la influencia de las teorías científicas, en especial las de Darmesteter (1930: 6) y Mason (1877: 7), que afirman respectivamente: «la conception de la grammaire comme science est, on peut le dire, une idée nouvelle, née avec la linguistique modernell; "Grammar (from the greek gramar letter) is the science which treats about speech or language») (apud Fávero y Molina 2006: 178). El autor distingue como sigue entre gramática y gramática portuguesa:

Grammatica é a systematisação logica dos factos e normas de uma lingua qualquer (...) Grammatica portugueza é a systematisação organica das normas e factos da lingua portugueza isoladamente considerada (Maciel 1926[1894]: 1 [la negrita es mía]).

La distinción que establece el gramático entre la sistematización lógica y la sistematización orgánica reside en que la primera se concibe como método empírico y deductivo. Es pues el análisis lógico general de los «principios que explican los hechos lingüísticos») (Cavaliere 2000). En cambio, la segunda concibe una lengua particular como un cuerpo, con componentes que se articulan en el funcionamiento del lenguaje.

Además de la gramática particular y la gramática como ciencia, Maciel reconoce otras tres especialidades que son la descriptiva o expositiva, la histórica y la comparativa. La primera se define como sistematización orgánica de los hechos y normas de una lengua. La segunda trata de la evolución de las lenguas y la última se dedica al análisis de dos o más lenguas comparadas entre sí, en sus relaciones y divergencias.

Maciel admite que la gramática general carece de finalidad normativa, en contraste con las gramáticas particulares. Entiende la gramática general más bien como una rama científica que estudia los principios abstractos del lenguaje, como la gramática histórica estudia los orígenes y la comparada estudia las relaciones: 
Ha tambem a grammatica geral, que se poderia chamar glossologia, isto é, o tratado das normas geraes e abstractas que se poderiam applicar á expressão do pensamento ou á linguagem ${ }^{25}$. Linguagem, diz Sayce, é a manifestação exterior do pensamento consciente ${ }^{26}$. Nestas condições seria para a descriptiva o que é a Biologia para a Botanica e a Zoologia (Maciel 1926[1894]: 2).

La gramática tiene como objeto principal de estudio la palabra y el examen de sus cuatro manifestaciones: el sonido, del que se ocupa la fonología; el organismo, que corresponde a la lexiología; la función, tratada en la sintaxis y, finalmente, el signo o señal, objeto de la semántica.

Una de las características más destacadas de la Gramática de Maciel son los schemas synopticos, que proporcionan un resumen del contenido o de la estructura misma de la disciplina. En general, los capítulos empiezan o terminan con un esquema. El que sigue corresponde al de la división de la Gramática:
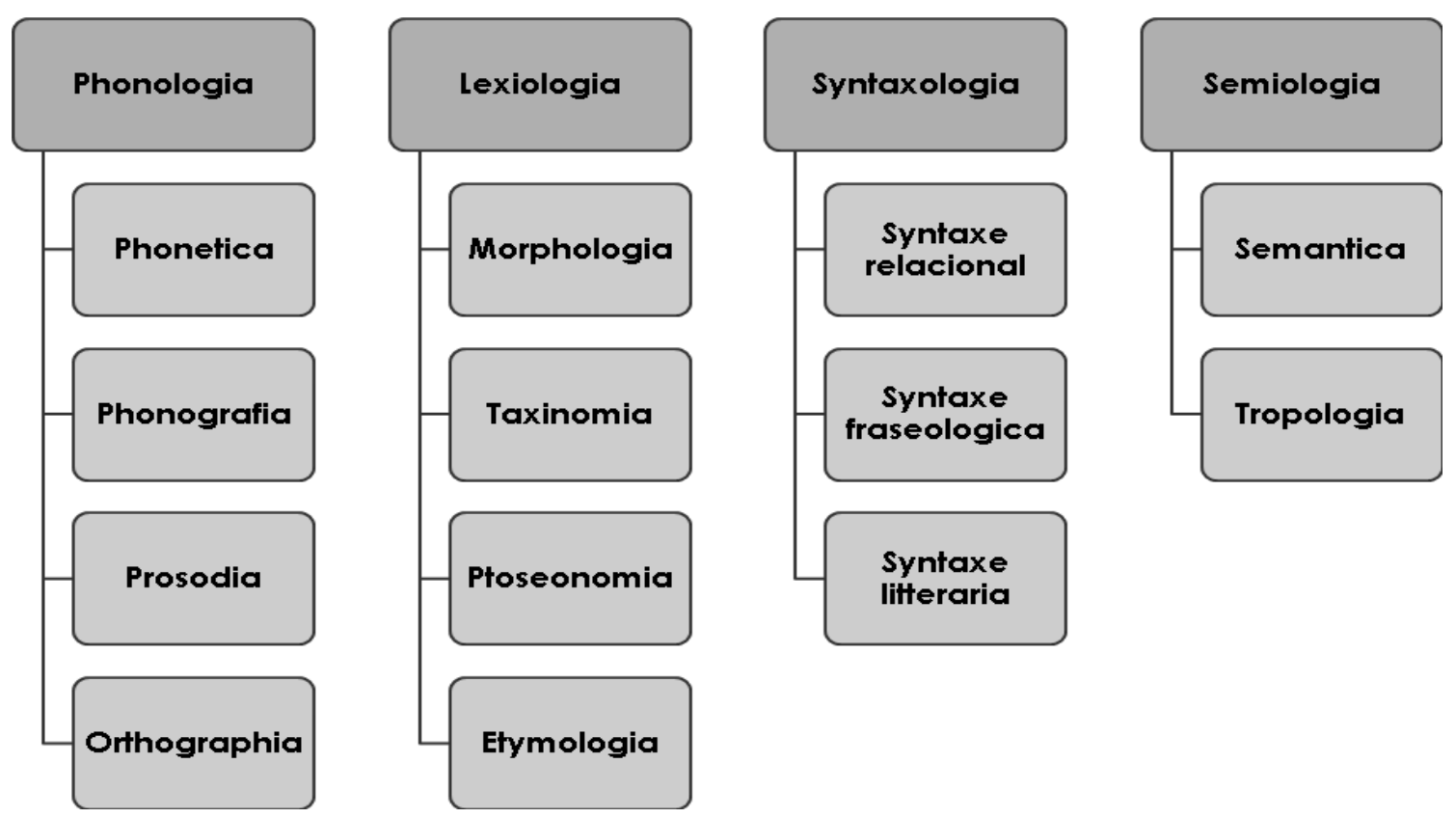

Tabla 5.8 La división de la Gramática de Maximino Maciel

\footnotetext{
${ }^{25}$ Max Müller, La science du langage, pag. 4 [nota del gramático]

26 Sayce, Philologie comparée, pag. 130 [nota del gramático].
} 
Una observación superficial de la división de la Grammatica puede llevar a inferencias equivocadas sobre el carácter conservador de la estructura propuesta por el gramático, en contraste con la de sus contemporáneos, que optaban por la división en dos partes. Sin embargo, conviene advertir que Maciel incluye una nueva disciplina, la semiología, y que separa los estudios léxicos y fonológicos. Además justifica la división en cuatro partes por el incremento de los estudios del significado:

A divisão tripartida da generalidade dos grammaticographos - em phonologia, lexiologia e sintaxilogia - não tem mais razão de ser, depois que o estudo da significação se individualizou, constituindo por si um ramo definido (...) (Maciel 1926[1894]: 3).

Esta división no tiene precedentes en la tradición brasileña, pero la estructuración no es totalmente original. Adolpho Coelho (1881) ya había presentado la propuesta de separación de los estudios léxicos y fonológicos. Además, el término fonología había sido utilizado por primera vez en la tradición brasileña en la Gramática de Júlio Ribeiro (18811-18852), como subdivisión de la lexeologia y parte integrante del análisis de las clases de palabras. Acerca de la semántica, Augusto Freire (18751-18772) ya había incluido la semiología en su Gramática, pero el estudio de los significados no fue desarrollado en las gramáticas posteriores a la de Maciel y solo recobró interés a mediados del siglo $X X$.

\subsubsection{El tratamiento de la fonética, la fonología y la ortografía}

Cada subdivisión de la fonología se ocupa del estudio del sonido o fonema en un aspecto: aisladamente, representado gráficamente, en cuanto a la cantidad y la tonicidad y como constituyente la palabra. La fonética corresponde al análisis de los sonidos aisladamente o correlacionados. Puede ser de dos tipos: descriptiva, que expone la formación de los fonemas y sus 
órganos; e histórica, que expone las modificaciones de la evolución de los sonidos. Respecto a esta última, señala:

A fonética histórica é a base lógica de quaesquer estudos comparativos ou etymológicos applicados á lingua ${ }^{27}$ (Maciel 1926[1894]: 6).

Para Maciel las «leyes de Grimm» tienen máxima relevancia no solo en la fonética sino también en la gramática histórica. El análisis de los cambios y transformaciones de los fonemas permite mostrar la filiación de las lenguas y comprobar las relaciones entre ellas.

Para el estudio fonético del portugués, Maciel introduce el concepto de triptongo y manifiesta su desacuerdo con otras gramáticas que defienden la inexistencia de los triptongos en la lengua vernácula (Maciel 1926[1894]: 14). La división de los diptongos en propios e impropios es la misma de Walker (1828) y Burgraff (1863), pero con cambios en la terminología, pues los denomina directos e inversos, respectivamente.

Maciel describe un fenómeno fonético propio del lenguaje familiar, el «tautosilabismo», que está relacionado con la repetición del sonido tónico de determinadas palabras, por ejemplo: «totó, vovó, dadáı»; también integran este grupo las palabras originadas en onomatopeyas. Reitera el gramático que este tipo de observaciones detalladas no son frecuentes en las gramáticas, pero -en su opinión- constituye uno de los elementos que adjudica superioridad a la gramática moderna, pues este tipo de explicación muestra el grado satisfactorio de alcance descriptivo (Maciel 1926[1894]: 21). De hecho, en ningún otro compendio, epítome o manual que haya precedido a la Grammatica Descriptiva, se han tomado en consideración tales aspectos.

Maciel admite ocho tipos de tildes en contraposición a las cuatro adoptadas por contemporáneos suyos. Introduce el «hífen» (-), la «cedilha» (ç), el «ponto abreviativo» (.) y la diéresis (") en la misma clase de los acentos. Justifica que todas esas señales que modifican la prosodia pueden ser llamadas

27 Henry, Gram. comparée du grec et du latin, pag. 1 [nota del gramático]. 
notações léxicas y por uniformidad de doctrina extiende el término acento a todas las notaciones (Maciel 1926[1894]: 28).

Además de las descripciones de los aspectos fonéticos, ortográficos y prosódicos, la fonología se ocupa de explicar la evolución de la lengua desde el latín hasta el portugués; de demostrar también, basado en la lingüística histórica, que el desarrollo y cambio lingüísticos afectan a otros planos, como al léxico. Como ejemplo, cita que las formas antes consideradas corruptas ahora son las que se utilizan y las que se consideraban cultas hoy son arcaicas.

Este cambio lingüístico, denominado por el autor corrupción fonética, es uno de los factores de transformación orgánica de las lenguas, y está regido por dos leyes biológicas: la ley de la transformación, que explica el cambio de fonemas mediante un fonema intermedio y la ley del mínimo esfuerzo, que consiste en la debilitación y caída de los fonemas. Esta última regla es ordinaria en el habla popular brasileña (Maciel 1926[1894]: 53-54).

La ortografía de las palabras en la Grammatica Descriptiva se apoya en tres criterios gráficos diferentes: el fonético, que tiene como base la pronunciación; el etimológico, que está fundado en el origen del vocablo; y el mixto o usual, que combina un criterio u otro según los casos, pues se admite que la pronunciación y la etimología no son criterios absolutos. El autor opta por la introducción de los tres sistemas para superar la polémica sobre la regulación de la escritura. Acerca de la reforma ortográfica, sostiene:

Tanto no Brasil como em Portugal diversas vezes, mas debalde, se tem tentado reformar a orthographia no presupposto de simplifical-a, aproximando-a do sistema phonetico.

A correcção graphica é um producto do tempo, independente d'este ou d'aquelle systema, e <<aprende-se mais por uma especie de memoria optica $>>$, segundo me diria sempre meu ilustrado collega Fausto Barreto (Maciel 1926[1894]: 56).

Maciel explica que de los tres criterios ninguno debe ser considerado aisladamente. En cuanto al sistema etimológico, opina que tiende a la conservación de grafías que ya no tienen razón de ser en contraste con la 
forma usual y simple de los vocablos. Por otro lado, considera que la dificultad de asentar la ortografía únicamente en el sistema fonético reside en que la base de este principio, la prosodia, es variable. Maciel advierte de las dificultades y consecuencias de este sistema:

A prosodia do vocabulo varia com os tempos, logares e os individuos, e até no mesmo individuo, de modo que lavrará a anarchia, a confusão, por não haver base menos variavel e mais fixa.

Este systema favorece a dialectação e o apparecimento de muitos homonymos 28 e desfigura a lingua $<<$ o queremos reduzil-a a um accordo de pronuncia e de graphica $>>29$ (Maciel 1926[1894]: 56).

El autor trata de resolver la cuestión con la misma estrategia de João Ribeiro (1887): entrecruza los criterios en un nuevo sistema en el que se alternan los principios etimológicos con los fonéticos, pero sin perder las reglas de uso. El resultado es, pues, un sistema completo:

As linguas immobilizam-se no systema etymologico; estragam-se no phonetico, desenvolvem-se no systema mixto (Maciel 1926[1894]: 59).

En este período la Academia de Letras pretendió imponer una grafía para la lengua portuguesa. Maximino Maciel critica tanto la iniciativa como a los autores que adoptaron la grafía académica y reitera que las reformas no se establecen, sino que son consecuencia del uso. El rechazo de la reforma por parte de los hablantes, principalmente brasileños, supuso el abandono de esta iniciativa, como pone de relieve el gramático:

Tudo passa. Assim se deslustraram as celebres academias literarias do século XVII, a escola gongorica, o romantismo e o actual nephelibatismo, morto na aurora da vida (Maciel 1926[1894]: 58).

\footnotetext{
28 Pacheco Lameira, Gram., pag 52 [nota del gramático].

${ }_{29}$ M. Kraff Bucaille, Causeries sur la langue française pag. 49 [nota del gramático].
} 


\subsubsection{El tratamiento de las partes de la oración}

Maciel denomina «lexeologia» al tratado de las palabras y lo divide en cuatro partes que estudian, respectivamente, la constitución y estructura de los vocablos, sus categorías o clases, su variabilidad y su origen. La primera corresponde a la morfología, que divide las partes de la palabra en «radical», que aporta el significado y los «affixos», que se aglutinan a este miembro central: el "suffixo» y el «prefixo». A diferencia de la mayoría de los gramáticos de la época, Maciel defiende que los radicales o raíces admiten algún tipo de variación, pues en particular pueden experimentar fenómenos de aglutinación. Las posibles combinaciones entre los «affixos» y el radical pueden ser de ocho tipos y, según el gramático, hay pocas palabras en la lengua que no se ajustan a estas fórmulas, que están íntimamente relacionadas a las propuestas de Fausto Barreto.

La antigua clasificación de las palabras en declinables e indeclinables o variables e invariables se resuelve en la Grammatica Descriptiva en palabras orgánicas (sustantivo, adjetivo, pronombre y verbo), que son aquellas que varían y presentan estructura morfológica apreciable; y palabras inorgánicas (adverbio, preposición, conjunción e interjección), que son las que no varían y carecen de estructura morfológica apreciable (Maciel 1926[1894]: 87).

La segunda parte de la «lexeologia», la «taxinomia», clasifica las palabras conforme a las categorias logicas con las que guardan relación (Maciel 1926[1894]: 116). Las palabras se distribuyen en tres grupos: las palabras nominativas -sustantivo, pronombre y verbo-, las modificativas -adjetivo y adverbio-, y las conectivas -preposición y conjunción-.

El sistema de clases de palabras propuesto por Maciel es el mismo que había utilizado Augusto Freire (18751-18772). Ambos autores coinciden incluso en la división de las tres categorías funcionales. Sin embargo, cabe señalar una importante diferencia. Según Freire (18751-187722), el verbo forma parte del grupo de palabras conectivas. En cambio, para Maciel, esta última clase está constituida solo por preposiciones y conjunciones, pues el verbo se integra en la 
clase de palabras nominativas, junto al sustantivo y al pronombre. Sin duda, contribuyó a generalizarse este cambio decisivo en la clasificación del verbo la decadencia de la función de cópula atribuida a esta clase de palabras por la gramática racionalista.

Maciel manifiesta el rechazo hacia los antiguos sistemas de clases de palabras, como la división clásica en nombre, verbo y partícula o la clasificación de Mason (1820-1900) en nocionales y relacionales. Según la doctrina de Larive y Fleury (1871), Maciel sostiene que las antiguas clasificaciones no están de acuerdo con la situación actual de las lenguas (Maciel 1926[1894]: 116).

Ciertos tipos de palabras que en la Grammatica Descriptiva no llegan a formar una categoría independiente han merecido la atención del gramático:

Os pronomes relativos pertencem ao grupo das conectivas, pois ligam as proposições; o participio será modificativo, ou nominativo, conforme a sua funcção de verbo ou de adjetivo; a interjeição não pertence á grammatica, é mais um grito, uma phrase latente e instantanea do que propriamente palavra, é a expressão de um sentimento indefinido e momentaneo (Maciel 1926[1894]: 116).

Maciel explica que los participios y los relativos pueden cambiar de grupo $y$, funcionalmente, podrían ser clasificados como modificativos, nominativos o conectivos, según el contexto. Por consiguiente, la clasificación propuesta por el gramático permite que los vocablos se muevan en otros ámbitos en virtud de la función que desempeñan, de manera que no están limitados por su categorización inicial. Así pues, los criterios funcionales se abren paso progresivamente entre los recursos heredados para definir y clasificar las partes del discurso.

La interjección queda excluida de las clases de palabras propiamente dichas analizadas en la Grammatica. De acuerdo con los logicistas, Maciel sostiene que es más bien una palabra sintética y natural que expresa sentimientos o gritos involuntarios. Sin embargo, aunque afirme que de esta categoría no se debe ocupar la gramática, el autor explica sus particularidades 
léxicas y sintácticas, y las divide, por un lado, en espontáneas, propias o esenciales y, de otro en «palavra interjeccional» y «expressão interjeccional»».

Maciel utiliza el criterio nocional para definir y clasificar los sustantivos. Así, la clase de palabras que designan los seres o las ideas se reparte en dos tipos: propio o individual y apelativo o común. Al primero pertenecen los personativos, locativos y abstractos, mientras que al segundo corresponden los objetivos, subjetivos, factivos y colectivos. Los propios tienen por característica esencial la individualización del referente y los apelativos designan a los sustantivos comunes.

El gramático brasileño llama personativos a los nombres de pila y a los apellidos, como por ejemplo Pedro Álvares Cabral (Maciel 1926[1894]: 117). Los factivos indican profesión o función social, como «padre, professor, rei, jornalista» (Maciel 1926[1894]: 117). Los colectivos se dividen en "igeraes, partitivos, extensivos, numéricos e específicos». Estos últimos pueden ser: orgánicos (a), aquellos cuyo significado resulta del radical de la palabra; e inorgánicos (b), cuyo sentido depende del contexto lingüístico en el que se utiliza el vocablo:

(a) Folhagem, criadagem, rapaziada, professorado, mestrança, organismo, corporação, confraria, ministerio, gritaria (Maciel 1926[1894]: 121).

(b) Bando (de ciganos, de aves, de salteadores), corja (de ladrões, de tratantes, de vadios), pilha (de sal, balas ou objectos arrumados), réstia (de cebolla ou alhos), [etc] (Maciel 1926[1894]: 121).

El gramático también explica el proceso de sustantivación de las palabras. Los sustantivos pueden cambiar de categoría interna -propio a común y viceversa- y los adjetivos, verbos y otras clases pueden convertirse en sustantivos mediante el uso del artículo.

El adjetivo se define como la palabra que modifica la comprensión y la extensión del sustantivo. Por comprensión y extensión, entiende el autor, las propiedades semánticas de las palabras que designan, respectivamente, el conjunto de cualidades de un sustantivo y el alcance del significado del 
vocablo a un mayor o menor número de referentes. Estas propiedades son inversamente proporcionales, pues a una mayor comprensión le corresponde una extensión menor del significado representado por el sustantivo.

La categoría se segmenta en adjetivos descriptivos, que atañen a la comprensión, y designativos, que modifican la extensión del sustantivo y equivalen, respectivamente, a los términos calificativos y determinativos. En este punto, Maciel justifica el cambio de terminología por la evolución que ha experimentado la gramática:

Os termos descriptivos e designativos estão mais de accôrdo com a grammatica moderna do que os termos qualificativos e determinativos; apenas têm estes por si o longo uso; mas as nomenclaturas se devem ir modificando, á proporção que se aprofunda o estudo dos factos (Maciel 1926[1894]: 123-124).

Los adjetivos descriptivos se dividen en extrínsecos e intrínsecos. Este último modifica el significado interior del sustantivo y aquél modifica el significado exterior. La organización de los modificantes depende de la relación que estos establecen con el sustantivo, de manera que un adjetivo no es intrínseco o extrínseco por sí mismo sino que se clasifica de este modo en virtud del sustantivo al que acompaña.

Ser extrinseco ou intrinseco depende da significação do substantivo, mas não da do adjectivo, ex.: casa branca (extrinseco), neve branca (intrinseco) (Maciel 1926[1894]: 125).

Forman parte de los adjetivos designativos los demostrativos, los posesivos, los indefinidos, los numerales y los articulares. Respecto a estos últimos, no forman una clase de palabras independientes como solía ser en la primera mitad del siglo XIX. Sin embargo, Maciel mantiene la misma concepción de la gramática racionalista, pues atribuye al adjetivo articular un carácter determinante del significado del sustantivo (Fávero 2006: 182): «designativo 
monosyllabico que individualisa a significação do substantivo de modo positivo e certo» (Maciel 1926[1894]: 126).

Respeto a la diferenciación entre los descriptivos y los designativos, el gramático sostiene que la serie de unidades que componen cada grupo, la posición junto al sustantivo, la conversión en adverbio, la variación de grado y la sustantivación son las propiedades que distinguen unos de otros y, a partir de esas reglas concluye:

Assim é que os descriptivos são adjetivos nominaes e os designativos são pronominaes (Maciel 1926[1894]: 131).

El pronombre o palabra de sustitución es aquella que puede ocupar el lugar del nombre o de cualquier expresión nominativa. Se divide en sustantivo y adjetivo. Considera el autor que los pronombres adjetivos son accidentales y, más que pronombres, son adjetivos que desempeñan esta función. Por ello, se dividen de manera similar: demostrativos, articulares, posesivos, indefinidos y relativos. Hay que mencionar que, para Maciel, los relativos desempeñan dos funciones: la de sustituto del sujeto y la de enlace de proposiciones, como las conjunciones (Maciel 1926[1894]: 131).

Los pronombres sustantivos son solamente aquellos que sustituyen a las personas gramaticales, es decir, los personales, sus formas nominales y las formas de tratamiento, como «Você» y «V. S $\mathrm{S}^{\mathrm{u}}$, también designadas pronombres de referencia -terminología aplicada al sánscrito por Monier (1819-1899)-. Maciel conserva la acepción de los pronombres de tercera persona «Elle» y «Ella» como demostrativos, según la concepción de los gramáticos filosóficos de la primera mitad del siglo.

Maciel define el verbo como la palabra de afirmación y de tiempo que sirve para afirmar y expresar simultáneamente un hecho. Las propiedades del verbo dejan de ser el modo, el tiempo y la persona. En su lugar, Maciel propone la predicación, la personalidad y la conjugación. Las propiedades tradicionales pasan a constituir variaciones de la conjugación. 
La nueva terminología y sistematización de la clase verbal es una característica importante de las gramáticas del último cuarto del siglo XIX. Con todo, no todos los compendios publicados en este periodo admiten novedades. Así, por ejemplo, en la Grammatica Portugueza de João Ribeiro (1887) subsiste la definición del verbo como expresión de acción, estado y existencia, y se mantienen las propiedades de modo, tiempo y persona, además de la división en transitivos e intransitivos.

La primera propiedad, la predicación, se refiere a la integridad de significado del verbo. Maciel distingue entre predicación completa, incompleta y "dupla». Las dos primeras corresponden a la antigua nomenclatura de intransitivos y transitivos. La clase verbal de predicación «dupla» constituye una novedad en la tradición gramatical brasileña. En las gramáticas del último tercio del siglo que aquí se han investigado a saber, las de João Ribeiro (1887), Júlio Ribeiro (1881'-18852) y Alfredo Gomes (1887), no se menciona esta categoría verbal.

Pues bien, según Maciel los verbos de doble predicación son aquellos que necesitan dos objetos o un objeto y un adjunto. En el primer caso, se denominan «biobjetivos» y en el segundo, «transobjetivos». Los de predicación incompleta se segmentan en directos, indirectos y adjuntivos. Los primeros no necesitan el auxilio de la preposición para unirse al objeto, los segundos son regidos por preposición y los últimos exigen un adjunto en lugar del complemento.

En sus estudios sobre la transitividad verbal, Dias $(2005,2008)$ afirma que Maximino Maciel considera que la clasificación del verbo en completos e incompletos de significado no reside en su acepción sino que deriva de su función en la predicación de la oración, y ésta a su vez puede requerir objeto o no. Además, en cuanto al fenómeno de la intransitividad de los verbos transitivos, Maciel es el único gramático de su tiempo que explica la existencia y el funcionamiento del concepto de transpredicação, cuando el verbo cambia de acepción por adecuación al uso. 
El gramático brasileño expone detenidamente el desfase de la teoría de los verbos adjetivos y sustantivos. Argumenta que la decadencia de esta doctrina se debe a los siguientes planteamientos:

1) El verbo ser presenta tres formas diferentes en latín.

2) En el estado actual de la lengua, los verbos adjuntivos (user, estar, ir, vir, andar, permanecer») serían también sustantivos.

3) Ser tiene la misma acepción de existir y acontecer.

4) Muchos de los supuestos verbos adjetivos en no pocos casos no equivalen a «ser+adjetivo».

5) Ser es el único verbo que está sujeto a elipsis.

6) Ser casi siempre desempeña la función de enlace y además no existe en muchas lenguas (Maciel 1926[1894]: 138).

El segundo atributo del verbo se refiere a su personalidad o integridad de forma. Puede ser «indefectivo» si presenta todas las personas y conjugaciones, o defectivo. Maciel divide los verbos defectivos en tres grupos: los impersonales, que no tienen sujeto; los personales, aquellos a los que les faltan algunas personas del verbo; y los unipersonales, que únicamente aceptan las terceras personas del singular y del plural. En cuanto a este último, insiste el gramático en diferenciarlo de los verbos impersonales. Los impersonales expresan en general hechos físicos de la naturaleza, mientras que los unipersonales, en su acepción propia, manifiestan hechos que tan solo pueden ser realizados por animales, aunque puedan ser empleados en acepciones distintas a la primitiva $y$, en este caso, serán uindefectivos»».

Por la tercera propiedad, la conjugación, los verbos para Maciel, se dividen en regulares e irregulares. Clasifica a estos últimos según el tipo de irregularidad en fuertes, débiles, gráficos y anómalos. Se distinguen así los verbos cuya irregularidad respectivamente está en el radical o en la desinencia, los que cambian la grafía para mantener la misma pronunciación y los que no se ajustan a ningún otro grupo. 
Las conjunciones y las preposiciones son consideradas palabras que relacionan y enlazan términos, respectivamente. Las primeras actúan en el ámbito de las palabras, por lo que Maciel las denomina intervocabulares, y establecen relaciones de estado o movimiento. El autor brasileño admite dos tipos de conjunciones: las subordinadas, que aportan a las proposiciones valores de tiempo, concesión, condición, causa, modo, proporción y finalidad. Según Maciel, las conjunciones coordinadas enlazan tanto palabras como oraciones mediante vocablos que expresan aproximación, alternancia, adversidad y conclusión.

Es interesante notar que Maciel prefiere utilizar los términos «aproximativo» y "alternativo» en lugar de "copulativo» y «disyuntivo». Sostiene que toda conjunción es copulativa porque enlaza y que es como mínimo conflictivo adoptar el término «disyuntivo» puesto que la conjunción nunca separa, sino que siempre une (Maciel 1926[1894]: 153).

Maciel reordena el estatuto categorial de determinadas partículas, como las tradicionalmente consideradas conclusivas y adversativas («entretanto, comtudo, todavia»), que en la Grammatica Descriptiva se convierten en adverbios. El gramático justifica este cambio con la explicación de que las preposiciones y conjunciones son elementos inmóviles en la estructura de la proposición, mientras que los adverbios pueden cambiar de posición. Así pues, los adverbios pasan a organizarse en diez grupos: lugar, tiempo, cantidad, afirmación, negación, duda, exclusión, modo, «conclusión» y «concesión».

La «ptoseonomia» en la obra de Maciel se dedica al tratamiento de la flexión de las palabras. En general, las formas de flexión verbal y nominal (número, grado, modo, tiempo y persona) siguen las mismas concepciones de los gramáticos anteriores que, a su vez, se remontan a los principios de la gramática tradicional.

Con respecto al tratamiento del género, Maciel indica que las palabras pueden ser masculinas o femeninas según el sexo natural o usual del referente. Con relación al sexo usual, el gramático aclara que se trata de un concepto que en la lengua se ha extendido por analogía a los objetos y seres inanimados. 
También resalta la inexistencia del género neutro en las lenguas románicas en virtud de su desarrollo, pues los sustantivos neutros del latín han evolucionado a masculinos o femeninos (Maciel 1926[1894]: 158).

Tanto en la Gramática de Maciel como en las demás obras contemporáneas suyas, se admite que el género depende de la significación, la terminación, la acepción, lo que en otras gramáticas corresponde al cambio de artículo, y la referencia, que se da solamente en las palabras «communs a dousı. En cuanto a la acepción, asegura el autor que será siempre el sustantivo femenino el que puede pasar a la forma masculina, pues nunca esta última deriva de la primera $y$, añade que la referencia únicamente discrimina sintácticamente palabras «communs a dous».

Asimismo, a diferencia de las gramáticas de Júlio Ribeiro (1881'18852), João Ribeiro (1887) y Alfredo Gomes (1887), Maciel niega la silepsis de género para justificar que la flexión se indica en la concordancia:

Para explicar estas phrases em que a concordancia se faz por semiosis, buscaram o artificio na pretensa syllepse de genero.

Então occorreria tambem syllepse de genero nos casos de palavras cujo genero estivesse indicado pela accepção (...), assim tambem com os nomres communs a dous.

A pretensa syllepse de genero não existe, porque, sendo ella uma modalidade da ellipse ou omissão de palavras, nenhuma existe, subentendivel nos casos a que nos referimos (Maciel 1926[1894]: 163).

Maciel dedica un $31 \%$ de la lexiologia a la etimología, entendida como el tratado de la constitución del léxico, su origen, formación y derivación. Explica por medio de las leyes etimológicas, que rigen los cambios fonéticos, la evolución de la lengua portuguesa y la procedencia del léxico, que puede ser latina, de lenguas extranjeras y de palabras primitivas del propio portugués. Traza también un panorama de la historia de la lengua desde las invasiones romanas hasta la actualidad. El gramático compara el proceso evolutivo del portugués con el que han experimentado otras lenguas románicas, como el español, el italiano y el francés: 
Assim pois, do latim se originaram os idiomas - portuguez, francez, italiano, hespanhol, valachio e o provençal 30 que tomaram 0 nome de linguas romanas ${ }^{31}$ cujas leis de formação mais ou menos são identicas, ou differetes apenas segundo as influencias mesologicas ${ }^{32}$ (Maciel 1926[1894]: 215).

Reconoce la contribución léxica tanto de lenguas europeas como de las amerindias en la variante brasileña. En el estudio sobre los hibridismos, describe y considera el influjo del tupí, los préstamos griegos, latinos y franceses, entre otros idiomas modernos (Maciel 1926[1894]: 258-260).

Además del estudio del origen y formación de cada una de las clases de palabras y sus flexiones, en el caso del verbo, Maciel analiza el papel de las lenguas subsidiarias del portugués (el árabe, las lenguas germánicas, el griego y las lenguas románicas). El autor amplía los contactos a otros idiomas, a los que denomina «elementos», y de éstos adquieren notoriedad las lenguas africanas $e$ indígenas con aproximadamente seis mil términos, según el autor. Los indigenismos predominan en los campos semánticos relacionados a la flora y fauna (Maciel 1926[1894]: 260).

Las alteraciones léxicas se someten -dice Maciel- a dos leyes biológicas: la asimilación y la disimilación, que corresponden a los fenómenos lingüísticos de introducción y decadencia de vocablos en la lengua, es decir, los neologismos y los arcaísmos. El gramático analiza varios factores que contribuyen a la creación de nuevas palabras: necesidades sociales, la literatura, nuevos descubrimientos en diversas áreas del conocimiento, cambios de hábitos y costumbres. En cuanto a los arcaísmos, señala el autor que las palabras pueden caer en desuso por la corrupción del significado, proceso que denomina «perjoração semántica» y por sinonimia.

\footnotetext{
30 O provençal reduziu ao estado de dialecto da lingua franceza, por não haver conseguido assumir os fóros de lingua de uma nacionalidade políticamente constituida [nota del gramático]. ${ }^{31}$ Ch Seignobos, Histoire de la civilisation; Meyer Lubke, Gram. des langues romanes; Brunot Gram. Historique; Diez Grammaire des langues romanes [nota del gramático].

32 Marc, Manuel de littérature française; Adolpho Coelho, Questões da lingua portuguesa; Theophilo Braga, Hist. Da Lit. Portugueza [nota del gramático].
} 


\subsubsection{El tratamiento sintáctico}

La tercera parte de la Grammatica Descriptiva, la «sintaxologia», está dedicada al el estudio de las palabras según sus diversas funciones y relaciones lógicas. Maciel distingue tres tratados sintácticos: la sintaxis relacional, que analiza la concordancia y la posición de la palabra en la proposición; la sintaxis fraseológica, que se ocupa de las expresiones en su sentido completo, como expresión del pensamiento; y la sintaxis literaria, que trata de la estética o estilística y cómo esta se manifiesta en la proposición.

La sintaxis relacional se ocupa únicamente de las relaciones que puede establecer cada una de las funciones sintácticas. El autor organiza las palabras en seis grupos conforme al papel que ejercen en la proposición. Distingue dos funciones fundamentales (subjetiva y predicativa) y cuatro accesorias (atributiva, objetiva, vocativa y adverbial). La función que desempeña un determinado vocablo en una sentencia deriva de la relación sintáctica y de la interdependencia recíproca que mantiene con otros términos oracionales.

Cabe relacionar el esquema propuesto por Maciel con la doctrina de Girard (1747) sobre las partes significativas de la proposición. La diferencia reside en que éste distingue siete funciones, mientras que aquél lista seis. En este mismo aspecto, se separa también Maciel de Júlio Ribeiro (1881'1-18852), pues su predecesor no hace mención de la función vocativa de la palabra. Además, es patente que el gramático prefiere mantener la nomenclatura original de Girard (1747), «función sintáctica», y no la adoptada por las gramáticas brasileñas anteriores y contemporáneas, «relación sintáctica».

Las partes de la oración son tantas cuantas las funciones sintácticas. Así, a una sentencia simple, que está formada por sujeto y predicado, se le adjudican términos accesorios como un objeto, un vocativo, un atributo o un adverbio. El sujeto es aquel del que se dice algo; el predicado es lo que se dice del sujeto; un atributo es el elemento que modifica al sustantivo sin el auxilio de un verbo; el objeto completa el sentido del verbo de predicación incompleta; y el vocativo es el elemento interjectivo de la oración. Estos son los elementos que expresan 
las funciones sintácticas que, a su vez, pueden ser desempeñadas por distintas clases de palabras.

El análisis del pronombre se y de la partícula o como pronombre demostrativo, el estudio de la sintaxis de la interjección y la llamada concordancia semiótica son las aportaciones más novedosas en esta primera parte de la sintaxis, según se expone a continuación.

Además de las concordancias verbal y nominal, el gramático describe dos nuevas relaciones sintácticas que o bien no se explican por las leyes sintácticas tradicionales, o bien traspasan el ámbito de la oración. Éstas se denominan "concordancia por atracção» y «concordancia semiótica», respectivamente. La primera consiste en la relación que el verbo establece con el adjunto y, por consiguiente, deja de concordar con el sujeto cuando este está representado por un verbo en infinitivo (a), o por un pronombre demostrativo (isso, isto, aquillo) (b), o cuando el adjunto y el sujeto pueden cambiar de función sintáctica (c), o aun cuando el sujeto es colectivo (d):

(a) Perdoar os erros e engrandecer bons intentos é do espírito generoso 33 (Maciel 1926[1894]: 314 [la negrita es mía]).

(b) Isto não são contos arabicos, mas factos certos ${ }^{34}$ (Maciel 1926[1894]: 314 [la negrita es mía]).

(c) A renda de Pedro são mil escados35 (Maciel 1926[1894]: 314 [la negrita es mía]).

(d) Dos Mouros pereceu a maior parte; uns no conflicto, outros na retirada 36 (Maciel 1926[1894]: 315 [la negrita es mía]).

\footnotetext{
33 Rodrigues Lobo, Obras [nota del gramático].

${ }^{34}$ A. Gusmão, apud Sel. de F. Barreto [nota del gramático].

35 A. Freire, Gram. Port [nota del gramático].

$36 \mathrm{Jac}$. Freire, apud Carneiro [nota del gramático].
} 
En no pocos casos la concordancia de género y número no se establece con los elementos de la oración. La Grammatica Descriptiva denomina "concordancia semiotica» a la de tipo extraoracional:

Concordancia semiotica ou latente é aquella em que as flexões não se governam pelas palavras expressas, mas por outras accommodadas ao sentido (Maciel 1926[1894]: 316 [la negrita es mía]).

Así, Maciel explica que tanto los sustantivos cuyo género se determina sintácticamente, es decir, los comunes de dos géneros (artista, intérprete, mártir, etc.), como algunos pronombres personales y de tratamiento ( $V . S^{a}, V$. Ex $x^{a}$, você, etc.) concuerdan con el verbo según el referente extralingüístico que designan. Este fenómeno había sido hasta entonces tema de análisis de la sintaxis figurada o de estilo y se justificaba, por medio de la silepsis, como una transgresión sintáctica.

Los dos nuevos tipos de concordancias citados se aplican, pues, a los casos en que se emplearía la figura de construcción (silepsis) para explicar la relación de género y número entre las palabras. La «concordancia semiótica» y la «concordancia por atracção» son, para Maciel, los recursos gramaticales que permiten sistematizar esta clase de construcciones y, al mismo tiempo, rechazar la silepsis de género:

A syllepse de genero foi sempre o subterfugio a que recorreram os que não aprofundaram os factos da lingua, para os explicarem à luz do bom senso (Maciel 1926[1894]: 163).

La partícula «o» en la Gramática de Maciel pertenece a dos clases de palabras, a los pronombres personales y a los demostrativos. Sintácticamente se le atribuye función de sujeto, de objeto directo e indirecto, de adjunto y de sustituto de frase. En las gramáticas anteriores a la Descriptiva, difícilmente se conseguía clasificar el término.

Así, en la Gramática de Júlio Ribeiro (18811-18852), la partícula «O» se corresponde únicamente con la clase de los pronombres sustantivos personales 
y no se reconoce que puede desempeñar otras funciones sintácticas diferentes a la de sustituto del sujeto. Por su parte, en la obra de João Ribeiro (1887) se advierte que la dificultad en diferenciar el artículo del pronombre y solo mediante recursos etimológicos el autor trata de aclarar la cuestión.

Augusto Freire (18751-18772) y Alfredo Gomes (1887), en fin, son los que más se acercan a la teoría propuesta en la Grammatica Descriptiva. Gomes defiende que «o» puede ser pronombre personal y demostrativo como equivalente de «aquelle» en este último caso. También advierte Gomes que o puede sustituir a más elementos que al sujeto. Pero, a diferencia de Gomes, Maciel se dedica a analizar la sintaxis del pronombre, además de detectar que el término también desarrolla funciones objetivas, atributivas, adjetivas, apositivas y de sustituto de frase.

En cuanto a la interjección, pese a afirmar, como ya se ha mencionado, que esta es una categoría de la que no se debe ocupar la gramática, el autor intenta sistematizar algunas reglas de su sintaxis. Pone de relieve que algunas interjecciones pueden desempeñar la función de vocativo (a) en una oración e incluso la de objeto indirecto (b), como se puede apreciar en los siguientes ejemplos:

(a) $<<$ Oh! Que não sei de nojo como o conte!

E vós ó bem nascida segurança

Da lusitana antiga liberdade>> Camões (Maciel 1926[1894]: 353).

(b) $<<$ Ai do homem que em dia de Mao fado,

(...)

Quiz afogar a dor que a tanto obriga

E ao social banquete festejado

Foi pedir de beber!>> D. Jayme, Ribeiro (Maciel 1926[1894]: 354).

La sintaxis fraseológica es el tratado de las proposiciones y de sus diversas relaciones en la estructura del periodo (Maciel 1926 [1894]: 354). La definición de proposición sigue siendo la tradicional de la gramática filosófica: pensamiento expresado por una o más palabras (Maciel 1926 [1894]: 354), que es la que 
adoptan también todos los gramáticos novecentistas de la tradición brasileña. Sin embargo, Maciel se diferencia de ellos al elegir el término proposición en lugar de frase, oración, cláusula o sentencia, y declara que no son términos sinónimos. Maciel aclara el significado de tales tecnicismos:

O termo oração se refere mais a um discurso inteiro, a uma sucessão de periodos; phrase, a uma expressão peculiar á índole de uma lingua; clausula, á contextura dos contractos jurídicos, as expressões que, dependentes subjetivamente entre si, se esclarecem e se completam (Maciel 1926[1894]: 357).

En esta parte de la obra, el gramático explica que el sujeto y el predicado son las dos partes que forman el periodo que, a su vez, puede ser simple o compuesto. Las proposiciones simples pueden ser de cinco tipos: expositiva, imperativa, optativa, interrogativa y exclamativa, mientras que las compuestas pueden ser coordinadas, subordinadas y complejas. Esta nueva categoría oracional, denominada "complexação», es una innovación en la gramática brasileña en este periodo. Evidentemente, la Grammatica Descriptiva no se limita al análisis de la oración, sino que comienza a extender el análisis sintáctico también hacia estructuras mayores. Esta nueva clase representa un indicio de esta ampliación del conocimiento sintáctico, puesto que las oraciones compuestas por «complexação» consisten en el enlace de dos o más proposiciones subordinadas y coordinadas.

El gramático utiliza diferentes criterios para clasificar las proposiciones. Las oraciones simples se organizan según su modalidad y las compuestas se distinguen por su significado. En la clasificación de las proposiciones coordinadas y subordinadas son aún más complejos los criterios que utiliza Maciel.

Las oraciones coordinadas presentan tres clasificaciones y cada una descansa en un criterio distinto. Pueden ser: 
1) "Sindéticas» O «asindéticas», si se relacionan mediante un conectivo o en ausencia de este.

2) Aproximadas, alternadas, adversativas o conclusivas, según su naturaleza sintáctica.

3) Expositivas, imperativas y optativas, por su función y significado nocional.

Las oraciones subordinadas siguen los mismos criterios y rasgos de las coordinadas, de modo que se dividen en:

1) Conjunccionaes o relativas, si se unen por medio de una conjunción o un pronombre relativo, respectivamente.

2) Sustantivas, adjetivas y adverbiales.

3) Subjetivas, objetivas, atributivas, predicativas y circunstanciales.

En la sintaxis fraseológica de Maciel, la elipsis explica únicamente los procesos de reducción y contracción de la oración. La proposición contracta consiste en la elisión de un término común a dos o más periodos subordinados. La proposición reducida es aquella en que ocurre la elipsis y, consecuente, la sustitución de un elemento sintáctico por otro. Esta clase de proposición difiere de la proposición latente o semiótica, que en esta última no requiere la sustitución de ningún otro elemento, pues su significado se desprende de la oración. En la gramaticografía brasileña por primera vez se distingue la proposición latente de la reducida y se asigna a la primera una interpretación fuera de la sentencia. Dice el autor:

Nestes casos ninguem ha que, tendo o sentimento da lingua, deixe de sentir a ellipse da proposição latente, como integral do pensamento (Maciel 1926[1894]: 373).

En la Grammatica Descriptiva, el verbo ya no ocupa la posición de cópula como en la doctrina logicista. Al contrario, ahora se le concede un 
estatuto central en el sistema proposicional, por lo que pasa a dirigir los demás componentes de la sentencia. Maciel se separa una vez más de la línea racionalista al distinguir tres órdenes oracionales, en lugar de los dos aceptados por la gramática hasta entonces: el directo o analítico, el indirecto o sintético y «transposto» o «interrupto». Explica el autor que un periodo está en orden directo cuando al sujeto se pospone el predicado; en orden indirecto cuando al sujeto se antepone el predicado y, por fin, en orden «transposto» cuando el sujeto está interpuesto en el predicado.

También se mencionan otros fenómenos transpositivos, como la anástrofe (transposición de los miembros de una oración simple), la «hydestrophe» (invasión de los miembros de una proposición en otra) y el hipérbaton (transposición de los miembros de una oración compuesta). Éstos, asevera Maciel, son más habituales en la estructura del verso que en la prosa.

La finalidad del cambio de orden sigue siendo la belleza y armonía en la expresión:

A ordem sempre depende do rythmo phraseologico, isto é, da somma de todos os accentos tonicos que, constituindo a accentuação geral da proposição, conferem á expressão belleza e harmonia (Maciel 1926[1894]: 377).

Con respecto al tema de los verbos impersonales, Maciel sostiene que en general los verbos que expresan fenómenos meteorológicos o naturales son aquellos que, en tercera persona del singular, no tiene sujeto conocido. Este sujeto es en realidad una incógnita «XX) cuyo valor es ajeno a cualquier teorización gramatical, es decir, una incógnita que representa la inexistencia del sujeto (Maciel 1926[1894]: 389).

Maciel se muestra totalmente en desacuerdo con los gramáticos que intentan explicar la impersonalidad de los verbos mediante elipsis del sujeto o mediante la aplicación a la lengua portuguesa de la teoría del pronombre «elle» de la gramática francesa: 
Assim é lógico que, desde que ao verbo se der o sujeito, deixa de ser elle impessoal, porque a defectividade ou falta do sujeito é o caracter fundamental da impessoalidade (Maciel 1926[1894]: 389).

Otras dos observaciones sobre este tema creemos que no habían sido descritas hasta esta Gramática. Maximino Maciel considera que hay verbos impersonales que pueden personalizarse según el contexto y el uso. Además, pone de manifiesto la existencia de otros verbos que no necesariamente expresan fenómenos de la naturaleza, pero que también pueden ser impersonales como «fazen» y «haver»):

Fazia hontem já tarde um nevoeiro espesso37 (Maciel 1926[1894]: 390).

As portas do templo monástico estavam cerradas havia tambem tres dias $^{38}$ (Maciel 1926[1894]: 396).

En la Grammatica Descriptiva se desarrolla especialmente el estudio de la impersonalidad del verbo «haver» y se insiste en que la antigua doctrina del sujeto oculto o latente no justifica este fenómeno lingüístico. Este es, además, uno de los pocos casos en el que el gramático trata de diferenciar el uso americano del peninsular. Maciel resalta los cambios característicos de la variante brasileña en cuanto al uso del verbo haver en dos aspectos principales:

1) Uso de las formas plurales del verbo, en lugar del singular, para marcar la concordancia con el objeto: haviam pessoas por havia pessoas.

2) Sustitución por el verbo ter: tinha muita agua na rua. Asimismo, observa que es un fenómeno que no se circunscribe al uso de un determinado grupo social, sino que es una norma generalizada:

Ainda na linguagem polida se não sanccionou, a substituição frequentissima do verbo haver por ter que constitue uma das feições mais

${ }^{37}$ G. de Azevedo, Selecta de Aulete [nota del gramático].

38 A. F. de Castillo, Quadros Historicos [nota del gramático]. 
características entre o nosso falar e o dos Portuguezes, nas relações familiares (Maciel 1926[1894]: 397).

La sintaxis literaria o estilística es el estudio de la forma exterior y artística de la expresión del pensamiento que tiene como punto de partida las condiciones individuales de producción y la naturaleza del asunto (Maciel 1926[1894]: 421). El gramático concibe la sintaxis como un proceso general y común a todos los individuos, mientras que el estilo es un proceso personal y específico de cada uno. En la sintaxis estilístita estas dos esferas se complementan. Su idea del estilo consiste en que éste es una característica innata del individuo, lo que constituye su forma original, propia y peculiar en la expresión del pensamiento (Maciel 1926[1894]: 420). Maciel también defiende que la constitución de esta personalidad literaria se puede perfeccionar conforme se desarrolla el conocimiento lingüístico.

Las formas de expresión se definen por cuatro rasgos: la precisión, que depende de la brevedad del enunciado; la concisión, que se asienta en la selección de un vocabulario estrictamente necesario; la prolijidad, que consiste en el uso excesivo de palabras de manera innecesaria; y la corrección, que es la aplicación de las normas gramaticales vigentes en la lengua.

Los modos de expresión lingüística pueden ser el verso y la prosa, formas totalmente abiertas a la interferencia y modificación por las figuras de la sintaxis. Son tres los cambios generales que pueden experimentar: cambios de omisión, de exceso y de transposición. El primer cambio se da de cuatro formas distintas denominadas elipsis, zeugma, asíndeton y silepsis. El segundo cambio puede ocurrir por medio de otras cuatro figuras: el pleonasmo, la repetición, el polisíndeton y la partícula decorativa o «hypersintáctica». Por último, el tercer cambio se manifiesta de tres modos: la anástrofe, el hipérbaton y la «hyperstrofe».

La «hypersintáctica» y la «hyperstrofe» son las dos figuras que distinguen la sintaxis literaria de Maciel de las demás gramáticas. La primera es la denominación del uso de palabras generalmente monosilábicas, como la interjección, el pronombre o el adverbio que sirven de adorno y aclaración a la 
frase. La segunda se refiere a la transposición anterior o posterior de los elementos en distintas oraciones.

En cuanto a los vicios de expresión, Maciel distingue entre los léxicos y los sintácticos. Estos son los solecismos y aquellos, los barbarismos. Los vicios léxicos son de cuatro tipos: "cacoepia», cacografía, "dialectismo» y extranjerismo. Los sintácticos son la «sínquise», la cacología, el anacoluto, la "dissinclise» y la perisología. Estos constituyen el grupo de los solecismos por construcción. El eco, la asonancia, el hiato, la colisión y la cacofonía (léase «cacofato») constituyen el grupo de los solecismos por audición.

Una vez más, la Gramática de Maciel se adelanta en la descripción de los hechos lingüísticos pues, por primera vez la gramaticografía brasileña, presenta un estudio detallado sobre los vicios y figuras del lenguaje. La evolución de estos estudios en la tradición académica española ha sido objeto de investigación (Gómez Asencio 2006: 23-80). En las gramáticas de sus predecesores, los vicios se reducían a tres: barbarismo, solecismo y arcaísmo. En cambio, la obra aquí analizada sistematiza las antiguas figuras en dos grandes grupos en los que se organizan todos los fenómenos, generalmente dispersos en otras gramáticas.

\subsubsection{La nueva semiología}

Antes de empezar el examen de la semiología, es relevante mencionar la originalidad que atribuye Maciel a esta parte de su trabajo. Afirma que la sistematización es de su propia autoría y que la extensión del estudio también es obra suya. Fávero y Molina (2006) cuestionan este hecho y argumentan que Augusto Freire (18751-18772) ya había estudiado e insertado la semiología en la Gramática Descriptiva.

Un breve análisis comparado de las gramáticas de Freire (18751-18772) y Maciel (1887[1894]) muestra que pese a que Freire había sido el primero en incluir el estudio semántico en su compendio, de hecho la sistematización, el 
desarrollo y la profundización de estos estudios tuvieron lugar en la Grammatica Descriptiva. La semiología de Freire se divide en exegética y técnica, esta con veinte páginas y aquella con tres, mientras que la semiología exegética de Maciel tiene dieciocho páginas y la técnica seis. Estas cifras muestran que el estudio de Maciel es, en efecto, algo más extenso que el de Freire.

En cuanto a la sistematización y el contenido del apartado también se observan diferencias, pues la «semiologia» de la Grammatica Portugueza (1875118772) estudia solamente las dieciocho causas particulares de los cambios de sentido de las palabras, mientras que la Grammatica Descriptiva examina cinco sistemas de significación: propia, traslata, etimológica, técnica e histórica; y tres tipos de alteraciones semánticas: «meliorativa», «pejorativa» y «neutra», que están sometidas a dos leyes: la generalización del particular y la especialización del general. Además, la tropología, mucho más concisa, forma parte de la semiología en esta Gramática, mientras que en aquella se incluye en la sintaxis literaria, pero sin nomenclatura. Por todo ello, parece que la aseveración de Maciel es totalmente justificada:

A systematisação da semiologia é toda nossa, pois ninguem, mais do que nós, Ihe deu maior desenvolvimento, tornando-a um corpo de doutrina (Maciel 1926[1894]: 467 [la negrita es mía]).

El tratado de la significación de las palabras se divide en semántica y tropología. Esta se dedica al estudio de los fenómenos relativos a la significación de los vocablos y a las acepciones que adquieren en la proposición. La semántica de Maciel aborda cambios y alteraciones de sentido en la evolución de la lengua a través del tiempo y del espacio.

Maciel divide la significación en cinco categorías: la propia, cuando la palabra es utilizada en su valor general; la traslata, cuando la designación propia se extiende a otros usos y por eso pierde significado; la etimológica, que constituye el conjunto de los significados originarios de cada vocablo, lo que le da su sentido completo; la técnica, que se refiere al vocabulario específico de 
las distintas áreas del conocimiento; y la histórica, que abarca las palabras originadas de hechos sociales como descubrimientos, inventos, etc.

Las alteraciones semánticas, según Maciel, consisten en el cambio del significado durante el desarrollo de la lengua en virtud de la variación temporal, espacial y social. Las palabras pueden cambiar de su significado propio a un concepto noble. En este caso será una alteración «meliorativa», o a un concepto despreciativo, que consiste en una alteración «pejorativa», e incluso cambiar de un significado a otro sin valor positivo o negativo.

Las leyes que rigen estas alteraciones, según Maciel, pueden ser de generalización del particular, cuando una palabra que antes se podía aplicar en varios contextos con el tiempo se especializa, y la especialización del general, que se asienta en el uso general de un vocablo que antes solo se podía emplear en situaciones específicas. Asimismo, las mudanzas de género, número y posición en la oración también pueden afectar a los sentidos de los vocablos.

De acuerdo con las doctrinas de Max Müller (1823-1900), el gramático manifiesta tres causas para las alteraciones semánticas: la alteración fonética, los cambios dialectales y los tropos, aunque sugiere la existencia de otras más. También reconoce la influencia de Bréal (1832-1915) en cuanto a la explicación de los cambios de significado por alteraciones fonéticas.

Segundo Max Müller, tres são as causas das alteração semántica: a alteração phonetica, dialectação e os tropos ${ }^{39}$; mas são tantas as causas, que escapam a qualquer systematisação.

Além disto, a significação póde sobreviver á alteração phonetica e até aproveitar-se desta40 (Maciel 1926[1894]: 475).

Las influencias de las ideologías positivistas y naturalistas se manifiestan respectivamente de dos modos en esta parte de la Gramática: en la reducción del número de tropos a cuatro (metáfora, metonimia, catacresis y sinécdoque),

\footnotetext{
${ }^{39}$ Max Müller, La Science du langage [nota del gramático].

40 Michel Bréal, Mythologie et Linguistique, pag. 300 [nota del gramático].
} 
y en la teoría del parasemismo, una clase de parasitismo lingüístico que estudia la absorción del significado de unos vocablos por otros.

En la penúltima parte de la obra, Maciel explica el uso de los signos gráficos en la lectura y redacción, y resalta que estos usos pueden variar según las provincias, los países, las personas y las intenciones a las que está expuesta la lengua. Finalmente, en la última parte muestra los análisis sintácticos de todos los tipos de oraciones coordinadas y subordinadas, en los que señala detalladamente cada función sintáctica y semántica de la oración.

\subsubsection{Estudios dialectales}

Maciel también aporta un detallado análisis de la construcción dialectal de la lengua portuguesa en Brasil. Las circunstancias que, en su opinión, favorecen la expansión de nuevos dialectos son la acción del ambiente (clima y localización), la coexistencia de dos o más lenguas en un mismo medio, el nivel de instrucción de la población, la lejanía entre la patria de la lengua y las nuevas regiones (colonia y metrópolis) y la ruptura de los lazos políticos, con la consiguiente autonomía y conversión del dialecto en lengua oficial.

Las características básicas que, según Maciel, diferencian una lengua de un dialecto son la diferenciación prosódica, la deformación de la significación, la coexistencia de vocablos regionales y la formación de construcciones no sintácticas. Evidentemente, para Maciel, las condiciones en las que se encuentra el país hacen del territorio brasileño un sitio propicio para el desarrollo de los dialectos:

Collidando o Brasil com todos os paizes da America, excepto com o Equador e o Chile, desde o norte e u oeste até o sul, é natural que se tenham desenvolvido codialectos nas fronteiras por transfusão, infiltração, alteração phonica e significativa de vocabulos, reciprocamente, das línguas collindantes ou limitrophes. (Maciel 1926[1894]: 449) 
Maciel distingue tres regiones dialectales en Brasil, en las que el portugués disuena tanto de la lengua culta y literaria como de la variante portuguesa: el «brasiloguyanense» o septentrional, el «brasilocastelhano» o meridional y el idiodialecto -estaduales o centrales-.

En la región norte del Amazonas, en virtud del contacto con las Guayanas fronterizas, la lengua portuguesa se caracteriza por la influencia del inglés, el holandés y el francés:

Ahi se estão collidindo, transfundindo e modificando vocabulos portuguezes, (...) em que excellem os termos concernentes á flora, á fauna, aos actos mais communs e ás imprescindencias ou necessidades quotidianas (Maciel 1926[1894]: 449 [la negrita es mía]).

Al oeste y sur de Brasil, principalmente el estado del Rio Grande do Sul, ha recibido la infiltración e influencia del castellano:

A codialetação local attinge as proporções de patente facto glótico, desde logo denunciavel a quem quer que por instantes ahi perlustre as nossas fronteiras (Maciel 1926[1894]: 449).

Los influjos han llegado a la conversación familiar, sobre todo en el vocabulario de los hechos cotidianos, de los objetos típicos de cada lugar, pero está presente también en la literatura. Según el autor, la influencia del español no se limita a la esfera léxica, pues también se extiende a la sintaxis y la prosodia.

Con todo, la comparación lingüística más exhaustiva se aplica a la diferenciación entre el portugués hablado en Portugal y en Brasil. El gramático observa diferencias prosódicas, léxicas y algunos cambios sintácticos, aunque en este último caso Maciel se muestra más prescriptivo que descriptivo:

Entretanto se não desculpam os brasileirismos de construcção, as expressões dyssyntacticas que não passam de inacceitaveis deslises, por isso que a liberdade, no exprimir os nossos juizos, nas nossas idéas, se tem de mover dentro da ordem de das normas da lingua; do contrario será 
anarchia, licença, indisciplina, de feito que ninguém se entenderá por fim, principalmente no Brasil com dez milhões de kilometros quadrados (Maciel 1926[1894]: 455).

Los principales rasgos sintácticos del lenguaje brasileño son: el empleo de las formas pronominales «elle», «ella» como objetos directos (a); el empleo de la forma pronominal «mim» como sujeto del infinitivo cuando es regido por la preposición para (b); el uso de la preposición em en lugar de a delante de verbos de movimiento (c); la posición de las formas pronominales (d); el uso del verbo ter en lugar de haver (e), entre otros «brasileirismos»:
(a) Vi elle [ por O vi]
(b) Para mim comer [por Para eu comer]
(c) Foi no jardim [por Foi ao jardim]
(d) Eis aqui o lugar onde eclipsou-se o meteoro fatal ás regias fontes (J. Magalhães) [por ...onde se eclipsou]
(e) Tem muitos lugares [por há muitos lugares] (Maciel 1926[1894]: 443).

\subsubsection{Resumen}

Las influencias de las corrientes histórico-comparadas, la adhesión a las doctrinas positivistas y naturalistas, así como el rigor en la descripción gramatical del portugués orientan la Grammatica Descriptiva de Maciel hacia un nivel de cientificidad que no se había alcanzado en otros compendios del periodo.

Aunque se le concede a las gramáticas descriptivas, en general, cierta intención pedagógica e incluso que este sea uno de los objetivos de la Grammatica Descriptiva, el análisis que aquí se ha presentado muestra que los logros de la obra son más científicos que propiamente didácticos. El tratado de Maciel va más allá del propio arte, no se limita a la clasificación, definición y estudio de los hechos, anomalías y reglas de una lengua a partir de una u otra tendencia metodológica, sino que avanza más bien hacia la teorización y sistematización de la lengua portuguesa en el contexto brasileño. 


\section{TERMINOLOGÍA Y terminOgRAFía en LA GRAMÁtiCA BRASILEÑA DEL SIGLO XIX}

\subsection{Interés historiográfico del metalenguaje}

En el campo de la Historiografía Lingüística del portugués todavía escasean los estudios sobre la terminología gramatical'. Por un lado, la mayoría de las investigaciones disponibles acerca de este tema se limita a aspectos generales sobre la elección de los gramáticos entre unos y otros términos y, en algunos casos, sobre los factores que pueden haber influido en la adopción o creación de una terminología en lugar de otra. En general, esta información no constituye el objetivo principal de los trabajos, pues apenas se encuentran referencias ocasionales a este tema en algunos análisis gramaticográficos, normalmente asociadas al influjo de las fuentes teóricas. Pero el tratamiento de la terminología suele carecer de método y sistematización. Por otro lado, en muchos casos los estudios terminológicos se centran en el análisis de diccionarios, como los trabajos de Gonçalves (2002c) y Verdelho (1998).

Respecto a los estudios historiográficos sobre la tradición gramatical brasileña, son raras las ocasiones en que se proporciona alguna observación acerca de la terminología y el vocabulario empleados por los gramáticos. Tampoco se ha valorado suficientemente la importancia de la nomenclatura técnica para precisar la evolución del pensamiento gramatical. Al parecer, este es un tema que aun no ha tenido mucha difusión entre los investigadores de esta tradición.

\footnotetext{
1 Recientemente, Swiggers (2009b) ha puesto de relieve que «el campo de la terminografía lingüística es un campo muy amplio, en el cual mucho queda por hacer, a la vez a nivel de estudios históricos y a nivel de reflexión metodológica» (Swiggers 2009b: 28).
} 
Pierre Swiggers (2006a, 2009b) ha señalado en diversas ocasiones la importancia del «estudio terminológico y terminográfico² de la terminología gramatical») (Swiggers 2009b: 11) para la Historiografía Lingüística. En efecto, el autor asegura que este tipo de análisis constituye una contribución fundamental para la comprensión de las estructuras lingüísticas en sí mismas (origen, evolución, cambios, etc.) y, en conjunto, para la interpretación de los cambios de doctrinas, periodos, tradiciones o modelos gramaticales:

Es la terminología del gramático [...] la que nos informa sobre la articulación de la gramática, y es ella la que hace resaltar el grado de explicitud y la que sustenta la argumentación del autor. De esta manera, el examen de la terminología de obras gramaticales [...] ofrece un cuadro criteriológico para un rastreo metodológico del quehacer gramatical [...] que se halla en ellas (Swiggers 2009b: 12).

Un estudio sistemático de la terminología gramatical brasileña puede aportar avances para la concepción actual de la evolución de la gramática decimonónica en Brasil y, comparativamente, poner de manifiesto las influencias, las innovaciones y las divergencias terminológicas (y teóricas) propias de cada gramático.

Pues bien, teniendo en cuenta el contexto de la terminografía lingüística del portugués, el objetivo de este capítulo es proporcionar una descripción terminográfica (no exhaustiva) de la terminología gramatical brasileña decimonónica a partir del análisis «histórico-terminográfico» (Quijada Van Den

\footnotetext{
2 En cuanto al problema de la definición de terminología y terminografía véase Terminologie et Terminographie linguistiques: problèmes de dèfinition et de calibrage (Swiggers 2006a). Aunque Pierre Swiggers (2009b) explica brevemente que «la primera [la terminología] sirve de objeto de descripción para la segunda [la terminografía], ésta tiene que apoyarse en una terminología teórica. Pero las dos comparten ciertas tareas: la de descripción (de "objetos"), la de transmisión y la de normalización; el último aspecto es más importante para la terminografía. La terminografía, apoyándose en una terminología teórica, implica tres dimensiones epistemológicas: (1) la dimensión de reflexión sobre el "sujeto conocedor" y el "objeto de conocimiento"; (2) la dimensión de reflexión sobre las prácticas sociales en relación con el uso de términos; (3) la dimensión de reflexión sobre las relaciones entre lenguaje, cultura y conocimiento» (Swiggers 2009b: 13).
} 
Berghe y Swiggers 2009b) contrastivo de las gramáticas más representativas de esta tradición publicadas en el siglo XIX.

La metodología adoptada en este estudio está basada fundamentalmente en los trabajos de Swiggers titulados La terminologie de la description du pronom dans la grammaire française du seizième siècle (2001), Terminologie et Terminographie linguistiques: problèmes de dèfinition et de calibrage (2006) y Terminología gramatical y lingüística: elementos de análisis historiográfico y metodológico (2009), entre otros textos de referencia.

En sus trabajos, Swiggers elabora un modelo metodológico para el estudio de la producción gramaticográfica, desde su punto de vista, aplicable especialmente a las tradiciones francesa y española. Por nuestra parte, creemos que este modelo puede (y debe) ser aplicado a otras tradiciones gramaticales.

El «análisis sistemático» que propone Swiggers (2009b) tiene en cuenta diferentes variables que afectan a la terminología gramatical (y lingüística), como por ejemplo la relación entre terminología y «aproximación descriptiva (y/o "evaluativa")» presente en un autor, obra o escuela; la reciprocidad entre la continuidad (y discontinuidad) de la descripción lingüística y de la terminología, y la dimensión conceptual de la terminología (Swiggers 2009b: 1314).

El autor también llama la atención sobre ciertos «marcos tipológicos» que ayudan a determinar «los procesos de constitución, de transformación/ adaptación y de transmisión de conjuntos terminológicos o de distintos términos técnicos» (Swiggers 2009b: 15), que son los tipos de tradiciones terminológicas (la formación de los términos), los tipos de «transferencia conceptual» (la procedencia de los términos) y tipos de estrategias de adaptación (la remodelación de la terminología a nuevas lenguas y gramáticas) (Swiggers 2009b: 15-18).

Antes de establecer el "guión metódico» del trabajo terminográfico, Swiggers determina «los fundamentos epistemológicos del examen metodológico» y el "cuadro sistemático» que sirve de base para el análisis. Los fundamentos se refieren a los componentes referenciales de una terminología 
lingüística (el contenido de la terminología), a la doble referencia de una terminología (a la teoría y al lenguaje), a la relación entre términos y conceptos y al estatuto lingüístico-informativo de una terminología; mientras que el cuadro sistemático está relacionado con los constituyentes terminológicos, el alcance de la terminología («terminología émica» y «terminología ética») y los condicionantes teórico-metodológicos (sistematicidad, economía, coherencia, etc.) (Swiggers 2009b: 18-23).

Finalmente, la descripción y el análisis sistemático de la terminología precisan, en primer lugar, los niveles de análisis que son, básicamente, los siguientes:

1) Análisis «monográfico» [...]: el tipo de análisis que se focaliza en la terminología de una obra o de un autor.

2) Análisis contrastivo o comparativo: el tipo de análisis que consiste en confrontar y comparar la terminología de varios autores [...] con referencia al mismo «objeto» [...].

3) A partir de trabajos analíticos se puede elaborar una síntesis, en la cual se estudia una terminología [...] vinculada a «un campo de referencia», en relación con los distintos aspectos de la descripción (y explicación) de este campo. Este estudio se puede (o se debe) limitar con respecto a un periodo histórico, a una tradición (nacional), a un (tipo de) modelo lingüístico (Swiggers 2009b: 24).

En segundo lugar, hay que tener en cuenta los «parámetros de construcción, inserción y funcionamiento de un "producto gramaticográfico"ll (autor, público, objeto de descripción, organización descriptiva, entre otros), además del origen, la naturaleza y la definición de los términos.

Por último, es importante «efectuar el "calibraje" de los términos» a partir de la determinación del campo de referencia de los términos y del reconocimiento de los procedimientos de definición, siguiendo el esquema que se muestra a continuación:

1) Campo de referencia de términos:

a) Términos idénticos en forma y contenido.

b) Términos formalmente idénticos, pero con contenido diferente. 
c) Términos formalmente idénticos y con contenido más o menos idéntico, pero con una aplicación diferente.

d) Términos formalmente diferentes, pero con contenido idéntico (o equivalente).

e) Términos formalmente diferentes, con contenido diferente, pero con una aplicación más o menos equivalente.

f) Términos formalmente diferentes y con contenido y aplicación diferentes.

2) Procedimientos de definición:

a) La incidencia de la definición (definitio rei o definitio nominis)

b) El contenido de la definición (definición esencial, formal o funcional).

c) La forma lingüística (por predicación copulativa, por predicación final, por predicación inclusiva o estipulativa) (Swiggers 2009b: 27-28).

En este sentido, el análisis terminológico y de descripción terminográfica de las gramáticas brasileñas decimonónicas pretende «definir los rasgos, la estructuración, los parámetros definitorios, la extensión y el alcance de [las] terminologías» (Swiggers 2009b: 18). A partir de esta descripción, se desprenderá el análisis contrastivo de la terminología de Antonio de Moraes Silva (1806),

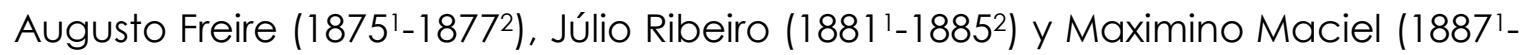
18942) y, por consiguiente, una síntesis (parcial) que compruebe la evolución de la terminología (y la doctrina) gramatical brasileña de este periodo.

\subsection{Terminología y terminografía de las partes de la gramática}

Esta descripción terminográfica se dirige primeramente a la terminología relacionada con la «macroestructura» de la gramática. En general, las gramáticas presentan cambios terminológicos con la finalidad de, por un lado, romper con la tradición (introducir nuevas teorías) y, por otro, alcanzar la simplificación y adecuación teóricas. El éxito de este vocabulario está casi siempre condicionado al cambio teórico o de contenido, pues la gramática tiende a preservar su metalenguaje tradicional (Lliteras 1996a: 132). En este 
sentido, la «temporalidad» y el grado de estandarización de un término pueden reflejar la vigencia y aceptación de un modelo o de una doctrina.

No obstante, la tendencia a la conservación del metalenguaje es una característica de la mayoría de las gramáticas de la tradición española y francesa (Lliteras 1996a), que también puede extenderse a estas obras brasileñas. La primera mitad del siglo XIX está marcada por la predominante influencia de la corriente racionalista, herencia de las escuelas europeas, en especial la francesa y la portuguesa. En cambio, en la segunda mitad del siglo, los autores brasileños aplican a la descripción del portugués las doctrinas histórico-comparada y positivista (especialmente los modelos alemanes) que, consecuentemente, determinan ciertos cambios de terminología.

\subsubsection{De la etymologia a la morphologia}

Las gramáticas de la primera mitad del siglo (representadas aquí por el Epítome de Moraes Silva) ${ }^{3}$ siguen las tendencias portuguesas en la «organización descriptiva» y en el vocabulario de las partes de la gramática. Con respecto a la segunda mitad del siglo, las innovaciones procedentes de los modelos históricocomparado y positivista han influido considerablemente en las obras de Augusto Freire, Júlio Ribeiro y Maximino Maciel.

Antes de proceder al análisis terminográfico, es importante ubicar nuestras fuentes primarias en la cronología de los términos (desde la «etymologia» hasta la «morphologia»).

Pues bien, en cuanto al Epítome, Moraes Silva denomina la primera parte como "Livro I-das palavras por si sós ou partes da sentença», sin que el autor presente variaciones para este término. Como el propio título indica, la primera parte corresponde, aproximadamente, a lo que después se llamaría «morfología».

\footnotetext{
${ }^{3}$ En el caso de que de este autor no se desprenda un comportamiento generalizado en cuanto a la terminología, se incluirá, además, la nomenclatura de otros gramáticos de la tradición brasileña.
} 
En la tradición gramatical portuguesa, Lobato (1770) utiliza el término «etymologia» y Dias de Souza (1804) no solo cambia el término sino también el contenido, pues emplea «orthologia» para referirse al estudio de los elementos que constituyen la palabra, el valor y etimología de los vocablos, la prosodia y la sintaxis.

La mayoría de los gramáticos brasileños posteriores a Moraes, como Frei Caneca (1817), Pereira Coruja (1835) y Sotero dos Reis (1865) conservan el término tradicional de «etymologia». En este mismo periodo, el gramático Olivier Grivet (1865) propone un cambio de terminología, que consiste en la sustitución de «etymologia» por «lexicologia». Augusto Freire sigue a Grivet (1865) al emplear el término «lexicologia». En cuanto a la Grammatica Portugueza de Júlio Ribeiro (1881), el autor mantiene la división en dos partes, como Moraes Silva, pero nombra los estudios con la palabra «lexeologia». Los autores posteriores a Ribeiro, como Silva Jr. y Lameira de Andrade (1887), siguen la propuesta del gramático mineiro cuando denominan esta parte de la gramática «lexeologia». Alfredo Gomes (1887), en cambio, llama «morphologia» al estudio de la palabra, pero acepta como equivalente el término «lexicologia». João Ribeiro (1887), por su parte, cambia el término y el contenido, pues divide la «lexeologia» en dos partes, denominadas «morphologia» (u «organographia») y «classificação» (o «taxinomia»). Finalmente, Maximino Maciel emplea el término «lexiologia».

En la tabla siguiente se puede observar, de manera esquemática y ordenada cronológicamente, la evolución desde «Livro I-das palavras por si sós ou partes da sentença» hasta «lexiologia»:

\begin{tabular}{|c|c|c|}
\hline Autor & Término & Equivalente \\
\hline Moraes Silva (1806) & $\begin{array}{c}\text { Das palavras por si sós ou } \\
\text { partes da sentença }\end{array}$ & \\
\hline Frei Caneca (1817) & Etymologia & \\
$\begin{array}{c}\text { Pereira Coruja (1835) } \\
\text { Sotero dos Reis (1865) }\end{array}$ & \\
\hline
\end{tabular}




\begin{tabular}{|c|c|c|}
\hline Olivier Grivet (1865) & Lexicologia & \\
\hline Augusto Freire (1875) & Lexicologia & \\
\hline $\begin{array}{c}\text { Júlio Ribeiro (1881) } \\
\text { Silva Jr. y Lameira (1887) }\end{array}$ & Lexeologia & \\
\hline Alfredo Gomes (1887) & Morphologia & Lexicologia \\
\hline João Ribeiro (1887) & Morphologia & Organographia \\
\hline Maximino Maciel (1894) & Lexiologia & \\
\hline
\end{tabular}

Tabla 6.1 Términos para el estudio de las clases de palabras

La expresión «Livro I -das palavras por si sós ou partes da sentença» solo es utilizada por Moraes Silva para referirse al mismo contenido de la parte tradicionalmente denominada «etymologia», término este último que en Brasil sobrepasa la primera mitad del siglo XIX. En cambio, la iniciativa de Moraes Silva, encaminada más bien hacia la definición de la disciplina que hacia la verdadera denominación de una materia, no se estandariza, de modo que forma parte del grupo de propuestas episódicas o de temporalidad breve.

Los términos «lexicologia», "lexeologia» y «lexiologia» solamente son citados en algunas gramáticas (temporalidad breve), razón por la cual no se estandarizaron en la tradición brasileña. De la Gramática de Grivet (1865) para la Gramática de Freire, el término «Lexicologia» mantiene la misma forma pero amplia su contenido (la relación entre término y concepto no es unívoca). Ribeiro, por su parte, sustituye el término «lexicologia» por «lexeologia» y conserva el concepto establecido por Freire. Finalmente, Maximino Maciel no solamente modifica la forma («lexiologia») y el contenido (excluye la fonología) de esta parte de la gramática sino también trata de justificar el cambio de terminología:

O termo lexicologia, geralmente usado, não explica satisfactoriamente essa parte da grammatica, pois lexicon significa diccionario; assim lexicologia será o tratado do diccionario; diga-se pois, lexiologia (Maciel 1926[1894]: 79). 
No obstante, el término adoptado por Maciel ya había sido utilizado por Freire para referirse a la «tambem chamada taxionomia, é a classificação das palavras em varias espécies ou categorias») (Freire 1894[1875]: 90). Así pues, el término «lexiologia» en la gramaticografía brasileña corresponde a diferentes conceptos.

A partir de Augusto Freire, la organización de la gramática se muestra más compleja. Los autores crean divisiones dentro de la macroestructura y, consecuentemente, emplean una nueva terminología (o aprovechan términos antiguos) para nombrar los nuevos contenidos. Así pues, Freire divide la «lexicologia» en tres partes:

1) «Phonologia»

a) «Phonetica»

b) «Prosodia»

c) "Orthoepia»

2) «Lexigraphia»

a) «Phonographia»

b) «Orthographia»

c) "Semiographia»

3) "Morphologia»

a) «Lexiologia»

b) "Organographia»

- «Flexionismo»

- «Etymologia»

Júlio Ribeiro, por su parte, divide la «lexeologia» en dos partes:

1) «Phonologia»

a) «Phonetica»

b) «Prosodia»

c) "Orthographia» 
2) «Morphologia»

a) "Taxeonomia»

b) «Kampenomia»

c) «Etymologia»

Al contrario de sus predecesores, Maximino Maciel confirma la "phonologia» como parte independiente de la gramática al lado de la «lexiologia». Los términos que utiliza para denominar las partes de estas dos materias son los siguientes:

«Lexiologia»

1) «Morphologia»

2) "Taxinomia»

3) «Ptoseonomia»

4) «Etymologia»

«Phonologia»»

1) «Phonetica»

2) «Phonografia»

3) «Prosodia»

4) "Orthographia»

La tabla siguiente muestra la terminología empleada por cada gramático considerando la equivalencia de los contenidos:

\begin{tabular}{|c|c|c|c|}
\hline Augusto Freire & Júlio Ribeiro & Maximino Maciel & Equivalente \\
\hline \multicolumn{4}{|l|}{ Phonologia } \\
\hline & Phonologia & Phonologia & \\
\hline \multirow[t]{2}{*}{ Morphologia } & Morphologia & & \\
\hline & & Morphologia & $\begin{array}{c}\text { Elementos morphicos das } \\
\text { palabras (M. Maciel) }\end{array}$ \\
\hline
\end{tabular}




\begin{tabular}{|c|c|c|c|}
\hline Lexigraphia & & & \\
\hline Phonetica & Phonetica & Phonetica & $*$ \\
\hline Prosodia & Prosodia & Prosodia & $\begin{array}{c}\text { Accentuação (J. Ribeiro/ } \\
\text { Orthophonia u orthoepia } \\
\text { (M. Maciel) }\end{array}$ \\
\hline Orthoepia & & & \\
\hline Phonographia & & Prthographia & \\
\hline Orthographia & Orthographia & Taxinomia & Taxionomia (A. Freire) \\
\hline Semiographia & & & Flexiologia (A. Freire) \\
\hline Lexiologia & Taxeonomia & Etoseonomia & (A. Freire)/ \\
\hline Organographia & & Eorphogenia o lexiogenia \\
\hline Flexionismo & Kampenomia & & Lexeogenia (J. Ribeiro) \\
\hline Etymologia & Etymologia & & \\
\hline
\end{tabular}

* Terminología referente a la «phonologia», parte Independiente de la «lexiologia» en la obra de Maciel.

Tabla 6.2 Terminología de la «lexeologia»

Augusto Freire fue uno de los primeros gramáticos de su tradición que utilizó el término «phonologia» para designar el estudio «dos sons articulados» (Freire 1894[1875]: 25), posiblemente debido a la influencia positivista (préstamo). Del mismo modo que su modelo teórico, este término gozó de buena aceptación entre los gramáticos posteriores, como Júlio Ribeiro y Maximino Maciel. Sin embargo, en las gramáticas de estos autores, la «phonologia» amplía su contenido, aunque no presenta variación de forma, de modo que al término «phonologia» corresponden diferentes conceptos. En el caso de Ribeiro, la «phonologia» incluye, además, el estudio de la representación gráfica de los sonidos («lexigraphia»). Maciel, por su parte, independiza la «phonologia», pero conserva la concepción (término + concepto) de Ribeiro.

El término «morphologia» se desarrolla de modo semejante a la «phonologia», pues ambos términos están vinculados al mismo modelo 
gramatical. Tanto Ribeiro como Freire consideran que la «morphologia» corresponde al estudio de las palabras «como seres já organizados, constitutivos da linguagem» (Freire 1894[1875]: 90) (clasificación, flexión y origen). Por su parte, Maciel circunscribe el contenido de la «morphologia» al estudio de los «elementos materiaes ou fórmas exteriores» (Maciel 1926[1894]: 80) de las palabras, es decir, el prefijo, el radical y el sufijo.

De acuerdo con los datos mencionados, el término «lexigraphia» presenta solamente una incidencia en las gramáticas brasileñas de este periodo (temporalidad breve). Augusto Freire es el único autor que emplea este término para referirse al estudio de la representación gráfica de los sonidos, contenido que corresponde actualmente a la ortografía.

El término «phonetica» está presente en la mayoría de las gramáticas brasileñas que se apoyan en el modelo historicista. Para Freire, este término se refiere tanto al estudio de los «sons articulados relativamente aos órgãos que o formam» (Freire 1894[1875]: 26) como a la descripción de las «leis que determinam a transformação dos sons nas diversas idades da lingua». En cambio, Ribeiro y Maciel consideran que la «phonetica» no hace referencia a este aspecto histórico y restringen su definición al «estudo do phonema» (Maciel 1926[1894]: 5).

El uso del término «prosodia» en las gramáticas brasileñas se debe a la influencia de la tradición más generalizada. A pesar de que este término no ha experimentado cambios en su forma y contenido, su localización en la gramática se ha modificado. En esta línea, en las gramáticas finiseculares analizadas, el término «prosodia» hace referencia a la «quantidade e [...] accentuação dos phoneması (Maciel 1926[1894]: 33). Respecto a este tema, cabe destacar además que Maciel se muestra consciente del problema terminológico al poner de relieve el arraigo del término «prosodia» en el metalenguaje gramatical y la dificultad de sustituirlo por otros términos, según el autor, más contemporáneos y adecuados al nuevo modelo teórico: 
A prosodia tambem se diz orthophonia orthoepia, termos mais expressivos, mais lógicos do que prosodia, mas este prefere-se por mais usado e mais familiar, apesar de que Soares Barbosa, contrario á doutrina de Sotero dos Reis, estatue differença entre prosodia e orthoepia: esta para as linguas vivas, e aquella para as mortas (Maciel 1926[1894]: 33).

El término «orthoepia» presenta solamente dos incidencias en la gramaticografía de este periodo (temporalidad breve). Es utilizado por primera vez en la Gramática de Freire en referencia al estudio de la pronunciación desde las perspectivas diacrónica y diatópica (Brasil, Portugal y sus regiones). La segunda incidencia ocurre en la Gramática de Maciel, que menciona este término como variante de «prosodia». Así, para estos autores el término «orthoepia» no responde a la misma concepción.

La «orthographia» constituye otro término que tradicionalmente forma parte del metalenguaje gramatical. Su evolución en la tradición brasileña acompañó el mismo proceso de desarrollo de la «prosodia», pues este término se mantiene sin cambios tanto en la forma como en el contenido, pero su posición en la «organización descriptiva» se modifica.

Los términos "semiographia» y «phonographia» fueron utilizados en esta tradición únicamente en las obras de Freire y Maciel. Con relación a Freire, se puede observar la diferencia del contenido para cada término: la «phonographia é o estudo das letras consideradas em sí mesmas» (Freire 1894[1875]: 58), mientras que la «semiographia trata das notações léxicas» (Freire 1894[1875]: 84). Sin embargo, según Maciel, estos términos son equivalentes y se refieren a un mismo contenido (letras + notações). Así, al comparar el término «semiographia» en las dos obras, es evidente que constituye un caso de términos idénticos, pero de contenido diferente. Esta misma idea puede extenderse al término «phonographia». En su definición, Maciel pone de manifiesto no solamente el origen del término "semiographia», resultado de la influencia del gramático portugués Adolpho Coelho, sino que también trata de establecer la equivalencia entre los términos: 
Alguns glotologos imperfeitamente designam esta parte da phonologia sob o nombre de phonica; mas, ao nosso ver, empregue-se o termo semiographia, que já se acha em Adolpho Coelho, designando o estudo descriptivo dos signaes ou symbolos, próprios da linguagem graphica.

O termo semiographia, é mais significativo, mais vasto do que phonica; constitue por si a sciencia dos signaes ou symbolos que podem mudar de aspecto de povo a povo.

Estes symbolos são as letras e as notações léxicas, cujo estudo methodico constitue a semiographia ou phonographia (Maciel 1926[1894]: 22).

Los términos «lexiologia», «taxeonomia» y «taxinomia», empleados respectivamente por Freire, Ribeiro y Maciel, constituyen un caso de términos formalmente diferentes con referencia a un mismo contenido, la clasificación de palabras. El caso particular del término «lexiologia», su cambio de referente ya ha sido señalado anteriormente, y en cuanto a los demás términos, se puede notar que también se deben al influjo de la corriente positivista y que no han tenido continuidad en el metalenguaje gramatical, siendo utilizados solamente en este periodo.

La «organographia» corresponde a otro ejemplo de terminología sin continuidad, pues su empleo se restringe a la Gramática de Augusto Freire. Este término se refiere al estudio de las flexiones y de la etimología en su conjunto, que en las gramáticas de Júlio Ribeiro y Maximino Maciel no vienen organizadas bajo ningún subtítulo, pero en los tres casos forman parte de los estudios morfológicos.

Respecto a los términos relativos al estudio de la flexión, se pueden observar en las tres obras el empleo de las formas "flexionismo», "flexiologia», «kampenomia» y «ptoseonomia» para referirse al mismo concepto. Los términos «flexionismo» y «flexiologia» son utilizados exclusivamente en la obra de Freire, pero tanto Freire como Ribeiro y Maciel concuerdan que «kampenomia»y «ptoseonomia» también se refieren a este contenido. En cuanto al empleo de estos términos, cabe señalar el punto de vista de Maciel al manifestar la equivalencia entre "kampenomia» y «ptoseonomia» y el (supuesto) origen de esta última forma: 
[El término «ptoseonomia» fue] formado por Júlio Ribeiro e até o acho preferivel ao termo kampenomia (Maciel 1926[1894]: 79).

El término "etymologia» es el más tradicional y estandarizado, pues está presente en la mayoría de las gramáticas brasileñas. A pesar de mantener la forma, a lo largo de este periodo, ha experimentado mudanzas de posición en la organización gramatical y sobre todo ha recibido distintas interpretaciones. A partir de la Gramática de Freire, la «etymologia» deja de designar una parte independiente de la gramática para integrarse en la morfología, pero con la finalidad de denominar el estudio del origen, la evolución y la constitución del léxico. Tanto Ribeiro como Maciel conservan esta concepción. Cabe señalar, por último, que Ribeiro llama la atención sobre la tendencia del metalenguaje gramatical a mantener las formas tradicionales:

Lexeogenia seria termo preferivel a Etymologia. Comtudo este ultimo tem em seu favor desde seculos a consagração universal: não póde, pois, ser substituído (Ribeiro 1881: 142).

En resumen, el análisis terminográfico de la terminología relativa a los estudios morfológicos muestra que el uso de los términos «phonologia», «morphologia», «phonetica»,, «prosodia», «orthographia» y «etymologia» entre las gramáticas finiseculares es bastante difundido. Se trata de términos que gozan de cierto grado de estandarización en este periodo, pues los gramáticos brasileños comparten la misma concepción. Así pues, en las obras analizadas estas formas corresponden, en términos generales, a un mismo objeto de estudio. Si bien estos términos son los más difundidos en la gramaticografía de este periodo, los gramáticos no renuncian a mostrar también las variantes de cada forma. Así, la «etymologia» es equivalente a «morphogenia», «lexeogenia» y «lexiogenia»; la prosodia corresponde también a «orthophonia», «orthoepia» y "accentuação»; y la umorphologia» es nombrada como «elementos morphicos dası. 
Acerca de los términos que designan respectivamente los estudios sobre las clases y flexiones de las palabras, al parecer, empezaban a adquirir un cierto grado de estandarización en este periodo. Aunque los gramáticos no coinciden en el empleo de «taxinomia», "taxeonomia», "lexiologia» y «flexionismo» para designar la clasificación de palabras y «ptoseonomia», «kampenomia» y «flexionismo» para nombrar el estudio de las flexiones, en general aceptan y reconocen las variaciones de los términos.

Cabe señalar, por último, que algunos términos adoptados por Augusto Freire en su Gramática han tenido poca o ninguna repercusión en las obras posteriores. Con todo, esta terminología se recupera años después en la Grammatica Descriptiva de Maximino Maciel. Algunas denominaciones como «orthoepia», «phonographia» y "semiographia» reaparecen como parte (o variantes) de la terminología adoptada en su obra.

\subsubsection{Syntaxe y syntaxologia}

Con respecto a la terminología de la sintaxis, Moraes Silva presenta en el Epítome el mismo recurso utilizado para nombrar la primera parte de la gramática, para evitar la terminología (y la división) más generalizada, el autor describe la sintaxis como «livro II -da composição das partes da sentença entre si ou sintaxe» y como variación de este término cita la expresión «Regras de Composição».

No obstante, la generalidad de los gramáticos posteriores a Moraes emplea el término «syntaxe», confirmando el estatus de forma ya consolidada en la tradición brasileña. El único intento de cambio de nomenclatura corresponde a la propuesta de Maximino Maciel, que, a finales del siglo XIX, utiliza el término «syntaxologia».

En la siguiente tabla se puede observar la incidencia de la terminología relativa a la sintaxis en las gramáticas brasileñas del siglo XIX: 


\begin{tabular}{|c|c|c|}
\hline Autor & Término & Equivalente \\
\hline Moraes Silva (1806) & $\begin{array}{c}\text { Da composição das partes } \\
\text { da sentença entre si ou } \\
\text { syntaxe }\end{array}$ & Regras de Composição \\
\hline Frei Caneca (1817) & & \\
Pereira Coruja (1835) & & \\
Sotero dos Reis (1865) & & \\
Olivier Grivet (1865) & & \\
Augusto Freire (1875) & Syntaxe & \\
Júlio Ribeiro (1881) & & \\
Silva Jr. y Lameira (1887) & & \\
Alfredo Gomes (1887) & & \\
João Ribeiro (1887) & & \\
\hline Maximino Maciel (1894) & & \\
\hline
\end{tabular}

Tabla 6.3 La presencia de la «syntaxe» y sus equivalentes en las gramáticas brasileñas

Del mismo modo que ocurre con la primera parte de la Gramática de Moraes, la expresión «livro II -da composição das partes da sentença entre si ou sintaxell constituye un neologismo que no se estandariza (temporalidad breve) y debido a su carga semántica, prescinde de definición.

Maciel es el segundo autor de esta tradición que intenta romper con la terminología tradicional y sustituye el término «syntaxe» por «syntaxologia». Este préstamo es una fuerte evidencia del influjo de la obra de Adolpho Coelho (1871), que utiliza esta forma para establecer «uma distinção ôntica entre a disciplina e o seu objeto» (Gonçalves 2004: 45). A diferencia de Moraes y Maciel, la generalidad de las gramáticas brasileñas de este periodo conserva tanto la forma («syntaxe») como el contenido de la sintaxis.

Respecto a la terminología de las partes de la sintaxis, los gramáticos Moraes Silva (1806), Frei Caneca (1817) y Pereira Coruja (1835) emplean respectivamente los términos "syntaxe de concordancia» y "syntaxe de regencia» y «syntaxe natural» y «syntaxe figurada». 
En la segunda mitad del siglo, la variación de formas es aún más frecuente. Así por ejemplo, los gramáticos Sotero dos Reis (1865), Silva Jr. y Lameira (1887) y João Ribeiro (1887) emplean las formas «syntaxe de palavras»y y «syntaxe de proposições», Augusto Freire (1875) utiliza la terminología «syntaxe gramatical» y «syntaxe litteraria», Júlio Ribeiro (1881) emplea los términos "syntaxe lexica» y "syntaxe logica» y Alfredo Gomes (1887), "concordancia», «regencia» y "collocação». La terminología de Maximino Maciel (1894) se ha mostrado la más innovadora entre los gramáticos brasileños de este periodo. El autor denomina las partes de la sintaxis como "syntaxe relacional», "ssyntaxe phraseologica» y «syntaxe litteraria».

La tabla siguiente refleja la evolución de la terminología de las partes de la sintaxis en las gramáticas brasileñas:

\begin{tabular}{|c|c|c|}
\hline Autor & Término & Equivalente \\
\hline Moraes Silva (1806) & & \\
Frei Caneca (1817) & Syntaxe Concordancia & \\
Alfredo Gomes (1887) & & \\
Pereira Coruja (1835) & Syntaxe Natural & \\
Sotero dos Reis (1865) & & \\
João Ribeiro (1887) & Syntaxe de palabras & \\
Silva Jr. y Lameira (1887) & & \\
Augusto Freire (1875) & Syntaxe Gramatical & \\
Júlio Ribeiro (1881) & Syntaxe Lexica & \\
Maximino Maciel (1894) & Syntaxe Relacional & \\
\hline Moraes Silva (1806) & & \\
Frei Caneca (1817) & Syntaxe de Regencia & \\
Alfredo Gomes (1887) & & \\
Pereira Corvja (1835) & Syntaxe Figurada & \\
Sotero dos Reis (1865) & & \\
João Ribeiro (1887) & Syntaxe de Proposições & \\
Silva Jr. y Lameira (1887) & & \\
Augusto Freire (1875) & Syntaxe Literaria & \\
\hline
\end{tabular}




\begin{tabular}{|c|c|c|}
\hline Júlio Ribeiro (1881) & Syntaxe Logica & \\
\hline Maximino Maciel (1894) & Syntaxe Phraseologica & Phraseologia \\
\hline Alfredo Gomes (1887) & Collocação & \\
\hline Maximino Maciel (1894) & Syntaxe Literaria & Estilistica \\
\hline
\end{tabular}

Tabla 6.4 Terminología de la sintaxis

El término «syntaxe de concordancia» es empleado por Moraes Silva para referirse a las uregras que ensinão a mostrar as connexões entre os nomes, e os adjectivos, e os verbosı (Moraes Silva 1824[1806]: 81). Esta concepción muestra que el autor conserva tanto la forma como el contenido atribuido a la sintaxis por la tradición más generalizada. Aunque esta terminología no haya sido adoptada por muchos gramáticos brasileños, a finales del siglo XIX todavía se publican obras que intentan recuperarla, como es el caso de la Gramática de Alfredo Gomes (1887).

Después de Moraes Silva, este término experimentó diversos cambios de forma y de contenido. Freire emplea en su Gramática el término «syntaxe gramatical» para referirse al conjunto «syntaxe de palavras» y "syntaxe de proposiçõesı. Se puede notar que el autor cambia no solamente la forma y el contenido de los términos sino también su posición en la macroestructura de la sintaxis. Por su parte, Júlio Ribeiro y Maximino Maciel sustituyen el término «syntaxe de palavras» por «syntaxe lexica» y «syntaxe relacional», respectivamente, pero conservan el contenido establecido por Freire.

Este procedimiento corresponde también al desarrollo del término «syntaxe de proposições». En la obra de Ribeiro, esta forma se modifica para «syntaxe logica» y en la de Maciel para "syntaxe phraseologica» o «phraseologia» manteniendo el mismo concepto.

El término «syntaxe litteraria» es utlizado solamente por Freire y por Maciel, en ambos gramáticas se observa la misma forma y el mismo contenido, es decir, la «syntaxe litteraria» en la gramaticografía brasileña "é o tratado do estylo nas suas diversas manifestaçõesı (Maciel 1926[1894]: 420). 


\subsubsection{Semiologia y sus variantes}

Respecto a la terminología de los estudios del significado, Augusto Freire y Maximino Maciel son los únicos gramáticos de esta tradición que presentan una teoría (y una terminología) semántica. Tanto Augusto Freire como Maximino Maciel emplean el término "semiologia» para designar el estudio del significado de las palabras. Sin embargo, solamente Freire presenta variaciones para este término («semantica»), «sematologia» y «semeiotica»).

Las partes de la "semiologia» en la Gramática de Freire se denominan «exegetica» y «technica» y corresponden respectivamente al estudio de la significación de las palabras y de la «leitura e dos signaes necesarios á interpretação do sentido da phrase»» (Freire 1894[1875]: 422). En cambio, en Maciel, la «semiologia» se divide en «semantica» y «tropologia». Estos términos se refieren, respectivamente, al «tratado da significação das palavras e das mutações ou alterações de sentido que podem experimentar no tempo e no espaço, impostas pela evolução da lingua» (Maciel 1926[1894]: 467) y al estudio de las figuras (sin definición).

Los términos «exegetica» y «semantica» constituyen formas diferentes pero que se refieren a un mismo contenido. En cambio, los términos «technica» y «tropologia» se diferencian tanto en forma como en contenido. Consecuentemente, se puede afirmar que la «semiologia» no posee el mismo contenido en las gramáticas de Freire y de Maciel.

La tabla a continuación ilustra la terminología que compone la disciplina «semiologia» en las obras de estos gramáticos:

\begin{tabular}{|c|c|}
\hline Augusto Freire & Maximino Maciel \\
\hline Exegetica & Semantica \\
\hline Technica* & Tropologia* \\
\hline
\end{tabular}

*Diferentes contenidos.

Tabla 6.5 Terminología de la semántica 
Finalmente, en las siguientes tablas se puede observar, de modo más esquemático y cronológicamente organizado, la evolución de la terminología relativa a las partes de la gramática en la tradición gramatical brasileña del siglo XIX:

\begin{tabular}{|c|c|c|}
\hline Autor & Término & Equivalente \\
\hline Moraes Silva (1806) & $\begin{array}{c}\text { Das palavras por si sós ou } \\
\text { partes da sentença } \\
\text { Da composição das partes } \\
\text { da sentença entre si ou } \\
\text { syntaxe }\end{array}$ & Regras de Composição \\
\hline $\begin{array}{l}\text { Frei Caneca (1817), } \\
\text { Pereira Coruja (1835) y } \\
\text { Sotero dos Reis (1865) }\end{array}$ & $\begin{array}{c}\text { Etymologia } \\
\text { Orthographia } \\
\text { Prosodia } \\
\text { Syntaxe }\end{array}$ & \\
\hline Olivier Grivet (1865) & $\begin{array}{c}\text { Lexicologia } \\
\text { Orthographia } \\
\text { Prosodia } \\
\text { Syntaxe } \\
\text { Pontuação }\end{array}$ & \\
\hline Augusto Freire (1875) & $\begin{array}{l}\text { Lexicologia } \\
\text { Syntaxe } \\
\text { Semiologia }\end{array}$ & $\begin{array}{c}\text { Semantica/ Sematologia/ } \\
\text { Semeiotica }\end{array}$ \\
\hline Júlio Ribeiro (1881) & $\begin{array}{c}\text { Lexeologia } \\
\text { Syntaxe }\end{array}$ & \\
\hline Silva Jr. y Lameira (1887) & $\begin{array}{l}\text { Lexeologia } \\
\text { Syntaxe }\end{array}$ & Lexicologia \\
\hline Alfredo Gomes (1887) & $\begin{array}{c}\text { Morphologia } \\
\text { Syntaxe }\end{array}$ & Lexicologia \\
\hline João Ribeiro (1887) & $\begin{array}{l}\text { Phonologia } \\
\text { Morphologia }\end{array}$ & $\begin{array}{c}\text { Phonetica } \\
\text { Organographia }\end{array}$ \\
\hline
\end{tabular}




\begin{tabular}{|c|c|c|} 
& $\begin{array}{c}\text { Classificação } \\
\text { Syntaxe }\end{array}$ & Taxinomia \\
\hline \multirow{2}{*}{ Maximino Maciel (1894) } & Phonologia & \\
& Lexiologia & \\
& Syntaxologia & \\
& Semiologia & Semasiologia \\
\hline
\end{tabular}

Tabla 6.6 Terminología relativa a la macroestructura gramatical y sus variaciones

\begin{tabular}{|c|c|c|c|}
\hline Contenido & Autor & Término & Equivalente \\
\hline \multirow[t]{2}{*}{ Sonido } & $\begin{array}{l}\text { Frei Caneca (1817) } \\
\text { Pereira Coruja (1835) } \\
\text { Sotero dos Reis (1865) } \\
\text { Olivier Grivet (1865) }\end{array}$ & Prosodia & \\
\hline & $\begin{array}{c}\text { João Ribeiro (1887) } \\
\text { Maximino Maciel (1894) }\end{array}$ & Phonologia & Phonetica \\
\hline \multirow{7}{*}{ Palabra } & $\begin{array}{l}\text { Frei Caneca (1817) } \\
\text { Pereira Coruja (1835) } \\
\text { Sotero dos Reis (1865) }\end{array}$ & Etymologia & \\
\hline & $\begin{array}{l}\text { Frei Caneca (1817) } \\
\text { Pereira Coruja (1835) } \\
\text { Sotero dos Reis (1865) } \\
\text { Olivier Grivet (1865) }\end{array}$ & Orthographia & \\
\hline & $\begin{array}{l}\text { Olivier Grivet (1865) } \\
\text { Augusto Freire (1875) }\end{array}$ & Lexicologia & \\
\hline & $\begin{array}{l}\text { Júlio Ribeiro (1881) } \\
\text { Silva Lameira (1887) }\end{array}$ & Lexeologia & Lexicologia \\
\hline & João Ribeiro (1887) & Classificação & \\
\hline & $\begin{array}{l}\text { Alfredo Gomes (1887) } \\
\text { João Ribeiro (1887) }\end{array}$ & Morphologia & Lexicologia \\
\hline & Maximino Maciel (1894) & Lexiologia & \\
\hline Oración & Frei Caneca (1817) & Syntaxe & \\
\hline
\end{tabular}






Tabla 6.7 Terminología de las partes de la gramática organizados según su contenido

\subsection{Terminología y terminografía de las clases de palabras}

Este análisis terminográfico de la terminología relativa a las clases y subclases de palabras está enfocado, particularmente, en las obras de Moraes Silva, Augusto Freire, Júlio Ribeiro y Maximino Maciel. La finalidad de este estudio es poner de manifiesto los cambios terminológicos (y teóricos) característicos de las gramáticas brasileñas decimonónicas y, a partir del nivel de estandarización de los términos y de la modificación de la forma y/o contenido de los términos, determinar el avance del metalenguaje gramatical en esta tradición. 


\subsubsection{La terminología del sustantivo}

Las gramáticas brasileñas de este periodo no reflejan cambios significativos con respecto a la forma o al contenido del término «substantivo». Moraes Silva emplea las formas «nome» y «substantivo», aunque el número de incidencias de este último término en el Epítome es bastante escaso. Augusto Freire trata de solucionar esta problemática terminológica uniendo las dos formas «nome sustantivo». En la obra de Ribeiro, se utiliza solamente el término «substantivo», pero todavía se mantiene las formas «nome» y «nome substantivo» como variantes. El último gramático analizado, Maciel, presenta el término «substantivo» sin ninguna presencia de variación. A pesar del constante cambio en las formas de este término, el contenido a que se refiere no se ha modificado en ninguna de las gramáticas.

Los sustantivos se dividen en la Gramática de Moraes en «nome abstracto» (o «substantivo abstracto»), «nome individual» (o «nome proprio»), «nome concreto» y «nome commun» (o «nome geral»). Augusto Freire mantiene en su Gramática las cuatro divisiones propuestas por Moraes pero cambia algunos términos: «abstracto», «proprio» (o «particulan»), «concreto» y «appellativo» (o "commum»). Ribeiro añade a la terminología de Freire los substantivos «collectivos», «verbaes» y «compostos» y como variante del «substantivo concreto» utiliza el término «material». En su propuesta terminológica, Maximino Maciel sustituye al «substantivo abstracto» por «subjectivo» y al "concreto» por «objectivo», conserva los términos «substantivos proprio», "colletivo» y «appellativo» y añade las formas «substantivo personativo», «locativo», «abstractivo»y «factitivo».

La tabla siguiente representa esta descripción terminológica de las subclases del sustantivo en las gramáticas de Moraes, Freire, Ribeiro y Maciel: 


\begin{tabular}{|c|c|c|c|c|}
\hline M. Silva & A. Freire & J. Ribeiro & M. Maciel & Equivalente \\
\hline Nome & $\begin{array}{c}\text { Nome } \\
\text { substantivo }\end{array}$ & Substantivo & Substantivo & $\begin{array}{c}\text { Substantivo (MS1806) } \\
\text { Nome (AF1875/JR1881/MM1894) } \\
\text { Nome substantivo (JR1881) }\end{array}$ \\
\hline Abstracto & Abstracto & Abstracto & Subjectivo & Abstracto (MM1894) \\
\hline Individual & Proprio & Proprio & Proprio & $\begin{array}{l}\text { Proprio (MS1806) } \\
\text { Particular (AF1875) }\end{array}$ \\
\hline Concreto & Concreto & Concreto & Objectivo & $\begin{array}{l}\text { Material (JR1881) } \\
\text { Concreto (MM1894) }\end{array}$ \\
\hline Commum & Appellativo & Appellativo & Appellativo & Commum (AF1875) \\
\hline & & Collectivo & Collectivo & $\begin{array}{l}\text { Multidão (JR1881) } \\
\text { Intensivo (MM1894) }\end{array}$ \\
\hline & & Verbal & & \\
\hline & & Composto & & \\
\hline & & & Personativo & \\
\hline & & & Locativo & \\
\hline & & & Factitivo & \\
\hline & & & Abstractivo & \\
\hline
\end{tabular}

6.8 Terminología de las subclases del sustantivo

Esta descripción muestra que las subclases del sustantivo experimentaron diversas mudanzas en la terminología, en la organización y, en algunos casos, también en el contenido. Este es el caso del «substantivo commum» que, en la Gramática de Freire, cambia de forma (usubstantivo appellativo») e incluye en el contenido los sustantivos concreto y abstracto:

Subdividem-se os nomes appellativos em concretos e abstractos (Freire 1894[1875]: 93). 
Ribeiro y Maciel también tratan de ampliar el contenido del «sustantivo appellativo», el primero le añade los sustantivos «collectivo», «verbal» y "composto», y el segundo los sustantivos «collectivo» y ufactitivo».

Por último, cabe destacar la preocupación de Maciel en justificar los cambios de terminología también en la descripción del sustantivo:

Empregamos abstractivo, em vez de abstracto, para uniformidade de nomenclatura na divisão dos substantivos próprios (Maciel 1926[1894]: 117).

As denominações de objectivo e subjectivo exprimem mais o facto do que as de concreto e abstracto e as irrisórias denominações de fictícios e imaginários. Além disso, os termos abstractos e concretos não satisfazem, no estado actual, ao rigoroso conceito da classificação ou taxinomia (Maciel 1926[1894]: 118).

Hay que reconocer el empeño de los gramáticos en introducir nuevos términos en el metalenguaje gramatical. Sin embargo, muchos de estos términos no lograron estandarizarse en la terminología.

\subsubsection{La terminología del adjetivo}

En la mayoría de las gramáticas brasileñas, el término «adjectivo» conserva tanto la forma como la definición (funcional). Sin embargo, la terminología de las subclases del adjetivo no goza de esta misma estabilidad. En este sentido, se puede observar en las gramáticas brasileñas considerables modificaciones de forma y contenido. Moraes Silva, por ejemplo, divide los adjetivos en "articular» y «attributivo». Esta terminología se mantuvo vigente hasta la Gramática de Augusto Freire, cuando este autor sustituye estos términos por «determinativo» y «qualificativo». Ribeiro determina en su obra el cambio de forma de «qualificativo» para «descriptivo» y conserva el término «determinativo». Maciel sigue a Ribeiro en el empleo del término «descriptivo» pero cambio el «determinativo» por «designativo». Es interesante notar que 
Maciel reconoce que la terminología debe acompañar los avances teóricos presentes en la gramática:

Os termos descriptivos e designativos estão mais de accordo com a grammatica moderna do que os termos qualificativos e determinativos; apenas têm estes por si o longo uso; mas as nomenclaturas se devem ir modificando, a proporção que se aprofunda no estudo dos factos (Maciel 1926[1894]: 124).

Pues bien, esta mudanza de terminología está acompañada, en algunos casos, del cambio de contenido. Así, el adjetivo «articulan», el «determinativo» y el «designativo» constituyen términos formalmente distintos y con contenidos también distintos. El «adjectivo articular» de Moraes incluye el artículo y los pronombres demostrativo, posesivo y relativo. En la obra de Freire, el «determinativo» designa el artículo y los pronombres demostrativo, posesivo, relativo, indefinido e uinterrogativo» (relativo usado en oración interrogativa). Para Ribeiro, el «determinativo» incluye los pronombres demostrativo, posesivo, relativo e indefinido, es decir, sin artículo e interrogativo. El término «designativo», empleado por Maciel, incluye el artículo y excluye los pronombres relativos. La inclusión del pronombre (excepto el personal) en la clase de los sustantivos parece ser una característica general de las gramáticas de este periodo. Aunque Júlio Ribeiro y Maximino Maciel reconocen al pronombre como clase de palabra independiente, en la práctica, el término «pronome» tiene el mismo referente del adjetivo:

O pronome adjectivo, como já se deu a entender na observação final do capítulo antecedente, nada mais é do que o adjectivo determinativo empregado na oração sem substantivo claro (Ribeiro 1881: 60).

Os pronomes adjectivos constituem uma funcção dos adjectivos designativos (Maciel 1926[1894]: 131).

La diferencia entre el contenido de los adjetivos «attributivo», "qualificativo» y "descriptivo» es bastante evidente en las obras de estos 
gramáticos. Para Moraes Silva el «adjectivo attributivo» incluye los adjetivos «simples», "comparativo», "superlativo» y «participio». Para Augusto Freire, el «adjectivo qualificativo» está compuesto de siete tipos de adjetivos: el «explicativo», el «restrictivo», el «gentilico», el «patrio», el «participio», el «possessivo» y el «verbal». En la obra de Ribeiro el «adjectivo descriptivo» incluye solamente los adjetivos «explicativo» y urestrictivo» y en la de Maciel, además de los que presenta Ribeiro, están el «locativo» y el «personativo». Una vez más, Maximino Maciel trata de justificar su terminología y afirma que las mudanzas de términos son resultado del avance teórico que se dio en la gramática en cuanto a este contenido:

Esta nossa divisão, em vez da antiga em explicativo e restrictivo, está mais de accôrdo com os factos, pois o pretendido adjectivo restrictivo explana, desenvolve e explica mais do que o próprio explicativo (Maciel 1926[1894]: 124).

La tabla siguiente muestra la correspondencia entre las terminologías presentes en las gramáticas de Moraes, Freire, Ribeiro y Maciel relativamente a su contenido:

\begin{tabular}{|c|c|c|c|c|}
\hline M. Silva & A. Freire & J. Ribeiro & M. Maciel & Equivalente \\
\hline $\begin{array}{c}\text { Adjectivo } \\
\text { articular }\end{array}$ & $\begin{array}{c}\text { Adjectivo } \\
\text { determinativo }\end{array}$ & $\begin{array}{c}\text { Adjectivo } \\
\text { determinativo }\end{array}$ & $\begin{array}{c}\text { Adjectivo } \\
\text { designativo }\end{array}$ & A. limitativo (JR 1881) \\
\hline Simples & Articular & Articular & $\begin{array}{c}\text { Artigo (MS1806) } \\
\text { A. definido } \\
\text { (MM M 1894) }\end{array}$ \\
Demonstrativo & Numeral & Numeral & Numeral & $\begin{array}{c}\text { Pron. demonstrativo } \\
\text { (MS1806/JR1881) }\end{array}$ \\
Possessivo & Possessivo & Possessivo & Possessivo & $\begin{array}{c}\text { Pron. possessivo } \\
\text { (MS1806/JR1881) } \\
\text { Conjunctivo }\end{array}$ \\
& Conjunctivo & Conjunctivo & & Demonstrativo \\
\hline
\end{tabular}




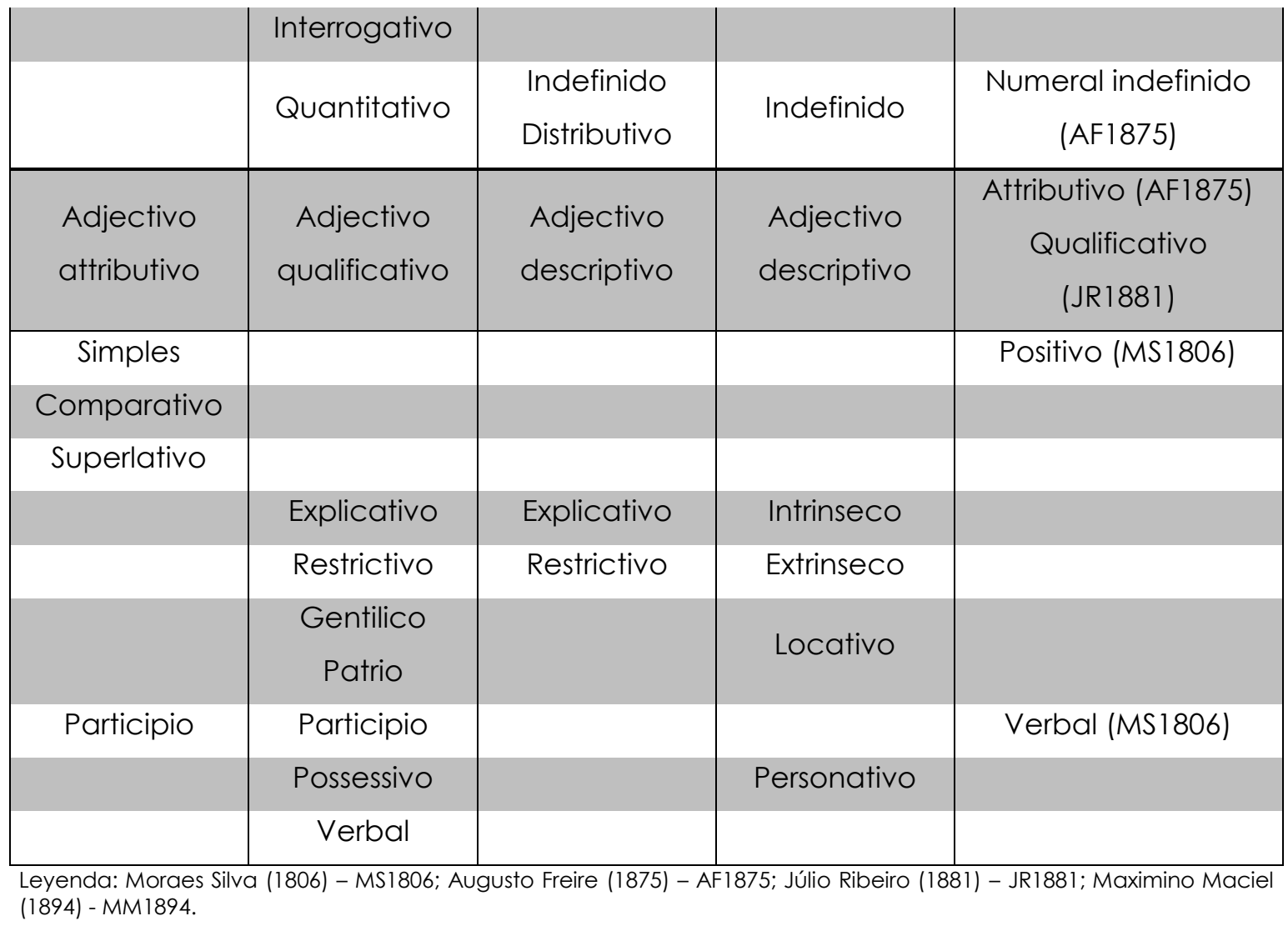

Tabla 6.9 Terminología de las subclases del adjetivo

De acuerdo con estos datos, se pueden identificar cuatro campos de referencia de los términos relativos a las subclases de los adjetivos:

1) Los términos que conservan tanto la forma como el contenido. Este es el caso del «adjectivo possessivo» (contenido: pronombres posesivos), del «adjectivo numeral» (contenido: numerales), «adjectivo demonstrativoly (contenido: pronombres demostrativos) y del «adjectivo participio» (contenido: forma no personal del verbo).

2) Los términos que cambian de forma pero conservan su contenido. Se puede citar los términos «relativo» y "conjunctivo» (contenido: pronombres relativos), «quantitativo», «indefinido» y «distributivo» (contenido: pronombres indefinidos), «gentilico», «patrio» y «locativo» (contenido: adjetivos gentilicios), «restrictivo» y «extrínseco» (indican 
accidente), «explicativo» e «intrínseco» (indican cualidad) y «possessivo» y «personativo» (contenido: derivados de nombres propios como socrático, dantesco). De hecho, Maximino Maciel manifiesta su desacuerdo con respecto al uso de los términos «gentilico» y «patrio» en lugar de «locativo»:

Estes [locativos] tem sido chamados gentilicos, patrios ou nacionaes mas estas denominações estão em desaccôrdo com os factos; assim prefiramos o termo locativo pois é mais genérico e mais apropriado do que qualquer dos outros. (Maciel 1926[1894]: 126).

3) Los términos que mantienen su forma pero cambian de contenido, como es el caso del "adjectivo possessivo», que puede referirse a los pronombres posesivos (meu, teu, seu, nosso) y a la «qualidade de ser alguem possuidor de algum objecto [socrático, manoelita, dantesto]» (Freire 1894[1875]: 97).

4) Los términos que cambian tanto la forma como el contenido. Este es el caso de los adjetivos «simples» y «articular». En la Gramática de Moraes, el contenido referente al término «adjectivo articular simples» es el artículo definido $(0, a)$. Augusto Freire establece, en cuanto a este término, cambios de forma y de contenido. Así, además del artículo (o, a, um, uma), el contenido del uadjectivo determinativo articular» incluye también el pronombre demostrativo «puro» (este, ese, aquel), «colectivo» (todo) y «distributivo» (cada, tal). El término «adjectivo designativo articular», citado en la Gramática de Maciel, se refiere únicamente al artículo definido $(o, a)$, siguiendo el modelo de Moraes.

Por último, cabe señalar también aquellos términos que no presentan continuidad en esta clase en la gramaticografía como el «interrogativo» (relativos usados en oraciones interrogativas), el «attributivo simples» (calificativos en general), el «comparativo», el «superlativo» y el «adjetivo verbal» (adjetivos derivados de verbos como vindouro, morredouro). 


\subsubsection{La terminología del verbo}

El término «verbo» en sí mismo no presenta variaciones de forma y de contenido en las Gramáticas de Moraes Silva, Augusto Freire, Júlio Ribeiro y Maximino Maciel, pero el metalenguaje relativo a los modos, los tipos de verbos, los tiempos y otros términos relacionados con esta clase de palabras, presenta importantes avances terminológicos (y teóricos).

Amparado por la doctrina racionalista, Moraes Silva identifica como modos verbales el uindicativo» o «mostradon», el «imperativo» o «mandativo»y el "conjunctivo» o «subjunctivo». Con respecto a las formas nominales del verbo, Moraes afirma que "são verdadeiros nomes verbáes abstractos» (Moraes Silva 1824[1806]: 41) los «infinitos pessoaes», propios de la lengua portuguesa, los «infinitos puros» y los participios «pretérito» y «presente», también denominados «supino»y «gerundio».

En la Gramática de Augusto Freire se puede notar que, por una parte, esta terminología ya se ha estandarizado en algunos aspectos y, por otra, empieza a especializarse cada vez más. Así pues, Freire mantiene la misma terminología de Moraes para designar los modos del verbo (uindicativo», «conjunctivo» e «imperativo»), acrecienta un nuevo modo, el «condicional» y excluye el «infinito pessoal» de las formas nominales para incluirlo también como modo verbal. Tocante a las formas nominales, el autor las denomina «infinito», «gerundio» y «supino».

Júlio Ribeiro trata de preservar el metalenguaje generalizado. El autor solo termina de consolidar en su tradición el uso de los términos «subjunctivo» (en lugar de "conjunctivo») y «condicional». Esta terminología termina de consagrarse en la Gramática de Maciel. En la Gramática de Ribeiro solamente son consideradas tres formas nominales, el «infinitivo», el «participio aoristo» y el «participio imperfeito».

En cuanto a los tipos de verbos, desde Moraes hasta Júlio Ribeiro la corriente racionalista acreditó la división del verbo en dos clases. Para Moraes 
los verbos se denominan «substantivo» y "adjectivo», para Freire son «substantivo» y «attributivo» y, para Ribeiro, «substantivo» y upredicativo». La postura renovadora (aunque tardía) fue la de Maciel, que excluyó de su Gramática esta división justificando que "a doutrina de verbo substantivo e adjectivo cahiu» (Maciel 1926[1894]: 137).

Con respecto a las divisiones del verbo adjetivo, Moraes Silva identifica los «activos» o «transitivos», los «de estado», los «neutros», los «reflexos», los «reciprocos» o «pronominaes», los «frequentativos», los «diminutivos», los «irregulares», los «defectivos» y los «auxiliares». De Moraes a Freire la división del verbo avanza considerablemente en cuanto a su organización y, por consiguiente, en cuanto a su terminología. Así, Freire divide los verbos «attributivos» del siguiente modo:

1) «Transitivo», que incluye el «proprio» o "activo», el ureflexivo» y el «pronominal reflexo».

2) «Intransitivo» o «neutro»: que se divide en «denominativo», uimitativo», «frequentativo», «inchoativo», «augmentativo», «diminutivo» y «negativo».

3) «Relativo».

El autor también nombra a los verbos según su conjugación en «auxiliar», «regular», «irregular», «pessoal»,, «impessoal»», «unipessoal» y «defectivo».

Júlio Ribeiro divide los verbos «predicativos» en «transitivos» e «intransitivos» y, según la conjugación, en «auxilian», «regulan», «irregulan», «impessoal», «defectivo», «periphrastico», «frequentativo», «terminativo» y «pronominal».

Las innovaciones que Maciel introduce en la descripción de esta categoría no se limitan solo a eliminar la "antiga classificação» de verbos en sustantivo y adjetivo. El gramático proporciona cuatro clasificaciones basadas en diferentes criterios. En cuanto a su relación con el predicado, el verbo puede ser «completo», «incompleto» o de «predicação dupla»; por su estructura, es «indefectivo», "defectivo» o «redundante»; según la conjugación, «regulan» o 
«irregular», y con respecto a su modalidad sintáctica, «auxilian» o «fundamental»». El autor aun establece otros dos criterios más de clasificación para distinguir entre las características personales y pronominales del verbo que, respectivamente, se denominan «pessoal», «unipessoal» e «impessoal»; y «reflexivo», «reciproco», «passivo», «indefinido» y «emphatico».

La terminología relativa a los tiempos verbales o, como llama Moraes, «épocas», no presenta muchas variaciones en cuanto a su nomenclatura, excepto por tiempos de indicativo pasado y condicional que en el Epítome de Moraes Silva son denominados, respectivamente, «do presente a respeito de uma época pasada», que corresponde al «pretérito imperfeito» (imperfecto en español), "do passado em época pasada», actualmente «pretérito perfeito» (indefinido en español), y «do futuro a respeito do presente e do passado» (condicional en español).

En la tabla siguiente, la nomenclatura más significativa con respecto a los verbos está organizada por autores, obedece la equivalencia de cada término en cuanto a su contenido y, además, enumera las variaciones citadas por los autores que muestra cierta relación entre las obras:

\begin{tabular}{|c|c|c|c|c|}
\hline M. Silva & A. Freire & J. Ribeiro & M. Maciel & Equivalente \\
\hline Substantivo & Substantivo & Substantivo & & \\
\hline Adjectivo & Attributivo & Predicativo & & $\begin{array}{l}\text { Adjectivo } \\
\text { (AF1875) }\end{array}$ \\
\hline \multicolumn{5}{|c|}{ Modos } \\
\hline Indicativo & Indicativo & Indicativo & Indicativo & $\begin{array}{l}\text { Mostrador } \\
\text { (MS1806) }\end{array}$ \\
\hline Imperativo & Imperativo & Imperativo & Imperativo & $\begin{array}{c}\text { Mandativo } \\
\text { (MS1806) }\end{array}$ \\
\hline \multirow[t]{3}{*}{ Conjunctivo } & Conjunctivo & Subjunctivo & Subjunctivo & $\begin{array}{c}\text { Subjunctivo } \\
\text { (MS1806/ } \\
\text { AF1875) }\end{array}$ \\
\hline & Condicional & Condicional & Condicional & \\
\hline & Infinito pessoal & & & \\
\hline
\end{tabular}




\begin{tabular}{|c|c|c|c|c|}
\hline \multicolumn{5}{|c|}{ Formas no personales } \\
\hline Infinito pessoal & & & & \\
\hline Infinito puro & Infinito & Infinitivo & Infinitivo & Infinitivo (AF1875) \\
\hline $\begin{array}{l}\text { Participio } \\
\text { presente }\end{array}$ & Gerundio & $\begin{array}{l}\text { Participio } \\
\text { Imperfeito }\end{array}$ & $\begin{array}{l}\text { Participio } \\
\text { presente }\end{array}$ & $\begin{array}{l}\text { Gerundio } \\
\text { (MS1806) }\end{array}$ \\
\hline $\begin{array}{l}\text { Participio } \\
\text { pretérito }\end{array}$ & $\begin{array}{l}\text { Participio } \\
\text { passado }\end{array}$ & $\begin{array}{l}\text { Participio } \\
\text { aoristo }\end{array}$ & $\begin{array}{l}\text { Participio } \\
\text { passado }\end{array}$ & $\begin{array}{c}\text { P. passado y } \\
\text { supino (MS1806) }\end{array}$ \\
\hline \multicolumn{5}{|c|}{ Tipos de verbos } \\
\hline Neutro & Intransitivo & Intransitivo & $\begin{array}{l}\text { Predicação } \\
\text { completa }\end{array}$ & $\begin{array}{l}\text { Neutro } \\
\text { (AF1875) }\end{array}$ \\
\hline \multirow[t]{5}{*}{ Activo } & Proprio & Transitivo & $\begin{array}{l}\text { Predicação } \\
\text { incompleta }\end{array}$ & $\begin{array}{l}\text { Transitivo } \\
\text { (MS1806/ } \\
\text { AF1875) }\end{array}$ \\
\hline & Relativo & & & \\
\hline & & & $\begin{array}{c}\text { Predicação } \\
\text { dupla }\end{array}$ & \\
\hline & Denominativo & & & \\
\hline & Imitativo & & & \\
\hline \multirow[t]{3}{*}{ Frequentativo } & Freqüentativo & Frequentativo & & \\
\hline & Inchoativo & & & \\
\hline & Augmentativo & & & \\
\hline \multirow[t]{2}{*}{ Diminutivo } & Diminutivo & & & \\
\hline & Negativo & & & \\
\hline \multicolumn{5}{|l|}{ De estado } \\
\hline \multirow[t]{3}{*}{ Auxiliar } & Auxiliar & Auxiliar & Auxiliar & \\
\hline & & & Fundamental & \\
\hline & Regular & Regular & Regular & \\
\hline \multirow[t]{4}{*}{ Irregular } & Irregular & Irregular & Irregular & \\
\hline & $L$ & & Pessoal & \\
\hline & & & Unipessoal & \\
\hline & Impessoal & Impessoal & Impessoal & \\
\hline \multirow[t]{3}{*}{ Defectivo } & Defectivo & Defectivo & Defectivo & \\
\hline & & & Indefectivo & \\
\hline & & Terminativo & & \\
\hline
\end{tabular}




\begin{tabular}{|c|c|c|c|c|}
\hline & & Perisphrastico & & \\
\hline Reflexo & Reflexivo & Pronominal & Reflexivo & \\
\hline \multirow[t]{4}{*}{ Reciproco } & $\begin{array}{c}\text { Pronominal } \\
\text { reflexo }\end{array}$ & & Reciproco & \\
\hline & & & Passivo & \\
\hline & & & Indefinido & \\
\hline & & & Emphatico & $\begin{array}{l}\text { Expletivo } \\
\text { (MM1894) }\end{array}$ \\
\hline
\end{tabular}

6.10 La terminología del verbo

A partir del análisis terminográfico de las denominaciones del verbo, se pueden identificar tres tipos de campos de referencia para los términos:

1) Los términos que conservan la forma y el contenido, como el «verbo substantivo», los modos «indicativo», uimperativo» y "condicional», las forma «infinito pessoal», los verbos «frequentativo» (verbos que expresan acciones consecutivas como batucar), "diminutivo» (chuviscar, choromingar), «auxiliar», «regular», «irregulan», «impessoal» y «defectivo».

2) Los términos que preservan el contenido pero cambian la forma. Este es el caso de los verbos «adjectivo», «attributivo»y «predicativo» y de los modos «conjunctivo» y «subjunctivo». De las formas no personales «infinito puro», «infinito» e «infinitivo»; «participio presente», «gerundio» y «participio imperfeito»; «participio pretérito», «participio passado» y «participio aoristo». De los verbos «neutro», «intransitivo» y de "predicação completa»; "activo», «proprio», «transitivo» y de «predicação incompleta»; «reflexo», «reflexivo» y «pronominal»; y «pronominal reflexo» y «reciproco».

3) Los términos que mantienen la forma pero cambian el contenido. Se puede citar, por ejemplo, el verbo «frequentativo» que en las 
gramáticas de Moraes y Freire se refieren a «verbos cuja a acção se repete muitas vezesı (Freire 1894[1875]: 105), como bracejar, batucar, etc. y en la Gramática de Ribeiro corresponde a una perífrasis de verbo + gerundio, como ulr indo-vir vindo-estar cahindo-andar estudando» (Ribeiro 1881: 67).

Es importante destacar también que algunos términos no se han estandarizado en el metalenguaje gramatical de este periodo. Este es el caso de los términos citados por un único autor, como «relativo», "predicação dupla», «denominativo», «imitativo», «ichoativo», «augmentativo», «negativo», "de estado», «fundamental», «pessoal», «unipessoal», «indefectivo», «terminativo», «perisphrastico», «passivo», «indefinido» y «emphatico». Sin embargo, algunos términos han logrado consolidarse, como los relativos a los verbos «defectivo», «regular», «irregulan», «auxiliar», «impessoal», «reflexivo»y «reciproco», que ya a finales del siglo se instituían en términos asociados a la clase verbal.

\subsubsection{La terminología del adverbio}

La terminología del adverbio en las gramáticas brasileñas no muestra muchas variaciones, salvo la introducción de nuevos tipos de adverbios a medida que avanza el estudio de la gramática. Moraes Silva, por ejemplo, distingue ocho categorías: «tempo», «lugar e distancia», «quantidade», «modo», «orden», «de affirmar», «de negan» y «de duvidan». Augusto Freire mantiene la misma división propuesta por Moraes a principios del siglo, pero añade dos nuevas clases, adverbio de «exclusão» y de «interrogar».

De las clases propuestas por Freire, Júlio Ribeiro excluye una y añade otras dos. De este modo, esta categoría se divide en: «tempo», «lugar», «quantidade», «modo», «orden», «affirmação», «negação», «dúvida», «exclusão», «designação» y «conclusão lógica». La terminología utilizada por Maciel no se diferencia en la práctica de aquellas que han propuesto sus antecesores, por lo que el autor 
divide los adverbios en nueve grupos: «tempo», «lugar», «quantidade», «modo», «affirmação», «concessão», «negação», «dúvida» y «exclusão».

La terminología relacionada con los adverbios no experimenta cambios profundos, pero se puede señalar un aspecto en el que los gramáticos se diferencian. Se trata de las locuciones adverbiales. Moraes las denomina ufrases adverbiaesı, mientras que Augusto Freire y Júlio Ribeiro emplean la expresión «locução adverbial»y y Maximino Maciel, «expressões adverbiaes». Es un rasgo propio de Maciel justificar sus preferencias terminológicas, así el autor no deja de argumentar la sustitución del término «locução» por «expressão» en la Grammatica Descriptiva:

Temos usado do termo expressão de preferencia ao termo locução, como DutReY, Gram. Latine, pois locução indica um dos processos de formação de palavras (Maciel 1926[1894]: 149).

La tabla siguiente describe de manera más concisa la evolución de esta terminología:

\begin{tabular}{|c|c|c|c|c|}
\hline M. Silva & A. Freire & J. Ribeiro & M. Maciel & Equivalente \\
\hline Tempo & Tempo & Tempo & Tempo & \\
\hline $\begin{array}{c}\text { Lugare } \\
\text { distancia }\end{array}$ & Logar & Logar & Lugar & \\
\hline Quantidade & Quantidade & Quantidade & Quantidade & \\
\hline Modo & Modo & Modo & Modo & \\
\hline Orden & Ordem & Ordem & & \\
\hline Afirmar & Affirmar & Affirmação & Affirmação & \\
\hline Negar & Negar & Negação & Negação & \\
\hline Duvidar & Duvidar & Dúvida & Dúvida & \\
\hline & Interrogar & & & \\
\hline & Exclusão & Exclusão & Exclusão & \\
\hline & & Designação & & \\
\hline & & Conclusão & & \\
\hline
\end{tabular}






\subsection{Terminología del adverbio}

A partir de este análisis terminográfico, se pueden identificar en la terminología de los adverbios dos tipos de relación entre término y concepto:

1) Los términos son idénticos en forma y en contenido: «tempo», «quantidade», «modo», «orden» y «exclusão».

2) Los términos varían en cuanto a la forma, pero conservan el mismo contenido. Este es el caso de «lugar e distancia», «logar» y «lugar»; «affirmar» y «affirmação»; «negan» y «negação» y «duvidan» y «dúvida».

Los demás términos introducidos por los autores («interrogar», designação», "conclusão lógica» y «concessão») en esta clase de palabras no tuvieron continuidad en el metalenguaje gramatical de esta tradición (temporalidad breve).

\subsubsection{La terminología de la conjunción}

Para Moraes Silva, las conjunciones pueden ser de nueve tipos: «copulativa», «disjunctiva», "condicional», «causal», "de concluir e inferir»», «comparativas»), «adversativas», «condicionaes» y «permissivas».

Augusto Freire, por su parte, organiza esta clase en dos grupos, las conjunciones «de approximação» y las «de subordinação». En la división de estos grupos el autor conversa la antigua terminología de Moraes, pero añade nuevos tipos de conjunciones. Las "de approximação» se denominan "copulativa», "disjunctiva», "adversativa», "conclusiva», "continuativa» y "explicativa»; y las "de 
subordinação» compreenden la «circunstancial», la «temporal», la «concessiva», la «final», la «modal», la «subjectiva», la «condicional» y la «causal»».

Ribeiro divide las conjunciones en «coordenativas» y «subordinativas». La «copulativa», la «disjunctiva», la «conclusiva», la «adversativa», la «explicativa» y la «continuativa» forman el grupo de las coordinadas. En las subordinadas el autor añade las "condicionales», las «causales», las "concessivas», las «temporales»y y las «integrantes».

Maciel propone la siguiente terminología (y una división) para las conjunciones "coordenativas»: "approximativa», "alternativa», "adversativa» y «conclusiva» o «illativa». Las «subordinativas» incluyen las «temporales», las «concessivas», las «condicionaes», las «causaes», las «modaes», las uintencionaes»" o «finaes», las «proporcionaes» y las «integrantes».

En la tabla siguiente se compara la terminología relacionada con las conjunciones que seleccionan los gramáticos brasileños:

\begin{tabular}{|c|c|c|c|c|}
\hline M. Silva & A. Freire & J. Ribeiro & M. Maciel & Equivalente \\
\hline & Approximação & Coordenativa & Coordenativa & \\
\hline Copulativa & Copulativa & Copulativa & Approximativa & \\
\hline \multirow[t]{2}{*}{ Disjunctiva } & Disjunctiva & Disjunctiva & Alternativa & Alternativa (AF1875) \\
\hline & Continuativa & Continuativa & & Transitiva (AF1875) \\
\hline Adversativa & Adversativa & Adversativa & Adversativa & \\
\hline \multirow[t]{5}{*}{$\begin{array}{c}\text { De concluir e } \\
\text { inferir }\end{array}$} & Conclusiva & Conclusiva & Conclusiva & $\begin{array}{c}\text { Illativa } \\
\text { (AF1875/ MM1894) }\end{array}$ \\
\hline & Explicativa & Explicativa & & \\
\hline & Subordinação & Subordinativa & Subordinativa & \\
\hline & Circunstancial & & & \\
\hline & Temporal & Temporal & Temporal & $\begin{array}{c}\text { Periodica o } \\
\text { circunstancial } \\
\text { propriamente dita } \\
\text { (AF1875) }\end{array}$ \\
\hline \multirow[t]{2}{*}{ Condicional } & Condicional & Condicional & Condicional & \\
\hline & Concessiva & Concessiva & Concessiva & Hyphothetica \\
\hline
\end{tabular}




\begin{tabular}{|c|c|c|c|c|}
\hline & & & & (AF1875) \\
\hline \multirow[t]{6}{*}{ Causal } & Causal & Causal & Causal & \\
\hline & Final & & Intencional & Final (MM1894) \\
\hline & Modal & & Modal & \\
\hline & Subjunctiva & & & \\
\hline & & & Proporcional & \\
\hline & & Integrante & Integrante & \\
\hline \multicolumn{5}{|l|}{ Comparativa } \\
\hline Permissiva & & & & \\
\hline
\end{tabular}

6.12 Terminología de las conjunciones

A partir de la relación entre la forma y el contenido de los términos, se puede clasificar esta terminología en dos tipos:

1) Los términos idénticos en forma y contenido, como las conjunciones «adversativa», "continuativa»», "explicativa», «temporal», "condicional»», «concessiva», «causal»», «modal» e «integrante».

2) Los términos que presentan formas diferentes y contenido idéntico, como por ejemplo las divisiones de las conjunciones en de "approximação» y "coordenativa» y de "ssubordinação» y "subordinativa», las conjunciones "copulativa» y "approximativa», «disjunctiva» y "alternativa», "de concluir e inferir» y "conclusiva» y «final» e «intencional»».

Este análisis terminográfico demuestra además que algunos términos ya se habían estandarizado en el último cuarto del siglo, como es el caso de las conjunciones «adversativa», «temporal», «condicional», «concessiva».

En cuanto a su terminología, Maciel muestra una considerable preocupación por adecuar el metalenguaje a los fundamentos gramaticales y por justificar los cambios terminológicos referidos también a las conjunciones. Así por ejemplo, se puede citar la observación del autor sobre la impropiedad del 
término «disjunctivo» y sobre la modificación del término «copulativo» por «approximativo»:

O termo disjunctivo não serve, pois disjunctivo é o que separa e a conjuncção liga, por isso há conflicto de idéas. (Maciel 1926[1894]: 153)

O termo copulativa é tão absurdo quanto improprio, pois toda conjuncção é copulativa, porque toda conjuncção liga, e a palavra tambem é adverbio de modo (Maciel 1926[1894]: 153).

En esta última cita se puede notar cierta crítica hacia las gramáticas anteriores, no solo por aceptar el término «copulativa» sino también por clasificar «tambem» entre las conjunciones copulativas, como se puede observar en las obras de Moraes, Freire y Ribeiro:

As Copulativas, [...] são, e, outrossim, tambem (Moraes Silva 1824[1806]: 74).

177. A conjunção coordenativa é

1) copulativa: e, tambem, nem (Ribeiro 1881: 70).

A copulativa une os termos [...]. Taes são: e, e bem, assim, não só... mas tambem, nem, tambem (Freire 1894[1875]: 109).

Con respecto al término «disjunctivo», cabe resaltar que Augusto Freire ya había propuesto el cambio de forma para conjunción «alternativa», que corresponde a la terminología que emplearía Maciel en su Gramática.

\subsubsection{La preposición y la interjección}

En la mayoría de las gramáticas, el estudio relacionado con la preposición y la interjección no presenta cambios de terminología, salvo la Gramática de Maciel. El autor proporciona una división de las preposiciones en «preposições proprias» o «essenciais», «palavras preposicionaes» y «expressões 
preposicionaes», mientras que la interjección puede ser «espontanea», "propria» o «essencial», «palavra interjeccional» y «expressão interjeccional»:

Temos preposições:

a) Proprias ou essenciaes, isto é, palavras de natureza preposicional [...].

b) Palavras preposicionaes, isto é, usada porém invariavelmente, como preposição [...].

c) Expressões preposicionaes, isto é, um grupo de palavras que, sempre terminando por preposição propria, é integralmente equivalente a uma preposição [...] (Maciel 1926[1894]: 149).

Temos interjeições:

a) Espontaneas, essenciaes ou proprias, isto é palavras destituídas de significação, mas que exprimem um sentimento ou sensação [...].

b) Palavras interjeccionaes, isto é, usadas interjectivamente [...].

c) Expressões interjeccionaes, isto é, um grupo de palavras interjectivamente empregado [...] (Maciel 1926[1894]: 156-157).

\subsection{Terminología y terminografía de la sintaxis}

En la tradición brasileña, las gramáticas racionalistas de la primera mitad del siglo XIX emplearon la misma terminología para referirse a los elementos que constituyen la oración. En este sentido, Moraes Silva distingue tres partes de la «sentença», el «sujeito», el «verbo»y el «attributo». Los cambios terminológicos posteriores fueron de cierto modo superficiales y solamente afectaron la mudanza de formas de algunos términos, como se puede observar en la terminología de Augusto Freire, que conserva la propuesta más generalizada (desde Moraes) y solamente modifica la forma «sentença» por «proposição».

No obstante, en las gramáticas de Júlio Ribeiro y Maximino Maciel, este metalenguaje cambia sencillamente. Ribeiro divide la «proposição» en «sujeito» y «predicado», este último está dividido en «cópula» y el «predicado propriamente dito», y Maciel emplea el término «objecto» en lugar de «predicado». Respecto al término «proposição» en particular, Maciel trata de 
justificar la prevalencia de esta forma sobre todas los demás que hasta entonces eran empleados en las gramáticas:

As proposições também se dizem clausulas, phrases, sentenças ou orações; mas todos esses termos se devem substituir pelo de proposição, por ser este mais geral e estar mais de accordo com as theorisações da lógica ${ }^{4}$ e simplificar mais o aprendizado (Maciel 1926[1894]: 356).

El orden de los elementos en la oración es otro aspecto sintáctico cuya terminología parece haber cambiado sencillamente. Moraes Silva identifica dos tipos de orden, el «natural» y el «inverso». Augusto Freire y Júlio Ribeiro emplean respectivamente los vocablos «directo» y "direito» para referirse al orden «natural»y y preservan el término «inverso». Maciel amplia esta clasificación y presenta tres órdenes sintácticos, el «analytico»; el «synthetico» y el orden «transposto» o «interrupto».

La Gramática de Moraes Silva todavía carece de estudios oracionales, pues, como ilustra el propio título de esta parte de la obra, su sintaxis trata de la composición de las partes de la oración, es decir, el autor trata de establecer las relaciones que unas palabras establecen con otras, en especial, por medio de la preposición. El gramático también analiza distintos aspectos sintácticos con respecto al uso de la preposición, la regencia de los verbos y la concordancia entre algunas clases de palabras.

\subsubsection{La terminología de las proposiciones}

El análisis de la terminología de las proposiciones atiende aquí únicamente a las gramáticas de Augusto Freire, Júlio Ribeiro y Maximino Maciel, debido a que las obras publicadas a principios del siglo, como el Epítome,

\footnotetext{
${ }^{4}$ Além disso, o termo oração se refere mais a um discurso inteiro, a sucessão de períodos; phrase, a uma expressão peculiar á índole de uma língua; clausula a contextura dos contractos jurídicos, as expressões que, dependentes subjectivamente entre si, se esclarecem e se complementam [nota del gramático].
} 
todavía carecían de un cuerpo de doctrina para sistematizar este tipo de estructura.

Pues bien, Augusto Freire presenta en su obra tres tipos de proposiciones, las "simples», las "absolutas» y las «subordinadas». Las oraciones simples se dividen en «declarativa» («positiva» y «negativa»), «interrogativa», «optativa», «imperativa» y «exclamativa». Las oraciones absolutas pueden ser «syndeticas» o «asyndeticas» y, por último, las proposiciones subordinadas, que comprenden las "circunstanciaes» («conjuncional», "qualificativa», «infinitiva preposicionada», «participio»), y las «integrantes» o «completivas» («subjuntiva», «interrogativa» e «infinitiva»).

La Gramática de Ribeiro emplea básicamente la misma clasificación de Freire. Así pues, las proposiciones se organizan en tres grupos: las oraciones «simples», que se dividen en «declarativa» («afirmativa» y «negativa»), «interrogativa», "condicional», «imperativa» y «exclamativa»; las oraciones "coordenadas», que comprenden las proposiciones "copulativa», "adversativa» y "contrastiva»; y, por último, las «subordinadas» que se constituyen de la "clausula substantiva», "clausula adjectiva» y "clausula adverbial»" ("de tempo», «de lugar», «de orden», «de modo» y «de dúvida».

El modelo de Maciel es el más avanzado hasta este periodo. El autor establece tres tipos de proposiciones:

1) Las «simples»: «expositiva», «interrogativa», «optativa», «imperativa» y «exclamativa».

2) Las de «coordenação», que pueden ser denominadas:

a) Según la presencia o ausencia de conectivos: «syndeticas» y «asyndeticas».

b) Según la conjunción que las une: «approximadas», «alternadas», «adversativas» e uillativas».

c) Según su función enunciativa: «expositiva», «imperativa» y «optativa».

3) Las de «subordinação», que pueden ser: 
a) Según el conectivo: «conjunccionaes», «relativas» y uindefinitas».

b) Según su naturaleza: «substantiva», «adjetiva» y «adverbial».

c) Según su función: «subjetiva», «objectiva», «atributiva», «predicativa» y «circunstancial».

Por último, el gramático también cita las proposiciones de «complexação». La tabla siguiente muestra la estructura de las oraciones de cada gramática y la equivalencia de las terminologías:

\begin{tabular}{|c|c|c|c|}
\hline A. Freire & J. Ribeiro & M. Maciel & Equivalente \\
\hline Simples & Simples & Simples & \\
\hline Declarativa positiva & $\begin{array}{l}\text { Declarativa } \\
\text { afirmativa }\end{array}$ & Expositiva & $\begin{array}{c}\text { Enunciativa/ } \\
\text { expositiva (AF1875) }\end{array}$ \\
\hline Declarativa negativa & $\begin{array}{c}\text { Declarativa } \\
\text { negativa }\end{array}$ & & \\
\hline Interrogativa & Interrogativa & Interrogativa & \\
\hline \multirow[t]{2}{*}{ Optativa } & & Optativa & \\
\hline & Condicional & & \\
\hline Imperativa & Imperativa & Imperativa & \\
\hline Exclamativa & Exclamativa & Exclamativa & \\
\hline Absolutas & Coordenação & Coordenação & \\
\hline Syndetica & & Syndetica & \\
\hline \multirow[t]{10}{*}{ Asyndetica } & & Asyndetica & \\
\hline & Copulativa & & \\
\hline & Adversativa & Adversativa & \\
\hline & Contrastiva & & \\
\hline & & Illativa & \\
\hline & & Approximada & \\
\hline & & Alternada & \\
\hline & & Expositiva & \\
\hline & & Imperativa & \\
\hline & & Optativa & \\
\hline
\end{tabular}




\begin{tabular}{|c|c|c|c|}
\hline Subordinação & Subordinação & Subordinação & \\
\hline \multicolumn{4}{|l|}{$\begin{array}{l}\text { Circunstancial } \\
\text { conjuncional }\end{array}$} \\
\hline \multicolumn{4}{|l|}{$\begin{array}{c}\text { Circunstancial } \\
\text { participio }\end{array}$} \\
\hline \multicolumn{4}{|l|}{$\begin{array}{c}\text { Circunstancial infinitiva } \\
\text { preposicionada }\end{array}$} \\
\hline \multicolumn{4}{|l|}{$\begin{array}{l}\text { Circunstancial } \\
\text { qualificativa }\end{array}$} \\
\hline Integrante subjunctiva & & & $\begin{array}{l}\text { Completiva } \\
\text { (AF1875) }\end{array}$ \\
\hline \multicolumn{4}{|l|}{$\begin{array}{l}\text { Integrante } \\
\text { interrogativa }\end{array}$} \\
\hline \multicolumn{4}{|l|}{ Integrante infinitiva } \\
\hline & Clausula substantiva & Substantiva & \\
\hline & Clausula adjectiva & Adjectiva & \\
\hline & Clausula adverbial & Adverbial & \\
\hline & & Conjunccional & \\
\hline & & Relativa & \\
\hline & & Indefinita & \\
\hline & & Subjectiva & \\
\hline & & Objectiva & \\
\hline & & Atributiva & \\
\hline & & Predicativa & \\
\hline & & Circunstancial & \\
\hline & & Complexação & \\
\hline
\end{tabular}

6.13 Terminología de las oraciones

La relación entre forma y contenido de los términos muestra que la terminología relativa a las oraciones puede organizarse en tres grupos: 
1) Los términos que conservan tanto la forma como el contenido, como las oraciones «declarativa negativa», «interrogativa», «imperativa», «exclamativa», "syndetica», "asyndetica», "adversativa», "substantiva», «adjectiva» y «adverbial».

2) Los términos que poseen formas diferentes y contenidos idénticos, como por ejemplo las oraciones «circunstanciaes conjuncionaes» de Freire y las «circunstanciaes» descritas por Maciel. Ambas se refieren a la subordinada empleada como oración adverbial.

3) Los términos que cambian de forma y (sencillamente) de contenido, como es el caso de las oraciones «declarativa afirmativa» y «expositiva», la primera incluye solamente aquellas oraciones que se construyen con indicativo, mientras que la segunda también considera las construcciones en el condicional.

La terminología empleada para designar las oraciones simples apenas se modifica durante este periodo, lo que pone de manifiesto la estabilidad que adquieren estos términos en el metalenguaje gramatical. Las oraciones compuestas presentan cambios más profundos a medida que evolucionan las doctrinas gramaticales. Estos avances teóricos imprimen en la terminología de cada obra un carácter individual, pues cada autor emplea un criterio de definición distinto, lo que se refleja en el uso de un vocabulario específico y adaptado a cada teoría. Este aspecto puede demostrar además que la evolución de estos términos acompaña a la normalización misma de la teoría.

\subsubsection{La terminología de las figuras y vicios del lenguaje}

En cuanto a la terminología de las figuras y vicios de lenguaje, aunque no presenta mucha variación de forma y contenido, se puede notar el aumento considerable de denominaciones, resultado de las nuevas propuestas de organización del contenido. 
En esta línea, Moraes Silva identifica cuatro tipos de «figuras de composição»: la «ellipse» (dividida en «zeugma» y «sillepse»), el «pleonasmo», la "enallague» y el "hyperbato» o usynchise»; y cinco tipos de "composições viciosas»: la «perrissologia», la «amfibologia», el «barbarismo» o «estrangeirismo», el «solecismo» y la «cacofonia».

La terminología (y teoría) de las figuras y vicios de lenguaje en la Gramática de Augusto Freire se muestra una de las más complejas de su tradición. En la obra de Freire figuran 18 tipos de vicios de lenguaje y más de 50 figuras, pero la mayoría de los términos introducidos (o creados) por el autor no vuelven a ser mencionados por ningún otro gramático.

Ribeiro, por su parte, parece seguir la tradición más generalizada. Respecto a los vicios de lenguaje, el gramático reconoce dos tipos: el «barbarismo» y el "solecismo», que se divide en "kakofonia», «hiato», "ekho» y «collisão». En cuanto a las figuras de lenguaje, cita las de «metaplasmo», como la «tmese» y la «anthítese»; y las de "syntaxe», que comprende la «ellipse», la «zeugma», la «syllepse», el «pleonasmo», el «hyperbato», la «anastrophe» y la «synkhysis»).

En la Gramática de Maximino Maciel parece ser más evidente la influencia de la terminología de Freire. Sin embargo, Maciel introduce términos nuevos que expresen una relación más directa con sus definiciones. Las figuras de sintaxis comprenden el «asyndeto», el «polysyndeto», la «hypersyntactica» y la «hyperstrophe», el «hyperbato», la «anastrophe», entre otros. Los vicios de expresión están divididos en dos grupos: el ubarbarismo» y el "solecismo». El primero se comprende la "cacoepia», la "cacographia», el "dialectismo» y el «extrangeirismo» y el segundo incluye la «synchyse», la «perrissologia», el «eco», el «hiato», la «collisão», el "cacophato», el «anacolutho», la «asonancia», entre otros.

La tabla siguiente muestra algunas de las figuras y vicios de lenguaje en las gramáticas de Moraes, Freire, Ribeiro y Maciel y la equivalencia de las terminologías: 


\begin{tabular}{|c|c|c|c|c|}
\hline M. Silva & A. Freire* & J. Ribeiro* & M. Maciel* & Equivalente \\
\hline Ellipse & Ellipse & Ellipse & Ellipse & \\
\hline Zeugma & Zeugma & Zeugma & Zeugma & \\
\hline Sillepse & & Sillepse & Syllepse & \\
\hline Pleonasmo & Pleonasmo & Pleonasmo & Pleonasmo & \\
\hline \multicolumn{5}{|l|}{ Enallague } \\
\hline \multirow[t]{14}{*}{ Hyperbato } & Hyperbato & Hyperbato & Hyperbato & Synchise (MS1806) \\
\hline & Synchisis & Synkhysis & & \\
\hline & Anthítese & Anthítese & & \\
\hline & Anastrophe & Anastrophe & Anastrophe & \\
\hline & Polysindeton & & Polysyndeto & \\
\hline & Tmese & Tmese & & \\
\hline & Paranomasia & & & \\
\hline & Epistrophe & & & \\
\hline & Prosopopéa & & & \\
\hline & Anaphora & & & \\
\hline & methaphora & & & \\
\hline & Ironia & & & \\
\hline & Metonymia & & & \\
\hline & Synecdoque & & & \\
\hline Perrissologia & Perrissologia & & Perrissologia & \\
\hline Amfibologia & Amphibologia & & & Ambiguidade (AF1875) \\
\hline Barbarismo & Peregrinismo & Barbarismo & Barbarismo & $\begin{array}{c}\text { Estrangeirismo } \\
\text { (MS1806) } \\
\text { Barbarismo (AF1875) }\end{array}$ \\
\hline Solecismo & Solecismo & Solecismo & Solecismo & \\
\hline \multirow[t]{8}{*}{ Cacofonia } & Cacophaton & Kakophonia & Cacophato & \\
\hline & Archaismo & & & \\
\hline & Neologismo & & & \\
\hline & Purismo & & & \\
\hline & Hiato & Hiato & Hiato & \\
\hline & Collisão & Collisão & Collisão & \\
\hline & Echo & Ekho & Echo & \\
\hline & & & Estrangeirismo & \\
\hline
\end{tabular}




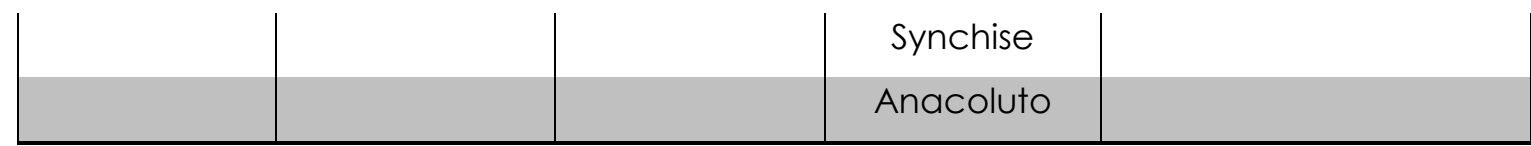

Leyenda: Moraes Silva (1806) - MS1806; Augusto Freire (1875) - AF1875; Júlio Ribeiro (1881) - JR1881; Maximino Maciel (1894) - MM1894.

* La terminología relativa a las figuras y los vicios en las obras de estos autores es considerablemente más extensa de lo que se muestra en este cuadro.

\subsection{Terminología de las figuras y vicios del lenguaje}

Esta descripción revela que se pueden clasificar las figuras y vicios de lenguaje en dos grupos según la relación entre las formas y los contenidos:

1) Los términos que conservan tanto la forma como el contenido son la «ellipse», la «zeugma», la «sillepse», la «pleonasmo», la «hyperbato», la «solecismo», la «perrissologia», la «anthítese», la «anastrophe», la «tmese», la «anfibologia», la «hiato» y la «collisão».

2) Los términos que conservan el contenido pero cambian de forma son los siguientes: «barbarismo», «peregrinismo» y «estrangeirismo»; "cacofonia», «cacophaton», «kakophonia» y «cacophato»; «polysindeton», «polysyndeto»; "synchisis» y usynkhysis»; y «eco» y «ekho».

\subsection{Terminología y terminografía de la semiología}

La primera Gramática brasileña que presenta un tratado semántico es la de Augusto Freire. Pese a la brevedad de sus estudios, Freire trata de describir los principales fenómenos que intervienen en la construcción del significado de un vocablo. Los términos propios de la semántica son todavía escasos en la obra, pues esta parte de la gramática se centra básicamente en la interpretación del sentido de la oración a partir del significado de los «termos».

La «semiologia» de Freire no parece ser lo suficientemente extensa y fundamentada teóricamente como para introducir en la tradición brasileña una 
terminología propia. Gran parte de su vocabulario deriva de otras partes de la gramática como la lexicología y la sintaxis. Así por ejemplo, el autor emplea términos como "synonymo», «mononymo», «polynomyno» y «antonymo», formas presentes tanto en otras partes de su obra como en otras gramáticas. En cuanto a los nuevos conceptos semánticos, como las leyes acerca del cambio de significado, se expresan mediante un lenguaje hibrido, carente de términos técnicos. Estos aspectos demuestran que la terminología sobre semántica todavía no había alcanzado un estatus técnico en la gramática brasileña del siglo XIX.

Maciel es el segundo autor en la tradición brasileña que emprende en su Grammatica Descriptiva un estudio independiente de semántica. El gramático manifiesta en su tratado que las palabras pueden agruparse según su tipo de «significação» o bien según la idea o el concepto que representan. En el primer caso, las palabras pueden ser de «significação propria», «traslata», «etymologica», «technica» e «historica». El segundo caso, similar al de Freire, determina que las palabras pueden ser "synonimas», "antonymas», «heteronymas», «polyonymas», «polysemicas» y «homonymas», según su idea o concepto. El siguiente tema tratado por el autor son las «alterações semanticas», que pueden ser «meliorativas» o «pejorativas».

Otros aspectos mencionados por Maciel son las «propriedades semanticas» de las palabras, denominadas "extensão» y "comprehensão»; y la «tropologia», que abarca la «metaphora», la "catacrese», la «metonymia» y la «synecdoque». Respecto a la «tropologia», el propio Maciel critica la antigua denominación de «figuras» y el empleo generalizado de una terminología anómala y excesiva y defiende el uso de un vocabulario más técnico y objetivo:

Assim como aos povos primevos, emquanto se não constituira a sciencia, se lhes antolhavam por todos os recantos myriades de deuses para a explicação dos phenomenos do Universo, assim aos rethoricos, aos grammaticos, aos professores, a legião das pretensas figuras, muitas vezes até para justificação de tantos erros e deslises quantos se lhes offereciam no dominio da linguagem, na constructura das proposições. 
Desvaneceu-se porfim esse pantheismo grammatical, passando os nomes das figuras a ser considerados termos technicos com que se designam certos factos e phenomenos das linguas.

Semiologicamente contemplados, estes factos se dizem tropos. (Maciel 1926[1894]: 477).

A pesar de la novedad de este estudio en la gramaticografía brasileña decimonónica y de la escasez de términos propios de semántica, se puede notar que Maciel es el responsable de la aplicación de un vocabulario suficientemente técnico y coherente con su doctrina gramatical, como se pone de manifiesto, por ejemplo, en los términos para clasificar los tipos de significación de las palabras y en la sustitución de «mudança de número» por «pluralisação».

\subsection{Resumen}

A lo largo del siglo XIX la gramaticografía brasileña ha presenciado muchos avances en su terminología. Desde las primeras gramáticas logicistas hasta la publicación de la Grammatica Descriptiva de Maciel, el metalenguaje gramatical se renueva, normaliza y avanza por la influencia de nuevos pensamientos y doctrinas. Los modelos gramaticales estudiados son los más representativos de los cambios que marcan el periodo decimonónico en Brasil y los primeros en esta tradición que aplican las innovaciones procedentes de los estudios europeos y americanos.

Las primeras gramáticas racionalistas, representadas aquí por la obra de Moraes Silva, se caracterizan por un lenguaje poco técnico, por el uso generalizado de términos tradicionales para nombrar las estructuras gramaticales, por la ausencia de referencias explícitas al origen de los términos, por la aplicación del vocabulario estandarizado en la gramática latina, por el 
conservadurismo frente al cambio e introducción de nuevos términos, entre otros aspectos.

Augusto Freire presenta en su manual una terminología más técnica comparada con las gramáticas racionalistas hasta este periodo, elude gran parte del vocabulario heredado de la tradición latina, confirma el nivel de estandarización con respecto a ciertos tecnicismos racionalistas e introduce nuevos términos gramaticales. Aunque son escasas las referencias del autor a sus fuentes teóricas, este análisis terminográfico pone de manifiesto que la obra se fundamenta en la filología positivista y comparatista de F. Diez y A. Epiphanio da Silva Dias, configurando esta como una de las precursoras del nuevo paradigma gramatical.

La Grammatica Portugueza de Júlio Ribeiro presenta un vocabulario tradicional cuando trata de los conceptos gramaticales de mayor recorrido histórico, como es la terminología relacionada con el estudio y clasificación de las partes del discurso, que al parecer se estandariza en este periodo. Sin embargo, el desarrollo de la sintaxis se manifiesta también en el empleo de un metalenguaje más moderno y acomodado a la teoría, pero carente de normalización.

En su Grammatica Descriptiva, Maciel organiza la terminología de forma más sistemática y adecuada a los conceptos que se pretenden designar. La preocupación por la terminología gramatical es evidente en las notas a pie de página y en las diversas observaciones que introduce el autor para la descripción del portugués. La elección de términos modernos, el rechazo del vocabulario tradicional heredado, la crítica a la terminología imprecisa y opaca, la objetividad y coherencia de su propuesta terminológica, son algunos de los aspectos más característicos del estudio de este autor.

A partir de este análisis se puede concluir que la terminología gramatical brasileña se caracteriza en la primera mitad del siglo por el uso extendido de un vocabulario conservador y respetuoso con la tradición, por la escasez de avances con respecto a la creación o aplicación de nuevos términos, por la precariedad del status técnico de este metalenguaje y, en cierto modo, por la 
consolidación del proceso de estandarización relativo a la nomenclatura heredada de los gramáticos del siglo XVIII.

La segunda mitad del siglo XIX está marcada por el avance de las teorías, la ampliación de las fuentes teóricas y el desarrollo de nuevos contenidos lingüísticos en la gramática. Estos factores han influido, en gran medida, en el cambio de la terminología gramatical de este periodo, que se encamina hacia la formación de manuales brasileños interesados por la difusión de una taxonomía precisa, moderna y acorde con su tiempo. El vocabulario tradicional fue en gran medida sustituido por nuevos términos, abundan los tecnicismos tanto en la nomenclatura como en el texto gramatical y, como consecuencia de las nuevas disciplinas, aumenta la necesidad de términos más objetivos y ajustados a la doctrina. Algunos términos que antes habían sido estandarizados caen en desuso en este momento y las nuevas denominaciones que empiezan a ser aplicadas comienzan su proceso de estandarización. Hasta finales del siglo, muchas de estas palabras todavía no pueden ser consideradas como parte del metalenguaje gramatical.

Las fuentes utilizadas por nuestros autores también desempeñan, como es lógico, un papel importante en este periodo, pues la mayoría de los términos técnicos procede de traducciones de las obras más representativas en la formación lingüística y filológica de las primeras generaciones de autores nacidos en Brasil. Es evidente, sobre todo en las obras de Ribeiro y Maciel, la aceptación de la terminología europea y americana en los estudios brasileños, que además de aplicarse a la descripción de la lengua portuguesa, sirvió de fuente de inspiración para el cambio de metalenguaje. 


\section{Cambios en la gramatización del portugués en el siglo XiX BRASILEÑO}

El objetivo fundamental de este capítulo consiste en determinar los cambios que ha experimentado la codificación del portugués durante el siglo XIX brasileño a partir de la descripción y del análisis de las definiciones, las divisiones y las clasificaciones que figuran en los manuales publicados por autores brasileños. Este estudio se centra particularmente en la materia gramatical de los tratados de Moraes Silva, Augusto Freire, Júlio Ribeiro y Maximino Maciel, que, en nuestra opinión, manifiestan (cuando no introducen) los principales avances que marcan la historia de la gramática en Brasil. Además, se pretende determinar los criterios de definición y clasificación empleados por los gramáticos del Nuevo Continente en la codificación del portugués. Esta investigación recoge tres criterios básicos (véase Gómez Asencio 1981 y Martínez Gavilán 1989):

1) El "criterio formal» designa las definiciones que señalan las particularidades de las palabras en cuanto a su forma (estructura material).

2) El "criterio semántico (o lógico)» distingue las definiciones que caracterizan las clases de palabras por su contenido (significado 0 referente extralingüístico).

3) El "criterio sintáctico» denomina los conceptos relacionados con la función (en el nivel morfológico y sintáctico) y posición sintáctica de las clases de palabras. Se utilizan aquí los términos "funcional» y «colocacional» para distinguir estos dos tipos de criterio sintáctico (Gómez Asencio 1981). 


\subsection{Evolución de la definición de gramática}

El Epítome de Grammatica Portugueza de Moraes Silva, como ya se ha demostrado anteriormente, se configura en el marco teórico racionalista y, a partir de este enfoque, la gramática es definida como «arte, que ensina a declarar bem os nossos pensamentos, por meyo de palavrası) (Moraes Silva 1824[1806]: III). Esta definición muestra que en este periodo una gramática consiste en un tratado de carácter pedagógico («arte que ensina») y de fundamento logicista, es decir, «la corrección vendría dada por la adecuación perfecta de lo que se dice con lo que se piensa, de la Gramática con la Lógica»l (Gómez Asencio 1981:20).

En cuanto a la distinción entre gramática universal y particular, se puede notar la estricta correspondencia entre las definiciones presentes en las gramáticas brasileñas y las de los manuales franceses. De hecho, en muchos casos constituyen más bien meras traducciones de las definiciones de las gramáticas francesas. En este sentido, la gramática general corresponde al «tratado teórico sobre el lenguaje hablado» (Gómez Asencio 1981: 24), mientras que la gramática particular consiste en la aplicación de este tratado (o estos principios) a la lengua portuguesa hablada:

2. A Grammatica Universal ensina os methodos, e principios de falar communs a todas as linguas.

3. A Grammatica particular de qualquer lingua, v. g. da Portugueza, applica os principios communs de todos os idiomas ao nosso, segundo os usos adoptados pelos que melhor o falão (Moraes Silva 1824[1806]: III).

Así pues, según Moraes, la gramática portuguesa es una obra pedagógica que enseña el uso de los que mejor hablan, basado en los principios universales.

Esta concepción, común entre los gramáticos de la primera mitad del siglo, se manifiesta de dos maneras en los tratados brasileños, o tratan de 
reproducir la primera definición conocida en esta tradición (la de Moraes), como es el caso de Pereira Coruja (1835), o presentan definiciones más cercanas (o adecuadas) a las fuentes francesas, como por ejemplo Frei Caneca (1817), que claramente diferencia «regra» (función de la gramática particular) de «principio» (objeto de la gramática general):

A arte de reduzir a regras os principios communs a todas as linguas (Frei Caneca 1817: 20).

É uma arte que ensina a declarar bem os nossos pensamentos por meyo de palavras (Coruja 1835: 1).

Pues bien, la Gramática de Augusto Freire revela que en la segunda mitad del siglo empieza a sobresalir un nuevo marco teórico. Su definición, en realidad, no constituye una muestra cabal del entonces reciente ideal positivistal, pero logra manifestar ciertas características de esta corriente gramatical:

\section{Gramática é o estudo dos factos e das leis da linguagem.}

Tem por fim a expressão do pensamento pela palavra, e por objecto o estudo das palavras (Freire 1894[1875]: 23 [la negrita es mía]).

La definición de Freire indica que los tratados gramaticales de este periodo empiezan a distanciarse poco a poco del pensamiento racionalista. El cambio de paradigma puede ser observado en la remodelación del objeto de estudio de la gramática, es decir, la gramática empieza a ser concebida como el estudio (reflexivo) de las leyes y de los fenómenos del lenguaje, no establece,

\footnotetext{
1 Hay que señalar que Freire no manifiesta seguir o romper con cualquier corriente gramatical. En este sentido, es importante poner de relieve que la presencia de estas raíces tradicionales (y racionalistas) no constituye necesariamente un fallo del gramático, pues uno hay modelo en estado puro 0 , dicho de otra forma, todos los modelos se tiñen de eclecticismo y éste es factor determinante en la mejora $o$ en la progresión en el conocimiento de las lenguas y de cada lengua concreta» (Gómez Asencio 2001 b: 39). «El gramático, en efecto, utiliza el utillaje teórico de que dispone para presentar su análisis de la lengua española [en este caso léase portuguesa] y las secuelas del modelo latino [y racionalista] se hacen irremediables, pero -y he aquí lo importanteno calca sin más: selecciona, decanta, modifica» (Gómez Asencio 2001 b: 44-45).
} 
ni reduce a reglas la lengua, con lo cual se elude el rasgo prescriptivo de la disciplina (al menos en la definición). La definición de Freire muestra además que, a partir de este momento, la expresión del pensamiento (aparentemente separada de la noción de corrección) constituye la finalidad de la gramática y no tanto su objeto de estudio. Se puede establecer algún paralelo entre esta definición y la del gramático histórico-comparatista C. Ayer (1876) en la Grammaire Comparée:

La grammaire est la science du langage. Elle a pour objet l'expression de la pensée par la parole.

Le langage est une faculté qui n'appartient qu'à l'homme et le distingue des animaux. II n'est pas le produit de l'invention et ne s'apprend pas comme un art; mais comme tous les dons naturels, il se développe par l'exercice. La grammaire n'enseigne donc pas comme l'on doit parler, mais comme l'on parle (C. Ayer 1900[1876]: 1).

El reconocimiento de otros métodos de descripción gramatical constituye otra novedad en el estudio de la gramática. Los autores empiezan a distinguir en sus obras otros enfoques de codificación de la lengua, además de la gramática general y la particular. Este fenómeno puede ser notado en la Gramática de Freire en la distinción que proporciona el autor de los cinco tipos de gramática: la «geral», la «particular», la «descriptiva», la «comparativa» y la «portugueza»:

Grammatica geral é estudo dos factos e das leis da linguagem em toda a sua extensão.

Assim entendida, é a grammatica geral o mesmo que glottologia ou linguistica, porque é a sciencia da linguagem [...].

Grammatica particular é o estudo dos factos e das leis de uma lingua determinada.

A grammatica é comparativa ou historica, quando estuda os factos da linguagem em diferentes épocas de uma lingua ou em differentes línguas, investigando que leis presidem as suas alterações.

A grammatica é descriptiva ou expositiva, quando se limita a expor os factos da linguagem, observados no emprego de uma lingua em uma dada época, abstrahindo do estudo de suas transformações. 
Grammatica portugueza é o estudo geral, descriptivo, historico e comparativo dos factos da linguagem e das leis que os regem, no domínio tão somente da lingua portuguesa (Freire 1894[1875]: 23-24 [la negrita es mía]).

En cuanto a la definición de gramática general, se puede observar que el concepto habitual (logicista) de principios comunes a todas las lenguas empieza a ser suplantado por la noción de uscience du langage» (C. Ayer 1900[1876]: 1). La influencia de la doctrina histórico-comparada determina también el reconocimiento (y la inclusión) de los estudios diacrónicos (gramática histórica) y sincrónicos (gramática descriptiva) en la codificación del portugués, es decir, que en la obra de Freire la gramática portuguesa, para constituir un tratado completo, debe comprender todas las perspectivas disponibles en materia lingüística.

En las gramáticas brasileñas publicadas después del tratado de Freire, los rasgos positivistas son aun más evidentes. Así, en la Grammatica Portugueza de Júlio Ribeiro, la definición de gramática ratifica algunas características del modelo precedente, en particular la exclusión (en la teoría) de las ideas de prescripción y corrupción, pero ahora no solamente se suprimen estas nociones de las definiciones sino que también se manifiesta claramente el desacuerdo con esta posición:

Grammatica é a exposição methodica dos factos da linguagem².

A grammatica, não faz leis e regras para a linguagem; expõe os factos della, ordenados de modo que possam ser aprendidos com facilidade. 0 estudo da grammatica não tem por principal objecto a correção da linguagem (Ribeiro 1881: 1 [la negrita es mía]).

Evidentemente, la Grammatica Portugueza representa, no solamente a través del metalenguaje sino también de las fuentes teóricas (véase $\S 5.3 .2$ ), los primeros intentos de aplicar a la gramática del portugués el paradigma histórico-comparado. Este modelo de definición se conserva hasta finales del

2 WILLIAM DWIGHT WHITNEY, Essentials of English Grammar, London, 1877, pag. 4-5 [nota del gramático]. 
siglo, como se puede observar en la Gramática de Maximino Maciel, que, salvo un cambio visible en el metalenguaje, sigue la misma base que empezó con Augusto Freire y Júlio Ribeiro:

Grammatica é a systematisação logica dos factos e normas de uma lingua qualquer (Maciel 1926[1894]: 1).

Cabe destacar además que Maciel recupera en su Gramática las definiciones de los tipos de gramática que, después de Augusto Freire, no volvieron a ser utilizadas por otros autores:

Grammatica descriptiva que tambem se diz expositiva, é a systematisação organica dos factos e normas proprios de uma lingua, isoladamente considerada.

Grammatica Portugueza é a systematisação organica das normas e factos da lingua portugueza isoladamente considerada

Grammatica histórica é a systematisação das normas e factos da lingua desde a sua origem até nossos dias, isto é, aquella que trata da evolução da lingua nos seus diversos períodos de formação.

Grammatica comparativa é a systematisação das normas e factos de duas ou mais línguas comparadas entre si, isto é, nas duas diversas relações e divergências (Maciel 1926[1894]: 1).

Es importante resaltar que en estas definiciones el autor conserva los principios positivistas e histórico-comparados y, al mismo tiempo, modifica la definición de gramática portuguesa, de modo que se corresponda con la definición de gramática descriptiva, lo que pone de manifiesto que a finales de la centuria la gramática portuguesa se identifica con una descripción inmanentista de la lengua portuguesa.

Estas definiciones demuestran que los gramáticos brasileños introducen progresivamente las doctrinas gramaticales, pero, en algunos casos, diferentes corrientes conviven en una misma obra. Consecuentemente, se puede notar que, a lo largo de esta centuria, las definiciones evolucionan hacia la superación de rasgos tradiciones y racionalistas, sustituidos por la adopción de 
los nuevos modelos teóricos. Este fenómeno es denominado por Swiggers (2006a: 17-18) como «sustitución» o «paráfrasis explicativa».

\subsection{Definición de las partes de la gramática}

La tradición brasileña presenta diferentes modelos de división de la gramática, que pueden ser organizados en 4 grupos:
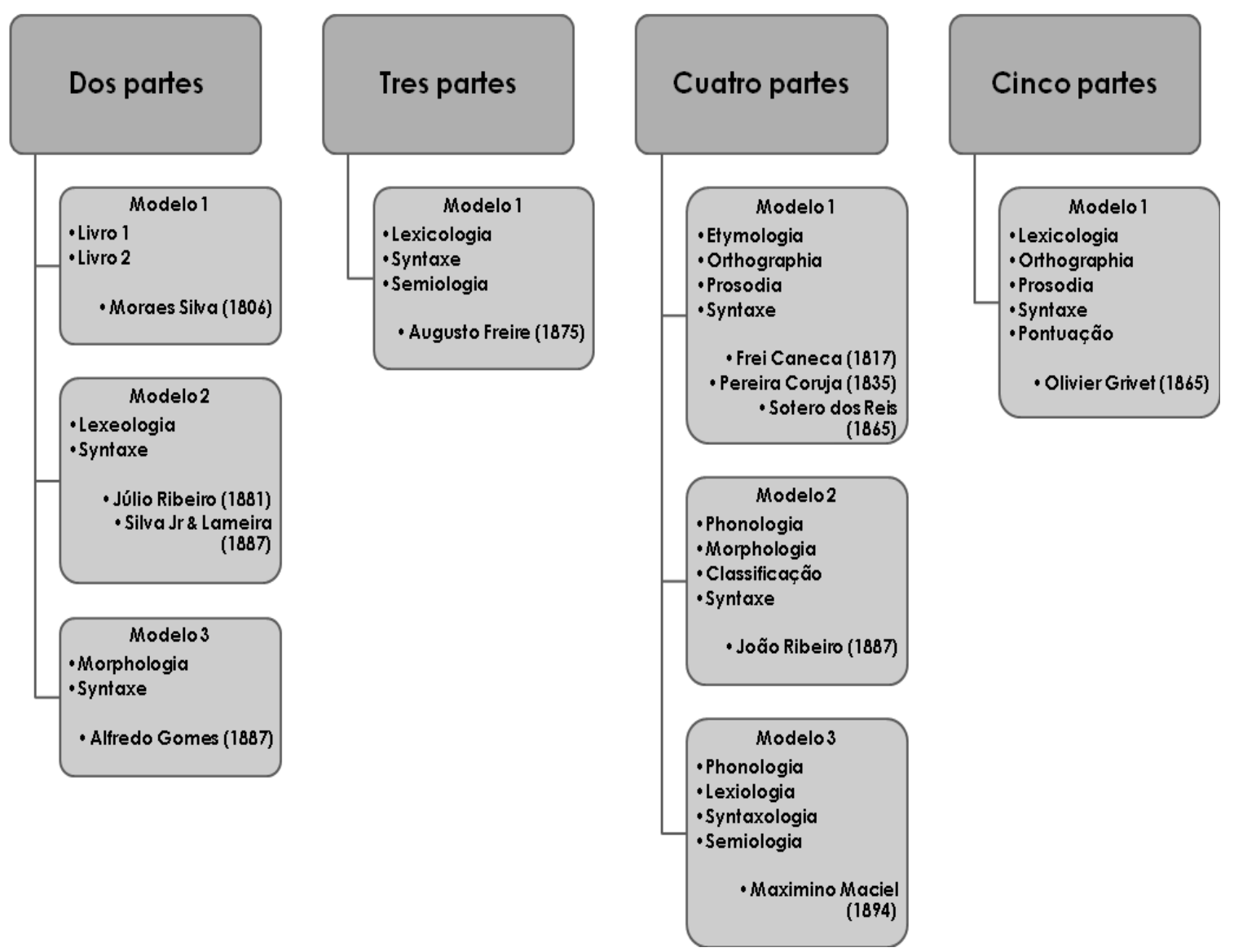

Tabla 7.1 Modelos de división de la gramática en la tradición brasileña

La diversidad de modelos de división de la gramática pone de manifiesto que la tradición brasileña, como otras tradiciones gramaticales, también se 
muestra bastante heterogénea en cuanto a la organización del contenido gramatical.

Pues bien, se puede notar que en la primera mitad del siglo predomina el modelo de cuatro partes (etimología, ortografía, prosodia y sintaxis) heredado de la tradición, salvo por Moraes Silva. El sistema de cinco partes constituye más bien una remodelación del sistema tradicional, con la sustitución de algún término y separación de la puntuación. El modelo en tres partes de Freire representa el cambio más profundo en la división de la gramática hasta este momento, pues, por primera vez en esta tradición, un sistema comprende el estudio de la palabra, de la oración y del significado. Las gramáticas posteriores - bien conservan el modelo de cuatro partes (con modificaciones en la terminología), o bien emplean el sistema de dos partes, pero en los dos casos se elimina la semántica. El último sistema de esta centuria es de Maciel, que divide la gramática en cuatro bloques, recuperando así el estudio del significado y separando la fonología de la morfología.

\subsubsection{Evolución de la definición de morfología}

En la tradición brasileña, el Epítome de Grammatica Portugueza es el único manual donde no se emplea una terminología y una definición para referirse al estudio de la morfología. Para el gramático Moraes Silva, esta primera parte de la gramática, según su sistema de división, se denomina «livro I - das palavras por sí sós ou partes das sentençası, sin subdivisiones y con un título que en sí mismo se define.

La mayoría de las gramáticas brasileñas que siguen la misma orientación racionalista de Moraes presentan el sistema tradicional de las cuatro partes, además de conservar los términos y las definiciones de la tradición. Así, el estudio de los constituyentes, las propiedades y las variaciones de las clases de palabras se denomina «etymologia». 
El paradigma positivista determina los cambios de terminología, definición y sistematización de la morfología y orienta (en distintos niveles) las obras publicadas en el último cuarto del siglo. Siguiendo esta línea, en las gramáticas de Augusto Freire y Júlio Ribeiro la «lexicologia» y la «lexeologia» son definidas del siguiente modo:

A lexicologia estuda as palavras individualmente considerando-as já em seus elementos materiaes, já em suas formas (Freire 1894[1875]: 25).

A lexeologia considera as palavras isoladas já em seus elementos materiaes ou sons, já em seus elementos morphicos ou formas (Ribeiro 1881: 3).

La influencia positivista en las obras de estos gramáticos es aun más evidente cuando se comparan las definiciones de los autores brasileños con el concepto de «lexicographie» que se halla en la Grammaire Française, lexiologie et lexicographie de C. Ayer (1851):

Lexicographie, qui traite des mots considérés quant à leurs éléments matériels et a leurs formes, est un travail presque entièrement neuf et d'une plus grande utilité pratique (C. Ayer 1851: II).

Estas definiciones revelan además que a lo largo de esta centuria la morfología también experimenta un cambio en su contenido. El estudio de las clases de palabras amplía el enfoque para el análisis de los elementos que constituyen las palabras (aislados y combinados entre sí) en la forma oral $o$ escrita y de las palabras según sus características formales y funcionales, sus variaciones, su origen y su evolución.

Este periodo encierra con la definición de «lexiologia» elaborada por Maciel, que llama la atención por el uso de un metalenguaje claramente influenciado por la corriente naturalista y por la separación de la fonología. En este primer modelo descriptivo de gramática, la «lexiologia» se refiere únicamente al estudio morfológico, taxonómico y etimológico de la palabra 
(aislada). Estos cambios de concepto se muestran en la definición a continuación:

Lexiologia é o tratado das palavras isoladamente consideradas, isto é, como organismos independentes (Maciel 1926[1894]: 79 [la negrita es mía]).

En cuanto a la fonología, los principales cambios que marcan la evolución de estos estudios se refieren a su posición en la constitución de la gramática (separada de la morfología) y su contenido (si incluye o no la ortografía). En la descripción de los modelos de división de la gramática ya se ha puesto de relieve que solamente a finales del siglo los gramáticos separan la fonología de la morfología. En el caso de su contenido, a partir de la gramática de Júlio Ribeiro los gramáticos empiezan a hacer constancia, explícita o implícitamente, de que el estudio fonológico debe incluir las diferentes manifestaciones de los sonidos, es decir, la fonética, la prosodia y la ortografía.

A phonologia trata dos sons elementares e fundamentaes da lingua, das modificações que soffrem taes sons constituidos em vocabulos e da correcta pronuncia destes (Freire 1894[1875]: 25).

A phonologia é o tratado dos sons articulados. A phonologia considera os sons articulados

1. Isoladamente, como elementos constitutivos das palavras;

2. Agrupados, já constituídos em palavras;

3. Representados por símbolos (Ribeiro 1881:3).

Phonologia é o tratado dos phonemas, isto é, dos sons constitutivos da palavra debaixo de todos os pontos de vista (3) (Maciel 1926[1894]: 5).

La prosodia y la ortografía son ejemplos de que muchos aspectos gramaticales tienden a estabilizarse, a pesar de la constante reformulación de la gramática y del influjo de distintas teorías. Durante todo el siglo estas materias

\footnotetext{
3 Henry, Gram. Comparée du grec et du latin, pag. 13, - A. Coelho, A lingua portugueza, pag. 4. Maciel, Gram. Analytica, pag. 3 [nota del gramático].
} 
conservan la terminología, la definición y el objeto de estudio y solamente presentan cambios relativos a su posición en la división de la gramática, como se puede observar en las siguientes definiciones:

A prosodia trata da quantidade e do accento das syllabas constituidas en vocabulos (Freire 1894[1875]: 43).

Prosodia é o tratado dos sons articulados em relação a sua intensidade comparativa, quando constituidos em palavras (Ribeiro 1881: 10).

Prosodia é o tratado da quantidade e accentuação dos phonemas na constituição do vocabulario (Maciel 1926[1894]: 33).

A orthographia ensina a escrever os vocabulos com rigorosa aplicação das leis da alteração phonetica (Freire 1894[1875]: 61).

Orthographia é o tratado da representação simbólica dos sons articulados (Ribeiro 1881: 22).

Orthographia é o tratado da representação graphica dos phonemas na constituição do vocabulo (Maciel 1926[1894]: 55).

Con todo, es posible observar claramente en las definiciones mencionadas la evolución de las expresiones gramaticales, desde un lenguaje ordinario, como «escrever vocabulos», pasando por un status parcialmente técnico, como en «representação simbólica», hasta alcanzar un status técnico, como es el caso de «representação graphica». Del mismo modo se presenta el cambio de «sons articulados» a «phonemas»».

Finalmente, la última innovación de la fonología en este periodo se refiere a la constitución de la fonética, sistematizada por primera vez en esta tradición en la Gramática de Augusto Freire. Según el autor, la fonética consiste en el análisis de los sonidos y de las leyes que regulan su alteración, es decir, las leyes fonéticas: 
Phonetica é o estudo dos sons articulados, considerados como elementos constitutivos dos vocabulos, e das leis que presidiram as suas alterações (Freire 1894[1875]: 25).

En las definiciones posteriores se suprime el estudio histórico de los fonemas, como se puede notar en las definiciones de Ribeiro y Maciel:

Phonetica é o tratado dos sons articulados considerados em sua máxima simplicidade, como elementos constitutivos das palavras (4) (Ribeiro 1881: 3).

Phonetica é o estudo dos phonemas, isto é, dos sons organicos da palavra, considerados em si ou em suas correlações (Maciel 1926[1894]: 5).

Debido a la mudanza en el marco teórico de las gramáticas, hubo un cambio de la terminología relativa a la descripción de las clases de palabras y sus atributos (clasificación, variación y evolución) y, del mismo modo que sucedió en diversas tradiciones, los gramáticos brasileños empezaron a denominar morfología lo que en la primera mitad del siglo se designaba, en parte, etimología:

A morphologia estuda as palavras como seres já organizados, constitutivos da linguagem.

Ella considera por isso em seu todo, classificando-as em varias especies; e em seus orgãos ou elementos morphologicos, explanando a doutrina attinente ás flexões, e á sua formação, já como derivadas, já como compostas de outras (Freire 1894[1875]: 90).

Morphologia é o tratado das fórmas que tomam as palavras para constituir a linguagem. A morphologia considera as palavras sob a relação de fórma

1. Como constituindo grandes grupos de idéias de que se compõe o pensamento.

2. Como entidades phonicas que se modificam individualmente para representar cada idéia particular.

3. Como originando-se umas das outras (Ribeiro 1881: 51).

\footnotetext{
4 Bergman, Résumé d'Études d'Ontologie Générale et de Linguistique Générale, Paris, 1875, pag 261 [nota del gramático].
} 
Morphologia é o tratado da palavra, organicamente considerada, isto é, com relação aos seus elementos materiaes ou fórmas exteriores (Maciel 1926[1894]: 80).

Estas citas muestran que a finales del siglo hubo además una restricción del contenido de la morfología. Freire y Ribeiro entienden por morfología la clasificación y el estudio de las variaciones y el origen de las palabras, mientras que para Maciel este estudio se limita a la descripción de los constituyentes de la palabra (prefijo, radical y sufijo). Esta diferencia se debe también a la posición que ocupa en los diferentes modelos de división gramatical, pues la «morphologia» de de Freire y de Ribeiro corresponde, en realidad, a la «lexiologia» de Maciel.

Respecto al estudio de la clasificación y la flexión de las palabras, todas las gramáticas analizadas mantienen el contenido y la definición:

Lexiologia, tambem chamada taxionomia, é a classificação das palavras em varias especies ou categorias, correspondentes ás idéas que exprimem (Freire 1894[1875]: 90).

Taxeonomia é a distribuição das palavras em grupos correspondentes aos grupos de idéias de se compõe o pensamento (Ribeiro 1881:51).

Taxinomia é a classificação das palavras em grupos segundo as categorias logicas a que correspondem (Maciel 1926[1894]: 116).

Flexionismo é a doutrina das flexões (Freire 1894[1875]: 114).

Kampenomia é o conjuncto das leis que presidem á flexão das palavras (Ribeiro 1881: 73).

Ptoseonomia ou kampenomia é o tratado da flexão das palavras (Maciel 1926[1894]: 157). 


\subsubsection{Evolución de la definición de sintaxis}

En la tradición brasileña, la sintaxis experimenta considerables cambios en la estructura, sistematización y definición de sus contenidos.

La mayoría de las gramáticas publicadas en la primera mitad del siglo fundamenta los estudios sintácticos en el análisis gramatical. Dicho de otra manera, esta parte de la gramática se ocupaba de la composición (o descomposición) de los constituyentes de la oración (sujeto y atributo), del tratamiento de las palabras en el interior de estas partes y de las relaciones (de concordancia y régimen) que podían establecer entre sí. Así, el estudio sintáctico todavía no consideraba la oración como una unidad sintáctica, sino que se centraba en la palabra (Gómez Asencio 1981, Calero Vaquera 2008).

Pues bien, como se puede notar también en el análisis del Epítome de Grammatica Portugueza (véase § 5.1.5), este paradigma sintáctico que tiene como tema central la palabra constituye el marco metodológico sirve de base para los estudios sintácticos desarrollados por Moraes Silva. Aunque el gramático no presenta una definición para la sintaxis, el título «livro II - da composição das partes da sentença entre si; ou syntaxell es suficientemente aclarador en cuanto a su objetivo y su objeto de estudio. El propio título pone de manifiesto que la "syntaxe» consiste en el estudio de las palabras que componen las partes de la oración (sujeto, verbo y atributo).

En cuanto a las definiciones de «syntaxe de concordancia» y usyntaxe de regencia», Moraes Silva también conserva el paradigma tradicional, pues la concordancia se centra en las relaciones básicas entre las palabras (sustantivoadjetivo y sustantivo-verbo) y la «regencia» se asienta en las nociones de «ordenación» y «rección» (Gómez Asencio 1981), como reza la tradición:

As regras que ensinão a mostrar as connexões entre os nomes, e os adjectivos, e os verbos se dizem syntaxe de concordancia (Moraes Silva 1824[1806]: 81). 
A palavra, que muda de caso, ou é acõpanhada de preposição, e é segundo termo de uma relação, se diz regida pela palavra antecedente correlata, ou pela preposição, ou pelo verbo: e as regras, que ensinão a mostrar as relações entre os nomes, por meyo das preposições, e casos, ou da collocação são a Syntaxe de regencia (Moraes Silva 1824[1806]: 83).

Finalmente, la definición de «syntaxe figurada» revela que la construcción oracional debe obedecer un orden lógico (el «orden natural» en el que se expresan los pensamientos) y toda inversión (o perturbación) de este orden es considerada un error, una incorrección y, por lo tanto, constituye su objeto de estudio:

Quando na composição não observamos as regras expostas, a sentença é incorrecta. Mas ás vezes a incorrecção é apparente, e dá uma nova figura, ou apparencia á composição, que por isso se diz figurada (Moraes Silva 1824[1806]: 103).

En la segunda mitad del siglo, se puede observar un gran avance en el tratamiento de la sintaxis. La ampliación del contenido permitió que los gramáticos establecieran divisiones más complejas $y$, por consiguiente redefinieran la disciplina y sus partes, de acuerdo con el nuevo objeto de estudio (la oración) y basados en el reciente paradigma teórico. En este contexto se inscribe el gramático Augusto Freire, cuya definición expresa claramente el propósito de la disciplina en este periodo. El autor entiende que sintaxis es el tratamiento de las palabras en cuanto constituyentes de la oración y de las oraciones relacionadas unas con las otras:

A syntaxe ensina a coordenar as palavras e as proposições, de modo que sejam a expressão pura e artística do pensamento (Freire 1894[1875]: 276).

A medida que avanza la centuria, las definiciones se muestran cada vez más complejas. Este es el caso de la propuesta de Ribeiro, que aporta a esta tradición un importante cambio en la concepción de las relaciones sintácticas. Por un lado, el autor conserva la opinión de sus predecesores y manifiesta que la 
sintaxis trata de las palabras relacionadas entre sí, pero, por otro lado, no reconoce que esta disciplina estudia las relaciones entre las oraciones, sino que considera más bien la estructura (simple o compuesta) de la oración. Dicho de otro modo, para el autor, una oración compuesta no está formada por varias oraciones (relacionadas) sino por «asserções»:

A syntaxe considera as palavras relacionadas umas com as outras na construção das sentenças, e considera as sentenças no que diz respeito a sua estructura, quer sejam simples, quer se componham de membros ou de clausulas (Ribeiro 1881: 193 [la negrita es mía]).

Es importante señalar que la concepción de Ribeiro no niega la existencia de las relaciones entre oraciones, sino que el autor no trata de este tema en su Gramática.

La interpretación de Ribeiro de los estudios sintácticos permanece hasta finales del siglo. En efecto, la definición de sintaxis de Maciel comparte esta misma concepción (aunque el desarrollo de la disciplina alcanza una mayor complejidad en la obra de Maciel). Así, la definición de Maciel también se centra en el análisis de los conjuntos de palabras («orgams elementares») que forman la proposición simple y compuesta:

Sintaxologia é o tratado das palavras, consideradas collectivamente, isto é, nas suas diversas funcções ou relações logicas.

A syntaxologia considera as palavras:

a) Como orgams elementares, exercendo funcções no organismo da proposição;

b) Constituido proposições integraes, necessárias á expressão de um pensamento;

c) Como grupos estheticos cuja fórma exterior se accomoda ás condições individuaes e á natureza do assumpto (Maciel 1926[1894]: 275).

En cuanto a la sintaxis de palabras, las principales diferencias que pueden ser observadas en las definiciones de Freire, Ribeiro y Maciel se refieren fundamentalmente al metalenguaje, como por ejemplo el intercambio entre los 
términos «proposição», "periodo» y usentença» para designar la oración y la introducción de términos característicos de la corriente positivista, particularmente por Maciel:

A syntaxe de palavras trata das palavras relacionadas entre si, formando a proposição ou o periodo simples (Freire 1894[1875]: 276).

A syntaxe lexica considera as palavras como relacionadas umas com outras na construcção de sentenças (Ribeiro 1881: 195).

A syntaxe relacional é o tratado das funcções e relações das palavras, isto é, da sua concordancia e posição no organismo da proposição simples (Maciel 1926[1894]: 275).

Con respecto a la sintaxis de las proposiciones, como se ha mencionado anteriormente, se registran cambios significativos en las definiciones de Ribeiro y Maciel comparadas con la definición de Freire, especialmente en el alcance del análisis de la oración, pues Freire estudia la relación entre las proposiciones, mientras que Ribeiro y Maciel tratan de las relaciones entre las estructuras (o grupos de palabras) que forman la oración:

A syntaxe de proposições trata das proposições relacionadas entre si, formando o periodo composto (Freire 1894[1875]: 350).

A syntaxe logica considera as sentenças no que diz respeito á sua estructura, quer sejam ellas simples, quer sejam compostas (Ribeiro 1881: 200).

Phraseologia é o tratado das proposições e das suas diversas relações na estructura do periodo (Maciel 1926[1894]: 354).

Un último aspecto que llama la atención en la Gramática de Ribeiro está relacionado con la exclusión de los estudios sobre el estilo y las figuras (sintaxis figurada o «litteraria»), que pasan a formar parte del apartado «additamentos». Esta omisión indica que en teoría el gramático prescinde de la noción de orden 
oracional, pero en la práctica, esta idea todavía está presente en su Gramática, aunque no forma parte de la sintaxis.

Por su parte, Augusto Freire y Maximino Maciel conservan la usyntaxe litteraria» en sus gramáticas pero no con la finalidad de justificar las estructuras supuestamente incorrectas y agramaticales de la lengua, como es el caso de Moraes, sino que determinan como su objeto de estudio las diversas formas de expresión lingüística:

Syntaxe litteraria ou a Estylistica trata do estylo (Freire 1894[1875]: 375).

Syntaxe litteraria ou estilistica é o tratado do estilo nas suas diversas manifestações (Maciel 1926[1894]: 420).

\subsubsection{Evolución de la usemiologia»}

En la gramaticografía brasileña, solamente Augusto Freire y Maximino Maciel sistematizan el estudio de la semántica y lo consideran un estudio independiente en la gramática. Aunque las «semiologias» de estos gramáticos presentan diferentes enfoques, ambas se centran en el estudio del significado, como muestran las siguientes definiciones:

Semiologia, tambem chamada semantica, sematologia ou semeiotica, é o estudo que, para interpretação do sentido total da phrase, se faz das translações ou mudanças, que, no tempo e no espaço, experimenta a significação das palavras, consideradas como signaes das idéias (Freire 1894[1875]: 419).

Semiologia é o tratado da significação das palavras em todas as suas manifestações (Maciel 1926[1894]: 467).

La diferencia más evidente entre las dos definiciones es sin duda el metalenguaje. La definición de Maciel se muestra más objetiva y simplificada que la de Freire. Cabe destacar además que, según Freire, hasta la publicación 
de su Gramática no había muchos estudios sobre la semántica, lo que justifica la ausencia de fuentes teóricas que avalen su «semiologia» (Freire 1894[1875]: 419). Maciel, por otra parte, cita a Bréal y Max Müller (véase capítulo 4) como sus fuentes teóricas (Maciel 1926[1894]: 467).

\subsection{Evolución de las definiciones de las clases de palabras}

Del mismo modo que las gramáticas brasileñas varían en cuanto a la división de sus partes, las clases de palabras presentan a lo largo del siglo XIX diferentes sistematizaciones. Incluso, es posible identificar en una misma obra diversos sistemas de clasificación, lo que puede indicar el uso de diferentes criterios de definición para una misma clase de palabras. Así, la tradición brasileña recoge sistemas de tres, siete, ocho, nueve y diez clases de palabras, como se muestra a continuación:
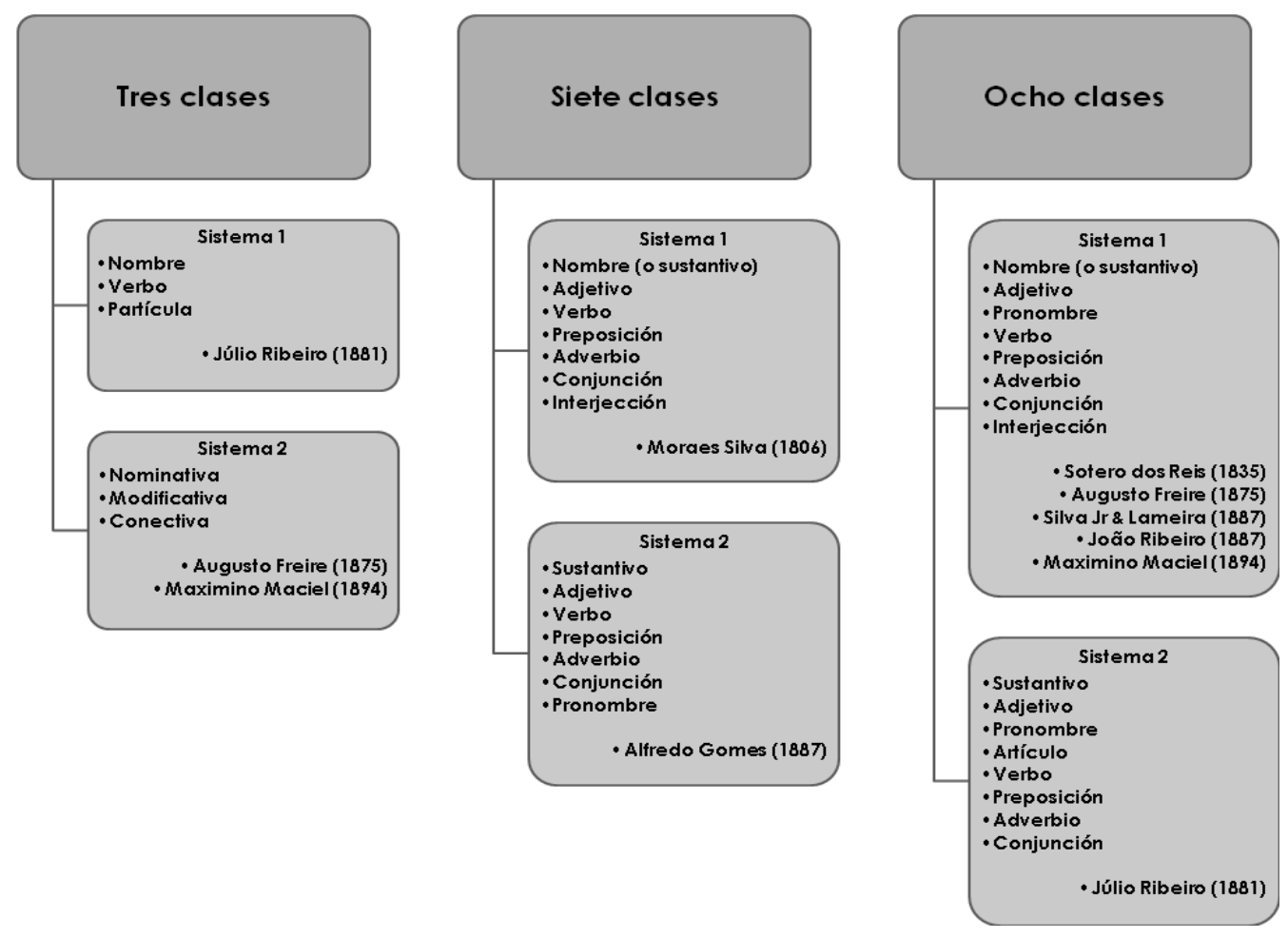

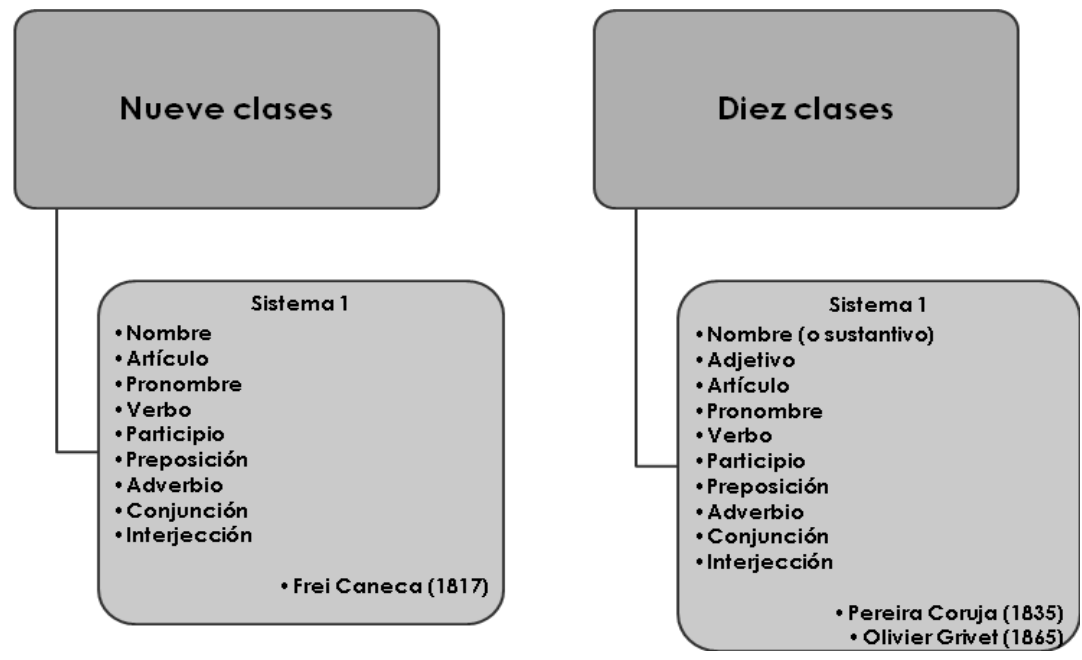

Tabla 7.2 Sistemas de clasificación de palabras en las gramáticas brasileñas

El sistema de tres clases de palabras citado en la Gramática de Júlio Ribeiro remonta a las obras del Brocense, Correas y Villalón (Gómez Asencio 1981: 103), pero al mismo tiempo que reconoce estas tres clases relacionadas con las tres uidéias de que se compõe o pensamento» (objeto, atributo y relación), el gramático estudia las clases palabras de acuerdo con el modelo de ocho categorías.

El segundo sistema de tres clases está representado en las obras de Augusto Freire y Maximino Maciel, pero las clasificaciones de estos dos autores se diferencian en cuanto a la ubicación del verbo. Para Freire el verbo forma parte de las palabras conectivas, mientras que Maciel lo incluye en las nominativas. Esta propuesta de Freire posiblemente recoge a la corriente filosófica francesa (calero Vaquera 1986, Martínez Gavilán 1989 y Zamorano Aguilar 2006) y la de Maciel constituye más bien una variación (o reinterpretación) del sistema descrito en la obra de Freire, una vez que no está citada en las fuentes primarias del autor.

El sistema de siete clases de palabras de Moraes Silva separa el adjetivo del sustantivo, incluye los pronombres personales en la categoría de los sustantivos, los demás pronombres y el artículo en los adjetivos y el participio en 
la clase de los verbos. En el último cuarto del siglo todavía hay remanentes de este sistema, como es el caso de la Gramática de Alfredo Gomes (1887) que presenta una división semejante a la de Moraes, con la diferencia de que el pronombre forma una clase independiente de los adjetivos y la interjección no es considerada clase de palabras.

En el primer sistema de ocho clases de palabras, utilizado por la mayoría de los gramáticos brasileños, el artículo forma parte del adjetivo y la interjección es contada como una clase de palabras independiente. La excepción a este sistema es la propuesta de Ribeiro que elude la interjección y considera el artículo como clase de palabras independiente.

El modelo de nueve clases de palabras es el tradicional, empleado en la Grammaire de Port-Royal y su único representante en la tradición brasileña es Frei Caneca (1817).

Finalmente, el último sistema del que dispone las gramáticas brasileñas de este periodo es el de diez clases de palabras, utilizado por Pereira Coruja (1835) y Olivier Grivet (1865). Al contrario de lo que afirman los estudios de Fávero y Molina (2006: 113), este modelo no guarda ninguna relación con la Gramática de Nebrija, sino que consiste más bien en el sistema tradicional de Port-Royal, con la diferencia de que en estas gramáticas el adjetivo forma una clase independiente del nombre.

Esta descripción muestra que durante el siglo XIX subsisten en la tradición brasileña diferentes propuestas de sistemas de clases de palabras, desde la clasificación más tradicional (la de Frei Caneca) hasta la más innovadora (modificativa, nominativa y conectiva). Hay que señalar que este nuevo sistema convive con la clasificación más generalizada, centrada en la palabra. Esta doble perspectiva puede indicar, por un lado, cierto arraigo de la tradición y, por otro, que los gramáticos ya reconocen en este momento que los sistemas de clases de palabras cambian de acuerdo con los criterios de clasificación.

Teniendo en cuenta este panorama, a continuación se presentan los principales cambios de las clases de palabras comunes a las gramáticas de Moraes Silva, Augusto Freire, Júlio Ribeiro y Maximino Maciel. 


\subsubsection{El sustantivo}

La mayoría de los gramáticos brasileños, a excepción de Frei Caneca, se refiere al sustantivo y al adjetivo como clases de palabras independientes, siguiendo la influencia de la escuela francesa del siglo XVIII (Gómez Asencio 1981. Martínez Gavilán 1989 y García Folgado 2003). En esta tradición, el sustantivo es definido en general a partir del criterio semántico, como se muestra en las siguientes definiciones:

Nomes [o sustantivos] são as palavras, com que indicamos as coisas, que existem por si, v. g. casa, pomo, homem; ou as qualidades, que representamos como existindo sobre si, v. g. alvura, riqueza, doçura, mansidão, \&c. (Moraes Silva 1824[1806]: 4).

Nome substantivo é a palavra que designa pessoa ou cousa: Camões, casa: é o sujeito por excellencia (Freire 1894[1875]: 91).

Substantivo é o nome de um objecto, de uma cousa, ex.: "agua, floresta, passaro" (Ribeiro 1881: 53).

Substantivo é a palavra que designa os seres da natureza ou então as ideias abstractas (Maciel 1926[1894]: 116).

Entre los autores brasileños es unánime (y prácticamente inevitable) hacer referencia a la realidad extralingüística en la definición de sustantivo. En las definiciones citadas, por ejemplo, ningún gramático trata esta clase de palabras a partir de la idea representada lingüísticamente sino a partir de la realidad en sí misma. Sin embargo, hay que señalar que esta perspectiva semántica es complementada, en algunos casos, por el criterio sintácticofuncional, como por ejemplo en la definición de Augusto Freire, que pone de relieve que esta clase de palabra desempeña necesariamente la función sintáctica de sujeto.

La definición de Ribeiro muestra que, aunque su Gramática es considerada innovadora en muchos aspectos, en la definición del sustantivo el 
autor no emplea ninguna nueva doctrina o nuevo criterio, es decir, todavía recoge las mismas estrategias de los gramáticos precedentes (criterio semántico y ejemplos). Además, llama la atención que Ribeiro elude de su definición la característica abstracta de los sustantivos, refiriéndose solamente a aquellos vocablos que representan elementos concretos de la realidad.

El uso de ejemplos parece ser un recurso bastante utilizado por estos gramáticos brasileños, pues, además de reforzar esta relación con la realidad, aclara la noción que expresa las definiciones. Maximino Maciel es el único gramático de esta tradición que no emplea en la definición del sustantivo este tipo de predicación.

\subsubsection{El adjetivo}

En las gramáticas de la tradición brasileña, el adjetivo está definido del mismo modo que en los sustantivos, bajo los criterios semántico y sintáctico, además de ser representado, en ciertos casos, a partir de ejemplos que detallan SU USO.

Pues bien, Moraes Silva no presenta una definición general, que recoja todas las características del adjetivo, sino que define separadamente las dos subclases de adjetivos que identifica en su Gramática, los articulares y los atributivos, a partir de los criterios semántico y sintáctico:

Os adjectivos articulares ajuntão se aos nomes geraes, ou communs, para determinarem o numero, a quantidade de individuos, de que falamos (Moraes Silva 1824[1806]: 8).

Dos adjectivos attributivos. Estes significão as qualidades existentes em algum objecto, v. g. branco, louro, manso, leal, amável, quando coexistem com homem, menino, \&c. (Moraes Silva 1824[1806]: 18).

Moraes Silva define el adjetivo articular a partir del criterio sintáctico «colocacional», señalando que esta clase desempeña la función de 
determinante siempre y cuando acompañe un sustantivo. Paralelamente, en la definición de adjetivo atributivo, el gramático emplea el criterio semántico haciendo referencia al contenido extralingüístico de esta categoría, es decir, el adjetivo no cualifica una palabra sino que representa un atributo intrínseco a un objeto de la realidad.

En la segunda mitad del siglo, la definición de adjetivo revela ciertos cambios como la elisión del uso de ejemplos, el incremento de la perspectiva sintáctica -a partir de este momento no es solo "colocacional» sino también funcional- y casi siempre acompañado del criterio semántico. En esta línea, Augusto Freire define el adjetivo como «nome que se junta ao nome appellativo, para o qualificar ou determinar. Dahí, a divisão do adjectivo em qualificativo e determinativo») (Freire 1894[1875]: 96). Del mismo modo, Freire presenta las siguientes definiciones de los adjetivos «qualificativo» y «determinativo»:

Adjectivo qualificativo é o que exprime a qualidade ou maneira de existir da pessoa ou cousa significada pelo appellativo a que se junta: é o attributo por excellencia. Dahi lhe vem o nome de attributivo (Freire 1894[1875]: 96).

Adjectivo determinativo é o que junto ao appellativo, fa-lo significar uma, algumas, ou todas as pessoas ou cousas da classe a que pertencem (Freire 1894[1875]: 97).

Es importante destacar que estas definiciones conservan la perspectiva extralingüística, pero, en este caso, el gramático ya es consciente de que esta relación objeto-cualidad se expresa lingüísticamente a través de la relación sustantivo-adjetivo. Las relaciones entre el sustantivo y el adjetivo en la Gramática de Júlio Ribeiro están ubicadas, en principio, solamente en el nivel gramatical, como muestra esta definición:

Adjectivo é uma palavra que descreve ou que limita o substantivo (Ribeiro 1881: 56). 
Para Ribeiro, el adjetivo no califica el sustantivo sino que describe la cualidad que es esencial al sustantivo. Esta noción es aun más evidente en la definición del «adjectivo descriptivo»:

O adjectivo descriptivo denota a qualidade ou a propriedade da cousa significada pelo substantivo a que elle se refere. (Ribeiro 1881: 56)

O adjectivo determinativo denota o numero, a posição ou qualquer outra limitação da cousa significada pelo substantivo a que elle se refere. (Ribeiro 1881:56)

Aunque Ribeiro define el adjetivo a partir del criterio sintáctico funcional, todavía se conserva el doble nivel de descripción (lingüístico y extralingüístico) en las definiciones de las subclases.

El último cambio en la definición del adjetivo consiste en la inclusión de las nociones de extensión y comprensión del significado por Maximino Maciel. Como hemos destacado (véase $\S 5.2 .4$ ), estos conceptos ya habían sido mencionados en la Gramática de Augusto Freire y, con anterioridad, los autores brasileños (en la mayoría de los casos, posiblemente por mera repetición de los predecesores o de las fuentes primarias) tenían conocimiento de que el adjetivo «funciona como modificativo del sustantivo en su comprensión (califica) o en su extensión (determina)» (Gómez Asencio 1981: 151). Solamente a finales del siglo Maciel relaciona explícitamente estos conceptos con las definiciones de las subclases del adjetivo:

Adjectivo é a palavra que modifica a comprehensão ou a extensão do substantivo (Maciel 1926[1894]: 123).

Adjectivo descriptivo ou qualificativo é aquelle que modifica a comprehensão do substantivo mediante uma idea de qualidade ou propriedade, ex.: homem alto, magro, pallido, nervoso, intelligente, sagaz, sabio (Maciel 1926[1894]: 124).

Adjectivos designativos ou determinativos são aquelles que limitam a extensão do substantivo definita ou indefinitamente (Maciel 1926[1894]: 126). 


\subsubsection{El pronombre}

En la tradición brasileña, Moraes Silva es el único gramático que no reconoce el pronombre como clase de palabra independiente. Así, en el Epítome, las subclases del pronombre están divididas por otras clases de palabras, el pronombre personal está ubicado en la categoría de los sustantivos y los pronombres demostrativo, interrogativo, posesivo, numeral y etc., son considerados adjetivos articulares (Moraes Silva 1824[1806]: 8-18). Sin embargo, después de Moraes, la mayoría de los gramáticos de esta tradición considera al pronombre personal como el pronombre por excelencia y el restante de las subclases como categorías del adjetivo. Esta concepción está representada, por ejemplo, en las gramáticas de Augusto Freire y Júlio Ribeiro.

En su Gramática, Freire define el pronombre basado en la noción más tradicional, a partir de los criterios sintácticos (funcional y colocacional), pues el autor destaca su función sustitutiva en el interior de la oración y señala su finalidad estilística. Además, el gramático introduce la relación entre los pronombres con las personas del discurso. Así, el autor define los pronombres como:

Pronome é a palabra que se põe em logar do nome ou do sujeito, para evitar a sua repetição [...]. Em portuguez, apenas ha pronomes pessoaes [...].

Pronome pessoal é o que indica a pessoa gramatical do nome ou do sujeito, em cujo logar está. (Freire 1894[1875]: 93-94)

Esta definición mantiene cierta relación con la concepción de Silvestre de Sacy (1849), pues ambos autores estudian «el pronombre según la función que desempeña en el discurso, con preterición del carácter estudiado de sustituto del nombre» (Ramajo 1987: 126).

Por su parte, Ribeiro recoge en su Gramática la concepción más tradicional de pronombre y lo define como «uma palavra usada em logar de um substantivol» (Ribeiro 1881: 59). El autor distingue además dos grupos de pronombres, a partir de la perspectiva semántica y del significado que aporta 
como sustituto del sujeto en la oración. El grupo del pronombre personal sustituye al sujeto sin limitar su significado y el de los pronombres adjetivos (demostrativo, el posesivo, el indefinido, el distributivo y el conjuntivo) limita el significado del sujeto. Aunque el autor describe distintos tipos de pronombres, reconoce que «nada mais é do que o adjectivo determinativo empregado na oração sem substantivo claro» (Ribeiro 1881: 60). Dicho de otro modo, para el gramático el pronombre propiamente dicho son los pronombres personales.

La descripción de pronombre que presenta Maximino Maciel coincide en líneas generales con la obra de Ribeiro, como se puede notar en la siguiente definición:

Qualquer palavra substituta do nome ou de qualquer expressão nominativa, ex.: eu, ninguém, quem quer que, cada um (Maciel 1926[1894]: 131).

Fundamentado en los criterios sintácticos, Maciel también divide esta categoría en pronombres sustantivos y adjetivos. El pronombre sustantivo sustituye "sempre os nomes, pois não exercem outra funcção» (Maciel 1926[1894]: 131) y el adjetivo «não substituem propriamente o nome, mas apenas evitam a repetição» (Maciel 1926[1894]: 131). La descripción de Maciel se distingue de la de sus predecesores especialmente por llamar la atención en lo que actualmente se denomina carácter fórico y deíctico del pronombre, como se muestra en las definiciones de las subclases de pronombres adjetivos:

Pronome demonstrativo é aquelle que substitue o nome, indicando uma relação de posição no espaço ou na proposição (Maciel 1926[1894]: 133).

Pronome articular é o proprio artigo definito, sempre que substituir na proposição um substantivo anteriormente expresso (Maciel 1926[1894]: 133).

Pronome relativo é aquelle que, conjuntando duas proposições, sempre se refere a um nome anteriormente expresso (Maciel 1926[1894]: 134). 


\subsubsection{El verbo}

En la primera mitad del siglo XIX, el verbo es considerado por los gramáticos brasileños como una palabra de afirmación que une el sujeto al atributo en una oración con el propósito de dar a conocer un determinado juicio y se divide en sustantivo (verbo único SER) y adjetivo (SER + atributo). Esta concepción es la defendida por Moraes Silva en el Epítome, que recoge los criterios sintácticos y semánticos y valora el verbo como upalavra com que declaramos o que a alma julga ou quer á cerca dos sujeitos, e dos attributos, das sentenças, com elle affirmamos e mandamos» (Moraes Silva 1824[1806]: 38). Se puede notar que la definición de Moraes solamente difiere de los principios logicistas al añadir la noción de imperativo e, implícitamente, relacionar estas dos propiedades con la división de los modos del verbo.

Esta concepción racionalista del verbo se conservó en esta tradición hasta el último cuarto del siglo XIX. Este estancamiento se muestra, por ejemplo, en la Gramática de Augusto Freire, que prácticamente emplea la misma definición de sus predecesores, compartiendo los mismos criterios de definición (sintáctico y semántico) y el mismo marco teórico. Así pues, el gramático afirma que el verbo es ua palavra que exprime affirmação ou mostra que a qualidade convem ao sujeito: é por conseguinte o nexo ou cópula que une o attributo ao sujeito»» (Freire 1894[1875]: 103). A partir de esta definición se puede afirmar que la principal novedad que presenta el concepto de verbo hasta este momento es la designación de su función sintáctica. En el contexto oracional, el verbo desempeña la función de «nexo» o «cópula».

Júlio Ribeiro es el primer gramático brasileño que asume una postura más especulativa con respecto a la doctrina verbal. El autor no solamente empieza a romper con algunas creencias racionalistas sino que también reflexiona sobre las diferentes concepciones que regularon el estudio del verbo. A partir de estas reflexiones, el autor concluye que el verbo debe ser definido como upalavra que exprime a existencia de uma relação entre duas idéiası (Ribeiro 1881: 61), es decir, el verbo declara o enuncia algo, ya sea afirmativo o negativo, sobre algo 
o alguien. En esta definición Ribeiro excluye de la definición del verbo el significado lógico de palabra de afirmación, pero conserva la función sintáctica de relacionar sujeto y predicado, aunque no lo expresa claramente.

El aspecto que más llama la atención en la Gramática de Ribeiro con respecto a esta clase de palabras es la descripción de las distintas definiciones del verbo en la historia de la gramática. Ribeiro recoge desde la teoría aristotélica sobre el carácter esencial del verbo, que para el autor constituye solamente una propiedad verbal, hasta la propuesta de la Gramática de PortRoyal, a la que el gramático se opone.

La Grammatica Descriptiva de Maciel no se aparta totalmente de los fundamentos tradicionales en la definición del verbo. Más bien al contrario, el gramático trata de conciliar las perspectivas tradicional y racionalista, emplea los criterios formal y semántico y define el verbo como «uma palavra de tempo que serve para affirmar e exprimir simultaneamente um factol) (Maciel 1926[1894]: 135). Sin embargo, al mismo tiempo que Maciel alude a las corrientes tradicional y racionalista en esta definición, la sistematización de la categoría verbal constituye la más compleja y detallada en esta tradición (véase § 5.4).

\subsubsection{La preposición}

Por lo común, la preposición ha sido definida tradicionalmente a partir de los criterios formal y sintáctico colocacional, prestando especial atención a su invariabilidad y su posición en la construcción de la oración. Así, en la corriente latinizante, la preposición es definida como la palabra indeclinable que se antepone al nombre e indica los casos. Esta interpretación ha permanecido vigente hasta la difusión de la hipótesis racionalista que enfatiza el valor lógico y semántico de la preposición. Consecuentemente, la Gramática de Port-Royal la define como la parte de la oración que establece una determinada relación 
entre dos objetos, estas relaciones pueden ser de lugar, tiempo, causa, orden y etc.

En la tradición brasileña, las gramáticas logicistas suelen combinar las perspectivas tradicional y racionalista en la definición de la preposición. En esta línea, Moraes Silva define esta clase de palabras de la siguiente forma:

As preposições (assim chamadas, porque se prepõem, ou põem antes dos nomes, a que se referem outros nomes correlativos antecedentes, e que as preposições atão entre si) servem de mostrar a connexão, e correlações, que o entendimento concebe entre dois objectos significados pelos nomes sós, ou modificados por adjectivos, ou verbos (Moraes Silva 1824[1806]: 64).

Esta definición se distingue por conciliar diferentes criterios. El autor emplea el criterio etimológico al definir la preposición a partir de la etimología del propio término, el criterio sintáctico se manifiesta en la función que desempeña la preposición en la oración (conectar) y el criterio semántico se presenta en el valor significativo que la preposición añade a la relación que establece entre los elementos de la oración. Cabe resaltar que la definición de Moraes no alude a los aspectos formales, como la invariabilidad de la preposición y su papel en la composición de palabras (en este periodo la mayoría de las gramáticas consideraba los afijos como preposiciones -función descrita en la sintaxis del Epítome-).

En la segunda mitad del siglo, los criterios empleados en la definición de la preposición parecen no variar, pero el lenguaje se modifica y los textos adquieren un carácter cada vez más técnico. Esta evolución puede ser observada en la definición de Augusto Freire que, al mismo tiempo que conserva los criterios formal y sintáctico, desarrolla la descripción desde una perspectiva más gramatical. Para el autor, la preposición constituye «uma parte invariável da oração, que liga complementos ao sujeito ou ao attributoı) (Freire 1894[1875]: 106).

Júlio Ribeiro, por su parte, trata de romper con las concepciones más arraigadas en la gramaticografía brasileña hasta este periodo y prescinde de 
características formales y sintácticas en la definición de la preposición, como los accidentes gramaticales, la posición en la oración o la función sintáctica, pero pone de relieve su valor semántico, es decir, el autor percibe que esta clase de palabras denota cierta carga significativa, y termina de aclarar su concepto por medio de ejemplos:

Preposição é uma palavra que marca a natureza de uma relação representada entre duas idéias, ex.: «dono de escravos - pão com manteiga» (Ribeiro 1881: 68).

En cuanto a la Grammatica Descriptiva, Maximino Maciel define la preposición a partir de los criterios sintáctico funcional y colocacional como una «palavra intervocabular que indica a relação syntatica entre dous termos» (Maciel 1926[1894]: 137-149). En primer lugar, llama la atención la comprensión de Maciel acerca de la posición que ocupa esta clase de palabras en la oración, pues, para el gramático, la preposición deja de estar antepuesta a un vocablo para ubicarse entre dos vocablos («intervocabular»). Además, su función es indicar la relación sintáctica entre dos elementos. Esta concepción, en parte, contrarresta la afirmación de Ribeiro, pues Maciel no reconoce valores semánticos en esta partícula, así la única relación que el gramático logra identificar está en la esfera sintáctica.

\subsubsection{El adverbio}

Los criterios más comunes aplicados a la definición de adverbio han sido el formal y el sintáctico, que describen su invariabilidad y su función como modificador del significado del verbo, del adjetivo y del mismo adverbio.

Desde la perspectiva racionalista, el adverbio se resume en una estructura sintáctica equivalente a la estructura preposición + nombre. La definición de Port-Royal prescinde del criterio formal (postura es común, creciente y anterior a la propia Grammaire) y del criterio sintáctico funcional, 
pues para esta corriente el adverbio constituye esencialmente un recurso de economía discursiva.

En la tradición brasileña, el adverbio no ha experimentado muchos cambios en su definición. Como primer representante de la doctrina racionalista en la tradición brasileña, Moraes Silva sostiene el mismo pensamiento filosófico y racionalista de la Grammaire y define el adverbio del siguiente modo:

Nós dizemos; v. g. amo com ternura, com constancia; e no mesmo sentido: amo ternamente, constantemente: está' naquelle lugar, ou ali; fez de boa mente, ou de má mente; cantar a revezes, ou alternadamente; \&c. Todas éstas frases com ternura, com constancia modificão o verbo amo, determinando o modo de amar; naquelle lugar, ou ali, determinão uma circunstancia do verbo estar; de boa mente, de má mente, modificão a acçao do verbo fez, \&c. Estas frases pois se chamão frases adverbiáes; as palavras que se substituem ás frases modificantes do verbo, como, bem, mal, agora, hoje, \&c. se dizem Adverbios (Moraes Silva 1824[1806]: 59 [la negrita es mía]).

Esta definición revela aspectos importantes de la concepción de Moraes no solamente en cuanto a su doctrina sino también a su metalenguaje. Con respecto a este último aspecto, llama la atención que el lenguaje empleado por el gramático es escasamente técnico, el autor no expresa las características formales ni sintácticas del adverbio y tampoco es determinante acerca de su rasgo semántico, sino que lo define a partir de su aplicabilidad, es decir, a través de ejemplos de los que se sobrentiende la equivalencia del adverbio y la estructura preposición + nombre. La influencia de los fundamentos racionalistas y sensualistas es evidente también en la afirmación del gramático de que esta categoría determina el modo y la circunstancia del verbo. Esta concepción muestra un cierto avance con respecto a la interpretación tradicional acerca de la «incidencia semántica del adverbio sobre el verbo» (García Folgado 2003: 85).

En la segunda mitad del siglo, los gramáticos recuperan los criterios formal, sintáctico y semántico para definir el adverbio. En la Gramática de Augusto Freire, por ejemplo, el autor llama la atención para el carácter 
invariable del adverbio (criterio formal), su función como modificador del adjetivo y, por consiguiente, del verbo adjetivo (criterio sintáctico) y el contenido semántico que atribuye al elemento con el que se relaciona:

Adverbio é uma parte invariavel da oração, que modifica o nome adjectivo, ou o attributo incluido ou não no verbo, accrescentando-lhe alguma circunstancia, ou fazendo-o exprimir os diversos graus, variantes, ou mutações da qualidade (Freire 1894[1875]: 106-107).

Respecto a la definición de Ribeiro, a pesar del cambio del metalenguaje, el autor conserva la misma base logicista de los gramáticos de la primera mitad del siglo:

Adverbio é uma palavra que determina a natureza de uma relação, encerrando em si ao mesmo tempo o segundo termo dessa relação.

Deprehende-se disto que o adverbio é uma reducção ou expressão abreviada da preposição com seu complemento em uma só palavra invariavel (Ribeiro 1881: 70-71 [la negrita es mía]).

De hecho, el carácter racionalista de esta definición es aun más evidente cuando se compara con la definición de preposición (véase $\S$ 7.3.5), pues se muestran prácticamente idénticas. La correspondencia entre estos conceptos se debe a que para Ribeiro el adverbio consiste en una forma abreviada del esquema preposición + nombre. El único avance considerable que esta definición presenta es el propio metalenguaje que el autor selecciona en su obra.

Maciel, por su parte, vuelve a aplicar los criterios formal y sintáctico para definir el adverbio. De este modo, el autor señala que el «adverbio é uma palavra invariavel modificativa do verbo, do adjectivo e até de outro adverbio, ex.: muito aprendemos, muito alto, muito dignamente») (Maciel 1926[1894]: 150).

Esta descripción muestra que los gramáticos brasileños oscilan entre la aplicación de los criterios formal y sintáctico y de la propuesta racionalista. En este sentido, y del mismo modo que ocurre en otras tradiciones, el adverbio no experimenta muchos cambios a lo largo del siglo. 


\subsubsection{La conjunción y la interjección}

La definición más generalizada con respecto a la conjunción se apoya también en los criterios formal y sintáctico. La mayoría de los gramáticos, ya sean clásicos o racionalistas, concuerdan en que esta clase constituye una parte indeclinable de la oración que sirve para enlazar palabras y proposiciones.

Las gramáticas brasileñas novecentistas no llegan a especular sobre el concepto de conjunción. Lo que se nota es que oscilan en la inclusión del criterio formal en la definición y en la admisión de su función como conector de palabras. Moraes Silva, por ejemplo, prescinde del criterio formal y deja el carácter invariable de la conjunción en un segundo plano; tampoco reconoce que esta clase puede relacionar las palabras entre sí. Así pues, el autor determina que las conjunciones deben definirse del siguiente modo:

As conjunções átão as sentenças, que tem algua connexão, ou correlação entre si, de semelhança de juizo, de opposição, de modificação (Moraes Silva 1824[1806]: 74).

En cambio, Augusto Freire procura añadir en su definición los dos aspectos omitidos por Moraes Silva. Además, el autor llama la atención sobre una característica que hasta este periodo no había sido mencionada en la gramaticografía brasileña. Se trata de la capacidad que presenta la conjunción para mantener dos niveles de dependencia de significado entre las oraciones, es decir, de enlazar simplemente dos oraciones o de establecer una dependencia entre ellas, como se destaca a continuación:

Conjuncção é uma parte invariavel da oração, que, para formar um corpo de discurso, ou liga palavras, proposições ou periodos a outros termos da mesma especie, approximando-os simplesmente; ou liga só uma proposição a outra, subordinando a segunda á primeira (Freire 1894[1875]: 108 [la negrita es mía]). 
Del mismo modo que Moraes Silva, Júlio Ribeiro contempla solamente una parte de la propiedad sintáctica de esta categoría y define la conjunción como «uma palavra que marca a natureza de uma relação representada entre dous juizos. A conjuncção representa entre dous juizos o mesmo papel que desempenha a preposição entre duas idéiası (Ribeiro 1881: 69). El gramático justifica que esta definición está fundamentada en la obra de Burgraff, y menciona que, de acuerdo con este autor, «a conjuncção só liga proposições, e a maioria dos exemplos em contrario explica-os elle [Burgraff] por meio de ellipses: na expressão tres e seis são nove opina o douto philologo que e seja uma verdadeira preposição equivalente de com» (Ribeiro 1881: 69).

Maciel, por el contrario, emplea la misma definición de Freire y define la conjunción a partir de su carácter formal y sintáctico como «uma palavra invariavel que liga duas proposições e às vezes duas palavras5) (Maciel 1926[1894]: 152).

En esta gramaticografía, la definición de la interjección también conserva su perfil más tradicional. Por un lado, la mayoría de los gramáticos concuerdan en que esta clase de palabra expresa los sentimientos y sensaciones del alma. Por otro lado, la diferencia que particulariza cada definición corresponde a las clasificaciones que esta categoría recibe por parte de cada autor. En este sentido, Moraes Silva entiende que la interjección equivale a una proposición completa, Augusto Freire la considera una parte invariable de la oración, Júlio Ribeiro la concibe como un sonido articulado, «grito animal, [que] não é palabra») (Ribeiro 1881: 73), y, por último, Maximino Maciel que juzga la interjección como palabra sentimental. Las definiciones de los gramáticos brasileños para esta clase de palabra se muestran a continuación:

Paixões violentas exprimem se em uma, ou poucas palavras, as quaes equivalem a uma sentença (Moraes Silva 1824[1806]: 76).

\footnotetext{
${ }^{5}$ Insistimos em admitir a ligação de palavras por algumas conjuncções coordenativas, pois a definição deve abranger o todo definido [nota el gramático].
} 
Interjeição é uma parte invariavel da oração, curta e viva, com que se exprimem os sentimentos subitos da alma (Freire 1894[1875]: 112).

Interjeição é um som articulado que exprime um affecto subito, ou que imita um som inarticulado (Ribeiro 1881: 72).

Interjeição é uma palavra synthetica, natural e expressiva dos nossos diversos sentimentos e sensações (Maciel 1926[1894]: 156).

\subsection{Evolución de conceptos sintácticos}

La tradición brasileña experimenta durante el siglo XIX un importante desarrollo en la sintaxis. Esta evolución es evidente en el aumento del espacio dedicado a los estudios sintácticos en las gramáticas y, especialmente, en el cambio de una perspectiva léxica por otra de tipo oracional.

Pues bien, en cuanto a la definición de oración, las gramáticas brasileñas decimonónicas se fundamentan en dos concepciones básicas, la de corte más tradicional y la racionalista. De acuerdo con la tradición, la oración constituye una «unidad lingüística dotada de sentido completo (sententiam perfectam)» (Ramajo 1987: 47) y ordenada según las reglas de colocación y relación de las palabras. Por su parte, la corriente racionalista determina que la oración corresponde a la expresión lingüística del pensamiento lógico, formada necesariamente por un sujeto y un atributo, relacionados entre sí mediante un verbo (ser).

En esta línea, la definición de oración que proporciona Moraes Silva recoge tanto el contenido formal, a partir de la alusión a los elementos que componen la oración, como el referencial lógico-semántico de la proposición, como se puede observar a continuación:

Da boa composição das partes da oração entre si resulta a sentença, ou sentido perfeito, com que nos fazemos entender, falando com palavras. 
Todas as sentenças se reduzem a declarar o que julgamos das coisas: v.g. este pomo é doce; João é virtuoso: ou aquillo que queremos, que as pessoas ou coisas sejão, fação, ou sofrão: v.g. Filho sè estudioso; trabalha; sofre-te com os trabalhos; está-me attento (Moraes Silva 1824[1806]: 78-79).

Se puede notar que en el primer párrafo de la definición el gramático hace hincapié a la importancia de la correcta disposición y relación de los elementos en la oración («boa composição») para una perfecta expresión y comprensión de su significado («sententiam perfectam»). Esta perspectiva aparece unida a la concepción logicista que privilegia la correspondencia entre producción lingüística y proceso mental. Basado en este presupuesto, Moraes Silva asevera que la oración no solamente afirma o declara, sino también expresa deseo, orden o influencia. Esta valoración de la finalidad imperativa de la oración es la principal aportación de Moraes Silva al concepto de oración. Con todo, esta novedad no llega a repercutir en las gramáticas posteriores.

La mayoría de las gramáticas publicadas hasta el último cuarto del siglo XIX conserva la base racionalista y prescinde de la definición de corte tradicional. Este es el caso de la definición propuesta por Augusto Freire, que se distingue por la ausencia de aspectos formales, como el orden y la relación de los constituyentes oracionales:

Proposição é o enunciado do juizo.

Juizo é o acto do entendimento, pelo qual affirmamos uma cousa de outra; ou, noutros termos, a percepção da relação de conveniencia entre duas idéas (Freire 1894[1875]: 277).

En sí misma esta definición no muestra cambios de tipo teórico o metodológico, pues Freire mantiene la misma perspectiva lógico-semántica que caracteriza los supuestos logicistas. Sin embargo, se puede poner de manifiesto el desarrollo del lenguaje gramatical, en el que sustituyen las expresiones de poco estatus técnico por una terminología más acorde con el contenido gramatical. 
A partir de la Gramática de Júlio Ribeiro la definición de oración retoma la base tradicional al mismo tiempo que abandona la noción racionalista. Así, Ribeiro define la oración como «uma coordenação de palavras ou mesmo uma só palavra formando sentido perfeito, ex.: As abelhas fazem mel - Os cães ladram - Morro» (Ribeiro 1881: 193). La expresión "sentido perfeito» conserva su acepción tradicional, que, en palabras de Ribeiro, significa «dizer alguma cousa a respeito de outra de modo completor (Ribeiro 1881: 193).

A pesar de revelar un cierto tradicionalismo por parte del autor, la definición de oración propuesta por Ribeiro presenta una destacable novedad para su tradición. Se trata del reconocimiento por parte del autor de la existencia de oraciones formadas por una única palabra con sentido completo.

La definición de Maximino Maciel es, en definitiva, la más objetiva de este periodo. El autor recoge la concepción de pensamiento lógico, ordenado y coherente expresado a través de palabras y añade la noción introducida por Ribeiro, que privilegia la expresión del «sentido completo» con una o más palabras:

Proposição é um pensamento, expresso por uma ou mais palavras (Maciel 1926[1894]: 354).

Pues bien, a partir de estas definiciones se puede observar que los intentos de definición de la oración en la tradición brasileña oscilan entre la perspectiva gramatical y la representación de una realidad lógica. A pesar de esta inevitable variabilidad en las definiciones, los autores logran progresar en la comprensión de oración, que pasa a referirse no solamente a un conjunto de palabras sino también una única palabra capaz de encerrar un todo inteligible.

La evolución de los estudios sintácticos presenta, entre otros rasgos distintivos, la valoración jerárquica de los constituyentes de la oración. En la gramática, normalmente se considera que la proposición está formada por tres elementos esenciales (sujeto, verbo y atributo), organizados en un orden de importancia (condicionado por el orden lógico y natural de la proposición) (Calero Vaquera 2008). A medida en que avanza la sintaxis, estos presupuestos 
se modifican y los gramáticos empiezan a prescindir de partes de la oración que anteriormente eran consideradas indispensables, como es el caso del sujeto.

En este sentido, las primeras nociones de sujeto en las gramáticas brasileñas recogen casi siempre la idea de importancia, de núcleo de la proposición (al lado del verbo). La definición de esta parte de la oración se fundamenta además en dos criterios distintos, el formal, relacionado con las clases de palabras que desempeñan esta función sintáctica (normalmente el sustantivo), y el criterio semántico, acerca de su referente extralingüístico (persona o cosa de quien se habla) (Lope Blanch 1979, González Calvo 1998, Osuna García 2006 y Calero Vaquera 2008). Estas características son fácilmente identificadas en las definiciones propuestas por Moraes Silva, Augusto Freire, Júlio Ribeiro y Maximino Maciel:

O sujeito, de quem se affirma, o qual deve ser um nome só ou modificado por articulares e attributivos (Moraes Silva 1824[1806]: 79).

Sujeito é a pessoa ou coisa a que convem alguma qualidade. É a idéa principal, o objecto do juizo (Freire 1894[1875]: 277).

O que representa a cousa a cujo respeito se falla: chamase sujeito (Ribeiro 1881: 194).

Sujeito é o ser de quem se diz alguma coisa (Maciel 1926[1894]: 276).

La definición de Moraes Silva contempla tanto el carácter formal (nombre modificado o no por adjetivo) como su valor semántico. Augusto Freire, por su parte, distingue solamente el punto de vista semántico del sujeto, al mismo tiempo que valora su importancia como idea principal de la oración. Finalmente, Júlio Ribeiro y Maximino Maciel definen el sujeto a partir de su carácter semántico, destacando su referente extralingüístico (o discursivo).

En la definición de atributo (o predicado), los gramáticos brasileños tienden a seguir los mismos criterios empleados para definir el sujeto de la 
oración, concediendo cierta uniformidad a los conceptos sintácticos. En este sentido, nuestros gramáticos definen el atributo del siguiente modo:

O attributo, que se declara por adjectivos attributivos; v.g. infeliz: outras vezes por nomes com preposições; v.g. "Pedro é sujeito de verdade, de honra;" por verdadeiro, honrado: ou "é homem sem honra" (Moraes Silva 1824[1806]: 79).

Attributo é a qualidade que convem ao sujeito: é a idéa accessoria (Freire 1894[1875]: 277).

O que representa o que se diz a respeito do sujeito: chama-se predicado (Ribeiro 1881: 194).

Predicado é aquillo que se diz a respeito do sujeito (Maciel 1926[1894]: 277).

A excepción de Moraes Silva, que define el atributo desde el punto de vista formal, especificando las categorías o estructuras gramaticales que pueden ejercer esta función sintáctica, los demás gramáticos brasileños optan por una definición basada en la perspectiva semántica, que destaca particularmente la relación que el atributo establece con el sujeto. En cuanto a la definición de Augusto Freire, es importante destacar que para el autor el atributo no alcanza el mismo nivel de importancia que el sujeto en la composición de la oración, pues el atributo constituye, según el gramático, una idea accesoria al sujeto.

A pesar del importante avance de la sintaxis durante el siglo XIX, que se manifiesta por ejemplo en el incremento del estudio de la oración, los conceptos básicos analizados son una muestra de que en las gramáticas brasileñas las definiciones sintácticas no presentan cambios sustanciales sino que más bien oscilan entre el paradigma tradicional y el racionalista. 


\subsection{Resumen}

Durante el siglo XIX las gramáticas brasileñas recibieron el influjo de distintas corrientes teóricas. Estas doctrinas han determinado, en diferentes niveles según los manuales, cambios en la codificación de la lengua portuguesa. Estas transformaciones afectaron a la propia división de la materia gramatical, que revela la importancia que adquirieron las disciplinas en la construcción de la gramática. En este sentido, la gramática brasileña que a principios del siglo estaba compuesta de morfología (clasificación y variación de las palabras) y sintaxis (concordancia, régimen y figuras), llegó a constituir a finales de este periodo un estudio completo de la morfología (composición, clasificación, variación, evolución y origen de las palabras), la fonología (formación, clasificación, pronunciación, grafía y combinación de los fonemas), la sintaxis (función sintáctica de las clases de palabras, constitución y clasificación de las oraciones coordinadas y subordinadas, figuras y vicios de lenguaje y estilística) y la semántica (clasificación de las palabras según sus propiedades semánticas).

Los principales cambios en la definición de gramática en la tradición brasileña durante el siglo XIX fueron la superación de las ideas de corrupción y corrección, predominantes especialmente en las gramáticas de la primera mitad del siglo, reemplazadas por el modelo descriptivo; la redefinición del objeto y del objetivo de estudio de la gramática; el reconocimiento de otras formas de codificación lingüística; el cambio de concepción de la lengua como expresión del pensamiento por la idea de organismo; finalmente, la sustitución de la concepción de gramática portuguesa como aplicación de los principios generales por la perspectiva descriptiva.

En cuanto a la morfología, son evidentes los cambios de terminología (el término etimología fue sustituido por morfología), la separación de la fonología, el incremento del contenido (comprende además el estudio de los constituyentes de la palabra, el origen y la evolución de los vocablos) y el 
metalenguaje, que a finales del siglo alcanza un nivel más técnico e incorpora diversos términos propios de la corriente naturalista.

La evolución de la sintaxis se caracteriza por la sustitución del estudio de la palabra por el estudio de la oración, la introducción de una nueva perspectiva de las relaciones sintácticas entre los miembros de la oración y el cambio en el objetivo de la sintaxis literaria, que deja de ser entendida como la parte de la gramática que sirve para explicar las construcciones agramaticales para tratar de las figuras de lenguaje y la estilística. Con todo, a pesar del importante avance de la sintaxis durante este periodo, los conceptos sintácticos básicos analizados aquí muestran que en las gramáticas brasileñas las definiciones de oración, sujeto y atributo (o predicado) no presentan cambios sustanciales, sino que más bien oscilan entre el paradigma tradicional y el racionalista. Esta conclusión puede quizá extenderse a otros conceptos sintácticos, como los de las figuras y vicios de lenguaje o de las oraciones coordinada y subordinada que tampoco presentan cambios profundos.

Finalmente, las definiciones y clasificaciones de las clases de palabras revelan la incoherencia por parte de los gramáticos brasileños en cuanto a la aplicación de los criterios de definición y la mezcla de paradigmas teóricos, especialmente en las gramáticas publicadas en la segunda mitad del siglo XIX.

En esta tradición, los gramáticos generalmente definen el sustantivo a partir de su carácter esencial, desde una perspectiva semántica, aunque hay autores que contemplan también su función sintáctica y prescinden de argumentos formales y etimológicos. La definición de sustantivos no presenta cambios profundos a lo largo del siglo XIX. En cuanto a los adjetivos, los principales cambios que marcaron su evolución fueron la superación de la relación de subsistencia entre el adjetivo y el sustantivo y del referencial extralingüístico, la determinación de los conceptos de comprensión y extensión del significado y, por último, la sustitución progresiva del criterio sintáctico por el semántico. Las transformaciones observadas en la evolución de los pronombres son fundamentalmente dos, la separación progresiva de la clase adjetiva y la percepción de su valor deíctico. La superación de la teoría del verbo único es, 
sin duda, la principal mudanza que afecta a la clase del verbo, aunque se conserva la concepción del verbo como palabra de afirmación. Respecto a las palabras invariables, cabe señalar que son las únicas en que los gramáticos recurren al criterio formal para complementar sus definiciones. Además, son las clases de palabras en las que los gramáticos tienden o bien al racionalismo o bien al tradicionalismo, pero en todo caso renuncian a introducir innovaciones sustanciales en el tratamiento de las partículas. 


\section{CONTRASTES ROMÁNICOS EN EL PROCESO DE CODIFICACIÓN DEL PORTUGUÉS}

\subsection{Introducción}

Este capítulo tiene la finalidad de estudiar la metodología contrastiva utilizada por los gramáticos brasileños en la descripción de la lengua portuguesa. A lo largo de la evolución de la gramática, los autores recurren a otras fuentes lingüísticas para profundizar en su estudio acerca de la lengua propia. Este recurso empleado en la generalidad de las tradiciones gramaticales persigue diferentes objetivos, de acuerdo con la época y la doctrina gramatical vigente, como la apología de la lengua, el estudio histórico y contrastivo, el estudio comparado de unidades gramaticales y comportamientos sintácticos de las estructuras lingüísticas con el fin de determinar la función y el uso de tales categorías.

Cabe señalar que cada uno de estos objetivos está relacionado con una determinada corriente gramatical. Las características que determinan estas corrientes influyen directamente sobre los objetivos del método contrastivo empleado en cada periodo. Lliteras (2010), en un estudio reciente acerca del proceso de codificación del español, identifica tres etapas en las que se aplica la metodología contrastiva con diferentes propósitos:

1) El discurso apologético característico del Siglo de Oro, que defiende la supremacía del español frente a otras lenguas, en especial el latín y el italiano.

2) El periodo racionalista que se caracteriza por orientarse hacia las comparaciones entre el español y el francés, debido a la preeminencia de esta última lengua en este momento. 
3) La corriente descriptiva que analiza el comportamiento sintáctico de ciertos elementos gramaticales del español comparados con otras lenguas románicas con el fin de clasificar y describir estas unidades gramaticales.

Con respecto a la tradición gramatical brasileña, se pueden identificar tres fases metodológicas que tuvieron lugar en el siglo XIX. Del mismo modo que ocurre en la gramaticografía española, las obras que aquí representan las principales etapas de la gramática decimonónica en Brasil analizan los contrastes lingüísticos de forma diversa y con distintos objetivos:

1) La primera fase, en la que figura el Epítome de Moraes Silva, se caracteriza por la influencia de la corriente racionalista, pero preservando ciertos rasgos renacentistas.

2) La segunda fase, representada por las Grammaticas Portuguezas de Augusto Freire y Júlio Ribeiro, corresponde al periodo de conciliación metodológica, en que las gramáticas brasileñas tratan de compaginar la doctrina historicista con la tradición y la norma.

3) La tercera fase constituye el periodo más bien descriptivo que propiamente contrastivo y tiene como principal exponente al gramático Maximino Maciel.

\subsection{El contraste racionalista en la obra de Moraes Silva}

Las primeras gramáticas del portugués escritas en Brasil, representadas aquí por el Epítome de Grammatica Portugueza de Moraes Silva, se caracterizan por 
desarrollar un estudio contrastivo del portugués basado principalmente en las comparaciones con el latín, aunque también se toma en consideración el reconocimiento de la influencia de otras lenguas románicas, en especial el francés.

En su aplicación de la metodología contrastiva al estudio del portugués, Moraes Silva observa principalmente los diferentes aspectos lingüísticos que la lengua objeto de estudio comparte con el latín, describe el origen de algunos elementos gramaticales comunes a las lenguas románicas y analiza los barbarismos y extranjerismos que proceden de otros idiomas.

En la introducción del Epítome, el autor explica algunas influencias del latín y del griego en la ortografía y en la fonética de la lengua portuguesa. Moraes Silva resalta por ejemplo que algunos signos de puntuación, como la marca de nasalización de las vocales en portugués, designaban las vocales breves del latín:

Para o til usaremos indistinctamente destes signaes ${ }^{-}$, apezar do segundo ser proprio para as sillabas breves no latim (Moraes Silva 1824[1806]: IV).

El gramático muestra también que la antigua grafía portuguesa de las vocales agudas deriva de la grafía latina y explica que esta representación gráfica sería más tarde sustituida por el acento agudo. El autor trata, además, de la propensión del portugués a la elisión de ciertos fonemas, del mismo modo que la lengua latina:

Concluiremos esta nota observando, que nos livros antigos se achão vogáes dobradas, para indicar se, que são agudas, ou que é aguda simples, v.g. faraa, por fará; outras vezes para mostrar que havia duas vogáes na lingua, donde se derivou a Portugueza, v.g. pòbov, pòvoo, de populo, cidadãao de cibdadano, vós farees de faredes mais antigo, como amaaes de amades do Latim amatis, que dizemos amais (Moraes Silva 1824[1806]: IX).

Os poetas sempre fazem elisão das nasáes com as vogáes seguintes, v.g. A ti se devem'os altos fundamentos: Parece que enverdecem' ali, mais cores: 
Floreciam' entre tanto novas flores. O mesmo é no Latim (Moraes Silva 1824[1806]: IV).

Moraes también reconoce en su obra los préstamos de la lengua griega. De acuerdo con el autor, los vocablos portugueses tomados del griego demuestran a través de la grafía que todavía guardan cierta relación con su lengua de origen, pues conservan algunas letras del alfabeto griego. Esta codificación, que obedece el criterio etimológico, es criticada por el gramático:

O Y usão muitos por I nas palavras derivadas da lingua Grega, v.g. hydra, synodo: mas é superfluidade (Moraes Silva 1824[1806]: IX).

En la obra se pueden identificar otras observaciones de Moraes sobre la etimología del portugués. Al estudiar la clase de los adverbios y los pronombres, el autor llama la atención sobre el origen y la constitución de determinados vocablos, como los adverbios agora y hoje, que provienen de palabras compuestas del latín; y los pronombres lhe y lhes, que derivan de partículas demostrativas latinas:

Os adverbios são destas palavras compostas, v.g. agora de hac hora Latinos; hoje de hoc die; ogano de hoc anno; boamente de bona mente; \&c.: Outrem outra pessoa; Ninguem nenhǔa pessoa [de neminem Latino] (Moraes Silva 1824[1806]: 4).

Elle tem os casos Lhe, e Lhes, e impropriamente the chamão pronome de terceira pessoa, sendo um adjectivo articular derivado do Latino ille, illa, illud, que no Portuguez se usa muito com ellipse do substantivo, a que pertence (Moraes Silva 1824[1806]: 14).

Moraes Silva no excluye de su estudio contrastivo los problemas sobre el origen dudoso de algunas partículas de la lengua portuguesa, sino que trata de averiguar las posibles etimologías de determinados elementos. Sin embargo, el gramático a veces no se declara partidario de una u otra opción, sino que más 
bien se muestra indiferente con relación al origen de ciertas formas siempre que se conozca su categoría gramatical. Así por ejemplo, el autor sigue este criterio de indefinición etimológica en el estudio del sufijo -mente para la formación de los adverbios:

Alguns pretendem, que mente vem do Latim mente, bonà mente; outros que do Celtico' ment, que significa modo [...]. Como quer que seja, Latino, ou Céltico, mente é um substantivo. D' antigamente (Moraes Silva 1824[1806]: 59 [la negrita es mía]).

No obstante, el gramático también pone de relieve algunas diferencias entre la lengua portuguesa y el latín. El autor explica en su obra, por ejemplo, que el portugués carece de verbos pasivos y también de formas de la declinación nominal semejantes a los casos latinos, que fueron sustituidos por las preposiciones. Además, cabe señalar la comparación que se establece entre estas dos lenguas y el inglés. Señala el gramático que en esta última lengua los nombres pueden relacionarse por medio de preposición o añadiendo $s$ al final del sustantivo que indica el poseedor de una construcción en genitivo latino:

Os Latinos tem verbos derivados dos activos, nos quaes se affirma, que o sujeito é paciente da acção do verbo activo, eu firo: áquelles verbos chamãoIhes passivos; nós não temos verbos passivos (Moraes Silva 1824[1806]: 48 [la negrita es mía]).

Em Latim por exemplo Templum significa Templo, Dominus Senhor; quando se quer pôr em relação de possessão, ou considerar o templo como coisa possuída, e do Senhor, o nome Dominus muda a terminação em Domini, e dizem Templum Domini. Em portuguez geralmente falando os nomes não se

\footnotetext{
1 En los primeros años del siglo XIX, algunos gramáticos portugueses, siguiendo la corriente francesa, defendían la teoría del origen céltico del portugués (Gonçalves 2001, 2004, Schäfer-Priess 2004). Sobre la recepción de la "celtomanía» en Portugal, Gonçalves (2009) señala que "aunque no conoció muchos adeptos entre los filólogos y gramáticos decimonónicos, lo cierto es que suscitó una polémica alimentada en textos académicos y en periódicos culturales y científicosi) (Gonçalves 2009: 292).
} 
varião na terminação para este fim, mas dizemos: "templo do Senhor:" onde a preposição de indica, que o Senhor é o possuidor do templo. [...] Em inglez usase da preposição of, ou de ajuntar um s ao nome: v.g. House of Peter, ou Peter's house; casa de Pedro, ou de Pedro casa, imitando o genitivo latino (Moraes Silva 1824[1806]: 82 [la negrita es mía]).

Además de las referencias a la lengua latina, el Epítome presenta también comparaciones entre el portugués, el francés y el italiano. En su estudio contrastivo, el autor brasileño no manifiesta predilección por alguna de estas lenguas, sino que explica el origen latino y reconoce la presencia de galicismos e italianismos en la lengua portuguesa de manera imparcial:

"Hi-vos d'hi, boca de praga:" ide-vos d'esse lugar [Cam. Filod. At. 2. SC. 5.], Este i, ou hi, adoptámos do Francez y, como hu [onde], ou antes u, antiquado, de où: "nom cries gallinhas, hu raposa mora." Ende antiquado [d'aí] do en Francez, ou inde Latino, corrupto o in em en á Franceza, como Sengradura de singler, \&c. "Sem quedar ende por contar hi rem:" sem ficar d'isso por contar ahi coisa (Moraes Silva 1824[1806]: 60).

Assim mesmo se diz Sótavento, por Sotovento do italiano Soto. Todos sabem, que os Peçanhas primeiros almirantes do mar, e sua tripulação, que elles assoldavão, erão italianos, d'onde ficarão termos italianos na Nautica: v.g. galeote, cómitre, gúmena, e outros (Moraes Silva 1824[1806]: 73).

El gramático también señala la influencia que recibe el portugués de algunas lenguas románicas, en particular del francés y del español. Pero este influjo suele ser objeto de críticas, no solo por parte de Moraes Silva sino también de muchos gramáticos portugueses de este periodo, como Fray Luis do Monte Carmelo (1767), Francisco José Freire (1842[1773]), António Pereira de Figueiredo (1792), António das Neves Pereira (1792, 1793), Pedro José da Fonseca (1799), entre otros (Gonçalves 2002a, 2005d, García Martín 2005 y Schäfer-Priess 2005), e incluso posteriores, como Fray Francisco de S. Luis (el Cardenal Saraiva) $(1816,1827$ ) y Antonio Maria de Almeida Neto (1884) (Gonçalves 2002a, 2005d). 
Las críticas de los gramáticos portugueses a la influencia española ${ }^{2}$ constituyen un fenómeno tradicional en la gramaticografía portuguesa debido al bilingüismo en Portugal entre los siglos XVI y XVIII (García Martín 2007, 2010). En las gramáticas renacentistas, "a visceralidade com que se pronuncia contra 0 empréstimo do castelhano justifica-se pela necessidade de afirmar a autonomia do português como língua de um reino também autônomo» (García Martín 2005: 28). Los estudios muestran que, después de la segunda mitad del siglo XVIII, la preocupación de los autores portugueses consistía en mostrar tanto las semejanzas como las diferencias entre las dos lenguas con el propósito de promover (o prescribir) la norma portuguesa (Buescu 1984 y García Martín 2007).

En cuanto a la presencia de galicismos, Gonçalves afirma en uno de sus estudios sobre esta influencia durante el siglo XVIII que «la importación de palabras y el calco de construcciones de origen francés era parte de una moda más general en la sociedad portuguesa y española (Lázaro Carreter 1985/ 1949', 255289)» (Gonçalves 2002a: 553). En este sentido, las críticas de los gramáticos portugueses a los galicismos tienen la finalidad de contener la "suposta decadência da língua nacionalıy y de defender el purismo lingüístico (Gonçalves 2005d: 45).

En general, los autores admiten que la presencia de algunos elementos foráneos corrompe la norma vigente del portugués, como es el caso de ciertas concordancias verbales, del empleo de la partícula se, de la variación del significado de algunos verbos y, evidentemente, de la «adopción - importación de extranjerismos léxicos» (Gómez Asencio 2006: 45):

\footnotetext{
${ }^{2}$ García Martín llama la atención sobre la escasez de estudios relacionados con la presencia del español en la lengua portuguesa: «En efecto, la atención que se ha prestado a los catellanismos del portugués es absolutamente deficiente, tal vez, en parte, como consecuencia de una tradición que tiende a negar el castellanismo, y remonta al menos a 1606, fecha de publicación de la famosa Origem da Língua Portuguesa de Duarte Nunes de Leão. Además del préstamo léxico, cabría analizar también la influencia del español en el ámbito fraseológico y sintáctico, área de estudios que se encuentra totalmente ignorada») (García Martín 2010: 18).
} 
"Os progressos forão quaés se devia esperar": é erro, deve ser: quaes se devião esperar, ou devião ser esperados. Quaes se devia esperar, é má imitação de um gallicismo correcto: on devoit les attendre, ou s'attendre; onde on é homme sujeito, e tem o verbo devoit no singular (Moraes Silva 1824[1806]: 51 [la negrita es mía]).

"As coisas tocante á Religião" é erro de concordancia, e um Gallicismo: deve ser tocantes como pertencentes (Moraes Silva 1824[1806]: 101).

Aconteceu-se é igualmente improprio, posto que este, e caiu-se, morreu-se, e semelhantes se achem nos bons autores imitando os Castelhanos (Moraes Silva 1824[1806]: 50 [la negrita es mía]).

A nossa lingoagem limpa, quando éramos Portuguezes, tinha: esqueceo-lhe o recado, ou esqueceo-se do recado. E tinha sua differença, esqueceo-me a pátria, e os amigos, e esqueci-me da pátria e dos amigos: o primeiro denota hum esquecimento deliberado, e suppoem matéria de esquecimento [...]. Picarse tinha sua significação certa, e sabida, hoje está augmentado á Franceza. A cada passo este, ou aquelle pica-se de prudente, de esperto, \&c. [...] Até o verbo Fazer está mui afrancezado: ora se diz por representar [...], ora por ser, servir (Pereira 1792: 454 apud Gonçalves 2005d: 55).

Estes termos ataque, e atacar naõ se usáraõ atégora na Lingoa Portugueza, senaõ em materia de guerra, como atacar o inimigo, atacar as peças de artilharia, atacar o fogo á mina: e naõ tinhaõ as significações figuradas, que se usaõ na Lingoa Franceza, e que os Portuguezes modernos, sem consultarem o uso, Ihes tem accommodado, como ataques da doença, fevre \&c., que dizemos em Portuguez usual e clássico, accessos (Pereira 1792: 437-438 apud Gonçalves 2005d: 53).

He hoje mui vulgarmente usado [el vocablo conducta] entre nós com a significação de procedimento, á imitação dos Francezes, Inglezes, Italianos e Castelhanos. (...). A pezar porém destas auctoridades [Morais Silva, o Pe. Pereira e Teodoro de Almeida], e uso freqüente, a opinião mais geral dos homens doutos, e intelligentes da Lingua Portugueza He contra este vocábulo, e por isso o reprovamos, e julgamos inadoptavel na referida significação (Saraiva 1827: 26 apud Gonçalves 2005d: 47). 
Para nuestro gramático, el uso en portugués de formas sintácticas propias de estas lenguas también constituye un barbarismo 3 y, por consiguiente, es un vicio de lenguaje que debe ser evitado:

O Barbarismo, ou Estrangeirismo, consiste no uso de palavras estrangeiras, e frases compostas com Sintaxe estrangeira, ou collocação tal: v.g. deu as penas, por foi castigado, que é um Latinismo; porque dar penas em Português é causálas, impò-las. "Proveu a natureza, que o corpo não fizesse mǔito negocio ao homem (4):" é outro Latinismo, por, désse pejo, incommodo: dar lugar bens; por, fazer cessão de bens (mal traduzido de cedere bonis). "Todos viemos em as hortas de Decio Bruto:", por ás hortas. Na construcção: "Isto tive da amizade que dicesse:" "Remédio da, que já se perdia, paz no mundo:" "Dá-nos Senhor aquella, de que necessitamos, paz." (Barros Gram.) (Moraes Silva 1824[1806]: 119 [la negrita es mía]).

Por otro lado, para algunos gramáticos de la tradición portuguesa de este periodo, como por ejemplo Pedro José de Figueiredo (1799) y Manoel Dias de Souza (1804), el barbarismo constituye un fenómeno relacionado solamente con las incorrecciones léxicas:

Consiste o segundo [barbarismo] na introdução de vozes peregrinas ainda não adaptadas, contra a propriedade, e pureza da linguagem; e commette-se na contextura per algum modo apartada do uso dos que fallam bem, e dos melhores escritores (José de Figueiredo 1799: 108-109 [la negrita es mía]).

\footnotetext{
${ }^{3}$ De acuerdo con Gómez Asencio (2006), el concepto de barbarismo quedo fijado en las gramáticas académicas como «atentado contra la ortografía o la prosodia en palabras sueltas y la impropiedad léxica (por extranjerismo, neologismo,...)», mientras que el solecismo correspondería a los «vicios de construcción» o de sintaxis (Gómez Asencio 2006: 32 [la negrita es mía]). Sin embargo, la definición de Moraes Silva suma a los «vicios de dicción» las incorrecciones de carácter sintáctico, pero ambos son resultado solamente de la influencia foránea, lo que excluye las demás ufaltas contra las reglas y propiedades» de la lengua.

${ }^{4}$ Má versão de "negotium facesseret" em o Lellio de Resende [nota del gramático].
} 
A esta pureza se opõe o uzo viciozo de alguma palabra, o qual se chama Barbarismo [...].

Tambem se comete Barbarismo quando se uza de palavras novas, e que o uso não tem ainda autorizado, como Detalhe palavra Franceza que corresponde ás nossas Pelo meúdo [...] (Dias de Souza 1804: 208 [la negrita es mía]).

Es evidente que la práctica contrastiva de Moraes Silva no se limita a comparaciones léxicas. El autor estudia también las semejanzas entre las lenguas románicas en ciertas relaciones sintácticas e incluso la presencia en portugués de otros idiomas como el inglés y el hebreo. Por un lado, el propósito de estas comparaciones parece ser la determinación de la procedencia del préstamo o de la influencia en portugués por imitación de la sintaxis francesa y latina, como en los siguientes casos:

Este modo de usar da palavra homem [sin el artículo] imitamos do Francez antigo hom, que se corrompeu em on [V. a Grammaire Générale \& raisonnée, Part. 2. Chap. 19. Pag. 574. \& Condillac, Grammaire, chap. 7. pag. 125, edit. De Genèe, 1780] (Moraes Silva 1824[1806]: 11).

Os Latinos tem participios, ou adjetivos verbáes, que referem o attributo a uma época futura, a que chamão participios de futuro. Nós os imitamos, e d'elles tomamos vindoiro, duradoiro, futuro, e poucos mais (Moraes Silva 1824[1806]: 45).

"Esforça Infante, nem c'o peso inclina:" o Imperativo inclina, por inclines do Subjunctivo, é um Latinismo. (Mausinho, African. F. 89. V.) Isto pelo que respeita aos modos dos verbos (Moraes Silva 1824[1806]: 45).

[...] o serem ellas feyas: o ser eu preso. Assim mesmo os Latinos usavão dos seus infinitivos: Nam istud ipsum non esse, cum fueris, miserrimum puto: [Cicer. Quaest. Tuscul. L. I. n. 12] e Horacio dice: nescius uti; metuens contingere; recitare timentis; culpari dignos; piger scribendi ferre laborem; \&c. V. Severim de Faria, Discurso 2. pag. 65. ult. edic. 1791 (Moraes Silva 1824[1806]: 41-42). 
Pero, por otro lado, la obra presenta algunas comparaciones entre el portugués y otras lenguas, como el francés, el inglés y el hebreo. Estas observaciones permiten afirmar que otra preocupación del gramático consiste en demostrar que las lenguas pueden presentar desarrollos sintácticos paralelos, de modo que ciertos procesos no necesariamente se explican como influencias directas, sino más bien como fenómenos generales comunes a lenguas sin parentesco genético, de acuerdo con los principios racionalistas ${ }^{5}$. A propósito de este tema, se pueden citar las explicaciones de Moraes acerca de algunos empleos del gerundio y del uso de algunas «locuciones prepositivas» (Gómez Asencio 2008):

Vẽi os gerundios com preposições mui frequentemente, á imitação do que se usa nas linguas Francesa: v.g. en riant, tout en jouant; e 'na Ingleza: v.g. in acting, em representando; in raising, em excitando. [V. Spectactor, $n^{\circ} 150$ ] Animus in consulendo líber: é de Sallust. Bell. Catil. na falta de Catão. [V. Terent. Andr. Act. IV. SC. IV. V. 32. In pariundo]. Na lingua Ingleza o gerundio serve de sujeito de preposições acõpanhado do artigo the: "the making of war": 0 fazendo, ou fazer d'a guerra [Spectator $n^{\circ} 73$ ]. Nós dizemos semelhantemente: "E sabendo elles, que me hão de achar com sigo, quando menos o esperarem, bastará para andarem espertos": onde sabendo elles está como o soberem elles... bastará para \&c. i. é, o gerundio personalisado por sujeito do verbo (Moraes Silva 1824[1806]: 42-43 [la negrita es mía]).

Os Hebreus tinhão o mesmo uso'6. V. Oleastri, Hebraism. Canon. 5. Non auferetur sceptrum de Jehudáh, \& Scriba de inter pedes ejus, donec veniat Silóh, \& ei obedientia gentim. Os Latinos usarão o mesmo: v.g. in ante diem; insuper rogos; desuper: nós dizemos d'entre muros; perante, empós, após de;

${ }^{5}$ Nos referimos específicamente a estos dos criterios:

1) La existencia de categorías universales, comunes a todas las lenguas (aunque en algún momento estos rasgos generales se confunden con el latín).

2) La creencia en que «los principios generales son los que la razón dicta, se deduce de la razón y no del análisis de las diversas lenguas» (Yllera 1983: 653).

${ }^{6}$ Este uso corresponde a "outras vezes [que] o nome se offerece ao nosso entendimento em duas relaçoes: v.g. a porta de sobre o muro: onde muro se offerece como possuidor da porta, e como lugar, sobre que ella estava» (Moraes Silva 1824[1806]: 66-67). 
Désno temo, Dèsde, de Des e De (Moraes Silva 1824[1806]: 67 [la negrita es mía]).

Sin embargo, la presencia de este tipo de reflexiones contrastivas en la Gramática de Moraes es muy escasa y además tal recurso metodológico no se manifiesta de forma explícita, como ocurre con las gramáticas finiseculares, que desarrollan la comparación entre el portugués y otras lenguas de acuerdo con los principios positivistas y la gramática histórica.

A pesar de que se considera el Epítome de Moraes una de las primeras obras representativas de la corriente racionalista en Brasil, son escasas las observaciones que reflejan una conciencia clara por parte del autor de la diferencia entre gramática general y gramática particular. Aunque el autor reconoce esta distinción en el prólogo del Epítome (véase § 5.1.3), el texto gramatical solo recoge descripciones aisladas y a menudo imprecisas sobre aspectos gramaticales característicos de otras lenguas sin identificar. Cabe señalar, además, que estas notas no parece que persigan una finalidad comparativa específica:

Em outras Linguas tem os verbos variações derivadas do mesmo radical, para lhe dar um sentido dobradamente activo; ou de uma acção reflexa sobre o sujeito mesmo \&c. tem variações, que indicão o sexo do sujeito, e cõpõem se mesmo com a negação \&c. (Moraes Silva 1824[1806]: 57 [la negrita es mía]).

Nas linguas, que tem casos, onde a transposição das palavras é mais livre, pode ser a construcção indirecta sem hyperbato, figura mais ordinaria nas linguas mais sujeitas á collocação directa (Moraes Silva 1824[1806]: 114 [la negrita es mía]).

En cuanto a los ejemplos que Moraes Silva utiliza para ilustrar fenómenos que él considera comunes a varias lenguas sin más precisiones, en la mayoría de los casos proceden del latín, que sigue siendo la lengua de referencia fundamental 
tanto para las generalizaciones como para mostrar las particularidades del portugués:

As diversas relações, que as coisas significadas pelos nomes tem entre si, em algǔas linguas se declarão, variando os finaes dos nomes, v.g. no latim, Dominus (o Senhor), em Domini (do Senhor), Domino (ao Senhor), Dominum (ao Senhor), Domine (ó Senhor). Estas diversas terminações dos nomes chamão se casos.

Nós em Portuguez temos algŭa semelhança de casos nos nomes seguintes, que os Grammaticos chamão Pronomes (Moraes Silva 1824[1806]: 5-6 [la negrita es mía]).

Em algŭas linguas o adjectivo attributivo simples, ou positivo, se altéra para indicar a mayoria, ou differença comparativa: v.g. doctus (douto) em Latim, varia se em doctior (mais douto), e doctissimus (muito douto); Minor (menor) Minimus (mínimo) (Moraes Silva 1824[1806]: 18 [la negrita es mía]).

Una vez más la práctica contrastiva de Moraes confirma la influencia racionalista en el Epítome, pues, como ocurre en la Minerva del Brocense (1562), el gramático «enumera [ciertos] rasgos que considera generales o comunes a todas las lenguas, pero implícitamente se deduce su creencia en la universalidad de algunos principios descubiertos en la lengua latina») (Yllera 1983: 653; Martínez Gavilán 1996).

En otros casos, el procedimiento contrastivo lleva a Moraes Silva a interpretar como carencias o rarezas del portugués formas gramaticales o estructuras sintácticas usuales en otras lenguas:

Outras linguas tem propriamente (isto é, em sentido e figura) verbos médios; doradamente activos, \&c. de que nós carecemos (Moraes Silva 1824[1806]: 50 [la negrita es mía]).

As preposições de algǔas linguas pospõem-se aos nomes regidos por ellas; v.g. na Lingua Persiana, e na Geral Brasiliana; os Latinos dizião quicum, mecum; os Inglezes pospõem mui frequentemente as preposições; nós raríssima vez: v.g. 
"Impor-te o jugo eu bem sei quem ha-de:" i.é, eu bem sei quem há [sem poder] de impor-te o jugo (Moraes Silva 1824[1806]: 64-65 [la negrita es mía]).

A propósito de esta última comparación, conviene destacar la referencia a lenguas exóticas, amerindias y asiáticas. El autor vuelve a destacar la particularidad de estas lenguas cuando trata de explicar la teoría del verbo sustantivo:

O mais notável é que em muitas Linguas falta verbo correspondente ao substantivo ser, como é na Chinesa, e nas dos Indios Galibis, e na Lingua geral dos Brasis, e quando querem affirmar ajuntão o sujeito ao nome com adjectivo: v.g. "Francici irupa:" Francezes (SC. São) bons; e negão por meyo do adverbio: "Francici irupa va:" litteralmente; Francezes bons não: sem verbo (Moraes Silva 1824[1806]: 57-58).

Estas observaciones demuestran que Moraes Silva reconoce que uno de los principales universales lingüísticos que sostiene la gramática racionalista, como es la clasificación del verbo en sustantivo y adjetivo, no puede ser aplicado a todas las lenguas porque carece de apoyo empírico. Sin embargo, el autor no aporta explícitamente argumentos en contra de esta afirmación logicista.

Finalmente, los gráficos siguientes muestran la proporción de cada lengua extranjera en el total de las referencias a otras fuentes lingüísticas y en los diversos dominios gramaticales de la obra de Moraes Silva: 

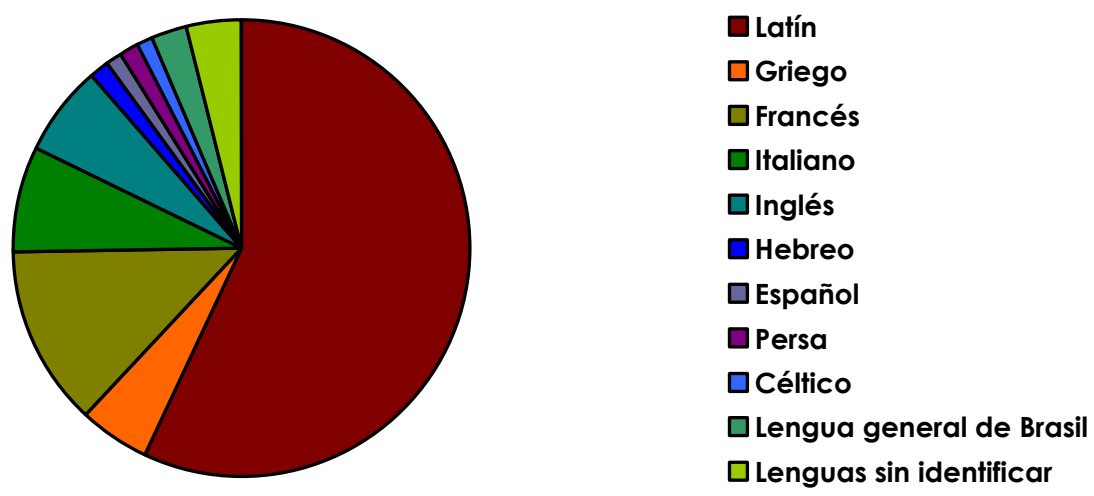

Gráfico 8.1 Las fuentes lingüísticas del Epítome de Moraes

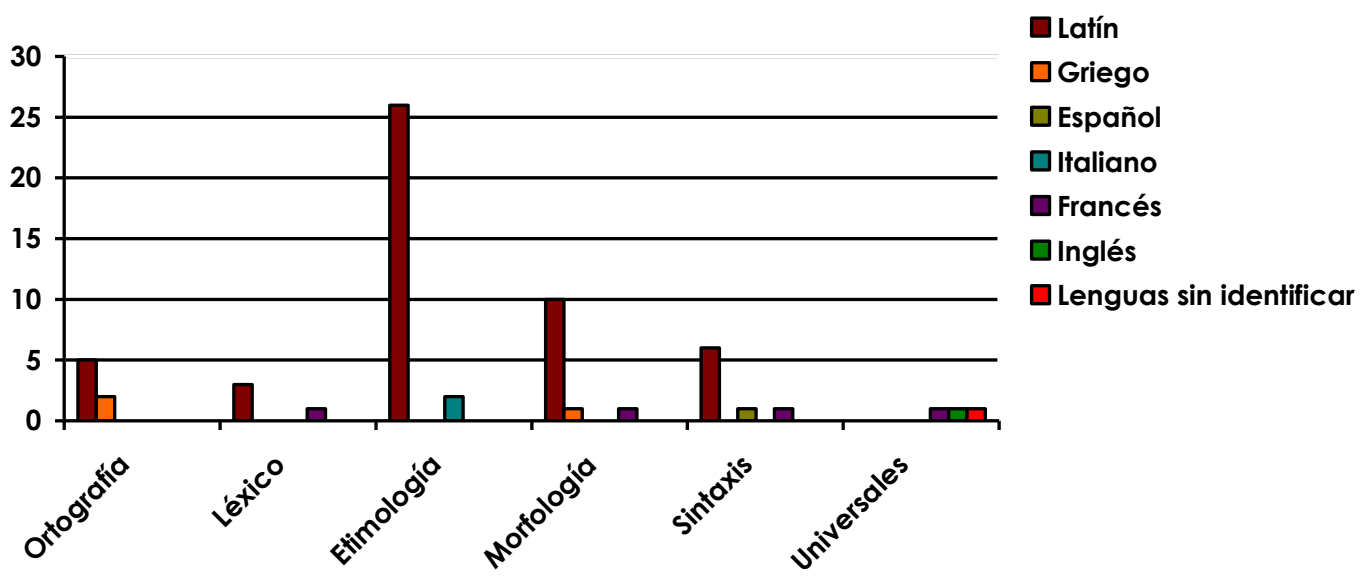

Gráfico 8.2 El dominio de los contrastes en el Epítome de Moraes

En resumen, Moraes Silva aplica a su obra una metodología contrastiva basada fundamentalmente en las comparaciones entre el portugués y el latín. Sin embargo, este recurso no convierte al Epítome en un tratado en el que predomine propiamente un discurso apologético, pues estas comparaciones no persiguen la defensa de la superioridad del portugués por su proximidad al latín, como era habitual en la tradición renacentista. El contraste interlingüístico que practica 
Moraes se limita simplemente a determinar la presencia (o ausencia) del latín en el portugués.

Este aspecto de la metodología contrastiva de Moraes, salvo diferencias muy puntuales, se identifica con las estrategias de descripción lingüística de los gramáticos portugueses del siglo XVII. De hecho, es comparable, por ejemplo, con los procedimientos empleados por Amaro de Roboredo (1619) en el Methodo grammatical para todas as linguas. Sobre las «diversas estratégias de descrição da língua» empleadas por este último autor y señaladas por Fonseca (2004: 94-97) destacamos las siguientes:

1) A descrição gramatical contrastiva, privilegiando o latim, mas intentando o gramático ampliá-la às línguas modernas.

[...] Só o português e o latim (esporadicamente, também o grego e o hebraico, línguas clássicas, em todo caso) servem de referência para esta gramática geral [en el caso de Epítome léase racionalista] e para o esboço do comparativismo que ela sugere?.

2) A observação de dois níveis de descrição gramatical, particular e geral/ universal.

[...] Trata-se, portanto, de uma exposição de características universais das línguas vulgares [para Moraes, particularmente del portugués], feita a partir da observação contrastiva com o latim (Fonseca 2004: 95-96).

El autor afirma también que la lengua portuguesa guarda cierta semejanza ya sea en el vocabulario o en alguna estructura sintáctica con el inglés y el italiano.

\footnotetext{
7 Talvez tenha sido esta autoridade do latim, enquanto modelo de organização de todas as línguas, que esteve na base do racionalismo gramatical, conforme nota Lia Formigari: "It is perhaps worth noting that all the great Renaissance grammars claiming to be investigations of the 'causes', i.e. of the intrinsic rationality and consistency of languages (such as Scaliger's De causis linguae latinae and Sanctius' Minerva) were in fact Latin grammars. Only by virtue of this self-imposed limit, could Scaliger, for instance, claim the title of science for his grammar" (1988:46) [nota de la autora]. Con bastante anterioridad, Yllera (1983) en su estudio sobre "lla gramática racional castellana en el siglo XVII: la herencia del Brocense en España» ya había destacado la presencia de estos rasgos en la Minerva y en la GGR.
} 
Aunque muy ocasionalmente, también resalta algunos aspectos del portugués con respecto a las lenguas asiáticas y amerindias.

Por último, la influencia del racionalismo en el método contrastivo de Moraes se manifiesta en las comparaciones entre el portugués y el francés, pero estas referencias no son tan representativas y frecuentes como las que establece con el latín. Cabe apuntar que predominan las características racionalistas en la metodología contrastiva de nuestro gramático, pues compara la lengua portuguesa con la latina con la finalidad de resaltar las semejanzas, las diferencias ("carencias», por lo general) y el origen de algunas formaciones sintácticas o léxicas, pero sin la intención apologética que animaba las obras renacentistas.

\subsection{Aplicación de procedimientos contrastivos en la Gramática de Augusto Freire}

Las gramáticas brasileñas publicadas en el último cuarto del siglo XIX, como se ha estudiado en los capítulos anteriores, muestran la influencia de diferentes orientaciones lingüísticas (la histórica y comparada y la positivista), pero al mismo tiempo también persiguen la descripción de la lengua contemporánea. Estos principios metodológicos 8 no solo han guiado, en mayor o menor medida, la aplicación de procedimientos contrastivos en la codificación del portugués, sino que además han determinado sus objetivos y características.

8 Debido a la profundidad y extensión del tema (véase Robins 1967, Koerner 1989, Černý 1998 y Auroux 2000), se expresa aquí solamente (y con mucha brevedad) aquellos criterios de la gramática histórica y comparada que nuestros autores parecen tener en cuenta (implícita o explícitamente) en sus procedimientos contrastivos:

1) La creencia en el parentesco de las lenguas.

2) El análisis y comparaciones morfológicas y fonéticas que determinen las afinidades entre las lenguas (F. Bopp [1791-1867], J. Grimm [1785-1863], F. Diez [1794-1876]).

3) La división de las lenguas en familias emparentadas genéticamente. 
En este sentido, el método contrastivo de las gramáticas brasileñas finiseculares trata de determinar el origen y las influencias que el vocabulario y las formas sintácticas portuguesas han recibido de otras lenguas. En general, este método se orienta hacia varios propósitos, entre los que se incluyen:

1) La comprobación de la doctrina heredada sobre la formación del portugués.

2) La identificación de los elementos gramaticales portugueses que provienen de préstamos lingüísticos.

3) El estudio de desarrollos paralelos en varias lenguas.

4) El reconocimiento de las diferencias entre los universales románicos y las propiedades particulares de cada idioma, especialmente del portugués brasileño?.

La Grammatica Portugueza de Augusto Freire constituye uno de los primeros manuales de la tradición brasileña en donde se introduce esta nueva perspectiva histórica ${ }^{10}$, lo que explica el considerable incremento del estudio etimológico, pues «O programa histórico-comparativo assentava também na reconstrução etimológica» (Gonçalves 2004: 46). Otra aportación significativa de esta obra consiste en el desarrollo del estudio comparado del portugués con las demás lenguas románicas. Este tipo de análisis alcanza una mayor amplitud con respecto

\footnotetext{
9 Leonor Lopes Fávero, en su más reciente publicación titulada «O discurso do poder em gramáticas da Língua Portuguesa dos séculos XVI a XIX») señala la postura vanguardista de Augusto Freire al reconocer en su gramática algunas características del portugués brasileño (Fávero 2010: 221).

10 Ricardo Cavaliere (2010) hace hincapié en el carácter innovador de obras anteriores a la de Freire, como la Grammatica Analytica de Charles Olivier Grivet (1865) y del Origem e filiação da lingua portugueza de Ernesto Carneiro Ribeiro (1871). Para el autor, estos textos constituyen «exemplo[s] da transição do "modelo racionalista" para o "modelo científico" que vem a implantar-se nas últimas décadas do século» (Cavaliere 2010: 115), pero no evoca la contribución de Augusto Freire que, como bien señala Fávero y Molina (2006) se muestra uinnovador ao adotar certos princípios da corrente histórico-comparativa») (Fávero y Molina 2006: 110).
} 
a la tradición anterior, limitada casi siempre a unos pocos fenómenos de contraste con el francés y el latín.

Pues bien, el estudio contrastivo de la Grammatica de Freire comprende, entre otros aspectos, los siguientes:

1) Descripción de los principales universales románicos.

2) Comparación entre las lenguas antiguas y las lenguas modernas.

3) Análisis de la evolución autóctona de las lenguas románicas.

4) Estudio de la influencia de otras lenguas en el portugués.

5) Desarrollo de un minucioso estudio etimológico del portugués.

La obra de Freire se caracteriza, en primer lugar, por el interés del autor en determinar con más seguridad que los gramáticos anteriores el origen de las palabras portuguesas. A pesar de mostrarse de acuerdo con que la variedad del vocabulario portugués se debe a la influencia tanto de las lenguas antiguas y románicas como de las lenguas exóticas, el autor reconoce que la principal dificultad para determinar el origen de las raíces del portugués es precisamente la variedad de lenguas que han formado su vocabulario:

Nas linguas modernas, analyticas, é de pouca importancia o estudo das raízes e fórmas thematicas, ao envez das linguas syntheticas, como o sanskrito, o grego e o latim.

No portuguez, em consequencia dos varios elementos historicos (latino, grego, céltico, germanico, phenicio, arabe, hebraico, africano, tupi, etc.) é difficil a determinação sincera e criteriosa de todas as raizes, e ás vezes por ventura impossivel. Só se podem determinar com segurança as gregas, as latinas, as germanicas e algumas celticas (Freire 1894[1875]: 115).

A pesar de reconocer la diversidad lingüística a la que la lengua portuguesa estuvo expuesta, el gramático privilegia las comparaciones con el latín y con algunas lenguas románicas. En este sentido, las observaciones de Freire se orientan 
hacia dos propósitos básicos. Por una parte, el autor trata de explicar el origen del léxico y de algunas estructuras sintácticas del portugués y, por otra, se ocupa de la comparación del uso de los elementos gramaticales en las lenguas románicas.

El método contrastivo de Freire también tiene en cuenta la comparación entre las lenguas antiguas y modernas, entre el portugués y las lenguas latina, francesa y española y, por último, entre el portugués de Brasil y el de Portugal.

En cuanto al contraste entre las lenguas antiguas y modernas, el autor incluye en su tratado los siguientes aspectos:

1) Análisis de los rasgos fonéticos y prosódicos que diferencian el griego y el latín de las demás lenguas románicas.

2) Determinación de las clases de palabras sin precedentes en lenguas clásicas, como el artículo.

3) Comparación entre estructuras gramaticales propias de las lenguas antiguas y sus equivalentes en las lenguas modernas.

La corriente historicista constituye una de las bases teóricas de la obra de Freire (véase § 5.2) que explica el interés del autor por la descripción del proceso evolutivo de determinadas características latinas en las diferentes lenguas románicas. En este sentido, la obra contiene algunas referencias al desarrollo de los rasgos fonéticos en las lenguas románicas. Así, por ejemplo, el autor explica la posición del acento portugués en contraste con otras lenguas (español, italiano, francés, inglés) 11 :

O lugar que o accento Tonico occupa nas palavras, varia de uma lingua para outra, e muitas vezes na linguagem familiar, de uma cidade para outra. Em nossa lingua, como na hespanhola e na italiana, ha tendencia manifesta

\footnotetext{
11 Augusto Freire explica que "são congêneres do português e, portanto, elementos naturais de comparação o italiano, o espanhol, o francês, o provençal e o valáquio, línguas romanas ou novolatinas») (Fávero y Molina 2006: 107).
} 
para collocar o accento phonetico na penúltima syllaba; dahi o possuirem estes idiomas maior numero de palavras graves que de exdruxulas e agudas. Esta tendencia, já manifesta na linguagem dos romanos, tem modificado a prosodia de muitas palavras.

Em latim, nos dissyllabos, o accento tonico está sempre na primeira syllaba; nos trissyllabos e polysyllabos, depende da quantidade da penúltima: si é longa, recae nella; si breve, na antepenúltima. Por analogia, os latinos accentuavam do mesmo modo os vocábulos que tomavam do grego ainda que outro fosse seu assento originario.

Em francez, cae o accento tonico na ultima syllaba, quando masculina ou sonora, mouton, cheval; e na penúltima, quando a ultima é feminino ou terminada por e mudo: aimable, lisible.

Na lingua ingleza, si se trata de dissyllabos, ha tendencia para accentua-los na penúltima; si de trisyllabos ou polyssyllabos, são elles em geral accentuados na antepenúltima, apezar de haver muitos vocabulos desta ultima especie como o accento na pre-antepenultima: territory, difficulty, e alguns que teem até na syllaba que precede a pre-antepenultima: preambulatory.

Em nossa lingua, não pode o accento vir na pre-antepenultima syllaba, salvo si por enclise, cujo caracter principal é atonisar vocabulos, se juntam variações dos pronomes a fórmas verbaes que sejam palavras graves: "Louvam-se-Ihes as virtudes" (Freire 1894[1877]: 48).

Los contrastes románicos que se ofrecen en la Grammatica Portugueza tienen como base el estudio de la fonética desde una perspectiva histórica. Así, el autor pone de relieve la influencia de fenómenos fonéticos en el proceso de formación de las lenguas románicas, como es el caso de la elisión y la apócope:

A assimilação apresenta um papel importante na formação das linguas romanas, principalmente por causa da elisão das vogaes atonas, que poz em contacto, em uma multidão de palavras, consoantes incompativeis (Freire 1894[1875]: 41).

[La apócope] É phenomeno caracteristico da formação das linguas romanas. (Freire 1894[1875]: 42).

Con respecto a la prosodia de las lenguas, el gramático pone de relieve que los rasgos fónicos propios del griego y del latín no subsistieron a los cambios 
lingüísticos, de modo que las lenguas modernas presentan una nueva pronunciación y acentuación:

No grego e no latim, linguas evidentemente musicaes, cuja verdadeira e exacta pronuncia hoje se ignora, era de summa importancia no perfeito conhecimento da quantidade de cada syllaba; mas, nas linguas modernas, cuja pronuncia é rápida, e passa como a correr pelas syllabas subordinadas, para accentuar fortemente a predominante, segundo se verifica no portuguez, e nos outros idiomas derivados do latim, é isso cousa de pouco momento (Freire 1894[1875]: 45-46).

La relevancia del estudio de Freire sobre los aspectos fonológicos de las lenguas románicas parece justificarse por el hecho de que la «escuela neogramática [...] [é] mais produtiva no campo da fonologia ou da fonética, excluindo a fisiologia dos sons, visto esta pertencer à fisiologia geral do homem, não à ciência da linguagem [...]» (Gonçalves 2004: 48).

A partir del contraste entre las lenguas clásicas y modernas, el gramático también pone de relieve los rasgos que las lenguas románicas no comparten con el latín. Para ilustrar esta oposición, Freire advierte claramente que el artículo constituye una clase de palabras propia de las lenguas románicas:

O artigo é uma forma nova e característica das linguas romanicas, cuja falta do latim classico causava não raro suas obscuridades, a despeito da opinião em contrario de Quintiliano (Freire 1894[1875]: 98).

Cabe señalar que, con tal observación, Freire se suma a los gramáticos brasileños del siglo XIX que habían reconocido este carácter románico del artículo. Sin embargo, interesa destacar que el autor fue uno de los primeros de su tradición en explicar que el artículo definido viene del demostrativo latino (ille, illa, illud): 
As fórmas $0, a$, os, as do artigo definido procedem de illum, illam, illos, illas, accusativos masculinos e femininos tanto do singular como do plural do adjectivo demonstrativo latino ille, illa,illud (Freire 1894[1875]: 205).

En cambio, Júlio Ribeiro (1881) afirmaría después que el artículo definido portugués procede de otro tipo de demostrativo latino (hic, haec, hoc):

289. $O$ artigo definido portuguez, cujas fómas flexionaes ou melhor variantes são 0 , a, os, as, deriva-se de hoc, hac, hos, has, fórmas do ablativo singular e do accusativo plural (270) do demonstrativo latino Hic, haec, hoc (Ribeiro 1881: 162163).

Las gramáticas brasileñas publicadas posteriormente demuestran que la etimología del artículo propuesta por Ribeiro no tuvo seguidores, mientras que la de Freire, por influencia propia o de sus fuentes, fue la que repercutió en los manuales finiseculares, como los de Alfredo Gomes (1887) y João Ribeiro (1887):

1. Os artigos portuguezes são dous: o e um.

2. O deriva de ILLUM, a de ILLAM, os de ILLOS, as de ILLAS pela deslocação do accento tonico da primeira syllaba para a segunda, facto observado nos comicos latinos, e pela suppressão dessa primeira syllaba por se ter tornado atona (Alfredo Gomes 1913[1887]: 222).

O artigo definito o, a deriva do accusatino latino illum, illam. dedit illam — deu-a (João Ribeiro 1889[1887]: 186).

En la primera mitad del siglo XIX, algunos autores portugueses, como Solano Constancio (1831) y P. José de Figueiredo (1827), defendían el origen griego del artículo definido, en el caso del portugués, y el latino para las demás lenguas románicas (español, francés e italiano):

A mim parece-me que o nosso artigo o foi tirado do grego ó, e o a de á. No castelhano el, la, no italiano lo, la, no francez le, la são ao meu ver o pronome 
ille, illa modificador e abreviador, e he certo que no latim corrupto das Gallias e da Hespanha se dizia ille sol, illa luna em vez de sol e luna. Os nossos escriptores antigos escrevião ho homem, ha mulher, e este $h$ me parece confirmar a minha conjectura, pois corresponde a aspiração branda do grego ó (Solano Constancio 1831: 56-57).

Tomou a lingua portugueza o articulo da grega, e esta parece o tomou da hebrea, como primeira e quazi mãi de todas as outras, senão é que desta lhe veio immediatamente por trato, e comunicação [...] (Figueiredo 1827: 116).

El último aspecto sobre el contraste entre las lenguas antiguas y modernas analizado por el autor se refiere al estudio de las estructuras gramaticales propias de las lenguas antiguas y sus equivalentes en las lenguas modernas. Siguiendo la tradición más generalizada, Augusto Freire también señala algunas propiedades de las lenguas clásicas, como los casos, que se conservan en ciertas lenguas modernas, como el alemán, pero fueron sustituidos por preposiciones en latín vulgar y estas mismas marcas de función sintáctica adoptaron las lenguas románicas:

Entre os gregos e os romanos, a terminação dos nomes variava tambem, para mostrar a funcção que desempenham na phrase. [...] Estas terminações chamam-se casos (do latim casus, queda). Assim entendidos, são os casos uma propriedade commum a quase todas as linguas antigas, e a muitas das modernas, da família aryana, como o allemão e as linguas slavas. Elles porem desapparecem das linguas romanicas, assim como do inglez, em que se conhece apenas uma especie de genitivo assignalado pela addição de um s ao radical do nome; e isto por effeito da tendencia analytica, já intensa no latim bárbaro, a qual foi substituindo as flexões dos casos pelo uso multiplicado de preposições (Freire 1894[1875]: 115).

Sobre la relación entre el portugués y el latín, Augusto Freire dedica su estudio a las características fonéticas compartidas por estas dos lenguas, en especial, a la conservación del acento tónico: 
No portuguez, como nas linguas suas congeneres, conservam as palavras o accento tonico na mesma syllaba das palavras latinas de que veem: anjo Ângelo de ângelus; e isto porque as syllabas fracamente articuladas ou pouco accentuadas estão mais expostas a perder-se que as que se pronunciam com um tom mais elevado.

Este facto da persistencia do accento latino, que constitue uma lei geral e absoluta, é de summa importancia, por sua influencia, na formação da lingua portugueza, de cujo estudo é o fio conductor (Freire 1894[1875]: 46).

Em latim, tinham os polysyllabos um accento secundario. Em portuguez, só em vocabulos, compostos por juxtaposição, como passatempo, intencionalmente, é elle notado (Freire 1894[1875]: 50).

El autor también recurre a los contrastes entre el portugués y el latín cuando se trata de determinar la procedencia de ciertas formas gramaticales, como las irregularidades relativas a la conjugación de los verbos terminados en zer y zir, y la formación del plural de los sustantivos:

As fórmas dos verbos acabados em zer, zir, devem todas escrever-se com a lettra $z$, e bem assim as dos da primeira conjugação, que se derivam de verbos latinos que a teem no thema: baptizar de baptizare. Assim tambiem a desinencia eza, exceptuada a dos nomes de origem latina, que pedem s: mesa de mensa (Freire 1894[1875]: 81).

O s é a característica do plural, desde a origem da lingua; e representa o plural do accusativo latino, caso que o portuguez mais tomou para typo geral dos substantivos, e que termina em s nas cinco declinações latinas, com excepção apenas dos nomes neutros (Freire 1894[1875]: 126).

Taes nomes [sustantivos que forman el plural con es] procedem em grande parte de nomes latinos da terceira declinação, de cujo accusativo conservam a desinencia intacta (Freire 1894[1875]: 128).

Las citas mencionadas muestran que Augusto Freire recurre a la etimología latina, por un lado, para justificar el empleo de determinadas reglas gramaticales 
del portugués y, por otro lado, para explicar aquellos casos en que la regla no debe ser aplicada. El gramático sigue un procedimiento semejante al describir algunos usos participios latinos en portugués:

Salta aos olhos a procedencia desta doutrina, attendendo-se á traducção latina dos exemplos supra mencionados: "Albani, regnante Tullo, a romanis victi sunt". "Milites, spolia gerentes, clamabant: 'vae victis!'” (Freire 1894[1875]: 146).

Dos participios futuros latinos em tus e dus (moriturus, $a$, um; educandus, $a$, um) são vestígios alguns substantivos e adjectivos em ouro e ando, que indicam ainda uma acção futura, como ancoradouro, lavadouro; duradouro, vindouro: examinando, doutorando; nefando, venerando (Freire 1894[1875]: 147).

Paralelamente a la relación entre el portugués y el latín, Freire alude a las diferencias con respecto a las lenguas románicas. El autor utiliza el contraste con el francés para apoyar su teoría acerca de los pronombres portugueses. En esta línea, afirma que el portugués cuenta solamente con un tipo de pronombre, el personal, pues el uso y la definición de esta clase de palabras no admite otras categorías, a diferencia del francés:

Noutras linguas, é que há pronomes demonstrativos, possessivos, etc., como na franceza, onde estão sempre pelo nome as fórmas celui, celle, ceux, celles; Le mien, la mienne, les miens, les miennes; etc., ou cuja índole repelle o uso dellas acompanhadas do nome (Freire 1894[1875]: 94).

En el estudio de los aspectos sintácticos, Freire manifiesta su desacuerdo con relación a la controvertida teoría vigente sobre la correspondencia del pronombre se con el pronombre francés on. Según el gramático, la función del pronombre indefinido portugués se fundamentaba en la siguiente afirmación: "O pronome indefinido se é sempre a expressão litteral do pronome indefinido francez on" (Freire 1894[1875]: 306). Sin embargo, para cuestionar la teoría hasta entonces vigente el gramático contrasta el proceso de evolución de las partículas se y on: 
Ligeiro confronto destas duas palavras basta para fazer convencer da palmar differença que entre ellas ha.

$1^{\circ} \mathrm{O}$ pronome indefinido francez on, que, no século $12^{\circ}$, tinha por graphia om, e, em tempos mais remotos, hom, nada mais é do que o nominativo do singular do substantivo latino homo, e significa propriamente un homme: "On lui amène son destrier." isto é "Un homme lui amène son destrier." Entretanto o pronome indefinido se vem do caso obliquo se do pronome latino sui, sibi, se.

Ha em portuguez o vacabulo hom ou homem, tomado em sentido indefinido, e usado sem artigo, que corresponde exactamente ao on francez, e cujo emprego foi pouco a pouco caindo em desuso: "Cá sem razom seria ao afflicto accrescentar hom afflicção. (D. Duarte)." Grão trabalho e custosa cousa é fazer homem o que deve (Souza)."

O on francez pois não tem actualmente equivalente directo em portuguez (Freire 1894[1875]: 306-307).

Además de las comparaciones con el latín y el francés, Freire también destaca la influencia de la lengua española. Sin embargo, el autor observa solamente dos prácticas ortográficas del español que sirven de modelo al portugués escrito, si bien la primera de estas observaciones se refiere a la lengua poética:

Modernamente, alguns bons poetas usam, á imitação dos hespanhoes, da lettra minúscula no principio do verso, quando o antecedente não termina por ponto final, de interrogação e de admiração (Freire 1894[1875]: 77).

Alguns á imitação dos hespanhoes, põem o ponto de interrogação e o de admiração antes da phrase, voltados de cima para baixo ( $\dot{z}$ ?), afim de advertir - leitor da interrogação ou admiração; mas esta prática não é geralmente seguida, com quanto recommendada por Jeronymo Soares Barboza, como acertada, quando a phrase interrogativa ou exclamantiva é algum tanto comprida, para se poder abranger toda a uma vista de olhos (Freire 1894[1875]: 440).

La metodología contrastiva de Freire también se extiende al estudio de las diferencias entre el portugués hablado en Brasil y en Portugal. El gramático 
desarrolla un tratado minucioso sobre los fenómenos que favorecieron las modificaciones en la pronunciación y la acentuación de los vocablos del portugués brasileño como el clima, los cambios sociales, la cultura literaria, entre otros aspectos (Freire 1894[1875]: 51-57):

A pronuncia, como tudo quanto existe, está sujeita á lei fatal da transformação. Ha de por isso variar continua y lentamente, por virtude da influencia que nella exercem o clima, os cataclysmos sociaes e o grau de cultura litteraria.

[...] O portuguez falado no Brazil apresenta innumeras differenças do que se maneja em Portugal; o do Rio de Janeiro, do do interior de S. Paulo, bem como este do Ceará ou das Alagoas. O mesmo se dá com muitas localidades dos estados, cujos modos de pronunciar diversificam dos das capitaes (Freire 1894[1875]: 51 [la negrita es mía]).

Aunque el criterio contrastivo se limita básicamente a la prosodia, el estudio que Freire presenta constituye un argumento a favor de la diferenciación entre el portugués americano y el europeo, pero también representa el comienzo de la consideración del portugués como lengua nacional de Brasil, pues se asume una norma culta que es capaz de identificarse con la unidad lingüística brasileña. En contraste con la norma, también se identifican las variedades lingüísticas en el contexto nacional, relacionadas solo con las comunidades brasileñas sin interferencias con la variación de la lengua en Portugal12 (véase $\S$ 5.2.2).

12 Este asunto ha sido estudiado desde el punto de vista histórico y sociolingüístico en algunas universidades brasileñas por diversos grupos de investigación. Se puede citar, por ejemplo, el proyecto «Enciclopédia das Línguas no Brasil» iniciado en 2003 en la Universidade Estadual de Campinas (UNICAMP) y coordinado por el profesor Eduardo Guimarães (www.labeurb.unicamp.br/elb última consulta 24 de abril de 2011). Estos investigadores concluyen que «A língua praticada nesse outro lado do Atlântico realiza de outra maneira a relação unidade/variedade. A unidade aqui não refere mais o português do Brasil ao de Portugal, mas à unidade e variedades existentes aqui mesmo no Brasil. [...] Há um giro no regime de universalidade da língua portuguesa que passa a ter sua referência no Brasil. Nessas condições, a variação não tem como referência Portugal, pois a diversidade concreta é produzida aqui mesmo no Brasil, na convivência [e] contato de povos de línguas diferentes [...]. Pela sua gramatização, o português no Brasil instala seu direito à universalidade, garantindo a unidade (imaginária) constitutiva de qualquer identidade. Paralelamente tem seus usos variados. Uma vez 
A propósito de los universales románicos, la Gramática de Freire, comparada con las obras anteriores, presenta un sensible incremento de la descripción de los aspectos fonéticos, morfológicos y sintácticos comunes a las lenguas derivadas del latín. En realidad, este desarrollo se debe al carácter más exhaustivo del tratamiento, pues los temas estudiados (el género, los casos latinos el artículo o algunas etimologías) apenas cambiaron con el paso de los años, como se puede observar en algunas de las citas anteriores y en la siguiente:

O genero neutro latino, já a obliterar-se sob o Imperio, perdeu-se nas linguas romanicas (Freire 1894[1875]: 121).

Paralelamente al estudio de los universales románicos, Augusto Freire se muestra partidario de la aplicación de algunos principios característicos de la gramática general, pues reitera, de acuerdo con la hipótesis racionalista, que ciertos fenómenos lingüísticos pueden afectar a la mayoría de las lenguas. Así pues, el autor también sigue el procedimiento contrastivo para reforzar los postulados racionalistas, como en el caso de la teoría del juicio afirmativo:

Todo o juizo é affirmativo. O seu enunciado ou a proposição é que pode tomar a forma negativa. Em inglez prova-se isto materialmente, por ser da índole dessa lingua estar sempre a negativa imediatamente junta do attributo, modificando-o: "the hat is not large" (Freire 1894[1875]: 103).

El recurso a los contrastes románicos para explicar reglas y usos de la lengua portuguesa es, quizá, una de las aportaciones más novedosas de la metodología de Freire. Esta característica del gramático se muestra, por ejemplo, en el empleo

conquistado seu direito à unidade, reconhece suas variedades [...] que the dão identidade para dentro e para fora» (Eni P. Orlandi www.labeurb.unicamp.br/elb/portugues/lingua brasileira.html). Desde nuestro punto de vista, el panorama descrito por Orlandi se corresponde con el periodo en que se inscribe la obra de Freire, pues en la Grammatica nuestro autor ya da muestras del influjo de este nuevo paradigma. 
de los contrastes románicos para legitimar un uso exclusivo del portugués, como el infinitivo personal en la proposición subordinada:

Com o fim de corroborar a doutrina exarada nesta regra 13, adduzimos os seguintes exemplos extrahidos de clássicos latinos: "sperare nos amici jubent" (Cicero). - Nossos amigos nos mandam esperar, isto é, mandam que nós esperemos". "Jubete istos foras exire (Terencio). - Mandae-os sair, isto é, que elles sáiam". "Lex peregrinim vetat ascendere in... (Cicero). - A lei prohibe subir o estrangeiro a..., isto é, que o estrangeiro suba a...".

Em razão de, em portuguez, não terem casos os substantivos, envolve sua difficuldade o saber quando tem o sujeito força de accusativo, si é elle como no terceiro exemplo, um substantivo. Solve-se porem essa dificuldade pelo processo da substituição (Freire 1894[1875]: 364).

En cuanto a su estudio etimológico (Freire 1894[1875]: 193-276, véase también § 5.2.4), Augusto Freire identifica la presencia de otras fuentes lingüísticas además de las lenguas clásicas y románicas en el vocabulario portugués. Nuestro gramático ofrece una lista de las palabras portuguesas derivadas de las lenguas amerindias, africanas, asiáticas, árabes y de otros idiomas europeos, como el euskera, el eslavo, el húngaro, entre otros:

Entre os vacabulos portuguezes, a que se tem com mais verosimilhança attribuido a uma origem euskara, citaremos: aba, abarca, balsa, bezerro, bizarro, charco, charro, griseta, esquerdo, mandrido, morro, sarrazina (Freire 1894[1875]: 232).

O dominio árabe, deixou, em cerca de trezentas palavras da nossa lingua, vestigios bem evidentes da sua influencia. Esses termos referem-se em geral á vida physica, aos usos domesticos, ás instituições civis, políticas e militares, á construcção, á philosophia, á medicina e ás sciencias naturaes (Freire 1894[1875]: 234).

\footnotetext{
${ }^{13}$ El autor se refiere a "quando [a proposição], sendo infinitiva pura, e servindo de complemento objectivo, constitue um latinismo, isto é, tem o seu sujeito força do accusativo, sujeito da oração infinitivo-latina») (Freire 1894[1875]: 364).
} 
São em grande numero os elementos herdados da lingua tupi [...]. No reino vegetal, este elemento tornou muito opulento o nosso vocabulario [...]. Por virtude deste elemento não é menos rico o nosso lexico, no que diz respeito a zoologia [...]. Tambem e consideravel o numero de nomes locaes que nos legaram os primeros habitadores do Brazil [...] (Freire 1894[1875]: 236-237).

Algumas palavras desta origem [africana] foram introduzidas no portuguez indirectamente pelos arabes até o seculo $14^{\circ}[\ldots]$; outras vieram directamente pelo commercio e trato entre portuguezes e africanos no seculo $15^{\circ}$ e no $16^{\circ}$ [...]; outras finalmente se immiscuiram no Brazil depois do seculo $17^{\circ}$ (Freire 1894[1875]: 237).

Alem dos elementos que nos vieram pelos conquistadores musulmanos da peninsula, temos recebido, desde a idade media, um numero assaz importante de termos das diversas linguas asiaticas, quer pela litteratura, quer pelo commercio (Freire 1894[1875]: 237).

Asimismo, en diversas ocasiones, nuestro gramático señala que el léxico de otras lenguas llega al portugués por medio de la influencia directa o bien a través del latín y del francés, como se describe en el caso del céltico:

Os elementos célticos do portuguez como das outras linguas romanicas, dividem-se em cinco classes:

1) Um certo numero de palavras [...] nos vieram dos dialectos célticos modernos.

2) Algumas palavras [...] são tiradas do latim antigo.

3) Algumas palavras [...] nos ministram os escriptores gregos ou romanos.

4) Algumas palavras [...] explicam-se por um radical celtico.

5) Do francez (Freire 1894[1875]: 232).

En este sentido, cabe destacar, por último, el reconocimiento de Freire de la profunda influencia del francés, no solamente en el léxico sino también en la sintaxis y en la semántica del portugués, además de aludir a su papel como lengua intermediaria del influjo de otras lenguas en el portugués: 
O elemento francez é sem contestação nos últimos tempos o maior factor barbaro da grammatica e do vocabulario. Por influencia do francez, o português é hoje mais analytico do que nos tempos classicos; a phrase vernacula vae perdendo o habito das inversões; os vocábulos teem soffrido continuamente modificações de sentido. Por virtude ainda dessa influencia, é que importamos, por meio delle, neologismos inglezes, allemães e até italianos (Freire 1894[1875]: 236 [la negrita es mía]).

Finalmente, se ilustra en los gráficos siguientes la incidencia de cada lengua extranjera en el total de las referencias a otras fuentes lingüísticas en la Gramática de Freire y los temas gramaticales a que se refiere:


Gráfico 8.3 Las fuentes lingüísticas en la obra de Freire 


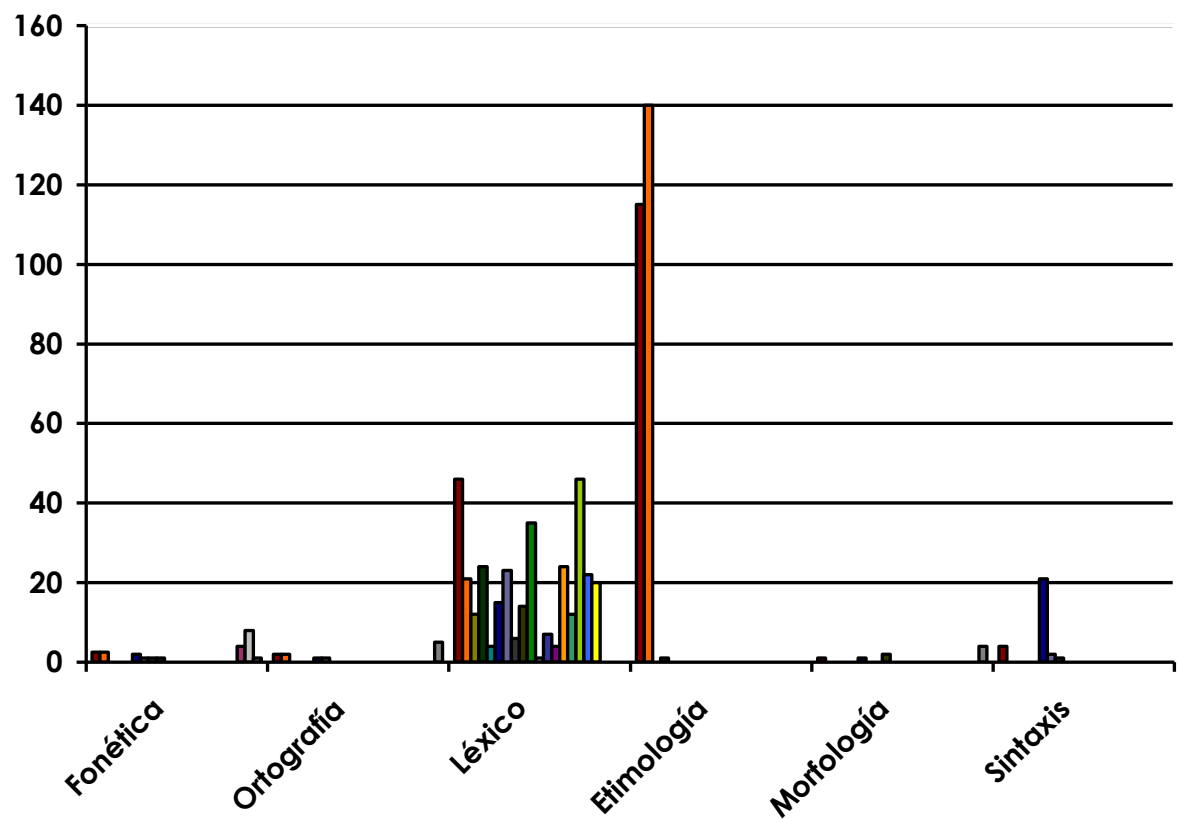

Latín

$\square$ Griego

$\square$ hebreo

$\square$ Árabe

$\square$ Fenicio

Francés

DEspañol

Italiano

口Inglés

$\square$ Alemán

$\square$ Provenzal

$\square$ Eslavo

$\square$ Húngaro

$\square$ Celta

$\square$ Euskera

口Tupí

$\square$ Lenguas africanas

$\square$ Lenguas asiáticas

$\square$ Brasil

$\square$ Portugal

$\square$ Lenguas rómanicas

Gráfico 8.4 El dominio de los contrastes en Freire

En resumen, el método contrastivo de Augusto Freire aporta considerables innovaciones a la gramaticografía brasileña decimonónica. Los aspectos contrastivos más relevantes que todavía no habían sido estudiados por los gramáticos de su tradición son fundamentalmente los siguientes:

1) La comparación entre las lenguas antiguas y modernas.

2) El tratamiento de los universales románicos.

3) El contraste entre el portugués americano y el europeo, especialmente en cuanto a los rasgos fonéticos.

4) El estudio detallado de la constitución del léxico portugués.

5) El incremento de la etimología.

El desarrollo de los contrastes románicos en la Grammatica Portugueza no solo pone de manifiesto la influencia de la corriente histórica y comparada sino que 
también se hace eco de las doctrinas de F. Diez (al que cita explícitamente) y de Adolfo Coelho (1868). Estas fuentes primarias se muestran particularmente presentes en el estudio etimológico que, del mismo modo que Coelho, se asienta uno encadeamento histórico, nas analogias e paralelos que permitem estabelecer filiações» (Gonçalves 2004: 45).

Por otro lado, siguiendo la tradición más generalizada, nuestro gramático desarrolla las comparaciones entre el portugués, el latín y el francés para precisar el origen y evolución del léxico, de las estructuras sintácticas y de las funciones gramaticales del portugués, pero también para reforzar los principios racionalistas que aun se aplican a la descripción de ciertos aspectos gramaticales.

\subsection{Alcance del método contrastivo de Júlio Ribeiro}

Después de la obra de Freire, la Grammatica Portugueza de Júlio Ribeiro constituye la segunda gramática de la tradición brasileña que estudia los contrastes románicos en el proceso de codificación del portugués desde un enfoque historicista. A pesar de no ser el primer autor que se inscribe en esta corriente, no hay duda de que Júlio Ribeiro es el más reconocido en su tradición por registrar explícitamente en su tratado las fuentes teóricas y las bases historicistas de su doctrina (Fávero y Molina 2006: 125-135).

Aunque la Grammatica de Ribeiro presenta significativos avances metodológicos en comparación con la de Freire, se propone aquí clasificar las dos obras en la misma fase de conciliación entre el historicismo, la tradición y la finalidad normativa. En efecto, los dos autores fundamentan el análisis en las mismas corrientes gramaticales $y$, consecuentemente, sus métodos contrastivos comparten características comunes como las siguientes: 
1) El estudio detallado sobre el origen y la evolución del vocabulario, de las estructuras sintácticas y de las funciones gramaticales del portugués.

2) El privilegio de las comparaciones entre el portugués, el latín y el francés.

3) La preocupación por la etimología.

Pues bien, la metodología contrastiva de Ribeiro toma en consideración el contraste entre el portugués y otras lenguas románicas, sobre todo el francés y el español; entre las lenguas románicas entre sí y entre el portugués brasileño y las lenguas románicas, con especial atención al español. Pero también se aplica con frecuencia al análisis de las relaciones etimológicas entre el portugués y las lenguas clásicas, particularmente el latín. Asimismo, el estudio de Ribeiro pretende consolidar algunos universales y contrastes románicos, reformular otros principios relativos a este tema defendidos por los gramáticos anteriores ${ }^{14} \mathrm{y}$ ampliar el estudio de las comparaciones hacia las variantes regionales del portugués brasileño, en lugar de limitarse a los contrastes con el portugués en general.

En la Grammatica de Ribeiro se analiza la influencia de las otras lenguas románicas en el portugués. La lengua objeto de contraste suele ser el francés, pero, en algunos casos, también es el español. Los temas más recurrentes en el análisis del autor son las diferencias en la grafía de los fonemas comunes a las dos lenguas, como /e/ y /o/, en la evolución de ciertos formantes derivativos procedentes del latín y en la semejanza de algunas construcciones, como se puede observar en las citas a continuación:

\footnotetext{
${ }^{14}$ La renovación gramatical que caracteriza la obra de Ribeiro en la tradición brasileña fue señalada por Coelho (2010) en su estudio sobre el metalenguaje y la descripción lingüística em la Grammatica Portugueza: "a postura adoptada por Ribeiro implica considerar uma revisão (aparentemente de carácter correctivo) de trabalhos anteriormente realizados, o que, por conseguinte, leva à (re)articulação de conceitos já amplamente conhecidos, mas pouco formalizados, sob a forma de definições efectivas» (Coelho 2010: 125).
} 
Em francez representa-se frequentemente e por ai, e o por au, ex.: «maison-vrai-auteur-chaud» (Ribeiro 1881: 6).

12) eiro: proveniente do suffixo latino arius, exprimindo a idéia de officio, ex.: "Carpinteiro (charpente, em Francez; [...]), ferreiro, padeiro, sapateiro» (Ribeiro 1881: 154).

Em Francez existe uma construcção analoga a esta [se refiere a casos del artículo indefinido como en «um como ninho - uma como nuvem»], com a differença, porém, de vir o artigo depois de comme, ex.: "IJ'aperçuz comme une forêt de mâts de vaisseauxı (Ribeiro 1881: 226).

A propósito de la influencia francesa, llama mucho la atención la nueva justificación de Ribeiro para la cuestión de las excepciones a las reglas del género. Según el autor, que en este punto no parece tener precedentes en la gramaticografía brasileña, el cambio del masculino en femenino de algunos nombres portugueses procedentes de masculinos latinos en -or se debe a la influencia anómala del francés en el proceso de evolución del género de los sustantivos:

Os substantivos latinos masculinos conservaram-se masculinos em Portuguez: assim Mundus, murus, filius deram Mundo, muro, filho. Os substantivos femininos portuguezes Cor, dor, flor vêm dos masculinos latinos Color, dolor, flos: esta anomalia é devida á influencia do Francez, em que só com tres excepções são femininos os substantivos de cousas inanimadas, derivadas de substantivos latinos masculinos em or. Na palavra Honra mudou-se o genero do radical Honor por influencia da terminação accidental feminina a (Ribeiro 1881: 148).

Esta afirmación muestra que para Ribeiro algunos galicismos del portugués permiten explicar formaciones antietimológicas, como en el caso del género, que tuvieron como resultado la corrupción de paradigmas latinos.

En cuanto al español, Ribeiro reconoce también su influencia especialmente en el portugués brasileño. El gramático señala que la presencia de sufijos españoles 
en la formación de sustantivos es frecuente en las fronteras con los países de habla hispana y que el uso de expresiones castellanas es común en algunos centros urbanos:

A) Suffixos que se junctam ao radical de substantivos:

1) aço: para nomes que exprimem percussão, golpe, ex.: «Lançaço, pistolaçol». Esta formação é muitissimo usada no Rio-Grande do Sul por influencia do Hespanhol das republicas limitrophes (Ribeiro 1881: 153).

Em Sorocaba, cidade da provincia de S. Paulo, que uma feira annual de bestas punha sempre em contacto com Orientaes e Correntinos, e onde a linguagem é ainda sensivelmente acastelhanada, tal locução é usadissima; ouve-se a cada passo: "Entre NO MAIS- Tire churrasco NO MAIS-Ensilhe NO MAIS o matungo» isto é "ENTRE, NÃO MAIS; entre sem cerimonia-Tire churrasco, NÃO MAIS;sem mais preambulos-Ensilhe o matungo, NÃO MAIS; nada mais tem a fazer sinão ensilhar o matungo». A existencia da locução no dialecto sorocabano só póde ser devida á influencia castelhana (Ribeiro 1881: 273).

Paralelamente, Ribeiro también presta atención a la influencia del español en determinadas construcciones sintácticas del portugués ${ }^{15}$. Este es el caso de la descripción que proporciona el autor sobre el acusativo preposicional. En su opinión, se emplea en las dos lenguas para evitar ambigüedad, aunque es más común en español:

463. Para evitar ambiguidade de sentido põe-se em relação adverbial o objecto de um verbo, quando esse objecto representa pessôa ou ser vivo em geral, ex.: "Cesar venceu a Pompeu—A mulher ama ao marido-O caçador matou ao leão». Esta regra, quasi de rigor na lingua hespanhola, não o é tanto em Portuguez: Camões escreveu «Quando Augusto o capitão venceu-Gente que segue o torpe Mafamede») (Ribeiro 1881: 230 [la negrita es mía]).

\footnotetext{
15 La influencia de la gramática española en la descripción de estas construcciones fue el objeto de estudio de Schäfer-Priess en el artículo titulado "Gramaticografia em contacto: as gramáticas portuguesas de Pedro José da Fonseca e Jerônimo Soares Barbosa e a Gramática de la Lengua Castellana da Real Academia Española de 1771\%.
} 
Además de las relaciones sintácticas entre el portugués y el español, la evolución de los tiempos verbales constituye otro aspecto importante en el estudio contrastivo de Ribeiro. Aunque el gramático reconoce que este desarrollo es un fenómeno característico de todas las lenguas románicas, la comparación entre formas verbales se limita fundamentalmente a las portuguesas y españolas con la finalidad de poner de manifiesto las diferencias en el proceso de evolución de estas dos lenguas:

Este tempo simples [futuro del subjuntivo], tanto no Portuguez como no Hespanhol é kharacteristico das transformações do verbo nas linguas romanicas, e, segundo Diez, provém do futuro perfeito latino. As fórmas hespanholas antigas aproximam este tempo da sua origem (podierol6potúerō) pela sua terminação em um o final: no Portuguez a falta de vogal na flexão approxima-o do infinito impessoal na primeira e na terceira pessôa do singular (Ribeiro 1881: 183).

Los contrastes relativos al comportamiento sintáctico de las lenguas románicas también son objeto de la atención del gramático. Ribeiro muestra algunas diferencias sintácticas para destacar una supuesta facilidad en el uso de ciertos elementos gramaticales de la lengua portuguesa comparada con las lenguas vecinas. Se observa esta intención en el estudio del participio concordado y del empleo de construcciones de tipo preposición + artículo tras conjunciones coordinantes:

A concordancia ou não concordancia deste participio auxiliar com o objecto do verbo é uma das grandes dificuldades da lingua franceza; o Italiano e o Hespanhol movem se mais livremente; o Portuguez emancipou-se de uma vez, e tornou invariavel o participio. Todavia, os antigos classicos o faziam

16 El autor se refiere a la forma del futuro del subjuntivo (amaro, podiero, fuero, etc.) propias del español antiguo hasta finales del siglo XIV (Menéndez Pidal 1944a. 1. 277 apud M. Lloyd 1987: 311). 
concordar, ex.: "Votos que em adversidades e doenças tinha FEITOS para remissão de quantas culpas tinham COMMETTIDAS-Porque sempre o achara bom servidor e leal e muito ditoso nos serviços que the tinha FEITOS. Ainda em Camões lê-se «E do Jordão a areia tinha VISTA» (Ribeiro 1881: 242).

A grammatica franceza, cujas leis a este respeito [se refiere a la omisión de la construcción preposición + artículo detrás de conjunción como en «Da Italia e da França ou Da Italia e França»)] são ferrenhas não nos póde servir aqui de modelo; o Italiano e o Provençal movem-se um pouco mais á vontade; só o Hespanhol gosa neste terreno da mesma liberdade que tem o Portuguez. A omissão ou a repetição do artigo depois de conjuncções subordina-se a regras especiaes já consignadas no logar competente (Ribeiro 1881: 272).

Paralelamente al análisis de las diferencias entre las lenguas románicas y el portugués, Ribeiro también describe algunas analogías entre estas lenguas. El autor presenta un estudio detallado de ciertos aspectos de la sintaxis portuguesa a partir de la observación del comportamiento de estructuras equivalentes en las lenguas románicas. Este es el caso, por ejemplo, de algunas explicaciones sobre usos del verbo fazer y haver en oraciones impersonales, la evolución del adverbio de lugar $\mid \mathrm{BI}>\mathrm{y}$, hi en las formas impersonales de haver y el empleo del subjuntivo o el infinitivo en las oraciones imperativas negativas:

Em Hespanhol e em Francez ha construcções identicas [se refiere al verbo fazer empleado en oraciones como «Faz annos que estou aqui-Faz mezes que nos vimos»], ex.: «Hace diez años-ll fait des éclairs». Gregorio de Tours escreveu em Latim: "Gravem hyemem facit». Si é authentica a passagem, e si a verdadeira lição não é "Gravis hyems fuit», como traz um unico manuscripto, este uso do verbo facere é antiquissimo (Ribeiro 1881: 255).

Em Italiano, Hespanhol, Francez e Provençal encontram-se construcções identicas [a «Ha homens-Ha fructas-Ha leis»], ex.: «Ha quindici giorni-Diez años ha- Il a des femmes-Non a tan fin aman cum mell. Ha a notar que em Francez moderno a construcção requer sempre o emprego do adverbio de logar y, e que em Italiano, Hespanhol, Provençal e Francez antigo ora apparece ella com um adverbio de logar, ora não. 
Em Portuguez antigo empregava-se tambem o adverbio, ex.: « Não ha hi quem me soccorra-Que geração tão dura ha hi de gente?. Hoje não é mais usado tal adverbio (Ribeiro 1881: 255).

Em Hespanhol é identica a construcção ["Não faças a outrem o que não quizeras que te fizessem a ti»]: «No firmes carta que no leas, ni bebas agua que no veas». Em Italiano substitue-se o imperativo pelo infinito presente: «Non ti scordar di me». Em Francez emprega-se só o imperativo: «Ne faites pas des folies». Em Latim usa-se quasi indifferentemente do imperativo ou do subjunctivo presente: «Ne concupisce ou ne concupiscas» (Ribeiro 1881: 239).

La sintaxis es la parte de la obra de Ribeiro que presenta el mayor número de comparaciones entre el portugués y las otras lenguas románicas. En general, las referencias muestran que la preocupación del gramático no consiste en describir la evolución de las estructuras sintácticas, sino más bien en ilustrar cómo los elementos comunes a las lenguas románicas se comportan en sus respectivas estructuras sintácticas y, consecuentemente, legitimar los usos sintácticos del portugués. Este es el caso de los ejemplos siguientes, que explican el empleo "pleonástico" de los pronombres, el uso del sujeto pronominal del infinitivo en acusativo y de la doble negación:

Estes processos pleonasticos, que contribuem muito para a clareza e elegancia da expressão, encontram-se em varias linguas romanicas, em Latim barbaro, em Latim classico, em Grego moderno, em velho Alto Allemão, em Inglez, em Dinamarquez, em Sueco. Diz-se, por exemplo, em Hespanhol: «Las ramas que [el] (sí, dice lo) peso de la nieve las desgaja-A mi hermano le parecel; em Latim barbaro: «psam civitatem restauramus eam»; em Latim classico: "Quem neque fides negue jusjurandum neque illum misericordia repressit» (Ribeiro 1881: 225-226).

Pronome, substantivo sujeito de um verbo no infinito dependente de um verbo no finito põe-se em relação objectiva, ex.: «Eu vi-o caminhar ás pressasDeixa-o inı. Esta syntaxe, commum a varias linguas romanicas, é tomada directamente do Latim, em o qual o sujeito do verbo no infinito vai para accusativo (Ribeiro 1881: 228). 


\begin{abstract}
O uso de palavras intensivas para negar com vehemencia era muito frequente em Latim: circum, granum, micam, passum, punctum, unguem e muitas [...]. Passum e punctum introduziram-se no Francez e sob as fórmas pas e point fazem hoje parte do fundo da lingua, ex.: "Je ne veux PAS-Je NE vais POINT». Em Gil Vicente lê-se «Triste pranto até Belem nem PASSO não se esquecia». Mica, miga, encontram-se no Italiano, ex.: "Ni mica trovo il mio ardente disio-Se sa miga». Gil Vicente usou em Portuguez do derivado migalha: «Não me presto ne migalha». A antiga palavra rem foi tambem muito usada, como intensiva, ex.: «Não valeu rem» (Ribeiro 1881: 262).
\end{abstract}

Aunque Freire había empleado este procedimiento contrastivo con anterioridad, puede afirmarse que esta es la primera vez en la tradición brasileña que se explican usos sintácticos del portugués por medio de la comparación entre las lenguas modernas, pero sin tomar en consideración preferente las diferencias con el latín y el francés.

Otros aspectos de interés sobre las comparaciones entre el portugués y otras lenguas románicas se presentan como críticas del gramático sobre el uso del francés y del español por parte de los lusohablantes. Las reflexiones de Ribeiro muestran que la interferencia del portugués puede producir dificultades de aprendizaje de otras lenguas próximas. Esta preocupación del gramático se manifiesta en algunas explicaciones sobre la pronunciación y sobre el uso del infinitivo flexionado, exclusivo del portugués y gallego, según el autor:

Com effeito, quem será capaz de saber a pronuncia exacta dos vocabulos "archeiro, archonte» só por vel-os escriptos? Não é a confusão originada de tal uso de lettras improprias um estorvo sério ao conhecimento perfeito da lingua franceza? Os vocabulos chirurgien e chiromancie, por exemplo, derivam-se ambos da mesma raiz kheir e todavia um pronuncía-se xirurgien e o outro kiromancie! (Ribeiro 1881: 30).

Esta particularidade da flexão do infinito, notada já nos mais antigos documentos da lingua portugueza, encontra-se tambem no dialecto gallego, ex.: "Para sairem e entrarem ». Nenhuma outra lingua a possue. Gil Vicente 
commetteu o erro de escrever em Hespanhol « Teneis gran razon de LLORARDES cuestro mal ». Alguns poetas do Cancioneiro Geral cahiram no mesmo engano. Camões que muito escreveu em Hespanhol foi sempre correcto (Ribeiro 1881: 240).

El contraste entre el portugués y el latín es todavía un recurso frecuente en las gramáticas de este periodo. La obra de Ribeiro sigue esta tendencia de la tradición brasileña. El latín es la lengua más citada por el gramático, con alrededor de cien referencias. El objetivo de estas descripciones contrastivas tampoco difiere del propuesto por otros autores de su tiempo, como Freire, pues Ribeiro trata de precisar el origen y el desarrollo del portugués, además de legitimar etimológicamente las reglas y los usos sintácticos de su lengua. En cuanto al alcance de estas citas, el autor contrasta la influencia del latín desde los aspectos fonéticos hasta la sintaxis. Ribeiro muestra, por ejemplo, que la influencia del latín fue determinante en la prosodia, la ortografía y la morfología derivativa del portugués, además de justificar los comportamientos sintácticos de los pronombres:

Escrevem-se tambem com en-especimen, gluten, hymen, hyphen, lichen (likhen melhor orthographia), pollen e outros vocabulos tomados do Latim sem mudança de fórma: em taes casos, porém, a teminação en não é nasal (Ribeiro 1881: 28).

277. Os prefixos portuguezes são tomados em sua quase totalidade do Latim e do Grego (Ribeiro 1881: 149).

Em Gil Vicente encontra-se «Fallo mui doce cortes». Já no Latim classico era corrente este uso, tomando o adjectivo a fórma neutra: «Dulce ridentem Lalagen amabo, dulce loquentem» (Ribeiro 1881: 191).

O, quando não designa pessôas, mas sim cousas, como nesta phrase «A Polonia perecerá, eu o prevejon, significa isso, vem do Latim illud e nos representa quasi o unico resto do gênero neutro que possuimos ainda em Francez. Eis o que nos explica porque ás perguntas "Sois vós a mãe deste menino?» ou "Sois vós a doente?» torna-se necessario responder «Eu a sou», isto 
é, "Eu sou a pessôa de que fallais»; ao passo que ás perguntas "Sois vós mãe? Estais vos doente?» a resposta deve ser «EU o sou-Eu o estou, ILLUD», isto é, "eu sou isso; é assim que eu estou; é o que me tendes perguntado; possuo a qualidade de mãe; estou em estado de doença». (Ribeiro 1881: 229)

El estudio de Ribeiro sobre la evolución del vocabulario todavía sigue el modelo más generalizado. A pesar de la influencia historicista, la etimología de la Grammatica Portugueza se limita al análisis de las bases latinas y griegas del portugués, pero con escasas referencias a los resultados en otras lenguas románicas que pudieran servir de contraste. Sin embargo, conviene notar que Ribeiro distingue la especialización de los estudios gramaticales, pues afirma que su obra no constituye un tratado histórico ${ }^{17}$ y añade que solamente una gramática con este carácter (diacrónico) podría incluir la romanística en la etimología:

Claro está que só uma grammatica especialmente historica e um diccionario etymologico poderão tratar detidamente das palavras portuguezas oriundas de todas estas fontes [fenicio, hebreo, árabe, celta, griego, gótico, provenzal, francés, español, italiano, euskera, inglés, alemán, persa, hindi, turco, eslavo, quimbundo, níger-congo y tupí], e quiçá de outras. Todavia, como a sciencia moderna tem com suas nomenclaturas resuscitado e universalizado o Grego antigo, é de utilidade uma lista das palavras gregas radicaes mais vulgarmente usadas (Ribeiro 1881: 159).

Con todo, es posible observar en la Grammatica algunas comparaciones ocasionales que ponen de relieve el proceso de evolución paralela del vocabulario en las lenguas románicas, como es el caso de los términos tio y tia y del sufijo ão:

Do Grego Theios, Theía. E' curioso que o Hespanhol, o Italiano, o Portuguez e o dialecto da Picardia tenham tomado este termo do Grego, deixando de

\footnotetext{
17 Con respecto al objeto de estudio de Ribeiro, Molina (2005) pone de relieve que nuestro gramático «preocupa-se com seu aspecto descritivo-normativo, numa perspectiva sincrônica» (Molina 2005: 524).
} 
parte os vocabulos latinos avunculus e amita dos quaes os francezes derivaram os seus oncle e tante. Tia, Tio (Hesp.), Zia, Zio, (Ital.) Thia, Thio, (Port.), Thie, Théion (dialecto picardo) (Ribeiro 1881: 41).

Resta agora saber como a terminação ane do singular se converteu em ão. A terminação ane pela quéda do e final reduziu-se a an, e este som era representado por am, ex.: "Cam, pam ». Ora mais tarde am leu-se ão, e dahi resultou a confusão e a homologação de fórmas diversas por origem. Capitan, gran, etc.. em Hespanhol; Capitaine, graine, etc.. em Francez, nos mostram a fórma em sua pureza primitiva. A mesma corrupção de an em ão se nota em grão, são, (gran, san) apocopes de grande, santo (Ribeiro 1881: 147).

En este sentido, cabe destacar también la posición adoptada por Ribeiro con respecto al origen del artículo. Según el autor, el artículo portugués -como el gallego- procede de los casos ablativo y acusativo del demostrativo latino hic (hoc, hac, hos, has). En su explicación, además de mostrarse en desacuerdo con otras etimologías, dedica atención al desarrollo paralelo de las formas del artículo románico a partir de demostrativos diferentes en las distintas regiones de la Romania. La cita siguiente muestra la teoría de Ribeiro con respecto al artículo:

289. $O$ artigo definido portuguez, cujas fómas flexionaes ou melhor variantes são o, a, os, as, deriva-se de hoc, hac, hos, has, fórmas do ablativo singular e do accusativo plural (270) do demonstrativo latino Hic, haec, hoc.

Como já ficou dito (134), o Latim classico não tinha artigo, e era tal falta uma causa de frequentes obscuridades no dizer. Nos fins quasi do Império, o povo, para clareza da phrase, começou a junctar aos substantivos os demonstractivos ille, hicce, hic, e esse uso é a origem do artigo romanico. Ille den le, la, les em Francez; el, lo, la, em Hespanhol; il, lo, la em Italiano, etc.. Hicce deu ce, usado ainda no dialecto picardo (ch'curé, ch'marichau). Hic deu em Portuguez $0, a$, derivados dos ablativos do singular hoc, hac, pela queda do $c$; e os, as, derivados dos accusativos do plural hos, has: em documentos antigos e mesmo em escriptos relativamente modernos encontram-se as fórmas ho, ha, hos, has, escriptas com $h$.

E' singular que quasi todos os etymologistas tenham desacertado a respeito da origem do artigo definido portuguez: Diez entende que elle tem certa apparencia particular, quase anti-romanica, e quer a fina força identifical-o 
com o el, lo, la hespanhol. Constancio fal-o vir do Grego. José Alexandre Passos segue a Constancio, e entra em explicações que tocam ao ridiculo. A origem do artigo acima exposta é intuitiva, e Leoni, comquanto cerebrino em suas lucubrações philologicas, andou com muito criterio neste ponto.

Todavia não se póde negar que houve no Portuguez e no Gallego luta pela existencia entre as formas lo, la, los, las e o, a, os, as (Ribeiro 1881: 162-163).

El origen del artículo portugués constituye un aspecto polémico entre los autores de este periodo. Algunos gramáticos de la primera mitad del siglo, como P. José de Figueiredo (1827), Solano Constancio (1831) y José Alexandre Passos (1865), defendían el origen griego del artículo definido portugués. En el último cuarto del siglo XIX, esta teoría fue en ocasiones cuestionada por autores brasileños como Freire y Ribeiro. En efecto, Freire destaca que la «pouca influencia exercida na lingua popular pelo grego, o foi por meio do latim que, não tendo artigo, não podia te-lo recebido da lingua grega»s (Freire 1894[1875]: 205-206) y Ribeiro afirma que estas explicaciones «tocam ao ridiculo».

Por otro lado, también hubo desacuerdos entre los gramáticos brasileños en cuanto a la hipótesis del origen latino. Este es el caso de la propuesta de Ribeiro (hoc, hac, hos, has), que no tuvo seguidores en su tradición, y la de Freire (ille, illa, illud), que repercute en las obras de João Ribeiro (1887) y Alfredo Gomes (1887). Así, interesa destacar que la etimología que defiende Ribeiro había sido rechazada por Augusto Freire en su Gramática:

Impugnam outros esta opinião, sustentando provir o artigo definido de hoc, hac, hos, has, fórmas masculinas e femininas do ablativo do singular e do accusativo do plural de hic, haec hoc, fundados no facto de outrora tambem se orthographar o artigo com h que consideram um vestigio daquellas fórmas.

Esta etymologia é inadmissivel pelas razões seguintes.

Não se podia ter dado a queda da lettra $c$, por ser isso contrario ao criterio historico, segundo o qual é ella, ou conservada, como em agora de hac hora, ou compensada pela nasalisação ou pela accentuação, quando desapparece, como em nem, sim, lá de nec, sic, illac. 
Alem disso é esta derivação contraria a origem do artigo definido das outras linguas romanas que, sem discrepancia, aceitam, como tal, o adjectivo demonstrativo latino ille, illa, illud (Freire 1894[1875]: 205).

A propósito de las descripciones acerca del origen y la evolución de las lenguas románicas, la Grammatica de Ribeiro refleja la fuerte influencia de los principios historicistas, principalmente en lo que respecta el estudio etimológico. En general, los criterios defendidos por el autor ya se habían utilizado en gramáticas anteriores. Esta continuidad permite suponer que, a pesar del cambio de contenidos e intereses, ya se habían consolidado en la gramaticografía brasileña las ideas principales sobre la evolución de las lenguas. Se advierte así, por ejemplo, en la descripción de los aspectos fonéticos del portugués:

Em Grego e em Latim a quantidade (khrónos, tempus) não dependia do accento tonico (tónos, tenor). Em Portuguez bem como na pluralidade das linguas modernas quantidade e accento tonico confundem-se, e só é considerada verdadeiramente longa a syllaba predominante (Ribeiro 1881: 12).

Dje é som romanico genuino: existe em Provençal, em Italiano, e no seculo XIII existia no Francez que o transmittiu ao Inglez, onde até agora se acha, ex.: «jealousy»). Em escriptos latinos do seculo IX encontram-se as fórmas pegiorentur, pediorentur, por pejorentur. Tche é tambem som romanico castiço: existe em Provençal, em Italiano, em Hespanhol, e existiu no Francez, donde passou para o Inglez: que ainda hoje o conserva, ex.: «chamben». A existencia de ambas estas fórmas no fallar do interior do Brazil prova que estavam ellas em uso entre os colonos portuguezes do seculo XVI. A antiguidade e a vernaculidade do tche attestam-se pela sua permanencia na linguagem do Minho e de Trás-os-Montes: como sabe-se, o povo rude e conservador tenaz dos elementos arkhaicos das linguas (Ribeiro 1881: 10).

Es interesante notar que Ribeiro también destaca el papel de la norma discursiva en la evolución de las lenguas románicas. El autor señala que no solo el uso en un ambiente específico sino también la evolución del vocabulario en el proceso de codificación de las lenguas pueden condicionar el carácter formal o 
informal, popular o erudito de las palabras. En particular, se refiere a la presencia de dobletes en las lenguas románicas, pero observa que mientras el latinismo o cultismo puede ser común, la voz patrimonial se distingue en cada idioma:

Muitas palavras latinas ao passarem para as linguas românicas tomaram duas fómas, uma popular, outra erudita. A fórma popular, producto fatal da evolução que transforma as linguas, tem sempre um cunho verdadeiramente nacional em cada idioma: a fórma erudita, introduzida pelos escriptores versados em latinidade classica, apezar de acceita e naturalisada, conserva quasi sempre seu ar extrangeirado (Ribeiro 1881: 167).

El último aspecto que sobresale en la metodología contrastiva de Ribeiro está relacionado con los universales románicos. Es sabido que este tema ya era común en las gramáticas brasileñas de este periodo. Incluso, algunas cuestiones mencionadas por el gramático habían sido tratadas por otros autores, como es el caso de los fenómenos fonéticos y ortográficos que incidieron en el proceso de formación de las lenguas románicas y de la derivación de algunos tiempos verbales:

Na transformação do Latim em Portuguez, bem como em outras linguas romanicas, nota-se

1) a persistencia do accento tonico latino, ex.: «amigo de amico,-_êmea de fémina,-hómem de homine,_- pállido de pállido».

2) a suppressão das vogaes breves que precedem a syllaba accentuada, ex.: «bondade de bonitate (suppressão de i) —relogio de hõrologio (suppressão de hõ)».

3) queda de lettras alterantes medias e até de syllabas inteiras, ex.: "alugar de adlocare (queda de $d$ ) -boi de bove (queda de $v$ )—dedo de digito (queda de gi) — dono de domino (queda de mi)—mãe de matre (queda de tr)—trigo de tritico (queda de ti)».

4) em geral a substituição de sons fortes por brandos, ou vice-versa, especialmente (Ribeiro 1881: 144) 
Deriva-se este tempo do plusquam perfeito latino já syncopado no periodo classico-cantassem por cantavissem. Esta formação é commum a todas as linguas romanicas (Ribeiro 1881: 183).

Todas as linguas romanicas, excepto o Valakio ou Romano, aproveitaram esta construção latina para exprimir o futuro (Ribeiro 1881: 181).

A propósito de los universales lingüísticos, se deja constancia aquí de que en la Grammatica Portugueza de Ribeiro son muy escasas las citas en las que el gramático describe los rasgos que considera universales en las lenguas. Las afirmaciones siguientes constituyen los únicos indicios que se ofrecen en la obra:

Em todas as linguas é o infinito empregado como substantivo (Ribeiro 1881: $55)$.

As verdadeiras interjeições são sempre as mesmas em todas as linguas (Ribeiro 1881: 192).

A tendencia que actualmente apresentam todas as linguas para tornaremse analyticas, é a causa da preferencia que cada vez mais tem a construcção direita, sobre a inversa (Ribeiro 1881: 281).

Los gráficos siguientes ilustran la presencia de otras fuentes lingüísticas en la Gramática de Ribeiro y los temas gramaticales a que se refiere: 


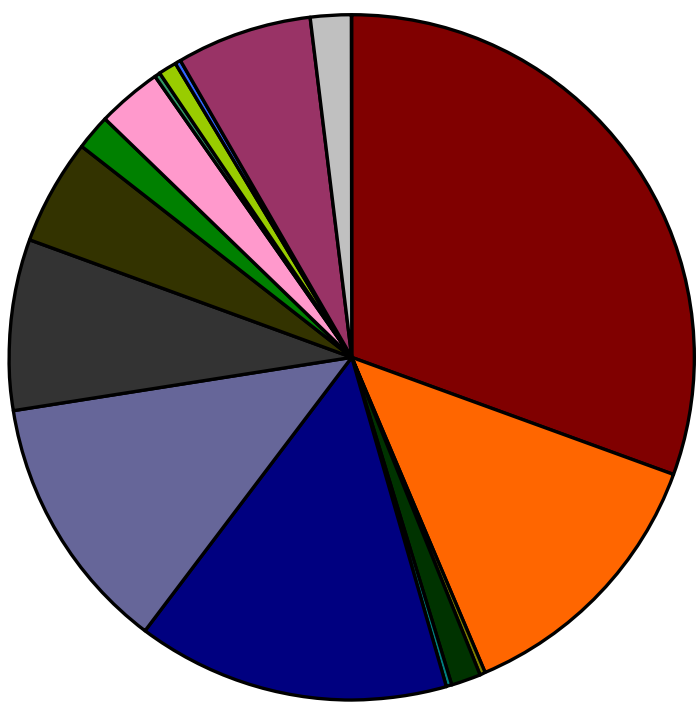

Latín
$\square$ Griego
$\square$ Hebreo
$\square$ Árabe
$\square$ Fenicio
Erancés
$\square$ Español
$\square$ Italiano
$\square$ Inglés
$\square$ Alemán
$\square$ Provenzal
$\square$ Euskera
$\square$ Tupí
$\square$ Lenguas africanas
$\square$ Brasil
$\square$ Portugal

Gráfico 8.5 Las fuentes Lingüísticas de Ribeiro

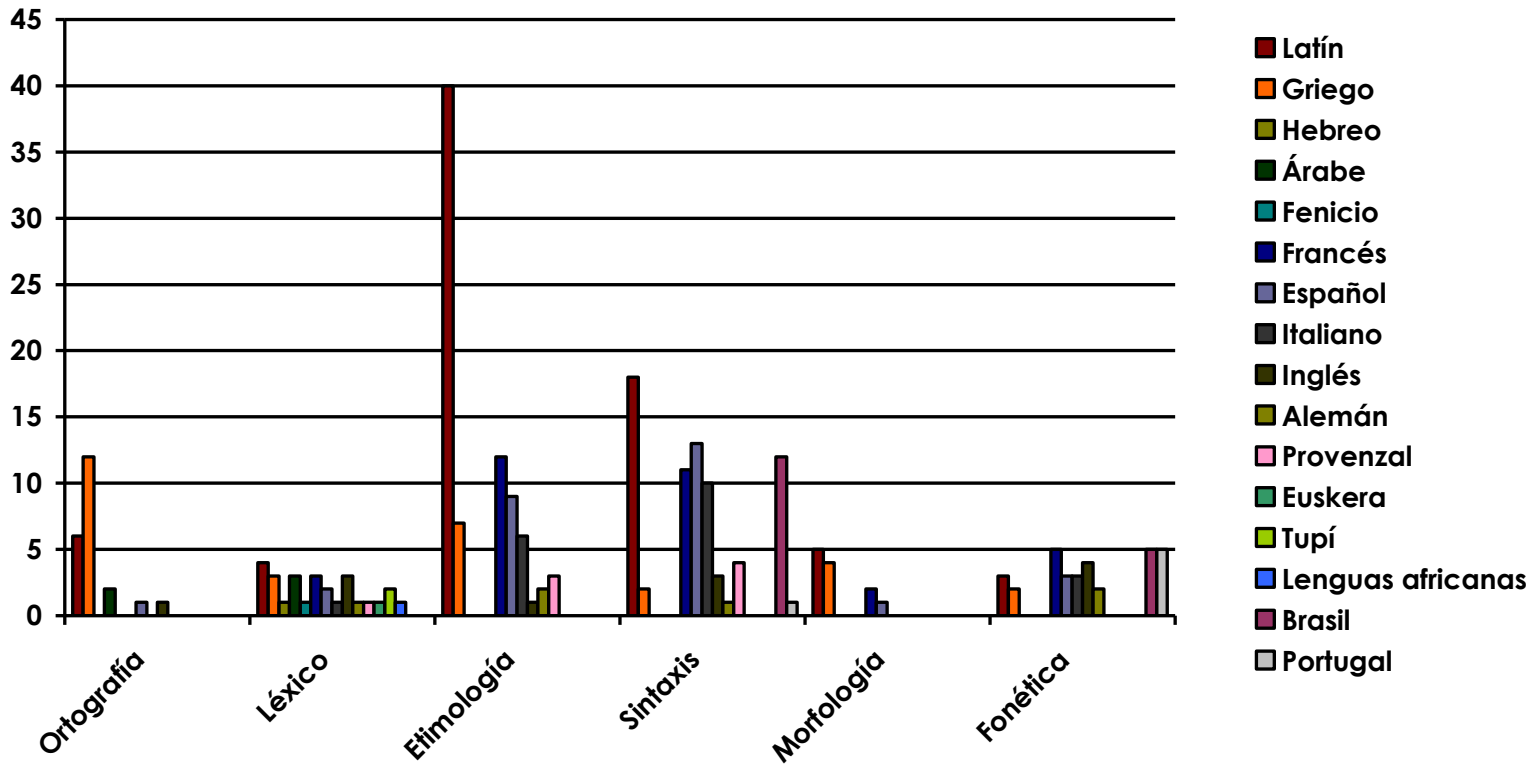

Gráfico 8.6 El dominio de los contrastes en Ribeiro 
En resumen, el método contrastivo de Ribeiro representa una importante contribución a la tradición brasileña, pues amplia los datos acerca de los universales lingüísticos y la evolución del portugués brasileño, extiende los contrastes románicos hacia otras lenguas como el español y el italiano, sin olvidar que además incrementa el estudio sintáctico. En cuanto a los objetivos de estas comparaciones, el gramático utiliza este procedimiento con la finalidad de describir analogías morfológicas y sintácticas en el proceso de evolución desde el latín (especialmente entre el portugués, el francés y el español), mostrar las influencias de una lengua sobre otra y proporcionar descripciones en general que faciliten el aprendizaje de otras lenguas.

Asimismo, cabe señalar que aunque Ribeiro reconoce algunas diferencias y semejanzas, así como desarrollos paralelos entre el portugués y otras lenguas románicas, se puede notar que el gramático conserva el procedimiento más común del racionalismo al privilegiar, en muchas ocasiones, las comparaciones con el francés, considerada en la época como la lengua de cultura por excelencia.

Pues bien, el análisis de la romanística en las obras de Augusto Freire y Júlio Ribeiro muestra que los métodos contrastivos de los autores coinciden en muchos casos, aunque la Gramática de Freire se inclina hacia la doctrina racionalista, mientras que Ribeiro tiende a privilegiar la perspectiva normativa. Las características comunes que más claramente aproximan los métodos de estos dos autores son el estudio sobre el origen y la evolución del vocabulario, de las estructuras sintácticas y de las funciones gramaticales del portugués; el privilegio de las comparaciones entre el portugués, el latín y el francés; el incremento de la etimología y la adopción de una perspectiva histórica y comparada. Al parecer, los autores también persiguen los mismos objetivos en sus respectivas aplicaciones del método contrastivo en el proceso de codificación del portugués, que son la descripción del origen y la evolución del portugués y, en cierto modo, la 
legitimación y justificación de las teorías y las reglas gramaticales por medio de la norma gramatical de otras lenguas.

\subsection{Contrastes románicos en la Grammatica Descriptiva de Maciel}

En el último cuarto del siglo XIX, la gramaticografía brasileña experimenta cambios profundos en la valoración de metodologías contrastivas. Las gramáticas basadas en la doctrina historicista dejan paso a las obras que emplean procedimientos descriptivos para la codificación normativa de la variante americana del portugués.

La Grammatica Descriptiva de Maximino Maciel es más que una obra modélica de esta fase. En realidad, constituye la gramática que inaugura la corriente descriptiva en la tradición brasileña. En este sentido, el método histórico y contrastivo es un procedimiento escasamente utilizado en la obra de Maciel, pues se limita a observaciones de carácter etimológico, como las que se presentan en el estudio de los afijos, de las expressões personativas, de los pronombres, de la formación de palabras, entre otros aspectos morfológicos y sintácticos.

Por el contrario, la metodología de Maciel se caracteriza más bien por la descripción inmanentista que propiamente por el interés histórico y comparado de las lenguas. En todo caso, las referencias románicas tienen como función principal la descripción de los rasgos históricos más relevantes para la comprensión y el aprendizaje de la lengua portuguesa.

El primer aspecto histórico-contrastivo que Maciel destaca en su Grammatica consiste en la observación de la presencia de elementos grecolatinos en el vocabulario portugués. El autor explica la tendencia de la lengua a mantener las formas originales de las raíces clásicas que componen las palabras portuguesas 
y defiende que la conservación de radicales cultos es de interés tanto científico como pedagógico, pues contribuye al conocimiento del origen y parentesco de los vocablos y además facilita el aprendizaje de otras lenguas, igualmente ricas en cultismos:

Nas linguas classicas - grego e latim, palavras ha que se confundem com as raizes, como em portuguez a palavra pé, ex.: pedestre, peanha, pedúnculo, pedestal (Maciel 1926[1894]: 82).

Constituindo as raizes latinas e as gregas os nucleos fundamentaes de cirstalisação dos vocabulos, devemos mantel-as, tanto quanto possivel, graphicamente intangiveis, visto que por ellas, como residuos organicos da tradição vocabular, descemos á filiação historica das palavras, descortinandoIhes o parentesco e a identidade de origem commun ás linguas novilatinas, facilitando-nos ellas o aprendizado destas e até o das linguas teutonicas -inglez, allemão- a que transfundiram o latim e o grego volumosa copia de vocabulos (Maciel 1926[1894]: 102).

Maciel también reconoce el legado clásico en la descripción de los prefijos:

Os prefixos são geralmente representados por preposições da lingua ou preposições latinas, palavras gregas, ex.: defender, interpor, antichristo, e ás vezes pelos advérbios bem, mal e menos, ex.: bemfazejo, bemquisto, maltratar, maldizer, menosprezar, menoscabar (Maciel 1926[1894]: 84).

Os prefixos modificam a Idea expressa pela raiz, dando ao thema geral as seguintes significações especificas, e podem ser latinos, gregos e portuguezes (Maciel 1926[1894]: 93).

La segunda aplicación del contraste histórico en la obra de Maciel persigue la finalidad de precisar la función de determinadas formas gramaticales. En efecto, el autor recurre a la etimología latina para justificar el carácter demostrativo de los llamados pronombres personales elle y ella. Sin embargo, el gramático no aporta 
más indicaciones sobre este punto, pues seguidamente se refiere a la procedencia de las formas oblicuas comigo, contigo, consigo, conosco y convosco:

Os pronomes elle, ella e suas variações são mais pronomes demonstrativos do que propriamente pessoaes; prova-o a historia da lingua. As fórmas migo, tigo, sigo, nosco e vosco, provindas de mecum, tecum, secum, nobiscum, vobiscum, se usam actualmente agglutinadas á preposição com, mas não existe mais pleonasmo, por se haver perdido a noção da proposição cum, cujos vestígios são as morphoses go y co ${ }^{18}$ (Maciel 1926[1894]: 132-133)

Maciel también llama la atención sobre ciertos rasgos gramaticales propios de las lenguas clásicas que se modificaron durante el proceso de desarrollo de las lenguas románicas. Algunos de estos rasgos, como es el caso del género neutro, ya habían sido estudiados por los gramáticos decimonónicos anteriores, de modo que el análisis del autor no aporta ninguna información nueva:

No grego, no latim, no inglez e outras linguas, ha o genero neutro, applicado quase sempre aos seres inanimados; mas nas linguas romanas perdeu-se toda a noção de neutro.

O genero dos nomes segue geralmente a declinação latina e o neutro passou para o masculino e as vezes para o feminino.

$[\ldots]$

O genero muda-se na evolução da lingua. Assim é que as palavras senhor, pastor, planeta, mar e outras já foram femininas (Maciel 1926[1894]: 158-159).

Sin embargo, otras características evolutivas del portugués $-y$, en general, de las lenguas románicas- creemos que no habían sido observadas hasta la Grammatica Descriptiva de Maciel, como por ejemplo la referencia al cambio de significado de las llamadas «expressões personativas» o patronímicos:

18 As expressões você, V.S. ${ }^{a}, V$.E. $^{a}$ e outras congêneres são igualmente pronomes pessoaes, pois exprimem o tratamento da pessoa a quem falamos e são por isso pronomes de referencia, applicando-se ao portuguez o que fez Monier Williams para o sanskrito na sua Practical Sankrit's Grammar, ex.: "Assim, vocês por esta historia de Portugal fora, vocês são uma enfiada de Ramires de toda a belleza." Eça de Queiroz [nota del gramático]. 
Nas expressões personativas a lingua portugueza se desviou da latina e assim as noções de patronymico, cognome, agnome de que se constituia o nome proprio, não tem mais valor nas linguas modernas, maximé na nossa. [...] Actualmente o patronymico já não indica filiação, pois si assim fosse, todo Alvares seria filho de um Álvaro; Rodriguez, de Rodrigo; Marques, de Marco; Peres, de Pedro; Vasques, de Vasco; Fernandes, de Fernando, similhantemente ao latim (Maciel 1926[1894]: 122).

En la misma línea, Maciel explica que, aunque los adverbios de modo terminados en -mente constituyen un elemento característico de las lenguas románicas, es importante reconocer que su origen se remonta al latín clásico:

Os adverbios, formados em mente, são productos das linguas novi-latinas, pois a palavra mente = modo, intenção, conceito, se usava geralmente precedida do adjectivo, e assim, juxtapondo-se a este, passou a constituir um adverbio de modo.

Na lingua erudita já havia exemplos, como em Virgilio: - "Mansi altamente repositum judicium Paridis" (Maciel 1926[1894]: 151).

Las comparaciones sintácticas entre el portugués y otras lenguas se reducen en la Grammatica Descriptiva a las descripciones del uso del superlativo, de la partícula se y de algunos extranjerismos sintácticos. En cuanto a formas del superlativo, Maciel ilustra con textos lusos la influencia latina en construcciones de superlativo absoluto portugués:

A lingua latina não possuia superlativo relativo: assim, sempre que o absoluto apparecia seguido do genitivo, de accusativo mediante inter ou do ablativo mediante ex, exercia igualmente a funcção do nosso relativo, ex.: "altissima arborum ou ex arboribus ou inter arbores".

Esta syntaxe é ás vezes seguida por escriptores de nota e assim ocorrem: - a altissima das arvores, o prudentissimo dos conselhos (Maciel 1926[1894]: 184). 
Sin embargo, el estudio de esta característica latina heredada por el portugués no supone una innovación en la gramaticografía brasileña, pues Ribeiro ya había aportado una explicación semejante:

Observação n. 6.) Por imitação da syntaxe latina servem muitas vezes os superlativos absolutos de superlativos relativos, ex.: «O optimo de todos-0 prudentissimo dos conselhos» em vez de «O melhor de todos- 0 mais prudente dos conselhos») (Ribeiro 1881: 219 [la negrita es mía]).

Con respecto al problema del empleo del pronombre se como sujeto de la oración, Maciel presenta un argumento en contra de la teoría ya generalizada en esta tradición, según la cual se defendía que se no puede desempeñar función de sujeto por proceder del acusativo latino. Por el contrario, el autor afirma que, independiente de su procedencia latina, esta función debe ser aceptada por la gramática, a ejemplo de otras lenguas que también presentan usos sintácticos comparables. En su argumentación, Maciel se declara partidario de las explicaciones inmanentistas en sustitución de los criterios historicistas, pues viene a afirmar, como Andrés Bello en la tradición española, que cada lengua tiene su propia gramática y que esta disciplina no puede separarse de la realidad del idioma:

Ao publicarmos as edições anteriores, já tinhamos sentido necessidade de admitir o se como sujeito, pois, tendo a lingua a sua individualidade syntactica, não importa que o se provenha de sui, sibi, se que não possue nominativo, adaptado á funcção de sujeito.

Si assim fosse, então jamais poderiam servir de sujeitos as palavras que se derivam directamente do accusativo, ex.: homem, nuvem, ordem, alguém, e todos os pluraes em que o s representa o expoente do accusativo.

Não o admittindo como sujeito, seremos obrigados a recorrer a subterfugios para explicarmos muitas phrases, taes como: vive-se, vae-se, precisa-se de, trata-se de, etc.

Alguns professores, sem minimo fundamento, reputam erroneas taes construcções, como si a grammatica não fosse o registro dos factos da lingua. 
Alem disso, todas as linguas tem um pronome monosyllabico, de funcção subjectiva para exprimir o sujeito indeterminado.

Assim é que no francez existe o pronome on, no Inglez one, no Allemão man. Como pois nos queremos obstinar em não darmos se por sujeito nos casos de que tratamos acima? (Maciel 1926[1894]: 330).

Este análisis también había sido defendido por Ribeiro en uno de los annexos de la Grammatica Portugueza. No obstante, las propuestas de Ribeiro y de Maciel se diferencian en la argumentación que presenta cada autor para justificar el empleo de la partícula se como sujeto de la oración. A propósito de la explicación de Maciel, es evidente que se fundamenta en el carácter descriptivo e inmanentista de la gramática y en su propósito de registrar el uso sincrónico de la lengua. En cambio, Ribeiro trata de legitimar este comportamiento del pronombre se a partir del contraste con otras lenguas románicas:

Indica-se tambem nas linguas romanicas a pluralidade indeterminada do agente de um verbo, unindo-se a esse verbo o pronome reflexivo se, considerado como mera particula apassivadora. Neste uso que remonta aos monumentos mais antigos do domínio romanico, cumpre distinguir dous casos:

$1^{\circ}{ }^{\circ}$ Expressão impessoal

A) com verbos transitivos

a) ITALIANO. Si dice. Si crede. Si sa. Non si può dire.

b) HESPANHOL. Se dice. Se cree. Se sabe.

c) PORTUGUEZ. Diz-se. Crê-se. Sabe-se.

B) com verbos intransitivos

a) ITALIANO. Si va. Si vien. Si vive.

b) HESPANHOL. Se anda. Se viene. Si vive.

c) PORTUGUEZ. Vai-se. Vem-se. Vive-se.

d) VALAQUIO. Se mearge. Se vine.

2..$^{\circ}$ ) Expressão pessoal. Neste caso o verbo, que só transitivo póde ser, regula-se pelo numero do sujeito.

a) ITALIANO. Il libro non si trova. I libri non si trovano.

b) HESPANHOL. Se teme uma borrasca. Si dicen muchas cosas.

c) PORTUGUEZ. Dá-se um baile. Plantam-se arvores.

d) FRANCEZ. Cela se fait. La maison se bâtit. 
Sendo o sujeito, como nos exemplos adduzidos, nome de cousa, nada oppõe-se a esta construcção; si é, porém, o sujeito nome de pessôa ou mesmo de ser vivo, a expressão póde ficar equivoca [...].

Fica, pois, demonstrado que as fórmas romanicas construidas com se bem como as fórmas latinas passivas, servem para exprimir a acção sem trazer a lume o agente, e para consignar a pluralidade indeterminada desse agente (Ribeiro 1881: 287-290).

El último aspecto contrastivo estudiado por Maciel es la cuestión de los extranjerismos. El gramático reconoce la incidencia de distintas lenguas en la morfología y la sintaxis del portugués, pero reclama especial atención a la fuerte presencia de galicismos. Es interesante notar que el autor cita dos fuentes principales que explican esta influencia del francés. La primera se refiere a los textos científicos y literarios, de donde proviene la mayor parte de los galicismos (sobre todo, se refiere a los léxicos), pero además atribuye a los desaliños de las traducciones las más significativas interferencias sintácticas:

${ }^{19}$ Effectuando-se quase toda a nossa cultura scientifica e literaria mais através da lingua francesa do que das outras, tem influido na portugueza os gallicismos mais omnímoda e abundantemente do que os demais estrangeirismos.

Desprezam-se ás vezes impatrioticamente os nossos melhores e mais excellentes vocabulos, substituindo-se por francezes, exs.: elite (escol), debutar (estrear), feérico (deslumbrante), misenscena (enscenação), soirée (saráo), chambre (roupão).

Até na syntaxe em que se patenteia o genio, a indole da lingua, hão influido os gallicismos em virtude do desalinho nas traduções francezas, mormente quando, não conhecendo o traductor sufficientemente a nossa, não the discrimina consciente e exactamente os processos syntacticos, os moldes e a estructura das duas linguas; ex.: rogar de (rogar que), se o diz (diz-se, dizemos, dizem), navio á vela (navio de vela), vestido em lã (... de lã), meia toda em seda (... de seda pura), etc.

\footnotetext{
${ }_{19}$ Muitas construcções que passam por gallicismos existiram na lingua portugueza antiga que as esqueceu, emquanto se perpetuaram na lingua franceza a cuja syntaxe se encorporaram [nota del gramático].
} 
Além disso excellem os abusos da ordem directa, dos adjectivos possessivos, dos pronomes pessoaes sujeitos sempre expressos e até de phrases francesas estereotypadas ou feitas literalmente traduzidas, ex. ...em questão ...abordar o assumpto, passar sob silencio (pretermittir), entre cão e lobo (ao crepúsculo) ao anoitecer, ao lusco e fusco (Maciel 1926[1894]: 436).

A continuación se muestran los gráficos que muestran la presencia de cada lengua extranjera en el total de las fuentes lingüísticas de la Grammatica Descriptiva y la incidencia de estos idiomas en los temas gramaticales:
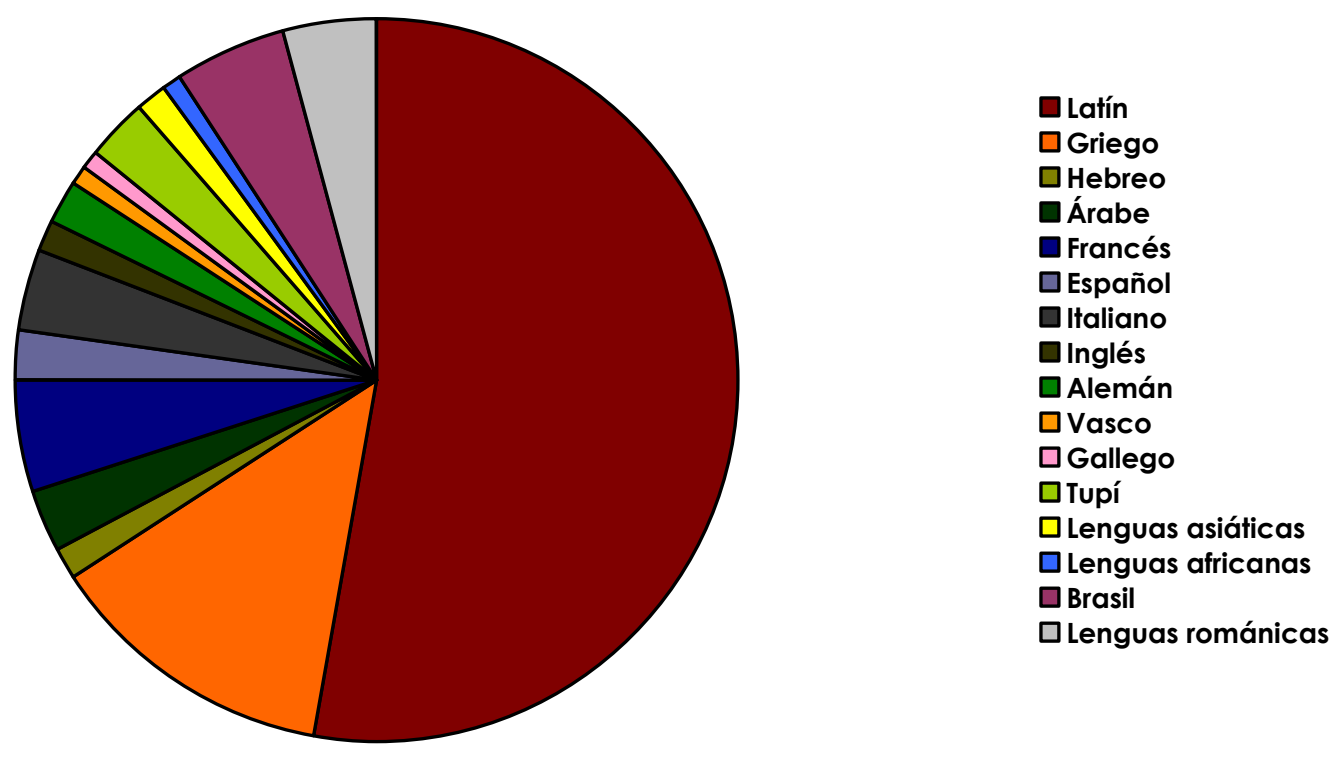

Gráfico 8.7 Las fuentes lingüísticas en la Grammatica Descriptiva 

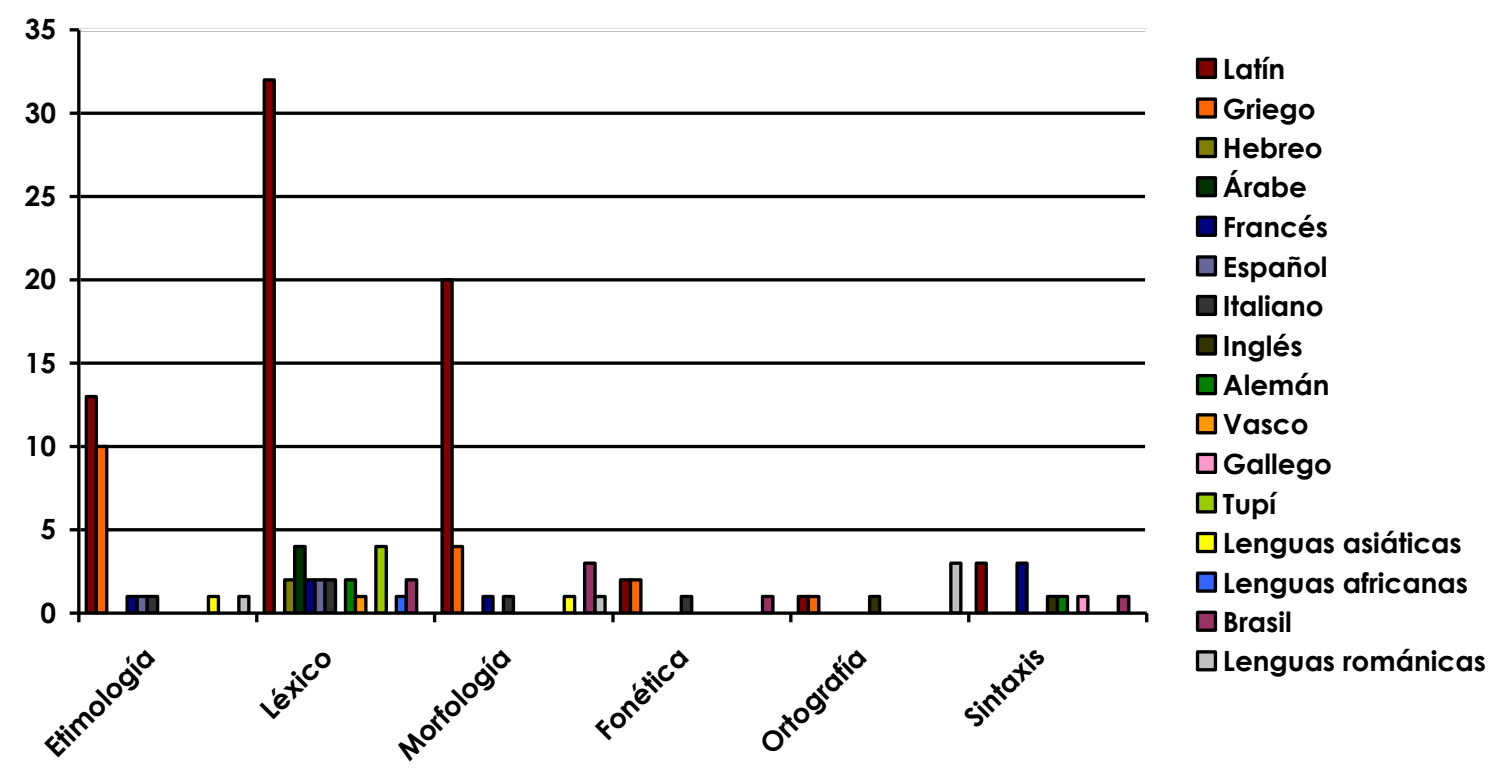

Gráfico 8.8 El dominio de los contrastes en la Gramática de Maciel

En definitiva, la principal aportación de Maciel a este periodo consiste, quizá, en la superación de la perspectiva histórica, e incluso racionalista, de los gramáticos anteriores con respecto al tratamiento del portugués y a su relación con otras lenguas. A pesar de las escasas observaciones que contrastan el portugués con las lenguas clásicas y modernas, la metodología del gramático alcanza dos objetivos:

1) Sostener la propuesta del cambio de clase de palabras para algunas formas gramaticales.

2) Promover el valor científico y pedagógico del aprendizaje del origen y la evolución del portugués.

Finalmente, la Grammatica Descriptiva de Maciel cierra este periodo de la gramaticografía brasileña con una propuesta de codificación del portugués que, 
por lo general, prescinde de los contrastes románicos, lo que constituye en sí mismo un avance entre las obras decimonónicas.

\subsection{Resumen}

Durante el siglo XIX, la tradición gramatical brasileña muestra un desarrollo muy particular del método contrastivo en el proceso de codificación del portugués. Este periodo está marcado por la presencia de tres fases metodológicas que presentan diferentes aplicaciones y objetivos gramaticales.

Las obras publicadas en la primera mitad del siglo XIX, que corresponde a la primera fase de esta aplicación metodológica, están fundamentadas en la doctrina racionalista, aunque mantienen ciertos rasgos renacentistas, como es el caso del Epítome de Moraes Silva. Las características racionalistas presentes en la metodología contrastiva de Moraes son las siguientes:

1) La preeminencia de los contrastes con el latín con la finalidad de determinar la presencia (o ausencia) de esta lengua en el portugués.

2) La ampliación de las comparaciones hacia el francés (lengua de mayor expresión científica en este periodo).

3) La descripción de los rasgos comunes a todas las lenguas (el verbo único, la sustitución de los casos latinos por preposiciones, la ausencia de género neutro, la construcción oracional directa, etc.) a partir del contraste entre el portugués, el francés y el latín.

Sin embargo, se puede notar que Moraes Silva todavía conserva la concepción renacentista de corrupción lingüística, pues para el autor los rasgos 
que el portugués comparte con el latín son considerados regularidades de la lengua, mientras que las diferencias entre las dos son interpretadas como carencias del portugués.

En la segunda fase, las obras de Augusto Freire y Júlio Ribeiro compaginan el historicismo con la tradición y el interés normativo. Aunque cada autor representa una contribución particular a su tradición, ambos son considerados aquí como referentes del periodo de conciliación metodológica en el tratamiento de los contrastes románicos. Freire es el primer autor brasileño que adoptó una perspectiva historicista, pero preservando algunos aspectos tradicionales y normativos, mientras que Ribeiro desarrolló este nuevo paradigma históricocontrastivo y, sin romper con la norma y la tradición, consiguió sintonizar su método con las corrientes contemporáneas.

Los rasgos tradicionales presentes en los métodos contrastivos de Augusto Freire y Júlio Ribeiro son los siguientes:

1) La preservación de las comparaciones entre el portugués, el francés y el latín para:

a) Precisar el origen y la evolución del léxico, de las estructuras sintácticas y de las funciones gramaticales del portugués.

b) Reforzar los principios racionalistas que aun rigen algunos aspectos gramaticales.

2) La conservación de los universales lingüísticos.

En cuanto a las características normativas, se pueden citar las siguientes:

1) Justificación de teorías y reglas gramaticales por medio de la norma gramatical de otras lenguas. 
2) Proporcionar descripciones en general que faciliten el aprendizaje de otras lenguas.

3) Atribuir a la influencia de otras lenguas, en particular del francés, la capacidad de corromper la norma portuguesa.

Finalmente, los rasgos historicistas son los que se muestran a continuación:

1) La descripción de analogías morfológicas y sintácticas en el proceso de evolución desde el latín.

2) El estudio de la influencia de unas lengua sobre otras.

3) La comparación entre lenguas antiguas y modernas.

4) El estudio de las alteraciones fonéticas.

5) El incremento del estudio etimológico.

6) El interés por las variantes del portugués.

7) El análisis de los desarrollos paralelos entre las lenguas románicas.

8) El predominio del estudio del léxico.

En la última fase, Maximino Maciel trata de superar esta metodología contrastiva, pues para el autor la función de la gramática se limita a registrar los hechos lingüísticos (Maciel 1926[1894]: 330), más que a comparar unas lenguas con otras, función esta última propia de la "grammatica comparativa» (Maciel 1926[1894]: 1). En este sentido, Maciel cambia la valoración de las metodologías contrastivas. Sus escasas referencias a otras lenguas cumplen más bien una finalidad pedagógica.

El eclecticismo doctrinal inevitablemente repercutió en los objetivos, la extensión y la profundidad de los estudios contrastivos. Este fenómeno es todavía más evidente en los tratados de Augusto Freire y Júlio Ribeiro, por el exhaustivo estudio de la evolución de las lenguas románicas, mientras que la obra de Moraes 
Silva se centra especialmente en el origen latino de la lengua portuguesa. En cambio, en la Grammatica Descriptiva de Maciel son muy escasas las observaciones relevantes que contrastan el portugués con otras lenguas. Pese a las diferencias que particularizan cada fase, no cabe duda de que la miscelánea teórica, que caracteriza la gramática decimonónica brasileña, también afecta a este procedimiento de análisis.

Los contrastes románicos en el proceso de codificación del portugués han dejado en la tradición gramatical brasileña tres concepciones contrastivas con bases, características y objetivos específicos. Este desarrollo ha permitido el avance del estudio contrastivo del portugués hacia un reconocimiento, por parte de gramáticos como Ribeiro y Maciel, de la necesidad y el interés de gramáticas contrastivas independientes que tomen en consideración la comparación interlingüística para el estudio de la lengua materna.

La tabla siguiente trata de resumir las características principales de los procedimientos contrastivos que llevan a cabo los gramáticos brasileños de nuestro estudio:

\begin{tabular}{|c|c|c|c|c|}
\hline Rasgos contrastivos & M. Silva & A. Freire & J. Ribeiro & M. Maciel \\
\hline Preferencia por el latín & Sí & Ocasionalmente & Ocasionalmente & - \\
\hline Idea de corrupción & Sí & Sí & Ocasionalmente & - \\
\hline $\begin{array}{l}\text { Preferencia por el } \\
\text { francés }\end{array}$ & $\begin{array}{c}\text { Muy } \\
\text { ocasionalmente }\end{array}$ & Sí & Sí & - \\
\hline $\begin{array}{c}\text { Presencia de otras } \\
\text { lenguas }\end{array}$ & $\begin{array}{c}\text { Muy } \\
\text { ocasionalmente }\end{array}$ & Sí & Sí & $\begin{array}{c}\text { Muy } \\
\text { ocasionalmente }\end{array}$ \\
\hline Predominio del léxico & - & Sí & - & - \\
\hline Estructuras sintácticas & $\begin{array}{c}\text { Muy } \\
\text { ocasionalmente }\end{array}$ & Ocasionalmente & Sí & $\begin{array}{c}\text { Muy } \\
\text { ocasionalmente }\end{array}$ \\
\hline
\end{tabular}




\begin{tabular}{|c|c|c|c|c|}
\hline Interés etimológico & Ocasionalmente & Sí & Sí & - \\
\hline Universales lingüísticos & - & Sí & Ocasionalmente & - \\
\hline Finalidad Normativa & - & Sí & Sí & Sí \\
\hline $\begin{array}{c}\text { Comparaciones entre } \\
\text { Brasil y Portugal }\end{array}$ & - & Ocasionalmente & Sí & Sí \\
\hline $\begin{array}{c}\text { Las variaciones del } \\
\text { portugués americano }\end{array}$ & - & - & Muy & Sí \\
\hline Finalidad pedagógica & - & - & Ocasionalmente & Sí \\
\hline Finalidad descriptiva & - & - & - & \\
\hline
\end{tabular}

Tabla 8.1 Contrastes románicos en los gramáticos brasileños decimonónicos 


\section{RESUMEN Y CONCLUSIONES}

Durante el primer siglo de producción gramatical brasileña, el proceso de codificación de la lengua portuguesa experimenta una evolución autóctona en el Nuevo Continente, protagonizada por las primeras generaciones de gramáticos nacidos en Brasil. Los autores brasileños aplican al estudio del portugués las principales novedades teóricas y metodológicas en sintonía con las corrientes europeas contemporáneas más representativas de la lingüística y la filología, como ha demostrado el análisis de las fuentes primarias que utilizaron los maestros brasileños.

El origen de la gramaticografía brasileña decimonónica se corresponde con la influencia de los modelos prescriptivos, racionalistas, de corte tradicional. La presencia en las obras examinadas de referencias a las obras de Arnauld, Lancelot, Nicole, Beauzée y Dumarsais manifiesta que los primeros gramáticos brasileños no solamente conocían a estos autores, sino que además trataron de aplicar a la lengua portuguesa los fundamentos logicistas y el racionalismo reformulado por los enciclopedistas. En conjunto, con la tendencia prescriptiva, este paradigma tradicional-racionalista permaneció vigente en la gramaticografía brasileña hasta el último cuarto del siglo XIX, pues incluso en el periodo en que vio la luz la Grammatica Portugueza de Augusto Freire estas doctrinas más arraigadas convivían con las corrientes más contemporáneas, como la histórico-comparada y la positivista.

Sin embargo, la confluencia de doctrinas que caracteriza la segunda mitad del siglo XIX brasileño se debe al compromiso de los gramáticos de alcanzar la modernización de la gramática. En este sentido, los autores, más acordes con su tiempo, tratan de evitar, en lo posible, las referencias a las corrientes que en este 
periodo se habían convertido en paradigmas gramaticales superados. Por este motivo, los gramáticos brasileños empiezan a prescindir de las citas textuales a fuentes renacentistas, muy ocasionalmente mencionan a autores racionalistas y se inclinan hacia la introducción de referencias histórico-comparadas. En este sentido, las citas textuales en las gramáticas brasileñas cumplen una doble función, pues, por un lado, respaldan e inspiran los cambios en la gramática, pero por otro lado, prestan notas de modernidad a los tratados gramaticales. Dicho de otro modo, los autores brasileños, en ciertas ocasiones, parece que utilizan a sus fuentes bibliográficas casi como recurso publicitario, pues algunas referencias a lingüistas y filólogos europeos no guardan apenas ninguna relación con la gramática.

No obstante, a partir de la Gramática de Júlio Ribeiro, aún se amplían y consolidan más las fuentes histórico-comparadas, al mismo tiempo que se adoptan nuevas teorías positivistas, en cierto modo por intermediación de los autores portugueses. Esta superposición (cuando no, mezcla) de teorías gramaticales alcanza mayor adecuación en el modelo descriptivo de Maximino Maciel, que cierra esta centuria con una perspectiva más juiciosa y coherente en la aplicación de las teorías lingüísticas y filológicas a su modelo de codificación de la lengua portuguesa.

Pues bien, la influencia foránea más arraigada a comienzos del siglo XIX en la nueva gramaticografía brasileña, como ya se ha destacado, se vincula a la corriente racionalista francesa, cuyos fundamentos inspiran en gran medida el Epítome da Grammatica Portugueza de Antonio de Moraes Silva (1806). Este autor sigue no solamente los supuestos fundamentales de Port-Royal, sino también los desarrollos posteriores de la filosofía gramatical, representada principalmente por los estudios de orientación enciclopedista y sensualista de Dumarsais, Beauzée y Condillac. Apoyada en estas fuentes, la obra de Moraes Silva llegó ser una 
referencia casi inexcusable para las gramáticas filosóficas brasileñas que siguieron a su publicación.

Entre los aspectos más característicos de la obra de Moraes Silva que se han puesto de relieve en este trabajo, cabe destacar aquí el interés del autor por superar la tradición latinizante y, por consiguiente, ofrecer un modelo de gramática racional del portugués que rompiera en cierto modo con la rutina heredada. Los principales rasgos distintivos que permiten relacionar el Epítome con una obra racionalista son fundamentalmente la teoría del verbo único, el cambio del criterio etimológico por el analógico en la clasificación de las palabras, la teoría de la elipsis y la creencia en los principios universales.

Asimismo, con Moraes Silva comienza el desarrollo del estudio sintáctico del portugués, preferentemente el de la variedad que corresponde al periodo clásico del idioma, a partir de un corpus de autoridades literarias. En este sentido, el carácter conservador del gramático, que tiende desatender el uso culto contemporáneo, constituye otra de sus conexiones con la doctrina racionalista. Así pues, la gramática del autor brasileño reúne características descriptivas y normativas, combina métodos inductivos y deductivos para el análisis gramatical, desarrolla el estudio sintáctico y, finalmente, avanza en la deslatinización de la doctrina gramatical de la lengua portuguesa.

Con todo, llama la atención el hecho de que Moraes Silva se muestra innovador en unos aspectos y tradicional en otros. Así, por ejemplo, el autor cambia la división clásica de la gramática en cuatro partes por las dos partes que comprende el Epítome. Pero, al mismo tiempo, no llega a proponer una denominación para esta nueva división.

En cuanto a los contrastes interlingüísticos, Moraes Silva aplica a su obra una metodología basada en la idea común del latín como lengua de referencia para explicar las propiedades del portugués, especialmente las que resultan del parentesco etimológico, pero también las que proceden de la evolución de las 
formas gramaticales neolatinas, como la carencia de verbos pasivos o de declinación nominal. Con todo, la influencia del racionalismo en el método contrastivo de Moraes también se manifiesta en las comparaciones entre el portugués y el francés, especialmente con el propósito de identificar la presencia de galicismos léxicos en la lengua portuguesa, aunque estas referencias no son tan representativas y frecuentes como las que establece con el latín.

Con respecto a la cuestión terminológica, en la Gramática de Moraes Silva se mantiene la postura más conservadora. El autor manifiesta un cierto tradicionalismo en las denominaciones de las partes de la oración y de los conceptos sintácticos, pues conserva los mismos términos de la tradición más generalizada. Esta conformidad indica que Moraes no reflexiona sobre el interés de la terminología en su obra, pues la cuestiona las etiquetas heredadas ni tampoco propone cambios en el metalenguaje gramatical. Además, el gramático conserva el lenguaje menos técnico, que se muestra por ejemplo en el uso extendido de los términos más comunes empleados para denominar estructuras gramaticales. En general, el Epítome carece de referencias textuales sobre el origen de los términos y su autor se resiste a la introducción de un nuevo vocabulario.

Esta gramática, que abre el primer siglo de estudios gramaticales de la lengua portuguesa en Brasil y que aquí representa los tratados publicados por autores brasileños durante la primera mitad de la centuria, puede ser considerada una obra determinante en la constitución del pensamiento gramatical brasileño decimonónico. El análisis del Epítome de Moraes ha demostrado que la gramatización de la lengua portuguesa en la primera mitad del siglo XIX brasileño empieza de acuerdo con una metodología predominantemente logicista y prescriptiva, de trasfondo conservador y que se desarrolla a partir del concepto de universal lingüístico. Las obras posteriores a Moraes Silva apenas se diferencian en cuanto a la aplicación de estos preceptos, pues las pequeñas modificaciones en la 
teoría y la metodología de estos tratados no llegan a representar un cambio sustancial en la orientación de los estudios gramaticales de esta tradición brasileña.

Tras la influencia racionalista, que en la gramaticografía brasileña se extiende -en mayor o menor grado- hasta bien entrada la segunda mitad del siglo XIX, el gramático Augusto Freire concibe el modelo más completo y novedoso de codificación de la lengua portuguesa hasta este momento. En palabras del propio autor, su obra persigue el objetivo fundamental de proporcionar un estudio general, descriptivo, histórico y comparado del portugués. A pesar del avance que supone la propuesta de una gramática portuguesa como la que Freire plantea, el autor brasileño no manifiesta sus intenciones de romper con la doctrina tradicionalracionalista de sus predecesores. Al contrario, se observa más bien la casi inevitable conciliación entre los diversos marcos teóricos disponibles en este periodo.

No obstante, este modelo de gramática definido por Freire constituye el primer intento de aplicar a la codificación de la lengua portuguesa una metodología descriptiva, de organización y clasificación de contenidos, próxima al campo de las ciencias naturales. Estos supuestos naturalistas han determinado en gran medida los cambios en la constitución de la gramática. En este sentido, Freire valora la posición y la relevancia de los elementos gramaticales $y$, por consiguiente, propone una clasificación y organización jerárquica de las materias que constituyen esta disciplina. La preocupación taxonómica del gramático, su interés por las divisiones y clasificaciones detalladas se puede notar, de entrada, en la propia división de la gramática, que se asemeja al esquema del árbol genealógico compuesto por August Schleicher. Así, Freire llega a clasificar y a etiquetar los más diversos tipos de accidentes, estructuras y fenómenos gramaticales que forman la lengua portuguesa.

Es importante destacar además que esta propuesta de Freire mantiene cierta relación con la producción lingüística del autor portugués Adolpho Coelho, 
que, a su vez, recogió las influencias de los fundamentos naturalistas, cuyo mayor exponente fue Schleicher. La Gramática de Freire constituye, pues, lo que denominamos aquí el primer modelo brasileño de análisis taxonómico de la lengua materna.

La constitución de este modelo taxonómico determinó también los principales cambios en la terminología adoptada por Augusto Freire en su Gramática. Esta sistematización, que procura establecer jerarquías entre cada una de las categorías y subcategorías necesarias para el análisis de las más mínimas diferencias en materia gramatical, influyó en la renovación del metalenguaje mediante la creación y adopción de términos hasta entonces prácticamente desconocidos en nuestra tradición. Freire formó, en efecto, una nomenclatura ampliada para dar cuenta de las nuevas especies que se proponía analizar.

Así, la Gramática de Freire dispone, por ejemplo, de la lista más extensa de figuras y vicios del lenguaje, ordenados de acuerdo con su incidencia léxica o sintáctica, oral o escrita, y relacionados entre sí, de modo que a una determinada figura corresponden vicios específicos. Con la misma finalidad taxonómica, Freire utiliza un conjunto de términos inspirados especialmente en la corriente positivista para denominar todo tipo de intersección y conexión que pueda establecerse en la gramática. Habilita para el portugués, en fin, un metalenguaje que se presenta más técnico, comparado con las obras racionalistas publicadas en este mismo periodo y que elude gran parte del vocabulario heredado de la tradición latina.

En cuanto a la difusión de esta terminología, al mismo tiempo que muchos de los términos introducidos por Freire no vuelven a reaparecer en las gramáticas posteriores, como los de las figuras y vicios de lenguaje y otros relacionados con la microestructura de la gramática, el vocabulario de las partes fundamentales de la disciplina alcanzó, en cambio, una repercusión considerable en las obras finiseculares. 
En el tratamiento de los contrastes románicos, Augusto Freire demuestra, por un lado, cierto conservadurismo al utilizar esta metodología con la misma finalidad de los gramáticos que le precedieron. Así como se observa en la obra de Moraes, también en la Gramática de Freire las comparaciones entre el portugués, el latín y el francés cumplen el propósito de poner de manifiesto los rasgos distintivos de la lengua portuguesa.

Pero, por otro lado, la metodología contrastiva de Freire representa un paso más en el estudio de las semejanzas y diferencias entre el portugués y otras lenguas románicas, tanto en los aspectos morfológicos como en los comportamientos sintácticos. El autor consiguió despertar el interés por la evolución de las unidades y las estructuras gramaticales de las diversas lenguas modernas, y no solamente de la lengua objeto de estudio, como se observa en el tratamiento de las formas verbales o en la cuestión del origen del artículo. Pero tal vez su contribución más relevante en el ámbito de la variación lingüística consistió en poner de relieve las diferencias fonéticas y prosódicas entre el portugués americano y el europeo, en ampliar el alcance de los universales lingüísticos a otros idiomas diferentes del latín y el francés, y en introducir algunos componentes de las lenguas amerindias y africanas en el estudio del origen y la constitución del léxico portugués.

Estas características permiten valorar la Gramática de Augusto Freire como uno de los modelos de referencia para la tradición brasileña decimonónica. Sin embargo, esta interpretación se desvía, en cierto modo, de los estudios actuales sobre esta obra, que tienden a limitarse fundamentalmente a los rasgos tradicionales de Freire. En realidad, los marcos tradicional y racionalista forman, en conjunto, el sustrato teórico tanto para el tratado de Freire como para la mayoría de las gramáticas de este siglo, de modo que el tradicionalismo no puede ser considerado, por sí solo, un argumento definitorio de esta Gramática. Por nuestra parte, hemos tratado de destacar aquí los elementos que distinguen esta Gramática de los demás manuales publicados durante este periodo. En definitiva, 
la obra de Freire constituye verdaderamente uno de los modelos más singulares de la tradición, especialmente por la compleja red de relaciones que se establece en la organización de la materia gramatical y por la inagotable capacidad del autor para formar en portugués una nomenclatura técnica que resuelva la designación de cada pieza de ese organismo que es su lengua materna.

Casi a finales de la centuria los estudios sobre la lengua propia se orientan decididamente hacia modelos normativos. La Grammatica Portugueza de Júlio Ribeiro constituye el prototipo más claro de esta nueva etapa. En efecto, Ribeiro proporciona a la tradición brasileña una gramática de la lengua portuguesa basada en un concepto amplio de codificación normativa con cierto trasfondo de los supuestos naturalistas e historicistas. Este eclecticismo metodológico se muestra en diversos aspectos de la gramática. En primer lugar, en las fuentes teóricas citadas por el autor, pues en la obra de Ribeiro se congregan desde gramáticos prescriptivos, autores de tratados pedagógicos, hasta neogramáticos, cuyos principios teóricos buscan relacionar la lingüística con las ciencias naturales. La tendencia conciliadora que se observa en los fundamentos teóricos de Ribeiro, y que coincide en gran medida con la perspectiva de Freire, indica que nuestro autor, al mismo tiempo que reconoce la necesidad de modernización de la gramática, conserva un cierto apego a la tradición.

Pero, por otra parte, en la concepción de la lengua también se entremezclan diversos fundamentos teóricos, desde los conceptos evolucionistas, que conciben la lengua como un organismo sometido a las leyes de selección, hasta la noción más lógica, de lengua como expresión del pensamiento. Un último aspecto que revela el eclecticismo de Ribeiro, y que además pone de manifiesto la incompatibilidad de algunas teorías adoptadas por el autor, se refiere a la concepción de verbo: al mismo tiempo que Ribeiro critica la concepción portroyalista, divide los verbos en sustantivo (usen») y adjetivo. 
Con todo, pese a la confluencia de diferentes metodologías, el carácter normativo distingue particularmente esta Gramática. La finalidad normativa se manifiesta en la Grammatica Portugueza en aspectos destacados, como la reprobación explícita de formas que el autor considera incorrectas, inaceptables o decididamente rechazables y, paralelamente, la aceptación y recomendación (o prescripción) de normas y usos. Asimismo, nuestro autor declara abiertamente su interés por establecer la norma lingüística del portugués culto $y$, naturalmente, muestra su preferencia por el análisis de la forma escrita en menoscabo de las variedades orales.

Esta orientación normativa se manifiesta además en la metodología contrastiva de Ribeiro, que utiliza las comparaciones interlingüísticas con la finalidad de legitimar y justificar las teorías y reglas gramaticales por medio de la norma gramatical de otras lenguas. Sin embargo, este no es el único objetivo de los contrastes románicos en la Gramática de Ribeiro. El autor también emplea este recurso con el propósito de describir el origen y la evolución desde el latín de determinadas formas portuguesas, como el artículo y los verbos. Pero además de apoyar la utilidad de los conocimientos históricos, Ribeiro establece analogías morfológicas y sintácticas entre el portugués y otras lenguas románicas para avalar determinadas reglas gramaticales y determinar el nivel de influencia de las lenguas extranjeras en el portugués.

En el tratamiento de la terminología, Júlio Ribeiro muestra estar de acuerdo con la nomenclatura empleada por los gramáticos contemporáneos. En este sentido, el gramático da continuidad al uso de la terminología que empezó a introducirse a partir de la Gramática de Freire, como se puede notar en la denominación de las clases y subclases de palabras y elementos sintácticos. Sin embargo, Ribeiro no se muestra tan prolijo como su predecesor, de modo que renuncia a dividir y subdividir la gramática y, con ello, también simplifica la nomenclatura. 
La Grammatica Portugueza de Júlio Ribeiro representa, pues, el modelo de gramática normativa de la lengua portuguesa que persigue el propósito de facilitar el aprendizaje de la lengua materna y, además, congrega diferentes marcos teóricos para la descripción de la norma culta del portugués. El intento de sistematizar y aplicar estas novedades teóricas y metodológicas a la codificación de la lengua portuguesa, aunque en ciertas ocasiones falta coherencia, constituye en realidad uno de los principales méritos del gramático.

Finalmente, el siglo XIX avanza en Brasil con la obra que aquí se considera el modelo más representativo de la corriente descriptiva en la gramaticografía de aquel país. Se trata de la primera obra de la que tengamos noticia que, acertadamente, lleva por título Grammatica Descriptiva. Su autor, el brasileño Maximino Maciel, presenta en este tratado un cambio de orientación importante en la historia de la gramática de la lengua portuguesa, al menos por dos aspectos fundamentales. Por una parte, la obra de Maciel supone la consolidación de algunas de las bases teóricas introducidas anteriormente por Augusto Freire y Júlio Ribeiro, como la corriente naturalista, que en el tratado de Maciel resulta coherente con el interés del autor por el desarrollo historicista que en la obra se refleja en la introducción al estudio etimológico del portugués.

Por otra parte, el rasgo quizá más sobresaliente de la obra de Maciel consiste en el rigor y la exhaustividad de las descripciones que proporciona el autor acerca de los diferentes niveles de análisis lingüístico que el propio gramático distingue de la lengua portuguesa. El extenso corpus literario contemporáneo que maneja el autor creemos que carecía de precedentes en la historia de la gramática portuguesa. Este rasgo muestra que Maciel basa el análisis y la formulación de las reglas gramaticales en los modelos de uso de la lengua, de modo que las normas en sí dejan de ser el objeto central del estudio gramatical 
para constituirse más bien en la consecuencia de observaciones empíricas del comportamiento lingüístico del portugués.

Las fuentes teóricas determinan en gran medida los cambios de terminología y metalenguaje en la Grammatica Descriptiva. La preocupación de Maciel por la coherencia y la modernidad de su tratado se muestra, por una parte, en el equilibrio entre la perspectiva descriptiva y las doctrinas contemporáneas. El gramático es capaz de seleccionar de forma juiciosa los contenidos que se aplican tanto a su modelo de gramática como a la lengua objeto de estudio y conciliar así diferentes paradigmas teóricos. Por otra parte, esta coherencia descriptiva también se manifiesta en el uso de un metalenguaje acorde con su modelo de gramática. En este sentido, los principales rasgos distintivos del estudio de Maciel son el empleo (o cambio) siempre justificado de la terminología, el uso de términos actuales y, por consiguiente, el rechazo del vocabulario más tradicional y desusado, las críticas a las etiquetas imprecisas e innecesarias y la objetividad de su propuesta terminológica.

La preferencia por la perspectiva descriptiva para la codificación del portugués en la Gramática de Maciel también determinó la valoración del método contrastivo. El gramático deja claro que prescinde de las constantes indicaciones de la procedencia, la evolución desde el latín y, especialmente, de las comparaciones entre el portugués y otras lenguas para amparar su descripción gramatical. Para Maciel, la codificación de la lengua portuguesa debe basarse únicamente en los fenómenos y elementos de esta lengua, cuyo comportamiento y uso legitiman las propias reglas gramaticales. Esta concepción inmanentista constituye en sí misma un avance entre las obras decimonónicas.

Finalmente, se puede concluir que las gramáticas de Antonio de Moraes Silva, Augusto Freire, Júlio Ribeiro y Maximino Maciel protagonizaron los principales avances teóricos y metodológicos de la gramática en Brasil durante el siglo XIX. 
422 Contribución a la historia de la gramática brasileña del siglo XIX

Estas obras determinaron los principales cambios en materia gramatical y marcaron la evolución de la gramática portuguesa en Brasil.

En definitiva, los gramáticos brasileños del siglo XIX no proponen un modelo homogéneo de descripción del portugués. Cada uno pretende renovar la gramática que su generación debe conocer como exponente de la codificación de la lengua propia acorde con los planteamientos más modernos de su tiempo, pero, en muchos casos, sin romper con las fórmulas definitivamente arraigadas. Sin embargo, este pensamiento entremezclado y, en algunos casos, contradictorio, sufrió reajustes durante toda esta centuria, hasta el punto de que, al cerrar el siglo, se vive un cambio de mentalidad en los gramáticos brasileños, orientado hacia la composición de obras originales y autónomas que, con el paso del tiempo, llegarían a definir el proceso de construcción de las ideas lingüísticas en la tradición gramatical brasileña. 


\section{BIBLIOGRAFÍA}

\subsection{Corpus}

Freire da Silva, Augusto. 1894[18751-18772]. Grammatica Portugueza (obra premiada pelo Governo Geral, em 1877, e quando ainda em $2^{a}$ edição). $8^{a}$ edición. Rio de Janeiro: Livraria Classica. 402 pp.

Freire da Silva, Augusto. 1906[18751-18772]. Grammatica Portugueza (obra premiada pelo Governo Geral, em 1877, e quando ainda em $2^{a}$ edição). $9^{a}$ edición. São Paulo: Augusto Siqueira \& Comp. 478 pp.

Maciel, Maximino. 1887. Grammatica Analytica. Rio de Janeiro: Francisco Alves.

Maciel, Maximino. 1916[18871-18942]. Grammatica Descriptiva baseada nas doutrinas modernas. $6^{\circ}$ edición. Rio de Janeiro: Francisco Alves.

Maciel, Maximino. 1926[18871-18942]. Grammatica Descriptiva (baseada nas doutrinas modernas) Aumentada e Refundida. 10 ${ }^{a}$ edición. São Paulo: Livraria Francisco Alves \& Cia. 513 pp.

Moraes Silva, Antonio de. 1813. Diccionario da Língua Portugueza. Epítome da Grammatica Portugueza. $2^{a}$ edición. Lisboa: Typographia Lacerdina.

Moraes Silva, Antonio de. 1824[1806]. Epitome de grammatica la lingua portugueza. Rio de Janeiro: Typographia de Silva Porto \& C $C^{a} 260$ pp.

Moraes Silva, Antonio de. 1826[1806]. Grammatica Portugueza. Rio de Janeiro: Typographia de Silva Porto, e comp. 260 pp.

Ribeiro, Júlio 1899[18811-1885²]. Grammatica Portugueza. 5a edición. São Paulo: Miguel Melillo-Editor. 365 pp.

Ribeiro, Júlio. 1881. Grammatica Portugueza. São Paulo: Tipographia de Jorge Seckler. 299 pp.

Ribeiro, Júlio. 1910[1881'-18852]. Grammatica Portugueza. 10ª edición. São Paulo, Rio de Janeiro y Belo Horizonte: Livraria Francisco Alves \& C. 361 pp. 


\subsection{Fuentes primarias}

Arnauld, Antoine et Claude Lancelot. 1988[1660]. Grammaire générale et raisonnée de Port-Royal, suive de: $1^{\circ}$ de la partie de la logique de Port-Royal qui traite des prépositions, $2^{\circ}$ des remarques de Duclot, de l'Académie française, $3^{\circ}$ du supplément à la grammaire générale de Port-Royal. Par l'Abbé Formant, et publiée sur le meilleure édition originale. Avec une introduction historique par $M$. A. Bailly. Géneve: Slatkine Reprints.

Ayer, Cyprien. 1875. Grammaire française, ouvrage destiné a servir de base à l'enseignement scientifique de la langue. Lausanne: $\mathrm{H}$. Georg.

Ayer, Cyprien. 1876. Grammaire de la Langue Française. Bâle y Lyon: H. Georg.

Bain, Alexander. 1855. The senses and the intellect. London: John W. Parker and son.

Bain, Alexander. 1859. The emotions and the will. London: John W. Parker and son.

Bain, Alexander. 1863. English Grammar. London: Longman, Green, Longman, Roberts and Green.

Bain, Alexander. 1868. Mental science. A compendium of psychology, and the history of philosophy. New York: D. Appleton and company.

Barboza, Jeronymo Soares. 1830[1822]. Grammatica philosophica da lingua portuguesa ou principios da grammatica geral applicados a nossa linguagem. $2^{a}$ edición. Lisboa: Typographia da Academia Real das Sciencias.

Barboza, Jeronymo Soares. 1864[1822]. Grammatica philosophica da lingua portuguesa ou principios da grammatica geral applicados a nossa linguagem. $4^{a}$ edición. Lisboa: Typographia da Academia Real das Sciencias.

Barros, João de. 1971[1540]. Gramática da língua portuguesa. Cartinha, gramática, diálogo em louvor da nossa linguagem e dialogo da viciosa vergonha. Reprodução fac-similada, leitura, introdução e anotações por Maria Leonor Carvalho Buescu. Lisboa: Faculdade de Letras da Faculdade de Lisboa.

Beauzée, Nicolas. 1974[1767]. Grammaire Générale, ou Exposition raisonnée des éléments nécessaires du langage pour servir de fondement à l'étude de toutes 
les langues, 2 vols. Edición facsímil con una introducción por B. E. Bartlett. Sttutgart-Bad Cannstatt: Friedrich Fromann Verlag.

Bello, Andrés y Rufino José Cuervo. 1988[1847]. Gramática de la lengua castellana. Ed. de Ramón Trujillo. Madrid: Arco Libros.

Bello, Andrés. 1981 [1847]. Gramática de la lengua castellana destinada al uso de los americanos. Santa Cruz de Tenerife: R. Trujillo.

Benot, Eduardo. 1900. Arquitectura de las lenguas. Madrid: Juan Muñoz Sánchez. 3 vols.

Benot, Eduardo. 1921[1910]. Arte de Hablar. Gramática filosófica de la lengua castellana. $2^{a}$ edición. Madrid: Libr. de los sucesores de Hernando.

Blake, Augusto Victorino Alves Sacramento. 1883. Diccionario Bibliographico Brazileiro. 7vol. Rio de Janeiro: Imprensa Nacional.

Bluteau, Rafael. 1712, 1716, 1721. Vocabulario Portuguez e Latino, Aulico, Anatomico, Architectonico, Bellico, Botanico, Brasilico, Comico, Critico, Chimico, Dogmatico, etc. autorizado com exemplos dos melhores escriptores portuguezes e latinos, e ofenecido a El-rey de Portugal D. João V. I a IV. Coimbra: Collegio das Artes de Companhia de Jesus. V a VIII. Lisboa: Officina de P. da Sylva.

Bopp, Franz. 1833. Vergleichende Grammatik, des Sanskrits, Zend, Griechischen, Hateinischen, Gothischen und Deutschen. Berlin: 2e edition. 1857-1860 (2 vol.) Traduction française par Michel Bréal. 1866-1874. Grammaire comparée des langues indoeuropéennes comprenant le sanscrit, le zend, l'arménien, le grec, le latin, le lithuanien, l'ancien slave, le gothique et l'allemand. Nouvelle édition 1885-1889 (5 vol.). Imprimerie impériale et imprimerie nationale.

Bréal Michel. 1897. Essai de sémantique (science des significations). Paris: Hachette.

Bréal, Michel. 1893. De l'enseignement de langues vivantes. Conférences faites aux étudiantes en lettres de la Sorbonne. Paris: Hachette.

Brozas, Francisco Sánchez de las. 1976[1587]. Minerva seu de causis linguae latinae. Traducción e introducción por Fernando Rivera Cárdenas. Madrid: Cátedra. 
Brunot, Jacques Charles. 1865. Manuel du libraire et de l'amateur de livres (tomo VI). Paris: librairie de Firmin Didot Frères, Fils ET C $C^{\text {te. }}$

Caneca, Frei Joaquim do Amor Divino. 1875[1817]. Breve Compendio da Grammatica Portugueza. Edición Póstuma. Recife: Typographia Mercantil.

Carlos Pereira, Eduardo. 1916. Grammatica Historica. Weiszflog Irmãos.

Carneiro Ribeiro, Ernesto. 1915[1890]. Serões Gramaticaes. Augmentada e cuidadosamente revista pelo autor. $2^{a}$ edición. Bahia: Livraria Catilina de Romualdo dos Santos.

Carneiro Ribeiro, Ernesto. 1950[1890]. Serões Gramaticaes. 5 $5^{a}$ edición. Bahia: Livraria Progresso Editora - Aguiar \& Souza Ltda.

Chassang, Marie A. 1880. Nouvelle grammaire française. Cours supérieur avec des notions sur l'histoire de la langue et en particulier sur les variations de la syntaxe du XVIe au XIXe siècle. Paris: Garnier.

Coelho, F. Adolfo. 1868. A lingua portugueza. Phonologia, etymologia, morphologia e syntaxe. Coimbra: Imprensa da Universidade.

Coelho, F. Adolfo. 1871. Sobre a Lingua Portugueza. En Frei Domingos Vieira, Grande diccionario portuguez ou thesouro da língua portugueza, publicação feita sobre o manuscripto original, inteiramente revisto e consideravelmente augmentado. 2 vols. IX-CCVII. Porto: Ernesto Chardron e Bartholomeu H. de Moraes.

Coelho, F. Adolfo. 1881. A lingua portugueza. Noções de glotologia geral e especial portugueza. Porto: Livraria Universal.

Coelho, F. Adolfo. 1891. Noções elementares de grammatica portugueza. Porto: Lemos \& $C^{a}$. Editores.

Condillac, Etíenne Bonnot de. 1776. Cours d'Étude pour l'instruction du Prince de Parme - Grammaire. Tomo I. Londres: Chez les Libraires François.

Constancio, Francisco Solano. 1831. Grammatica analytica da lingua portugueza. Rio de Janeiro: Laemmer. 
Coruja, Antônio Álvares Pereira. 1875[1835]. Compendio de Grammatica da Lingua Nacional. $2^{a}$ edición. Rio de Janeiro: Typographia Esperança.

Coruja, Antônio Álvares Pereira. 1888[1852]. "Coleção de Vocábulos e Frases Usados na Província de São Paulo do Rio Grande do Sul" en Revista do Instituto Histórico e Geográfico Brasileiro. XV Tomo. 2a edición. 205-238. Rio de Janeiro: Typographia Universal de Laemmert.

Cunha, A. Estevão da Costa e. 1883. Principios de Gramática Histórica e Comparada. s/c. s/e. [manuscrito].

Darmesteter, Arsène. 1937[1887]. La Vie des Mots. Paris: Librairie Delagrave.

Dias de Souza, Manuel. 1804. Grammatica Portugueza segundo a doutrina dos mais celebres grammaticos conhecidos assim nacionaes como estrangeiros. Coimbra: Real Imprensa da Universidade.

Diez, Friedrich. 1874-1877[1836']. Grammaire des langues romanes. Trad. par A. Brachet, G. Paris y A. Morel-Fatio. Paris: Vieweg.

Dumarsais, Cesar Chesnau. 1971. Oeuvres choises. Edición facsímil con una introducción por H. E. Brekle. Stuttgart-Bad Cannstatt: Friedrich Fromann Verlag.

Dumarsais, Cesar Chesnau. 1988[1730]. Des tropes ou des diférens sens dans lesquels on peut prendre un même mot dans une même langue. Chez la Veuve de JB. Paris: Brocas. Réédition présentée, commentée et annotée par F. Douai. Paris: Flammarion.

Ferreira, Francisco S. 1819. Elementos de grammatica portugueza. Imprenta Regia. Lisboa.

Figueiredo, Pedro José de. 1799. Arte da Grammatica portuguesa, ordenada em methodo breve, facil e claro, of erecido a sua alteza real o ser.mo sr. D. António, principe da Beira. Lisboa: Régia Oficina Tip.

Gomes, Alfredo. 1913[1887]. Grammatica Portugueza. 15a edición. Rio de Janeiro, São Paulo y Belo Horizonte: Livraria Francisco Alves.

Gómez Asencio, José J. 2001. Antiguas Gramáticas del Castellano /Clásicos Tavera, Serie VIII: lingüística y antecedentes literarios de la Península lbérica - vol. I/ n 53). CD-ROM. Madrid, Fundación Histórica Tavera. 
Grimm, Jacob. 1853[1848]. Geschichte der Deutschen Sprache. 2a edición. 2 vols. Leipzig: S. Hirzel.

Grivet, Charles Adrien Olivier. 1886[1881]. Nova Grammatica Analytica da Lingua Portugueza. Rio de Janeiro: Leuzinger.

Humboldt, Wilhelm Von. 2000. Sur le caractère national des langues et autres écrits sur le langage. Édition bilingue allemand-français de D. Thouard. Paris: Sevil.

Larive et Fleury. 1871. La première année de grammaire. Paris: A. Colin.

Leão, Duarte Nunes de. 1983[1606]. Ortografia e Origem da Língua Portuguesa. Introdução, notas e leitura de Maria Leonor Carvalho Buescu. Lisboa: Imprensa Nacional - Casa da Moeda.

Lobato, Antônio José dos Reis. 1824[1770]. Arte da grammatica da lingua portugueza. Lisboa: Typographia Rollandiana.

Mason, Charles Peter. 1867. Analytical Latin Exercises. Accidence and simple sentences. London: Benjamin Pardon.

Mason, Charles Peter. 1877. English Grammar: including the principles of grammatical analysis. $22^{a}$ edición. Toronto: Adam Miller and Co.

Mello Moraes, A. J. 1859. Corographia historica, chronographica, genealogica, nobiliária e política do Imperio do Brasil. Rio de Janeiro: Tipographia Brasileira.

Moraes Silva, Antonio de. 1789. Diccionario da Lingua Portugueza, composto pelo Padre D. Rafael Bluteau, reformado, e acrescentado. Lisboa: Officina de Simão Thaddeo Ferreira.

Moraes Silva, Antonio de. 1890[1789]. Diccionario da Lingua Portugueza. 2 vols. Rio de Janeiro: Editora Empreza Literaria Fluminense.

Müller, Max. 1859. A history of ancient Sanskrit literature. London: Edinburg, Williams and Norgate. Paris: B. Duprat. Leipzig: R. Hartmann.

Müller, Max. 1861. Lectures on the science of language. London: Longman, Green, Longman, Roberts and Green. 
Murray, Lindley. 1795. English Grammar. York.

Oliveira, Fernão de. 1975[1536]. Gramática da Linguagem Portuguesa. Introdução, leitura actualizada e notas por Maria Leonor Carvalho Buescu. Lisboa: Imprensa Nacional - Casa da Moeda.

P.S. 1909. Syntaxe e Grammatica histórica da lingua portuguesa. Pelotas e Rio Grande: Livraria Americana Pinto \& C.

Pereira da Silva, J. M. 1858. Os varões ilustres do Brazil durante os tempos coloniáes. Paris: Livraria de A. Franck.

Pereira, Luis Marcelino. 1798-1800. Discurso sobre las mejoras y menoscabos que recibió la lengua Castellana en los siglos XVII y XVIII. Manuscrito. Real Academia Española.

Priestley, Joseph. 1762. A course of lectures on the theory of language and universal grammar. Washington: W. Eyres.

Reinach, Salomon. 1886. Grammaire latine à usage dês classes supérieures. Paris.

Ribeiro, João. 1933. A Língua Nacional: Notas Aproveitáveis. 2a edição. São Paulo: Companhia Editora Nacional.

Salvá, Vicente. 1988[18301-18478]. Gramática de la lengua castellana según ahora se habla. Estudio y Edición de Margarita Lliteras. Madrid: Arco Libros.

San Pedro, Benito de. 1769. Arte del Romance castellano dispuesta según sus principios generales y el uso de los mejores autores. Valencia: Benito Monfort.

Saraiva, Francisco de São Luis. 1824-1828. Ensaio sobre alguns synonimos da lingua portuguesa. Volumen 1 y 2. Lisboa: Academia Real das Sciencias.

Saraiva, Francisco de São Luis. 1827. Glossario das palavras e frases da lingua francesa, que por descuido, ignorancia, ou necessidade se tem introduzido na locução portuguesa moderna: com o juizo critico das que são adoptaveis nella. Lisboa: Tipografia da Academia Real das Sciencias de Lisboa.

Sarmento, Hermínio. 1917. Gramática histórica e comparativa da língua portuguesa. Póvoa de Varzim: Livraria Povoense. 
Schleicher A. 1861. Compendium der Vergleichenden Grammatik der Indogermanischen Ursprache. H. Böhlau: Weimar.

Silva Dias, A. Epiphanio da. 1894[1870]. Grammatica Portugueza Elementar. 9a edición. Lisboa: Livraria Escolar de Ferreira Machado \& $C^{a}$ - Editores.

Silva Jr., Manuel Pacheco da y Boaventura Plácido Lameira de Andrade. 1894[1887]. Grammatica da Lingua Portugueza. 2a edición. São Paulo: Livraria Classica de Alves \& C.

Sotero dos Reis, Francisco. 1871[1866]. Grammatica Portugueza (Acomodada aos principios gerais da palavra seguidos de inmediata aplicação practica). $2^{a}$ edición. Maranhão: Typographia de R. d'Almeida \& C. Editores.

Varnhagen, F. A. de. 1852. Biografias de Brasyleiros Illustres ou de Pessoas Eminentes que serviram no Brazil ou ao Brazil. tomo XV. Revista do Instituto Histórico e Geográfico Brasileiro.

Whitney, William Dwight. 1899[1877]. Essentials of English Grammar. Boston: Ginn \& Company Publishers.

\subsection{Fuentes secundarias}

Aarsleff, Hans. 1975. "The eighteenth century including Leibniz". En Current Trends in Linguistics 13, 1. 383-479. La Haya: Mouton.

Aarsleff, Hans. 1982. "B. la Semantique et Saussure". En HEL 3, II. 115-133.

Agud, Ana. 1990. HUMBOLDT, Wilhelm von. Sobre la diversidad de la estructura del lenguaje humano y su influencia sobre el desarrollo espiritual de la humanidad. Traducción y prólogo: Ana Agud. Barcelona: Anthropos. Madrid: Ministerio de Educación y Ciencia.

Alonso, Amado. 1951-1972. "Introducción a los estudios gramaticales de Andrés Bello". En Prólogo a la edición de la Gramática de la lengua castellana de A. Bello y R. J. Cuervo. IX-LXXXVI. Caracas. 
Alter, S. G. 1993. William Dwight Whitney and the science of language. 2 vols. Dissertation: University of Michigan.

Altman, Cristina. 1996. "Questões em historiografia lingüística". En Revista da ANPOLL, n² 2. 45-77.

Altman, Cristina. 1997a. "As Gramáticas das 'Línguas Gerais' Sul-Americanas como um Capítulo da Historiografia Lingüística Ocidental." En M. Fernández Rodríguez, F. García Gondar y N. Vázquez Veiga (eds.), Actas del I Congreso Internacional de la Sociedad Española de Historiografía Lingüística A Coruña, 1821 de febrero de 1997. 151-160. Madrid: Arco Libros.

Altman, Cristina. 1997b. "Tupi or not Tupi, that s the question - the grammars of general languages and the missionary enterprise". En Annual Meeting of the North American Association for the History of the Language Science. Chicago: Conferene Handbook.

Altman, Cristina. 1998. A Pesquisa Lingüística no Brasil (1968-1988). 117-125. São Paulo: Humanitas.

Altman, Cristina. 2003. "As línguas gerais sul-americanas e a empresa missionária: linguagem e representação nos séculos XVI e XVII". En José Ribamar Bessa Freire y Maria Carlota Rosa (Org.), Línguas Gerais Política Lingüística e Catequese na América do Sul no Período Colonial. 57-83. Rio de Janeiro: EdUERJ.

Altman, Cristina. 2007. "Artigos e Pronomes na Tradição Lingüística Missionária da Língua mais Falada na Costa do Brasil". En Martina Schrader-Kniffki y Laura Morgenthaler García (eds.), Romania en interacción: entre historia, contacto y política. Ensayos en homenaje a Klaus Zimmermann. 837-854. Frankfurt am Main: Iberoamericana/Vervuert.

Altman, Cristina. 2009. "Retrospectivas e perspectivas da historiografia lingüística no Brasil". En Revista Argentina de Historiografia Lingüística, V. 1, 2. 115-136. Publicación electrónica: http://www.rahl.com.ar/Revistas/ll\%20-\%202009/altmanRAHL-(2)2009.pdf (última consulta 04/06/2011).

Amor Couto, Manuel. 2004. "Gramática e teorização lingüística em Portugal: a Gramática Filosófica de Jerónimo Soares Barbosa". En Revista Galega de Filoloxia - 5. 11-30. Publicación electrónica: http://hdl.handle.net/2183/2613 (última consulta 03/06/2011). 
Amsterdamska, O. 1987. Schools of Thought. The development of linguistics from Bopp to Saussure. Dordrecht: Springer.

Aquarone, S. 1958. The life and works of Emile Littré. Leyden: Sythoff.

Araújo, A. M. 2003. A herança de João de Barros e outros estudos. São Luiz: Academia Maranhense de Letras.

Arens, Hans. 1975. La lingüística. Sus textos y su evolución desde la antigüedad hasta nuestros días. Versión española de José María Díaz-Regañón López. Madrid: Editorial Gredos.

Assunção, Carlos. 1997a. "Uma leitura da introdução da Arte da Grammatica da Lingua Portugueza de Reis Lobato (1770)". En Revista da Faculdade de Letras do Porto "Linguas e Literaturas" S. 2, V 14. 165-184. Porto.

Assunção, Carlos. 1997b. Para a História da Linguística em Portugal - Reis Lobato, Gramático Pombalino. Lisboa: Associação Portuguesa de Lingüística.

Assunção, Carlos. 1999. "A gramática de Reis Lobato (1770) e a Gramática de la Lengua Castellana da RAE (1771): duas gramáticas do poder". En M. C. H. Salido y M. A. Esparza Torres (eds.), Estudios de historiografía lingüística hispánica ofrecidos a Hans-Josef Niederehe. 25-37. Vigo: Departamento de Filología Española de la Universidad de Vigo - Publicaciones del área de lengua española, 4.

Assunção, Carlos. 2000. A Arte da Grammatica da Lingua Portugueza de Antonio José dos Reis Lobato - estudos, edição crítica, manuscritos e textos subsidiários. Lisboa: Academia de Sciencias de Lisboa.

Assunção, Carlos. 2002. "As classes de palavras: dos primórdios a Cunha \& Cintra". En M. A. Esparza Torres, B. Fernández Salgado y H. J. Niederehe (eds.), SEHL 2001 - Estudios de Historiografía Lingüística (Actas del III Congreso Internacional de la Sociedad Española de Historiografía Lingüística - Vigo, 7-10 de febrero de 2001). 15-24 (Tomo I). Hamburg: Helmut Buske Verlag.

Assunção, Carlos. 2007. "As primeiras gramáticas escolares vernáculas oficiais de Espanha e Portugal". En A. Marcos De Dios (ed.), Aula Ibérica. 281-292. Salamanca: Ediciones Universidad de Salamanca. 
Assunção, Carlos y Gonçalo Fernandes. 2007. Roboredo, Amaro de: Methodo Grammatical para todas as Linguas. Edição facsimilada. Prefácio e Estudo Introdutório de Carlos Assunção e Gonçalo Fernandes. Vila Real: Centro de Estudos em Letras, Universidade de Trás-os-Montes e Alto Douro. Colecção Linguística, 1.

Aver, Anita y Ingrid Tieken-Boon van Ostade. 2007. "Robert Lowth and the use of the inflectional subjunctive in eighteenth-century English". En Ute Smit, Stefan Dollinger, Julia Hüttner, Ursula Lutzky y Gunther Kaltenböck (eds.), Tracing English through Time: Explorations in Language Variation. 1-18. Vienna: Braumüller.

Auroux, Sylvain (ed.). 1989-1992. Historie des ideés linguistiques, 2 vols. Lieja y Bruselas: Pierre Mardaga.

Auroux, Sylvain. 1973. L'encyclopédie: "grammaire" et "langue" au XVIIle siècle. Paris: Maison Mame.

Auroux, Sylvain. 1979. La sémiotique des Encyclopédistes. Paris: Payot.

Auroux, Sylvain. 1984. "Linguistique et anthropologie en France (1600-1900)". En Rupp-Eisenreich (ed.), Histories de L'anthropologie (XVIe-XIXe siècles). 291-318. Paris.

Auroux, Sylvain. 1985-1986. "La teoría de los tiempos en la gramática general francesa (Beauzée y Destutt de Tracy)". En E.L.U.A. 3. 287-312

Auroux, Sylvain. 1988. "La grammaire générale et les fondements philosophiques des classements de mots". En Langages, 23e année, 92. 79-92.

Auroux, Sylvain. 1992a. "Le processus de grammaticalisation et ses enjeux". En S. Auroux (ed.), Historie des ideés linguistiques, 2 vols. 11-64. Lieja y Bruselas: Pierre Mardaga.

Auroux, Sylvain. 1992b. "Les parties du discours et leurs critères". En S. Auroux (ed.), Historie des ideés linguistiques, 2 vols. 581-590. Lieja y Bruselas: Pierre Mardaga.

Auroux, Sylvain. 1992c. A Revolução Tecnológica da Gramatização. Campinas: Editora da UNICAMP. 
Auroux, Sylvain. 1996. "Beauzée, Nicolas". En Harro Stammerjohann (ed.), Lexicon Grammaticorum. 79-80. Tübingen: Niemeyer.

Auroux, Sylvain. 2009. "Instrumentos lingüísticos y políticas lingüísticas: la construcción del francés". En Revista Argentina de Historiografia Lingüística, V. 1, 2. 137-149. Publicación electrónica: http://www.rahl.com.ar/Revistas/ll\%20\%202009/auroux-RAHL-(2)2009.pdf (última consulta 04/06/201 1).

Auroux, Sylvain, E. F. K. Koerner, Hans-Josef Niederehe y Kees Versteegh (eds.). 2000-2006. History of the language sciences: an international handbook on the evolution of the study of language from the beginning to the present. Berlin $y$ New York: De Gruyter.

Baggioni, Daniel. 1988. "La linguistique européenne et les langues exotiques". En J.M. Racault (ed.), "L'Exotisme" Cahiers du centre de recherches Litt. et Hist. Centre Inter-Disciplinaire de Recherches Afro-indien-océaniques 5. 19-31.

Baggioni, Daniel. 1996a. "Hovelacque, Abel". En Harro Stammerjohann (ed.), Lexicon Grammaticorum. 223. Tübingen: Niemeyer.

Baggioni, Daniel. 1996b. "Sylvestre de Sacy, Baron Antoine Isaac". En Harro Stammerjohann (ed.), Lexicon Grammaticorum. 901-902. Tübingen: Niemeyer.

Baggioni, Daniel. 1996c. "Vinson, Julien". En Harro Stammerjohann (ed.), Lexicon Grammaticorum. 976-977. Tübingen: Niemeyer.

Baron, Dennis E. 1982. Grammar and Good taste. Reforming the American Language. New Haven: Yale University Press.

Barreto, F. y Carlos Laet. 1921. Antologia Nacional. 9ª edición. São Paulo: Paulo de Azevedo e Cia.

Barros, Diana Luz Pessoa de. 1997. "A propósito do conceito de discurso urbano oral culto: definições e imagens". En D. Preti (org.), O discurso oral culto. São Paulo: Humanitas.

Barros, Diana Luz Pessoa de. 2000. Os discursos do descobrimento: 500 e mais anos de discursos. São Paulo: EdUSP. 
Barros, Diana Luz Pessoa de. 2005. "O discurso da Norma nas gramáticas portuguesas do século XVI". En Estudios Portugueses 5 - Revista de Filología Portuguesa. 11-24. Salamanca: Luso-Española de Ediciones.

Barros, Diana Luz Pessoa de. 2008. "Linguagem popular na gramática e no dicionário". En Investigações - Linguística e Teoria Literária. V.21, n² 2.

Bartlett, Barrie E. 1975. Beauzée's Grammaire Generale. Theory and Methodology. Serie Janua Linguarum - Series Maior/ Studia Memoriae Nicolai van Wijk dedicata 82. Mouton: De Gruyter.

Bastos, Neusa Barbosa. 2006. Lingua portuguesa: reflexões lusófonas. São Paulo: Editora da PUC-SP.

Bastos, Neusa Barbosa, Regina Helena Pires de Brito y Vera Lúcia Harabagi Hanna. 2006. "Gramaticografia novecentista: raízes maximianas". En N. Barbosa Bastos y D. Vesaro Palma (orgs.), História Entrelaçada 2: a construção de gramáticas e o ensino de língua portuguesa na primeira metade do século XX. IP-PUC/SP. 61-81. Rio de Janeiro: Editora Lucerna.

Bastos, Neusa Barbosa y Dieli Vesaro Palma (Orgs). 2004. História entrelaçada: A construção de gramáticas e o ensino de língua portuguesa do século XVI ao XIX. São Paulo: IP-PUC/SP; Rio de Janeiro: Lucerna.

Battisti, C. 1937. "Guglielmo Meyer-Lübke e la linguistica contemporanea". En Arquivum Romanicum 21. 419-435.

Bechara, Evanildo. 2010. "Um capítulo esquecido na historiografia lingüística do português: a obra da Manuel de Melo (Aveiro, 1834 - Milão, 1884)". En C. Assunção, G. Fernandes, M. Loureiro (eds.), Idéias Lingüísticas na Península Ibérica (séc. XIV a séc. XIX), Volume 1. 43-52. Münster: Nodus Publikationen.

Bergheaud, Patrice. 1979. "De James Harris à John Horne Tooke: Mutations De L'Analyse Du Langage. En Angleterre Dans La Deuxieme Moitie Du XVIIIe Siècle". En Historiographia Linguistica, 6/1. 15-45.

Bergounioux, G. 1984. "La science du langage en France de 1870 a 1885: du marché civil au marché étatique". En LFr 63. 7-41. 
Bessa Freire, José Ribamar y Maria Carlota Rosa (Org.). 2003. Línguas Gerais Política Lingüística e Catequese na América do Sul no Período Colonial. Rio de Janeiro: EdUERJ.

Blecua, J. M. 1973. Revolución en la lingüística. Barcelona: Salvat.

Bloomfield, L. 1964. Lenguaje. Traducción al español de Alma Flor Ada de Zubizarreta, prólogo de A. Escobar. Lima: Universidad Nacional Mayor de San Marcos.

Boléo, Manuel de Paiva. 1948. "Adolfo Coelho e a filologia portuguesa e alemã no século XIX". En Biblos XXIII. 607-691.

Borges Neto, José. 2010. "A ANALYSE LOGICA de Carneiro Ribeiro em seus SeRões Grammaticaes (1890)". En C. Assunção, G. Fernandes, M. Loureiro (eds.), Idéias Lingüísticas na Península Ibérica (séc. XIV a séc. XIX), Volume 2. 649-656. Münster: Nodus Publikationen.

Borrego Nieto, Julio. 2008. "La norma en las gramáticas de la Real Academia Española". En LEA, 1. 5-36.

Borsche, Tilman. 1981. Sprachansichten: Der Begriff der menschlichen Rede in der Sprachphilosophie Wilhelm von Huboldts. Sttutgart: Klett-Cotta.

Bréal Michel. 1995. De la grammaire comparée à la sémantique: textes de Michel Bréal publiés entre 1864 et 1898. Peeters Publishers.

Brekle W. E. y B. Asbach-Schitker. 1975. "Introduction". En Sacy, Principes de grammaire générale. 5-40. Sttutgart: Bad Cannstatt.

Breva-Claramonte, Manuel. 1980. "La teoría gramatical del Brocense en los siglos XVII y XVIII". En RFE 10, 2. 351-372.

Breva-Claramonte, Manuel. 2001. "El signo en el nacimiento de la gramática "general': de Platón al Brocense". En M. Maquieira Rodríguez, M. a D. Martínez Gavilán y M. Villayandre Llamazares (eds.), Actas del II Congreso Internacional de la Sociedad Española de Historiografía Lingüística, León, 2-5 de marzo de 1999. 17-34. Madrid: Arco Libros.

Breva-Claramonte, Manuel. 2002. "La lógica interna como método historiográfico. Su aplicación a la Minerva (1587) del Brocense". En M. A. Esparza 
Torres, B. Fernández Salgado y H. J. Niederehe (eds.), SEHL 2001 - Estudios de Historiografía Lingüística (Actas del III Congreso Internacional de la Sociedad Española de Historiografía Lingüística - Vigo, 7-10 de febrero de 2001). 25-34 (Tomo I). Hamburg: Helmut Buske Verlag.

Buescu, Maria Leonor Carvalhão. 1978. Gramáticas Portuguesas do século XVI. Amadora, Portugal: Biblioteca Breve - Instituto de Cultura Portuguesa.

Buescu, Maria Leonor Carvalhão. 1983. Babel ou a ruptura do signo. A gramática e os gramáticos portugueses do século XVI (Temas Portugueses). Lisboa: Imprensa Nacional - Casa da Moeda.

Buescu, Maria Leonor Carvalhão. 1984. Historiografia da Língua Portuguesa. Lisboa: Livraria Sá da Costa Editora.

Buescu, Maria Leonor Carvalhão. 2000. "Le premières descriptions gramaticales du Portugais". En S. Auroux, E. F. K. Koerner, H. J. Niederehe y K. Versteegh (eds.), History of the language sciences: an international handbook on the evolution of the study of language from the beginning to the present. 756-764. Berlin y New York, De Gruyter.

Bustos Gisbert, Eugenio de. 1997. "Gramática y lingüística en los Siglos de Oro: a propósito del verbo". En Cuadernos de Filología Hispánica, $n^{\circ} 15$. 101-111. Madrid: Servicio de Publicaciones UCM.

Cabrera, C. 2005. "Sobre el principio etimológico en la ortografía castellana". En L. Santos Ríos, J. Borrego Nieto, J. F. García Santos, J. J. Gómez Asencio y E. Prieto de los Mozos (eds.), Palabras, norma, discurso. En memoria de Fernando Lázaro Carreter. 215-224. Salamanca, Ediciones Universidad de Salamanca.

Cadernos da associação portuguesa de lingüística. 1995. Lembrar Adolfo coelho (1847-1919) $1^{\circ}$ caderno. Lisboa: APL.

Cagliari, Luiz Carlos. 1985. "A escrita na gramática de Jerônimo Soares Barbosa". En Anais de Seminários do Grupo de Estudos Lingüísticos (GEL). 93-97. Bauru: São Paulo.

Cagliari, Luiz Carlos. 2008. "A descrição fonética na Grammatica da Lingoagem Portugueza (1536) de Fernão de Oliveira". En Alfa São Paulo, 52 (2). 565-577. 
Calero Vaquera, María Luisa. 1986. Historia de la gramática española (18471920) de A. Bello a A. R. Lenz. Madrid: Editorial Gredos.

Calero Vaquera, María Luisa. 2008. "Análisis lógico y análisis gramatical en la tradición española: hacia una (r)evolución de sintaxis". En Gramma-Temas 3: España y Portugal en la tradición gramatical. 11-42. León: Universidad de León.

Calero Vaquera, María Luisa. 2010. "Sintaxis y gramática escolar en la España Del siglo XIX: su proyección en Hispanoamérica". En C. Assunção, G. Fernandes, M. Loureiro (eds.), Idéias Lingüísticas na Península Ibérica (séc. XIV a séc. XIX), Volume 1. 67-84. Münster: Nodus Publikationen.

Calvo Fernández, Vicente y Miguel Ángel Esparza Torres. 1993. "Una interpretación de la gramática castellana de Nebrija a la luz de la tradición escolar". En Cuadernos de Filología Clásica, Estudios Latinos 5. 149-180. Madrid: Editorial Complutense.

Câmara Jr, J. Mattoso. 1971. Problemas de Lingüística Descritiva. Rio de Janeiro: Editora Vozes.

Câmara Jr, J. Mattoso. 1974. Dicionário de Filologia e gramática (referente à Lingua Portuguesa). São Paulo: J. Ozon Editor.

Câmara Jr, J. Mattoso. 1975. História e Estrutura da Língua Portuguesa. Rio de Janeiro: Padrão.

Cardoso, Simão. 1986. A gramática filosófica de Jerônimo soares Barbosa reflexos da gramática geral. Dissertação de mestrado em lingüística portuguesa descritiva. Apresentada á Universidade do Porto. Porto.

Cardoso, Simão. 1994. Historiografia gramatical (1500-1920): lingua portuguesa autores portugueses. Revista da Faculdade de Letras. Series línguas e literaturas anexo 7. Porto: Faculdade de Letras do Porto

Cardoso, Simão. 2004. "O estudo da palavra na gramática portuguesa no séc. XVI". En A. M. Brito, O. Figueiredo y C. Barros (orgs), Lingüística Histórica e História da Língua Portuguesa (Actas do Encontro de Homenagem a Maria Helena Paiva - Faculdade de Letras da Universidade O Porto, 5-6 de noviembre de 2003). 73-87. Porto: Universidade O Porto, Faculdade de Letras. 
Carneiro Ribeiro, Danilo. 1939. Ernesto Carneiro Ribeiro: sua vida e sua obra. Rio de Janeiro: José Konfino Editor.

Carreter, Fernando Lázaro. 1985[1949]. Las ideas lingüísticas en España durante el siglo XVIII. Barcelona: Editorial Crítica.

Carvalho, Jairo Dias de. 1993. "Antonio de Nebrija e Fernão de Oliveira". En Estudos universitarios de língua e literatura. Homenagem ao Prof. Leodegário A. de Azevedo Filho. 195-198. Rio de Janeiro: Tempo Brasileiro.

Casteleiro, J. Malaca. 1980/81. "Jerónimo Soares Barbosa: um gramático racionalista do século XVIII". En Boletim de Filologia, XXVI. 101-110.

Catroga, Fernando. 1976. "Os inícios do positivismo em Portugal. O seu significado político e social". En Revista de História das Ideias, 1. 287-393.

Catroga, Fernando. 1977. "A importância do positivismo na consolidação da ideologia republicana em Portugal". En Biblos, vol. 53. 285-327.

Catroga, Fernando. 1998. "positivistas e republicanos". En Luis reis torgal et alii (eds.), História da História em Portugal (séculos XIX e XX). A História através da História - Lisboa temas e debates. 101-134.

Cavaliere, Ricardo. 2000. Fonologia e Morfologia da gramática científica brasileira. Rio de Janeiro: Editora da UFRJ.

Cavaliere, Ricardo. 2002. "Uma proposta de periodização dos estudos lingüísticos no Brasil". En Confluência: revista do instituto de língua portuguesa, $n^{\circ}$ 23. Rio de Janeiro.

Cavaliere, Ricardo. 2003. "O Epítome de Antonio de Moraes Silva na historiografia gramatical brasileira". En Confluência: revista do instituto de língua portuguesa, $n^{\circ} 25$. Rio de Janeiro.

Cavaliere, Ricardo. 2010. "A Corrente Racionalista na Gramática Brasileira no Século XIX". En C. Assunção, G. Fernandes, M. Loureiro (eds.), Idéias Lingüísticas na Península Ibérica (séc. XIV a séc. XIX), Volume 1. 107-118. Münster: Nodus Publikationen.

Cawthra, Gillian Mary. 1996. "Müller, Friedrich Max". En Harro Stammerjohann (ed.), Lexicon Grammaticorum. 658-659. Tübingen: Niemeyer. 
Černý, Jirí. 1998. Historia de la Lingüística. Cáceres: Universidad de Extremadura.

Chaudhuri, N. C. 1974. Scholar extraordinary: the life of professor the right Honourable Friedrich Max Müller. London: PC.

Chervel, André. 1977. ...Et il fallut apprendre à écrire á tous les petits Français: Histoire de la grammaire scolaire. Paris: Payot.

Chevalier, Jean-Claude. 2006[1968]. Historie de la syntaxe. La naissance de la notion de complément dans la grammaire française (1530-1750). Paris: Éditions Champion.

Chilton, C.W. 1954. "Lindley Murray - a forgotten figure". En Studies in Education 2. 144-50.

Chomsky, Noam. 1964. Current Issues in Linguistic theory. Mouton: The Hague.

Coelho, Jacinto do Prado et alii. 1948. "Subsídios para a bibliografia de F. Adolpho Coelho". En Revista de Faculdade de Letras. T. XIV $2^{a}$ serie, n 1. 97-123. Lisboa.

Coelho, Sonia. 2010. "As partes da oração em Rudimentos da Grammatica Portugueza de Pedro José da Fonseca". En C. Assunção, G. Fernandes, M. Loureiro (eds.), Idéias Lingüísticas na Península Ibérica (séc. XIV a séc. XIX), Volume 1. 129-138. Münster: Nodus Publikationen.

Colombat, Bernard. 1996. "Lancelot, Claude". En Harro Stammerjohann (ed.), Lexicon Grammaticorum. 546-547. Tübingen: Niemeyer.

Crego García, Ma Victorina. 2003. "Reflexiones sobre la clase de palabra pronombre". En ELUA, n 17. 203-221.

Curtius E. R. 1960. "Bonner Gedenkworte auf Friedrich Diez". En Gesammelte Aufsätze zur Romanischen Philologie. 412- 427. Bern y München: Francke.

D'Amat, R. 1956. "Auguste Brachet". En M. Prévost y R. d'Amat (eds.), Dictionnaire de biographie française. Paris VII. 128.

Decobert, C. 1989. "L'orientalisme des Lumières à Sacy". En Revue du Monde Musulman et Méditerranéen 52/53. 59-62. 
Delesalle, S. y J. C. Chevalier. 1986. "La linguistique, la grammaire ef l'école, 1750-1914". Paris. 250-310.

Delesalle, S. 1987. "Vie des mots et sciences des significations: Arsène Darmesteter et Michel Bréal". En DRLAV 36/37. 265-314.

Delesalle, S. 1996a. "Bréal, Michel". En Harro Stammerjohann (ed.), Lexicon Grammaticorum. 128. Tübingen: Niemeyer.

Delesalle, S. 1996b. "Darmesteter, Arsène". En Harro Stammerjohann (ed.), Lexicon Grammaticorum. 225. Tübingen: Niemeyer.

Delgado, Feliciano. 2001. "Fuentes de Hervás para su clasificación de las lenguas americanas". En M. Maquieira Rodríguez, M.a D. Martínez Gavilán y $M$. Villayandre Llamazares (eds.), Actas del II Congreso Internacional de la Sociedad Española de Historiografía Lingüística, León, 2-5 de marzo de 1999. 317326. Madrid: Arco Libros.

Desmet, Piet. 1996. La linguistique naturaliste en France (1867-1922). Leuven: Peeters Publishers.

Desmet, Piet y Pierre Swiggers. 1995. De la grammaire comparée à la sèmantique: textes de Michel Bréal publiés entre 1864 et 1898. Serie Orbis Supplementa. Leuven: Peeters.

Desmet, Piet y Pierre Swiggers. 1996. "Brachet, Auguste". En Harro Stammerjohann (ed.), Lexicon Grammaticorum. 128. Tübingen: Niemeyer.

Dias, Luiz Francisco. 2005. "Problemas e desafios na constituição do campo de estudos da transitividade verbal". En $M^{a}$ Elizabeth Fonseca Saraiva e Janice Helena Chaves Marinho (org.), Estudos da língua em uso: relações inter e intrasentenciais. 101-122. Belo Horizonte: Núcleo de Estudos da Língua em Uso-Grupo de Estudos Funcionalistas da Linguagem, FALE/ UFMG.

Dias, Luiz Francisco. 2007. "A constituição do fato gramatical em três fases: a gramática brasileira". En Línguas e instrumentos lingüísticos $n^{\circ}$ 20. 41-56. Campinas: Pontes.

Dias, Luiz Francisco. 2008. "Articulação sintática em gramáticas brasileiras do século XIX". En Letras Santa Maria v. 18 n. 2. 125-134. jul./dez. 2008. 
Dias, Luiz Francisco y Maria Auxiliadora Bezerra. 2006. "Gramática e Dicionário". En Guimarães E. \& Zoppi-Fontanta, M. (org), Introdução às ciências da linguagem: a palavra e a frase. 13-37. Campinas: Pontes.

Dominicy, Marc. 1984. La naissance de la grammaire moderne. Langage, logique et philosophie à Port-Royal. Bruxelles \& Liège: Mardaga.

Dominicy, Marc. 1987. "L'analyse du langage à Port-Royal, A propos d'un livre de Jean Claude Pariente". En Archives et Documents de la SHESL, [première série], 8. 28-112.

Dominicy, Marc. 1996. "Arnauld, Antoine". En Harro Stammerjohann (ed.), Lexicon Grammaticorum. Tübingen: Niemeyer.

Donzé, Roland. 1967[1971]. La Grammaire générale et raisonnée de Port-Royal, Contribution à l'histoire des idées grammaticales en France. Berne: Francke

Donzé, Roland. 1970. La gramática general y razonada de Port-Royal. Buenos Aires: Eudeba.

Douay-Soublin, Françoise. 1976. "Rationalisme et grammaire chez Dumarsais". En Parret, Herman (dir.), History of Linguistic Thought and Contemporary Linguistics. 383-409. Berlin, New York: Walter de Gruyter.

Douay-Soublin, Françoise. 1996. "Dumarsais (Du Marsais), César Chesn[e]au". En Harro Stammerjohann (ed.), Lexicon Grammaticorum. 259-260. Tübingen: Niemeyer.

Duarte, Sonia. 2010. "A presença da GRAE em Peixoto (Porto 1848) e Cervaens y Rodriguez (Porto 1895)". En C. Assunção, G. Fernandes, M. Loureiro (eds.), Idéias Lingüísticas na Península Ibérica (séc. XIV a séc. XIX), Volume 1. 177-189. Münster: Nodus Publikationen.

Dubois et alii. 1978. Dicionário de lingüística. São Paulo: Cultrix.

Echegoyen, Ana. 2001. "Humboldt: cada lengua, cada provincia del mundo". En M. Maquieira Rodríguez, M. ${ }^{a}$ D. Martínez Gavilán y M. Villayandre Llamazares (eds.), Actas del II Congreso Internacional de la Sociedad Española de Historiografía Lingüística, León, 2-5 de marzo de 1999. 363-372. Madrid: Arco Libros. 
Elia, Silvio. 1975. Ensaios de Filologia e Lingüística. São Paulo: Editora Grifo.

Ernesto d'Andrade y Alain Kihm. 1997. "O Coelho crioulista". En Ivo Castro (ed.), Actas do XII encontro nacional da Associação Portuguesa de Linguística, 2. 387392)

Escavy Zamora, Ricardo. 2002. "El Brocense y su teoría del pronombre en el contexto renacentista". En M. A. Esparza Torres, B. Fernández Salgado y H. J. Niederehe (eds.), SEHL 2001 - Estudios de Historiografía Lingüística (Actas del III Congreso Internacional de la Sociedad Española de Historiografía Lingüística Vigo, 7-10 de febrero de 2001). 77-92 (Tomo I). Hamburg: Helmut Buske Verlag.

Escavy Zamora, Ricardo. 2010. "Darwinismo y lingüística española: en el bicentenario de Darwin y el sesquincentenario de On the Origins of Species". En C. Assunção, G. Fernandes, M. Loureiro (eds.), Idéias Lingüísticas na Península Ibérica (séc. XIV a séc. XIX), Volume 1. 189-200. Münster: Nodus Publikationen.

Escoriza Morena, Luis. 2001. "La variación lingüística en el marco de la semántica histórica francesa". En M. Maquieira Rodríguez, M. a D. Martínez Gavilán y M. Villayandre Llamazares (eds.), Actas del II Congreso Internacional de la Sociedad Española de Historiografía Lingüística, León, 2-5 de marzo de 1999. 399406. Madrid: Arco Libros.

Esparza Torres, Miguel Ángel. 1996. "Trazas para una historia de la gramática española". En Casado Velarde y otros (eds.), Scripta Philologica in memorian M. Taboada Cid. 47-74. Universidad de la Coruña.

Esparza Torres, Miguel Ángel. 1997. "Sobre las relaciones entre historiografía lingüística y la concepción de la lingüística como ciencia". En J. A. de Molina Redondo y J. de D. Luque Durán (eds.), Estudios de lingüística general (III) (Trabajos presentados en el II Congreso Nacional de Lingüística General, Granada, 25-27 de marzo de 1996). 107-122. Granada: Método Ediciones.

Esparza Torres, Miguel Ángel. 2008. Bibliografía temática de historiografía lingüística española: fuentes secundarias (BiTe). Hamburg: Helmut Buske Verlag.

Esparza Torres, Miguel Ángel. 2009. "La gramática española del siglo XIX: estado actual de la investigación y perspectivas". En Revista Internacional de Lingüística Iberoamericana, volumen VII, $n^{\circ} 1$ (13). 11-40. 
Esteves Rei, J. 2010. "Espaços lingüísticos, temas e métodos de comunicação, da escola do ratio studiorum à reforma pombalina e ao liceu liberal: o caso das publicações em Goa, de 1821 a 1876". En C. Assunção, G. Fernandes, M. Loureiro (eds.), Idéias Lingüísticas na Península Ibérica (séc. XIV a séc. XIX), Volume 2. 743-754. Münster: Nodus Publikationen.

Fávero, Leonor Lopes. 1996. As concepções lingüísticas no século XVIII: a gramática portuguesa. Campinas: Editora da UNICAMP.

Fávero, Leonor Lopes. 2002a. "A gramática de Júlio Ribeiro". En Revista Anpoll 13. 79-90. São Paulo: Humanitas.

Fávero, Leonor Lopes. 2002b. "Epítome da Grammatica Portugueza: uma gramática portuguesa ou brasileira?". En B. J. Caniato y E. Miné (eds.), Abrindo Caminhos, Coleção Via Atlântica, n² 2. 267-277. São Paulo: USP.

Fávero, Leonor Lopes. 2005. "Século XVIII - A língua portuguesa no Brasil e o discurso do poder". En Gonçalves, Miguel, Soares da Silva, Augusto, Coutinho, Jorge, Martins, José Cândido y Ferreira, Maria José (orgs.), Gramática e Humanismo - Actas do Colóquio de Homenagem a Amadeu Torres (Braga, 2022 de abril de 2005). 317-330. Braga: Aletheia.

Fávero, Leonor Lopes. 2010. "O Discurso do Poder em gramáticas da Língua Portuguesa dos séculos XVI a XIX". En C. Assunção, G. Fernandes, M. Loureiro (eds.), Idéias Lingüísticas na Península Ibérica (séc. XIV a séc. XIX), Volume 1. 215 222. Münster: Nodus Publikationen.

Fávero, Leonor Lopes y Márcia A. G Molina. 2004. "Historia das idéias lingüísticas: origem método e limitações". En Revista Anpoll 16. 131-146. São Paulo: Humanitas FFLCH/ USP.

Fávero, Leonor Lopes y Márcia A. G. Molina. 2006. As concepções lingüísticas no século XIX: a gramática no Brasil. Rio de Janeiro: Editora Lucerna.

Fávero, Leonor Lopes y Márcia A. G. Molina. 2007. "A gramática luso-brasileira e o método científico". En Filologia e Lingüística Portuguesa, n 9. 27-42.

Fávero, Leonor Lopes, Neusa Barbosa Bastos y Sueli Cristina Marquesi. 2007. Língua Portuguesa: pesquisa e ensino. Volumen 1. São Paulo: Editora da PUC-SP. 
Fernandes, Gonçalo. 2002. Amaro de Roboredo, um Pioneiro nos Estudos Linguísticos e na Didáctica das Línguas. Tese de Doutoramento. Vila Real: Universidade de Trás-osMontes e Alto Douro.

Fernandes, Gonçalo. 2006. "João de Barros (1496-1562), um pedagogo precursor de Iohannis Amos Comenius (1592-1670)". En A. Roldán, R. Escavy Zamora, E. Hernández Sánchez, J. M. Hernández Terrés y M. I. López Martínez (eds.), Caminos actuales de la Historiografía Lingüística (Actas del $V$ Congreso Internacional de la Sociedad Española de Historiografía Lingüística, Murcia 7-1 1 de noviembre de 2005). 561-576. Murcia: Servicio de Publicaciones de la Universidad de Murcia.

Fernandes, Gonçalo. 2009. "A Primeira Gramática do Português como Língua Estrangeira (Lugduni 1672)". En Teresa Bastardín Candón y Manuel Rivas Zancarón (eds.), José María María Martín (dir.), Estudios de Historiografía Lingüística (Actas del VI Congreso Internacional de la Sociedad Española de Historiografía Lingüística. Cádiz: 6-9 de noviembre de 2007). 205-220. Cádiz: Servicio de Publicaciones de la Universidad de Cádiz.

Fernandes, Gonçalo, R. Ponce de León Romeo y Carlos Assunção. 2007. Roboredo, Amaro de Verdadeira Grammatica Latina. Edição facsimilada. Prefácio de Amadeu Torres e Estudo Introdutório de Gonçalo Fernandes, Rogelio Ponce de León e Carlos Assunção. Vila Real: Centro de Estudos em Letras, Universidade de Trás-os-Montes e Alto Douro, Colecção Linguística, 2.

Fernandes, Rogério. 1973. F. Adolpho Coelho - para a história da instrução popular. Lisboa: Instituto Gulbenkian de Ciência. Centro de Investigação pedagógica.

Férnández Pérez, Milagros y otros. 1999. "El diccionario de lingüística: autores, objetivos, estructura y muestras de su contenido". En M. Fernández Rodríguez, F. García Gondar y N. Vázquez Veiga (eds.), Actas del I Congreso Internacional de la Sociedad Española de Historiografía Lingüística A Coruña, 18-21 de febrero de 1997. 271-300. Madrid: Arco Libros.

Ferreira Coelho, Olga. 2003. "Léxico, ideologia e a historiografia lingüística do século das identidades". En Revista Letras, n 61 - especial. 153-166. Curitiba: Editora UFPR. 
Ferreira Coelho, Olga. 2008. "Os nomes da língua: configuração e desdobramentos do debate sobre a língua brasileira no século XIX". En Revista do Instituto de Estudos Brasileiros n. 47. 139-160. São Paulo.

Ferreira Coelho, Olga. 2010. "Metalinguagem e descrição lingüística: breve análise de uma gramática do português". En C. Assunção, G. Fernandes, M. Loureiro (eds.), Idéias Lingüísticas na Península Ibérica (séc. XIV a séc. XIX), Volume 1. 119-128. Münster: Nodus Publikationen.

Fonseca, Maria do Céu. 2004. "Historiografia lingüística portuguesa: o contributo do século XVII". En A. M. Brito, O. Figueiredo y C. Barros (orgs), Lingüística Histórica e História da Língua Portuguesa (Actas do Encontro de Homenagem a Maria Helena Paiva - Faculdade de Letras da Universidade O Porto, 5-6 de noviembre de 2003). 89-105. Porto: Universidade O Porto, Faculdade de Letras.

Fonseca, Maria do Céu. 2005. "As questões de método, razão e uso na produção gramatical portuguesa do século XVII". En Gonçalves, Miguel, Soares da Silva, Augusto, Coutinho, Jorge, Martins, José Cândido y Ferreira, Maria José (orgs.), Gramática e Humanismo - Actas do Colóquio de Homenagem a Amadeu Torres (Braga, 20-22 de abril de 2005). 347-356. Braga: Aletheia.

Fontes, Susana. 2010. "Pedro José de Figueiredo: (des)continuidade nas classes de palavras em A Arte da Grammatica Portugueza". En C. Assunção, G. Fernandes, M. Loureiro (eds.), Idéias Lingüísticas na Península Ibérica (séc. XIV a séc. XIX), Volume 1. 257-266. Münster: Nodus Publikationen.

Formigari, Lia y Gabriel Poole. 2004. A history of language philosophies. Amsterdam y Philadelphia: John Benjamins Publishing.

Fragoso, Élcio Aloisio. 2006. O discurso da estilística na história da produção gramatical e na constituição da lingua nacional. Tesis doctoral dirigida por Eni de Lourdes Puccinelli Orlandi. Campinas: Unicamp.

Fries, Dagmar. 1989. "Limpia, fija y da esplendor" La Real Academia Española ante el uso de la lengua. Madrid: Sociedad General Española de Librería, S.A.

Fuertes Gutiérrez, Mara. 2002. "Estado de la cuestión en los estudios sobre Lorenzo Hervás y Panduro". En M. A. Esparza Torres, B. Fernández Salgado y H. J. Niederehe (eds.), SEHL 2001 - Estudios de Historiografía Lingüística (Actas del III Congreso Internacional de la Sociedad Española de Historiografía Lingüística Vigo, 7-10 de febrero de 2001). 513-524 (Tomo I). Hamburg: Helmut Buske Verlag. 
Galán Rodríguez, Carmen. 2001. "W. von Humboldt: la voz de las cosas, el clamor de las lenguas". En M. Maquieira Rodríguez, M. D. Martínez Gavilán y M. Villayandre Llamazares (eds.), Actas del II Congreso Internacional de la Sociedad Española de Historiografía Lingüística, León, 2-5 de marzo de 1999. 417422. Madrid: Arco Libros.

Gamillscheg, A. 1936. "'Wilhelm Meyer-Lübke' zum Gedächtnis". En ZFSL 60. 385406.

García Folgado, M. J. 2005. La gramática española y su enseñanza en la segunda mitad del siglo XVIII y principios del siglo XIX. Tesis doctoral dirigida por María José Martínez Alcalde. Valencia: Universitat de Valencia.

García Folgado, M. J. 2003. "El Arte del Romance Castellano de Benito de San Pedro: los fundamentos de la principal gramática preacadémica del siglo XVIII". En BRAE 83. 51-110. Madrid: Real Academia Española.

García Folgado, M. J. 2004. "Motivaciones para el estudio de la gramática española en el siglo XVIII". En Analecta Malacitana Revista de la Sección Filología de la Facultad de Filosofía y Letras. 91-116. Universidad de Málaga XXVII.

García Jiménez, María Luisa. 1992. "El castellanismo en portugués". En M. Ariza, R. Cano, J. M. a Mendoza y A. Narbona (eds.), Actas del II Congreso Internacional de historia de la lengua española. 1031-1042 (Tomo I). Madrid: Pabellón de España.

García Martín, Ana María. 2005. "Esteriótipos lingüísticos e apologia do português: apontamentos sobre um subgênero da historiografia lingüística". En Estudios Portugueses 5 - Revista de Filología Portuguesa. 25-44. Salamanca: LusoEspañola de Ediciones.

García Martín, Ana María. 2007. "Sobre la referencia al castellano en la tradición gramatical del portugués". En A. M. De Dios (ed.), Aula Ibérica. 209-218. Salamanca: Ediciones Universidad de Salamanca.

García Martín, Ana María. 2010. "El bilingüismo luso-castellano en Portugal: estado de la cuestión". En Aula Ibérica Online. Publicación electrónica: http://www.filologiaportuguesa.es/aulalbericaActual l.asp?.cod=3

(última consulta 03/06/2011). 
García Martín, Ana María y Pedro Serra. 2007. "Lengua, nación, imperio: Ensayo y apunte bibliográfico para un estudio de las relaciones lingüísticas entre Portugal y España (s. XIX)". En Magalhães, Gabriel (coord.) - Relipes: Relações lingüísticas e literárias entre Portugal e Espanha desde o início do século XIX até à actualidade. 263-329. Salamanca: Celya.

Garrido Vilchez, Gema Belén. 2001. "La huella de Salvá en la GRAE de 1854". En J. A. Bartol Hernández, S. C. Matellán, C. F. Juncal, C. Pensado, E. Prieto de los Mozos y N. S. G. de Herrero (eds.), Nuevas aportaciones al estudio de la lengua española (investigaciones filológicas). 135-144. Salamanca: Luso Española de Ediciones.

Garrido Vilchez, Gema Belén. "Las gramáticas de la Real Academia Española: de 1713-1796". En III Simposio Internacional El castellano y sus gramáticas: "La gramática española en el siglo XVIII" (1700-1835). Salamanca: 20-22 de mayo de 2009. (e.p.).

Gärtner, Eberhard (Org.). 1997. Pesquisas lingüísticas em Portugal e no Brasil. Frankfurt/Main: Vervuert. Madrid: Iberoamericana.

Gauger, H. M. et. al. 1981. Einführung in die Romanische Sprachwissenschaf. Darmstadt.

Gipper, H y P. Schmitter. 1979. Sprachwissenschaf und Sprachphilosophie im Zeitalter der Romantik. Tübingen: G. Narr Verlag

Gómez Asencio, José J. 1981. Gramática y categorías verbales en la tradición española (1771-1847). Salamanca: Acta Salmanticensia Studia Philologica Salmanticensia Anejos. Estudios 5. Ediciones Universidad de Salamanca.

Gómez Asencio, José J. 1985. Subclases de palabras en la tradición española (1771-1847). Acta Salmanticensia Studia Philologica Salmanticensia Anejos. Estudios 13. Salamanca: Ediciones Universidad de Salamanca.

Gómez Asencio, José J. 1999. "Gramáticas latinizantes: deslatinización de la gramática" en J. Fernández González y otros (eds.), Lingüística para el siglo XXI vol. II. 819-826. Salamanca: Universidad de Salamanca.

Gómez Asencio, José J. 2000a. "El prólogo como como programa. A propósito de la <<GRAE>> de 1771". En Boletín de la Real Academia Española 80. 27-46. 
Gómez Asencio, José J. 2000b. "El prólogo como proemio: la GRAE de 1796". En Cuestiones de actualidad en lengua española. 71-80. Salamanca: Universidad de Salamanca - Instituto Caro y Cuervo.

Gómez Asencio, José J. 2001 a. "Absolutamente relativos: así (parece que) son". En J. A. Bartol Hernández, S. C. Matellán, C. F. Juncal, C. Pensado, E. Prieto de los Mozos y N. S. G. de Herrero (eds.), Nuevas aportaciones al estudio de la lengua española (investigaciones filológicas). 145-164. Salamanca: Luso Española de Ediciones.

Gómez Asencio, José J. 2001 b. "Lo latino de las gramáticas del español". En M. Maquieira Rodríguez, M.a D. Martínez Gavilán y M. Villayandre Llamazares (eds.), Actas del II Congreso Internacional de la Sociedad Española de Historiografía Lingüística, León, 2-5 de marzo de 1999. 35-54. Madrid: Arco Libros.

Gómez Asencio, José J. 2002a. "El prólogo como advertencia: el caso de la GRAE de 1870". En M. a Dolores Muñoz Núñez et al. (eds.), IV Congreso de Lingüística General (Cádiz, 3-6 de abril de 2000). 1229-1239. Cádiz: Servicio de Publicaciones de la Universidad de Cádiz.

Gómez Asencio, José J. 2002b. "Los prólogos académicos de 1854 y 1858". En M. A. Esparza Torres, B. Fernández Salgado y H. J. Niederehe (eds.), SEHL 2001 Estudios de Historiografía Lingüística (Actas del III Congreso Internacional de la Sociedad Española de Historiografía Lingüística - Vigo, 7-10 de febrero de 2001). 197-212 (Tomo I). Hamburg: Helmut Buske Verlag.

Gómez Asencio, José J. 2006. "Los 'vicios de dicción' de las gramáticas académicas (1880-1962)". En A. Roldán, R. Escavy Zamora, E. Hernández Sánchez, J. M. Hernández Terrés y M. I. López Martínez (eds.), Caminos actuales de la Historiografía Lingüística (Actas del $V$ Congreso Internacional de la Sociedad Española de Historiografía Lingüística - Murcia 7-11 de noviembre de 2005). 23-80 (Tomo I). Murcia: Servicio de Publicaciones de la Universidad de Murcia.

Gómez Asencio, José J. 2008. "El tratamiento de lo que ahora se llama 'locuciones prepositivas' en sesenta y cuatro gramáticas del español (1555-1930) [2]". En Gramma-Temas 3: España y Portugal en la tradición gramatical. 75-104. León: Universidad de León. 
Gómez Asencio, José J. "La gramática española de 1800 a 1835" en III Simposio Internacional El castellano y sus gramáticas: "La gramática española en el siglo XVIII" (1700-1835). Salamanca: 20-22 de mayo de 2009. (e.p.).

Gonçalves, Filomena. 1996. "A ortografia na antiga gramaticografia portuguesa. As gramáticas do século XIX". En Actas do XI Encontro da Associação Portuguesa de Lingüística. 39-52. Lisboa: Colibri.

Gonçalves, Filomena. 2001. "A celtomania - um tópico da 'Lingüística Romântica'". En Diana 1-2. Revista do Departamento de Lingüística e Literaturas da Universidade de Évora. 41-58.

Gonçalves, Filomena. 2002a. "La doctrina de António das Neves Pereira: purismo, vernaculidad y perfección en el siglo XVIII". En M. A. Esparza Torres, B. Fernández Salgado y H. J. Niederehe (eds.), SEHL 2001 - Estudios de Historiografía Lingüística (Actas del III Congreso Internacional de la Sociedad Española de Historiografía Lingüística - Vigo, 7-10 de febrero de 2001). 549-558 (Tomo II). Hamburg: Helmut Buske Verlag.

Gonçalves, Filomena. 2002b. "Notas sobre as 'Prosas Portuguesas' de Rafael Bluteau e a Historiografia Lingüística do século XVIII". En Filosofia e Lingüística Portuguesa 5. 7-25. São Paulo: Humanitas, FFLCH - USP.

Gonçalves, Filomena. 2002c. "A terminologia lingüística nos finais do século XIX: os primeiros dicionários terminológicos em língua portuguesa". En Revista Portuguesa de Humanidades 6. 91-110. Braga: Faculdade de Filosofia da UCP.

Gonçalves, Filomena. 2002d. "Notas sobre a pontuação e a gramática no século XIX". En História da Língua e História da Gramática - Actas do Colóquio. 91-110. Braga: Universidade do Minho, Centro de Estudos Humanísticos.

Gonçalves, Filomena. 2003. "La terminología lingüística a finales del siglo XIX: los primeros diccionarios terminológicos en lengua portuguesa". En Alexandre Veiga (ed.), Anexos de Moenia - Gramática e Léxico em Sincronia e Diacronia. Um contributo da Lingüística Portuguesa. Col. Lucus Lingua, n 14. 105-114. Universidad de Santiago de Compostela.

Gonçalves, Filomena. 2004. "Notas sobre o positivismo lingüístico em Portugal no século XIX: sobre a Lingua Portuguesa (1871), de F. Adolpho Coelho". En Diacrítica, Ciências da Linguagem, n 18. 29-56. Braga: Universidade do Minho Centro de Estudos da Humanidade. 
Gonçalves, Filomena. 2005a. "Da 'francezia' ou o problema das palavras afrancesadas no século XVIII: as idéias de António das Neves Pereira". En Estudios Portugueses 5 - Revista de Filología Portuguesa. 45-62. Salamanca: LusoEspañola de Ediciones.

Gonçalves, Filomena. 2005b. "Nótulas para uma Historiografia Lingüística de Setecentos: A língua portuguesa segundo João Baptista de Castro". En M. Gonçalves, A. Soares da Silva, J. Coutinho, J. C. Martins, y M. J. Ferreira (orgs.), Gramática e Humanismo (Actas do Colóquio de Homenagem a Amadeu Torres - Braga, 20-22 de abril de 2005). 383-402. Braga: Aletheia.

Gonçalves, Filomena. 2005c. "Revisitando o texto preambular setecentista: a produção metalingüística em português". En M. A. Marques, E. Köller, J. Teixeira, A. S. Lemos (eds.), Ciências da Linguagem: 30 anos de Investigação e Ensino. 99116. Braga: Universidade do Minho - Instituto de Letras e Ciências Humanas.

Gonçalves, Filomena. 2006a. "El portugués como dialecto del castellano: historia de una teoría entre los siglos XVII y XVIII". En A. Roldán, R. E. Zamora, E. H. Sánchez, J. M. Hernández Terrés y M. I. López Martínez (eds.), Caminos actuales de la Historiografía Lingüística (Actas del $V$ Congreso Internacional de la Sociedad Española de Historiografía Lingüística - Murcia 7-1 1 de noviembre de 2005). 729-741 (Tomo II). Murcia: Servicio de Publicaciones de la Universidad de Murcia.

Gonçalves, Filomena. 2006b. "Treinta años de la historiografía lingüística del portugués". En M. Villayandre Llamazares - Actas del XXXV Simposio Internacional de la Sociedad Española de Lingüística. León: Universidad de León - Dpto. de Filología Hispánica y Clásica. 732-753. Publicación electrónica: http://www3.unileon.es/dp/dfh/SEL/actas.htm (última consulta 02/06/2011).

Gonçalves, Filomena. 2008a. "Recreação filológico-lingüística com a geração de Cenáculo". En Olinda Santana (ed.), Actas do XI Encontro Internacional de Reflexão e Investigação: Língua, Cultura e Património (24 e 25 de Maio de 2007). Universidade de Trás-os-Montes e Alto Douro.

Gonçalves, Filomena. 2008b. "Desagravo da gramática portuguesa (1820-1824) - Contribuições para uma historiografia das polêmicas gramaticais em Portugal". En Ana Maria Brito et al. (orgs.), Colóquio Gramática: História, Teorias, Aplicações. 169-190. Porto: Faculdade de Letras, DEP/DEPER. 
Gonçalves, Filomena. 2008c. "Un repaso al concepto de 'nombre proprio' en la gramaticografía portuguesa de los setecientos". En Gramma-Temas 3: España y Portugal en la tradición gramatical. 105-124. León: Universidad de León.

Gonçalves, Filomena. 2009. "Ideas pedagógicas y lingüísticas en el liberalismo portugués: algunos apuntes". En Teresa Bastardín Candón y Manuel Rivas Zancarón (eds.), José María María Martín (dir.), Estudios de Historiografía Lingüística (Actas del VI Congreso Internacional de la Sociedad Española de Historiografía Lingüística. Cádiz: 6-9 de noviembre de 2007). 279-294. Cádiz: Servicio de Publicaciones de la Universidad de Cádiz.

Gonçalves, Filomena. 2010. "Contrastes gramaticales entre el español y el português: A comparative view of the Spanish and Portuguese languages (1831)". En C. Assunção, G. Fernandes, M. Loureiro (eds.), Idéias Lingüísticas na Península Ibérica (séc. XIV a séc. XIX), Volume 1. 339-350. Münster: Nodus Publikationen.

Gonçalves, Filomena. "La conexión portuguesa: gramáticas portuguesas y castellanas del siglo XVIII". En III Simposio Internacional El castellano y sus gramáticas: "La gramática española en el siglo XVIII" (1700-1835). Salamanca: 20-22 de mayo de 2009. (e.p.).

Gonçalves, Filomena y Clotilde de Almeida Azevedo Murakawa (orgs.). 2007. Novas contribuições para o estudo da historia e da historiografia da língua portuguesa. São Paulo: Cultura Acadêmica.

González Luis, Francisco. 1994. "La Gramática de la Lengua Tupí de José de Anchieta y su dependencia de la gramática latina." En R. Escavy Zamora, J. M. Hernández Terrés, A. Roldán (eds.), Nebrija V Centenario: 1492-1992 (Actas del Congreso Internacional de la Sociedad Española de Historiografía Lingüística). 101-114 (Tomo II). Murcia: Servicio de Publicaciones de la Universidad de Murcia.

Greimas, Algirdas Julien y Joseph Courtés. 1979. SÉMIOTIQUE Dictionnaire raisonné de la théorie du langage. Paris: Hachette. Traducción de A. Dias Lima, D. L. Pessoa de Barros, E. Peñuela Cañizal, E. Lopes, I. Assis da Silva, Ma J. Castagnetti Sembra y T. Y. Miyazaki. Dicionário de Semiótica. São Paulo: Cultrix.

Greive, E. 1970. "Wilhelm Meyer-Lübke". En Bonner Gelehrte: beiträge zur Geschichte der Wissenschaften in Bonn. 200-213. Bonn: Röhrscheid. 
Guimarães, Eduardo. 1996. "Sinopse dos Estudos do Português no Brasil: a gramaticalização brasileira". En E. J. Guimarães y E. Orlandi (orgs.), Língua e Cidadania. 127-138. Campinas: Pontes.

Guimarães, Eduardo y Eni P. Orlandi (orgs.). 1996. - Língua e Cidadania. Campinas: Pontes.

Guimarães, Eduardo y Diana Luz Pessoa de Barros (eds.). 2002. History of linguistics 2002 - Selected papers from the Ninth International Conference on the History of the Language Sciences (27-30 Agosto de 2002, São Paulo-Campinas). Amsterdam y Philadelphia: John Benjamins Publishing Company.

Gumbrecht, H. U. 1986. "Un soufflé d'allemagne ayant passé: Friedrich Diez, Gaston Paris and the genesis of national philologies". En RomPH 40, 1-37.

Gutiérrez, Marco A. 2001. "Historiografía lingüística y edición crítica: propuestas para la adecuación de intereses comunes". En M. Maquieira Rodríguez, M. ${ }^{a}$ D. Martínez Gavilán y M. Villayandre Llamazares (eds.), Actas del II Congreso Internacional de la Sociedad Española de Historiografía Lingüística, León, 2-5 de marzo de 1999. 523-528. Madrid: Arco Libros.

Hallewell, Laurence. 1985. O livro no Brasil. São Paulo: Edusp.

Hamburger, J. 1988. Monsieur Littré. Paris.

Harnois, Guy. 1928. Les théories du langage en France de 1660 à 1821. Paris: Société d'édition "Les Belles Lettres".

Hassler, Gerda. 1994. "Las lenguas del Nuevo Mundo en las teorías lingüísticas del siglo XVIII". En R. Escavy Zamora, J. M. Hernández Terrés, A. Roldán (eds.), Nebrija $\checkmark$ Centenario: 1492-1992 (Actas del Congreso Internacional de la Sociedad Española de Historiografía Lingüística). 115-126 (Tomo II). Murcia: Servicio de Publicaciones de la Universidad de Murcia.

Hassler, Gerda. 2002. "Textos de referencia y conceptos en las teorías lingüísticas de los siglos XVII y XVIII". En M. A. Esparza Torres, B. Fernández Salgado y H. J. Niederehe (eds.), SEHL 2001 - Estudios de Historiografía Lingüística (Actas del III Congreso Internacional de la Sociedad Española de Historiografía Lingüística Vigo, 7-10 de febrero de 2001). 559-586 (Tomo II). Hamburg: Helmut Buske Verlag. 
Hassler, Gerda. 2010. "A discussão sobre a origem e o gênio da língua portuguesa desde Duarte Nunes de Leão (1606) até Francisco Evaristo Leoni (1858): integração e transformação de conceitos europeus". En C. Assunção, G. Fernandes, M. Loureiro (eds.), Idéias Lingüísticas na Península Ibérica (séc. XIV a séc. XIX), Volume 1. 373-384. Münster: Nodus Publikationen.

Hassler, Gerda. "Textos gramaticales de referencia en la Europa del siglo XVIII". En III Simposio Internacional El castellano y sus gramáticas: "La gramática española en el siglo XVIII" (1700-1835). Salamanca, 20-22 de mayo de 2009. (e.p.).

Hernando Cuadrado, Luis Alberto. 1997. "La teoría gramatical del Brocense". En Cuadernos de Filología Hispánica, n¹2. 165-178. Madrid: Servicio de Publicaciones UCM.

Hernando Cuadrado, Luis Alberto. 2001. "Sobre el tratamiento del adjetivo en la GRAE (1771-1930)". En M. Maquieira Rodríguez, M.` D. Martínez Gavilán y M. Villayandre Llamazares (eds.), Actas del II Congreso Internacional de la Sociedad Española de Historiografía Lingüística, León, 2-5 de marzo de 1999. 551562. Madrid: Arco Libros.

Hiersche, R. 1985. "Zu etymologie und sprachvergleichung vor Bopp". En H.M. Ölberg et al. (eds.), Sprachwissenschaf Forschungen - Festschrift für Johann Knobloch. Innbruck. 157-170.

Hjelmeslev, L. 1976[1928]. Principios de gramática general. Madrid: Gredos.

Huisman, D. 1981. Actes du Colloque Émile Littré. Paris.

Huisman, D. 1984. Dictionnaire des philosophes. Paris: Presses Universitaires de France.

Hymes, Dell. 1974. "Introduction". En D. Hymes (ed.), Studies in the History of Linguistics: traditions and paradigms. 1-38. Bloomington: Indiana University Press.

Iglesias Bango, Manuel. 2001. "La formación de las ideas sintácticas en las gramáticas académicas de principios de siglo: la posible influencia de J. Cejador y Frauca". En M. Maquieira Rodríguez, M. ${ }^{a}$ D. Martínez Gavilán y M. Villayandre Llamazares (eds.), Actas del II Congreso Internacional de la Sociedad Española de Historiografía Lingüística, León, 2-5 de marzo de 1999. 573588. Madrid: Arco Libros. 
Iordan, I. 1970. An introduction to Romance Linguistics. Oxford.

Jakobson, R. 1971. "The World response to Whitney's principles on linguistic science". En M. Silverstein (ed.), Whitney on language: Selected wrintings of William Dwight Whitney. XXV-XLV. Cambridge.

Joly, André. 1972. "Introduction". En James Harris, Hermès ou recherches philosophiques sur la grammaire universelle. Genève: Droz.

Joly, André. 1976. "James Harris et la problématique des parties du discours à l'époque classique". En Parret H. (ed.), History of Linguistic Thought and Contemporary Linguistics. 410-430. Berlin, New York: De Gruyter.

Jones, Bernard. 1983. "William Barnes on Lindley Murray's English Grammar". En English Studies, 64. 30-35.

Kemmler, Rolf. 2005. "António José dos Reis, gramático pombalino". En Gonçalves, Miguel, Soares da Silva, Augusto, Coutinho, Jorge, Martins, José Cândido y Ferreira, Maria José (orgs.), Gramática e Humanismo. Actas do Colóquio de Homenagem a Amadeu Torres (Braga, 20-22 de abril de 2005). 429448. Braga: Aletheia.

Kemmler, Rolf. 2010. "O Compendio de grammatica latina e portugueza (1829) de José Vicente Gomes de Moura (1769-1854)". En C. Assunção, G. Fernandes, M. Loureiro (eds.), Idéias Lingüísticas na Península Ibérica (séc. XIV a séc. XIX), Volume 1. 469-482. Münster: Nodus Publikationen.

Koerner, E. F. Konrad. 1977. "The Humboldtian trend in Linguistics". En Paul J. Hooper (ed.), Studies in Descriptive and Historical Linguistics: Festschrift for Winfred P. Lehmann. 145-158. Amsterdam: John Benjamins.

Koerner, E. F. Konrad. 1978. Toward a Historiography of Linguistics : Selected Essays. Amsterdam: John Benjamins.

Koerner, E. F. Konrad. 1982. "The Neogrammarian doctrine: breakthrough or extension of the Schleicherian paradigm. A problem in linguistic historiography". En Papers from the 3rd International Conférence on Histórica! Linguistics, Current Issues in Linguistic Theory, XIII. 129-152. Amsterdam: John Benjamins. 
Koerner E. F. Konrad. 1989a. "Franz Bopp (1791-1867)". En Practicing Linguistic Historiography. 291-302. Amsterdam y Philadelphia: John Benjamins.

Koerner, E. F. Konrad. 1989b. "August Schleicher and linguistic science in the second half of the 19th century". En Practicing Linguistic Historiography. 325-375. Amsterdam: John Benjamins.

Koerner, E. F. Konrad. 1994. "Gramática de la Lengua Castellana de Antonio de Nebrija y el Estudio de las Lenguas indígenas de las américas; o, hacia una historia de la lingüística amerindia". En R. Escavy Zamora, J. M. Hernández Terrés, A. Roldán (eds.), Nebrija V Centenario: 1492-1992 (Actas del Congreso Internacional de la Sociedad Española de Historiografía Lingüística). 17-36 (Tomo I). Murcia: Servicio de Publicaciones de la Universidad de Murcia.

Koerner, E. F. Konrad. 1999. "History of Linguistics: Attainments and challenges". En M. Fernández Rodríguez, F. García Gondar y N. Vázquez Veiga (eds.), Actas del I Congreso Internacional de la Sociedad Española de Historiografía Lingüística A Coruña, 18-21 de febrero de 1997. 15-30. Madrid: Arco Libros.

Koerner, E. F. Konrad. 2000-2006. "The development of linguistic historiography". En S. Auroux, E. F. K. Koerner, H. J. Niederehe y K. Versteegh (eds.), History of the language sciences: an international handbook on the evolution of the study of language from the beginning to the present. 2802-2820. Berlin y New York: De Gruyter.

Koerner, E. F. Konrad y H. J. Nieherehe (eds.). 2001. History of Linguistics in Spain/ Historia de la Lingüística en España. Vol. 2. Amsterdam y Philadelphia: John Benjamins.

Kohut, Karl. 1982. "El humanismo castellano del siglo XV. Replanteamiento de la problemática". En Giuseppe Bellini (dir.), Actas del VII Congreso de la Asociación Internacional de Hispanistas, Venecia 1980. 639-647. Roma: Bulzoni Editore.

Kosarik, Marina. 1990. "A contribuição dos primeiros gramáticos portugueses na formação do canone gramatical moderno". En Revista de História. Vol. 10. 55-60.

Kosarik, Marina. 2000. "La lingüística ibérica en los siglos XVI-XVII y el contexto cultural de la época". En Actas de la II Conferencia de Hispanistas en Rusia, Moscú 19-23 abril de de 1999. Madrid: Ed. Embajada de España en Moscú MAE. Publicación electrónica:

http://hispanismo.cervantes.es/documentos/kosarik.pdf 
(última consulta: 02/06/2011).

Kramer, Johannes. 1996. "Meyer-Lübke, Wilhelm". En Harro Stammerjohann (ed.), Lexicon Grammaticorum. 635. Tübingen: Niemeyer.

Kuhn, Thomas. 1970. The structure of scientific revolutions. $2^{\circ}$ edición. Chicago: University of Chicago Press.

Lapesa, Rafael. 1980[1942]. Historia de la lengua española. Prólogo de Ramón Menéndez Pidal. $8^{a}$ edición refundida y muy aumentada. Madrid: Gredos.

Leite, Marli Quadros. 2005. "A hiperlíngua brasileira na construção da norma lingüística gramatical: um estudo de gramáticas do século XIX". En Estudios Portugueses 5 - Revista de Filología Portuguesa. 103-112. Salamanca: LusoEspañola de Ediciones.

Leite, Marli Quadros. 2006. Metalinguagem e discurso: a configuração do purismo brasileiro. São Paulo: Editora Humanitas.

Leite, Yonne. 2005. "Arte de Gramatica da Lingua mais Usada na Costa do Brasil. A criterion for evaluation". En Zwartjes, Otto y Cristina Altman (eds.), Missionary Linguistics II/Lingüística Misionera II. Orthography and Phonology. 191-204. Amsterdam y Philadelphia: John Benjamins.

Lépinette, Brigitte. 2001. El francés y el español en contraste y en contacto, siglos XV-XVII: estudios de historiografía lingüística: lexicografía, gramática, traducción. Universitat de València.

Lépinette, Brigitte. 2002. "La perspectiva histórica en las gramáticas francesas para españoles (1880-1900)". En M. A. Esparza Torres, B. Fernández Salgado y H. J. Niederehe (eds.), SEHL 2001 - Estudios de Historiografía Lingüística (Actas del III Congreso Internacional de la Sociedad Española de Historiografía Lingüística Vigo, 7-10 de febrero de 2001). 277-292 (Tomo I). Hamburg: Helmut Buske Verlag.

Lepschy, Giulio C. 1990. Storia della Linguistica. Bologna: ॥ Mulino.

Liebrucks, Bruno. 1965. Sprache und Bewußtsein, Band 2: Sprache. Wilhelm von Humboldt. Frankfurt a. M.: Akademische Verlagsgesellschaft.

Lliteras, Margarita. 1992a. La teoría gramatical de Vicente Salvá. Madrid: Sociedad General Española de Librería, S.A. 
Lliteras, Margarita. 1992b. "Benito de San Pedro frente a la tradición nebricense". En Bulletin Hispanique, tome 94, 2. 505-527.

Lliteras, Margarita. 1996a. "De la etimología a la analogía en la historia gramatical española". En M. Casado Velarde et al., (eds.), Scripta philologica in memorian Manuel Taboada Cid. 131-141 (Tomo I). A Coruña: Servicio de Publicaciones Universidad A Coruña.

Lliteras, Margarita. 1996b. "La recepción del enciclopedismo en la Gramática de V. Salvá. El tratamiento del artículo". En R. Lorenzo (ed.), Actas do XIX Congreso Internacional de Lingüística e Filoloxía Románicas (Universidade de Santiago de Compostela, 1989). 169-184. A Coruña: Fundación "Pedro Barrié de la Maza, Conde de Fenosa".

Lliteras, Margarita. 1997. "Sobre la formación del corpus de autoridades en la gramática española". En E. F. K. Koerner y H. J. Niederehe (eds.), Historiographia Linguistica XXIV - 1/2. 57-72. Amsterdam: John Benjamins.

Lliteras, Margarita. 2000. "La gramática de Bello y sus fuentes hispánicas". En C. Schmitt y N. Cartagena, La gramática de Andrés Bello (1847-1997) (Actas del congreso-homenaje celebrado con motivo del ciento cincuenta aniversario de la Gramática destinada al uso de los americanos). 82-102. Bonn: Romanistischer Verlag.

Lliteras, Margarita. 2001a. "Hacia la descripción del español hablado: la Arquitectura de las lenguas de Eduardo Benot (1889)". En M. Maquieira Rodríguez, M. a D. Martínez Gavilán y M. Villayandre Llamazares (eds.), Actas del II Congreso Internacional de la Sociedad Española de Historiografía Lingüística, León, 2-5 de marzo de 1999. 645-656. Madrid: Arco Libros.

Lliteras, Margarita. 2002. "La recuperación de la gramática española en el siglo XVII: del uso conflictivo al uso de la razón o propiedad castellana". En M. A. Esparza Torres, B. Fernández Salgado y H. J. Niederehe (eds.), SEHL 2001 Estudios de Historiografía Lingüística (Actas del III Congreso Internacional de la Sociedad Española de Historiografía Lingüística - Vigo, 7-10 de febrero de 2001). 293-306 (Tomo I). Hamburg: Helmut Buske Verlag.

Lliteras, Margarita. 2008. "Del género derivativo al género flexivo". En GrammaTemas 3: España y Portugal en la tradición gramatical. 125-148. León: Universidad de León. 
Lliteras, Margarita. "El trabajo gramaticográfico inicial de don Vicente Salvá (1786-1849)". En III Simposio Internacional El castellano y sus gramáticas: "La gramática española en el siglo XVIII" (1700-1835). Salamanca: 20-22 de mayo de 2009. (e.p.).

Lliteras, Margarita. "Contrastes románicos en el proceso de codificación del español". En XXVle Congrès International de Linguistique et de Philologie Romanes. Valencia: 6-11 de septiembre de 2010. (e.p.).

Llorente, Antonio. 1967. Teoría de la lengua e historia de la lingüística. Madrid: Alcalá.

Llorente, Antonio y J. Mondéjar. 1974. "La conjugación objetiva en español". En RSEL, 4. 1-60.

Lope Blanch, Juan M. 2001. "De plagios y rivalidades". En M. Maquieira Rodríguez, M. ${ }^{a}$ D. Martínez Gavilán y M. Villayandre Llamazares (eds.), Actas del II Congreso Internacional de la Sociedad Española de Historiografía Lingüística, León, 2-5 de marzo de 1999. 657-662. Madrid: Arco Libros.

Lope Blanch, Juan M. 2002. "El doble magisterio de Eduardo Benot". En M. A. Esparza Torres, B. Fernández Salgado y H. J. Niederehe (eds.), SEHL 2001 Estudios de Historiografía Lingüística (Actas del III Congreso Internacional de la Sociedad Española de Historiografía Lingüística - Vigo, 7-10 de febrero de 2001). 307-312 (Tomo I). Hamburg: Helmut Buske Verlag.

Lozano, Carmen. 1992. Aportación gramatical renacentista a la luz de la tradición. Valladolid: Secretariado de Publicaciones - Universidad de Valladolid.

MacCawley, J. D. 1967. "The phonological theory behind Whitney's Sanskrit Grammar". En H. I. Aronson et al (eds.), Languages and areas Studies presented do George V. 77-85. Bobrinskoy: Chicago.

MacCawley, J. D. 1973. "William Dwight Whitney as a syntactician". En B. Kachru et al. (eds.), Issues in Linguistics Studies presented to Henry and Renee Kahane. 554-568. Urbana: Chicago.

Maio Coutinho, Telma Maria Barrias. 2010. "O século XVIII na Historiografia Gramatical Portuguesa: de Fernão de Oliveira a Pedro José de Figueiredo". En 
C. Assunção, G. Fernandes, M. Loureiro (eds.), Idéias Lingüísticas na Península Ibérica (séc. XIV a séc. XIX), Volume 1. 147-156. Münster: Nodus Publikationen.

Malkiel Y. 1976. "Friedrich Diez and the birth pangs of Romance Philology". En E.F. Tuttle (ed.), Friedrich Diez Centennial Lectures. 1-15. Berkeley.

Manchester, Martin. 1985. The Philosophical Foundations of Humboldt's Linguistic Doctrines. Amsterdam y Philadelphia: John Benjamins.

Maquieira, Marina. 2008. "La formación de palabras: Nebrija (1492) y Oliveira (1536)". En Gramma-Temas 3: España y Portugal en la tradición gramatical. 149165. León: Universidad de León.

Marçalo, Maria João. 2005. "Na pista de Amadeu Torres: gramática da língua e gramática da comunicação". En Gonçalves, Miguel, Soares da Silva, Augusto, Coutinho, Jorge, Martins, José Cândido y Ferreira, Maria José (orgs.), Gramática e Humanismo - Actas do Colóquio de Homenagem a Amadeu Torres (Braga, 2022 de abril de 2005). 479-486. Braga: Aletheia.

Marçalo, Maria João. 2010. "A noção da transitividade em Augusto Epifânio da Silva Dias: Contributo para o estudo das idéias lingüísticas no século XIX". En C. Assunção, G. Fernandes, M. Loureiro (eds.), Idéias Lingüísticas na Península Ibérica (séc. XIV a séc. XIX), Volume 2. 549-560. Münster: Nodus Publikationen.

Martí Sánchez, Manuel. 1994. "Nebrija y Oliveira: examen contrastivo". En R. Escavy Zamora, J. M. Hernández Terrés, A. Roldán (eds.), Nebrija V Centenario: 1492-1992 (Actas del Congreso Internacional de la Sociedad Española de Historiografía Lingüística). 403-420 (Tomo III). Murcia: Servicio de Publicaciones de la Universidad de Murcia.

Martí Sánchez, Manuel. 1996. "Barros, João de". En Harro Stammerjohann (ed.). 1996. Lexicon Grammaticorum, Who's Who in the History of World Linguistics . Tübingen: Max Niemeyer Verlag.

Martínez Alcalde, María José. 1992. "La doctrina ortográfica de Benito de San Pedro y su impugnación por Benito Martínez Gómez Gayoso". En Bulletin Hispanique. Tome 94, 2. 529-557.

Martínez Alcalde, María José. 1996. Morfología histórica de los posesivos españoles. Universitat de València. 
Martínez Alcalde, María José. 2001. "Gramáticas y ortografías españolas preacadémicas en el siglo XVIII". En Koerner, E. F. Konrad y H. J. Nieherehe, (eds.), History of Linguistics in Spain/ Historia de la Lingüística en España. Vol. 2. 195-214. Amsterdam y Philadelphia: John Benjamins.

Martínez Alcalde, María José. 2002. "Descripción y valoración de la norma meridional: del 'vicio' a la norma panhispánica". En M. A. Esparza Torres, B. Fernández Salgado y H. J. Niederehe (eds.), SEHL 2001 - Estudios de Historiografía Lingüística (Actas del III Congreso Internacional de la Sociedad Española de Historiografía Lingüística - Vigo, 7-10 de febrero de 2001). 325-339 (Tomo I). Hamburg: Helmut Buske Verlag.

Martínez Alcalde, María José. 2008. "Los posesivos en la tradición gramatical española (de Nebrija a la primera gramática académica)". En Gramma-Temas 3: España y Portugal en la tradición gramatical. 167-197. León: Universidad de León.

Martínez Alcalde, María José. 2010. "El libro primero del Arte de Romance Castellano (1769) de Benito de San Pedro: función, objetivos e influencias". En C. Assunção, G. Fernandes, M. Loureiro (eds.), Idéias Lingüísticas na Península Ibérica (séc. XIV a séc. XIX), Volume 2. 561-574. Münster: Nodus Publikationen.

Martínez Gavilán, María Dolores. 1989. Las ideas lingüísticas en España en el siglo XVII: los tratados gramaticales. Tesis doctoral dirigida por Dr. D. Lidio Nieto Jiménez. León: Universidad de León.

Martínez Gavilán, María Dolores. 1990. "Normativismo y antinormativismo en la tradición gramatical española del siglo XVII". En Contextos VIII/ 15-16. 129-151.

Martínez Gavilán, María Dolores. 1994. "Tradición e innovación en la teoría gramatical española del siglo XVII". En R. Escavy Zamora, J. M. Hernández Terrés, A. Roldán (eds.), Nebrija V Centenario: 1492-1992 (Actas del Congreso Internacional de la Sociedad Española de Historiografía Lingüística). 421-436. Murcia: Servicio de Publicaciones de la Universidad de Murcia.

Martínez Gavilán, María Dolores. 1996. "La originalidad de Gonzalo Correas y su influencia en la tradición gramatical española". En Enrique Serra Alegre y otros (eds.), Actas del I Congrés de Lingüística General. 87-94. Valencia: Universidad de Valencia. 
Martínez Gavilán, María Dolores. 2006. "Sobre el supuesto racionalismo del Arte de la Lengua Española del Padre Villar". En A. Roldán, R. Escavy Zamora, E. Hernández Sánchez, J. M. Hernández Terrés y M. I. López Martínez (eds.), Caminos actuales de la Historiografía Lingüística (Actas del $\mathrm{V}$ Congreso Internacional de la Sociedad Española de Historiografía Lingüística - Murcia 7-1 1 de noviembre de 2005). 1079-1098. Murcia: Servicio de Publicaciones de la Universidad de Murcia.

Martínez Gavilán, María Dolores. 2007. "Racionalismo y tradición escolar en el Arte de Nebrija reformado por el P. Juan Luis de la Cerda". En Peninsula - Revista de Estudos Ibéricos, $n^{\circ}$ 4. 327-246.

Martínez González, Antonio. 2006. "Las partes del discurso en la gramática filosófica de Jiménez Aquino". En M. Villayandre Llamazares, Actas del XXXV Simposio Internacional de la Sociedad Española de Lingüística. 1237-1255. León: Universidad de León - Dpto. de Filología Hispánica y Clásica. Publicación electrónica: http://www3.unileon.es/dp/dfh/SEL/actas.htm (última consulta 02/06/2011).

Meier H. 1965. "Zur Gesch. Der Romanischen Ełymologie". En ASNS, 201. 81-109.

Michael, Ian. 1970. English Grammatical Categories and the Tradition to 1800. Cambridge: University Press.

Michael, Ian. 1996. "Lowth, Robert". En Harro Stammerjohann (ed.), Lexicon Grammaticorum. 588-590. Tübingen: Niemeyer.

Miranda Menéndez, Fernanda. 2001. "Contribuição para a historiografia lingüística portuguesa: o manuscrito do "Diccionario de Moraes'". En M. Maquieira Rodríguez, M. ${ }^{a}$ D. Martínez Gavilán y M. Villayandre Llamazares (eds.), Actas del II Congreso Internacional de la Sociedad Española de Historiografía Lingüística, León, 2-5 de marzo de 1999. 705-714. Madrid: Arco Libros.

Miranda, Luis. 2006. "Las primeras gramáticas del español y de las lenguas indígenas del Perú. El proceso de gramatización". En J. L. Girón Alconchel y J. J. de Bustos Tovar (coord.), Actas del VI Congreso internacional de historia de la lengua española (Madrid, 29 de septiembre a 4 de octubre de 2003 Vol. 2). 2253-2267.

Moldenhaver, G. 1938. "Verzeichnis der Veröffentlichungen con Wilhelm MeyerLübke". En ZFSL 61. 385-440. 
Molina, Márcia A. G. 2005. "Língua portuguesa e Gramática Portuguesa". En Gonçalves, Miguel, Soares da Silva, Augusto, Coutinho, Jorge, Martins, José Cândido y Ferreira, Maria José (orgs.), Gramática e Humanismo. Actas do Colóquio de Homenagem a Amadeu Torres (Braga, 20-22 de abril de 2005). 519528. Braga: Aletheia.

Molina, Márcia A. G. 2008. "Pensamento e Ideologia na Constituição do Saber Lingüístico do Homem Brasileiro do Século XIX". En Antonio Moreno Sandoval (ed.), Actas del VIII Congreso de Lingüística General. 1390-1400. Madrid: Universidad Autónoma de Madrid.

Molina, Márcia A.G. 2010. "Um estudo das gramáticas da infância - Brasil: final do século XIX". En C. Assunção, G. Fernandes, M. Loureiro (eds.), Idéias Lingüísticas na Península Ibérica (séc. XIV a séc. XIX), Volume 2. 605-616. Münster: Nodus Publikationen.

Moraes, Rubens Borba de. 1983-1958. Bibliographia brasiliana. Rare books about Brazil published from 1504 to 1900 and works by brazilian authors of the Colonial period. Revised and enlarged edition. Los Angeles: University of California. Rio de Janeiro: Kosmos.

Morpurgo Davies, Anna. 1987. "'Organic' and 'organism' in Franz Bopp". En H. M. Hoenigswald y L. F. Wiener (eds.), Biological Metaphor and cladistic classification. 81-107. Philadelphia: University of Pennsylvania Press.

Morpurgo Davies, Anna. 1992. "History of Linguistics: Comparative-Historical Linguistics". En W. Bright (ed.), International encyclopedia of linguistics, vol. 2. 159163. Oxford: Oxford University Press.

Mourelle de Lema, Manuel. 2002[1968]. La teoría lingüística en la España del siglo XIX. $2^{a}$ edición aumentada. Madrid: Grugalma Ediciones.

Müller, G. A. (ed.). 1902. The life and the letters of the Right Honourable Friedrich Max Müller. 2 Vol. London: Longman.

Murakawa, Clotilde de Almeida Azevedo. 2006. "Léxico e gramática no Diccionario da Lingua Portugueza (1813) de Antonio de Moraes Silva". En Alfa: revista de lingüística. São Paulo: 50 (2). 55-67. 
Nascentes, Antenor. 1939. Estudos filológicos. Rio de Janeiro: Civilização Brasileira.

Navest, Karlijn. 2007. "Marginalia as evidence: The unidentified hands in Lowth's Short Introduction to English Grammar (1762)", Historiographia Linguistica 34/1: $1-18$.

Nebrija, Antonio de. 1980[1492]. Gramática de la lengua castellana. Estudio y edición de Antonio Quilis. Madrid: Editora Nacional.

Nebrija, Antonio de. 1992[1492]. Gramática de la lengua castellana. Introducción y notas de Miguel Ángel Esparza y Ramón Sarmiento. Madrid: Fundación Antonio de Nebrija.

Negri, Lígia. 2010. "Criterios definidores da classe dos pronomes em diferentes gramáticas de língua portuguesa". En C. Assunção, G. Fernandes, M. Loureiro (eds.), Idéias Lingüísticas na Península Ibérica (séc. XIV a séc. XIX), Volume 2. 641648. Münster: Nodus Publikationen.

Nelson, G. 1996. "Harris, James". En Harro Stammerjohann (ed.), Lexicon Grammaticorum. 390-391. Tübingen: Niemeyer.

Nerlich, Brigitte.1990. Change in language Whitney, Bréal and Wegener. London y New York: Taylor \& Francis.

Niederehe, Hans-Josef. 1999. "La lingüística española en el contexto internacional: centros de irradiación y periferias". En M. Fernández Rodríguez, F. García Gondar y N. Vázquez Veiga (eds.), Actas del I Congreso Internacional de la Sociedad Española de Historiografía Lingüística A Coruña, 18-21 de febrero de 1997. 91-108. Madrid: Arco Libros.

Niederehe, Hans-Josef. 2004. "La gramática de la lengua castellana (1492) de Antonio de Nebrija". En I. G. Betancourt, P. Máynez y A. H. de León Portilla (coords.), De historiografía lingüística e historia de las lenguas. 35-50. México D. F.: Siglo XXI Editores.

Niederehe, Hans-Josef. 2005. Bibliografía cronológica de la lingüística, la gramática y la lexicografía del español (BICRES). Desde el año 1701 hasta el año 1800, Amsterdam/Philadelphia: John Benjamins Publishing Company. 
Niederehe, Hans-Josef y H. Haarmann, (ed.) 1976. In memoriam Friedrich Diez: Akten des Kolloquiums zur Wissenschaftsgeschichte der Romanistik - Trier, 2-4 de octubre. Ámsterdam: John Benjamins.

Nieherehe, Hans-Josef. y Antonio Quilis, (eds.). 1986. History of Linguistics in Spain/ Historia de la Lingüística en España. Amsterdam y Philadelphia: John Benjamins.

Oiticica, J. 1945. Manual de Análise (léxica e sintática). Edição refundida. São Paulo: Livraria Francisco Alves.

Orlandi, Eni. 1997. "O estado, a gramática, a autoria". En Relatos 4. 6-11. São Paulo: Publicação do Projeto História das idéias lingüísticas.

Orlandi, Eni. 2001. "Formação de um espaço de produção lingüística: a gramática no Brasil". En História das idéias lingüísticas: construção do saber metalingüístico e constituição da língua nacional. 7-38. Mato Grosso: Unemat Editora.

Osselton, N. E. 2003. "Bishop Lowth converted: An English grammar for Catholics in the late eighteenth century". En English Studies 84/5. 448-452.

Padley, G. A. 1976-1985. Grammatical Theory in Western Europe, 1500-1700. The Latin Tradition. Cambridge: Cambridge University Press.

Paiva, Maria Helena. "Juizos explícitos e norma lingüística nos gramáticos portugueses quinhentistas". En A. M. Brito, O. Figueiredo y C. Barros (orgs), Lingüística Histórica e História da Língua Portuguesa (Actas do Encontro de Homenagem a Maria Helena Paiva - Faculdade de Letras da Universidade 0 Porto, 5-6 de noviembre de 2003). 275-300. Porto: Universidade O Porto, Faculdade de Letras.

Paiva, Maria Helena. 2009. "Variação e mudança no vocalismo átono quinhentista: práticas escriturais e juízos normativos". En Linguística Revista de Estudos Linguísticos da Universidade do Porto, Vol. 4. 85-1 10.

Paustian, P. R. 1977. "Bopp and the 19th century distrust of Indian grammatical tradition". En Indogermanische Forschungen, 82. 39-49.

Penha, João Alves Pereira. 1989. "Soares Barbosa e os gramáticos do século XIX". En Sebastião Expedito Ignácio (org.), Estudos Gramaticais, Série "Encontros" - 
Publicação do Curso de Pós-Graduação em Lingüística e Língua Portuguesa, ano II, n. ${ }^{\circ}$ I. 49-65. UNESP: Campus de Araraquara.

Percival, W. Keith. 1976. "The applicability of Kuhn's Paradigms to the History of Linguistics". En Language, 52. 285-294.

Percival, W. Keith. 1992. "History of Linguistics: The Renaissance". En W. Bright (ed.), International encyclopedia of linguistics, vol. 2. 152-155. Oxford: Oxford University Press.

Percy, Carol. 1997. "Paradigms lost: Bishop Lowth and the 'poetic dialect' in his English grammar'. En Neophilologus 81. 129-144.

Pinto, Rolando Morel. 1961. "Gramáticos portugueses do renascimento". En Revista de Letras. V. 2. 123-143. Assis: Faculdade de Filosofia, Ciências e Letras de Assis.

Poch Olivé, Dolors. 2006. "Los sonidos del español en la Gramática de la lengua castellana de Vicente Salvá". En J. L. Girón Alconchel y J. J. de Bustos Tovar (coord.), Actas del VI Congreso internacional de historia de la lengua española (Madrid, 29 de septiembre a 4 de octubre de 2003 Vol. 2). 2013-2026.

Ponce de León Romeo, Rogelio. 1996. "La Pedagogia del latin en Portugal durante la primera mitad del siglo XVII: cuatro gramáticos lusitanos". En Peninsula Revista de Estudos Ibericos, n². 365-375. Madrid. Servicio de Publicaciones U.C.M.

Ponce de León Romeo, Rogelio. 2000. Aproximación a la obra de Manuel Álvares: Edición Crítica de sus De Institutione Grammatica Libri Tres,Tomo I, Estudio Preliminar. Tese de Doutoramento. Madrid: Departamento de Filología Latina da Faculdad de Filología da Universidade Complutense.

Ponce de León Romeo, Rogelio. 2001. "En Álvarez en Vernáculo: Las Exégesis de los De Institutione Grammatica Libri Tres en Portugal durante el Siglo XVII". En Revista da Faculdade de Letras do Porto, Línguas e Literaturas. 317-338. Porto: ॥ Série. Vol. XVIII.

Ponce de León Romeo, Rogelio. 2002. "O Brocense na teoria gramatical portuguesa no início do Século XVII". En Revista da Faculdade de Letras da Universidade do Porto. Série "Línguas e Literaturas", 19. 491-520. 
Ponce de León Romeo, Rogelio. 2003. "La difusión de las artes gramaticales latino-portuguesas en España (siglos XVI-XVII)". En Península. Revista de Estudos Ibéricos, $n^{\circ} 0.119-145$.

Ponce de León Romeo, Rogelio. 2004. "El tratamiento de infinitivo flexionado en los tratados gramaticales latino-portugueses renacentistas". En Boletín de la Sociedad Española de Historiografía Lingüística, 4. 53-64.

Ponce de León Romeo, Rogelio. 2005a. "Os verbos em confronto: considerações sobre a tipologia verbal nas Artes gramaticais portuguesas setecentistas (16991758)". En Gonçalves, Miguel, Soares da Silva, Augusto, Coutinho, Jorge, Martins, José Cândido y Ferreira, Maria José (orgs.), Gramática e Humanismo - Actas do Colóquio de Homenagem a Amadeu Torres (Braga, 20-22 de abril de 2005). 449464. Braga: Aletheia.

Ponce de León Romeo, Rogelio. 2005b. "Fuentes españolas en la primera polémica gramatical portuguesa del siglo XVIII (1721-1736)". En Península. Revista de Estudos Ibéricos, $n^{\circ}$ 2. 365-375.

Ponce de León Romeo, Rogelio. 2005c. Aproximación a la obra de Manuel Álvares. Edición crítica de sus "De institutione grammatica libri tres". Madrid: Servicio de Publicaciones de la Universidad Complutense. 1. CD-Rom.

Ponce de León Romeo, Rogelio. 2006. "Un capítulo de la historia de las ideas sintácticas en Portugal: en torno a la teoría sintáctica del Ars grammaticae pro lingua Iusitana addiscenda (Lyon, 1672) de Bento Pereira (S. I.)". En: Forma y función 19. 11-30. Bogotá: Facultad de Ciencias Sociales y Humanas de la Universidad Nacional de Colombia.

Ponce de León Romeo, Rogelio. 2008a. "Gramaticografía portuguesa en la España ilustrada: breves consideraciones sobre el Acento y artificio gramatical de la lengua portuguesa (1795) de Lorenzo Hervás y Panduro". En Península. Revista de Estudos Ibéricos, $n^{\circ}$ 5. 55-64.

Ponce de León Romeo, Rogelio. 2008b. "Fuentes españolas en la primera gramática latina de Amaro de Roboredo". En Gramma-Temas 3: España y Portugal en la tradición gramatical. 239-265. León: Universidad de León.

Pozuelo Yvancos, José María. "Norma uso y autoridad en la teoría lingüística del siglo XVI". En E. F. K. Koerner y H. J. Niederehe (eds.), Historiographia Linguistica 11 - 1/2. 77-94. Amsterdam y Philadelphia: John Benjamins. 
Pullum, Geoffrey. 1974. "Lowth's grammar: A re-evaluation". En Linguistics 137. 63-78.

Quadros Leite, Marli. 2002. "The brazilian hyperlanguage Mark in the traditional grammar of the 19th century". En Guimarães, Eduardo y Pessoa de Barros, Diana Luz (eds.), History of linguistics 2002: Selected papers from the Ninth International Conference on the History of the Language Sciences (27-30 Agosto de 2002, São Paulo-Campinas). 75-86. Amsterdam y Philadelphia: John Benjamins Publishing Company.

Ramajo Caño, Antonio. 1987. Las gramáticas de la lengua castellana desde Nebrija a Correas. Salamanca: Ediciones Universidad de Salamanca y los autores.

Ranauro, Hilma. 1997. Contribuição à historiografia dos estudos científicos da linguagem no Brasil: Sílvio Elia e João Ribeiro. Tempo Brasileiro/FEUC.

Ranauro, Hilma. 2003. "O legado de Jerônimo Soares Barbosa". En Revista Portuguesa de Humanidades, n. 7. 1-2. 253-265. Braga: Universidade Católica Portuguesa - Faculdade de Filosofia de Braga.

Ranauro, Hilma. 2005. "Jerônimo Soares Barbosa: sua contribuição ao estudo e ao ensio do português no Brasil". En Gonçalves, Miguel, Soares da Silva, Augusto, Coutinho, Jorge, Martins, José Cândido y Ferreira, Maria José (orgs.), Gramática e Humanismo - Actas do Colóquio de Homenagem a Amadeu Torres (Braga, 2022 de abril de 2005). 579-590. Braga: Aletheia.

Read, Allen Walker. 1939. "The motivation of Lindley Murray's Grammatical work". En Journal of English and Germanic Philology, 38. 525-539.

Reid, S.W. 1977. "An index to Robert Lowth's Short Introduction to English Grammar". En Studia Neophilologica 49. 135-137.

Rey, A. 1970. Littré, L'Humaniste et les mots. Paris.

Rey, A. 1996. "Littré, Maximilien Paul Émile". En Harro Stammerjohann (ed.), Lexicon Grammaticorum, 579-580. Tübingen: Niemeyer.

Richter, E. 1936. "Wilhelm Meyer-Lübke". En ASNS 170. 197-210. 
Ridruejo, Emilio. 1985. "El tratamiento de los modos verbales en la Gramática de la lengua castellana de Vicente Salvá". En Miscellània Sanchis Guarner. 263-268. Valencia: Universidad de Valencia.

Ridruejo, Emilio. 2001. "Sobre la lingüística naturalista en España: la obra de Cejador y Frauca". En M. Maquieira Rodríguez, M. ${ }^{a}$ D. Martínez Gavilán y M. Villayandre Llamazares (eds.), Actas del II Congreso Internacional de la Sociedad Española de Historiografía Lingüística, León, 2-5 de marzo de 1999. 803814. Madrid: Arco Libros.

Ridruejo, Emilio. 2002. "Sobre la recepción en España del positivismo lingüístico". En M. A. Esparza Torres, B. Fernández Salgado y H. J. Niederehe (eds.), SEHL 2001 - Estudios de Historiografía Lingüística (Actas del III Congreso Internacional de la Sociedad Española de Historiografía Lingüística - Vigo, 7-10 de febrero de 2001). 653-668 (Tomo II). Hamburg: Helmut Buske Verlag.

Ridruejo, Emilio. "La aportación de Jovellanos a los Estudios gramaticales sobre el español". En III Simposio Internacional El castellano y sus gramáticas: "La gramática española en el siglo XVIII" (1700-1835). Salamanca: 20-22 de mayo de 2009. (e.p.).

Robins, R. H. 1967. Breve historia de la lingüística. Madrid: Paraninfo.

Rodrigo Mora, M. José. 2006. "Lingüística comparada y gramática normativa en la España del siglo XIX". En A. Cancellier, M. C. Ruta y L. Silvestri (coord.), Scrittura e conflitto (Actas del XXI Congreso Aispi - Atti del XXII Convegno Aispi: CataniaRagusa 16-18 mayo / Vol. 2). 231-242. Publicación electrónica: http://cvc.cervantes.es/literatura/aispi/pdf/20/ll_16.pdf (última consulta 02/06/2011).

Rojo, Guillermo. 2001. El lugar de la sintaxis en las primeras gramáticas de la Academia. Discurso de ingreso en la Real Academia Española. Leído el 7 de octubre de 2001. Madrid.

Rosa, Maria Carlota. 1995. "Acerca das Duas Primeiras Descrições Missionárias de Língua Geral". En Amerindia. Revue d'Ethnolinguistique Amerindienne 19/20. 273-184.

Sahlin, Gunvor. 1928. César Chesneau Du Marsais et son rôle dans l'évolution de la grammaire générale. Macon: Protat Frères, Imprimeurs. 
Saint-Gérand. J. P. 1996. "Ayer, Nicolas-Lovis-Cyprien". En Harro Stammerjohann (ed.), Lexicon Grammaticorum. 58. Tübingen: Niemeyer.

Salmon, Georges. 1905. Silvestre de Sacy (1758-1838). 2 Vol. Le Caire: Imprimerie de l'Institut français d'archéologie orientale.

Santos, Maria Helena y Carlos Assunção. 2005. "Das coordenadas históricoculturais e epistemológicas contextualizadoras e caracterizadoras da Gramática Filosófica da Linguagem portuguêza, de João Crisóstomo do Couto e Melo". En Estudios Portugueses 5 - Revista de Filología Portuguesa. 113-122. Salamanca: Luso-Española de Ediciones.

Santos, Maria Helena. 2010. "Sobre algumas intuições pré-teoréticas emergentes na gramaticografia portuguesa oitocentista". En C. Assunção, G. Fernandes, M. Loureiro (eds.), Idéias Lingüísticas na Península Ibérica (séc. XIV a séc. XIX), Volume 2. 795-804. Münster: Nodus Publikationen.

Sarmiento, Ramón. 1986. "La doctrina gramatical de la RAE (1870)". En Revista Filológica Románica, IV. 213-224. Madrid: Editorial de la Universidad Complutense.

Sarmiento, Ramón. 2002. "Descripción y norma en la gramática de Andrés Bello (1847)". En M. A. Esparza Torres, B. Fernández Salgado y H. J. Niederehe (eds.), SEHL 2001 - Estudios de Historiografía Lingüística (Actas del III Congreso Internacional de la Sociedad Española de Historiografía Lingüística - Vigo, 7-10 de febrero de 2001). 439-464 (Tomo I). Hamburg: Helmut Buske Verlag.

Schimitter, P. 1996. "Bopp, Franz". En Harro Stammerjohann (ed.), Lexicon Grammaticorum. 120-121. Tübingen: Niemeyer.

Schlerath, B. 1990. "Franz Bopp 14 sept. 1791-23 oct. 1867". En W.W. Briggs y W. M. Calder III (eds.), Classical Scholarship A biographical Encyclopedia. 7-12. New York: Garland Pub.

Schweickard, W. 1996: "Diez, Friedrich Christian". En Harro Stammerjohann (ed.), Lexicon Grammaticorum. 240-241. Tübingen: Niemeyer.

Schäfer-Priess, Barbara. 2000. Die portugiesische grammatikschreibung Von 1540 bis 1822: entstehungsbedingungen und kategorisierungsverfahren vor dem hintergrund der lateinischen, spanishchen und französischen tradition. Tübingen: Max Niemeyer Verlag. 
Schäfer-Priess, Barbara. 2004. "Zur «Keltomanie» in Portugal". En Volker Noll y Sylvia Thiele (eds.), Sprachkontakte in der Romania, Zum 75. Geburtstag von Gustav Ineichen. 249-257. Tübingen: Max Niemeyer Verlag.

Schäfer-Priess, Barbara. 2005. "Gramaticografia em contacto: as gramáticas portuguesas de Pedro José da Fonseca e Jerônimo Soares Barbosa e a Gramática de la lengua castellana da Real Academia Española de 1771". En Estudios Portugueses 5 - Revista de Filología Portuguesa. 123-130. Salamanca: Luso-Española de Ediciones.

Silva, Ana Alexandra. 2010. "Uma perspectiva do século XIX sobre a função "Complemento Circunstancial" - Ponte para o século XXI". En C. Assunção, G. Fernandes, M. Loureiro (eds.), Idéias Lingüísticas na Península Ibérica (séc. XIV a séc. XIX), Volume 2. 813-824. Münster: Nodus Publikationen.

Silva, Maurício. 2005. "Reflexões acerca do sentido da historia na Historiografia Lingüística". En IV Jornada Nacional de Filologia: A Filologia de ontem, de hoje e de amanhã, 4 de abril de 2005 - USP.

Silva, Maurício. 2006a. "A questão ortográfica na Grammatica da Lingoagem Portugueza (1536) de Fernão de Oliveira: uma introdução". En Alfa São Paulo 50 (1). 23-38.

Silva, Maurício. 2006b. "A gramática brasileira novecentista: uma história" en Revista Letra Magna - Revista electrónica de divulgación científica en lengua portuguesa, lingüística y literatura, año $03-n^{\circ}$ 4. Publicación electrónica: http://www.letramagna.com/gramatical.pdf (última consulta 02/06/2011).

Silva, Maurício. 2006c. "Fundamentos do discurso gramatical brasileiro: a Grammatica Portugueza (1887) de João Ribeiro". En N. B. Bastos y D. V. Palma (orgs.), História Entrelaçada 2: a construção de gramáticas e o ensino de língua portuguesa na primeira metade do século XX. IP-PUC/SP. 41-60. Rio de Janeiro: Editora Lucerna.

Silverstein, Michael. 1996. "Whitney, William Dwight". En Harro Stammerjohann (ed.), Lexicon Grammaticorum. 1007-1009. Tübingen: Niemeyer.

Harro Stammerjohann (ed.). 1996. Lexicon Grammaticorum, Who's Who in the History of World Linguistics. Tübingen: Max Niemeyer Verlag. 
Sternemann, R. 1984a. Franz Bopp und die vergleichende indoeuropaïsche Sprachwissenschaf. Innsbruck: Id.

Sternemann, R. 1984b. "Franz Bopps Beitrag zur Entwicklung der vergleichenden Sprachwissenschaf". En ZfGerm, 5. 144-158.

Stone, J. R. 2002. The essential Max Müller: on language, mythology, and religion. Palgrave: Macmillan.

Subbiondo, Joseph L. 1976. "The Semantic Theory of James Harris: A study of Hermes (1751)". En Historiographia Linguistica, 3. 275-291.

Swiggers, Pierre. 1984a. "Grammaire et logique à Port-Royal. A propos des fondements d'une linguistique générale". En Sprachwissenschaft, 9. 333-352.

Swiggers, Pierre. 1984b[1989]. "La grammaire de Port-Royal et le 'parallélisme logicogrammatical'". En Orbis, 33/1-2. 29-56.

Swiggers, Pierre. 1992. "History of Linguistics: Seventeenth- and EighteenthCentury Europe". En W. Bright (ed.), International encyclopedia of linguistics, vol. 2. 155-159. Oxford: Oxford University Press.

Swiggers, Pierre. 1997. Historie de la pensé linguistique. Analyse du langage et réflexion linguistique dans la cultura occidentale, de l'antiquité au XIXe siècle. Paris: Presses Universitaires de France.

Swiggers, Pierre. 2006a. "Terminologie et Terminographie linguistiques: problèmes de définition et de calibrage". En F. Neveu (ed.), La terminologie linguistique: problèmes épistémologiques, conceptuels et traductionnels. Syntaxe et sémantique 7. 13-28. Caen: Presses Universitaires de Caen.

Swiggers, Pierre. 2006b. "À propos de la place de la syntaxe dans la grammaire: de Buffier à Girard". En Lenoble-Pinson, Michèle y Delcourt, Christian (eds.), Le point sur la langue française: Hommage à André Goosse. 333-349. Bruxelles: Le livre Timperman.

Swiggers, Pierre. 2009a. "La historiografía de la lingüística: apuntes y reflexiones". En Revista Argentina de Historiografia Lingüística, V. 1, 1. 67-76. Publicación electrónica:

http://www.rahl.com.ar/Revistas/1\%20-\%202009/swiggers-RAHL-(1)2009.pdf (última consulta 04/06/2011). 
Swiggers, Pierre. 2009b. "Terminología gramatical y lingüística: elementos de análisis historiográfico y metodológico". En Res Diachronicae Revista Digital, vol. 7. 11-35. Publicación electrónica: http://www.ajihle.org/resdi/docs/Numero7/Ponencias/Swiggers Pierre.pdf (última consulta 03/06/2011).

Swiggers, Pierre. 2010. "Gramática razonada y aproximación funcional: el Tratado de Gregorio Herráinz (1885)". En C. Assunção, G. Fernandes, M. Loureiro (eds.), Idéias Lingüísticas na Península Ibérica (séc. XIV a séc. XIX), Volume 2.835850. Münster: Nodus Publikationen.

Swiggers, Pierre. "La gramática general/filosófica francesa y su recepción en España (siglo XVIII e inicios del siglo XIX)". En III Simposio Internacional El castellano y sus gramáticas: "La gramática española en el siglo XVIII" (17001835). Salamanca: 20-22 de mayo de 2009. (e.p.).

Swiggers, Pierre y C. Quijada Van den Berghe. 2009. "La terminología del pronombre en la gramática española, de Nebrija (1492) a A. Bello (1847): algunos apuntes". En Res Diachronicae Revista Digital, vol. 7. 263-292. Publicación electrónica:

http://www.ajihle.org/resdi/docs/Numero7/Seminario/SeminarioPronombre.pdf (última consulta 03/06/2011).

Swiggers, Pierre y Sara Szoc "Au Carrefour de la (méta)lexicographie, de la terminographie, de la grammaticographie et de la linguistique contrastive: la terminologie grammaticale dans les grammaires de l'italien aux Pays-Bas". En XXVle Congrès International de Linguistique et de Philologie Romanes. Valencia: 6-11 de septiembre de 2010. (e.p.).

Tieken-Boon van Ostade, Ingrid. 1996. "Murray, Lindley". En Harro Stammerjohann, (ed.), Lexicon Grammaticorum. 662-663. Tübingen: Niemeyer.

Tieken-Boon van Ostade, Ingrid. 1997. "Lowth's corpus of prescriptivism". En Terttu Nevalainen and Leena Kahlas-Tarkka (eds.), To Explain the Present: Studies in the Changing English Language in Honour of Matti Rissanen. 451-463. Helsinki: Société Néophilologique.

Tieken-Boon van Ostade, Ingrid. 2000. "Robert Dodsley and the Genesis of Lowth's Short Introduction to English Grammar". Historiographia Lingüística XXVII. 
Tieken-Boon van Ostade, Ingrid. 2001. "Lowth's Short Introduction to English Grammar reprinted'. En Publishing History 49. 5-17.

Tieken-Boon van Ostade, Ingrid. 2008. "The 1760s: Grammars, grammarians and the booksellers'. En Tieken-Boon van Ostade (ed.), Grammars, Grammarians and Grammar-Writing in Eighteenth-Century England. 101-124. Berlin/New York: Mouton de Gruyter.

Tieken-Boon van Ostade, Ingrid. 2010. The Bishop's Grammar. Robert Lowth and the Rise of Prescriptivism in English. Oxford: Oxford University Press.

Timpanaro, S. 1973. "Il contrasto tra I fratelli Schlegel e Franz Bopp sulla struttura e la genesi delle lingue indoeruopee". En Critica Storica, 19. 1-38.

Torres, Amadeu. 1982. "Gramaticalismo e especulação. A propósito da 'Grammatica Philosophica' de Jerónimo Soares Barbosa". En Revista portuguesa de filosofia - Actas do I Congresso Luso-Brasileiro de Filosofia. 519-542. Braga: Faculdade de Filosofia.

Torres, Amadeu. 1998. Gramática e Lingüística. Ensaios e outros estudos. Braga: Universidade Católica Portuguesa, Faculdade de Filosofia - Instituto de Letras de Ciencias Humanas. Centro de Estudos Lingüísticos.

Torres, Amadeu. 2004. "O contributo conceptual das gramáticas filosóficas para a história da língua portuguesa". En A. M. Brito, O. Figueiredo y C. Barros (orgs), Lingüística Histórica e História da Língua Portuguesa (Actas do Encontro de Homenagem a Maria Helena Paiva - Faculdade de Letras da Universidade 0 Porto, 5-6 de noviembre de 2003). 385-395. Porto: Universidade do Porto, Faculdade de Letras.

Torres, Amadeu. 2005. "Verney e as correntes coeva e posterior do filosofismo gramatical". En Rio-Torto, Graça Maria, Figueiredo, Olivia Maria y Silva, Fátima (orgs.), Estudos em homenagem ao Professor Doutor Mario Vilela. Vol. 1 y 2. 71 78. Porto: Faculdade de Letras da Universidade do Porto.

Torres, Amadeu. 2010. "O gramaticalismo filosófico de Jerônimo Soares Barbosa (1822) e os seus primeiros discípulos no Brasil". En C. Assunção, G. Fernandes, M. Loureiro (eds.), Idéias Lingüísticas na Península Ibérica (séc. XIV a séc. XIX), Volume 2. 851-864. Münster: Nodus Publikationen. 
Trabant, J. 1986. Apeliotes oder Der Sinn der Sprache. Wilhelm von Humboldts Sprach-Bild. München: Fink.

Van den Bosch, L. 2002. Friedrich Max Müller: a life devoted to humanities. Leiden, Boston: Brill.

Vasconcelos, José Leite de. 1922. Epiphanio Dias - sua vida e labor scientifico (oratio de sapientia pronunciada na sessão da abertura solene da Universidade de Lisboa em 10 de Dezembro de 1921). Lisboa: Imprensa Nacional.

Velando Casanova, Mónica y M. a José García Folgado. 2001. "Tres siglos de prólogos en la gramática española (1492-1771)". En M. Maquieira Rodríguez, M. ${ }^{a}$ D. Martínez Gavilán y M. Villayandre Llamazares (eds.), Actas del II Congreso Internacional de la Sociedad Española de Historiografía Lingüística, León, 2-5 de marzo de 1999. 965-974. Madrid: Arco Libros.

Verburg, P.A. 1950. "The background to the linguistic conception of Bopp". En Lingua, 2. 438-468.

Verdelho, Telmo. 1982. "Historiografia Lingüística e Reforma do Ensino. A propósito de três centenários: Manuel Álvares, Bento Pereira e Marquês de Pombal". En Brigantia. Vol. II, nº 4. 347-356. Bragança.

Verdelho, Telmo. 1995. As origens da gramaticografia e da lexicografia latinoportuguesas. Aveiro: Instituto Nacional de Investigação Científica.

Verdelho, Telmo. 1997. "Epiphanio". En Biblios Enciclopedia VERBO literaturas de lingua portuguesa. 2.

Verdelho, Telmo. 1998. "Terminologias na lingua portuguesa. Perspectiva diacrônica". En Jenny Brummer (ed.), La historia dels llenguatges iberoromanics d'especialitat (segles XVII-XIX): solucions per al present. 98-131. Barcelona: Institut Universitari de Linguistica Aplicada. Universitat Pompeu Fabra.

Vila Rubio, M. ${ }^{a}$ Nieves. 2001. "La historiografía lingüística: observaciones terminológicas y conceptuales". En M. Maquieira Rodríguez, M. ${ }^{a}$ D. Martínez Gavilán y M. Villayandre Llamazares (eds.), Actas del II Congreso Internacional de la Sociedad Española de Historiografía Lingüística, León, 2-5 de marzo de 1999. 1003-1014. Madrid: Arco Libros. 
Vilela, Mario. 1982. "A 'ilustração' na teoria da linguagem do Cardeal Saraiva (homenagem a E. Coseriu, Tubingen, RFA)". En Luis Filipe Lindley Cintra (dir.), Boletim de Filologia - Centro de Lingüística da Universidade de Lisboa - Tomo XXVII. 411-426. Lisboa: Instituto Nacional de investigação Científica. Centro de Lingüística da Universidade de Lisboa.

Vorlat, E. 1959. "The sources of Lindley Murray's 'The English grammar'". En Leuvense Bijdragen, 48. 108-125.

Wächtler. K. 1991. "William Dwight Whitney's essentials of English grammar for the use of schools (1877)". En G. Leitner (ed.), Traditional grammars: An intern perspective. 39-55. Amsterdam y Philadelphia.

Wagner, Joachim. 1973. Nicolas Beauzée (1717-1789) und die Tradition der Grammaire générale. PhD. Dissertation: University of Bochum.

Yllera, Alicia. 1983. "La gramática racional castellana en el siglo XVII: la herencia del Brocense". En Serta Philologica F. Lázaro Carreter, I. 649-665. Madrid: Cátedra.

Zamorano Aguilar, Alfonso. 2001. Gramaticografía de los modos del verbo en español. Córdoba: Servicio de Publicaciones de la Universidad de Córdoba.

Zamorano Aguilar, Alfonso. 2002. "Teoría y estructura de los prólogos en los tratados gramaticales españoles (1847-1999)". En M. A. Esparza Torres, B. Fernández Salgado y H. J. Niederehe (eds.), SEHL 2001. Estudios de Historiografía Lingüística (Actas del III Congreso Internacional de la Sociedad Española de Historiografía Lingüística, Vigo, 7-10 de febrero de 2001). 489-502 (Tomo I). Hamburg: Helmut Buske Verlag.

Zamorano Aguilar, Alfonso. 2006. "Nuevas aportaciones al racionalismo gramatical del siglo XIX. El modelo teórico de Fernández Monje". En M. L. Calero Vaquera, F. Osuna García, y A. Z. Aguilar (eds.), Studia Lingüística et Philologica: In memorian Feliciano Salgado (1926-2004). 261-291. Córdoba: Servicio de Publicaciones Universidad de Córdoba.

Zimmermann, Klaus (ed.). 1997. La descripción de las lenguas amerindias en la época colonial. Frankfurt am Main: Vervuert; Madrid: Iberoamericana.

Zimmermann, Klaus. 2005. "Traducción, préstamos y teoría del lenguaje: la práctica transcultural de los lingüistas misioneros en el México del siglo XVI". En 
Zwartjes, Otto y Cristina Altman (eds.), Missionary Linguistics II/Lingüística Misionera II. Orthography and Phonology. 107-136. Amsterdam y Philadelphia: John Benjamins.

Zwartjes, Otto. 2000. Las Gramáticas Misioneras de Tradición Hispánica (siglos XVI-XVII). Rodopi.

Zwartjes, Otto. 2002. "The Description of the Indigenous Languages of Portuguese America by the Jesuits during the Colonial Period. The impact of the Latin grammar of Manuel Álvares". En E. F. K. Koerner y H. J. Niederehe (eds.), Historiographia Linguistica 29 - 1/2. 19-70. Amsterdam y Philadelphia: John Benjamins.

Zwartjes, Otto y Even Hovdhaugen (eds.). 2003. Missionary Linguistics I/Lingüística Misionera I. Amsterdam y Philadelphia: John Benjamins.

Zwartjes, Otto y Cristina Altman (eds.). 2005. Missionary Linguistics II/Lingüística Misionera II. Orthography and Phonology. Amsterdam y Philadelphia: John Benjamins.

Zwartjes, Otto, Gregory James y Emilio Ridruejo (eds.). 2007. Missionary Linguistics III/Lingüística Misionera III. Morphology and Syntax. Amsterdam y Philadelphia: John Benjamins. 


\section{APÉNDICE}

Portada del Epítome de Grammatica Portugueza de Moraes Silva (1824[1806])

${ }^{\circ}$ GR A M M ATICA

\section{PORTUGUEZA}

PO R

ANTONIO DE MORAES SILVA.

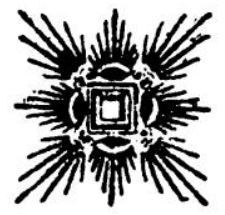

RIO DE JANEIRo,

NA TYPOGRAPUIA DE BILVA PORTO, E COMP.

1824. 


\section{GRAMMATICA PORTUGUEZA}

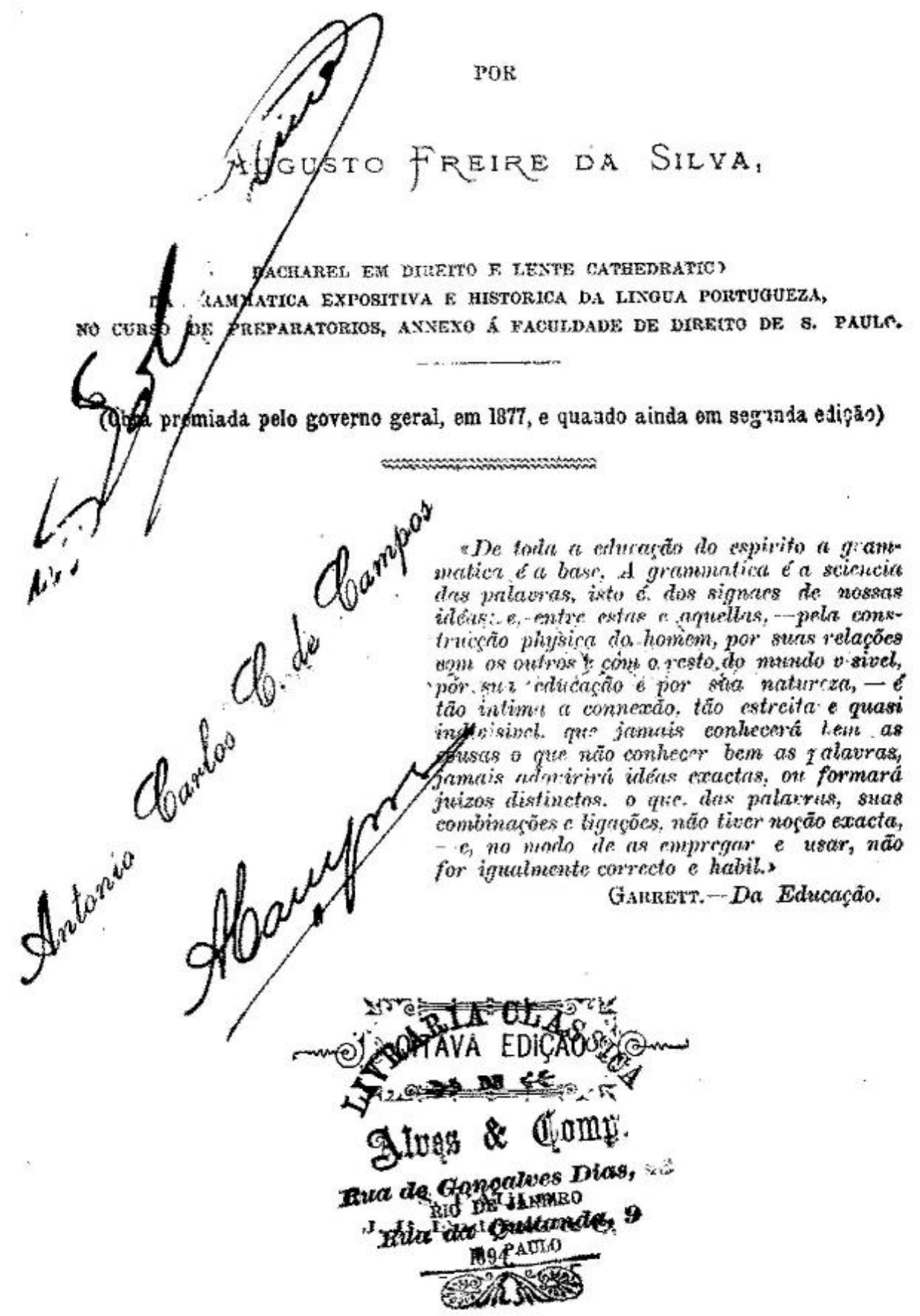


Portada de la Grammatica Portugueza de Augusto Freire da Silva (1906[1875]) Novena Edición

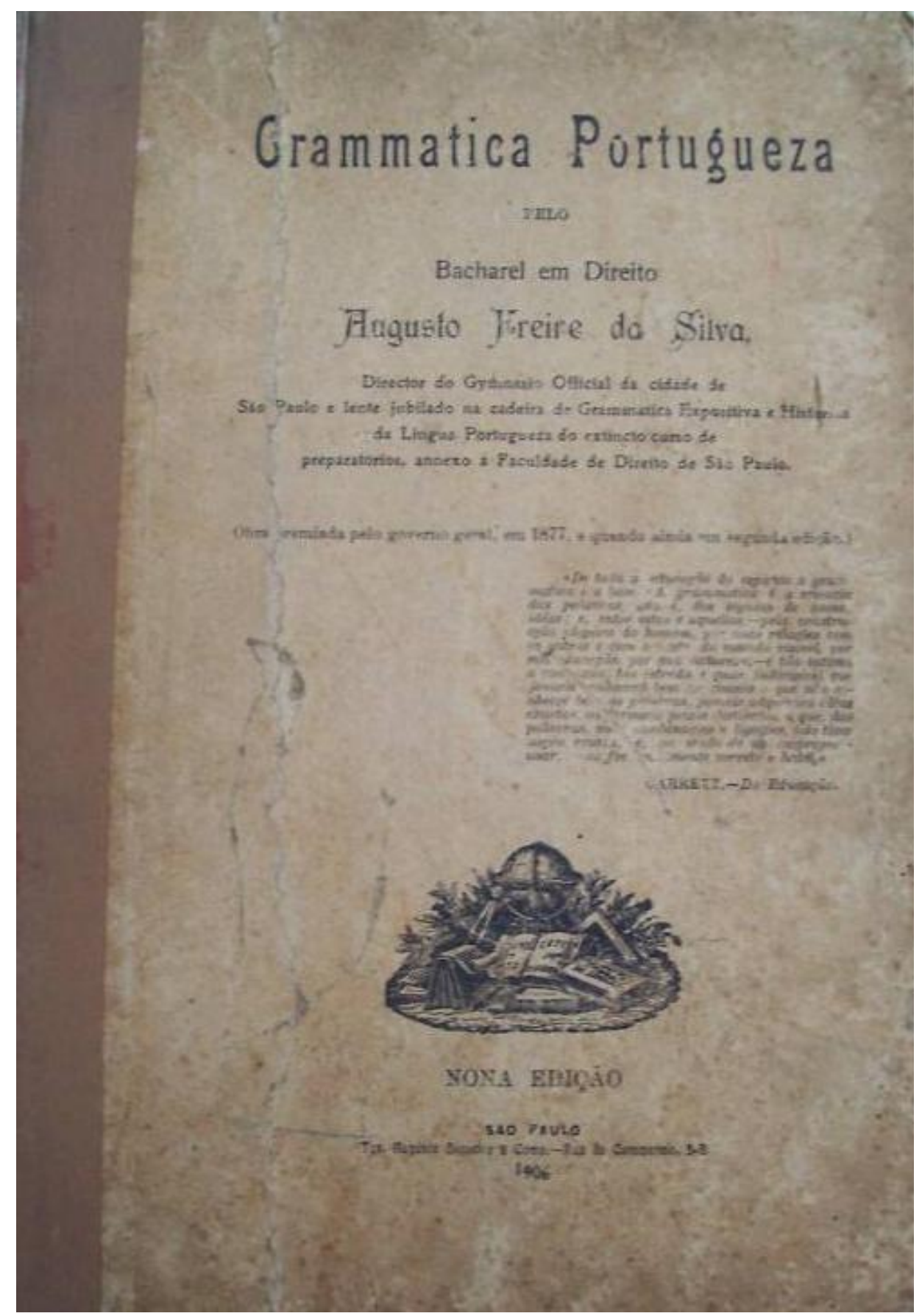




\section{GRAMMATICA PORTUGUEZA}

POR

\section{JULI0RIBEIR0}

Tentei ensinar aos meus naturaes o que eu de outrem não pude apprender. DUARTE NUNES DE LEÃO

Pour les langues, la methode essentielle est dans la comparaison et la filiation. - Rien n'est explicable dans notre grammaire moderne si nous ne connaisons notre grammaire ancienne. LITTRE'.

En aucune chose peut-être, il n'est donné à l'homme d'arriver au but : sa gloire est d'y avoir marché.

GUIZOT.

\section{SÃo PAULO}

Typ. de Jorge Seckler, Rua Direita, 15 
Dedicatoria de la Grammatica Portugueza de Júlio Ribeiro (1881)

Primera Edición

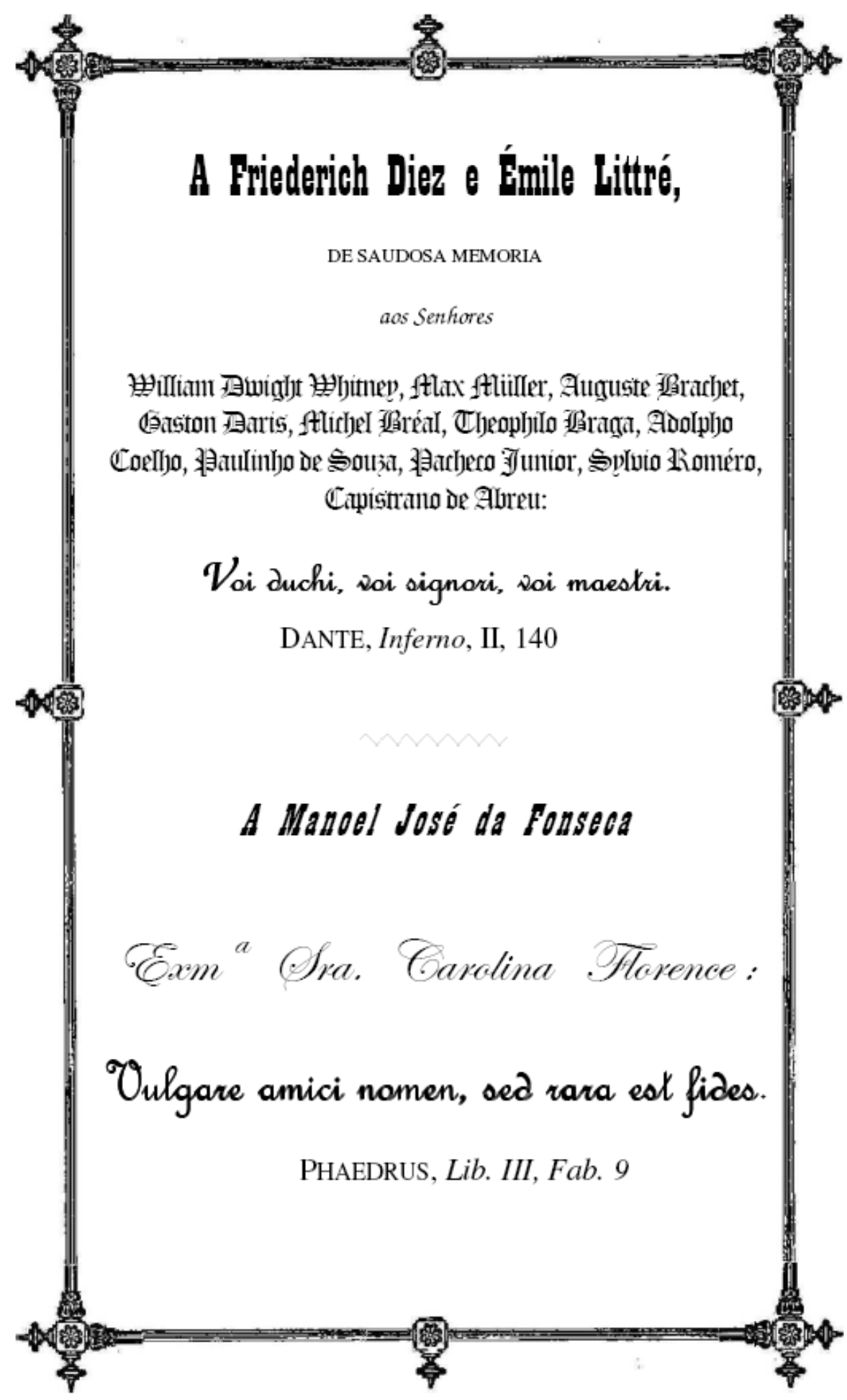


Portada de la Grammatica Portugueza de Júlio Ribeiro (1899[1881])

Quinta Edición

\section{UULIO RIBEIRO}

\section{Grammatica Portugueza}

Tentei ensinar aos meus maturaes - que en de outrem não pude aprender.

DUARTE NUNES DE LEAO.

Pour les langues, la methodé essentielle ent hase la comparasson et la fliation-Rien n'est expliatshe dans notre grammaire moderne, si nous ne coninaissons notre grammaire ancienine.

LITTRÉ.

En ancune chose, peut-être, it wist

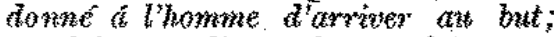
sa glowe est d'y atobr morcher.

GUIzoT.

'QUUNNTA EDIÇCOOC, CUIDADOSAMENTE REVISTA

POR

\section{João Vleira de Almeida}

PROFESSOR DE PORTUGUEZ

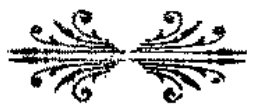

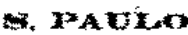

MIGURL, MELHLCC-EDTTOR

65. Rua de s. Bento, 65

1899 


\title{
GRAMMITTICA PORTUGUEZA
}

\author{
JULIO RIBEIRO
}

Tentei ensinar aos meus naturaes o que eu de outrem não pude aprender.

DUARTE NUNES do LeÃo.

Pour les langues, la méthode essentielle est dans la comparaison et la filiation. - Rien n'est explicable dans notre grammaire moderne, si nous ne connaissons notre grammaire ancienne.

\section{LITTRE.}

En aucune chose, peut-être, il n'est donné à l'homme d'arriver au but;'sa gloire est d'y avoir marché.

GUIZOT.

\section{DECIMA EDIÇ ÃO}

\section{Livraria Francisco Alves $\boldsymbol{d}$ C.}

166, Rua do Ouvidor, 166 - RIO DE JANEIRO

Rua de S. Bento, 65 - S. PAULO

Rua da Bahia, 1055 - Bello Horizonte

\section{1}


Portada de la Grammatica Descriptiva de Maximino Maciel (1914[1894]) Quinta Edición

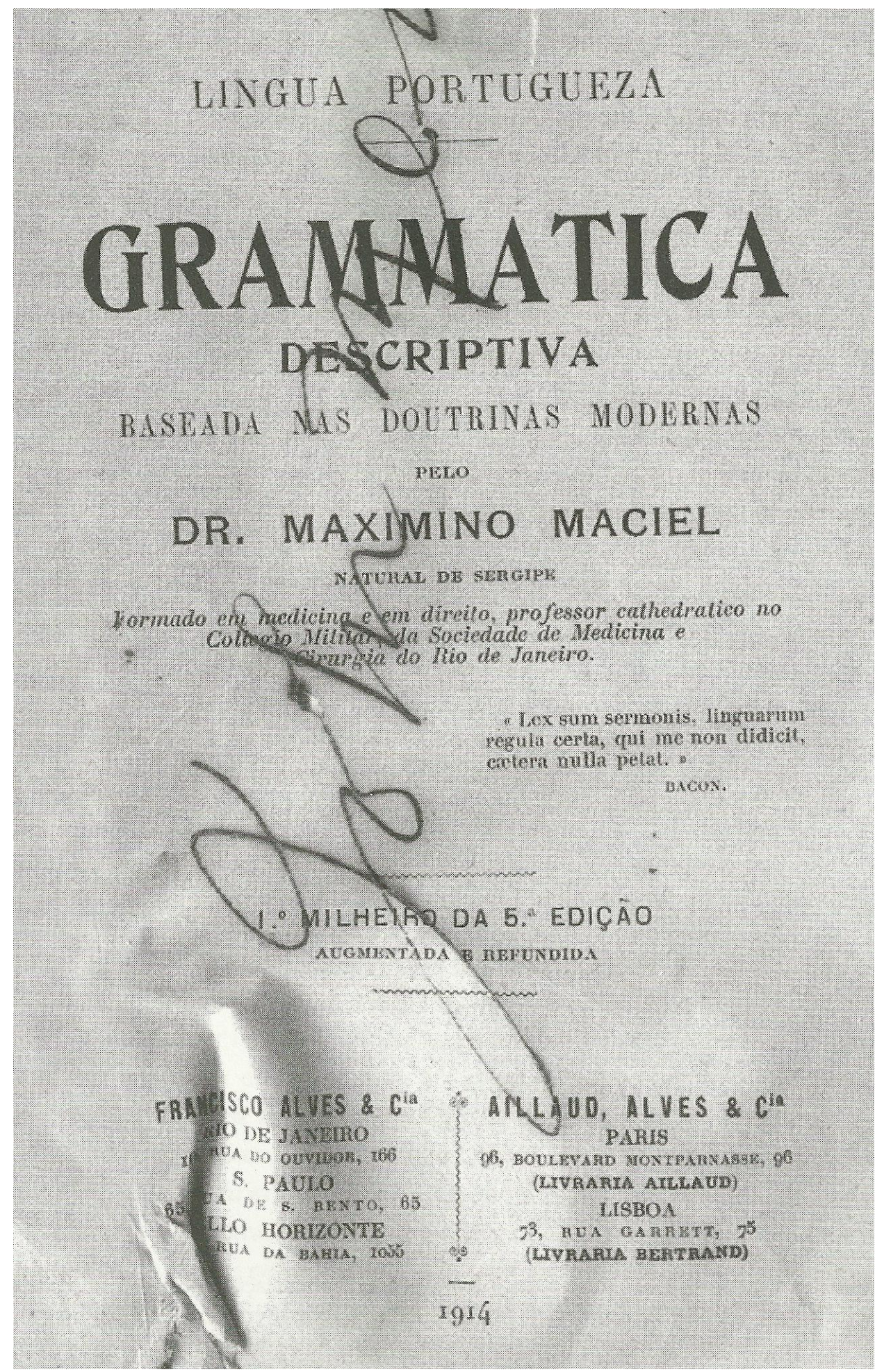




\section{2 ÍNDICE DE TABLAS Y GRÁFICOS}

\subsection{Tablas}

1.1 Cronología de las principales gramáticas brasileñas del siglo XIX 16

4.1 Fuentes primarias de los gramáticos brasileños del siglo XIX 95

5.1 División de la Gramática de Augusto Freire 130

5.2 Los adjetivos en las gramáticas de Sotero dos Reis y Augusto Freire

5.3 Modelo oracional de Sivestre de Sacy

5.4 Modelo oracional de Augusto Freire

5.5 División de la Gramática de Júlio Ribeiro

5.6 Modelos de división de la gramática en la tradición brasileña

5.7 Las clases de palabras en las gramáticas brasileñas

5.8 La división de la Gramática de Maximino Maciel

6.1 Términos para el estudio de las clases de palabras

6.2 Terminología de la «lexeologia»

6.3 La presencia de la «syntaxe» y sus equivalentes en las gramáticas brasileñas

6.4 Terminología de la sintaxis

6.5 Terminología de la semántica

6.6 Terminología relativa a la macroestructura gramatical y sus variaciones

6.7 Terminología de las partes de la gramática organizados según su contenido

6.8 Terminología de las subclases del sustantivo

6.9 Terminología de las subclases del adjetivo

6.10 La terminología del verbo

6.11 Terminología del adverbio 
6.12 Terminología de las conjunciones 287

6.13 Terminología de las oraciones 293

6.14 Terminología de las figuras y vicios del lenguaje 297

7.1 Modelos de división de la gramática en la tradición brasileña 309

7.2 Sistemas de clasificación de palabras en las gramáticas brasileñas

8.1 Contrastes románicos en los gramáticos brasileños decimonónicos

\subsection{Gráficos}

8.1 Las fuentes lingüísticas del Epítome de Moraes 361

8.2 El dominio de los contrastes en el Epítome de Moraes 361

8.3 Las fuentes lingüísticas en la obra de Freire 378

8.4 El dominio de los contrastes en Freire 379

8.5 Las fuentes lingüísticas de Ribeiro 395

8.6 El dominio de los contrastes en Ribeiro 295

8.7 Las fuentes lingüísticas en la Grammatica Descriptiva 404

8.8 El dominio de los contrastes en la Gramática de Maciel 405 